

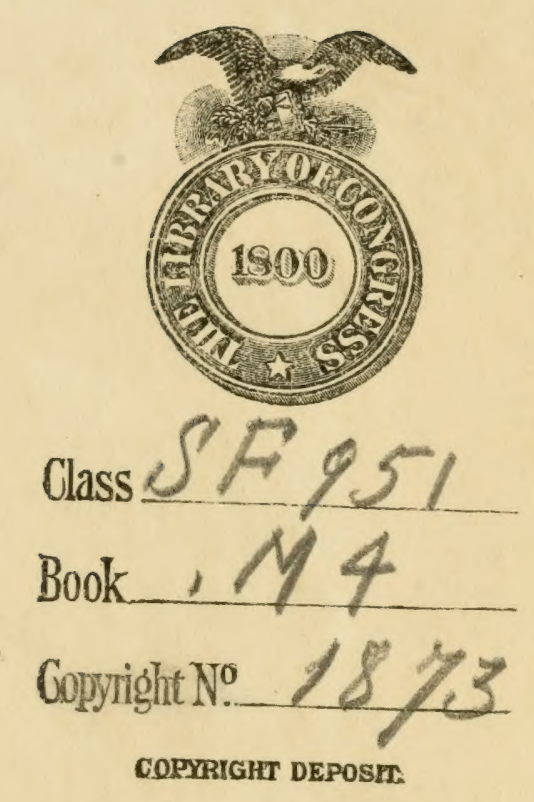





$\frac{2348}{4390}$ 


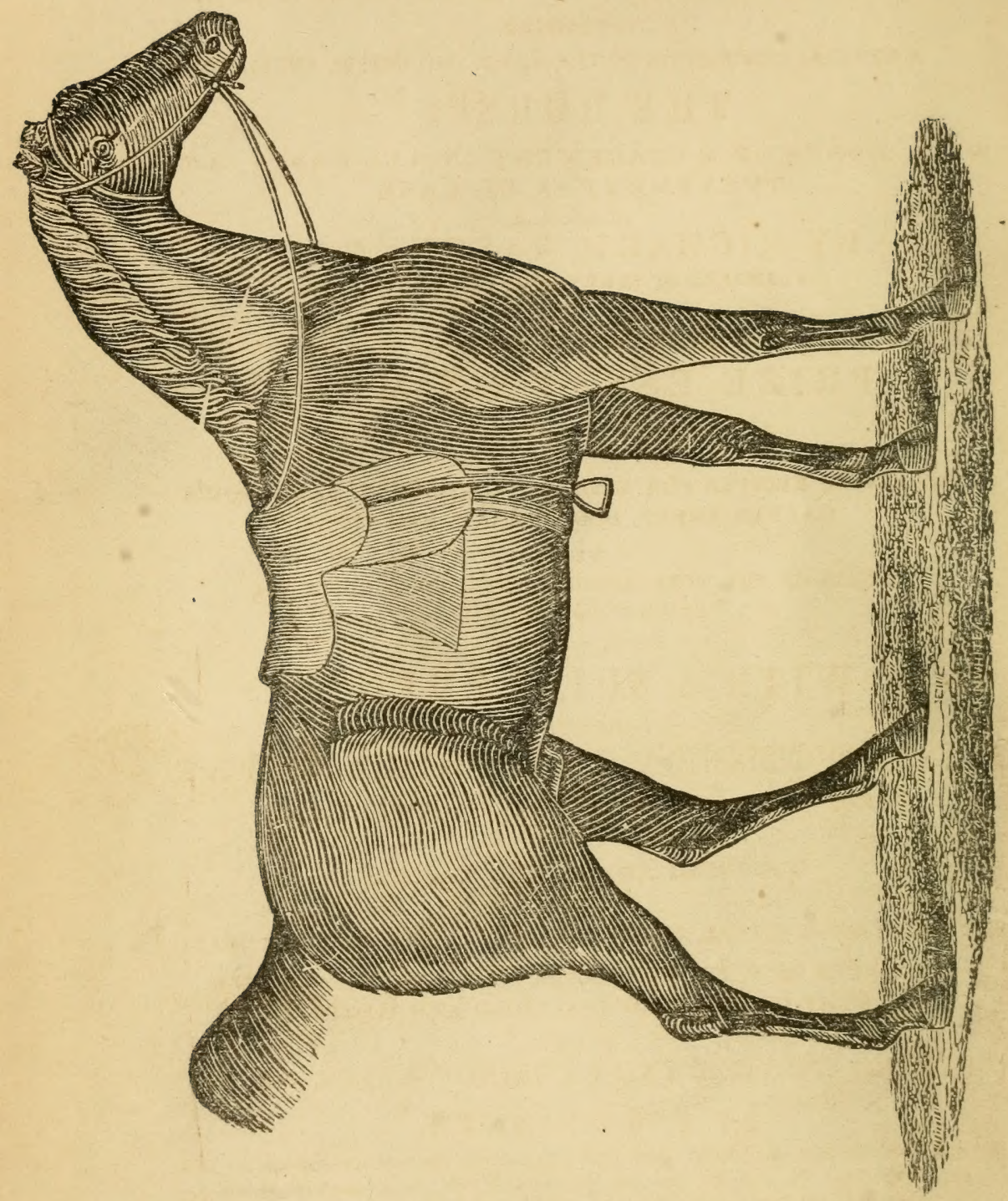


Mason's Farriet and Stud-Book-New Edttion.

\title{
THE GENTLEMAN'S
}

\section{NEW POCKET FARRIER: COMPRISING}

A GENERAL DESCRIPTION OF THE NOBLE AND USEFil ANIMAL,

\section{T H E H O R SE;}

WITH MODES OF MANAGEMENT IN ALL CASER, AN TREATM ENT IN DISEASE.

BY RICHARD MASON, M.D. FURMERLY OF SURRY CÓUNTY, VIRGINIA.

TO WHICH IS ADDED,

A PIIZE ESSAY ON MULES: A N A P P E D I X,

CONTAINING RECIPES FOR DISEASES OF HORSES, OXEN, COKS

CALVES, SHEEP, DOGS, SWINE, ETC. ETC.

WITH

ANNALS OF THE TURF, AMERICAN STUD-BOOK, RULES FOR TRAINING, RACLNG, ETC.

\section{WITH A SUPPLEMENT:}

\author{
COMPRISING
}

AN ESSAY ON DOMESTIC ANIMALS, ESPECIALLY THE HORSE,

WITH REMARKS ON TREATMENT AND BREEUING;

TOGETHER WITH

TROTTING AND RACING TABLES,

SHOW ING

THE BEST TIME ON RECORD, AT ONE, TWO, THREE, AND FOUR MILE HEATY,

PEDIGREES OF WINNING HORSES, SINCE 1839; AND OF THE

MOST CELEBRATED STALLIONS AND MARES;

WITH

USEFUL CALVING AND LAMBING TABLES, \&c. \& c.

\section{B Y J. S. SK I N N R,}

Editor now of the Farmers' Library, New York; Founder of the American Farmer, in 1818 :

and of the Turf Register and Sporting Magazine, in 1829. being the first Agrasul-

tural and the first Sporting Periodicals established in the United Statea.

P H I L A D ELP H I A :

CLAXTON, REMSEN \& HAFFELFINGER,

1873. 


\section{SF951 \\ $\mathrm{M} 4$ \\ 1873}

Entered, according to Act of Congress, in the year 1872 , by CLAXTON, REMSEN \& HAFFELFINGER, in the Office of the Librarian of Congress, at Washington.

STRREOTYPED BY J. FAGAN * SON, PHILADELPHIA. 


\section{HPERACE.}

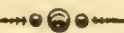

Few subjects can more justly claim the attent!on of the pubiic, than that noble and useful anima, the horse; and there are few indeed of any moment, that have met with more neglect from society. Not more than one or two authors in the United States have lurned their attention to this interesting subject. This neglect, in which every individual is so deeply interested, must have proceeded from the low standing in societv to which the horse has been sunk by men destitute of veracity, too often having the opportunity of dealing in those invaluable animals, committing frauds, making false statements of age, gaits, condition, \&c. to the injury of those who are unfortunate enough to confide in their nssertions, or to deal with them.

In this little work, whose size is calculated for the pocket, I shall endeavour to guard the unsuspecting rgainst the arts of the jockey, and to point out so plainly the difference between an elegant and a common horse a good and bad horse, a sound and an unsound horse that any person may become a tolerable judge, by reading this little book with attention, however unfamiliar the subject may have been heretofore. It is my object to be useful rather than offend, or appear learned. I shall avoid all hard names, technical terms. Er..; and will offer to the public the information I 
possess, with candour and simplicity. In a work of this nature; the claim to entire originality must be relinquished: so far from attempting it, I confess 1 have, in a few instances, made quotations from other authors, when I have found from experience they contrined matter, useful, clear, plain, and familiar for my purpose. I hope this acknowledgment will be received in place of marks of quotation.

Amongst the great number of animals under the iontrol of man, the excellent horse, unquestionably, is the most serviceable. How often do we see him the sole dependence of the poor farmer and his family, with whom he divides the morsel, shares in the toils, and by slowly turning up the soil, not only keeps the:n tree from want, but fills the barn with plenty! Trace nim from the lowest to the highest situation, you will find him faithful, affectionate, and no less useful. In every species of farming, the horse bears the principal burden, and is the means of increasing wealth and bappiness. In the transportation of foreign growth and manufactures to the interior of our country, and the exportation of the protuce of the United States, the faithlul horse affords a speedy conveyance to and from the water's edge. For the quick communications by posts and stages, even with the most remote parts of the union, we are indebted to the horse. Even our happy republican govermment has been established. protected, defended, and administered, by the means and aid of these noble animals. Men of every profession, must all acknowledge the benefit derived from him; indeed he has been the very spring of wunctuality and attention to business of almost every description. The horse, in his nature, is mild, patient, rorgiving, and affectionate. After being hard nsed, half starved, and unmerciti $\because$ heaten, who resol. 
lects ever to have seen him appear to fecl tho injug. pout over his scauty allowince, or discover hatrea towarls his cruel master? View his gentleness and lindiness to a sot, who has indulged too long over his glass, often bending, tmmine and yiclding to his giddy head; and finally, when lie is prostrated in the dist, now often does the sargacious animal, when compelled to troad on him, bear lightly and tenderly; and when lose, appear unwilling to leave the helpless drunkard: how often on his back are we conveyed in safety at night amidst dificulties, dangers, and unfamiliar roads? And where is the rraveller that does not re. collect that when returning on his jomrney, and in search of his home, when a road before munoticed. had bewildered and stopped his progress, how readily and how faithfully has the horse thown his ears towards the right road, and with quickening steps dis wrered his eagerness to reach his home? See him in the race, resolute, caner, and deliented, swclling erery vein, and exerting erery musete and filne to win the frim. Pehold him in the ficld of batte, furous, in

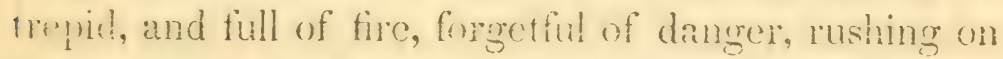
the print of the hayonet, delighting in the erlitering of arms, and panting for virtury. Thew hin in the civil and more hapy circles of domestic life, in the scrvice of the rich, the liberal, and the happre proudly and smouthly rolling belind him the rattling eharion weels, with an aspect lively, gay and cheerfil. If to an animal like this, I can lie the cause of abldiog to his comfort, improving his condition, making lim fat, relieving his pain, lemerng disease, and sometimes save life, I shall feel as il I hath rentiered a servicos to ite community at larere, and perfirmed a part of tha rask assigned me. 
When the reader reflects that a large volume has been written on the anatomy of the horse's foot alone, he will easily conceive my confined, embarrassed, and cramped situation; having to treat of so many difierent parts and subjects, within the scope of two hundred pages. In doing of this, it will be impossible for me to give more than the skeleton or bare outline of the interesting theme, which $I$ hope, at some future day, will be filled up and completed by some more fortunate genius. 


\section{TABLE OF CONTENTS,}

ro

MASON'S FARIER.

Appendix to Mason, PAge $195 \mid$ Journey, treatment on Pás 5

Addenda to Mason, 289 Keeping 23

Age,

Breeding and raising,

72 Legs

82

76 Lampass

103

29 Lock Jaw 148 do. do. by Broadnax

Blooded horse, to choose

Lost appetite

149

Blaze or star

37 Marks

79 Mane and tail

78

Body

Broken wind

Bots or grubs

Bruises

81 Moon Eyes

85

98 Mange

92

Big head

118 Mash

137

132 Mules

156

140 Narrow heels

159

Blisters

153

Bleeding

Carriage horses

$15 \tau$

Neck and shoulders

101

19

Castrating colts

Crib biting

Chest founder

Colds

Colic or Gripes

Clyster or glyster

Docking

Ostler

82

60 Pricking

48

97 Poll evil

45

100 Purging or Diarrhcea 151

150 Race horse 22

113 - rider 24

Diseases, infectious to prev.

Diarrhoea or purging

Diabetes

154

152

158

Driving

Excessive fatigne

Eyes, good and bad

moon

Foxing

Futtening

Founder, chest

Founder

Farcy

Fistula

Fomentations

Galls, wind

Gravel in the bladder

86.

86

92

\section{8}

63 String halt 99

- Horses, English modo

of management. \&c.

Ring bone

Saddle horso

Stables

39

Star or Blaze

Shoeing 83

Starting 93

Stumbling $\quad 95$

Spavin $96^{\circ}$

100 Splint

102

110 Scratches $\quad 117$

105 Strangles 123

145 Stone or gravel in bladder 124

155 Strains 133

104 Staggers 134

124 Surfeit 138

128 Sore tongue $\quad 140$

154 Saddle galls $\quad 150$

Glyster or clyster

Ilead

Heels, narrow

Hoofs

gravel in

Hiciebound

Iluoks or Haws

80 Sitfasts

151

101 Spot a white horse $\quad 157$

85 'Treatment on a journey ijs

128 Wind broken 98

137 IVind galls 104

121 Wounds 123

\begin{tabular}{ll|ll} 
Hinny and Mule & 159 & Wall's receipt & 158 \\
Irfojtious diseases to prev"t. 126 & Yellow water & 125
\end{tabular}

Irfojtious diseases to prev't. 126) Yellow water 125 


\section{CON'TENTS OF APPENDIX.}

IJ The following are Numbered instead of being Paged.

Altcrative medicine for live stock

Astringent medicines for live stock

Balls and drinks, mode of giving to horses

Balls, cordial cough, \&c. used in Veterinary practice

Belly, diseases of

Bladder, inflammation of

Bloody urine in horses

Blistering

- Siveating of Liquid

Bleeding

Blisters used in Veterinary

Pharmacopaia

Blood or bog spavin

Bloody. ray (see dysentery)

Blown or hove in cattle

Blast or hove in sheep

Blood rot in do.

Buwels, inflamention of

Bone spavin and splints

Braxy or dysentery in cattle

- in sheep

Broken wind

Bridle sores

Broken knees

Ciatarrhal fever in horses

Capulet of the hock in do.

Canker or quittor in do.

Castration, nicking, docking and cropping

Castrating lambs, \&c.

Catarrh or influenza in cattle

Cattle surgery

- obstetrics

- - vermin on

C'alves, diseases of

Calving

Chronic cough

Clysters used in Veteinary Medicine

Claveau, or sheep pax

Clystering

Vondition of horses

Cungh, chronic

... - - in sneep

118
Colic, red or enteritis

No. 15

53

_ in horn cattle 189 and 194

131 Corns in the feet of horses 101

Cracks

95

111 Cud, loss of 198

Cutting in feet of horses $\quad 108$

147 Curb of the hock in horses 92

39 Cutting and spaying pigs 243

62 Daisy or turning in caitle 199

193 Diseases of horses, see horse

Diseases in feet of horses 96

120

126

138

89

196

187

220

222

45

87

196

224

37

26

85

13

81

106

125

241

$2: 13$

1 i:

2011

204

209

207

205

36 and 218

.143

214

i22
Founder $\quad 98$

Contraction $\quad 99$

Pumiced foot $\quad 100$

Corns III]

Burning thrush $\quad 103$

Sand Cracks 104

Pricks 105

Quittor and canker 106

'Treads $10 \%$

Cutting 1118

Diarrhœa or looseness $\quad 5 \%$

Din cattle 195

210

242

Diuretic used in Veterinary Medicine

151

Diseases of horn'd cattle 173, 183

Diabetes, profuse staling or pissing evil

Drinks and balls, mode of giving in Vet. Surgery

Drinks in Vet. medicine

Dysenteric inflammition 49

Dysentery or braxy in cattln 196

- in sheep 2:

Dogs, diseases of 241

Asthmi 245

Sure eyes 248

Colic

Cough

Fits 254

Inflamed bowels $\quad 2.55$

Inflamed lungs $\quad 256^{\circ}$

Madness 257

Worming whelps $26 ?$

Minge 263--Worms . 2614
Sancer $\quad 219$

Distemper 2.12 
Finurocations used in Ve. terinary practice

Epirdenic fever or pest

Eijepsy

Eyos, horses, diseases of

Farcy,

Feet, founder of

Fetlock, strains of the

Fever in horned cattle $174 \&$ is3

Hever medicine, used in ve. terinary practice

Fistulous withers

Firing

Fret, culic gripes or gullion

Flux, slimy, see dysentery

Frontal worms in sheep

Fomentations in veterinary surgery

Founder of the feet

Foot stoppings for horses

Foul in the foot in outtle

Fout rot in sheep

Fumigations used in veteri. niry practice

ixall in sleep

(rid in do.

Gogrgles in do.

Glander =

Glanderous rot in sheep

Grease

firavel and stone in horses

(iripes, solic, fret or gullion

Gintta serena

Gullirn, colic, gripes or fret

Honsfa, disenses of

${ }_{i} n$ and out of con.

dition, and when

diseased.

$2,3,4$

Inflammatory diseases 5

Diseases of the head

Neck

Chest

Skin

Glanders und farcy

Diseasis of the ex. tremicir 8

D:scraes of the Feet

liepatit: $t=$ yellows

tide bourd

Hocf Liquid fus veterinary practice

Hove or blown in cattle

$H$ oru distemper or horn ait
157

28

121

54

236

113

96

$166^{\circ}$

202

232

157

224

$2: 33$

233

71

$21 \%$

93

65

53

20

53

1

5

71

71

76

96

58

70

162

187

208 Murrain in sheep

local horses horses in cattle rain in sheep ver in liorses
Hove blast or wind colic ir sheep

No. 220

Hogs, see swine

Hydatids or staggers in she्2, 223

Inflammatory fever in horse diseases

General 6

Local 7

Inflammation of the brain or phrenitis

Inflammatory fever in horse diseases, general

Iufluenza or catarrh fever in

Inflammation of the lungs in

Inflammation, of the howels 45

—_ of the liver 58

- in sheep $\quad 222$

Incontinence of urine $\quad 63$

Influenza or catarrh $\quad 177$

Inflammation of the stomach

Inflammation of the kidneys or red water 191

Inflammation of the bladder 193

Jaundice in sheep 223

Knees broken, in horses 85

Lampass or mouth disease 25

Lambs, castration of 241

- diseases of 238

Liver, chronic inflammation of 58

- diseases of in horses $\quad 58$

Lock jaw, in horses $\quad 11$

Looseness or diarrhœa $\quad 52$

Lungs, inflammution of 31

Malignant fever in horses 15

Madness, canine $25 \%$

Mange bif

- in Dogs 263

Mallenders and sallenders St

Malignant epidemic or mur-

Megrims 17

Morfounder or cutaırhal fe.

Moon blindness or opthalmia 1!

Mineral poison 40

Murrain or pest 15

- - in cattle $\quad 179$

21f: 
Nech, liseases of

No. 28, 30

Q Oolhalmia or blindness

Ointuments used for horses, cattle, sheep, dc. by Vete. rinary practitioners

Olstetrics in cattle

Overreach or tread in the feet

Pest or murrain

Peripneumonia or inflamed lungs in sheep

Pendro, a disease in sheep

Pinning do. in do.

Pharmacopœia in horses and cattle

Poll Evil

Poison, mineral

—, vegetable

$\longrightarrow$, in sheep

Poultices in Veter. surgery

Pneumonia or inflammation of the ungs

Pliysicking Process

Pricks in the feet

Pumiced foot

Purging medicine in Veterinary practice

Puckeridge or wornals in cattle

Pigs, see swine

Quittor and canker in the feet of horses

Salivation

Sand cracks

Sallenders and mallenders

Setons

Scalding mixture for poll evil

Scouring or diarrhea in hirn. ed cattle

Scour in sheep

Scah or slab in sheep

SHEE, diseases of

Sore thiroat

Staggers i. horses

- - in cattle

Staggers in sheep

Surdy

$$
\text { in sheep }
$$

Strangles, vives or ives

Etranguary or suppression of urue

\section{9}

Stone or graves in horses No. 66

Stomach staggers in sheep inflammation of 219

Strain in the shoulder $\quad 76$

- in the whirl bone 78

- in the stifle 80

- in the back sinews 81

—- of the log 82

$\longrightarrow$, of the fetlock and cof.

fin joints 83

Shoulder strains in horses $\quad 76$

Splints and bone spavins 86

Spavin, blood and bog 89

Skin, diseases of in horses 65

Surfeit

Surgery in cattle $\quad 199$

Swelled neck 30

SwINE, diseases of 242

- cutting and spaying 243

Tag-belt in sheep $226^{\circ}$

Tetanus or locked jaw in horses

Teeth

Throat, diseases of $\quad \ddot{29}$

Thick wind or pneumonia $\mathbf{3 4}$

Thoroughpin or blood spavin 89

Treads or overreach in the feet $10 \%$

Ticks in sheep, to destroy 2411

Turnsick, in horses 17

- in sheep $2: 33$

Urinary organs of horses, diseases of

Urine, suppression of , $\quad 63$

— bloody or stranguary 63

- incontinence of $\quad 63$

Veterinary operations on horses

Veterinary Pharmacopæia 127

Vives or ives $\quad 24$

Vermin on cattle 203

Warbles $6 \mathrm{~d}$

Warts 69

Wash medicines used by ve. terinary practitioners 167

Wind broken or pneumonia 3?

Whirl bone strains 78

Worms in horses 57

in slieep 236 and 237

Wounds, treatment of 110

Wornals or puckeridge $20 \%$ 


\section{CONTEXTS UF APPENUX}

Worm under the horn, a dis. ease in sheap,

Watery head in sheep

Wind colic in do.
No, 233

233

221
Yellows or liver complaint No. 58 , hot, in cattle 190 and $19^{-}$ 22 



\section{THE}

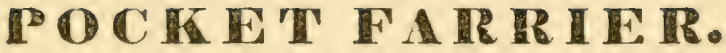

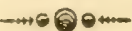

\section{SADIDLE HORSE.}

Wnw a horse is purchased for the saddle arone, 1 is to be presumed he must be clear of all defects. strike the fancy, entirely please the eye, and, from his happy symmetry and due proportion of form, stanu the second beauty in the world. When this is the case, he is seldom disposed of at too high a price.Amongst the great number of people in the United States, I inn induced to believe, there are but few grood judges of a hor'se calculated for the saddle Indeed, they are better informed upon almost an, other subject that can be mentioned. Yret the Vingrnians have a large number of fine horses, and are accused of devoting too inuch attention to that beatiful animal. Among all the difficulties attending the affairs of common ife, there is not, perhaps, a greater than that of choosing a beantiful, an elegant, or good horse. Nor will this appear strange, when we consider the number of circurnstances that are to be taken intw" ronsideration, with regard to shape, size, morements, imhs, marks, eyes, colour, agge, \&c. \&c.-which are so various that it would fill a volume to describe; and indeed the best judges are often obliged to content themselves with gruessing at some things, muless they have sufficient time to malie a thorough trial. If I were asked, what were the two most beantitul ohien 
In nature, I would answer, that woman, love $y$ woman, hefore whose charms the soul of man bows with reverence and submission, stands unparalleled; next to this matchless paragon, " beautiful horse displays nature in her highest polisu and greatust perfection; his gay and cheerful appearance, proudly prancing and bounding, his elegance of shape, smoothness of limbs, polish of skin, due proportion of form, and gracefulness of action, united to a mild, soft, faithful, and patient disposition, raise him far above the rest of the brute creation. I shall now proceed to lay down some rules, and to give some hints, for the examinauon of a horse previous to a purchase being made, to prevent the liberty of exaggeration, which is too frequently taken by dealers in those animals, and which too often terminates to the serious injury of the purchaser.

It is to be much lamented, that men who entertain a proper idea of honour in all the common aftairs of life, so soon as they become the owner of a horse. feel at liberty, without being sensible of doing violence to their morals, to knock off two or three years from his real age, and express themselves, with apparent delight, of services, gaits, and qualities, to which he never had any sort of claim or pretention; carefully keeping a secret every vice and defect to which he is subject. I do not pretend to say this is the case with all who exchange or sell a horse, but that it has often occurred no person will deny. If a fraud can be practised at all, it is sufficient reason for the inexperienced and unsuspecting to be placed on their guard. When a horse is offered for sale, I would advise the purrhaser to ask one question, viz: Is he in all respects ferfectly sound? Should a cheat be practised on you, under such circumstances, an action would die againgt 
the seller, and damages could be recoverabic; but be your own judge, not permitting any declaration thas may be made by the seller, to alter your opinion of form, age, condition, movements, action, \&c. As the eyes of a horse are the most important organ, first let him undergo a strict examination; ascertain his age, examine his figure and action; guarding yourself agrainst being toc much pleased or fascinated with the appearance of a new object; view his feet and legs; large ridges on the hoofs, or very flat feet, discover a horse to be subject to founder: large gouty legs, with enlarged tendons indicate strains and other injuries. examine his hind legs, with great attention, just below the hock and inside the hind knee; if there is any unnatural prominence or knot, unlike the other knee, it wears the appearance of a spavin, which renders a horse of but little value. Splint, which appears on the inside of the fore legs, and wind-galls, upon the ancles, are unpleasant to the eye, but seldom produce seriolis lameness; they furnish plain proof that a horse has been serviceable, and are very seldom productive of any other injury than stifliness, as he advances in years. Ride yourself, for the purpose of trying his gaits and qualities; as a rider accustomed to a horse, by private signs, such as manner of riding, bearing on the bit, le aning forward or backward, holding the heels close t' his sides, \&c. \&c. \&c., can make a dull horse appear gay and spirited, a wild horse gentle, a stumbler clear footed, one that is blind appear to see, and a starting horse free from that great objection. \&c. \&c Before mounting him, examine his knees, to discover if they are skinned, the hair off, or scarred; those are strong symptoms of his politeness to a fault. Ride with your tridle loose over any uneven ground: if he is in the haluit of stumbling, he will very readily inform voli: 
then approach some object offensive to the sight; it he appears much alarmed, stoppingr suddenly, and nttempting to turn round, paying but little respect to the bearing of the bridle, you may judge he has been long in the habit of that bad practice. Ride him in all his different gaits, to ascertain if they are smooth, easy, and agrecable; move him about a mile, out and oack, in fully half speed; frequently stopping hin suddenly to try his wind, also if he is spavined; if his wind has been injured, he will blow unnaturally; making a loud wheezing noise, with great difficulty of breathing. While warm, ride him in cold water above the belly; after which let him cool fifteen or twenty minutes, and if he is spavined, and has received temporary relief, by applications of any kind, the disease will make its appearance so plain, that you will discover evident marlis of lanneness. The spavin is often relieved for a time; and in a few instances has been permanently cured, by blistering, bathing with double distilled spirits, \&c. The brisk exercise, $\& c$. is intended to bring on a return of its elfects, $\therefore$ ease the animal should have had temporary relief from that distressing disease.

Having given such hints as I am persuaded will lead to the discovery of any material defects in a horse about to be purchased, I shall now procecd to the description of a horse that I consider elegant and fit for the saddle.

In order that he may have just claim to beanty ans elegance, his head must be small, thin, bony, and tanering; his countenance lively and cheerful; his ears quick of action, high, erect, narrow, thin, and ponting together; nis eyes kurge, round, full, and black. sparkling with cheerfulness, yet hushing his agitating rassions: "nte orter ant! ohedience: hos nostrils larese 
and expanded, and when in motion, disclosing a deer red colour; his brow and forehead smooth, and nor too flat; his nose somewhat rising, of good turn, and a little inclined to the Roman shape; his neck long. thin, delicate, and arched, forming a beautiful grada. tion from the breast and shoulders; his mane half the width of his neck, thin and smooth; his shoulders high tapering, and thrown well back ; his breast plump, full, and of moderate width; his fore regs straight, flat, sinewy, and thin; his arms large and muscular; his back short, and not too much swayed for strength and durability, but pretty even and straight; his body rather round and swelling than flat, and of proportionable size; his flanks plump and fill, and the last rib approaching near the hip bones; his hips and butrocks full, round, and well covered with muscles; his shine broad; his tail well placed, and naturally or artificially elegant, which adds much to his firure and gay appearance; his thighs long, from the hip to the naunch bone large and bulging with muscles; his hocks broad, sinewy, bony, and clear of puff's; his hind less from the hocks short. bending a little rather than straight, flat, and sinewy; his pasterns " noderate ength, small and bony; his hoofs cupped, smali, romo. and smooth; his hind parts not tucked, but of easy tun and graceful slope; when mounted his appearance ahould be bold, loftr, and majestic; his eyes shinng with intrepidity and fire; his movements licht and any as a phantom, with a fairy step, that would scal cely break a dew drop; his actions smroth and rraceful; his colour should suit the taste of the pur. chaser, though a mahngany bay is certainly the bes Bolour; his marks large, of irregnlar white, to light up the countenance, and at least two white lears, which will ard much to his beauty-though it must 'we ar 
kunwledged, that all parts of a horse that are white are much more tender than any other colour. When a horse is rode by any person for you to judge of his gaits, you should have him mored towards you, from you, and finally by you, as you may have the opportunity of discovering, if there is any turning in and out about his knees and ancles, before or behind, which is very objectionable. A well shaped horse will track as true, or his legs will follow each other in as direct a line, as the wheels of a well constructed carriage.For him to be considered a good riding horse, he should move with ease to himselt, and pass over the ground with great rapidity. Hard steps, short going, and great apparent labour, is offensive to the sight, unpleasant to the rider, and fatiguing to the horse himself. With respect to the colour of horses, people differ very widely; a black horse, with white face and legs; a grey, or a mahogany bay, with white marks, when well kept, are all showy colours; but for actual service, experience has proved, that dark colours, without any white feet, are far preferable; for who ever recollects to have seen a black, sorrel, or bay horse, with a bald face and four white legs, distinguish himself on the turf, in four mile heats? I am inclined to believe there is no first rate race horse, of that de. scription, within the United States.

I have, perhaps, stated some facts relative to horse jocker's, in a manner so plain and candid, as to draw from them their displeasure. My object is not to offend, but to instruct and be useful to those who want experience on the supject, for which this little book is designed

The annexed engraving (See Frontispiece) presents $\mathrm{nv}$ iden of an e'czant saddle horse; by a referer.ce to 



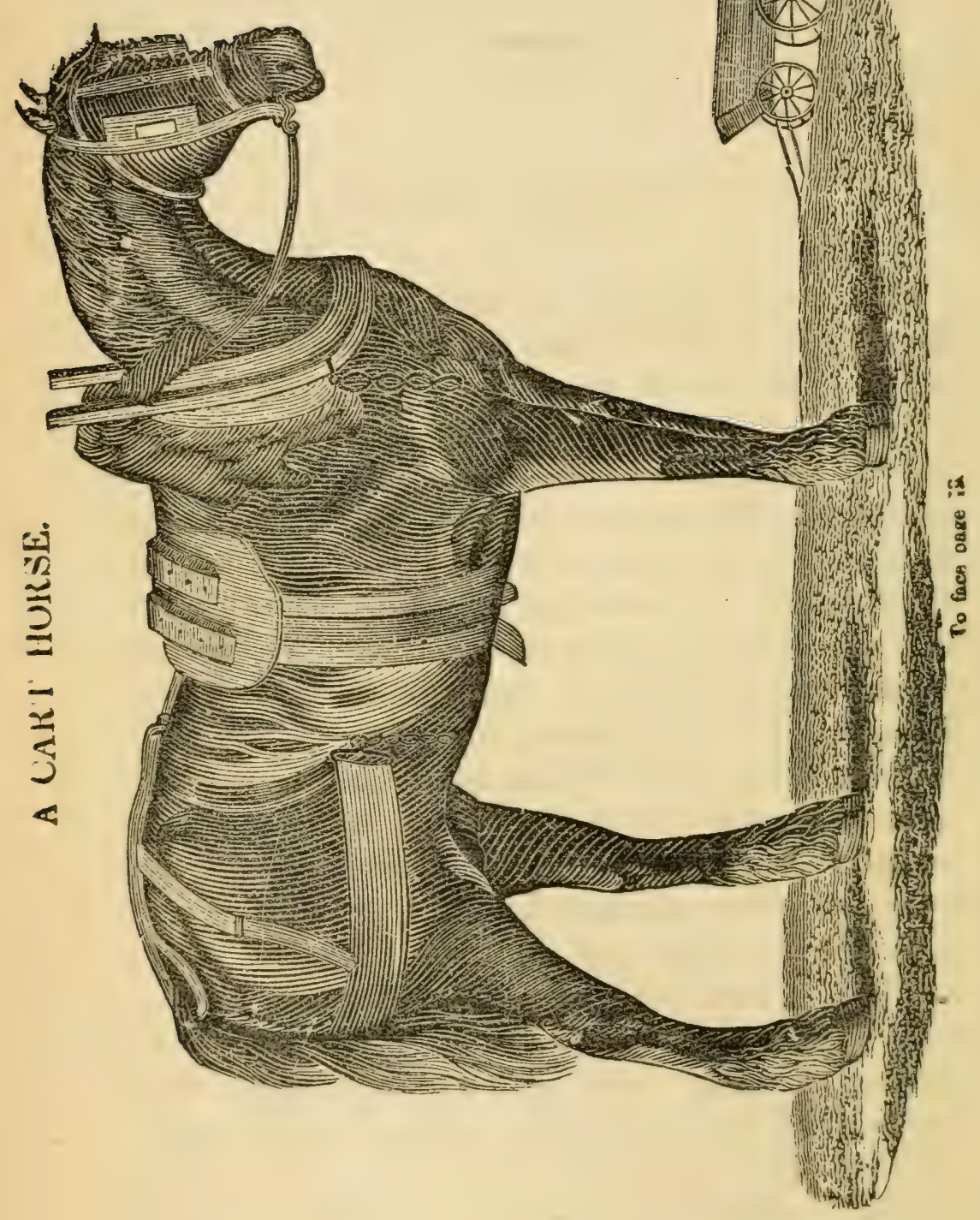


which, the judgment of a purchaser will not on.l we oenefited, but meet with eonsiderable support.

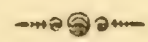

\section{CARRIAGE HORSES.}

Honses intended for a carriage or draft of any sescription, should be from five feet to five feet four inches high; though there are many excellent and truly valuable draft horses of much smaller size. The greatest attention should be paid to their habits, temper. gutality, and disposition. A horse that has been once frightened in harness, never again is safe for tha* emplorment. So retentive are their memories, that they do mot foret an alarm of that kind during their whole lives. For the want of experience on this subject, horses that have been frightened in harness have been hitched in carriages, which too often has been the ratuse of the untimely death of many amiable females and helpless children. Indeed, a pair of good and weli matched. gentle carriage horses, is rarely to be met with: as so many good qualities, together with a similarity of are, colour, size, and marks, is required to make them complete and valuable. Thrir eyes should be grond, carriage lofty, bodies propertionanly large, treasts full and wide, their whole bodies hearily museded: their heads, neeks, and ears deheate; their iegs large, sinewy, and bony; their pasterns short. and their hoofs moderately large, and not too that. They should he fre from starting, stumbling, and kirking 
and meir dispositions patient, gentle, and obedient. It very often happens that horses are kept together as a inatch, on account of their colour and similarity of. marks, when no respect is paid to their difference of form, spirit, and movements, which often differ as widely as the mettled racer from the dull cart horse When thus badly matched, they would very som be separated by a good judge, and nothing short of necessity should ever permit them to draw together. Carriage horses should carry good tails, naturally or artificially, which adds much to their gay and elegant appearance; presenting figures ready, apparently, to move upon the wind, whilst they are perfectly gentle and manageable. Horses of difierent colours, whose spirit, size, and movements are similar, are a much better match in harness than those of the same colour, with three or four inches difference in height; or one dull, and the other spirited; one young, the other old; une fat, the other poor; one with a bald face and white legs, the other with white legs; or one active, and the other clumsy.

I have thus taken up the time of the reader, to make him the better judge, and give him a correct idea of a bad match of carriage horses, which will assist him much in selecting those that are good. After being thoroughly satisfied about the shape, age, condition, dzc.., of a pair of earriage horses you may be about to purchase, it will be necessary, in justice to yourselt, to try them in harness; though the seller will assure you they are as gentle as lambs, true as honour, and finally, the best pair of horses in the world; although It is possible for such a stitement to be a fact, I woula advise that a trial shuuld be male, and the purchase hecome nis own judge: for which purpose have them iucheci in a carriage, and driven several times uf and 
anwn the steepest hill that the road may zross, which is most convenient: if they have any tricks, or are not true draft horses, it can be readily discovered: next, for the purpose of discovering if they have ever been alarmed in harness, fiequently open and shut the carmage door. alsomove and rattle the steps; if they have sver been frightened in harness you will very soon be zompelled to desist; then by coming to their front, and with attention observing their ears and eyes, you wil! be informed to your entire satisfaction, if they are safe

Horses that have been once alarmed in harness, so soon as they hear any rattling noise behind them, begin to grow restless, sinking or squatting behind, holding the head high, snorting, fetching long breatls, moving the ears with grent quickness, at the same time showing the whites of their eyes. Let me warn the reader argainst the purchase of such horses; they arc unfit and unsafe for the use of a family. Horses fir harness, that are fiery and fretful, are very objectionable, and should always be avoided; but great care should be taken to distinguish between animals of this description, and those that are eager and spirited; the former begin to prance and tret the moment they are out of the stable, until they exhaust themselves with fatigue; but the latter endeavour only to be first in the chase, or foremost in the field, and are truly valuable: possessing those qualities that resemble prudence and courage; the others, intemperate heat and rashness. Whenever carriage horses are driven, they should be moved off fifteen or twenty steps in a slow walk, without the cracking or flourishing of a whip, which is so much the custom, and which is very frequently the cause of high tempered horses refusing to draw. sfter which their speed may be quickened to whatever gait you may prefer, by the use of some kind word 
10 which all horses should be ascustomed. it is ierg much the practice with drivers to leave their horses standing in a carriage, without any person to hold ihem, for hours tngether. Having seen the worst of consequences result from this practice, (and with horses under the character of being gentle,) I would recom mend that drivers should never give up their reins until they are prepared with some person sufficiently strong to hold them. By using such precaution, the overturning and breaking many fine carriagres, and the ruiping for ever many valuable and elegant carriage horses, would be avoided.

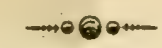

\section{RACE HORSE.}

I $\mathrm{T}$ is a remarkable fact, that horses run in all shapes. But most generally, those excel upon the turf, that are of the following form: head and neck thin, small, and delicate; eyes large, plump, and full of expression; nostrils wide, red, and expanded; throttle large; shoulders high, thin, and running very far back; breast plump, full, and wide; body long, round, and rather light than heavy; back short as possible; thighs long, large, full, and bulging; fore arm large and swelling towards his breast; hocks broad, strong, and bony; legs of moderate size, thin, flat, and sinewy; pasterns rather long and small, than otherwise; feet of proportionable size to the balance of his form; though, of the two extremes, small is the best; he should be nervous, tractable, ind of gooa spirit, and he should be from five feet to five feet four inches high. Such a horse, we.s managed, kept and placed in races, will seldom lail in ristinguish himself on the turf. 


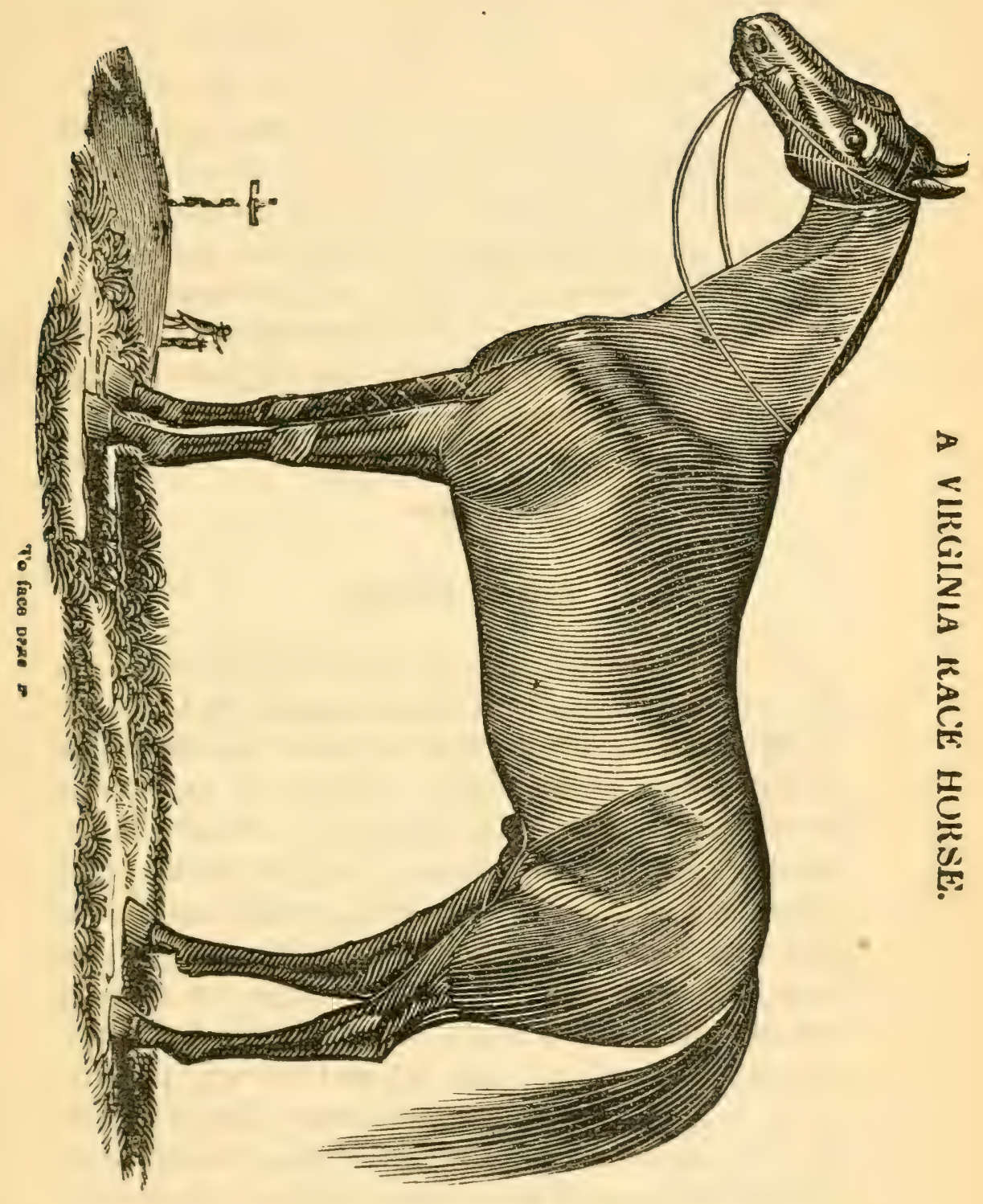





\section{KEEPING}

Trie keeping a horse for a race is attended with much trouble, and requires great attention: but is more simple than is generally believed by persons wanting experience on that subject.

A large majority of grooms, even to the present day are in the habit of giving to race horses large quantities of physic, (though the number engaged in tnis practice has been diminished within the last ten years,) and for the sake of those very valuable animals, I hope ere long, such an injurious practice will be entirely abolished. All the medicine on earth will never give to a horse speed and bottom, that is naturally deficient in those respects; and if he is affected at all by its use, it must operate to his disadvantage.

The plainest and simplest mode of keeping horses. has proved much the best, to all who have ventured, in defiance of old opinions and customs, to use that course. When a horse is in health, the medicine generally given by grooms, has the effect of relaxing the inuscles, enfeebling the system, and expanding the pores of the skin. I am clearly of opinion, that those large doses, which are so often given, never cause a horse, when running, to fetch a longer breath, braced his muscles, added to the elasticity of his tendons, in vigorated his system, or gave him, in any way, extra powers to perform the task assigned him; but on the contrary, are frequently the means of throwing a worse out of order, that in all probability, under difierent treatment, would have proved successfi!, if not master on the turf: indeed, this has sometimes been proved br the change of owners, and when a gooo 
horse has fallen :nto the hands of one that has olserver plain and simple treatment- the horse that previous to the change never was more than second or third best has run with more than anticipated success.

But trany old and ignorant grooms who have neves been benefited by experrence, and all the knowledge they possess have been handed to them by persons equally ignorant with themselves, are under a belief, that unless a horse swallows a certain number of wind halls, that it is impossible he can win a race; added to which, they are extremely superstitious, and some, even at the present day, confide in tricks and witchcraft. It is to be much regretted that a good horse snouid e er fall into the hands of such blockheads.

The first thing necessary in the keeping a race horse is, a good $\log$ stable, about fifteen feet square: then provide a plenty of good and sweet old corn, fodder and oats, and a suflicient quantity of clean and dry straw, to change his bed every two or three days.

Most horses, when first talien up for the purpose of heing kept, require bleeding; which a groom can always be a judge of from the appearance of the animal. Good cluths, girts, \&c. should be provided and kept on the horse, except at the hours for rubbing, which should be regularly three times a day; in the morning, and evening after practice, and at twelve o'clock; for which purpose a curry-comb, brush, straw and a large woollen cloth, must be provided and well used. Good rubbing assists in putting a horse in order, and places on his skin a beautiful gloss. His legs must be washed three times a day in clear cold water. after which they must be rubbed dry with straw, anci the naked hand rubbed over the ancles and pasterns. lintil a small degree of warmth is felt The stable should be kept perfectly clean. 
A ho/se should be given such practice as $\mathrm{h}$ ic is well able to bear. As those animals frequently difler in cvery respect so widely from each other, it is impos. sible to lay down any rule that should gorern, relative to the speed or quantity of practice necessiry for horses in training. I wall only remark, that a horse should be practised in a moderate gallop, the distance he is intended to be run, moving briskly every time he passes the stand, and for a short distance on the back of the ground: he then should be walked about a mile, and agrain gallopped in manner first directed. Some fleet and delicate horses require very little practice indeed; while other hardy and hard bottomed horses require and can bear verv hard practice. But the appetite of a horse is the best criterion, as relates to that sulject.

If a horse refuses to eat, it is an evidenor that his practice is either too hard or too quick; when he eats heartily, it is a proof that he is able to bear what is given him. When a horse is first taken into keeping, his allowance for the first two or three days, should be rather short; which should be offered four times a day. His exercise should be walking, for the first three or four days; two or three times the distance, or round the course of nis contemplated race; after when time, his food may be increased with his exercise, and he may be regularly fed with from two quarts at a fied to four quarts. His food should be often changed and prepared thus : his hommony (Indian corn ground coarse) should be first winded, then thrown into clean water, so as to separate the part that is nutritious from the husk and chaff; the oats should be lightly beaten II a common hommony mortar, to separate the $n$ from the hull or chaff; which may be blown off; his fodues shocild be stemmed whenever it is discorered he nus 
'oo much belly. A horse never should be drawn suddenly, as nothing is more weakening.

'The best medicine on earth, that can be employed in keeping of a horse, to give him wind and bottom, as the grooms term it, is good and sweet food. A greater propurtion of old oats, hay, or hommony, opens the bowels; and a large proportion of fodder and oats, when prepared in the way directed, has the reverse effect; so that by using food that actually contains nourishment, and will certainly benefit your horse, you may place him in whatever kind of order you think proper, without using those medicines which have a certain tendency to weaken and relax him. About two mashes during the time of keeping, is very beneficial; the first as soon as you commence; the second, about eight days previous to his running; composed of one gallon of bran, one table spoonful of flour os sulphur, and one tea spoonful of saltpetre. Most grooms are in the habit of giving one, two, or three sweats, during the time of keeping; which method of hardening the flesh I am much opposed to. If a horse is tno gross, gradually increase his exercise, which will have the desired effect. Whenever a horse has to undergo one of those sweats, he is so much weakened and relaxed, as to require at least one week to recores his strength. Should a horse, in keeping, lose his appetite, it can readily be restored, by a single innocent drench, composed of a quarter of an ounce it asafœida, one table spoonful of salt, and one quart of sassafras tea. Good food, regular feeding, moderate exercise, and strict attention to rubbing, are of much more importance and benefit to a horse in keeping, than the aammistering of large doses of physic, which !ns rature does not require.

When a horse is wel! kept, he wili nor appear very 
fat, but his flesh will be very firm and hard; his legs and ancles must be perfectly cool, and not puffed or swelled; his eyes should be lively, anà countenance cheerful: he should possess no bad habits, but te: tractable, gentle, and manageable; his actions smooth and graceful ; he should be taught patience; and often fractised in starting around the race course, never permitting him to go ofl, until the word GO is given. Many advantages result in a race, to a horse, being properly broke in starting.

After a horse has gone through his practice, and has been well rubbed, \&c. \&c. his feet should be stuffed, (during the time of his standing in the stable) with fresh cow manure, or clay and salt, to prevent his ancles from swelling or being heated; his legs should be bathed once a week, with equal parts of old peach brundy and fresh butter, or sweet oil and vinegar, stewed over the fire until well mixed, and applied warm as the hand can bear it.

Whenever a horse commences his brisk exercise. the under part of his ancles should be occasionaliy greased, to prevent their cracking and the scratches being produced. The heels of most young horses crach, during their exercise, unless this precaution is used; fresh butter, sweet oil, or hog's lard, answers well for that purpose.

The subject of keeping horses is so extensive, that tc treat fully on it, would require a book at least the size of this; the reader, therefore, must be conter with the few hints and few pages I have devoter tu this subiect. 


\section{RACE RIDER.}

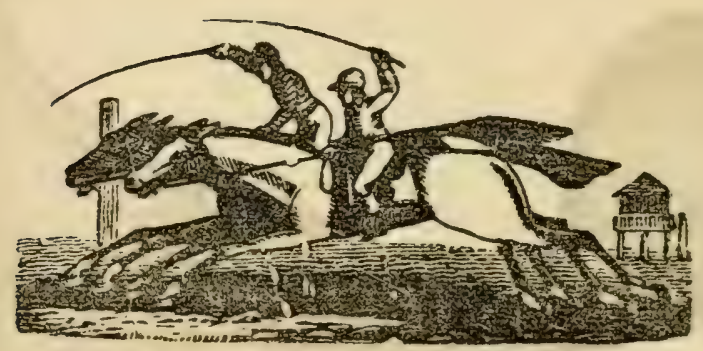

'I'r hecome a valuable and a good race rider, reciume more capacity, judgment, experience, and honour, than are often found in boys in the habit of riding. And no person can be successful on the turf, unless he can place the utmost confidence in his rider; whose in. tegirity and honour it would be advisable frequently to put to the test. Boys are sometimes so young, foolish, and destitute of principle, as to receive bribes and promises: preventing the best horse from winning, to the disgrace of all concerned, and the serious iniury of his owner, who, in such cases, never should taul to make an example of all persons engaged in the villany.

A good race rider will have the pad of his sadule wet, before he mounts, to keep it firm in its place; he will try his stirrups, and prove them long enough to raise himself about two or three inches clear of the saddle: he will then tie his bridle a length that will allow his horse, when he bears him gradually ari: steadily, to run at his sase, without being jerked or jostled; he should never make a false start, but come up even and go off smoothly, withont fretting or zausing his ne se to rear; and above all other things 


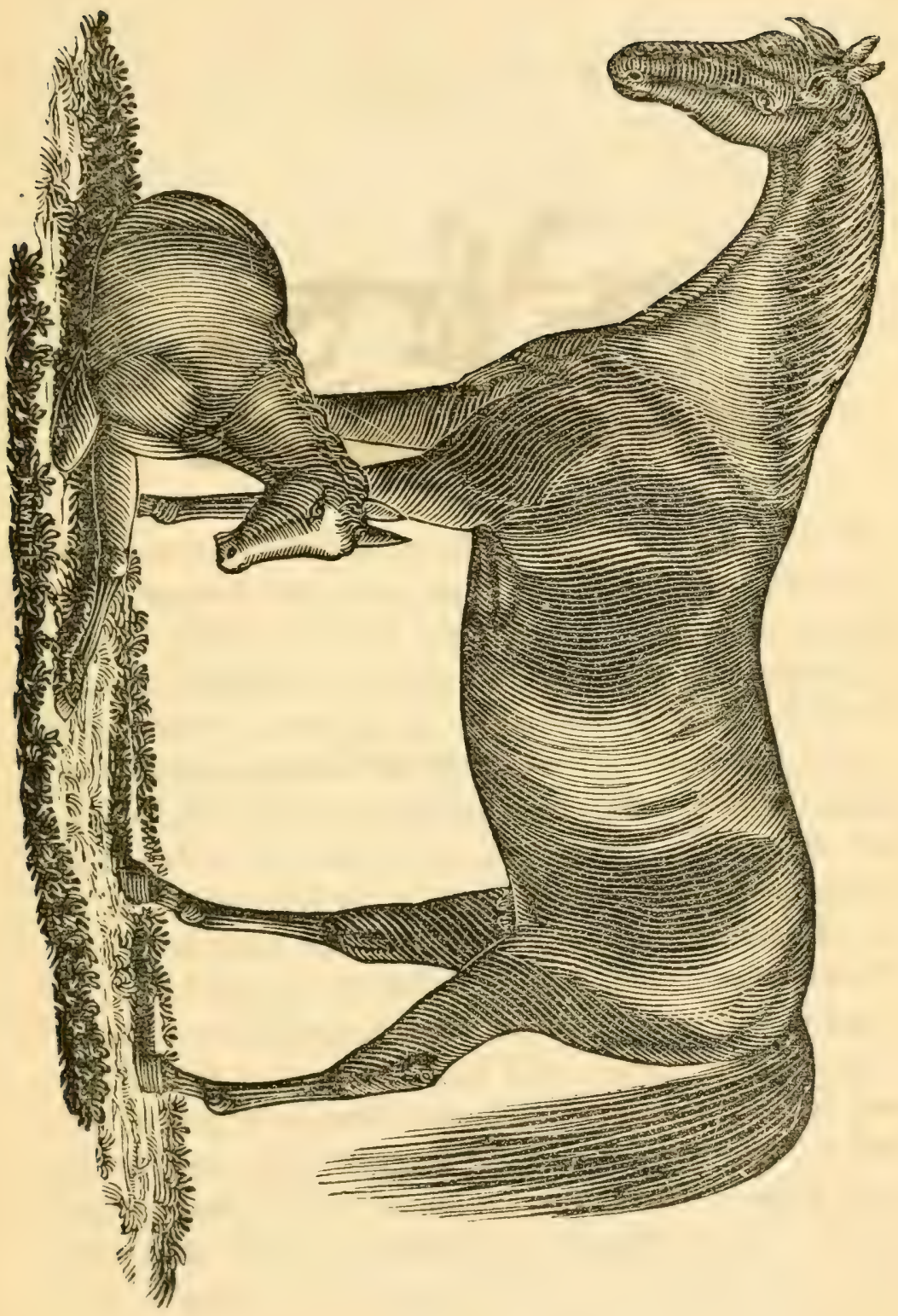



strict and pointed attention should be paid to the ondirs given, and they rigidly adhered to.

A rider should bear a little forward, steadily as possible, and without altering the attitude of his bouly, when whipping, pushing, or running at his ease, taking great care to remain steady in his stirrups, holding his elbows close, and his hands low.

A rider, after rumning his heat, should never dismount, or give up his horse to ary other person, until it is his turn to prove his weight, and is directed to come to the stand.

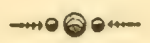

THE

\section{BREEDING ANI) RAISING OF HORSES.}

Tre breeding and raising of horses, to most persuns, is a very amusing and pleasing task; but it is attended with much trouble and expense, unless well managed. und then it becomes not only a subject of profit, but is well worth the attention of any person, whose situation will admit of it, for the purpose of making a fortune.

The raising of cold blooded or common horses, is generally a disadvantage to any peison, being neither interesting or profitable. A colt three years old, of the above description, seldom costs the owner less than one hundred and twenty dollars; and when he makes a sale, twice out of three times that sum cannot be shtained; consequently there is a loss, independent of trouble. But colts, three or four years old, from: the best stnck in the Inited States, of large size and 
having distingurshed themselves on the turf, have st manded from one hundred to one thousand pounds.!

By raising and running such horses, large sums of money have been accumulated in the United States, and particularly in Virginia, where the blood, speed, and beauty of horses, are equal to any in the world.

Much has been stated by English authors, on the subject of blood, form. and speed of the English horses; particularly Dorimant, Bay Malton, Eclipse, Highflyer, Matchem, Shark, Childers, \&c. \&c. \&c. But could the blood, form, speed, and bottom, of our American horses, Brimmer, Chanticleer, Leviathan, Virago, Surprise, Florizel, Potomac, American Eclipse, \&c. \&c. \&c. have been contrasted with them, I am induced to believe they would have had the same claim to the page of record and superior performance.

True it is, that of Flying Childers it is stated, thit ne run a mile in a few seconds over a minute. My regard for the life of every human being, particularly a valuable race rider, induces me to wish our herses may never perform the mile in that time, though we have several amongst us whose speed is unknown, although they were on the turf several years, contending with very fine race horses.

I must confess, that for a horse to run a mile in a minute, or eighty-two and a half feet in a second, fas stated) surpasses any idea that 1 have entertained of the velocity that a horse was capable of.

In order to raise a heautiful and grood racer. a slunl should be made choice of. that will be a grood cross, and of the best blood; not less than five feet two, though five feet four inches high, is a preferable size. He should be well proportioned, elegantly formed, of mahu. gany bay coluur, and clear of all defects. perticu 
Iaily spavin and blindness: and should nct only have poved himself in possession of speed on the turt, but bottom also; and should be a sure foal getter.

A mare should be made choice of, not less than five feet high, with a delinate head and neck, great length of body, large belly, and above all other things, one that has proved herself, by her colts, to be a grood breeder.

When you commence breeding with a mare of this kind, you are almost certain of raising a valuable colt. But when you commence with one untried, you run a great risk of losing time and raising a horse of the 120 dollar price, unless the mare, or stock from which she originated, was first rate and remarkable for their fine colts. Indeed there appear's to be the same similarity in the blood of horses that exist in men, as respects their good and bad qualities, shape, \&c. \&r: We find vice common throughout some families, while we see virtue reigning in others. One breed of horses, under every care and attention, will only raise you a coarse horse or pony; whilst good blooded horses. even half starved and under every disadvantage, will show strong marks of beauty, activity, and size; and after winning from his master kind treatment, often becomes the champion of the turf. I have known several first rate race horses that were once plough and draft horses.

A brood mare, that has produced one or two good racers, from a good cross, in all probability will, at nny time produce one, when under similar advantiges. When a colt is foaled early in the spring, he will be under every benefit that can be derived from size strength, and age; consequently, it would be advisable: to put a mare to horse at such time as would produre a colt abont the fifteenth or twentieth of 1 pril. A 
mare generally goes with foal eleven months and as miny days as she is years old. A colt foaled in April, when three years old would have to carry no more weight in a race field than one foaled in August; which would give to the one first foaled a difference of three months of age, and of equal blood and under similar advantages. The one first foaled ought very certainly to prove best on the turf, from three to seven years old After your mare has been put to the horse of your choice, she should not be confined during her preg. nancy, but a house or shed about twelve feet square. should be built for the purpose of sheltering her from the rain or bad weather; the south side of this house should be left entirely open, so that the mare might come in or go out at pleasure : and a manger and rack should be confined in it for the purpose of feeding. A good bed of straw, and that frequently changed, will add much to her comfort, and she will be induced to sleep under the shelter if the litter is kept clean.Adjoining this house there should be a lot, cnclosed with post and railing, containing from one to four acres of ground, clear of snags, grubs, and stumps; in which the mare should be confined about two oi three weeks previous to her foaling: she will then be convenient to assistance, should any be necessary.

Mares frequently produce colts at fourteen or fifteen years of age, and sometimes twenty; but from five to twelve years of age, from experiments made, appears in be the most valuable part of a mare's life for raising colts. Experience has also proved the great advan tage resulting to the form and size of a colt, from setting him get thin upon grass alone, two or three limes previous to his being three years old; after which imme he may be constantly pushed as much as possibie.

When the dam and sire of a colt are small, it is to 
be presumed a colt produced by then will make a smail horse, although there may be no ohjection to the blood: and if he makes a race horse, it will be of the unprofitabie kind. He may be a winner at three years old; at four years old, sccond best; and being tro sinall to carro weight, he never can win again. Such a horse will not command a high price with a judge of horses, as it is evident tinat a large horse, with the same weight, will beat a small one, when they are equal in all respects except size. Indeea', for the purpose of draft or riding, a large horse will command double the sum of a small one, which plainly proves the importance ot breeding from a large stock.

When a colt arrives at the age of two and a half years, it is time he should be handled, and taught the use of the bit. It is of great consequence he should be first gentled by a person who well understands the management of horses, to prevent bad habits; as first impressions are never entirely removed from nuan or beast. 
I Thr following is the mode of raising B!onded Horses, as pursued by Win. E. Broadnax, of Brunswick County, Virginit.] 'FKOM THE AMFRICAN FARMER.]

\section{MODE OF RAISING BLOODED HORSES.}

"In the first place, be particular in selecting a gond stock to bresd from. When the mare is near foaling, let her be to herself, and if early in the season, let her have a good roomy stable to foal in; and in good weather, let her and her colt be turned into a lot, (ot wheat I prefer.) Wean the colt the first of October in a stable, until it is done snickering after its dam; then turn it in a lot; if you have more than one, they will do best together.

"Stable them at night, and turn them out in the day exceft in very bad weather: force them all you can the first winter. To do this, their principal food should be cut vats moistened with a due proportion of corn meal sprinkled over and mixea with them. Most foals are apt to be too delicate; forcing them, and keeping them warm at night, will increase the size of tre.r limbs in proportion to the weight of their bodies. After they are one year old, they should not be kept so fat, nor yet permitted to get poor. A stud colt, which is intended to be kept as such, should be separated from other horses at a year old, and stabled of nights; his rack and manger should be so high as to strain him a little to get food; the windows of the stable should also be high, as he will be looking out at them: by these means his shoulders will be thrown back, and his withers raised. If it be wished to increase his quarrers, enlarge his muscles, and other material parts, keep him in the stable frequently, for several days wgether, which will animate him; then turn him o'dt in 
a lot, and encourage him to run and exert himself a:i you can, as his parts will acquire size and strength in proportion to the use made of them.

"I would recommend a mare of good form and thorough blood, thuugh she cost the most, because her colts would cost "o more to raise them than those frum an ordinary mare, and would probably sell for more than three or four times as much. The reason I would wean in a stable is, that in the usual way of weaning in cornfields, \&c. the colts run themselves poor before they are weaned. I prefer wheat lots for mares and colts, because they like it better than any thing else, and $I$ think it agrees better with them. I find outs made use of as above stated, not only the most healthy and best, but also the cheapest food for mares and colts. In pursuing the course which has been laid down, I obtained the following results :

"I selected a mare which I knew to be of gond stock, but from improper raising was only four feet six inches high, and very delicate: The first remova: from her was four feet ten inches; the second remova five feet; the third was five feet two incnes: the fourth was five ieet six inches." 


\section{RAISING OF COLTS.}

Tive following answers were returned by William $R$. Johnson, to questions propounded by J. Murshall, of Fauquier Co. Va.'

"Senate Chamezer, February 4, 1829.

1. Keep the colts in pretty good order, not too fat, until they are too years old, then break them gently.

2. Keep them in lots, it does not matter as to size, taking care not to allow them to see other horses more than possible.

3 and 4. Grass lots are best, and short grass.

5. Dry food mostly - when young, cut oats.

6. Give corn in the winter; oats in the summer; not inore at a time than they eat clean. When they are once fat very light feeding is best.

7. It is not at all necessary to rub them until they are two years $r^{\prime} d$.

8. Wean the colts at about six months old.

Should the above answers to your questions not be sufficiently explicit, they will be with great pleasure udded to.

\section{Respectfully,}




\section{[FROM THE AMERIOAN FARMER.] $\sim 9$ \\ THE BLOODED HORSE.}

Yow to choose a race horse by his external appearance, and to bo a judge of his symmetry by angular demonstration.

\section{RULES.}

1st. Draw a base line from the stifle joint along the onttom of the chest to the extreme point of the eibow. and to the shoulder-blade joint.

2dly. Draw a line from the curb or hock by the hip joint above the back, to an imaginary point.

3dly. Draw another line from the point of the s'roulder, ranging with the shoulder, and passing abo e the back, until it intersects the line at the imaginar: print.

4thly. Draw a line from the intersecting poin of the shoulders, giving the same declension until it in ersects the base line.

5 thly. From the stifle to the point of the lattock thence to the hip, aint, thence declining to the tifle.

6thly. Draw a line from the hip to the $b$, e line right angular declension, then to the shoulder 1, to the chest.

7thly. Then draw a straight line, regardle $s$ of the curve of the back, to a straight line intersecti.ug at the shoulder at the beginning of ti.e crest.

8thly. Then take a line from the point of the shourder, and angular degree, ranging vith the shouiderblade to the top of the crest.

athly. Then, regardless of the risung of the crest 
draw a straight line from the top of the shoulder-blade to intersect with the point of the former line.

Thus the real symmetry of a grand and beautiful horse, possessed with muscular powers and strength, is formed by a right-angled triangle; and the farther finm it a race horse's form is, the less pretensions that norse has to beauty, speed, hottom, or lastingness, ability to carry weight, or actıvity.

A thick, upright shoulder, is a very certain mark of a "stumbler," and is fit for no use whatever but the slow draft.

A low coupling in the back, is a true mark of weak uess; it denotes want of strength, lastingness, ability to carry weight, or speed.

A low loin, is a certain mark of weakness, and a weakly and washy constitution.

But a rising loin, of ability to carry weight, speed activity, and lastingness, and a good constitution, sym metry, beauty, and muscular strength.

A race horse's legs cannot be too short.

$A$ great declivity, and thin shoulders, denotes speed.

A narrow breast, weakness

A horse's breast bone, formed like that of the rabbit, denotes also speed, and it is the best form for a race. horse.

A short, broad hock, denotes strength: a broad stifle: well let down to the curb or hock, denotes bottom or lastingness, strength, and activity.

There are not two race horses in five hundred, properly formed in the knees; which should be small, jivested of superfluous appendages, and strong; they aenote activitv and strength. 
A lax, bending pastern, denotes also speed; a long norse is preferable to a short one, because he can cover a great deal of ground, and can bear pressing hetter and longer.

The race horse, upon the whole, whose form in general, is composed of the essential properties of the following animals, viz. the rabbit, grey hound, and ostrich-is the best.

\section{Gorwond.}

\section{December 6, 1827.}

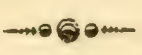

The following is the English mode of manngement and working of Race Horses.

In the managing and wolking of race horses, three things are to be considered: the preparation of the horse, the conduct of the rider, and the after treatment of the horse. The preparation of a race horse for running a race is not the wo k of a few days, if there be any great dependence un the success. A month at least, is required to harden his muscles in training, by proper food and exercise, and to refine his wind, by clearing his body to that degree of perfec. tion that is attainable by art. It is first necessary 10 ascertain correctly the present state of the horse, as whether he be low or high in flesh; and in either rase, a proper estimate should be formed of the time snd means required to bring him into true running condition. 
If u race horse be low in flesh, it is necessary to mdge of the cause of such state, and to act accordingly. It is to be remarked, that spices are less to be dependerl on for this purpose than generous food, as malt mashes; and if any thing of the kind be used, let it be the simple cordial ball. Feed trequently, and by little at a time: while he is thus low, let his exercise be walking only, and by no means spare his water, or he will become hide-bound: carefully watch him, that full feeding may not disagree by making his heels swell, or his coat unthrifty ; and if such appearances occur, mash him and begin his scourings, otherwise abstain from physic until he is in better health. As he improves in condition, increase his exercise, but not to such a degree as to make him sweat: his food must now be the best oats and beans, with wheaten or barley bread; the beans and oats are to be put into a bag and beaten until the huils are $a^{\prime \prime}$ off, and then winnowed clean; the bread instead of being chipped in the common way, is to have the crust clean off.

If the horse be in good flesh and spirits when taken up for his month's preparation, cordials are altogether unnecessary; and the chief business will be to give him good food, and so much exercise as will keep him in wind, without over-sweating or tiring his spirits.-When he takes larger exercise afterwards, towards the end of the month, it will be proper to have some horses in the place to run against him. This will put him upon his mettle, and the beating them will give him spirits. This, however, is t. be cautiously observed, that ne has not a bloody heat given him for itin days or a fortnight before the plate is to he run for: and that the last heat that is given him the day before the race, must be in his clothes: this will make him run with greatly more vignur when stripped for the race. and feeling the 
cold wind on every part. In the sceond week, the hurse shumbl have the same food and more exercise; and in the latst fortnight he must have dried oats, that have been hulled by beating: after this jockeys wet them with the whites of eggrs beaten up, and then laid out in the sun to dry; and when dry as tefore, the horse is to have them: this sort of food being considered by them as very light of digestion, and very good for the creature's wind. The beans in this time should be griven more sparingly, and the bread should bo made of three parts wheat and one part beans, or of wheat and brrley in equal parts. If he should become costive under this course, he must then have bran-water to drink, or some ale and whites of eggrs beaten togrether ; and keep his body moist. In the last week all mashing is to be omitted, and barley-water given him in its place: and every day, till the day before the race, he should have his fill of hay; then he must have it given him more sparingly, that he may have time to digest it: and in the morning of the race day, he must have a toast or two of white bread soaked in ale, and the same isst before he is led out of the field. This is an excellent method, because the two extremes of fulness and fisting are at this time to be equally avoiaed; the one heating his wind, and the other oceasioning a faintness that may make him loose. After he has had his food, the litter is to be shook up, and the stable kept quiet, that he may be disturbed by nothing till he is taken nitt to run.

In the choice of a rider for womning a race, it is necessary, as far as possible, to select one that is uot only expert and able, but honest. He mist have a verv close seat, his knees being turned r:lose to the saddle shirts, and held firmly there; atıd the toes turnea inwards, so that the spurs may be turned outwards io 
the norse's belly; his left hand governing the horse mouth, and his right the whip. During the whole time of the race, he must take care to sit firm in the saddle, without waving or standing up in the stirrups. Some jorkeys fancy the last a becoming seat; but it is : ertain that all motions of this kind do really incommode the horse. In spurring the horse, it is not to be done by sticking the calves of the legs close to the horse's side, as if it were intended to press the wind out of his body; but on the contrary, the toes are to be turned a little outwards, and the heels being brought in, the spurs may just be brought to touch the side. A sharp touch of this kind will be of more service toward the quickening of a horse's pace, and will sooner draw blood than ne of the common coarse kicks. The expert jockey will never spur his horse until there is great occasion, and then he will avoid striking him under the fore bowels, between the shoulders and the girt; this is the tenderest part of a horse, and a touch there is to be reserved for the greatest extremity.

As to whipping the horse, it ought always to be ilone over the shoulder, on the near side, except in very hard running, and on the point of victory; then the horse is to be struck on the flank with a strong jerk; for the skin is the most tender of all there, and most sensible of the lash. When a horse is whipped and spurred, and is at the top of his speed, if he clap his ears in his pole or whisk his tail, it is a proof that the juckey treats him hard, and then he ought to give him us much comfort as he can, by sawing the snafile tack wards and forwards in his mouth, and by that means torcing him to open his mouth, which will give him wind, and be of great service. If there be any high wind stirring in the time of riding, the artful jockey will let his adversary lead, holding hard behind him, 
ill he sees an opportunity of giving a lnose; yet in this case he must leep so close behind, that the other norse may keep the wind from him ; and that he, sittung low, may at once shelter himself under him, a'su nssist the strength of the horse. If the wind happen to be in their back, the expert jockey is to keep directly behind the adversary, that he may have al. the advantage of the wind to blow his horse along, as it were, and at the same time intercept it in regard to his adversary.

When running on level smooth ground, the jockey is to beat his horse as much as the adversary will give him leave, because the horse is naturally more inclined to spend himself on this ground; on the con trary, on deep earths, he may have more liberty, as he will there spare himself.

In riding up hill the horse is always to be favoured, by bearing him hard, for fear of running him out of wind; but in rumning down hill, if the horse's fee! and shoulders will bear it, and the rider dares venture his neck, he may have a full loose. If the horse have the heels of the rest, the jockey must always spare him a little, that he may have a reserve of strength to make a push at the last post.

On the jockcy's knowing the nuture of the horso that is to run against him, a great deal depends; for by managing accordingly, great advantages are to be obtained : thus, if the opposite horse is of a hot and fiery disiosition, the jockey is either to run just behind him or cheek-by-jole with him, making a noise with the whip, and by that means forcing him on faster than his rider would have him, and consequently, spending him so much the sooner : or else keep him just before him its such a slow gallop that he may either overreach, on bo 
Ireadiug on the lieels of the fore horse, endanges tumbung over. Whatever be the ground that the adversary's horse rums worst on, the cunning jockey is to ride the most violently over; and by this means it will often happen, that in following he either stumbles or claps on the back sinews. The several corrections of the hand, the whip and the spur, are also to be observed in the adversary, and in what manner he makes use of them : and when it is perceived bv any of the symptoms of holding down the ears, , whisking the tail, or stretching out the nose like a pig, that the horse is almost blown, the business is to licep nim on to his speed, and he will be soon thrown out or distanced. If the horse of the opponent looks dull, It is a sign his strength fails him; and if his flanks beat much, it is a sign that his wind begins to fail him, and his strength will soon do so too.

The afler management of a horse that has run, in cludes the treatment between the heats, and the treat ment after the race is over. After every heat, there must be dry straw and dry cloths, both linen and woollen, ready to rub him down all over, after taking off the sweat with what is called a sweat-knife; that is, a picce of an old sword blade or some such thing. After the horse has been well rubbed, he should be chafed all over with cloths wet in common water, till the time of starting again. When it is certainly known that the horse is good at the bottom, and will stick at the mark, he should be rode every heai to the best of his performance; and the jockey is, as much as possible, to avoid riding at wly particular horse, or stating for any, but to ride out the whole heat with tine best speed he can. If, on the contrary, he has a fir:ry horse to ride, and one that is hard to manage, riard mrullied, and dillicult to be held, he is to be started 
behind the rest of the horses with all imaginats conlness and gentleness; and when he begrins to ride at some command, then the jockey is to put up to the a her horses; and if they ride at their ease, and are hard held, they are to be drawn on faster; and if it be preceived that their wind begins to rake hot, and they want a sob, the business is to lieep them up to that spred; and when they are all come within three quarters of a mile of the post, then is the time to push for it, and use the utmost speed in the creature's power.

When the race is over, the horse is immediately to be clothed up and rode home; and immediately on his roming into the stable, the following drink is to be given him: Beat up the yelks of three eggs, and put them into a pint and a half of sound ale, made warm ; and let it be given with a horn. After this, he is to be rubbed well down, and the saddle-place rubbed over with warm water and vinegar, and places where the spurs have touched, with the sanne; atter this he should have a feed of rye bread, then a good mash, and at some time after these as much hay and oats as he will eat. His legs, after this, should be bathed some time with a mixture of vinegar and water.

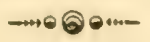

\section{HOSTLER.}

No situation that a serv ant can be placed in, requ:res more activity, sobriety, strength, attention, and industry, than that of an hostler. And how often do we sec weak, lazy, careless, crippled, and even extreme. rid men, worn out with age and infimity, plateed in snat employmeni? Indecd, those are sition mabe 
choice of that are unable to perform labour of $2 m$ description. Nothing can be more agreeable to : fatigued traveller, than to place his norse in possession of every pleasure, every comfort possible, after. his having faithfully performed a hard ride, or on a journey, which he cannot have the opportunity of doing, unless a fit person is selected for an hostler.

Many fine horses and stables have been destroyed by carelessness. Hustlers that smoke pipes or segars, are unfit for that employment.

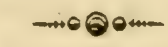

\section{S'TABLES.}

Notning conduces more to the health of a hurse, than a good and wholesome stable. It should be built upon a high, airy, and firm situation, that the horse, in bad weather, may come in and go out clean. No animal delights more in cleanliness than the horse, or to whom bad smells are more disagreeable and perni. cious. Great attention should be paid to the removal of all oflensive and putrid matter, to prevent the farcy and other troublesome and distressing diseases, which frequently proceed from such neglect. A log stable is preferable to any other, on account of its admitting a free circulation of air in summer; and by the use of slabs or straw in winter, can be made warm and comfortable. Opposite to each stall there should be a littice or window, with a shutter; by which means you can, at pleasure, either welcome the cheering breeze, or bas out the threatening storm. The rack should lie smowth, high. and firmly fastened to the wall; which wiit provent a horse injuring his eyes, skinning his 
face, and doing himself other injury when foeding The upright pieces in a rack should be four, or fou ard a half inches apart, to prevent long food from being unnecessarily wasted. The halter should never be tied to the rack, (several fine horses havine been ruined by such carelesness, ) but should be passed through a ring in the manger, and confined to a longer or smooth piece of wood, weighing about a pound With a halter of this description, there is no danger of a horse's hanging, alarming, or injuring himself. A stall should be four and a half or tive feet wide, which will allow him to lie down with comfort. 'The stable floor should be planked, to make the coat of hair show to advantage; but a dirt fluor is far preferable, when a horse is wanted for actual service: there is a moisture received by the hoof from the earth, which is absolutely necessary to make it tough and serviceable. Either kind of stable floors should be a little raised towards the manger, to turn the urine from the stall, which produces an unpleasant smell, and (when permitted to stand a length of time) "ery unwholesome vapours. When the size of a stable is calculated for several horses, the partitions between the stalls should be neatly and smoothly planked low enough to the floor, to prevent the horse when lying down, getting his legs through, and high enough at top to prevent them from smelling, biting, and molesting each other. A plentiful bed of clean, dry straw affords. to a fatigued or travelling horse, as great a welcome as his food, and is as necessary in a stable as the vitchfork, curry-comb, and brush. 


\section{NICKING.}

Nicking a horse has been generally believed to be sttended with much difficulty, and to require great ingenuity and art to perform the operation. The nicking a!one, is by far the easiest part, as the curing and pullying requires considerable attention and trouble. Nicking is an operation performed for the purpose of making a horse carry an elegant artificial tail, which adds much to his beanty and value. A horse may be finely shaped, even without fault, except carrying a bad titil, and he will not command a larger sum than one of very lonse and ordinary shape elegantly nicked. One thus operated on, will have an appearance or gaiety, sprightliness, aud lile, which cannor be given by art in any other way ; inced, it very trequently happens the tail sells for one fourth the value of the horse, which argues strongly in farour of the operation being performed on every tolerable likely horse, that is naturally deficient in that respect.

Some are of opinion, and particularly our plain, good old farmers, who are in the habit of raising fine: horses, that nicking is injurious, weakening the back, unstringing the tendons, relaxing the muscles about the hind parts, causing a horse frejuently to fall and sone:times to catch upon their ancles behind, almost breaking the rider's buck; in all of which they are entirely mistaken, and would readily be convinced of the fact, if they were to study the anatomy of the horse. Every tendon, muscle, nerve, artery, \&c. that is separated in nicking, is always cut in docking; and we do not find it the result of experiment, that a hosse with a long tall is mire durable, stronger, reo 


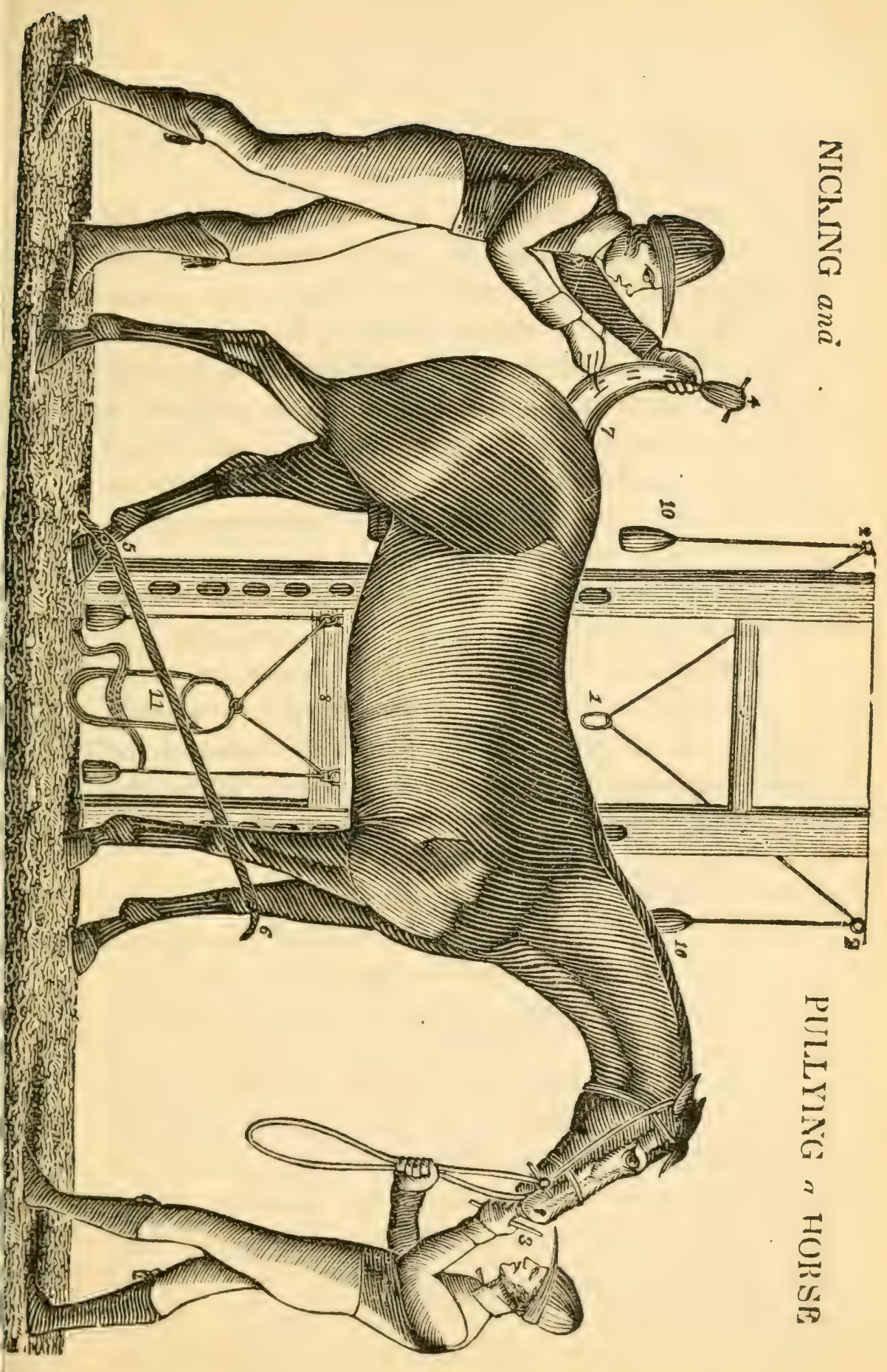



from catching or sinking behind, than a horse that has been docked. Nicking will never make a bad horse a good one, or a good horse a bad one.

'The opinion unfavourable to nicking, no doubt, has taken its rise from many delicatc, weak, long-legged horses being nicked for the purpose of selling them. When the operation succeeds well, the horse assumes a new appearance, being more like a dancing master than a grave digger, after which ine will continue to practise his old habits of catching behmd, or making a bow, although he appears as if he could glide upon the wind. This elegant tail causes them to forget this is the same tender and weak horse that was in bad halits before he was nicked; and almost proves, without reflection, that nicking is the cause of his apparent weakness. Indeed if such opinions were founded on fact. all horses that had been nicked, would fall and catch behind, whenever they had to descend a small hill. I have never known an instance of a horse catching behind after being nicked, that was not in the habit previous to the operation being performed.

Before I describe the operation of nicking, it may be necessary to inquire into the effect, or how the elevation of the tail is brought about. In order to du this, and judge of the operation with propriety, we must consider the tail elevated or raised by one set of muscles, ending in large tendons, and depressed or drawn down by another; the muscles and tendons that elevate the tail, are stronger and more numerous, and nearer to the bone than those that depress it; they are closely connected to the bones of the tail by fleshy fibres, and terminate in strong tendons at the cxire mity. The tendons that throw down or depress the ail, are two in number, and may be found within a 
quarter of an inch of the outer sirles of the iail, next wo the hair. There are three arteries; two large, on the vuter side and immediately under the tendons, and one in the centre between the two nearer the bone, all runnıng into a longitudinal direction, and decreasing in size to the extreme end.

To perform the operation of nicking, it is first necessary the horse should be well secured, to prevent his kicking or doing other injury; a twitch is to be put on his upper lip, but not so high as to prevent his breathing; a cord is to be made fast to the fetlock of one of his hind legrs, thence carried forward and made fast to his fore leg above the knee, which will effectually prevent his doing injury during the operation.-[See Plave.]

I eing now coufined, you are ready to commence the operation, which chiefly consists in a transverse dirsion of those depressing tendons of the tail, and sur h a position afterwards as will keep their extremitur s again from coming into contact; so that an intervaning callous fills up the vacuity, and elevates, erects, and props the tail. There are three diflerent modes of nicking, all of which I will proceed to explain, riving an opportunity to any person, about to perform the operation, to make their selection.

To make a horse carry an elegant tail, is attended with some uncertainty, as much depends upon the spirit, disposition, form, size of the bone of the tail de. \&c. \&c. A horse of good spirit, tolerable shay e, and a small bone in the tail, can be made to carry an elegant tail with the greatest ease; particularly if he sarried a tolerably natural tail. But a dull, leather neaded, flop-eared horse, with a remarkable large bone n his tait, will set you a task, although you may buteab 
the bone in two ar three places-indeed there is sn much difference in horses, that some judgment must be exercised about the mode best to be adopted l", the accomplishment of the object in view.

Nothing can more disfigure the appearance of a horse, than to be half nicked. 'The form of the tail, when this unfortunately happens, departs from the simplicity of nature, and never attains the elegnnce of art.

The first mole of nicking I shall describe, is the simplest, and attended with the least trouble; and although it succeeds well, twice out of three times, yet I think inferior to the other two I shall presently describe. Being prepared with a sharp knife and a crooked piece of iron or buck's horn, for the purpose of performing the operation.

1st. Have a twitch placed upon his nose as directed n the engraving annexed.-Figure 3.

2d. With a strong rope, confine his left hind leg to his left fore leg, above the linee._Figures 5 \&. 6.

3d. Plat the tail close and neatly, from the ront to the end, clubbing or turning it orer a small stick.figure 7 .

4th. Turn the tail up, with a strong atm that can kecp it firm and steady, in a direct line with his rum $\mu$ and back-bone.-Figure 7 .

5th. With a sharp knife make an incision on each side of the tail about three inches long, in a longitn. dinal direction, about two inches from the root, and nlout a quarter of an inch from the outer edge of the tail. next to the hair: so soon as you get through the skin, you will find exposed the two large tendons. 
fith. Make a second pair of incisions, similar to the lirst, commenemg within about two inches of the termination of the first.

7th. Make one other pair of incisions, in length pro. portioned to the length of the tail, taking care to leavo about two inches at the end.

8th. With a crooked iron or horn, take up the ten dons at the first incision, as near the reot of the tail as possible, and cut them smoothly in two.

9th. Take up the tendons at the second incision, and by using strength, draw those in the first incision out at the second.

10th. Draw those of the second out at the third mcision, and cut them off smoothly.

11th. Wash the tail in strong salt and water, and take from the neck vein half a gallon of blood, three times within a week.

12th. The horse may be turned out or used moderately, and should be fed on green or light food; his tail should be washed clean, with soap and water, three or four times within a fortnight; by which time, in all probability, he will be entirely well. A horse nicked in this way will require no pulleying, provided the tail is well strained up, with a strong arın, twice a day.

The second mode of nicking is attended with moje trouble than the first: but with the greatest certainty of a horse carrying an elegant tail. Having confined the horse as first directed, and prepared yourself with u sharp knife-

1st. Malie an incision entirely across the under yart of the horse's tail, deep enough on each side to cut in two the depressors or tendons, but shallow in the middle, and about two inches from the root os 
the tail When the depressors are entirely cut in two, one end of them will suddenly draw towards the rump, and the other will slip or shoot out of the wound about half an inch, which must be cut ofl smoothly and even with the wound.

$2 \mathrm{~d}$. The second incisions must be made like the fisst, from which they must be distant about trree inches.

3d. The third incisions should be made like the second, except deeper. If any artery should be cut, it is no cause of alarm: as a plentiful bleeding is of infinite service in speedily curing the tail thus operated on, and the blood is easily stopped by wrapping the tail up with a small quantity of salt, added to a handful of flour, or by placing him in the pulleys; though from a gallon to a gallon and a half of blood would not be too much to lose.

4th. After nicking, the tail should be washed in strong salt and water, and the horse may not be pulleyed for three or four days, at which time all blood, dirt, \&c. should be carefully removed, not only from the under part of the tail, but from amongst the hair also, and should be kept clean until he ss cured, which will be abont three weeks; by which time should he not be fat, his condition will be m'xch improved.

5th. The tail should be taken out of the pulleys every three or four days, inplatted, and washed clean with strong soap-suds.

(ith. Bleed every fire or six days, taking from a nalf to a grallon of blood at each bleeding, and if the tail appears much inflamed, bleed oftener; it will emove fever and inflammation, and cause the woundy to real very quick. 
7th. ITis fond should be easy of digestion, light and cool, such as bran, oats, or green food of any lind If the root of the tail should be inflamed, (which is very often the case after pulleying,) or should small biles appear, apply a little tincture of myrrh, copperas, or blue-stone water. It very often happens, that the hair in the tail of a nicked horse shows a disposition to drop, which should be prevented, by washing the tail in sharp vinegar, and keeping it nice and clean with soap-suds. The matter discharged from the wounds, if permitted to remain amongst the hair for twenty-four hours, will take it off as readily as a knife. It is of very great importance to prevent this, is the best nicked horse in the world will look ugly, if he has little or no hair in his tail; besides, it generally takes twelve months to replace it.

Horses are sometimes nicked, when their blond is III a bad state, which is the cause of their tails swelling and showing marks of violent inflammation; to remove which, it will be only necessary to bleed plentifully and apply a poultice inade of a strong decoction of red oak bark and corn meal

If this operation should be performed in a season of the year when flies are troublesome, the tail and buttocks of the horse should be anointed with stur. geon's vil, which will eflectually remove thein.

$i$ shall now proceed to describe the third and best mode of nicking every description of horses; ani which, if well attended to, will seldom or never fail to succeed.

1st. The stall, pulleys, halter, and manger, shocid wll be prepared for the recepnon of a horse, previous (1) boung nicked, as directed in the engraving prefixcd. The pulleys (figure 2) about six or eight fect 
apart, and about the same distance from the stable floor, over each side of the stall, and firm.ly fastened to the wall; a smooth and small cord is then to be passed through each of the pulleys, and to each end must be confined two equal weights, as figure 10 ; the halter should be constructed and listened as figure 11; the trough should be securely fastened to the stall or wall, to prevent its being pulled down, (figure 8,) the stall should be three or three and an half feet wide, and not deep enough to allow a horse to rub and disfigure his tail, as figure $\mathbf{9}$.

$2 \mathrm{~d}$. The horse should be confined, as figures 5,6 , and 3, and the tail closely and neatly platted up and clubbed at the end, or turned over a small stick, and securely tied with a waxed string, as fignes 7 and 4.

3d. Being provided with a sharp knile and a crooked piece of buck's horn, and the tail being turned up hy a strong arm, in a direct line with the back bone, as before mentioned, commence the operation by matiing a transverse incision, immediately acoss the tail, one and a half inches from the root, and deep emongh to separate entirely the tendons on each side of the rinder part of the tail, which will be found about a fluarter of an inch from the hair on the outer edge; this incision in the middle may be shallow. The large arteries lie so immediately under the tendons, that they are often wounded or separated in performing this operation, which will be a great advantage in the heraling of the wounds, instead of doing injury by the loss of blood. But whenever a horse may have bied from one to two gallons, the bleeding will readily stop hy placing the tail in pulleys, or by applying a smati ciluatity of flour and salt to the wound, and wrap the tail up moderately tight with a inen mux, from the rout to the end. 
Ath Make two incisions lengthwise or longitudinally, (commencing about two or two and a half inches from the cross or transverse incision, ) and about three inches in length, which will expose the large tendons on each side.

5th. Make two other incisions of the same kind, commencing about one inch from the second, and in length running within about two inches of the end of the tail.

6th. Make a transverse incision within half an inch of the termination of the longitudinal incisions, (or those made lengthwise, pretty deep.

7th. With a buck's horn take up the large tendons in the second incisions, and draw the ends out of the first; take up those in the third and draw the ends out of the second, and at the upper part of the wound cut off the tendons even and smooth.

8th. With a strong arm strain up the tail opposite the second incisions, until the bone slips or breaks; treat the tail opposite the third incisions in the same manner-also the fourth and last, which shouid be made across.

9th. Wash the tail in strong salt water, and the horse may be placed in a stall, turned in a pasture, or elsewhere, for two or three days.

10th. Wash the wound and tail clean with strong soap suds, and place the horse in the pulleys, by passung a smail wose (Figure 1) over the stick confined III the hair, at the end of the tail-(Figure 4.)

11 th. Take from the neck vein half a gallon of blood, sach week, until he gets well; or double the quantity should the tail be much inflamed. He should remain in the pullevs about three weeks, in order to give the new flesh time to get lirm, and should be washed onco 
a day wibl castile soap, so that it may be ke it entirely clean. The tail should be taken out of the pulleys twice a week, the hair unplatted, and permitted to remain down all night, and the horse changed to a clean and large stall, with a good bed of straw, for the purpose of sleeping and refreshing himself. Before he is again confined, he may be rode two or three hundred yards, slow, and without being fretted. Whilst standing in the pulleys, his legs should be frequently bathed with pot-liquor, in which bacon was boiled; vinegas and sweet oil, or lard and spirits of any kind; and a mash should be given him at least once a week, of one gallon of bran or oats, with a table spoonful of powdered brimstone, and one tea spoonful of saltpetre; not permitting him to drink for six hours after. wards. His halter should be made of substantial materials, to prevent his breaking loose whilst confined in the pulleys, pulling the hair out of the end of the tail, and doing himself other injury. A bucket of salt and water may be given twice a week during his confinement, which will be very grateful to the taste and cooling to the system.

12th. Great pains should be taken to have the weights to the pulleys equal, in order to keep the tail in a perpendicular direction, and prevent it from turning to either side during the time of healing; as a horse tha: carries his tail round to one side, instead of being elegantly nicked, is ruined. The wounds, occasionally should be washed in blue-stone or copperas water, which will cause them to heal rapidly; the horse should have as much green and light food as he can eat, such as bran, oats, \&c. Some horses that aro nicked in this way, and are pulleyed only four or rive nays. carry very handsome tails; but 1 am of opmon: 
(1) ensure suecess, it is necessary they should be kept in the pulleys until the wounds are perfectly well.

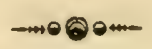

\section{PRICKING.}

T're pricking a horse has proved to be as useless an operation as it is simple, seldom or never having the desired effect; consequently the practice should be abolished. Many nicked horses fail to carry good tails; and much less is it to be expected from a horse that is pricked. I would recommend that the operation should never be performed.

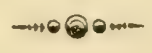

\section{FOXING.}

To fox a horse is an operation so simple, that it can be performed by almost any person. The only skill is, to select such horses as will be improved by being foxed. There is an instrument generally used for this purpose - hut the operation can be performed very correctly without it. The simplest and easiest mode 1s, to take a very small paint-brush, and with paint .hat will form a contrast to the colour of the horse, mark the ears of the shape and length you prefer; inen place on his nese a twitch; have one of his for: 
lecs held up; and with a sharp knife cut off the enirs. carefully following the line which was previously marle with the brush; the skin will immediately slip down and leave the gristly part a little naked, which mus. be washed in salt and water once a day for about a week, after which they should be greased with a little sweet oil, fresh butter, or hog's lard, and they will get entirely well in two or three weeks. A horse with a sınall, thin, delicate head, will always be much improved by being foxed. But a horse with a fleshy, heavy, thick, or long head, will show with less advantage after his ears are cut off, even if he carried them extremely bad previous to the operation.

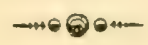

\section{DOCKING.}

Dockrva a horse is an operation so simple, as to re quire but little skill or judgment in its performance $\Lambda$ twitch is to be placed upon the upper lip of the horse, but not so high as to prevent his breathing, (as in the engraving for nicking, figure 3,) -one of his fore legs must be held up to prevent his kicking or doing other injury, and a waxed string must be tied rery tight twice round the tail, just above the: place where it is to be cut off; a large block of wood is to be placed upon his rump, and the tail turned up and raid smoothly on the block; then, with a sharp instru ment, you may cut the tail the length you prefer. (though horses docked short generally carry the bes! mils.) or after the waxed string is securely tied, take 
the tail in ene hand, and a large knife (sharuened on a mrick to give it a rough edge) in the other, and with ease, at one strolie, you may cut the tail in two: then take a piece of iron, moderately hot, place a little rosin in the wound, and sear it, recollecting to cut of the waxed string two or three days afterwards, and grease the tail with a little fresh butter or sweet oil, which will cause it to heal very quickly afterwards. When a horse is docked, the same tendons, arteries, and nerves are separated, that are divided in nicking; and it is very rare that a hurse's life is endangered or lost in consequence of performing either operation.

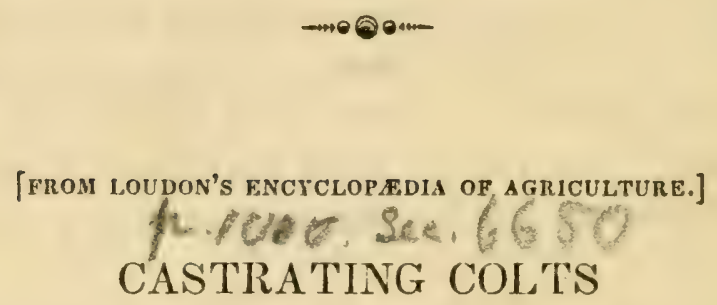

ThE time for castrating or gelding of colts is asually when they are about a year old; although this operation is frequently suspended till the second year, especially when it is intended to keep them on hand, and without employing them in labour till the following season. Parkinson disapproves of delaying this operation so long, and recommends twitching the colts, a practice well known to the ram breeders, any time after a week old, or as soon after as the testicles are come down; and this method, he says. he has followed himself, with great success. Blainc's remarks on the subject of castration appear worshv of notice: he says, when the breed is particu 
'arly gnod, and many considerable expectations are cormed on the colt, it is always prudent to want till twelve months: at this period, if his fore parts are corresfondent with his hinder, proceed to castrate; but if he be not sufficiently well up before, or his neck be too long and thin, and his shoulders spare, he will assuredly improve by being allowed to remain whole six or eight months longer. Another writer suggests for experiment, the spaying of mares, thinking they would work better, and have more wind than geldings. But he does not appear to have been aware that this is by no means a new experiment; for Tusser, who wrote in 1562 , speaks of gelding fillies as a common practice at that period. The main objection to this operation is not that brood mares would become scarce, as he supposes; but that, by incapacitating them from breed ing, in case of accident, and in old age, the loss in this expensive species of live stock would be greatly enhanced. An old or lame mare would then be as worthless as an old or lame gelding is at present.

[The following mode of castrating colts is taken from Mr. Skinnes American Turf Register and Sporting Magazine.]

The operator must in the first place provide himself with a strong rope, a couple of clamps for each colt, (if he intends altering more than one,) a little paste. a ball of twine or good thread, and a phial of the following mixture:

R. Two tea-spoonfuls of red preciptule, ('ne do. if corrosive sublimate,

t) be well ground separately, and then intimately mixed. 'The clamp is made thus: Take a piece of 
r:lder six inches long and from three quarters to one meh in diameter; bark it, and split it through the middle, and having taken out the pith, cut one adjoining end of each piece with a slope, from the inside out. wards, about an inch, and notch it on the outside, as also the other end that is not sloped, that they may be securely tied together. Fill the hollows nicely with the paste, and sprinkle over it some of the mixture in phial. Then place the sloped ends together in such a mamer that the other ends will be separated about an inch, and tie them by several turns of the thread in that position, thus:

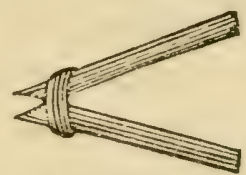

Every preparation being made; the colt thrown and carefully tied; the integuments of the testicles are to be laid open, the stone pulled out, and the epididymis separated from its adhesion to the lower end of the testicle as in the ordinary way. The cord is then caught in one of the clamps, which is pressed hard upon it, and firmly tied at the open end. When this is accomplished, the cord must be cut directly ofi, close to the edge of the clamp, and a little more of the above mixture snould be sprinkled upon the ends exposed by the knife. After the operation is concluded, the clamps should be suffered to remain on eighteen or twenty-four hours. They may then be taken off by penning the rolt in a confined place, and cutting the strings which te their blunt ends. Neither swelling, nor stiffness, nor any other inconvenience follows this operation, and the animal appears, after he is relieved of the clamps, as well as ever he was. This method may, with equal efficacy, he applied to every other anıma! whose ago or size renters the old way precarious. 


\section{FATTENING.}

To fatten a horse in a short space of time, has gencrally been considered a very great art, and attunded with much difficulty. Some authors are of opinion, it is necessary for a horse to swallow a certain quantity of medicine to produce the desired effect; while others rely on an uncommon or peculiar kind of food; but experience has proved that both opinions are erroneous, and that the few simples which I shall here recommend, together with good rubbing and a particular manner of feeding, will accomplish the fattening of a horse that is not a garran or extremely poor, within three or four weeks. After your stable is prepared, (as directed in pages 46 and 47 ,) provide a plenty of good sweet corn, hommony, aats, bran, and fodder; also a sufficient quantity of straw to keep him with a comfortable and clean bed; then notice, the condition of the animal, for the purpose of bleeding in the neck. Should he be very poor, take from him only one quart of blood; if in tolerable plight, two quarts - cpeating the bleeding at the expiration of every eight or ten days, until he is fat. Take of flaxseed one pint, boil it to a strong tea of one quart; take of powdered brimstone, one table spoonful; salt-petre, one tea spoonful; of bran, one and a half gallons; mix them all together, scalding the bran with the tea, forming a mash; which may be given every eight days: not permitting the horse to drink cold water for eight or ten hours afterwards. Take of asafœtida (which can be procured from any apothecary's shop) half an ounce; wrap it in a clean linen ragr, and nail it in the bottom of the manger where the animal is fed; at first the horse will eat unwillingly where it is placed. but in a few days he will grow remarkably fonu of $k$ 
When you commence kind treatment towards a horse that has been cruelly used, let it be with great caution, or you may produce a founder or some other Injury; those serviceable animals being too often hard used and half starved. For three or four days, allowance a horse you contemplate fattening, to two and z half gallons a day, six or eight bundles of fodder, rr an equal quantity of hay; after which you may cep your rack constantly full of long food, and never sermit the manger to be entirely empty: taking care $\supset$ change the food every day, giving the largest proportion of bran, viz.:-bran and hommony, bran and oats, bran and corn, bran alone, oats, corn, hommony, \&c. \&c. The food moistened occasionally with strong sassafras tea, produces an admirable effect; it whets the appetite, enriches the blood, and opens the bowels. Whenever a horse is fed, all dust, sour food, \&c. should be removed from his manger, which should be washed twice a week with vinegar and salt; this kind of attention will aid the appetite and keep the manger sweet and clean. If the season of the year you undertake to fatten in, affords green food of any sind, a little about twelve o'clock would assist you much in accomplishing your object. In the bucket in which you water, throw a handful of salt, two or three times a week; it becomes very grateful to the taste, after a few days' confinement, and will prevent his pawing and eating dirt. If the object is to fatten a .rorse as speedily as possible, giving to him unusual Lfe and spirits, he should not be brought out of the stable, nor even led to water. But if flesh is to be placed upon a horse to render hard service, I would recommend moderate exercise once every three days i:arefully avoiding fretting or alarming him; more in ury may be done a horse by fretting him one day 
than you can remove in a week by the kindest treat. nent. The hoofs should be cleaned out every mon ing and evening, stuffed with clay and salt, or fresh cow manure, to keep the feet cool and prevent a swelling in the legs. A plenty of good rubbing is absolutely necessary for the placing of flesh speedily on a horse ; and a blanket as a covering, at any time except the summer months, will place on his coat of hair a beautiful gloss, and add much to his comfort and apparent value.

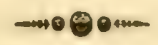

\section{EXCESSIVE FA'TIGUE.}

Fon a horse to undergo very great fatigue without injury, requires at least one week's preparation. Previrus to entering him on his journey, he should be fed plentifully on solid old food, such as corn, fodder. hay or oats, and smartly exercised from five to ten miles a day. He should be well rubbed two or three times every twenty-four hours, which will very readily have the effect of making his flesh not only firm, but hard. I have no doubt, from the experiments I have made, that any tolerable good and active horse may be rode one hundred miles, in a pleasant long day, withsut receiving any permanent injury, by observing the treatment I shall here recommend. Experience has proved that rainy or drizzly weather is more favourable to the performance of an excessive hard ride, than a day that is fair or sultry, with sunshine; rain has .ne effect of keeping him cool, suppling his limbs, of muistening and refreshing him. On the night jut. 
vious to his engaging in this laborious undertaking feed your horse with one and a half gallon of oats, or one gallon of corn and six bundles of fodder; in the rrorning feed with one quart of oats or corn only, and offer some salt and water, of which a horse is apt to driuk but little early in the morning. You then set ont on your journey, in such speed as is proportioned to the distance you contemplate going in the day. A rider, who is compelled to perform a long journey in haste, and with certainty, in a given time, should be extremely particular in his manner of riding. He should bear lightly and steadily on his bridle and stirrups, never jerking, checking, or stopping his horse suddenly, or change his gaits too frequently; all these things have a tendency to weaken and fatigue a horse extremely. A good rider will more resemble the light and airy movernents of a feather, than the duli and leaden gravity of a bullet; the same horse can convey a good rider twenty miles farther in a day than he can one unskilled in this necessary and elegant accomplishment. After progressing about fifteen or eighteen. miles, refreshment will be necessary, not only for the horse, but the rider also. You will then give him a bucket of salt and water with two handfuls of corn meal thrown therein, and one quart of oats or corn; at twelve o'clock and at dinner time, feed and water in the same manner. Great care should be taken to prevent your s.orse from drinking cold pond or well water or indulge in any inviting rivulet he may meet in his road, more than to moisten his mouth. It is a prac tice among hostlers, when they have no particular directions, to plunge horses that are tirer and heated nt twelve o'clock, into cold pond water; in preference, to which I would advise that their legs should be well rubbed with about half a pint of any kind of spinits 
Your last feed being at two o'clock, or dinner tinıe, your horse will require nothing more until night. The day's ride being performed, turn him into a lot to roo. and wallow; after which let him be placed in a stal., on a gond bed of straw. 1st. Offer him a bucket of water. 24. Remove all dirt and dust from his legs and ancles with soap and warm water. 3d. Bathe him from his belly to his hoofs with equal parts of vinegar and spirits, to which add a little sweet oil, fresh butter, or hog's lard, stewing them all together, and make use of the mixture as warm as the hand can bear it. 4th. He must be well curried, brushed, and finally folished with a sheepskin or woollen cloth. 5th. His feet should be nicely cleaned out, and stuffed with clay and salt, or fresh cow manure. 6th. He should be fed with one gallon of old corn, or one and a half gallons of oats, and six bundles of old fodder. Your horse being now in possession of every attention and comfort you could offer him, will soon be refreshed, forget his hard service, and be again prepared, by the next morning, to obey you whither you may direct his footsteps. If you have more than one day's journey to perform with great rapidity, observe the same rules of feeding, watering, and attention, as directed for the first day, except the feed at twelve o'clock, which quantity must be doubled. Many elegant and high spirited horses have been ruined and rendered useless by persons wanting experience on the above subject, who were disposed to treat those faithful animals with every kindness in their power; yet being under the neces sity of performing a long journey in a limited time, and not knowing that the will of a heated and fatigued horse should be controlled, they have permitted him to eat as much as he pleased, or when heated, to drink as much cold pond or branch water as his great inirst 
would induce him; which have often been the means of nroducing cholic, founder, and other diseases, that too frequently prove fatal in the hands of a common farrier, to which title every hostler, blacksmith, and every blockhead of a servant, who does not even understand the currying of a horse, have pretensions. The loss of two or three quarts of blond, to a horse that has undergone excessive fatigue, will remove the soreness and stiffness of his limbs, the natural consequence of violent exertions.

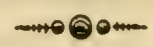

\section{TREATMENT ON A JOURNEY.}

To perform a long journey, with comfort and ease to a horse, and satisfaction to the rider, requires some attention to the feeding, for eight or ten days previous to the setting out. A horse uncommonly fat, running late at grass, fed with unsubstantial food, such as bran, \&c. or unaccustomed to exercise and fatigue, is very unfit to perform a journey on, unless prepared by being fed on old and solid food, for eight or ten days, such as corn, fodder, oats, or hay, and given moderate exercise. A horse about half fat is in the best situation to bear the fatigue and labour of a journey by following the mode of treatment I shall here recommend. If he is only a tolerably gond one, by the time ne reaches his journey's end, should it last four or five weeks. his condition will be much improved, if he is not entirely fat. ist. It is necessary to have your norse shod with a good and substantial set of shoes, 
taking care that they fit easy, set well, and are not placed so near the inside of the foot as to cut the ankles in travelling, which often produces stiffness. considerable swelling of the legs, and sometimes lame. ness. 2d. Examine your saddle, valise, portmanteau, harness, \&c. as the case may be, to discover if they fit with ease and comfort to your horse, taking care to let them undergo the same examination every two or three. days. For a saddle to fit properly, it must be neither wide enough in the tree to slip upon the shoulders, or so narrow as to pinch or break the skin on the withers, the bolstering or stuffing in the pannels should bo adapted to the hollow spaces on each side of the back bone or spine. When thus properly fitted, a crupper will be useless. 3d. Your valise should be fastened on by passing two straps underneath two pieces confined to the valise pad, and through two loops at the back of the saddle; by which means it will be kept steadily in its proper place, and the rider will not be perplexed by its swinging first on one side, and then on the other, and the danger of the horse having a sore back from friction will be avoided. The only difference between the customary way of fastening a valise and the one I here recommend, is the passing straps through the loops to the back of the saddle.

On the night previous to your commencing your journey, after your horse is placed on a good bed of straw, and is well rubbed, feed with two gallons of oats, or one and a half gallons a old corn and hommony, and eight or ten bundles of fodder, or a quantity of hay equal to it. In the morning feed with half a gallon of oats, after which offer a buckes of water. It is customary for horses to be watered before being fed; but it is much better not to water them until afterwards; a large draught of water verw uften 
destroys the appetite, and makes a horse dull and sluggish for a whole day afterwards. When he is watered in this way, he seldom drinks too much, and his mouth is washed clean and is moist when he commences his journey. It also measurably destroys his incclination to drink out of every stream he may cross in the road, which is so tiresome and unpleasant to a rider.

Being now completely prepared for the contem. plated journey, the following rules must be strictly observed. 1st. Never permit your horse, while travelling, to drink cold branch, well, or pond water, or more than is necessary to wet or moisten his mouth. 2d. Every time you stop to feed, (which will be morning, breakfast, and dinner tıme, give him a bucket of water, made a little salt, with about two handfuls of corn meal stirred in it; he will very soon grow fond of it, and indeed prefer it to any other drink; it cools the system, relieves thirst, and contains considerable nutriment. 3d. Whenever you stop for the purpose of breakfasting, let your horse cool about ten minutes; then feed with half a gallon of oats or corn, and two bundles of fodder, not forgetting to offer him again the water, meal, and salt. 4th. At dinner time observe the same treatment as dirested at breakfast. 5th. At night (having arrived at the place you intend stopping at) have your horse turned into a lot, for the purpose of wallowing, cooling, \&c. 6th. With soap and water have all dirt removed from his legs. 7th. Have him placed on a good bed of straw, then take of spirits of any kind half a pint, of vinegar half a pint. nıx them together, and let his legs be rubbed with the mixture until they are dry. 8th. Let him be well curried, brushed, and rubbed with straw. 9th. Water hun plentifully, 10th. Feed him with two gailons of sals, or one and a half gallons of curn or hommony; 
and eight or ten bundles of fodder. 11th. I cet hrs hoofs be nicely cleaned out and stuffed with fresh cow manure; this application keeps them tough, moist, and cool. 12th. Change your food as often as possible, carefilly avoiding using any that is new, or just gathered. () bserve the above rules to your journey's end, except your horse should prove a great feeder, and in that case you may indulge him a little; but the quantity ] have here recommended, is enough for any common horse when travelling. It may not be amiss to remind the young traveller to inspect his horse's shoes once a day, and whatever appears amiss about them to have immediately rectified. It frequently happens that the skin of young horses, unaceustomed to travel, is chafed and scalded by the friction of the girth; the part, washed clean with a little soap and water, and then washed with a little salt and water, will immediately sure and toughen the skin.

It often happens at little baiting places or country averns, (met with on the road by travellers,) that towards the end of harvest, servants are apt to feed with green oats or wheat, in consequence of the scarcity of fodder, unless otherwise directed; food of this kind is poison to a travelling horse, and will produce a liarrhoea and extreme debility. It would be much ...tter he should not have long food for two weeks, ihan to give it to him green from the field. When persons travelling are not attentive to their horses, they are frequently given mouldy oats and corn, which is productive of the worst effects ; there being but few kinds of food that can be given a horse, that will terminate his existence more speedily. Many of those valuable animals have been destroyed by such means, when the owners have been frequently at a loss to know with what disease or from what cause they had died 


\section{AGE.}

To I: able to aiscertain the age of a horse, with tolerahie certainty, from three to nine years old, is a subject of considerable importance to every pcrson who may have occasion to purchase. Unless we possess this information, we are subject to the imposition and to become the sport of every jockey, whose vice and depravity frequently surpass those of the most untractatle horse. Some judges undertake to tell the age until a horse is fifteen or twenty years old, which in my opinion is impossible ; they merely make a guess, without any rule by which they are governed, and four times out of five they labour under a mistake. If I am enabled to describe such marks and appearances as will make any person a judge of a horse's age, from three to nine's years old, I shall conceive I have performed a useful task, and shall be the means of preventing many impositions. Horses that have not arrived at three years of age, are unfit for use, and those that are more than nine, decrease in value, with great rapidity. All that are particularly fond of horses, will always be filled with regret on viewing an elegant horse worn out with old age, yet possessing strong marks of beauty, and even former fine and graceful actions. It is to be much lamented that so beautiful an animal should so soon feel decay and be no longer useful. I shall proceed to lay down such rules for ascertaining the age of a horse, as will enable any nan to speak with tolerable certainty on that subject. livery horse has six teeth above and below; befort he arrives at the agre of three he sheds his two middle peeth by the young teeth rising and shoving the olu 
ones out of their place. When he arrive: at the arges of three, he sheds one more on each side of the middl: teeth; when four years old, he sheds his two r.orne: and last of his fore teeth; between four and hive he cuts his under tusks, and when five will cut his upper tusks, and have a mouth full and complete his teeth appearing to have their full growth, excep! the tusks, and will be even, regularly placed, ant pretty much grooved on the inside, with hollows $a_{1}$ a very dark brown colour. There is always a very plain diflerence between colts' and horses' teeth; thif colts' being without grooves and hollows, and never so large and strong. Some horses are without upper iusks even to the end of their lives; but this is not common. The appearance of the lower tusks, and them fully grown, is the most certain proof that the horse is five years old, even if one of his colt's teeth remains unshed. At six years old, the grooves and hol. lows in a horse's mouth begin to fill up a little, and their tusks have their full growth, with their points sharp. and a little concave or hollow on the inside. At sever. years old, the grooves and hollows will be pretty weli filled below, except the corner teeth, leaving where the dark brown hollows formerly were, little brown spots At eight, the whole of the hollows and grooves are filled up, and you see the appearance of what is termed smooth below. At nine years old there very often appears a small bill to the outside corner teeth; the point of the tusk is worn off; and the part that was concave begins to fill up and become rounding; the squares of the middle teeth begin to disappear, and the gums leave them small and narrow at top. Iealers in horses sometimes drill or hollow the tecth with a graver, and black the hollows by using a hot non, for the purpose of passing an old horse for a young 
one. upon those who have but little or no experienre upon the subject. But a discerning eye will readily discover the cheat, by the unnatural shape and blackness of the hollows, the dulness and roundness of the tusks, together with the want of squares to the front teeth. and by many other visible marks, which denote the advanced age of a horse.

Between nine and ten years of age, a horse generally .oses the marks of the mouth, though there are a few exceptions; as some horses retain good mouths until they are fourteen or fifteen years ola, with their teeth white, even, and regular, and many other marks of freshness and vigour. But when a horse grows old, it may be discovered by these indications, which commonly attend old age, viz.: The gums wear away and leave the roots of the teeth long and slender; the roots grow yellow, and often brownish; the bars of the mouth (which are always fleshy, plump, and dry, in a young horse, and form so many distinct, firm ridges,) in an old horse, are lean, smooth, and covered with saliva, with few or no ridges. The eyes of a young horse appear plump, full, and lively; the lids with few wrinkles, the hollows above the ball small. and no gray hairs upon the brow, unless they proceed from the colour or marks of the horse. The eyes of an old horse apper: sleepy, dim, and sunk, and the lids loose and very much shrivelled with large hollows and the brow grav. The countenance of a young horse is bold, gay, and lively; while that of an old one is sad, dejected, and melancholy, unless mounted, and artificial means used to give him spirit.

The chin of a horse, in my opinion, is by far the best mark to enable you to ascertain his age, inasmuch as it does not admit of the practice of those as ts, by 
which the jockey so often passes off an old broken down horse for a young one. The appearance of the chin can be changed only by nature: and he who will become an attentive observer, will soon be convinced, that it is not more difficult to tell an old horse from " young one, by the appearance of their chins, than it is for a skilful physician to distinguish a cheek of health from one that is wasted, diseased, and superannuated.

The chin of a young horse is round, full, plump, full of wrinkles, and the pores close and small; that of a horse advanced in years, flat, wrinkled, flabby, and the pores open and large. Indeed, after some experience, together with particular attention to this mark of age, there will be but little difficulty of ascertaining, with certainty, the agre of a horse from three to nine yeirs old. I have sometimes met with travellers on the road, whom I never before had seen, and in travelling along, have told the agre of their horses by their chins. An examination of the lips and nostrils of a horse. may aid, corroborate, and strengthen the opinion of age, founded on the appearance of the chin. The lips and nostrils of a young horse are smooth and free from wrinkles, while those of an old one abound in them.

Were I in pursuit of truth and honour, I neves should seek them in the lower class of dealers in horses or horse jockeys. Whenever they have a horse to dispose of, they assure a purchaser he possesses every des:rable quality, \&c. and whenever they have efferted a sale, they smile at their success, ana expose every vice to which the horse was addicted, to the nex? person they meet.

The physiognomy of a horse will assist much in ascertaining his age; but the chin is certainly the *afest guide. 
[FROM THE AMERICAN FARAEER.]

\section{AGE BY FEELING}

A monderful discovery recently made in an old Horse's age.

"Tis to the pen and press we mortals owe, All we believe, and almost all we know."

Since the age of that noble animal, the horse, after a rertain period of life, (that is to say) after the marks in his incisors and cuspidati are entirely obliterated, to be able to ascertain his age, with any tolerable degree of certainty, appears to the generality of "horse age. judges," to be a subject of very much uncertainty. I now take the liberty of laying before the public, through the medium of your paper, an infallible method, (subject to very few exceptions) $o^{r}$ ascertaining it in such a manner, after a horse loses his marks, or after he arrives to the age of nine years or over; so that any person concerned in horses, even of the meanest capacity, may not be imposed upon in a horse's age, from nine years of age and over, more than three years at farthest, until the animal arrives at the age of twenty years and upwards, by just feeling the submaxillary bone, or the bone of the lower jaw.

This method I discovered, by making many anatomical observations on the skulls of dead horses and repeated dissections. In order, therefore, to elucidats the above, I must in the first place beg leave to remark: tha the submaxillary bone, or the lower jaw brone 
of all voung horses, about four or five rears of agre. immediately above the bifurcation, is invariably thich and very round at the bottom; the cavity of said bone being very small, contains a good deal of marrow, and generally continues in this state until the animal arrives at that period which is generally termed an "aged horse," or until the animal acquires his full size in

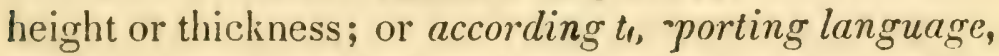
is completely furnished, with very little variation. But after this period, the cavity as aforesiad becomes larger, and more marrow is contained therein. Hence the submaxillary bone becomes thinner and sharper a little above the bifurcution.

This indelible mark may always be observed in a small degree in horses above eight years of age; but at nine years old it is still more perceptible. It continues growing a little thinner and sharper at the bottom until twelve years of age. From thence until fifteen, it is still thinner, and about as sha:p as the back of a case knife near the handle. From this period until the ages 18, 19, 20, and upwards, it is exceedingly so; and is as sharp, in many subjects. as the dull edge of that instrument.

\section{RUIES.}

1st. Put your three fingers about half an inch or an inch immediately above the bifurcation, and grasp the submaxillary bone, or the lower jaw bone. If it is :lick at the sides, and very round indeed at the bottom, the animal is most certainly under nine years of age.

2d. If the bone is not very thick, and it is per ccivably not very round at the bottom, he is from num: to twelve years old, and so on. From twelve to filicers, the bone is sharper at bottom and thinner at une 
siles, the bottom is generally as sharp as the back of a case knife; and from 15 to $18,19,20$, and upwards, without many exceptions, the bone, when divested of its integuments, is as sharp as the dull edge of that instrument.

3d. Allowances must always be made between heavy, large western ir wagon horses, or carriage horses, and fine blood. 1 ones. By practising and strictly attending to the above rules, upon all descriptions of horses, the performer in a little time will become very accurate in the accomplishment of his desires, more especially if he attentively observes the lower iaw bone of dead horses"

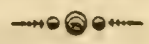

\section{MARKS.}

Perunps there is no subject to be found, that adinits of a greater diversity of opinion, than the form and number of marks necessary to constitute the beauty of a horse. Many white marks, when of irregular shape, and handsomely placed, give to a handsome horse a gay and sprightly appearance, lightening up the countenance, and forming a beautiful contrast to his colour. Indeed, marks are sometimes so irregularly and fanci. iully placed, as not only to please, but to delight most persons who are judges on this subject; while others of such regular, common, and uniecoming shape. and so u: naturally placed as to be unfavourable to beauty and have a tendency to disfigure the animal they aro 
intended to beautify; sûch as a face blazed large, high. and regular, like an ox ; the two fore legs white abov $\epsilon$ the knees, and no white behind; one white leg to the knee, behind on the right; one fore leg white to the knee before on the left : a bald face and no white lews a dim blaze, commencing with an awkward star, cnl-1ing with a snip on the one side, \&c. \&c. A horse without marks, always has a deadness in his aspect-and one well marked, always appears the more bcautiful for it. But it must be acknowledged, by every person of experience, that a horse with white feet, is much more tender than one without them. Even in cases of lameness not proceeding from accident, nine times out of ten, if a horse has a white foot, that will be the one that will first fail him. White feet are also more subject to the scratches and other diseases, than those of different colours, and a very remarkable fact exists, that I never have seen or heard, in my life, of a first rate iour mile heat racer, that had a bald face and white legs to the knees.

White marks add to the beauty of a horse, but les sen his services.

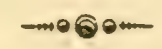

\section{BLAZE OR STAR.}

Wuev we bave a pair of horses that matcn well every respect, except that one has a blaze or star "II the face, it becomes very interesting and important to know how to make their faces match, and to give 
them blazes or stars precisely alike. This may be done in the following manner:-

Number 1.-Take a razor and shave off the hair the form and size you wish the blaze or star to be made: then take a small quantity of oil of vitriol, and with a feather anoint the part once, which will be quite sufficient. After the application of the vitriol, the part will become a little sore and inflamed; which may be readily removed and healed up, by washing the sore with copperas water. Great care should be used to prevent the vitriol from getting on clothes, as it wil entirely destroy them.

Number 2.-Take a piece of oznaburgs the size you want the blaze or star: spread it with warm pitch and appry it to the horse's face: let it remain two or three days, by which time it will bring off the hair clean, and make the part a little tender; then take of elixir vitriol a small quantity; then anoint the part two or three times; or, of a very common weed called asmart, a small handful, bruise it and add to it aboui a gill of water, use it as a wash until the face gets well, when the hair will grow out entirely white.

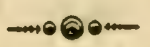

\section{HEAD.}

Trif head of a horse should be small, bony, thin, and delicate; his jaws wide apart, yet thin : his throtue large and arched; his ears long, thin, narrow, high and pointing together; his eyes prominent large and 
full, of a dark cinnamon or black colour, bright, lively, and shining; his nostrils wide, red, and expanded; his moutb and lips thin, small, and plump; his chin fulh sharp, and delicate; his face rather of a Roman order than straight, with irregular white, either in a star or blaze, to give expression and light up the countenanre

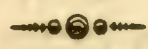

\section{BODY.}

Tire body of a horse should be large, in $\mathrm{i}$ ropiortion tn the balance of his frame, compact, round, and swelling; his flanks plump and full; and his last or small est rib, approaching near the hip bone, which is never placed too near the point of the shoulders; the back should be very short, smooth, and nearly even, neither swayed nor humped; the hips wide apart, full, round, and even with the body. A horse with a light flat body, open and gaunt about the flanks, with high spirit. long legs, \&c. is unfit for any purpose, except for show; and that not for more than two or three hours: for his rider, after that time, as well as every spechator, will discover him sinking undur fatigue, and corcpletely giving up. 


\section{NECK AND SHOULI)ERS.}

Tue neck of a horse should be long, thin. and delrate (indeed they are never too long or too delicate) growing deeper from the joining of the head to the shoulders; the upper edge should form the half of an arch, gradually falling in height and shape from the head to the shoulders; the mane should be thin, smooth, and in length half the width of the neck.The shoulders of a horse should be thin, high, and thrown very far back; for experience has proved, that those with low shoulders and high rumps, although they may have many good parts, can never show to advan lage, and seldom make good saddle or race horses.

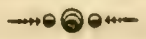

\section{LEGS.}

Tue tore legs of a horse should bear a just proporcion to his size; the arms large, long, and full; the legs bony, Hat, and sinewy; the pasterns rather long than otherwise, and tolerably straight. Small lean arms, a bending back or trembling of the knees, bow ıegs, small and round legs, extremely delicate back sinews, or those unnaturally large, indicate weakness or some injury, and should be avoided. 'The hind parts of a horse, from the hip bone to the houk, should ve of great length; the thighs and muscles should be 'ull, large, and bulging; the hock hroad, sinewv and 
strong; the hind legs flat, smooth, bony, and fult or sinew, clear of knots, and rather crooked in the hock than straight; the pasterns of moderate length, small and rather straight than otherwise. The horse should be neither knock-kneed or bow-lcgged, or his feet surned in or out; as a horse thus statyed, moves ugiy and never can be sure fonter.

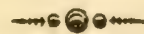

\section{SHOFING}

Diseases are sometimes produced in the feet, from which a horse is never again free during his life; it is therefore important that a valuable horse should not be placed in the hands of every blockhead who pleases to call himself a horse shoer, but entrusted only to persons of known skill. For a horse to be well shod, the hoof should be pared with a buttress, (instead of giving in to the cruel and injurious practice of burning the foot with a red hot shoe until it fits,) smooth and level, to a reasonable size; the frog should be nicely trimmed. in shape a little convex, rather lower than the foot: the shoes should be made of good and tough iron, and? precisely the shape of the hoof after being trimmed, not so wide between the heels as to show on the out. side, or so narrow as to cramp the foot, and produce narrow heels, (which is a very troublesome disease) The nails should be made of old horseshoes, or some. other tough iron, with small heads, and drove reguiar, smooth, and even: not high enough to, each the 
quick, yet with hold sufficient to confine the shoe three or four months. The points of the nails should be formed into neat and small clinches, and should be well driven up

Some taste may be displayed in the rasping and shaping the hoof, after the shoe is confined. When it .s left more sharp than flat around at the toe, it adds much to its beauty and neat appearance.

When a horse is well shod, if water is poured upon the bottom of his foot, it will not pass between the hoof and the shoe. A smith, who resided in Williamsburg, in the year 1804, was in the habit of shoeing in this exact and elegant style. Shoes for draft horses, that have seldom occasion to go out of a walk, should be heavy, strong, and with high heels, and pointed at she toe with steel.

Horse shoeing is what every worker of iron. who has acquired the name of a blacksmith, pretends to be well skilled in; but there are few indeed in possession of sufficient knowledge on that subject, to make it safe to place under their care a horse of value, for the purpose of being shod. To perform this operation correctly, and without present or future injury, requires not only good skill and judgment, but a thorough acquaintance with the anatomy of a horse's foot, which is a know redge but few of our blacksmiths are in possession of, and is the cause of so many horses being rendered useless. Almost all the diseases in the feet, are, more or less, the result of bad shoeing, by wounding muscles. -eiris nerves, or arteries in this way. 


\section{HOOFS.}

Tie hoofs of a horse should be proportinned to his size; of a dark colour, smooth, tough, and nearly ritund; not too flat nor too upright, and the bottom hollow. White hoofs are much more tender than any other colour, nor do they retain or bear a shoe so well. One that is flat, turning up at the toe or full of ridges, or flat and pumiced on the under side, strongly indicates jounder or other injury. If the hair lie smooth at the top of the hoof, it is an evidence of its being good, should there be nothing unnatural in its shape; but if tne hair stands up and appears rough, and the flesh swelled a little beyond the circle of the hoof, it is a proof the foot is in some way diseased and a ring bone may be apprehended.

\section{- \\ MANE AND TAIL.}

Tre mane and tail of a horse, when the hair is even, smooth, long, and well proportioned, adds much to the beauty, boldness, and majesty of his figure. Great juilgment and taste may be displayed in the trimming and proportioning those two ornaments. A very large horse, even if elegant, appears mean and trifling if you attach to him a little rat tail; one very small with a monstrcus long, bushy tail; or a square, narrow hipped, lathy horse, with a small bob tail, onl, servey 
to point out his imperfections, and attach to his an. pearance an idea of insignificance and meanness. Ont with a remarkably long body, with a thin switch bob tail, bears no better proportion than the legs and thighs of a dwarf to the head and body. A large horse, roached and bobbed, never shows to advantage, as the appearance of the riding horse is given up, and the round and snug appearance of the nimble footed pony can never be attained. For a horse to look well with a bob tail, he should be plump, round, full, and compact; but all tails that are full of hair, show to much more advantage than those that are thin and frizzled.

Previous to a tail's being trimmed, great respect should be paid to the shape and proportion of the horse, and the tail should be made an equal proportionable part. The manes of all horses, except ponies, should be long, smooth, and reaching at least half way down the neek; nothing can more disfigure him than a short frizzled mane: it even alters, apparently, the shape of the neck, and when once in this situation, it will take twelve months to grow of proper length. The mane of a horse may be combed two or three times a day, as a thin mane looks well; but his tail, if well proportioned and elegant, should not be combed oftener than twice a week.

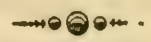

\section{GOOD ANU BAD EYES.}

Tur eye is an organ of more use and more value than any that belongs to the horse, and should alwayg undergo an examination by a purchaser with the 
greatest attention and mmuteness. Nothing can more affert his value than the want of vision; as any siegant horse, that would readily command in cash two hundred dollare, if blind, in all probability, would be w sll sold at fifty dollars, which plainly proves the necessity and imprortunce of using on this subject the greatest caution.

'To give a full description of the anatomy of a horse's eyc, would take up more ronm and time than can at present be devoted to this topic: the reader must be content with a description of those parts most familiar and most important.

The eyc is the organ of sight, whereby the ideas of all outward objects are represented to the common sensory; its form is a convex globular, covered by its proper lids, and enclosed within an orbit or socket: the eyclids preserve the eye from dust or external injury, and an expansion of the muscles and shin, the inner membrane being of an exquisite contexture, that it may in no manner hurt or impair the surface of the eye: their edges have a cartilaginous or gristly rim, by which they are so fitted as to meet close together at pressure; the orbit or cavity in which the eye is situated, is lined with a very pliable, loose fat, which is not only easy to the eye in its 1 arious motions, but serves to keep it sutficiently moist, as the lachamalial giands, seated in the outer corner of the eye, serve to moisten its surface, or wash off any dust or dirt that way happen to get into it: at the inner corner of the eye, next the nose, is a carbuncle, which some are of orinion is placed to keep that corner of the eye from being entirely closed, that any tears or gummy mutter may be discharged even in time of sleep, or into the muncture lachamalia, which aro little holes for the 
purpose of carrying off any superfluous moisture or tears into the nose: the eye has four coats or membranes, and three humours; the first membrane is called tunika adnata, and covers all that part of the eye that in a man appears white, but in a horse is variegated with streaks and spots of brown, and being reflected back, lines the inside of the eyelids, and by that inversion becomes the means to prevent motes, dust, small fles, or any extraneous matter getting behind the eyeball into the orbit, which would be extremely dangeious: this coat is full of blood vessels, which appear in little red streaks on the human eye when inflamed, and when there is but little white in the eyes of horses, they appear fiery, and the eyelids, when opened and turned back, look red: the second coat has its forepart very strong and transparent, like horn, and is therefore called the cornea; and the other part, which is opaque and dark, is called the schlerotis: under the cornea lies the iris, which in a horse irclines to cinnamon colour: the middle of this membrane, or coat, is perforated for the admission of the rays of light, and is called the pupil: under the iris lies the processes ciliares, which go ofl in little rays, and in a sound eye are plainly to be seen. As often as these processes contract, they dilate the pupil, which may always be observed in places where the ight is small; but in a strong light, the circular fibres of the iris act as a sphincter muscle, and lessen the size of the pupil; and therefore a dilated and wide pupil, in a strong light, is generally an evidence of a bad eye. Under the schlerotis lies the choroides, which is the third coat of the eye : in men it is of a dusky brown but in horses the greater part of this coat is white, which enables them to see bodies of all colours better than nen in the night, as white reflects all colours 
But horses and other anmals that feed on grass, have some parts of this membrane of a light green, which enables them to see with little light, and makes grass an object that they can discern with greatest strength, and therefore it is sometimes called tunicia uvea, from its resembling the colour of a grape. The innermost or fourth coat is called the membrana retina, which is only an expansion of the optic nerve upon the choroides, and encompasseth the glossy humour like a net. By the continuation of the rays of light upon the fine filaments of this membrane, all the external images are conveyed by the optic nerves to the brain. Within the coats of the eye are seated the three humours that chiefly compose the eyeball; the first is the aqueous or watery humour, which lies foremost and seems chiefly as a proper medium to preserve the crystalline humours from injuries in case of wounds, bruises, or any other external cause. Behind the aqueous humour lies the crystalline lens, in a very firm membrane called arena, being like a spider's web-its use is to refract the rays of light that pass through it, so that all the rays proceeding from the same point of any object, being first refracted on the cornea, may be united on the retina-the vitrenus humour lies behind the crystalline, being concave on its foreside to make a convenient lodgement for the crystalline, and its hinder part convex agreeable to the globular form of the eye, upon which the tunica retina and choroides are spread: this humour possesses a space larger than the uther two, and being of a hue like a light coloured green glass, is a proper medium, not only to keep the crystalline hunıur and the retina at a proper distance from each other, but by is colour to prevent the rays of light falling ton for 
ribly ux.un the áter, which might weahen or impair vie sight.

The eyes of horses differ so widely in their appearance, that the best judges will be sometimes mistaken as to their power of vision; but I shall here recommend such modes of examination as will rarely dereive, having already descrihed that organ fully, when in its most perfect state.

For the purpose of making a fair trial of a horse's cyes, that you suspect to be bad, and to ascertain their quality,

1st. Have him confined in a dark stable about fifteen minutes, then led hastily out into a strong light: if he winks fast, wrinkles his brows, throwing his head up as if desirous of receiving more light, and moves his ears backwards and forwards slowly, in an unmeaning manner, his eyes are not good.

2d. If his eyes appear sunk, with the lids shrivelled or very much swelled, it is a proof they have received an iniury.

3d. It the ball of the ayo appears covered with a film, or the remains of one about the corners, with the pupil large and light coloured, without occasionaliy contracting with a look wild and vacant, his cyes are diseased.

4th. If he can be rode against a tree or any other object which he should avoid, and which should alarm him, his eyes are bad.

5th. If when moved he lifts his feet high and awkwardly, and appears not to know where he is about to Hace them, you may immediately conclude he is llind.

6 th. If when rode over small gullies or old corn glound, he blunders much, and requires the constant attention of the rider to guide him, his cyes are not groud. 
7th. If you shake your hand near his eyes in sucti a manner that he cannot feel the wind from it, and he pays no attention to it, by winking quick, and moving his ears, his eyes are such as should not be made choice of.

8th. If at night, when you approach him with a candle, and the pupil of his eye looks large, of a light blue colour, without having near its middle, and on the upper part, little rough spots, of a dark brown colour, resembling moss, or if the pupil contains large white opaque lumps, the horse is either blind or occasional!y subject to blindness, and shoula be avoided by a purchaser.

The eyes of some horses are very subject to films, which have been sometimes removed by large bleedngs, or the use of double refined loaf sugar, or glass Dottle, powdered. Eves thus affected are much to be dreaded, as it is very difficult to discover them. One hard ride will make a horse blind; and one large bleeding will remove the film. To detect such eyes, examine minutely the corners, as the film leaves those parts of the eye last, and will appear there, when it has been removed from the middle of the eye for several days.

The eyes of a horse are never too large, but very frequently too small; and when shaped like a pig ${ }^{\circ}$, are neither durable nor handsome, and form a serious objection. The wall or white eyes are truly valuable, boing much hardier and less subject to disease thar: eyes of any other description; for who ever recollects to have seen a horse blind, or even with diseased eves. that had wall eyes? and unquestionably they can seo better in the night than a horse withot them. 
The eges of a horse should be large, round, full lively, dark coloured, clear, and shining, that you may see far into them; and when moving, but little of the white should appear. Dealers in those animals are very apt to endeavour to lead a purchaser from any defect he by chance may discover about a horse. to some part without fault, or some of his best parts; and as to eyes, speak of them as if they were of little or no consequence. Purchasers should always be on their guard when dealing with men that possess so much artifice and cunning.

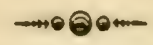

\section{MOON EYES.}

WE sometimes observe the eyes of a horse to change s lour, and to vary in appearance monthly. Eyes thus affected, are called moon eyes, from the prevailing opinion that the affection increases or decreases with the course of the moon; insomuch that in the full moon the eyes are muddy, discharging a thin ichorous water so sharp as sometimes to excoriate the skin, and at new moon clear up again. At first appearance of this disease, the eyes are much swelled, and very often shut, and the whole eyeball of a muddy brown; the veins of the temple, and near the eyes, appear remarkably full of blood, and both eyes are seldom aflected at the same time. I Large bleedings, and the eyes wished frequently in cold water, give temporary relief; but this disease is the forerunner of a cataract, which seldom admits of a cure; the cases generally end in sundness of one, if not botn ẹes. 
The eyes of horses are very frequently wounded and injured by blows, flics, accidents, \&c. which car: always be distinguished from diseased eyes by a proper examination. To perform a cure, when thus injured, wash them three or four times a day in rlean, cold spring water, after which repeat the washing, adding a small quantity of sugar of lead to the water. when the eye gets strong enough to open of its own accord, in the light. Should a film appear on the sirface, (which is absolutely necessary, if the eye has received a wound, before it can heal,) take of double refined loaf sugar, or glass bottle powdered to a fine dust, a small quantity in the end of a quill; blow it in the eye affected, every third morning for a week: bleed at least three times within the week, taking about half a gallon of blood at each bleeding; if the horse is not disposed to go blind, the cure will in a sho! ${ }^{4}$ time be completed.

\section{ำดง \\ STARTING.}

Horses, as well as men, sometimes acqune han habits, of which they can but seldom divest themselves. Starting is one among the worst habits a horse can possess, and has a tendency to reduce his value at least one fourth, in consequence of endangering the life of any persun who may back him. A good rider has sometimes been thrown by his horse in starting, that would have defied his agility in any other way.

A rider never can guard against a starting horse, as he gives no notice of his intentions, by the moving of 
his ears, eyes, manner of going, \&c. as they generally do in rearing, jumping, kicking, sullenness, and such vices. Some few horses are broke of starting by mild means, others by cruel treatment ; but whoever engages in it, at least runs the risk of breaking his own neck before his object is accomplished.

A horse subject to starting, labours under an ocular deception, or rather an optic defect, seeing nothing perfectly, or in proper shape or colour; and can as easily make a scare-crow of a little bush or chunk, that may happen to lay in his road, as the most frightful object that could meet his sight.

To ascertain that a horse starts, is very easy indeed. Mount him yourself, ride first slow, and then fast, towards and by such objects as are offensive to the eye, and you will readiily discover if he possesses that bad nabit.

Some horses that are free from this objection, will notice particularly all objects they meet, and may sidle a little; but a starting horse, on approaching any objec that may displease him, whether frightful or not, will either suddenly spring from one side of the road to it? other, jump back, or when going in a full gallop, stop suddenly, turn round, and run in an opposite direction from the one he was groing. Such horses are neitier agrecable or safe for any kind of service. 


\section{STUMBLING.}

'Trie stumbling of a horse may be either natural or produced by accidents, such as splint, wind galls, sinew strains, shoulder sprains, withers injured, \&c. \&c. but whether produced by accident or natural defect, cannot be remedied. 'All horses, and particularly those that go well, stumble more or less; but there is a very wide distinction between a light tip or tourl: on the foot, and a stumble that will bring a horse and sometimes his rider flat in the dirt. Horses given to this practice, are very much lessened in value, and can never be rode by any person aware of his bad quality. without being in pain, dreading every time ne lifts his feet, that all will be prostrate? in the dust.

To ascertinit it a horse stumbles,

1st. Examine well his knees, to discover if they are scarred, or the hair knocked off.

2d. Take him amongst uneven ground, small gullies, or old corn ground, and let him be rode with the bridle hanging slack upon his neck, in all the different gaits he has been accustomed to, and if he is in the habit of stumbling, he will very soon make a sufficient number of low bows to convince you of the fact.

$3 d$. When a horse stumbles and immediately springs off, appearing alarmed, it is a proof that he is an old offender, and is under the apprehension of having one sther flogging added to the great number he nad, no doubt, receiven for the same fault. Such a horse 1 consider unsafe, and therefore cannot recommend him to purchasers; he being not so good, even for a slow dralt, as one possessing more activity. 


\section{SPAVIN.}

A spavined hor'se may be considered as one completely ruined, for a permanent cure can rarely be effected, if attempted, even on its first appearance.

'The spavin is a lump, knot, or swelling, on the inside of the hock, below the joint, that benumbs the limbs, and destroys the free use of the hind legs. It causes $n$ horse to be extremely lame, and to experience, apparently, very excruciating pain.

In the purchase of a horse, great respect should be paid to his bringing up his hind parts well, as a spavined horse never makes a full step with the leg affected; also to the shape of his hocks, in order to discover if there is any knot or unnatural prominence about the joint, which is an evidence of the spavin. When a horse is thus diseased, he is unfit for any kind of service, even the meanest drudgery, being in constant pain, and unable to perform. Horses sometimes have the spavin, when there is no lump apparent near the joint, the disease being seated in the joint. To detect such spavin, and to prevent a cunning fellow (who may have given the animal rest, blistered and bathed the part with double distilled spirits, and formed a temporary relief,) from imposing on a purchaser, have the horse rode in three quarters speed, about one mile out and back, occasionally fretting, cracking, and drawing nim up suddenly and short; after which let him be rode in cold water up to the belly; then piace him in a stall without interruption, for about half an hour, by which lime ho will be perfectly cool; then have him led out, ard moved gently: if he has received a temporary 
clire of the spavin, he will show lameness. A bliste of Spanish flies applied to the part afferted (after shaving off the hair) with a bath of strong spirits or rinegar, and a week's rest, will frequently suspend the lameness produced by the spavin for a time, but a radical cure may not be exnected.

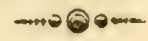

\section{CRIR BITING.}

Crib Bitrang is one amongst the number of bad habits to which some horses are addicted. It consists in his catching hold of the manger, grunting and sucking in wind, until he is almost ready to burst. To discever this vice, it is only necessary to have a horse fed: whenever they eat, at least one half of his victuals is wasted, by t.ieir catching hold of the manger, grunting, straining, and swallowing large quantities of wind every two or three mouthfuls, which produces the cholic and other distressing diseases.

Whenever this very bad habit is acquired, it is practised as long as the animal lives. Many experiments and fruitless attempts have been made to remedy it, but withont success. An elegant horse, when once he becomes a crib bitcr, is reduced in value to little or nothing. He always looks hollow, jadei. and delicate, and is inrapable of rendering service its any situatior 


\section{BROKEN WIND}

Broken Wind is one amongst the number of incurable cliseases to which the horse is subject. When affected with this disease, he is disagreeable to his rider, and is of but little value, however beautiful or elegant he may be in his appearance. All the boasted pretensions of farriers to cure, are vain and frivolous, since their utmost skill, now and then, can only palliate the symptoms, and mitigate their violence.

It is easy to discover a broken winded horse. By giving him a little brisk exercise, he will draw up his rlanks and drop them suddenly, breathe with great difhculty, and make a disagreeable wheezing noise. The seat of the disease appears, from dissection, to be in the Iungs; the heart and lungs being found of twice their natural size, which prevents their performing their office with ease, in the action of respiration.

Broken wind is sometimes produced in a horse by excessive fatigue, heavy drafts, sudden changes from heat to cold, and other cruel treatment. It would be advisable to dispose of such horses at any price, as they are not worth their feeding.

This complaint, I helieve, does not admit of perfect cure: but by much cire may be greatly relieved. The food should he compact and nutritious, such as corn and old hay. Carrots are excellent in this case, is are parsnips and beet roots, probably on account of line saccharine matter they contain. I have heard ihat molasses has been given in the water (which shoula be ir very small quantities) with very great aneress. Some have ased tar water; others prises 
the effects of line water; init the greatest dependence should be in very sparing supplies of substantial foca. The exercise ought to be regular, but never beyond a walking pace. If the symptomatic cough should be troublesome, take away about three quarts of blor.d every other day.

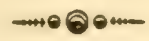 \\ STRING HALT.}

Trre string halt affects horses in their hind legs, and consists in a false action or involuntary use of a muscle, which twitches one of the legs almost up to the belly, and sometimes both. The string halt is produced by a muscle being over strained, or a violent blow on the hind parts. Good rubbing, and baths of warm vinegar and sweet oil, aflord momentary relief, but a permanent cure may not be expected. A horse hus injured, is incapable of faithfully performing a journey, although he may be rode four or five miles without appearing to sink with fatigue. Such a horses is very objectionable, being uneasy to the rider, and must give pain to every person who is in the hathit of seeing him rode. 


\section{CHEST FOUNDEI.}

Tine chest founder appears to be a disease but hille understood by farriers in general; they are, however, not backward in offering many remedies, and speak of some with much confidence, when they propose performing a cure. But experience has proved, beyond the possibility of a doubt, that the chest founder is one of those dreadful diseases to which the horse is subject, that admits of no cure. I can here be of more use, by speaking of its seat, and describing its symptoms to a purchaser, than by pretending there exists, for that disease, a specific medicine, or propose its use to the owner of such an unfortunate animal.

The chest founder is sometimes produced by violent exerc'se on a full stomach, and drinking large quantities of cold branch water; by the use of mouldy bran, corn, or oats, or by eating large quantities 0 : green food, such as oats, wheat, peas, \&c. while performing hard labour.

From dissection, it appears that the seat of the disease is in the lungs; the heart and liver are also considerably enlarged, insomuch that there is not room for them to perform their office with ease. The liver, ıungs, diaphragm, and surrounding parts, are all covered with large brown spots, and are much inflamed.

A horse that is chest foundered, will straddle or stake with his fore legs, showing an unwillingness to bring his feet together; and if they are placed near each other, he will not permit them to remain so for a mirute. Indeed they are frequently twelve on 
eighteen inches apart, which is caused by a fulness, and continual uneasiness about the chest: the carily being too small to contain the lungs, \&c. in then enlarged situation with ease.

The hind legs are free from the palsied appearance of those before, and it is not difficult to distinguisn it from a common founder, as it is wanting in all its symptoms, except the stiff and numbed appearance of the legs

Large bleedings and half an ounce of aloes, given internally in a ball, have sometimes afforded momen. tary relief. No effectual remedy has yet been discovered. A horse labouring under this disease, is worth but little more than his board, as he is unable to bear fatigue, or undergo severe service.

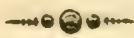

\section{NARROW HEELS,}

Is a disease that often produces lameness without the master of the horse knowing from what cause it proceeds : often examining his legs, cleaning his hoots, paring the frogs of his fect, \&c. \&c. without paying any respect to the shape of the horse's heels, which are always close together and unaturally shaped.

A horse with narrow heels is unfit to travel, as iee is tender footed, and goes cramped, short, and is al. ways subject to lameness, more $v_{i}$ less.

Narrow heels is the effect of shoes being permitted to remain on a horse that is not used, for three us tou 
month, which cause the heels to grow together, pincr ing and confining the coronet.

The cure is simple, though tedious. Have his shoes taken off and his feet cut down as small as possible, witheut injuring the quick; then turn him out upon a marsh or low ground, where his hoofs may be constantly moist for three or four months, and his heels will expand, his hoofs again assume their natural shape, and the horse will be fit for any kind of service.

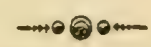

\section{SPLINT.}

THe splint is a hard lump or excrescence that grows upon the fore legs of a horse between the fetlock and the knee. It is unpleasant to the eye, but seldom does injury, unless situated on the back of the leg and immediately under the large tendons, in which case iameness is always produced, and the cure rendered difficult.

When the splint is situated in the usual place, and grows so large as to be unfavourable to beauty-to remove it, bathe the part with hot vinegar twice a day, and have the knot or splint rubbed with a smooth round stick, after bathing for ten or fifteen minutes; by the expiration of a week the knot will perceptibly decrease in size, and finally, in a short time will disappear.But should such means not have the desired effect. shave off the hair over the lump, and apply a blister of Spanish flies. which in a short time will effectually remove it. 
The splint, when first making its appeirance, will cause a horse to limp a little: and, as he advances in years, may stiffen him, and cause him to stumble. But I have never known any serious injury to resuli from such an excrescence, unless placed beneath the arge tendons.

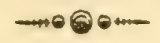

\section{L.AMPASS.}

A LI, young horses are subject to the lampass, and sirme suffer extremely before it is discovered.

It is a swelling or enlarging of the gums on the nside of the upper jaw : the growth is sometumes so luxuriant as to prevent a horse from eating with any comfort. The cure is simple; and after being performed, a horse will improve in his condition with great rapidity.

Take a hot iron, flat, sharp, and a lictle crooked at the end, burn the lampass out just below the level or the teeth, using great care to prevent the hot iron from bearing or resing upon the teeth. Aiter the operation is performed, the horse should be given a little bran or ineal, with a small quantity of salt in it.

Some farriers have recommended cutting for the lampass, which only gives momentary relief, and would require the same operation to be performed every three or four months: but when it is once burnt sut, it neve. ngan makes its appearance. 
WIND GALLS.

Wind Galls are spongy and flatulent humours, that make their appearance on both sides of the leçrs, just above the pastern joint or fetlock. It is seldom that a horse is found entirely clear of them, particularly about the hind legs, if he be much used.

They are produced by hard usage, strains, bruises, \&c. \&c. of the back sinews or the sheath that covers them, which by being over-stretched, have some of their fibres ruptured; whence probably may ooze out the fluid which is commonly found with the included air.

When wind galls make their first appearance, they are easily cured by a bath and bandage. Boil red oak bark to a strong decoction, add some sharp vinegar and a little alum, let the parts be fomented twice a day, warm as the hand can be held in it ; then take a woollen cloth, dip it in the bath, and bind the ancle up, tight as possible, without giving pain to the horse.

Should this method not succeed, after a thorongh trial, the swelled or pufted parts may be opened with a sharp knife; but blistering with flies is less dangerous, and generally attended with equal success.

Wind galls give to a horse a gouty and clumsy appearance; but I have never known lameness produced by them, or any other injury, except that of stiffening his legs as he advances in years. They furnish strong proof that the animal has rendered much service 


\section{FARCY.}

Tux farcy is a contagious disease among horses. and is more to be dreaded than any malady to which they are subject.

It sometimes makes its appearance on a particular part, while at other times it spreads its horrid ravages through the whole system. It may be found in the neighbourhood of each blood vessel, following the track of the veins, and when inveterate, appears to thicken their coats and integuments. Its characteristics are a fulness and hardness of the veins, a number of small lumps or buds on the limbs or lower parts of the body, which at first appearance are hard, but soon turn into soft blisters, and which (when broken) discharge an oily or bloody ichor, and turn into foul, spreading ulcers. In some horses it appears in the head only, in others near the external jugular or plate veins, inside the fore arms, on the hind parts, near the large veins inside the thighs. about the pasterns, and particularly about the knees of the horse, which are frequently swelled until they appear deformed.

The poison of the farcy appears to be slow in its operation, as a horse will frequently linger and dwindle away for six or nine months, and the ulcers increase in number and size, until the flesh appears almost disposed to fall from the bones, before lile is destroyed. The appetite of a horse thus diseased is generally good to the last, but his hair looks dead, and his eyes sad and desponding.

'The farcy, in its first stage, readily admits of a rure hut after ruming on a horse for a length or time 
and the absorbents or lymphatics about the ulcers become inflamed from an ahsorption of poisonous mat. ter, the cure is rendered extremely difficult.

Whenever the farcy rises on tue spine, it shows yreat maingnancy, and is considered dangerous, particularly to horses that are fat, and full of blood. When it is general in the system, as is sometimes the case, it rises on several parts of the body at once, forming many large and foul ulcers, causing a profuse running of greenish corrupted matter from both nostrils, and soon terminates the existence of the animal by general mortification.

In the lower limbs the farcy sometimes remains concealed for a great length of time, and makes so slow a progress that it is often mistaken for a wound, or some other disease. A single bud will sometimes appear opposite the pastern joint, and run upwards in an uneven and knotty form; and unless some steps are taken to check its progress, it will slowly steal upon the animal until it becomes general in the sys. tem, and finally centres in the lungs; shortly after which a gangrene ensues, and the horse is unburdened of a life that is not only painful to himself, but to all that behold him.

To effect a cure in this distressing disease, in is first stage bleed three times the first week, taking lialf a gallon of blood at each bleeding, feed principally on bran, oats, or any food easily digested, and the long food green, (if to be had;) remove all filth from or about the staole, taking care to keep it neat and clears afterwards; give three mashes a week, of bran, scalded with sassafras tea, one table spoonful of powdered orimstone, and one tea spoonful of saltpetre (not per. 
mitting the horse to drink for six hours alterwards, ) take half an ounce of asafoutida, which can be pro cured in any apothecary's shop; wrap it ir. a clean linen rag, and nail it in the bottom of the manger in which he is fed: al! his cirnk must be equal quantitics of sassatras boiled in water to a strong decoction, and half an ounce of asafoetida should be placed in his watering bucket in the same manner as directed for the manger; the buds or ulcers should be washed once a day with blue-stone or copperas water, and if the knees or ancles are swelled, spread on a jiece of buckskin mercurial ointment, and bind them up as tiglst as possible without giving pain.

The second week bleed twice, taking half a gallon of olcod each bleeding, if the horse is in tolerable order; or if poor, only half the quantity; give the same number of mashes as directed for the first week, also the same drink, taking care to renew the asafortida in the manger and bucket, should it be sufficiently exhausied to require it.

The third week bleed but once, taking one quart of blood; in other respects observe the same treatment as directed for the first and second weeks. The horse should be moderately exercised about a mile, twice a day, and occasionally should be offered a little hommony, as a change of food, to keep up his appetite.

By the time your attentions for the third week expire, if the disease is only local, it will not only be remuved, but the plight of the horse will be muen improved.

When the farcy make its appearance epidemically; the cure is rendered dilficult, and will require the aid of more active medicine. Prepare and gire to a horse 
thus diseased, a ball. every nignt for a week, composed of twenty-five grains of calomel, a quarter of an ounce of powdered fennel seed, a smail quantity of syrup of any kind, and as much crumb of loaf bread as will make a ball about the size of an English walnut; all buds or ulcers should be washed clean in blue-stone water, after which they shonld be well rubbed around with mercurial ointment once a day; a narrow pitch plaster should be laid on at the joining of the head and neck, in the direction of the throat latch, for the purpose of taking off the hair, which will happen in two or three days; after which, a lump of mercurial ointment, about the size of a hickory nut, must be rubbed on the naked part, amongst the large glands of the throat, until it is entirely absorbed, every night and morning, until the expiration of the week; added to which, the treatment generally may be the same as before recommended in the more simple stage of the farcy, with these exceptions;- the drink should never be cold, but the air taken off, or milk warm; the mashes without sulphur, during the week the balls are given, as the sulphur counteracts the effects of the ralomel and ointment; he should not be bled, and great care should be used to prevent his getting wet, and catching cold in any way while under the course of physic.

At the expiration of the first week, stop with the balls anu ointment for a week, adding sulphur to the mashes, as directed in the first stage of farcy. At the expiration of the second week, stop with the sulphur, and again commence with the balls and ointment. Go on in this manner, continuing to change the medicine ench week: until the cure is performed. 
It may sometimes happen that a horse's mouth will become sore before the expiration of a week, when taking the balls and using the ointment. Whenever this is discovered, stop with the balls, and add sulphur to the mashes, which will readily remove the soreness about the mouth.

The farcy is so contagious that it often destroys horses of every description upon a plantation, and leares the plough of industry standing still in the farmer's field. Not long since, a gentlemen in the county of Sussex, lost upwards of forty horses by this fata! disease, without being able to save one. For the Denefit of those who have more than one horse, I would recommend the use of asafœtida in the manger, watering bucket, and to the bridle bit, to prevent the farcy from dealing out destruction to their whole stock. I have made a fair experiment with this simple preventive, by placing a horse violently aflected with it, and which fell a victim to it, in the same stable with one in health, without any ill consequenres resulting from their contiguous situation.

The farcy has visited several farms within the United States, with effects so dreadful, as not only to destroy every one of the species, without respect tc age, but even occupied in triumph the walks and resting places of its prey. Nor could the disease be diverted from its stand, or completely eradicated. until stables, shelters, pens, iitter, straw, \&c. \&c wore entirely consumed and redued to ashes. 


\section{RING BONE.}

TuE ring bone partakes of the nature of the spavin, and frequent'y proceeds from the same cause. It makes its appearance on the lower part of the pastern, and sometimes immediately opposite the coffin joint. It is a hard and bony substance, and generally reaches half way round the ancle, which gives to the ancle an unnatural apperrance, and causes the horse to go stiff and lame. Its name has proceeded from its resemblance to a ring. It seldom admits of a cure, consefuently a horse diseased with it is worth but little.

When the ring bone first makes its appearance, blisters of flies have sometimes been employed with success. But after growing to full size, and remaining some length of time, to offer a remedy would be deceitful and presumptuous.

Remedy. - A strong preparation of corrosive sublimate added to Spanish flies and Venice turpentine, and mixed with hog's lard, will often dissolve a ring bune \&c.

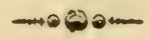

\section{FOUNUER.}

T'He injury sustained by horses, called founder, 19 sometimes the effect of the cruelty of his master, and a: other times brought on by injudicious treatment; hut it mos. frequently produced by carelessness, or 
a want of knnwledge of the treatment necessary to those excellent animals on a journey.

Although the horse is endowed with the strength and powers of the lion, yet he seldom exerts either to the prejudice of his master. On the contrary, he shares with him in his labours, and seems to participate with hin in his pleasures. Generous and persevering, he gives up his whole powers to the service of his master; and though bold and intrepid, he represses the natural fire and vivacity of his temper, and not only yields to the hand, but seems to consult the inclination of his rider.

But it must continue to be a matter of regret to every feeling mind, that these excellent qualities should be so often shamefully abused in the most unnecessary exertions; and the honest labours of this noble animal thrown away in the ungrateful task of accomplishing the purposes of an unfeeling folly, or lavished in gratifying the expectations of an intemperate moment.

$\Lambda$ horse may be foundered by excessive hard rides, permitting him to plunge deep into cold water, while hot and sweating, and drinking his fill of cold pond water, eating large quantities of new corn and fodder, and then briskly exercised; over feeding with bran alone whilst performing hard labour, drinking plentifully at every branch in travelling, feeding with more than a horse can eat after being half starved, violent exereise on a full belly, or not permitting a horse who has travelled in a hot sun all day, to cool thoroughly. before he is given as much as he can eat, drink, \&c.

s'ymptoms of a Founder.-The symptoms that ind. cate an approaching founder, are so few and so :ommon, that the most ignorant persons will rarely be 
mistaken. Great heat about the legs, pasterns, and ears, a soreness in the feet, together with a stiffness so great in all his limbs that the animal frequently refuses to move, unless force is used; his flanks and cower part of his belly draws up, his hide becomes bound or tight, his legs thrown a little more forward than in his usual or natural position; a constant thirst, and very often a considerable swelling of the ancles, \&c. \&c.

Remedly for a Founder.-So soon as you are convinced that your horse is foundered, take trom his neck vein at least one gallon of blood; give a drench of one quart strong sassafras tea, one table spuonful of saltpetre, and a quarter of an ounce of asafoetida, and do not permit him to drink for five or six hours; at the expiration of which time, should he not be evidently better, repeat the bleeding, taking half a gallon of blood, and give another drench: at night offer him some bran or oats, scalded with sassafras tea, and if it can be procured, let him have green food, fresh from the field, for it has the happy effect of opening the bowels, and cooling the system: his feet should be nicely cleaned out, and stuffed with fresh cow manure: his drink should be at least one half sassafras tea, with a small handful of salt thrown therein.

By the morning, should the horse be better, nothing firther is necessary, only being careful not to over feed him. But should there be no change for the netter, tie a small cord just above his knees, and with a ancet or fleam bleed in a vein that runs around the :oronet, just above the hoof; take from each leg a vint of blood: give a pound of salts dissolved in three half pints of water, in form of a drench; kecp his feet stuffed with fresh cow manure, ard bathe his legs with 
equal parts of sharp vinegar, spirits and sweet o!! or lard. By attention to these directions, in two or three days the horse will again be fit for service.

A horse in this unpleasant situation requires great attention. Whenever they are foundered, they search for a bank of manure to stand on, which should always be prevented, as its heat increases the fever.

Horses slightlv foundered, have sometimes been cured in a few hours, by standing them in pond water or mud, or by bleeding in the mouth, but those reme. dies are uncertain, and are not so much to be relied on as those first recommended.

A foundered horse is generally very much reduced in flesh, before a cure is effected; and is always more subject to founder afterwards.

Large ridges on the hoofs, or a turning up of the fert, are strong indications of old founders or other iniuries.

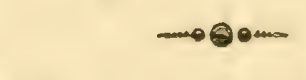

\section{COI.IC OK GRIPES.}

Tine colic is a disease to which the horse is very subject; and as often proves fatal, in consequence of improper treatment, as any disease attendant on that animal.

It may be produced by improper feeding, watering, or riding, and sometimes by a want of energy in the stomach and bowels, occasioning a spasmodic con. striction of the intestines, and a confinement of air some horses are naturally disposed to colic, while 
others, even with improper treatment, are seldom or never attacked with that dangerous disease.

The pangs of the colic appear so excruciating, ano all the symptoms so violent, as to alarm, generally, those unaccustomed to it, and cause them to be apprehensive of dangerous consequences; but by using the remedies I shall here offer, the cure will be made easy, and the animal speedily relieved from this painful situation.

Symptoms. - The symptoms of the colic commence with great restlessness and uneasiness in the horse's manner of standing, frequently pawing, voids small quantities of excrement, and makes many fruitless attempts to stale: kicks his belly with his hind legs: often looks round to his flanks, groanirg, expressive of the pain he feels: lies down, rolls, gets up again, and sometimes for a moment, appears to find relief. But the pain soon returns with double violence: his ears are generally cold, and he often sweats about the flanks and shoulders: his body swelled, and he frequently shows a disposition to lay down in great haste.

A Table for distinguishing between the Colic or Gripes, and in. flammation of the Bowels of Horses, by the symptoms that mark the character of each.

\section{Spasmodic or Flatulent Colic.}

1. Pulse natural, though some. times a litte lower. (1)

2. The horse lies down and rolls upon his back.

3. The legs and ear are genesally warm.

4. Attacks suddenly, is never preceded, ind seldom accompaine 1 by any symptoms of fever.

5. There are frequently short ıncermissiuns
Inflammation of the Bowels.

1. Pulse very quick and small

2. He lies down and suddenly rises up again, seldom rolling upon his back.

3. Legs and ears generally cold.

4. In general, attacks gradual. ly, is commonly preceded, and aiways accompanied by symptoms of fever.

5. No intermissions can !o :b served. 
(1) Pulse Nutural.-When in health, the pulsalfrons or strokes are from thirty-six to forty in a minute; those of large, heavy horses being slower than those of the smaller; and those of old ones, slower than those of young animals. When either are just off " auick pace, the strokes increase in number; as they do if he be alarmed or animated, by the familiar cry of the hounds.

(2) Pulse very quick and small.-Fever, if the simple or common kind, usually increases the pulsations to doukle the healthy number. As the fever increases in violence, and particularly in cases of inflammation of the bowels, the pulse beats still higher, and reaches to a humdred in a minute, or more. To ascertain either state, the attendant should apply the points of his fingers gently to the artery which lies nearest the surface. Some prefer consulting the temporal artery, which is situated about an inch and a half backward from the corner of the eye. Others again, and they are the greater number, think it best to feel it underneath the edge of the jaw bone, where the facial artery passes on under the skin only to the side of the face. In either case, too great pressure would stop the pulsation altogether; though by so trying the artery against the iaw bone, will prove whether it be in such a rigid state of excitement as attends high fever; or elastic and springy, slipping readily from under the finger, as it does when health prevails, and the strokes follow each othe $r$ regularly. The presence of high fever is further ina sated by a kind of twang, or vibration. given by the pulse against the finger points, resembling much such as would be felt were we to take hold of a distendeo whip. cord or wire between the fingers and cause it io vibrate like a fividestring, sharpl:

Wheseas, 10 
health, a swell is felt in the vibration, as if the string were made of soft materials, and less straitened. Languid? or slow pulse, and scarcely perceptible in some of the beats or strokes, indicates lowness of spirits, debility, or being used up: if this languor be felt at intervals only, a few strokes being very quick, and then again a few very slow, this indicates low fever, in which bleeding would do no harm, \&c.-[A. Turf. R. \&. S. Mag.]

Remenies. - Number 1. Take from the neck vein half a gallon of blood; take of laudanum one ounce, or mint tea onc quart, milk warm; mix them well in a bottle, and give the contents as a diench; let the horse Le well rubbed under the belly, and prepare and give an injection of meal, water, molasses, salt, and hog's lard, milk warm.

Number 2. Take of mint tea one and a half pints; gin, or any spirituous liquor, half a pint; mix them well in a bottle, and give them as a drench, taking care to rub him well. Should it not have the desired effect in fifteen minutes, repeat the dose.

Number 3. Take of camphor a quarter of an ounce oil of turpentine half an ounce, mint tea one pint; miy them in a bottle, and give them as a drench. Confine the horse in a close stable, cover him with three or four blankets, and under his belly place a large tub of boiling water, which will readily throw him into a profuse sweat, and relieve him from pain.

Number 4. In addition to the above, clysters oughr .0 be administered, by injecting the following ingledients, viz.: water half a gallon, salt one handful, oil of any kind one pint, molasses one pint; mix the whoie, and inject it; and repeat it every hall hour, until the irwels arf; well opened. 


\section{SCRATCHES.}

True scratches is a disease which soon places a horse in such a situation as to render him unfit for any kind of service. When it is permitted to run upon a horse for a length of time, without any remedy being applied, the ankles and legs swell very much, and lameness is produced in so great a degree, that he is scarcely able to move.

The scratches are produced from many different causes. as hard riding, dirty stables, legs left wet at night without being rubbed, standing in his own manure or mud, in the stall where he is confined, \&c. \&c. Although much intlammation may appear, and the disease discover much inveteracy, the cure is not difficult.

Remedies.-Number 1.-Remove the horse to a clean stall: with strong soap suds wash his legs and ankles nicely; clean out his feet; then wash every part, inflamed or sore, in strong copperas water, twice a day, until the cure is performed: take half a gallon of blood from the neck vein, and give a mash twice a week, of one gallon of bran, one tea spoonful of saltpetre, and one table spoonful of powdered brimstone. Great attention should be paid to the cleanliness of the stable.

N'umber 2. After the horse is placed in a clean stall and his legs and ankles nicely washed with warm soap suds, take of blue-stone, one sunce; of alum. four ounces, to which add half a gallon of strong decoction of red oak bark, stir them together until the a!um and blue-stone are dissolved; then wash the cracks, sores, or inflamed parts, twice a day, and the 
rure will be effected in a very short tme. Ligat or green food would be preferable to any other, for a liorse thus diseased, until the cure is performed.

Number 3. After washing the legs and ankles clean with soap suds, take of flower of sulphur or powdered brimstone, one table spoonful; hog's lard, one table spoonful; mix them well together, and anoint the sores and parts inflamed twice a day. A horse will get well much sooner confined in a clean stall, than by running at large.

Number 4. Boil poke-root to a strong decoction, and bathe the ankles twice a day. In all cases a clean stable will aid you much in making a quick cure of the scratches.

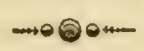

\section{BOTS OR GRUBS.}

Tre bots or grubs are smail worms that are found in the stomach; their colour is brown or reddish, and they seldom exceed three quarters of an inch in length. At one extremity they have two small hooks, hy which they attach theinselves, and the belly appears to be covered with very small feet. They are most frequently found adhering to the insensible coat of the stomach, and then they do not appear to cause any considerable uncasiness or inconvenience. Sometimes nowever, they attach themselves to the sensible part, and du great injury to that important organ, producing irritation, emaciation, a rough coat of hair, hide bound unc cough. It is astonishing with what force these worms adhere, and how tenxcious they are of life. 
It is proved beyond doubt, by experiments marde, that this worm, like the caterpillar, undergoes several changes. It is originally a fly, which deposits its eggs in the horse's coat, causes an itching, and induces him to bite the part. In this way he swallows the eggs, which by the heat of the stomach are brought into life, and are sometimes so numerous as to eat their way entirely through the stomach and destroy the animal. Indeed they seldom fail to attack a horse with great violence, whenever his stomach is empty, and endanger his life.

Numberless experiments have been made upon the grubs, after they have been taken from a horse that had died, to discover what medicine would soonest destroy their lives, that could be safely given. But all endeavours as yet upon that subject, have been fruitress. It appears that they will live in any nedicine that can be given to a horse, nearly as long as they can live wihout eating. All the benefit that results from experience on this subject, to me, merely serves to break the hold and expel those dangerous worms, when they are so mischievously engaged.

After describing the symptoms attending the grubs I shall offer some remedies which have saved the lives of many horses.

Symptoms.-A horse attacked by the grubs, fre quently lies down and looks round to his shoulders, groans, whips his tail between his hind legs, frequently curns up his upper lip, and has a very hot fever, which may be discovered by feeling his ears.

Reuedres.-No. 1. Talie of copperas iwo tahle spoonfuls; water milli warm, one pint; Jisso!ve :ne 
copperas, and give it as a drench. If the horse is not relieved in fifteen minutes, repeat the dose.

No. 2. Take of linseed or sturgeon's oil, one pint, and give it as a drench. If the horse is not relieved in fifteen minutes, repeat the dose.

No. 3. Take of molasses, one pint; milk, one pint : give it as a drench, and repeat the dose.

No. 4. Take of fresh meat of any kind (raw) half a pound, cut it into four or five pieces, and force it down the horse's throat; it will immediately induce the grubs to break their hold.

No. 5. Take two ounces of Ethiop's mineral and give it to your horse in his feed, and in a day or two afterwards give him a purge; then you may give him a decoction of bitter herbs, to prevent their return.

No. f Give your horse (after taking molasses and milk) a quart or two of fish or beef brine, as a drench. From recent experiments, salt appears to have the property of killing worms : these insects placed in $\varepsilon$ solution of this substance die immediately.

No. 7. Drench the horse with half an ounce of saltpetre dissolved in common water, and in about fifteen minutes drench with half an ounce of aum dissolvea in like manner. Let the horse have no water for twenty-four hours after.

An active purge will be absolutely necessary imme diately after the use of either of the above remedies Une pint of soft soap added to a pint of molasses with a handful of salt, will answer very well. Re. pea: the dose, should it not operats in frur or firo 


\section{HOOKS OR HAWS.}

Tire hooks or haws in a horse, is the growing of a horny substance upon the inner edge of the washer or caruncle of the eye, which may be found in the inner corner next to the nose. When this disease makes its appearance, the washer or caruncle is enlarged with greut rapidity, and the ligament that runs along the edge of this membrane, becomes extremely hard, or like a cartilage, and whenever it arises to this state, it draws, compresses, and causes great pain to the eyes, produces a tightness of the skin, a stiffiness of the hind legs, and finally a general spasmodic attection throughout the whole system.

As the eyes of a horse are often inflamed, and sometimes diseased, without their having the hooks, for the purpose of ascertaining the fict, take hold of the bridle. and raise the horse's head as high as you can with convenience reach: if he is diseased with the hooks, the wisher or caruncle; of the eye, whule his nead is raised up, will cover at least on half the surfuc of the eye ball. When this is the case, lake a :ommon sized needle with a strong thread, place on the horse's nose a twitch, to prevent his moving; then take in your thumb and finger the washer or caruncle of the eye, and pass the needle through it abuut a quarter of an inch from the outer edge, and inside the horny substance; draw it gently with the needle and thread, until you have a fair chance of performing the operation; then with a sharp knife cut the piece out, taken up with the needle, which must not he larger than one fourth the size of a four pence half penny: 
wash the eyes for two or three mornings with salt atd water, bathe his legs up to his belly in equal parts ot warm vinegar, spirit and oil, or fresh butter, and give a mash of one and a half gallons of bran or oats, one :able spoonful flour of sulphur, one tea spoonful saltpetre, and the cure will be performed in all probability in four or five days.

Great care should be taken not to cut too large a piece from the caruncle, as it disfigures the eyes, and scmetimes produces blindness.

\section{ON CUTTING OUT HOOKS OR HAWS.}

"Before I was acquainted with this subject, twn years ago, I had two fine young horses sacrificed to this mistaken and ruinous operation. Ignorant quacks do not know that the horse has a membrane peculiar to the animal, which is at pleasure drawn over the eye. The enlargement of this, by a fever, produces the appearance, which, in jockey slang, is called the nooks. Reduce the fever by depletion, such as bleeding plentifully, purging, \&c. and have the horse well rubbed, and the hooks will disappear; that is, the membrane is restored to its natural size and office, which is to clear the eye from dust, \&c. accidentally entering it. I need not montion the cutting out of this useful membrane umnecessary, as I have proved the uselessness of this nreration, by restoring a horse without it a few days ago.

\section{[Amercoran fiamer.]}

$$
\text { W. V. MURRAY" }
$$




\section{S'TRANGLES.}

TH飞 strangles is a disease to which horses are very suljert, particularly those that are young. It consists in a rumning at the nose, and an inflammation and swelling of the glands, about the under jaw and throat. It is sometimes attended with high fevers, destroys the appetite, causes a horse to look sad and dejected, and dwindle away in an astonishing manner. Sometimes the inflammation extends to the muscles of the tongue, and is attended with so much heat and pain, that until matter is found, the horse swallows with the utmost difficulty, unless his drink is held up to him.

The strangles proceed from many causes, violent colds, sudden changes of air or climate, extreme hard labour after habits of idleness, shedding teeth, or whatever may produce pain, or bring on a flux of humours at any critical time upon the throat and jaws, and like most other diseases, requires strict attention, for the cure to bo performed in a short time.

symptoms of the Strangles. - The approach of the strangles may be known by a dulness of the countenance, watery eyes, a distressing cough, running at the nose, glands enlarged beyond the jawn, loss of appetite, und a constant thirst, without ocira able to drink, unless the water is placed as 'ight as his head, in its natural position.

Remedy.-Bleed four tmes within a week, taking from the neck vein half a gallon of blood at each bleekung; give a mash twice a week, of one gallon of bran or oats, scalded with one quart of sassafras tea, wich the addition of one table spoonful of powdered brim 
srone, and one tea spoontul of saltpetre. Take or asafotida half an ounce, divide it, placing one half in his manger, the other in his watering bucket. Feed principally with green food, if to be had, if not, such as is iight, couling, and easily digrested.

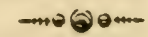

\section{STONE OR GRAVEI. IN THE BLAIDDER.}

Fortunately the stone is a disease not very com. mon amongst horses; but whenever it makes its appearance, unless some remedy is immediately employed, :ts consequences are to be much dreaded. It consists in small gravel or stones being lodged in the bladder, which prevents a free discharge of urine, and produces the most excruciating pain. The horse will linger and pine away, until he can scarcely support the burden of life.

As the stone is a disease which has but seldom, if ever, struck the attention of farriers, I consider myself frortunate in being able to offer to the public a simple remedy, which has been employed with astonishing success by a gentleman in a neighbouring county. In one case, when the following remedy was used, three stones and a quantity of grit was discharged from the bladder.

Symptoms.-Frequent stretching, groaning, and many fruitless attem pts to pass water, which will finally be dischargec by a few drops at a time, with great apparent pain, a shrinking of the flesh, although the aypetite is good, no fever, but a dull, sluggish, and sleepy aprearance, wanting much in his usual spirits 
Remely.--Take of marsh-mallows, water melon seed, and asparacrus, of each two large handfuls, bril them in three quarts of water to one quart, and add one tea spconful of saltpetre, and g:ve the whole as a drench, after being nicely strained

Take of sweet oil or fresh butter one table spoonful, grease his sheath, and draw out gently and grease his penis, also grease the large seam from the penis up near the anus; and with the hand, bearing a little, stroke the seam downwards to the end of the penis, for ten minutes every hour, until the horse has a urinary discharge; which, in all probability, will take place in one or two hours after taking the drench Should some blood be passed, it may be no cause of alarm, and will clearly prove there is gravel in the urinary passages. Repeat the drench in three hours, should the desired eflect not be produced.

\section{$+\cdots \cdot 0 \cdot \cdots$ \\ YEI,LOW WATER.}

The yellow water is very common in the western country among horses; and being infectious, is sometimes brought into this state by drove horses. It is extremely fatal in its consequences, unless some remedy is employed shortly after it makes its appearance. For the benefit of the public, I consider myself fortunate to be able to recommend such medicines for its curu as have been fairly tried, by a gentleman of Brunswick, and proved eflectual. 
Syrnptims of Yellow Water.-The characteristics of this disease, are a dusky yellowness of the eyes, lips, and bars of the mouth; a dull, sluggish, appearance: a loss of appetite; the excrement hard, dry. yellow, and sometimes of a pale or light green; the urine uncommonly dark, of a dirty brown colour, and when discharged a length of time, lias the appearance of blood.

Remedy.-Take of asafoetida one ounce; camphorated spirits. four table spoonfils; warm water one pint; mix and give them as a drench, for three or four mornings successively. Take of bran one and a hall gallons, flour of sulphur one table spoonful, antimony twenty grains, saltpetre twenty grains; mix them well tusether, and, with a strong decoction of sassafras, scald the bran, forming a mash, which must be given three nights in a week, not permitting the hor'se to get wet, or drink water, except it is milk warm. His stable should be a comfortable one, and he should have a clean bed of straw placed under him. Bleed twice in the neck vein, taking half a gallon of blood at each bleeding, within the week; let his exercise be regular and moderate, and by the expiration of nine or ten day's, he cure, in all probability, will be performed.

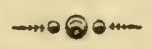

\section{TO PREVENT INFECTIOUS DISEASES.}

As most diseases that are infectious endanger the II $\mathrm{e}$ of a horse, I consider it important to every owner ot those useful animals, to be able to use a medicine that will act against or prevent those diseases that are 
contagious. 1 have been in the habit of owning from one to eight horses at a time, for fifteen years, and in all that time never lost a horse. I cannot help believing my success, in this respect, has been much indebted to the constant use of the asafœtida, which I consider one of the most valuable and innocent medicines ever used amongst horses. It not only drives off diseases of almost every kind, but it keeps up the appetite, produces a remarkable fineness in the coat of hair, and gives such life and spirits as to induce even an old horse to attempt the attitudes and movements of the gay and mettled racer.

The value of the asafotida is at present but little known for the use of horses; but whenever it shall have been used or brought into notice, its remarkable effects, no doubt, will prove what I now say. Its virtues are acknowledged and remembered with pleasure, by all those who have used it in their stables.

The asafoetida is produced from a plant called perennial, and is a native of Persia: it has, however, borne fertile seeds, in the open air, in the botanical garden of Edinburgh. The gum resin is producen from the roots of plants which are at least four years old. When the leaves begin to decay, the stalk in rwisted off and the earth removed from about their large tapering roots. The top of the root is some time afterwards cut off transversely, and forty-eight hours afterwards the juice which has exuded, is scraped ofl; and a second transverse incision is made: this opera. tion is repeated until the root is entirely exhausted o fuice: after being seraped off, the juice is exposed to the sun to harden. It is brought to us in large rrregular masses, composed of various little shining umps of grains, which are partly of a whitish colour. partiy red- 
dish, and partly of a violet hue; those masses $\mathrm{ks}$ accounted best which are clear, or a pale reddist, cr. lour, and variegated with a number of elegant white tcars. This drug has a strong fetid smell, somewhat like that of the garlic, and a bitter acid, biting taste. The smell resides entirely in the essential oil, which arises in distillation. It is the most powerful of all the fetid gums, and is a most valuable medicine. It acts as a stimulant, anti-spasmodic, expectorant, emmenagogue, and anthelmintic, and its action is quick and pene. trating.

When a small piece of the asafietida has been placed in the manger of a horse in health, I have known hirr to stand for months in a stall next to one violently diseased without taking the infection, or any ill con sequence resulting from their contiguous situation.

Preventive. - Take of asafotida, one ounce, divide it and wrap each piece in a clean linen rag; nail one in the bottom of the manger the horse is fed in, the other in the bottom of the bucket in which he is watered. The above quantity will last about three months; at the expiration of which time it must be replenished.

A small piece confined to the bridle bit, will have the same eflect when a horse goes from home, or enters on a journey.

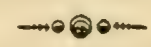

\section{GRAVEL, IN THE HOUFS.}

'TuE gravel in the hoof is an incident that happens w morses in travelling, and is brought on by small stones or grit getting between the hoof and shne, setliing to the quick, and then inflame and fester; it pro- 
auces lameness and causes a horse to undergo ve?: excruciating pain. The first step necessary for a horse's relief is, to have his shoes taken off and get the stone out. You may readily ascertain where they lie, by pressing the edge of the hoof with a pair of pincers. After all the gravel is removed, which may be known by a discontinuation of the blackness of the place, the wound caused by cutting for the gravel may be easily healed by melting together equal parts of bees-wax, rosin, fresh butter or sweet oil, and pouring the mixture on the wound, warm as the animal can bear it, without giving pain. Then warm a little tar or pitch, and pour a small quantity over the wound and its neighbouring parts, to keep out the dust and detend the foot from any hard substance for a few days, by which time it will get well.

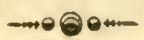

\section{WOUNDS.}

A wounn is generally defined a separation of the parts in any member of the animal body by some instrument. In all fresh wounds made by cutring instruments, there is rothing more required than bringing the lips of the wound into contact, by sewing a bandage, provided the part will allow of it. For wounds of the hips, or other prominent parts, and across some of the large muscles, the stitches are ap: to burst by the horse's lying down and getting up in the stall. In such cases the lips of the wound snould not be brought close together-one stitch is enough 
for a wound two inches long, hu: in large wounds shey should be an inch or more apait.

Should the wound bleed much from an artery's being divided, it will be necessary to secure it by passing a crooked needle underneath, and tying it with a waxed thread; but if the artery cannot be got at in this way, apply a small quantity of flour and salt to the mouth of the bleeding vessel, which will very soor: have the desired effect. Care should be taken to keep it there, by proper compress or bandage, until a scar. scab, or crust is formed, otherwise it will elude your expectations, and frequently alarm you with fresh bleedings. After the lips of the wound are brought together, by this needle or bandage, it needs only to be covered with rags, dipped in spirits of any kind, or spirits of turpentine, and a little lint placed lightly within the edges of the wound, taking great care to keep it entirely clean, with strong soap suds, and as free from motion as possible. Whenever a wound be comes much swelled or inflamed, or discovers marks of mortification, frequent bleedings and the application of a red oak poultice or mush, will have a won derful effect. Should the wound be disposed to heal very rapidy, and turn out what is termed proud Hesh, by washing it with a little blue-stone water, it will, in a very short time, shut in, and the wound entirely heal.

'The cure of most wounds is effected by the simplest methods, and it is often of much more consequence :o know how to dress a wound, than what to dress it witn, and in this consists the chief art of this branch of surgery; for the most eminent in that profession have long discovered that a variety of ointments, -aves, and grease, are unnecessary in the cures of most wounds and sores. and they have according!y 
discarded the greatest part formerly in repute for that purpose; repeated observations having taught them, that after digestion, or after healthy matter is formed, nature is disposed to heal up the wound fast enough herself. Some respect should be paid to the diet of a horse, as bran, oats, and green food keep the bowels open, and are free from that heat which the use of corn and fodder will produce in the system. I will here ofler a few more simples that have proved beneficial in the cure of wounds, sores, \&c.

The first operation necessary in all sores, wounds, Sc. about a horse is, to remove all dirt, matter or extraneous bodies, with strong soap suds, after which,

No. 1. Take of spirits, half a pint; alum, one ounce; honey, one gill; mix them well together, and wash the wound night and morning.

No. 2. Take of copperas, two ounces; clean water, one quart; wash the wound or sore twice a day.

No. 3. 'Take of sugar of lead, a quarter of an ounce; fair water, one quart; use it twice a day.

No. 4. Take spirits of turpentine and wet the wound once a day.

No. 5. Take of blue-stone, a quarter of an ounce: fair water, one quart; wash the wound every morning.

Punctured wounds, from thorns or other accidents, are generally of the most painful kind, and require great attention; a bread and milk poultice, or a mush, made by boiling red oak bark to a strong decection, beating the bark very fine and throwing in as much corn meal as will make it of proper consisteney should be applied until healthy matter appears, to gether with fomentations: after which, to effect a speedy cure, use any of the above romedies recom. mended. 
Wrunds in the feet, from shoeing, nails, thorns, or other accidents, are generally attended with murh trouble, and are often productive of very fatal consequences when neglected. Such wounds should have old dirt, grit, \&c. carefully removed with warm greasy water; after which, take of bees-wax, tar, and sweet oil, equal parts; stew them well together, and fill the wound, hot as the horse can bear it without experiencing pain; then pour on a little warm pitch, to prevent grit and dirt getting to the wound, and to protect the foot, while sore and tender, from the hard ground.

\section{$-m \cdot 00$}

\section{BRUISES.}

Bruises proceed from external injury, and when no remedy is employed, are sometimes attended with violent inflammation, and after bursting and discharg ing large quantities of matter, of a dark red colour and extremely offensive smell, often terminate in a mortification, whlch soon puts a period to the life of the animal.

Take of vinegar, one quart; laudanum, half an ounce; sugar of lead, quarter of an ounce; mix them well Ingether, and apply it to the bruise three or four times n day; if the part bruised will admit of it, apply a flannel doubled and wet with the mixture, which will be the means of keeping the bruise continually moist if by this method the swelling does not subside, apply 
u poultice made of a strong decoction of red oak bark and meal, once a day, until the swelling abates; but in bruises that cannot, by these means. be dispersed, and by pressing with the finger you ascover that matter is formed, then the shortest way is, to open the skin and allow the bruise to discharge its contents: after which it will heai in a very short time, by keeping it entirely clean with soap suds alone. But after discharging the matter, if the wound should appear rotten and of dark colour; indicating mortification, togethe. with any very considerable inflammation, bleed plen. sifully ; feed on bran, oats, long green food, or light food of any kind, and again apply the red oak poultice, which will very soon cure the inflammation, cleanse and alter the appearance of the wound. After which, any of the simples recommended for wounds, may be employed in speedily healing.

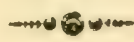

\section{STRAINS.}

Śrrarns, in whatever part of the horse, either produced from running, slips, blows, or nara riding, are the relaxing, over-stretching or breaking ine muscles or tendinous fibres. 'A strain, unless uncommonly bad, may be cured in a short time, by applying the following remedies:

Number 1. Take of sharp vinegar, one pint; spirit. of any kind, half a pint; camphor, one ounce: $\mathrm{mix}$ them well together and bathe the part injured twice a 
day; a piece of flannel wet with the mixture and wrap ped around the part, will be very beneficial; take from the neck vein half a gallon of blood.

No. 2. Take of opodeldoc (which can be procurea from any apothecary's shop) a piece the size of a marble, and rub it on the strained part with the nakea hand until the hand becomes dry, twice a day : shoula the injured part resist both these remedies, you may conclude the injury is a very serious one, which rothing but time can relieve, and the horse must he turned out upon grass a sufficient length of time fior nature herself to perform the great operation.

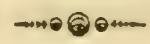

\section{STAGGERS.}

THE staggers is a very common as well as a very fatal disease among horses of all ages: though young horses are more subject to it than those advanced in years.

Many various opinions have been offered to the public, and some with much confidence, relative to the arigin and seat of this disease. But few, if any, as vet, have investigated the subject with correctness.

The staggers, in my opinion, are produced by permitting a horse to feed on grass in the spring and fall, late at night and early in the morning; for early in the morning and late in the evening, the fields and pastures are covered with a poisonous web, which is spun and spread upon the grass by a small spider. So rapidily, so industriously $d$ ies this little insect work, 
that in the space of one night, not a blade or spire of grass has been left untouched. This web, catching the dew-drops on its bosom, causes the fields in the morn ing to glisten and sparkle as if covered with a thin sheet of ice. A horse that feeds upon a pasture in this situation must, of course, collect large quantities if this web and dew, and very often the spider itself. They act upon the horse, producing delirium, griddiness, apoplexy, and sometimes death. The lungs appear to be the principal seat of this disease; for in cases of dissection they have been found much enlarged, and covered with large brown spots; smell very offensively, and have some appearance of mos tification.

The large quantity of poison trasen into the stomach acts upon its nerves, and the sympathy that exists between that organ and the large nerves of the head, accounts for the dull, giddy, and dejected countenance of the aninal, and has induced many to believe the stagrgers was confined to that part alone. The poison is then removed from the stomach by the activity of the lymphatic and absorbent vessels, thrown into the circulation of the blood, diffused over every part of the system, and finally carried by the arteries into the lungs, through which all the blood in the body of a horse passes many times in an hour, and undergoes a change. Sometimes a determination of blood to the head takes place, which generally ends fatally, producing a furious delirium, the horse throwing himself about with great violence, making it dangerous ior any person to venture near him.

Symptoms.-The symptoms of the staggers are a drowsiness, eyes iiflamed, half shut, and full of tears, the appetite bad, the disposition to sleep gradually mcreased, feebleness, a continual hanging of the head 
or resing it on the manger, rearıng, falling, and lying in a state of insensibility, walking a small circle for a considerable length of time, the ears hot, with a burn. ing fever, \&c. \&c. \&c.

Remedy.-Take from the neck vein half a gillun of blnod, three times in a week; take of sassafras tea, three half pints; plantain juice, half a pint ; asafoetıda, half an ounce; saltpetre, one tea spoonful; mix and give them as a drench three mornings in a week; give an injection composed of one pint of meal, two quarts of water, one quart of molasses and one spoonful of hog's lard; let the horse be moderately exercised, and whenever he is standing should be well rubbed; give a mash rwice a weck, composed of one gallon of bran, one table spoonful of sulphur, one tea spconful of saltpetre, one quart of boiling sassafras tea, and a eighth of an ounce of asafœtida, not permiting the horse to drink cold water for six hours afterwards. Should he be much mended by this treatment, nothing more will be necessary, except feeding him on bran, or light food of any kind; but should he appear to receive no benefit from these attentions, in four or five days, take of calomel, twenty-five grains ; of opium, two drachms; camphor, two drachms; powdered fennel-seed, one drachm; of syrup, of any kind, a sufficient quantity to make the ingredients into a ball, which may be given every morning for four or five days, by which time the horse will get well il his disease will admit of a cure.

IIorses that are confined in a stable never have the staggers; consequently it would be advisable for every person, whose situation will admit of it, to con fine their horses, particularly at night, during tho spring and fall months 


\section{MANGE.}

Tue mange in horses is a disease of the skin, which 1. generally rough, thick, and full of wrinkles, especully about the mane, tail, and thighs, and the little lair that remains on these parts stands up very nuch like bristles.

The ears and eye-brows are sometimes attacked, and in a short time are left quite naked. The mange is an infectious disease: indeed so much so, that if a horse is carried into a stable where one that is mangy has been in the habit of standing, he will be almost certain to take the infection, unless the litter has been removed and the stable properly cleansed and aired. Proper attention will make the cure easy.

Remedy.-Take of powdered brimstone and hog s ard an equal quantity, mix them well together and anoint the part affected twice a day, bleed plentifully and give two or three mashes (composed of bran, sulphor, saltpetre, and sassafras) within a week, by which time a cure will be performed.

A clean stable and nice bed of straw will and much in accomplishing the object in view.

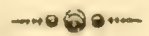

\section{HIDE BOUND.}

A Horse is said to be hide bound when his skin will not slip under the pressure of the hand, hur sticks as fast to the ribs as if it was glued. 
Hor ses are sometimes hide bound in consequerice of fecling the effects of sume violent disease, and it is often a bad symptom; but generally, this tightness of the skin proceeds from poverty, cruel usage, and sometimes from worms.

The first thing necessary for performing a cure is, in offer better treatment to the animal, giving him plenty of light food, such as bran, oats, \&c. and a clean stable with fresh litter. Then take from the neck vein half a gallon of blood; at night give a mash composed of one gallon of bran, scalded with sassafias tea; one table spoonful flour of sulphur or powdered brim. stone, and one tea spoonful of saltpetre; not permitting him to drink for six hours afterwards.

On the second day, at twelve o'clnck, take of copperas, two table spoonfuls; of warm sassafras tea, one quart; saltpetre, one tea spoonful, mix and give them as a drench. Have the horse well rubbed, and in a few days he will be entirely relieved.

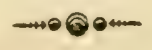

\section{SURFEIT.}

Tue surfert is a common disease among horses tha. have been cruelly or injudiciously treated. Sudden changes from heat to cold, plunging deep into cold water and drinking plentifully after being excessively hari rode, unsound food, being turned from a warm and comfortable stable out into the cold air, night drws, \&c. de, often produce surfeit. 
Symptoms.-The surfeit first makes its appearance with many fine and small lumps under the skin, a partial falling off of the hair, and a constant itching: at length a great number of scabs are formed, and some small ulcers, and unless some remedy is employed, the whole coat of hair falls off and the norse becomes covered with scabs: the hair in the mano and tail will be nearly rubbed off; and the little remaining will stand erect.

Remedy.-Take from the neck vein on the first and fourth days of the week, half a gallon of blood; give a mash of one gallon of bran, one table spoonful of sulphur, one tea spoonful of saltpetre, and a quart of hot sassafras tea, well mixed together, three times within a week, not permitting him to drink for six hours whenever a mash is taken.

Give three drenches within the week, composed of one quart of sassafras tea, and one tea spoonful of saltpetre, each. Change the horse's litter frequently; keep his stable clean, and do not permit him to get wet.

Take of hog's lard and sulphur, equal parts, mix them and anoint the horse where the surfeit appears worse, once a day; and by the expiration of a week. if the horse is not entirely well, he will be much benefited, and nothing more will be necessary, except giv. ing him food that is light and easily digested, anv ubserve towards him kind treatment. 


\title{
SORE TONGUE.
}

TAKE four ounces sugar of lead, four do. bole am. moniar, eight do. alum, burned.

The whole to be put in three quarts of good vinegar. and the horse's mouth washed or swabbed two or three times a day, keeping the bit out of the mouth. The above is enough for six horses.

\author{
-ே0・ா- \\ [FROM THE AMERICAN FARMER.]
}

\section{BIG HEAD.}

I HAve noticed several essays in your valuable paper, the "American Farmer," on the subject of "big head in norses," and as I have never seen any description of this disease, or any cure recommended, I will endeavour to communicate what my limited experience on that subject has taught me:

About twelve years ago the disease made its ap. pearance in this neighbourhood, and befo re a remedy was found out, many losses were sustained, by the death of the horses which were diseased. One of my neighbours lost horses to the value of six or seven thousand dollars, among them some of the best blood. ed mares and colts. I lost one only, and the first and only one, a brood mare, which had it about that time. Varicus applications were made to cure it, such as driving in spirits of turpentine by rubbing the parts aflected, and liolding a red hot iron near the place : 
turning, bruising, and cutting, were also resorted to, but in every case that I saw or heard of, the disemse tarminated in the death of the animal. At length white arsenic was recommended, but by whom it was first discovered, I am ignorant. I had occasion, about four years ago, to try it on a fine Archy mare, then in foal by Archy: she was affected on both sides of the face, and I succeeded in curing her: she produced a horse colt, whilst she was under the operation of the arsenic. At about two years old the colt was affected on one side of the face. I had recourse to the arsenic and completely eradicated the disorder, leaving only a slight scar, though the mucus membrane of the nostril was so much injured as to cause a difficulty of breathing through it. The mare was still more affected, as both nostrils were nearly closed, and her head continued to be much larger than before she was taken with the disease, though generally in good order, and occasionally worked. She has, however, produced three fine colts since, none of which has as yet been affected with the big head. I designed to have trained her first colt, but in consequence of the affection of his nostril, I declined the idea. He is now four years old. enjoying fine health, and possessing great vigour as a s:allion. I am thus particular in detailing the character of the animals who have been cured, that it may be seen how little horses are affected by the disease after it has been cured. I have known the arsenic exhibited in at least twenty cases, in all of which it cflected a cure, and I think I can say, that it is ars infallible remedy. I will now endeavour to descrine the disease, and the recipe.

Symptoms-Iuss of appetite, a drooping of the head and a disinclination to move about-a slighs 
weeping from the eye on the side affected--in a short time a local swelling appears on the side of the face in a direct line between the eye and nostril, which on being pressed hard with the finger causes the animal 10 wince, and by rubbing it gently with the hand, appears to give ease to him-an eniargement of the jaw bone, and a considerable decline in flesh. I have not discovered that the disease is atterded with fever; if it is suffered to run long, it causes an affection of the ioints-they become puffed, as if inflated with wind, and in a short time those swellings become filled with pus, and ultimately break, and a discharge of purulent matter issues from the joints, and the animal falls, to rise no more without help. It is supposed to be infectious only in this last state of the disease.

Cure.-As soon as the swelling on the side of the face appears, take a piece of white arsenic about the size of a common field pea, (or about six or eight grains pulverized and wrapped in fine paper, of a size only sufficient to contain it,) make an incision in the skin, immediately over the hard tumour, insert the arsenic (or the paper containing it,) and with a needle and thread make one suture or stitch, tie the ends of the inread in a hard knot, bleed the horse, and turn him out alone in a good pasture. or if it is cold weather, put him in a stable, removed from other horses, and feed him on light fond-in a few days the effects of the arsenic will be discoverable by a considerable swelling of the head, nose, and face, which will increase until the power of the arsenic is exhausted-if both sides of the face are operated on at the same time, the head will swell to an enormous size-in about a month, or six weeks, the arsenic will have developed its efficacy by the appearance of a circular piece of 
skin, and the porous bone of the face which extunds as far as the seat of the disease, or the influence of the arsenic on the affected part; this circular development extends as far as the affected part only, and is quite callous and nearly detached from the sound skin, leaving the wholesome flesh in its natural state. In a month or six weeks longer, this circular part becomes entirely detached on its periphery from the sound skin, and adheres to the side of the face by a few slight integuments about its centre, which soon decays, (or it may be cut off,) and the diseased parts drop out in a mass, leaving a hideous wound; then may be seen the porous bone of the face, resembling honeycomb, which soon becomes covered with sound flesh and skin: the wound may be soon healed by using cenmon applications, though I have made use of what we farmers in the country call pot liquor, as a wash, and anointing the place with an ointment made by bruising the leaves of the common polie-weed, (pinytolacia decandra) and extracting the juice by pressure, and stewing it in hog's lard, or of the Jamestown weed, or thorn apple, (datura stramonium,) prepared in the same way. These applications may be made use of with advantage as soon as it is discovered that the parts begin to separate. If the weather be warm it may be necessary to anoint the parts with a mixture of common tar and hog's lard, or the juice of elder stewed in hog's lard, in order to keep away the blow fly, which will be attracted to the parts by the offensiveness of the scent emitted. It cannot be expected that a horse whicli has thus been operated upon, wil, regain the beauty of his head, particularly if he be an old horse, or has been affected on both sides of tine ace, or the disease has been suffered to run too long 
before applying the remedy: this is evidenced by the appearance of my mare. 1 suffered the disease to run too long, because I was fearfui that the arsenic might injure the foal, but was induced to risk it rather than lose the mare: the stallion on the contrary, exhibits the effects of it in but a slight degree. It may be proper to remark, that a less quantity of arsenic will answer for a colt than for an old horse; and that it ought to be inserted as high up on the face as the seat of the disease will admit of ; perhaps on the upper edge of the swelled part will answer the same end.

Another remedy has been communicated to me, which is much more simple; and if it be a remedy, certainly possesses great advantages over the one on which I have been treating. I have never known it tried, but I am induced to believe that it is a remedy, both from its analogy to the arsenic, and from the authority from which I derived my information. It is this : Instead of the arsenic, take half a pint of strong ashes, (hickory 1 suppose,) put them into a tin cup, (of about a pint measure,) smaller at the mouth than at the bottom, say about one and a half inches at the mouth in diameter ; fill the cup or pot with water, and let it boil for half an hour, or until the water has been evaporated, or absorbed by the ashes, cord the horse's nose in the usual way, or otherwise confine him, in order that he may be still, and apply the mouth of the cup to the part affected, with the ashes quite hot and nearly dry, having previously covered it with a thin cloth to prevent the ashes from coming in contact with the skin of the horse, and hold it in that position until the heat has subsided, when it may he removed: in a day or two the parts will exhibit a gluey exudation. which will disappear in the course of a week, Inaving 
ar. unconsiderable sore like a burn, which may be son cured by treating it as such. It may be necessary in some cases to make the second application. The norse may be used as usual at the time, and when the wound heals up, scarcely any scar will remain.

$O r$, Take blood from the neck vein and bathe the swelled parts with spirits of turpentine once or twice a week, rubbing it in with a hard brush until you discover the swelling is stopped: the lumps always remain, but as they cease to grow the horse gets better.

Or, Give stramonium (Jamestown or Jimeson weed) in doses of one drachm, mixed with his feed for severai days, then turning him out for two or three months.

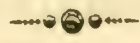

\section{FISTULA.}

The fistula in the withers, generally proceeds from some blow or bruise, and is the most disagreeable disease $\mathrm{tr}$ which a horse is subject. I would recommend it to every person, whose situation will admit of the sacrifice, to dispose of a horse thus unfortunately affected, for whatever sum he would bring, or even give him away, sooner than be at the expense and trouble, and run the risk of performing a cure which. If completed, would be tedious, and the horse be much lessened in value in consequence of being disfigured by the scar which unavoidably will be left. The remedy here recornmended is severe, but it will have the desircu effect more speedily than any other. 
So soon as the fistula assumes a formidabie appear. ance, fomentations of bitter herbs should be employed, such as wormwood. camomile, bay leaves, mullen. ife-eveslasting, \&c. boiled in water to a strong decoction, and after being strained, should be applied hot as the horse can bear it without giving pain, by nieans of large woollen cloths. This application promotes suppuration, and when matter is formed let the tumour be opened, so that its contents may be completely evacuated; after which let the sore be nicely washed with strong soap suds, and apply the following ointment once a day:-Take of verdigris, half an ounce copperas, half an ounce; oil turpentine, one ounce; ointment of yellow rosin, four ounces; to be well mixed togrether. As soon as healthy matter is discharged from the fistula the ointment may be discrntinued, and nothing more will be necessary, except kepping it perfectly clean with strong soap suds.

When the fistula first makes its appearance, it may be removed or prevented by placing a rowel or seion in each shoulder, just below the sivelled or inflamed part which should be kept running two or thrse weeks.

\section{-mคดองท- \\ POLL-EVII.}

The poll-evil, like the fistula, proceeds from some ulow, bruise, or external injury, and its consequences are much to be areaded. A horse thus diseased would be weii sold almost at any price, though the cure is tolerably sercain, yet extremely siow. The poll-evil 
is an abscess or swelling found in the sinews, between the noll bone and the uppermost vertebra of the neck. immediately on the poll or nap of the neck. Wher. this swelling first makes it appearance, bathe it frezuently with hot vinegar; and if the hair be fretted off, with an oozing through the skin, make use of equal parts of vinegrar and spirits of wine; but if there be an itching, with heat and inflammation, the safest way will be to bleed plentifully, and apply a red oak poul. tice, whic! will sometimes disperse the swelling and put an end to the disease. But whenever the tumour is critical, having all the signs of matter, and appears not benefited by the applications already recommended, it will be advisable to bring it to a head as speedily as possible, with the following poultice: Corn meal, marsh mallows, oil turpentine, and hog's lard. When the tumour becomes ripe or full of matter, it may be either opened or permitted to break of itself; if opened with a knife, great care should be used to prevent wounding the tendinous ligument that runs along the neck under the mane. When the matter appears to be on both sides, the tumours must be opened on both sides, and the ligament between remain undivided; it the matter flows in great quantities, resembling melted glue, and is of an oily consistence, it will require a second incision, especially if any cavities are discovered by the fingers or probe; these should the opened by the knife, and the wound should be dressed with spirits of turpentine, honey, and tincture of myrrh. unti! light and thick coloured matter is found. C'leanse the sore well with strong soap suds and a sponge: then take of verdigris, half an ounce; oil of turpentine, four ounces; of blue-stone, two ounces; ol green copperas, half an ounce; mix them well 1 ). gether, and hold them over a fire until thev are as nul 
as the horse can bear them: then pour them into tho itscess and close the lips by one or two stitches; this is to remain for several days without any other dres. sing, except bathing with spirits of wine. Should matter flow in great abundance, and of thin consisten$\mathrm{cy}$, the above application must be again repeated unti. the matter decreases in quantity, and becomes of a whitish colour and healthy appearance.

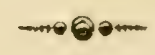

\section{L.OCK-JAW.}

THe lock-jaw is sc, fatal in its consequences, that 11 is a fortunate circumstance it occurs so seldom amonirst horses.

It commences with a difficulty in mastication, and shostly after the jaws are so completely and immoveably closed, that it is with much difficulty that medicines can be administered. The muscles of the neck appear much contracted, and the animal appears to suffer great pain.

The lock-jaw is frequently brought on by trilling c'auses, such as cuts, wounding of nerves, tendons, \&c. Generally speaking, the cure is very uncertain; but it will chiefly depend on opium, the warm bath, and other antispasmodics. Sometimes the sudden application of cold water, in great quantities, has been gerviceabre; friction of turpentine oil or spirits, generaily proves useful, as does a clyster marle with two 
ounces of spirits of hartshorn, four ounces of ofl of turpentine, and the yelks of three or four eggs, mixed with a quart of strong ale and gin or whiskey. It is a great object to promote urine, sweat, \&c. Opium, camphor, and copious bleedings, have been found. in sume cases, very beneficial; and when they liave failed, hartshorn, ether, opium, and brandy, have been employed with some success; though the lockiaw is often a symptom of approaching dissolution and frequently defies the power of any kind of medi. cine that can be employed.

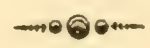

\section{LOST APPETITE.}

Horses lose their appetites from various causes, viz:-Excessive fatigue, want of a change in food, dirty fodder, mouldy corn, or a dirty manger, \&c. \&c. but most frequently by the approach of some disease. So soon as you discover a horse has lost his appetite, observe the following treatment, viz:-

Take from the neck vein half a gallon of blood; take of asafoctida, a quarter of an ounce; salt, one table spoonful; sassafras tea, one quart; mix and give them as a drench.

On the second dity, take of glauber salts, one pound; warm water, one quart; after dissolving the salts give it as a drench, and in two or three days the appetite will be restored, unless the animal is lahouring under some disease, which may be ascertained by the symptoms. 


\section{COLDS.}

Noturng is more common than colds among horses. of all agres. They are frequently produced by a want of good rubbing after violent exercise, which strikes a chilliness and dampness over the whole body ; being changed from a warm and comfortable stable to one cold and open; standing out late in dew at night plunging deep in cold water while heated in a profuse perspiration; all of which have a tendency to check the perspirable matter and contract the pores of the skin.

Colde sometimes produce a slight running at the nose : the remedy is simple and almost certain-bleed plentifully.

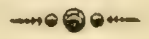

\section{SADDLE GALLS.}

SADDLE GílLs are generally occasioned by an unequal pressure of the saddle, or by a saddle being badly fitted to a horse's back, and if neglected they grow into very ugly and truublesome sores. When these inflamed tumours are first discovered, cold water alone is frequently sufficient to disperse and drive them. away, if applied as soon as the saddle is pulled off but when that will not have the desired effect, by washing them twice a day in the mixture I shall here recommend, the cure will be readily performed.'l'ake of sharp vinegar, one gill; spirits, of any kind, une gill: sweet oil or fresh butter, one table spoonful: tu tre well mixed before used. 


\section{SITFASTS.}

Sitrasts proceed from the part being freqlicntiy vruised with a saddle, until it becomes extremely hird. and after remaining some length of time it is not unlike a horny substance. The cure cannot be performed unless the knife is used for the purpose of cutting it entirely out. After which the fresh wound can be healed with the greatest ease, in a very short time, by using either of the following mixtures:

No. 1. Take of brandy, half a pint; honey, half a pint ; alum, two ounces.

No. 2. 'Take of blue-stone, a quarter of an ounce; spirits of turpentine, two table spoonfuls; spring wuler. one pint.

No. 3. Take sugar of lead half an ounce; alum, one ounce; copperas, half an ounce; let them be well mixed, and the sitfast washed twice a day, after ine wound is washed clean with soap and water.

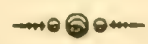

\section{DIARRHEA OR PURGING.}

A diarringa amongst horses seldom occurs and is easy of cure. It may be produced by a suppression of perspiration or by an increased secretion of bile.

The following ball (No. 1.) generally gives relief. but should it not have the desired effect, No. 2 inay be employed.

No 1. Take of sıe. aloes, six urachms; Castile soap, four drachms; and syrup enough to form 'ne isall 
No 2. Take of opium, one drachın, antimons, three drachms ; powdered ginger, two drachms; anc svrup enough, of any kind, to form a ball.

It wil. benefit a horse very much by keeping num warmily clothed while labouring under this disease.

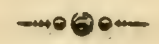

\section{DIABE'TES.}

A Diabetes is a profuse staling or a constant discharge of water; it is attended with great weakness, luss of flesh and appetite, with every appearance of decay and approaching dissolution.

It is frequently the result of old disorders, surfeits, excessive hard rides, \&c. \&c. A horse of a delicate and weak constitution is extremely difficult to cure, as he suon loses flesh and appetite, his hair becomes rough, his eyes weak, sad, and dejected, and in a very short time he is unfit for any kind of labour. But if the following remedies are employed, when the disease first makes its appearance, if the horse possesses a tolerable good constitution, the cure, by proper attention, can be rendered almost certain.

Remedy.-No. 1. Take of opium, one drachm; asafoetida, two drachms; powdered ginger, two ditto ; red oak hark, powdered, one ounce; syrup of any kind, a sufficient quantity to make two balls for one duse, which must be repeated three times within a week, and the horse must not be permitted to drink an musual quantity of water. A little salt thrown into - Jhat he is permitted to use, will be found very beneficial 
No. 2. Take of red wine, one punt; water, one pint; gum Arabic, one ounce; mix and give thern as a drench three times within a week.

No. 3. Take of salts of hartshorn, three drachms; opium, one drachm; powdered ginger, two drachms: liquorice, half an ounce: syrup, of any kind, a sufficient quantity to make the ingredients into two balls. which may be given twice within a week. Nourishing food, moderate exercise, and a clean, wholesome stable will assist much in effecting a cure.

$m$ Q

\section{BLISTERS.}

Prevrous to the application of a blister to any part of a horse, the hair should either be shaved or cut ofl as close as possible; the blistering ointment should be regularly spread with a warm knife on a stout piece of oznaburgs; and during the operation of the blister, the horse should be tied short to prevent his biting the part or doing other injury.

Blister-No. 1. Take of Spanish flies half an nunce, oil turpentine one ounce, hog's lard four ounces; mix them well and the blister is ready for use.

No. 2-Take of tar, four ounces; vitriolic acid two drachms, oil of origanum, half an ounce; hog's lard. two ounces; Spanish flies, two ounces. This 'llistel is excellent for the spavin. 


\section{CLYSTER OR GLYSTER.}

1 ; clysters very often are the means of saving nor: es' lives, I shall here recommend the best and sim. plest mode of administering them. Take a large bladder, cut off the neck and soften it in warm water, take a pewter pipe, common reed, or any other sinooth tube, nine or ten inches long and not more than an inch in diameter; the clyster must then be poured through a funnel into the bag, and securely tied around one end of the tube; the otner must be made perfectly sinooth and rounding, well oiled, and introduced into the anus several inches; the liquid in the bladder must be forced through the tube by pressure with the hand.When a clyster is given, a horse should be placed with his head down hill, and if he refuses to stand, a twitch should be put upon his nose.

Glysters are of three kinds-opening, anodyne, and nourishing. For the first purpose take a gallon of warm water, with from half a pound to a pound of common salt dissolved in it; to which add four or five ounces of olive or linseed oil. For the second, take two drachms of solid opium, dissolve them, or rather mix them well with about half a pint of warm water, and add from a quart to three pints of Indian meal or wheat flour gruel. For the third purpose, rich broths, wheat flour gruel, and other nourishing fluids are recommended. With respect to the firsi kind of glysters, it may be observed that gruel is commonly preferred to warm water : but according to my experience, the latter does just as well as the former as to the second, tincture of opium may be substiu 
ted for solid opit $\mathrm{n}$, and is by some preferred $\mathrm{s}$ it but tne quantity should not exceed two ounces, on account of the sp rit in which this opium is dissolved. 'The third kind of glyster is required only in lock-jaw, or in diseases of t te throat which prevent swallowing, and in these its ut lity seems to be very questionable. As soon as the g'y ;tel has been injected, the tail should be kept slose to he fundament for a few minutes to prevent its being too hastily returned. This is particularly necessary when the anodyne clyster is em. ployed. The pipe must be oiled or greased before it is introduced, and if its passage be obstructed by hard dung lodged in the gut, the hand should be gradualiy introduced in order to remove it.

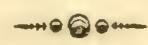

\section{FOMENTATIONS.}

Fonentatrons are generally made of bitter herbs. such as wormwood, camomile, mullen, bay leaves, sutherwood, life-everlasting, \&c. \& c. boiled in water to a strong decoction, strained off, and applied with large woollen cloths, hot as the animal can bear it that it is intended to benefit. The efficacy of fomentations often depends on the length of time they are employed, and their being frequently repeated.

Poultice.-The following mixtures will be found useful as a poultice:

No 1. Take of bran, one quart; of sharp vinegar (scalding hot) half a pint; hog's lard, one table spoonful-mix them for use. 
No. 2. Take of red oak bark a sufficiency to boil tn one quart of strong decoction; take of Indian meal, a sufficient quantity to form the poultice.

No. 3. Take of sharp vinegar, half a pint ; of meal one quart; of hog's lard, two table spoonfuls; pour a sufficient quantity of boiling water to form it into a mash, when it will be ready for use.

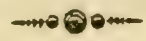

\section{MASH.}

A masn is generally given to a horse for the purpose of cooling the system, opening the bowels, and for disguising different kinds of medicines which may be necessary to be administered; which if given in any other way, would be attended with trouble and difficulty, and would not be productive of effects so salutary.

Mash.-No. 1. Take of bran one gallon, sassafras tea (scalding hot) one quart, powdered brimstone one cable spoonful, saltpetre one tea spoonful.

No. 2. Take of oats one gallon, flour sulphur one table spoonful, saltpetre one tea spoonful, boiling wate: one quart.

No. 3. Take of bran one gallon, salts (glauber, four ounces, sulphur one table spoonful, sassafras tea (scalding hot) one quart-let them be well mixed and given milk warm, not permitting the horse to drink cold water for six hours afterwards. 


\section{BLEEDING.}

T'ne bleeding of a horse is so common and simple, that but little instruction can be necessary for the performance of the operation. The blood should always be caught in some vessel for the purpose of judging of its quantity and quality; if after it has coagulated a iight buff coloured jelly forms the surface, it is an evidence of the inflammatory state of the blood. Blooa drawn from a healthy horse very soon coagulates and appears like a uniformly red jelly, with a small quantit of fluid, resembling water, floating on the surface. . consists of two parts - the red jelly (termed crassa. mentum) and the water or serum; the former may be separated into two parts by washing the red globules and coagulable lymph.

Bleeding is extremely beneficial in many diseases, and with safety from one quart to one and a half gal lons may be taken at one time.

\section{$\rightarrow+\infty$ ๑m \\ TO SPOT A WHITE HORSE}

\section{WITI BLACK SPOTS.}

ТАке litharage, three ounces; quick lime, six ounces; beat it fine and mix it together: put it into a pan ard pour a sharp ley over it; then boil it and you watl have a fat substance swirn on top, with which anoist the horse in such places as you design to have blar.k and it will turn to the colour immediately, 
It has the same effect in changing hair that is red into a black colour, with only this difference, viz. :Take an equal quantity of lime and litharage, and instead of boiling it with ley, boil it only with fresh water; what swims at top, is fit for use and will answer your expectation; what hairs you anoint with it in the evening, will be black the next morning.

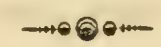

\section{DRIVING.}

IT may be generally remarked, that men who drive fast have swift horses; not that they drive fast because they have swift horses, but because fast driving makes horses swift. A horse may commonly be trained to a dull and heavy, or to an airy and fleet gait. Nature unquestionably does much; but education does far more towards producing the great difference in the speed of horses, than most men are willing to allow. Horses are more frequently injured by driving them beyond their habitual pace, than beyond their native power. The best direction for the education of horses is, "drive fast and stop often."

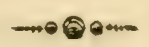

\section{A TRIBUTE TO TIIE HORSE.}

\section{JOHN WALL'S RECIPE.}

TAKe hali a pound of saltpetre, half a pound of dium, and half a pound of alum salt; pulverize and mix them well tugether, and every eight days give nım a table spoonful in his food; his coat, flesh, and "rinis will soon reward his master for his care. 


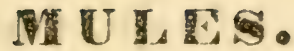

\section{$-m \times 60 m$ \\ MULE AND HINNY,}

\section{HYRRIDS OF 'THE HORSE AND ASS. \\ Lamechn}

Tre mule is the hybrid produce of an ass witr 3 mare; having a large clunsy head, long crect ears. a short mane, and a thin tail.

The hinny is the hybrid produce between the shr:ass and a stallion; the head is long and thin, the ears are like those of a horse, the mane is short, and the tail is well filled with hair. The himny is much less common than the mule, because, being less hardy and useful than the other, he is never cultivated.

The mule, commonly so called, is much valued for the saddle, and for drawing carriages in Spain, Portugal, Italy, and the East, and in the warmer parts of America. In those countries where great attention is paid to the breed, it is as till as the horse, exceedingly well-limbed, but not so handsome, especially about the head and tail. These animals are mostly sterile; some, indeed, have thought that they are altogether incapable of producing their kind; but some few instances have occurred, in which female mules have had foals, and in which even the male has impregnated females both of the ass and horse species, though sucn instances are exceedingly rare.

The mules made use of in the southern parts of Europe, are now brought to an asionishing perfection as well as great size. They are usually black, struns 
wel-limbed, and large, being mostly bred out of fine Spanish mares. They are sometimes fifteen or six teen hands high, and the best of them worth forty or fifty pounds. No creatures are so proper for large burdens, and none so sure footed. They are much stronger for draft than our horses, and are often as thick set as our dray horses, and will travel several months together, with six or eight hundred weight upon their backs. Some think it surprising that these animals are not more propagated here, as they are su inuch hardier and stronger than horses, less subject to diseases, and capable of living and workiı,y to twice the age of a horse. Those that are bred in cold countries are more hardy and fit for labour than those brea :n hot; and those which are light made are fitter for riding than horses, as to the walk and trot; but they are apt to gallop rough; though these do it much less than the short-made ones. The general complaint made against them is, that they kick and are stubborn; but this is owing to neglect in breeding them, for they are as gentle as horses, in countries where they are bred with proper care.

In the breeding of mules, mares that are of a very large breed and well made, should be employed. They should be young, full of life, large barrelled, but smalled limbed, with a moderate sized head, and a good forehead. It is found of advantage to have the foals from the time of their being dropped often handled, to make them gentle: it prevents their hur ing themselves by skittishness and sudden frights ; and they are much easier broken at the proper age, and become docile and istrmless, having nothing of that viriousness which is so commonly complained of in wese anımals. They may be broken at three years 
orr. but should never be permitted to do much hard work till four, as they are thus secured from being nurt by hard labour, till they have acquired strengih enough to bear it without injury. An expert breeder of these animals found, that feeding them tou well while young, though it made them very fat, was far from being any advantage to them; as it was not only incurring a much larger expense than was any way necessary, but also made them wonderfully nice and delicate in their appetites ever after, and also by increasing their weight of flesh, rendered them more sulject to strains and hurts in their morning gambols. He therefore contented himself with giving them food enough to prevent their losing flesh, and to keep up their growth without palling their appetites with delicacies, or making them over fat; he also took care to defend them from the injuries of the weather by allowing them stable room, and good litter to sleep on, besides causing them every day to be well rubbed down, with a hard wisp of straw, by an active groom. This was scarcely ever omitted, particularly in cold, raw, wet weather, when they were least inclined to exercise themselves. When three years old, mules are proper for use.

The shoe for the mule is for the fore foot very similar to that which farriers call the bar shoe. It is very wide and large, especially at the toe, where it sometimes projects four inches and upwards beyond the hrof. This excess is given it with a view to enlarge the basis of the foot, which is in general exceedingly narrow in this animal. The shoe for the hind feet is open at the heels like a horse's shoe; but is lengthened at the toe like the preceding one. Mules are, however. by no means invariahly shod in this manner: " 
is not unusual to shoe them either like horses or asses. as they approach the one or the other in size or work requitred.

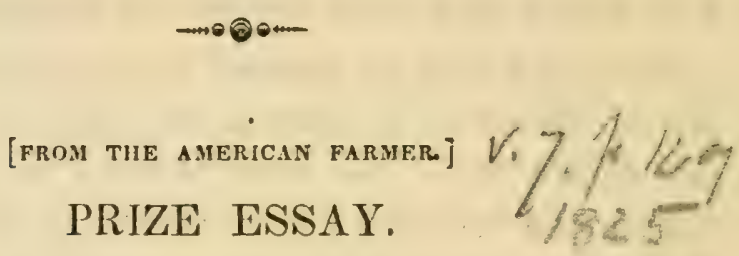

[The premium of a silver cup, of thirty dollars value, offered by Robert Oliver, Esq. to the auther of the best essay on the natural !history of the Mule, and its value for the general purposes of agrı. culture, in comparison with horses, was awarded by a committee, appointed by the Trustees of the Maryland Agricultural Socie:\%, to the author of the following essay.]

\section{A DISSERTATION ON THE MULE,}

With the vicw of promoting an improvement in the brced, and of demonstrating the utility of employing him as a substitute for the horse, in the labours of husbandry, canals, \&c.

By Samuel. Wyleys Pomeroy.

"- Opinion is the queen of the world-it gives motion te the springs, and direction to the wheels of power."

"Knowledge is power."-Bacon.

John Quincy Adams.

Soon after the accession of Charles III. to the c own of Spain, his subjects were prolibited by a severe edict, from wearing flupped hats and long cloaks; which caused an insurrection that obliged him to fle from Madrid, after witnessing the massacre of nearly one hundred of his Walloon guards; and might have terminated in a revolution, but for a speedy revoca non of the edict and banishment of his ministers. An eminent writer introduces the history of the occurrence, by observing, that "it is easier to conquer half 
the world than to subdue a single prejudice or error, most nations having a superstitious attachment to thosehabituaes which they derive from their ancestors, that seem to come along with them into the world, and with which they were nursed and brought up."

Perhaps it may be deemed by many quite as visionary or absurd to attempt an introduction of the mule as a substitute for the horse, for the purposes of agriculture and hackney employments, as was the project of the Spanish monarch for compelling his subjects to wear the French costume, to the exclusion of one they had been so long accustomed to look upon "as a distinction which was the birth-right of every true Spaniard;" and as we may suppose, so congenial to the indolent habits for which that nation had long been proverbial.

It must be acknowledged that there are serious, though I trust in this agre of improvement, not insurmountable impediments; for we have to combat not only hereditary prejudices, or to speak more correct'y such as have proceeded from a deficiency of means and want of knowledge, to develope the raluable properties and to subdue propensities of a contrary character in this hybrid race, but we are met at the threshold by the same species of pride which the Spaniards manifested in regard to their costume, founded on the enthusiastic, I may almost say superstitious, attachment to the horse.

It is believed that a vast portion of our fellow citizens, and I may with propriety add the people or Great Britain, from whom we have derived some inveterate prejudices as well as those illustrious cxam. ples that have had such a powerful influence in leading our couniry to the high destinies that await her. to nor 
consider trat a mule, especially a well bred one. would be in himself and in their view, one of the best formed and most distinguished of animals, if they had never seen a horse; they must admit, however, that he holds the second rank instead of the first, and it is principally from this circumstance that so little attention has been paid to him in both countries. Comparison is the chief cause of his degradation-they look at and give their opinions not of himself, but comparatively with the horse. They seem not aware that he is a mule-that he has all the qualities of his nature, all tire gifts attached to the connecting and final link of two distinct species, and think only of the figure and qualities of the horse which are wanting in him, and that he ought not to have; for he possesses those of more intrinsic value, which the supreme Author of nature has denied to both of his parents.

There are few subjects of animated nature that have engaged the attention of the most eminent naturalists, more than the genus Equus, to which the horse and ass, with their hybrid offspring, are assigned. Linnaus, with a view to establish, by new arguments, his doctrine, or theory of the sexual systern of plants, which Spallanzani had attempted to overturn, illustrated their generation by pursuing the chain of nature from the animal to the vegetable kingdom; and has taken prominent examples from the two different pruductions of mules. He says, "from the mare and male ass procecds the mule, properly so called, which in its nature, that is, in its medullary substance, nervous system, and what Malpigh calls the keel, (carina, buttom in sportsmen's languagre, is latent in, and derived from the mase. But in its cortical substance. and outward form, in its mane and tail, resembles 
the ass. Between the female ass and the horse. the other kind of mule is engendered, whose nature. or medullary substance, resembles that of the ass: but its outward form and cortical structure, or vascular system that of the horse."*

The latter kind was called Hinnus by the ancients hence the modern name Hinny. They were not held in much estirnation by the Romans, according to Pliny, who describes them as difficult to manage, and so slow that little service could be derived from ther.. Buffon has noticed this animal, which he says "is smaller than the mule, as it preserves the diminutive stiature of the ass." Hinnys were seldom propagated; but it is said that a number have lately been bred in Spain, probably in consequence of the destruction of mares in the peninsular war, and are represented of good size, and more beautiful than the mule: that is, they resemble the horse much more. I understand a few have been bred upon the Spanish Main, no doubt from a similar cause that led to the system in Spain; and if my information is correct, some have been recently shipped to the West India Islands, but are by no means esteemed so hardy, or valuable for service, as mules.

Notwithstanding mules have a disposition to propa gate, there have been but two or three well authenticated instances recorded of their having bred; ana those productions were considered monšers. Buffon was indefatigable in his researches on the subject: and although he admits that it is possible for both males

* See "A Dissertation on the Sexes of Plants" by Sir Ulıarle. Iirneus-read before the Imperial Academy of Sciences at Sit Petorsburgh, Sept. 6, 1760, and which obtained the premium ó one bunclied ducats. 
and females to propagate, he is confident that therr marents are of a species distinct from each other. $\mathrm{He}$ says " the ass is not a horse degenerated," as some had supposed, "he is neither a stranger, an intruder, nor a basturd; he has, like other animals, his family, his species, and his rank; his blood is pure and untainted, and althourh his race is less noble, yet it is equally good, equally ancient as that of the horse." This profound naturalist continues a very minute and eloquent comparison between the horse and ass; some of his expressions I have taken the liberty to apply to the mule and the horse in a preceding paragraph.

It may promote the object in view to enter exten. sively upon the history of the ass; and we commence with the supposition, that when men became so far civilized as to have burdens to carry, or required to be carried themselves, this animal was the first domesticated for that purpose-and it is reasonable to infer that those of the least spirit and most tractable, were put in requisition in the first instance; when by breeding in and in, without any care in the selection of sire or dam, became in process of time degenerated to a very inf $f_{\text {eror }}$ grade. Be this as it may, it is an unquestionable fact that different races of the ass now exist, possessing properties as distinct as are found in the species of camel. For instance, the Bactrian or single himched camel, called the dromedary, by far the most sumerous race, being lightly formed, exhibits great activity, and is able to traverse vast tracts with the speed of a high mettled race horse. The Arabian cannel, with two protuberances on his back, is considerably larger, of much stronger form, travels at a pace seldom exceeding three miles an hour, and is sapuble of conveying such burdens, that the Arabs 
stye nim, emphatically, the ship of the desert; yot they are of the same species-a cross between them breed and constitute another variety, which multiply and according to Buffon, have the most vigour, and we preferred to all others.

Ancient writers recognise three or four distinct varicties of the ass. According to the learned $\mathrm{Dr}$ Harris, four different races are indicated in the origi. nal Hehrew scriptures, viz: Para, Chamor, Alun, and Orud.*

The wila ass ( $P$ ur $(a$,$) was a native of Arabia, De.$ serta, and those countries which formed the great Babylonian empire. They are now found in Southern Tartary, in the mountainous districts and saline plains of Persia-are migratory in large herds, visiting in winter the Northern parts of India, and said to be so fleet that no horse can overtake them in the chase.-. This race is frequently alluded to by the inspired poets and prophets; and afturd similies diametrically opposite to those drawn fiom the domestic race. The sublime description of the former in the book of Job, exhibits such a contrast, that I trust its insertion in this place will not be deemed improper.

"Who from the forest ass his collar broke, And manumized his shoulders from the yoke? Wild tenant of the waste, I sent him there Among the shrubs, to breathe in freedom's air.

- Sce the "Natural History of the Bible, by Thaddeus Mason Ilitris, D. D. 1 vol. 8vo. Wells \& Lilly, Boston." A work woulc earnestly recommend to those readers of the sicred volume whe are desirous to be better acquainted with many allusions to sub jects of natural history, fomded on their nature, habits, and cha licteristic qualities, developing beantiful similies, which would odserwise lie concealed-and enabling them to judge noro cor sectly of the propriety of auch allusions. 
S vift as an arrow in his speed he flies;

Sees from afar the smoky city rise;

Scorns the throng'd street, where slavery drags her load

The loud voic'd driver and his urging goad:

Where e'er the mountain waves its lofty wood,

A boundless range, ne seeks his verdant food."

Scott's Version.

We find, that at a very early period of sacred his. iory, the commor domestic ass (Chamor,) was employed in all the menial labours of a patriarchal family, while a nobler and more estimable animal (Aton,) was destined to carry the patriarchs, the well born; and those on whom marks of distinction were to be conferred. They constituted an important item in a schedule of the pastoral wealth of those times; of course attracted particular attention and care. David we are told, had an officer, apparently of high dignity, appointed expressiy to superintend his stud of high bred asses, or Atonoth.

There was another race that has been mentioned by A ristotle, and by 'Theophrastus, whom Pliny quotes, which they denominated the wild mules that bred (hemi-onos,) and were found in Cappadocia and Africa. There can be but little doubt but this is the Hemionus or wild mule of the Mongalian Tartars, so particularly described by professor Pallas; and that it is not a hybrid, but actually of the species of ass resembling a mule.* This race is identified by Dr. Harris with the Orud of scripture.

The wild ass of Northern and Western Africa, whose flesh was so much admired by the Roman epi-

* Herodotus says, that in the army of Xerxes, which invaded areece, there were "chariots of war drawn by wild asses." M. salcher, a celebrated commentator, renders them zebres in his French trinslation, which he supports from Oppian, lib. 3 v. 18?. bu it is a well known that the zebra is of a suecies rentirely 
cures, may, I believe, be ranked as another distme: race. Adanson, a French naturalist, who visited the river Senegal, more than half a century ago, describes thinse brought from the interior by the Moors, as so essentially different from any he had seen in Europe, (probably those of Spain, Savoy, or parts of France adjoining,) it was with difficulty he could recognise them to be the same species-neither do they answer the description of the wild ass of Asia, of which we have been speaking. But his account of them corresponds with the diminutive domestic race introduced from Africa, partioularly those from Senegal and the Cape de Verd Islands; and from which the small race now in Europe and in this country, may with great probability claim their origin.

'The Arabian ass, like the horse of that country, is considered as the most estimable of his species-and there are strong reasons for concluding that he is descended from the Hebrew Aton, so highly valued by Abraham and by the patriarchs, judges, and kings, at subsequent periods of sacred history; and that the same race has been preserved in the ancient land of Uz, in some degree of purity to the present time Indeed, there can be but little doubt on the subject, if we adınit the fact, that the habits, manners, and pur suits of the descendants of Ishmael have continued, with scarcely an iotu of variation, from the day they took rank among the nations of the earth. "Tho position is greatly strengthened by the information J

distinct from the ass; and Buffon asserts that none were ever dis covered out of Africa, and there only in the southern hemisphere. It is therefore highly probable, that those alluded to were the hems. onus, which are described as much larger than the wild ass, and cearer the size and form of the zebra. Seo Beloc's Herodotus. Polymnia, chity. 86. 
received sume years since from an intelligent travelles of undoubted veracity, who had visited Arabia on the south-western side of the peninsula to Mocha; and on the eastern, as far as the mouth of the Tigris. Hr represented the superior race of asses of that country as most beautiful-of perfect symmetry, great spirit, activity, and vigour. He had seen those that could not be purchased for less than four or five thousand dollars-an enormous price, considering the value of money among those people.* I understand from him, that the Arabs were as tenacious of preserving the pedigrees of their horses, as the most careful breeder for the turf in England-and not less so of their asses. The descent of some of them they trace to those in the train of the queen of Sheba, when she visited Solomon -as they aiso do that of their horses to the numerous stud of that wise and gallant king.

Dr. Harris supposes the wild ass (Parra) to be the Onager of the ancients; and that the Aton was of a diflerent kind. My impressions coincide with the opinion of the learned divine-but may not writers of different periods have confounded the wild ass with the Aton in their representations of the Onager? for it is not improbable, but that the Atom was of the most improved breed known, produced from crosses of a choice selection of the domestic, the wild ass, and the Hemionus, or wild mule-which last Professor Pallas recommends to complete the perfection of the species. 'This supposition is supported by Buffon, who infers

* Neibuhr remarks, "there are two sorts of asses in Arabia; the maller or lizy ass, as little valued there as in Euorpe; and a large and high spirited bred, which are greatly valued, and seli at a very bigh price; I preferred them to horses.' Sue Noibuhr's Warole n Aralua. 
as a certain fact, that by a cuoss of the remotest of diflerent races of the ass, the most buautiful produc. tions are obtained.

Mules were in use ard highly esteened at a remote period of antiquity; and are mentioned in scripture as of importance in the equipage of princes. Hero. dotus, who is styled the father of profane history, frequently speaks of them; and it is known that they were introduced in the chariot races at the Olympic games in the seventicth Olympiad, about five hundred years before Christ. The Romans well knew their value. Pliny informs us, from Varro, that $Q$. Axius, a Roman senator, paid four hundred thousand sersterces, upwards of thirteen thousand dollars, for a male ass, for the propagation of mules. And he says further, that the profit of a female ass in breeding stock for the same purpose, was estimated in Celteberia, now the kinglom of Valencia in Spain, at a like sum. We may infer from a passage in Tacitus, and in Plutarchs life of Marius, that mules were generally employed to transport the bargage of the Roman armies; and that it is not improbable the superior officers rode those of a high grade, having their horses led except when they engaged an enemy. It seems that the dilletanti of Rome held them in great estimation, as we are informed that the mules of Nero and Poppea were shod with gold and silver-not plates, as iron shoes are now formed, but the whole soof en. closed.

Columella, who in the reign of the Emperer Clauaus. vublished the most valuable treatise on the hushand, and economy of the Romans that nas been handra down to us, has given vory particular directions for oreeding asses and mules. He was a native of Cadiz. 
and owned estates : Spain, where it appears that the inest mules were then bred.

As it is not requisite to pursue our history of the mule any farther among the ancients, we shall drop their appellation of male and female ass, and adopt the modern one of Jack and Jennet.

Spain has continued to support the reputation for a superior race of mules to the present period: and it is probable, that the Arabian breed of Jacks were introduced by the Moors, when they held possession of that fine country, which, by crosses and the effeats of climate and soil, have formed two valuable races, which we shall notice in the sequel. The Portuguese race have been generally considered as differing but little from the Spanish; those, however, that have come within my view appear evidently inferior. It was not until near the close of the sixteenth century, that coaches were used in France; before which, it is said, the nobles rode to court, parliament, \&c. on mules, that were brought from the vicinity of the Alps and Pyrenees. They were usually black, of large size, well made, and mostly bred from fine Spanish mares. Savoy has long been noted for an excellent breed of mules. None very extraordinary are found in Italy: those used by the Velterino, are strong and of a respectable size, but of a sluggish and debased spirit. Very little can be said of those animals in Great Britain. The Catholic prelates brought over a number of superb mules, prior to the Reformation, but in the reign of Elizabeth so little was known of them, that a writer of that period says, "in Devon. shire some were produced by a Jack brought from France, and were knocked on the head by the people, who viewed them as monsters." A superior race of miules were bred in Flanders from Jacks introduced by 
the Spanish inunarchs while they held dominion m that country. Fifty of them were brought to England by the Dulie of Cumberland, presented him by the Empress Queen, and from their beautiful appearance, engaged the attention of a few individuals; but the spirit soon subsided, notwithstanding those who bred and used then were warm in praise of their utility.

Among a voluminous mass of treatises on agriculture and rural economy, publisher in that country for near a century past, scarce a line cau be found devoted to the mule; except by Dr. Anderson, who, in his "Recreations in Agriculture," has made a few judi cious remarks on the subject.

In Sir George Staunton's account of Lord Macartney's embassy to China, we are told that mules are valued in that economical empire at a much higher price than horses. In our own country, prior to the war of the revolution, a few Jacks of an ordinary kind were imported; a small number of mules bred; and all exported to the West Indies. I have reference to New England, as I am not aware that any attention was paid to the system in the middle, or Southern States, though it is not improbable that some valuable mules may have been raised by the farmers and planters for their own use. When peace took place, the price of mules in the West Indies excited attention to the breeding of them. which was principally confined to Connecticut; and several cargoes of the small race of Jacks were imported from the Cape de Verd Islands, and St. Michael's, one of the Azores. It should be observed, that the exportation of Jach.s from Spain or any of her colonies, was strictiy prohibited. and continued to be until after the peniusular war.There might have been, however, a few smuggled. 
from the Spanish part of Hispaniola into Cape Fran cois, and from thence introduced, but they were vastly mferior so the Spanish Jacks. From this miserable storil a system of breeding mules commenced, the best calculated to deteriorate any race of animals that has been, or could be devised, since their creation. The purchaser of a Jack when about to commence mule dealer, made little inquiry concerning him but of his capacity to propagate a mule. He placed him ir a district where there was the greatest number of mares of qualities so inferior that their colts would not compensate their owners for the expense of taking them to a horse, and contracted to purchase their mules at four months old. Those are kept in herds, with precarious shelter in winter, having ample opportunities afforded them, to mature and transfer that propensity for kicking, which seems at first merely playful, into an habitual means of defence, to be exercised when the biped or any other race of animals approach them. In this kicking seminary they remain two years, and ase then driven to market. At subsequent periods, a few Jacks of higher grades were procured, from which a small number of good sized mules were bred, and a iew of them broke. The breed of Jacks have somewhat improved, and mule dealers are now located in most of the New England States and some parts of New York. But the system as above detailed, with few exceptions, has continued; and it is from such a race of Jacks and such a system of breeding and management, that the mules have been produced, with which the farmers and planters of Maryland, Virginia, and the Southern States, have been supplied from New England; and such have furnished a criterion for n great portion of our countrymen to form an estimato of the value and properties of this degraded animal. 
It affords great pleasure to be enabled, for a shrm time at least, to pursue our investigations in a higher sphere.

Several of my friends who had viewed the Jacks and mules, at Mount Vernon, in the life time of (ieaeral Washington, gave such glowing descriptions of them, and understanding that part of that stock was inherited by George W. P. Custis, Esq. I was induced to address a few queries to him on this subject; this gentleman with his characteristic urbanity, very promptly furnished replies, with liberty to make such nse of them as I pleased, and I cannot do better than to transcribe them from a letter received about three vears since. Mr. Custis observes:

"The Royal Gift and Knight of Malta, were sent to General Washington about the year 1787-the Gift. with a Jennet a present from the King of Spain ; and said to have been selected from the royal stud. The Knight I believe was from the Marquis de Lafayette, and shipped from Marseilles. 'The Gift was a huge and ill shapen Jack, near sixteen hands high, very large head, clumsy limbs, and to all appearance little calculated for active service; he was of a grey colour, probably not young when imported, and died at Mount Vernon but little valued for his mules, which were unwieldly and dull. The Knight was of a moderate size, clean limbed, great activity, the fire and ferocity of a tiger, a dark brown, nearly black colour, white belly and muzzle; could only be managed by one groom, and that always at considerable personal risk. He lived to a great age, and was so infirm towards the last as to require lifting. He died nn my estate in New Kent, in the State of Virginia, abuut 1 sug ar 1803. His mules were all active, spirited. 16 * 
and seivicuable; and from stout mares attained con siderable size.

"General Washington bred a favourite Jack calle Compound, from the cross of Spanish and Maltese 'The Knight upon the imported Spanish Jennet. This Jack was a very superior animal; very long bodied, well set, with all the qualities of the Knight, and the weight of the Spanish. He was sire of some of the finest mules at Mount Vernon, and died from accident. The General bred mules from his best coach mares, and found the value of the mule to bear a just proportion to the value of the dam. Four mules sold at the sale of his effects. for upwards of $\$ 800$ : and two mole pairs at upwards of $\$ 400$ each pair; one pair of these mules were nearly sixteen hands high. 'The only Jacks I know of at present, of the genuine Mount Vernon stock, are, one sold by me to Judge Johnson. of South Carolina, for five hundred dollars, at two rears oid: one given by me to Williarn Fitzhugh, Esq. of liavensworth, and one which I believe is possessed by my uncle, Geore Calvert, Esq. of Riversdale.

"The Jack purchased by Judge Johnscn, I have unde: siood, has a very high reputation in the South.

"I J pon iosing my groom (Peter) who was the first and last groom to the Mount Vernon Jacks, I parted - vith my stock.

"There are many Jacks that have come into th." country of late years, but of their value and proper. ties I am unable to speak, though I rather presume they are generally small, and only fitted to get mules for the cotton cultivation in the light lands of the South. some very fine mules are raised about Hagerstowr, Miryland, from Jacks of the old breed; they are ined from stout wagon mares. 
"As to my opinion of the value of mules, I shail always appear extravagant. I have scarce a horse on my estates for agricultural purposes, nor would I ac cept of one as a gift, (except for road wagons,) of which I have no need, as my property lies on navigable water. Nothing ever was so good as mules for the uses of this, our southern country ; they live longer, eat less, and above all, are better suited to our slaves, than any other animal could possibly be: their strength, patient endurance of privation and hardships, slender pasturage, exposure-and in short, all those ills to which animals are subject where slaves are their masters, give to mules a decided preference in all the agricultural States of the South.

"I do not know of any being trained to the purposes of pleasure carriages. They are often ridden, and go pleasantly, with great surety of foot. I have no doubt but that in time, they will generally be used for carriages, and would particularly suit mail coaches; they are very swift, and have great durability in travelling."

The Knight of Malta, mentioned by Mr. Custis, was unquestionably the first Maltese Jack ever brought to the United States. The second came in the frigate Constitution, on her return I think, from her first cruise in the Mediterranean; and I have understood was sold in the district of Columbia, or one of the adjoining States. Since that time a number have been introduced by officers of the navy from Malta, and the large Spanish breed from Minorca and Majorca. From the Nount Vernon and those stoclis, some fine mules have been bred in the middle States, and probably farther South. A few valuable Maltese Jaris nave neen ins ported in merchant ships. 
The impressions received, when on a visit to the West Indies in my youth, by observing, on the sugar plantations, the severe labour performed by mules in cane mills, induced me when I commenced farming, to purchase the first well broke mule I could light on; and notwithstarding le was so small as to require a vehicle and harness constructed purposely for him, his services were found so valuable, and the economy of using those animals so evident, that I was stimulated to great exertions for procuring several others of iarger size; in this I succeeded, after great difficulty to such an extent, as to have had more labour performed by them on farm and road, for thirty years past, than any pesron I presume, in New England; and every day's experience has served to fortify my conviction of the superior utility of the mule over the horse, for all the purposes for which I have proposed him as a candidate. And it should be considered, that those I have used were of an ordinary breed, vastly inferior to such as may be easily produced in our country, by attention to the introduction of a suitable race of Jacks, and a proper system of breeding and management. The question occurs, how is this to be effected? I will premise, that there exists a strong analogy between three varieties of the horse, and those of the domestic ass, considered the most valuable. We have the Arabian, the hunter, and the stout cart-horse. 'There is the heavy Spanish Jack, with long slouching ears, which Mr. Custis has described, that answers to the cart-horse; another Spanish breed called the Anda'usian, with ears shorter and erect, of tolerable size. plenty of bone, active, more spirited, and answering to the hunter. Then comes the Arabian Jack, with ua:s always erect, of a delicate form, fine limbs, and liui, of fire and spirit. Judicicus crosses from !hrese 
varictics, will be required to produce such find of mules as may be wanted for general purposes. $F_{\text {inon. }}$ the small Jack of African origin, with a list down his back and shoulders, are bred a small race of mules, by far the most hardy of any. With attention to selection in breeding the Jacks, with, perhaps, a dash of some cross of the foregoing description, a stock of mules may be produced, preferable to all others for the light lands and cotton culture of the middle and Southern States.

To procure any number of Arabian Jacks from their native country, is hardly practicable at the present time. Erypt has been celebrated by Somnini and other travellers, for superb Jacks of the Arabian breed, which probably has been often improved by those introduced by the pilgrims from Mecca. I apprehend no great difficulty in obtaining them from that country. There is, however, no question but the Maltese Jacks are of the Arabian race, more or less degenerated. The most of those brought to this country that I have seen, were selected on account of their size, and had been used to the draught. I should recommend the selection of those that are esteemed most suitable for the saddle, as likely to possess greater purity of blood. A Jack of this kind, was a number of years since imported from Gibraltar, that had been selected by a British officer at Malta; and very much resembled the Knight of Malta described by Mr. Custis. I found upon a careful examination, that he differed but little from the description I had heard and read of the true Arabian race; indeed I could dis cover some prominent points and marks, that agreea with those found by professor Pallas to belong to the Memionus or wild mule of Mongalia. From this Jack nave bred a stock, rut of a large Spanish Jennes is 
the Andalusian breed, that correspond very minutoly with Mr. Custis's description of Compound bred by General Washington, and also a mule, that now, not three years old, stands fifteen hands, and has other proints of great promise.

Such have been the ravagres of war and anarchy in Spain for a long time past, that the fine race of Jacks that country once possessed have become almost extinct. In Majorca, and probably some part of the coast of Spain opposite, the large breed may be obrained; and there formerly was a superior race in Andalusia, which it is hoped have been preserved.Crosses on one of these broeds by the Arabian or Maltese, I consider indispensable to furnish a race of Jacks for the production of the most desirable mules, uniting the weight and bone of one, with the spirit and vigour of the other, although their height will in a great measure depend on the mares, yet if sired by full blooded Maltese Jacks, their limbs are too skender and their pasterns too long for hieavy draught; but for the saddle, especially from blood mares, they are admirable, and out of stout mares suitable for light carriages.

My attention has been but lately directed to breeding mules; and those intended only for my own use. The system adopted is to halter them at four months, and have ine males emasculated before six months old, wrich has great influence on their future conduct, aud is attended with much less hazard and trouble, than it delayed until they are one or two years old, as is the general practice. If they are treated gently and fed vccasionally out of the hand, with corn, potatoes, \&c. they soon become attached; and when they find that "every man's hand is not against them," will have no piopensity to direct their heels against him, and soon orget ther have the power. In winter they should 
be tied up in separate stalls, and often rubled down. By such treatment there is not more danger of having a vicious mule than a vicious horse; and I am decidedly of opinion, that a high spirited mule so managed and well broke, will not jeopardize the lives or limbs of men, womer, or children by any means so much as a high spirited horse, however well he may have been trained.

The longevity of the mule has become so proverbial, that a purchaser seldom inquires his age. Pliny gives an account of one, taken firom Grecian history, that was eighty years old; and though past labour, followed others, that were carrying materials to build the temple of Minerva, at Athens, and seemed to wish to assist them ; which so pleased the people, that they ordered he should have free egress to the grain market. Dr. Rees mentions two that were seventy years old in England. I saw myself in the West Indies a mule perform his task in a cane-mill, that his owner assured me was forty years old. I now own a mare mule twenty-five years old, that I have had in constant work twenty-one years, and can discover no diminution in her powers; she has within a year past often taken upwards of a ton weight in a wagon to Boston, a distance of more than five miles. A gentleman in my neighbourhood has owned a very large mule about fourteen years, that cannot be iess than twenty-eigh" years old. He informed me a few days since, that he could not perceive the least failure in him, and would not exchange him for any farm horse in the country. And I am just informed, from a source entitled $t$ perfect confidence, that a highly respectable gentlema: and eminent agriculturist, near Centreville, on the Eastern Shere of Maryland, owns a mule that is 
thirty-five years old, as capable of labour as at any former period.

The great Roman naturalist, in one of the most beantiful passages of his elaborate history of nature, observes that "the earth is constantly teased more to furnish the luxuries of man than his necessities." * We can have no doubt but that the remark applied with great justice to the habits of the Romans in the time of Pliny; and I am much mistaken if ample proofs cannot be adduced, that it will lose none of its force or truth, at this present period, in all northern climates, or any section of the United States where the horse is employed for agriculture as well as for pleasure. Far be it from me, however, to disparage this noble animal; on the contrary, I feel a strong attachment for him, and at the same time a full conviction, that the substitution of the mule, for the purposes before stated, as extensively as may be consistent with the requisite production of each species, will have the effect of restoring the horse to the station from which he has been degraded, and place him as in former ages, upon a more dignified footing, an object of ac knowledged luxury; and thereby introduce a more

* "It is the earth that, like a kind mother receives us at our birth, and sustains us when born. It is this alone, of all the elo ments around us, that is never found an enemy to man. The body of waters deluge him with rains, oppress him with hail, and drown him with inundations; the air rushes on in storms, prepares the tempest, or lights up the volcano; but the earth, gentle and indul. gent, ever subservient to the wants of man, spreads his walks vrith flowers, and his table with plenty; returns with interest every good committed to her care, and though she produces the poison, she still supplies the antidote, though constantly teased more to furnish the luxuries of man, than his necessities, yet even to the lest, sho continues her kind indulgence, and when life is over. she piously indes his rematns in her bosom."

Pliny's Natural History, Book II. Chap. 63. 
correci system of breeding and management, in which aur countrymen are so generally deficient, consequently $\because$ re pertect animals and such an advance in the price of them, that will aftord the farmer what he is now a stranger to-such remuneration as will make his brood mares a profitable species of stock. And it is obvious that the system will be followed by an improvement in the breed of mules, in the same ratio as the miserable race of scrub mares, which are now consuming the profits of agriculture, shall become extinct.

It does not appear that the horse was employed by the ancients for any purpose of husbandry. The ox and ass drew the plough and the wain, and performed all kinds of drudgery until after the feudal system was established in Europe, when the numerous retainers of the feudal lords, who held their lands by the tenure of performing knight's service, found themselves under the necessity of making the horses they were obliged to keep, contribute towards their support in the cuitivation. From this time I believe, we may date, and from this cause may be attributed the introduction of the horse for the purposes of agriculture. Since that period, the history of Europe is little else than the annals of war and its preparations; and no material for that scourge, except the deluded human victims, seems more necessary than the horse-accordingly we find that throughout the whole country, from the Rhine or the Seine, to beyond the Danube and Vistula, which has been the principal arena, the system of agriculture has embraced, extensively, the breeding of horses of different grades and forms adapted to the several uses in war. Indeed whole provinces were appropriated almost exclusively to the rearing those animals fon disposal to the different combatants; and it must bo 
obvions, that their general use in husbandry, at the same time, would follow as a necessary consequence. It cannot be expected therefore, but that the Dutch and Germans who have emigrated to our country. should bring with them such strong predilections for the horse, which have continued with most of thei descendurits, especially in those sections where com munities of that respectable and industrious portion of nur population have been located. In Great Britain, to the causes which have produced the effects described on the continent, may be added the insular position of the United Kingdoms, vulnerable from numberless and distant points, the horse has been considered, in connexion with the unconquerable spirit of the nation, as one of the most efficient means of repelling invasion : a circumstance that would of itself be sufficient to account for the over-weaning attachment to this animal. But identified as his services have been for a long period, with the convenience, sports, and recreations, of all ranks and classes, and the science of vreeding and training, forming a characteristic feature, it could not excitc surprise, if the approach of that terrible spectre famine, should produce little or no effect in the reduction of the number. And although somg $r, f$ the most distinguished characters in the nation eminent for their practical knowledge in rural econ omy, have been for half a century advocating the substitution of the ox for the purposes of agriculture, and demonstrating the feasibility, economy, and vast saving of food, yet it is said the number of labouring oxen have lately diminished and horses increased. Five millions of the latter are now supposed to subsist in the United Kingdom, and two-thirds employed in husbandry-consurning, at a moderate estimate. the 
product of twenty millions of highly cultivated acres !* And what is the consequence? consumption follows so rlos: upon supply, that at every season of harvest, let the preceding one be never so abundant, fast sailing vesrels are found in the various ports, with their anchors atrip, to convey intelligence of the result, to all parts of the world where a surplus of bread corn is grownexciting such an interest in our own country, that the farmer on the shores of Erie and Ontario, and on the banks of the Ohio, may be seen reading bulletins of British weather-the rain and sunshine of every day in August and the two following months - often within thirty days after the time of their publication in Londors or Liverpool. Can it be supposed that in a country where an attachment to the horse borders so nearly upon infatuation, that the question of the utility of the mule as a substitute, would be seriously agitated, or engage scarce a momentary investigation?

In no country is the mule better adapted to all the purposes of husbandry, for which the horse is used, than in every section of our own. And it would be highly desirable to be able to exhibit a calculation of the actual saving, in dollars and cents, by his employment--but unfortunately no correct data can be had. And as I consider such calculations, unless founded upon experimental facts, and those multiplied, to be as " tinkling cymbals," I shall merely submit a desultory

* Mr. Pitt, in an able "Essay on the consumption of corn," pullished by the Board of Agriculture, in 1806, estimates that eisch draught horse, employed on roads, canals, and mines, in pleasure carriages of all descriptions, and carts in cities, consume the average product of four acres for oats and beans, and thrce acres for hay. It is stated in the same essay, tnat "the aggregute of oats imported into England (only) for twenty years, ending in $1: 97$, amounted to the enormous quantity of $8,655.046$ qunar les $\mathrm{s}^{m}$-. apwards of sixty-rine millions of hushels: 
romparison between the mule and the horse, derived from such facts as my own experience, and information from authentic sources, will justify the assumption of.

From what has been stated respecting the longevity of the mule, I think it may be fairly assumed, that he does not deteriorate more rapidly after twenty years of age, than the horse after ten, allowing the sanie extent of work and similar treatment to each. The contrast in the mule's freedom from malady or disease, compared with the horse, is not less striking. Arthur Young, during his tour in Ireland, was informed that a gentleman had lost several fine mules by feeding them on wheat straw cut-and I have been informed that a mule dealer, in the western part of New York, attributed the loss of a number of young mules, in a severe winter, when his hay was exhausted, to feeding them exclusively on cut straw and Indian corn meal. In no other instance have I ever heard or known of a mule being attacked with any disorder or complaint, except two or three cases of inflammation of the intestines, caused by gross neglect in permitting them to remain exposed to cold and wet, when in a high state of perspiration after severe labour, and drinking to excess of cold water. From his light frame and more cautious movements, the mule is less subject to casualties than the horse. Indeed, it is not improbable, but a farmer may work the same team of mules above twenty years and never be presented with a farrier's bill, or find it necessary to exercise the art himself.

Sir John Sinclair, in his "Reports on the Agricul. ture of Scotland," remarks that " if the whole period of a horse s lapour be fifteen years, the first six may ne equal in value to that of the remaining nine: thereiore, a horse o. ten years old after working six yeas 
may be worth half his origrinal value." He estmmates the annual decline of a horse to be equal to fifiy pe: cent. on his prine every six vears, and supposes one out of twenty-five that are regularly employed in agriculture, to die every year : constituting a charge of four per cent. per annum for insurance against diseases and accidents. He considers five acres of land, of medium quality, necessary for the maintenance of each horse, and the annual expense, including harness, shoeing, farriery, insurance, and decline in value, allowing hirn to cost two hundred dollars, to exceed that sum about five per cent. which is the only difference between the estimate of this illustrious and accurate agriculturist, and that of a respectable committee of the Farmers Society of Barnwell district, South Carolina, who, in a report published in the Charleston Courier, of $23 \mathrm{~d}$ of February last, state, that "the annual expense of keeping a horse is equal to his value!" 'The same committee also state, that "at four years old a horse will seldom sell for more than the expense of rearing him." That "the superiority of the mule over the horse, had long been appreciated by some of then most judicious planters-that two mules could be raised at less expense than one horse-that a mule is fit for service at an earlier period, if of sufficient sizewill perform as much labour, and if attended to when first put to work, his gait and habits may be formed to suit the taste of the owner." This report may be considered a most valuable document, emanating as it does, from enlightened practical farmers and planters: III a section of country where we may suppose a horse man be maintained cheaper than in Marvland or any State farther North.

I am convinced that the small breed of mules wil! consume less in proportion to the labour they are 
capable of performing, than the large race, but 1 shal: confine the comparison to the latter-those that stand from fourteen and a half to rising of fitteen hands, and equal to any labour that a horse is usually put to. From repeated experiments in the course of two winters, I found that three mules of this description, that were constantly at work, consumed about the same quantity of hay, and only one fourth the provender that was given to two middling sized coach horses moderately worked. And from many year's' attentive observation, I am led to believe that a large sized mule will not require more than three-fifths to two-thirds the food to keep him in good order, that will be necessary for a horse performing the same extent of labour. Although a mule will work and endure on such mean and hard fare, that a horse would soon give out upon, he has an equal relish for that which is good; and it is strict economy to indulge him, for no animal wili pay better for extra keep, by extra work. But if by hard fare, or hard work, he is reduced to a skeleton, two or three weeks' rest and good kceping will put him in flesh and high condition for labour. I have witnessed several such examples with subjects twenty years old; so much cannot be said of a horse at that age. The expense of shoeing a mule the year round, does not amount to more than one-third that of a horse, his hoofs being harder, more horny, and so slow in their growth, the shoes require no removal, and hold on till worn out-and the wear, from the lightness of the animal, is much less.

In answer to the charge generally prevalent against the mule, that he is "vicious, stubborn and slow," I ras assert, that out of about twenty that have been employed on my estate, at different periods during a comuse of thirty years, and those picked up cniefiy on 
arcenunt of their size and spirit, wherever they could be founa, one only had any vicious propensities, ant those might have been subdued by proper management when young. I have always found them truer pullers and quicker travellers with a load, than horses. 'Therr vision and hearing is much more accurate. I have used them in my family carriage, in a gig, and under the saddle: and have never known one to start or run from any object or noise: a fault in the horse that continually causes the maiming and death of numbers of human beings. The mule is more steady in his draught and less likely to waste his strength than the horse: hence more suitable to work with oxen; and as he walks faster, will habituate them to a quicker gait.But for none of the purposes of agriculture does his superiority appear more conspicuous than ploughng among crops, his feet being smaller and follow each other so much more in a line, that he seldom treads down the ridges or crops. The facility of instructing nim to obey implicitly the voice of his driver or the ploughman, is astonishing. The best ploughed tillage land 1 ever saw, I have had performed by two mules tandem, without lines or driver.

There is one plaus:ble objection often urged against the mule, that "on deep soils and deep roads, his feet being so much smaller than those of the horse, sink farther in; but it should be considered that he can extricate them with as much greater facility.

Few can be ignorant of the capacity of the mule to endure labour in a temperature of heat that would be destructive to the horse, who have any knowledge or the preference for him merely on that account, in tne IVest Indies, and in the Southern States.

It is full time to bring our comparison to a close, which I shall do by assuming the position, that the 
farmer who substitutes mules for holses, wilı nave this portion of his animai labour performed, with the expense of one spire of grass instead of two; which may be equal, so far, to making "two spires grow where one grew before." - For although a large sized mule will consume somewhat more than half the food necessary for the horse, as has been observed, yet if we take into account the saving in expense of shoeing, tarrery, and insurance against diseases and accidents, we may safely affirm, that a c'ear saving of one half can be fully substantiated. But in addition to this, the mule farmer may calculate, with tolerable certainty, upon the continuation of his capital for thirty years: whereas the horse farmer at the expiration of fifteen years, must look to his crops, to his acres, or a bank, for the renewal of his-or perhaps, what is worse, he must commence horse jockey at an early period.

The intense interest with which the public mind is at present occupjed on the subject of canals now in operation and progress, encourages me to offer the mule as an important auxiliary in the economy of their management; as I trust, it will not be denied, that on the cheapness of transportation on them, depends their utility as well as profit to the stockholders. The mule seems so peculiarly adapted for the labour on canals, that compared with the horse, he may be considered almost equal to a locomotive j" wer engine. Among the advantages we have enumerated respecting his use in husbandry, the most of which are applicable to canal litbour, that of the much greater security from diseases and casualties, which must necessarily require a grea! number of supernumerary horses, to prevent interruption in the line of passage, is not the least importan. onr is the very trifling expense at which the mule can we suported during the winter months, as he will beas 
Deing taken of his feed till the berats are about to be launched in the spring, and in a few days can be made tit for efficient duty-while a horse will require at least half feed if he does nothing, or must be fed high for some time before he can resume the labour that will be demanded of him. The same advantages may be derived by his employment on railways.

In a communication published in the Utica Observer, the 16th of May, inst. by Henry Seymour, Esq. one of the canal commissioners of New York, it is stated that a packet boat on the Erie Canal, requires a team of three horses to tow sixteen miles, going eighity miles in the twenty-four hours, including stoppages and detention at locks ; the relays demanding fitteen horses for each nautical day. If it takes five days for a boat to be towed from Lake Erie to the Hudson, seventy-five horses will be required. I am not certain but it may be done in a less time, but as there must always be supernumeraries kept, we shall be within bounds to estimate that number. In the same communication the expense of each horse is estimated at fifty cents per day, I presume for subsistence only, without reference to interest or deterioration of capital, for the object of the estimate seems merely to show a comparison between the packet boats and freight boats, on a question of profit and loss: as it is remarked that "many contingent expenses might be added to both." Taking this data, it. will cost thirty-five dollars per day for the horse subsistence of a single packet boat. The freight boats require two, and allowing for the time occuried In taking in and discharging their cargoes, with the other necessary detentions, average forty miles per day - which being double the time of the packet boats, although they may not require the same number of relays, the expense cannot materially differ. From 
these premises we may conclude, that fir every boat navigating the grand Erie Canal, there must be expended three lundred and seventy-five dollars for the subsistence of the horses, each time they tow her from thic Lake to the Hudson and back.* Now, if this can be done as effectually by mules for one half this sum and with an extension of capital free of interest, fifteen years longer than that vested in horses, the aggregate of this immense saving will appear by ascertaining the number of boats at the present time on the canal. But this is out of my power, and I should, perhaps, lead the reader nearer the verge of incredulity, were I to offer iny prediction what that number will be thirty years hence, the ordinary period of a mule's labour, and which will then be some years less than a single century since the prime mover and guardian of this stupendous undertaking, the present Governor (De Witt Clinton) of New York, first saw the light of Heaven.

I cannot resist an impulse to exhibit the mule in one other point of view. For the movement of machinery, the employment of this animal, when judiciously selected. has met with a most decided preference, in comparison with the horse, independent of the economy in using him. And if we consider the rapid and probably progressive increase of labour-saving machines, in every department where they can he made subservient to the requirements of society, it is

* This estimate (threc hundred and seventy-five dollars) is the maximum of expense for subsistence and other items, supposing tho whole number of horses should be required for one boat; but they will unquestionably be employed for a succession of other boats. And should all the relays perform a tour on the line every day, the minimum of expense would be seventy: five dollars for eact. woat. Facts derived from further information may onahle us to is the medium 
evident that there will be a corresponding aemand $f n$ animal power, as well as for that more potent, derived frum the elements; and although tne latter may vastly predominate, yet should the horse be employed, and his increase for other purpuses continue, as it now does in the ratio of population, the number, at no very distant period, may become as alarming in our own. as it is at present in our mother country. And not withstanding we may feel secure, from the extent of our territory and extreme diversity of soil and climate, but, above all, from being in possession of Indian con-the GOLDEN FLEECE found by our "pilgrim rathers," when they first landed on these shores; yet such prculiar advantages may not insure us against the visitations of one of the most distressing calamities that a feeling community can possibly be subjected to

B) igliton, Mass. May 27, 1825.

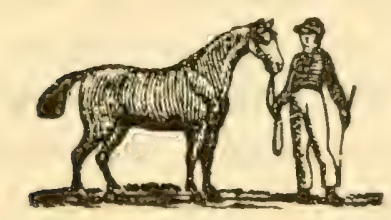





\title{
A P PEN DIX
}

\author{
TO \\ MASON'S FARRIER:
}

\author{
CONTAINING \\ OBSERVATIONS AND RECEIPTS
}

FOR THE

CURE OF MOST UF THE COMMON DISTEMPERS.

INCIDENT TO

UORSES, OXEN, COWS, CALVIES, SHELP, LAIIBS, SWIVE, IDOGS, \&c. dec.

SEI ECTRD FROM VARIOL'S AUTHORः 



\section{A I I E N D X}

moจㅇ..

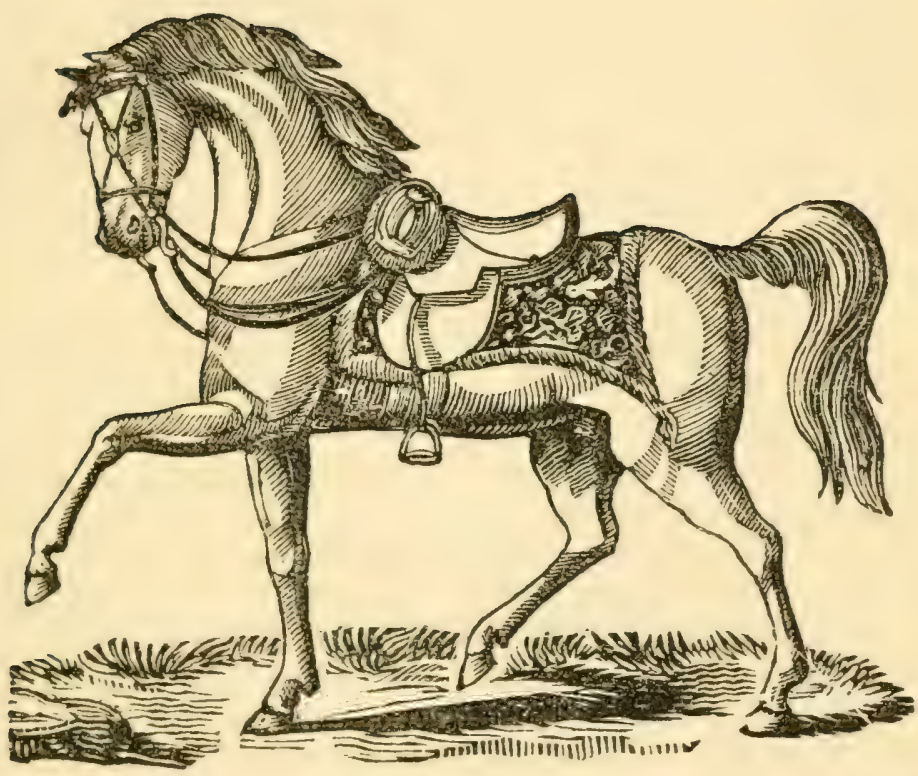

(1) THE DISEASES OF THE HORSE.

1. The diseases of the horse are as numerous and as mportant as his complicated structure and the artili cial state of his present mode of life would lead ons io expect. Until of late the treatment of these discases was confined to the hands of ignorant farriers presumptuous grooms, or shoeing smiths; and the fite of the animals was commensurate with the wretched treatment they were subjected to The establishmem 
of a scinoul for the reterinary art, has disseminated ar improve 1 practice, and spread improved practitioners throughout the country; and we would earnestly recommend an application to one of established reputation in all cases of difficulty and danger. But as it is not always that such a one is within reach, to enable the agriculturalist to have in his own hands the means of informing himself, or to being a check to others, we submit a concise view of the diseases of the head, neck, trunk, and cxtremities, preceded by some general observations.

\section{GXNERAL REMARKS}

\section{On the Helthy and Diseased State of the Horse.}

2. Condition of Horses.-Being in condition, in stable language, signifies not only perfect health internally, but such an appearance externally, as the philosopher would call unnatural, or at least artificial : while the amateur considers it as an essential requi. site tu the other qualities of the horse. 'I'his external condition is denoted by a sleek, short, shining coat, with a degree of flesh neither bordering on fatness nor emaciation. Even in this sense of Ine tern, condition must be varied according to the uses of the a limal. In the cart horse, provided there be a sleekness of coat, looseness of hide, sound wind, freedom from grease or swelled !egs with good digestion; a fulness and rotundity of bulk, instead of detracting from his beauty or impeding his exertions, will add to the one and assist the other. In the couch horse, the hackney, the hunter, and the racer, a different condition is expected, varying in different degrees from that of the cart horse. In both cart horse and racer, it is equally necessary that the various internal organs whousd be in a state to act uninterruptedly for the bensfit of the whole; but in addition to this, it is necessary to the racer, that the greatest possible quantity of animal fibres should be condensed into the smallest possible bulk, and that the absorption of all useless fat and other interstitial matter should be promoted by every possible means, as essentially necessary to unite lightness of body with full strength and elasticity. It is in the attempts tu produce weh a state in its full perfection, that all the secrets of taining consivi is whether a total departure from natural ru'es, by 
annatural heat, deprivation of light, stimulating food, sestraint from water, and excessive clothing, are best calculated to promote It, admits of much doubt; and it is to be observed that the dawr. of reason and science appears to be shining through the crevices of these darkened casements ; for even at Newmarket the system has lately much relaxed from its artificial rigor.

3. To bring a horse into condition, not only should the purposes e is intended for be taken into account, but also his previous state. If he be taken up from grass with much flesh on him, it is evident that what is required is to remove the soft instertit:al mat. ter it may be supposed he has gained by green food, and to replace it by hard flesh; and also to produce a sleekness of coat and beauty of appearance. To accomplish these ends, the horse should be accustomed to clothing and the full heat of the stable by degrees only; and also by degrees nnly to the meditated change of food; which is best done by mashes. In two or three days a mild dose of physic may be given, during all which moderate exercise only should be allowed, as walking, but which may be continued two hours at a time. After the physic has set, begin to dress his coat, increase his exercise and his food, and accustom him to an inc ease of warnth. In four or five days time again mash him for two days and give a second dose of physic, a little stronger than the first. (123) After this still further increase his warmth, his exercise, and his food, by which his belly will be taken up, his flesh will harden and his coat begin to fall. A third dose of physic or urine balls, \&c. are only necessary in the training of hunters, \&c. and even in these, a gradual increase of exercise, rather long continued zlaan violent, with proper food, will effect the end, if not so quickly, more beneficially to the animal. To bring a lean horse into condi. tion, a somewhat different plan should be pursued. If from grass, stıll mash him for a day or two, by no means stint him in his water, and with his mash let oats be also soaked. If oats be speared of malted, it will produce flesh sooner. But even here, give the horse moderate walking exercise, and if he be not too much reduced, add a mld dose of physic to prevent his heels flying, or his getting hide-bound by the increased food; but if great emaciation forbid the plyysic, give him nightly an alterative. (Vet. Pharm. 129, No. 1.1 As his alpearance improves, gradually harden his food and increase his exercise.

4. Diseased condition of horses. What has been already sald ple teu to that olteration from one state to another, neither being an 
unheshty one, which custon has rendered necesary; thus a man in training for running or fighting, and a man out of training, are both considered equally healthy. But there are circumstances that urorluce a morbid state of condition different from all these. It is common to hear persons say "my horse is sadly out of condition, and I cannot tell either what is the matter with him, or how to get nim into better case." Various are the causes that may produce this: a sudden alteration of the food, or temperature, or of habits altogether, may becnme a cause. Removing a horse from grass to a heated stable, full feeding, and hard exercise, will often do it: therefore these changes should always be gradual. Bad food, as mow-burnt hay, musty oats, beans, \&c., likewise mineral waters, foul vir, \&c., are frequent causes. Diabetes, or profuse staling, is often brought on by these means, and the condition of the horse becomes greatly reduced. It is requisite, therefore, to enquire whether any of tnese errors are in existence, and to immediately remove them: but it often happens that the stomach has become relaxed and the hide become bound; neither of which readily remove, even though the original evil may be arnended. When the relaxed stomach has produced lampas, treat the mouth as described under that disease $(25$,$) but the stomach itself must be principally$ attended to.-First mash and give a dose of physic; after it lus set, commence the treatment, if the horse be of a full habit, by moderate bleeding and a nightly alterative. (Vet. Pharm. 129, No, 1 or 2.) Buf if he be not in full, but in low flesh, commence isy a daily tonic, (Vet. Pharm. 130, No. 1 or 2,) which will gradu ally remove the swolling within the mouth, and loosen the hide A sudden cold apslied to the skin often brings on a want of con dition with surfeit. In which case, bleeding, with nightly altera. tive, (Vet. Pharm. 129, No. 1 or 2,) with or without an assistant dose of physic, as the hahits of the horse may require, constitute the proper treatment. Worms form another cause of morbid con. dition which are to be removed as described (57.) Excessive fatigue is also productive of a bad state of condition, which often proves very obstinate. Turning out to very good grass is the quickest eure, and when that is impracticable, soiling in the stable, or feeding with carrots, parsnips, beet root, \&c. will be food restora uves; as medicines give tonics daily. (Vet. Pharm. 130, No.1 or 2.) It will be only necessary to add, that in considering the state of a borse's condition, the effect is apt to be mistaken for the cause, ano the symptoms for the disease. Hide-bound and lampas are not in themsel res any thing more than effects, or symptoms; the formuer Aeing cosnmonly, and the latter always dependent $r n$ a derangan 
atate of the stomach: both are therefore to be treated accoraingly. Exactly the same will apply to all the other symptoms of mortid condition.

\section{Inflammatory Diseases of the Horse.}

5. The inflammatory diseases of the horse are numerous, but his fevers are few: a febrile state being generally brought on by the inflammation of some important organ. Inflammation may be considered as general or diffused, and local or confined, and both seem to arise from an affection of the blood vessels, and perhaps from a peculiar state of the blood itself.

6. General or diffused inflammation constitutes fever or extensive inflammatory affection, and appears to consist in an increased action of the heart and arteries, accompanied with an increase of heat. In some instances where the fever is purely symptomatic, and dependent on the inflammation of some important organ, as the lungs, or the intestines, the circulation appears retarded rather than increased, from interruption arising to its passage through the heart.

7. Local or confined inflammation is also dependent on an affection of the blood vessels, but confined principally to the blood vessels of the part affected. It is betokened by redness in the skin, tumour or swelling, heat and tenderness, with pain. Inflammations, both diffused and local, are brought on by excitements, such as over feeding, excessive heat, reaction produced after cold, and the reaction produced by inordinate exertion. Those more exterior, arise from injuries, the applscation of improper substances, \&c. Inflammations terminate in various ways; but it is to be remarked that in consequence of the very large circulatory system of the horse, his febrile affections ragre highter 
and terminate sooner tnan in man. The usual ter mination of inflammatory affections in the horse, are by resolution, effusion, suppuration, and gangrene. Scirrhus is not at all a common termination of inflammation in the horse.

8. Inflammation of the brain, (phrentis) brain fever, phrensy iever, staggers, mad and sleepy. There are few diseases more tikely to be mistaken by inexperienced farriers than this; it is not to be wondered at, therefore, if indifferent persons should be led inta crror by it. It appears in two forms, a violent frantic une, and a sleepy lethargic one; and the latter appearance is also common to a disease, not dependent as this is, on idiopathic inflammation of the brain; but on a paralytic affection of the stomach, and thence it is called stomach staggers. This latter affection, however, may be distinguished from the former by attending to the colour of the eyelids, nose linings, mouth, \&c. which in stomach staggers are usually more yellow than red; whereas in sleepy staggers, they are more red than yellow. Inflammation of the brain shews itself in general cases by disinclination to food and motion, drowsiness, accompanied ky a heaviness and closing of the eyelids, with moisture and red. aess of them; and also of the linings of the mouth and nose. Sumetimes these symptoms increase, until the horse becomes comatose, and after a few frightful struggles, sinks to rise no more. In these cases the pulse is apt to be oppressed instead of in. sreased. But most frequently after the first stages he becomes furious, plunges about, and is vicious to himself and others, ap proaching to a state of madness, in which state he continues till he sinks from his own exertions, when he rises again to renew his violencc.

9. The cause of staggers may be various: the immediate aro either an original accumulation of blood within the brain, or the translation of the inflammation of some organ to the brain: as a remote cause is often brought on by too full feeding, without suf ficient exercise, and particularly in horses at one time working ve:y hard, and at another suffered to remain inactive; but which horses, whether used or not, are equally fed. Sudden cold, vio. innce, \&c. may bring it on.

10 The treatment of staggers should be begun by alstracting e verv lalge mantity of hlond promptly, by opeuing both jugular 
end letting the horse bleed to the amount of ten or ever twelpe quarts; repeating the same until the delirium ceuses. Aner the nirst bleeding, hack rake, throw up a laxative ciyster, (Vet Pharm. 143.) blister the head, promote a current or free air in the stable, and treat altogether as directed under wther febrile in. fections.

11. Locked jaw, stag-evil, or tetanus, arises from cold, excessiva fatigne, sometimes perhaps from worms, but more often from a wounc of some part, as pricks in shoeing, \&c. Such wound is scldom in a recent state; but after two or three weeks continuance, sometimes after it has healed even: it follows docking, gelding and nicking freriuently; and is preceded by a flabby unliealthy state of the wound. It appears as an affection of the brain, which. transmits its morbid irritation, particularly to the nerves attachea to muscles, by which they become cramped, or may be considered as in a high state of action, giving the horse a peculiar look of energy, as though immediately stopped from full speed; with his nostrils extended, his head raised, and his noss carried forward; his legs straddle wide, and his tail is cocked and quivers, as after viclent exercise. The jaws will now be found, if not closed, yet nearly so, when he is called jaw set.

12. The trentment is not often successful, hut, however, it is snfficiently frequent that it is so, to deserve the utmost attention Blaine informs us that enormous bleedings have succeeded; but he places his principal dependence on the application of cold by neans of ice, or of constant dashing with cold water, with an active hister applied the whole length of the spine. Balls of camphor and opium, to the amount of two drachms eaci, may be givep every three hours. If any room remain in the mouth, the ball naty be passed up by means of a stick, or it may be given as a drink hy means of a syringe, and even when the mouth is entirely closed, he informs us we may give a drink by the nostrils. Moorcroft used cold also. Fearon, on the contrary, has experienced benefit from a bath, heated to ninety degrees, and kept at that emperature for three hours. White recommends camphor and opium; Wilkinson of Newcastle, has been very sucerssful by leeping up heat and stimulus over the skin in general, by means of newly stripped sheep skins put on hot. Perhaps if he body mere previously rubbed with oil of turpentine one part, and common oil two parts, it might assist Wilkinson's plan. When locked aw arises from nicking, it might be prudent for a veterinar 
eurgaon to dissect down on the nerves of the tail, and divide them; and when from nicking, it would be advisable to cut off another portion of the tail, which practices in both instannes would afford a moderate chance of saving the animal. It. is necessary further to remark, that it is of great consequence that the bowels be kept free from fæces, by raking and clysters. With regard to the latter they are very important in this disease, as a medium. commonly the only onc, of giving support. A horse has been kept alive on nourshing clysters alone, for seven or eight days. (Vel. Phurn. 145.)

13. Catarrhal fever, epidemic catarrh. influenza, distemper, cold morfoundering: \&c. These names apply to one common disease which often in rainy, variable seasons appears as an epidenic, and affects thousands of horses at once. It is observed to be par ticularly prevalent in this form in the spring of some years, more than of others. It is not contagious like the more malignant form, but is brought on as an epidemic by the same causes being applied to nearly all subjects alike; which are alterations of heat with cold, moisture, and dryness, \&c. In crowded cities and large towns, it is more prevalent than in more open situations, and it is more frequently found in the young than in aged horses. Wnere it does not exist as an epidemic, it is brought on by an accidental cold taken. It is of great consequence to distinguish it from pure inflammation of the lungs, with which it is very apt to be con. fnunded; and which mistake is often a fatal one, from the treatment being in some essential particulars different. Inflammation of the lungs commences by a short cough, without much other disturbance to the health, than the pain it gives the horse to cough, but which is often so considerable as to make him stamp his feec while coughing. If a horse in the distemper coughs early, it is not a hollow, harsh sounding, and distressing cough of this kind-if he expresses uneasiness, it is principally from a sore throat, which is very common in distemper, but by no means common in pueumonia. The sore throat in distemper gives the horse a dis position to refuse his food, or he chews it and lets the quid fa. witnout swallowing it. He refuses water, particularly if it bo placed on the ground; his cough is quick, short, and usually sounds more moist than harsh and dry; but though common, thio is not anvariably the case; his eyes are heavy and moist, his breathing is quickened, and his ears and legs are alternately hot and cold His nose on inoking anto it is redder than usual, and sometims 31. glands as well subnaxillary or jaw glands, as his protid o 
vives are tumefied. On the second or third day, excessive weakneso comes on; the cough becomes more painful, the pulse is quick enrl, and the nose begins to run. After which the horse eithes runs ot the disease by this suppuration, or it goes on to destroy him by the height of the fever, and degree of weakness produced no by suffocation from water in the chest. Now and then, although -movery takes place, an obstinate cough is left; and in a tew case he disease terminates in glanders.

14. The treatment may in some cases be cut very short, for as in almost every instance a shivering fit begins the disease, so when many horses are in a stable, and the disease is very prevalent, those who have not been attacked should be watched, and tho moment such an attack does take place, give of sweet spirit of nitre, or when not at hand of spirit of hartshorn, an ounce, in a pint of sound ale. Exercise the horse briskly, then well hand rub him, clothe him warmly; and it is more than prohable that the disease will be cut short. But should it proceed, or shuuld tho disease have gone on unobserved to the appearance of the symp. Lom detialed, begin by bleeding moderately, if the horse be not already weak; or if there have not appeared the running of matter from the nose. If there have, the bleeding had better be dispensed with, unless the fever appe $\mathbf{~}$, from the quick full pulse and red. ness of the inner surface of the nostrils and eyelids, to be still so considerable as to require it; in which case we must not bo deterred from one moderate bleeding; and which, if the febrile symptoms do not abate, may be even repeated. It will, however, in general cases, be advisable to avoid bleeding after the second lay of the attack, or after the running has appeared from the nose, , $r$ after considerable weakness has come on. In all cases a very cool temperature is essentially requisite; hot stables, or hot clothing are very pernicious, but particularly the former. A hood is not improper over the head, because it encourages the running to make an early appearance; and for this reason a warm mash may advantageously be hung round the neck three or four times a day. Before the running commences, give night and morning, the fever powder (Vet. Pharm. 157, No. 1 or 2.) in a mash os lrink; after the running has come on, or as soon as the weakneas has become considerable, give night and morning either of tho Ever drinks (Vet. Pharm. 158, No. 3 or 4.) Malt mashes, when tho weakness is grent, are proper; at other times, bran mashes with plenty of chilled water are best. To relieve the throat, ruv the outsicle with muld liquid plaster, (Vet. Pharm. 142,) and if the weather lie warm enough to allow it, wo or three hours tanning 
out in a ficid each day is proper. Green meat in the stable, when it can be procared, should likewise be given.

15. Mulignant epidemic, murrain, or pest. Now and the- the dis. temper or intluenza assumes a character of uncommon malignance, which is happily not frequent here, but not unfrequent in conti. nental countries, sweeping off a third of the horses and kint without any means being found sufficient to arrest its progress. In these cases it is found highly contagious, attacking almost all the horses as well as cattle within its sphere of action, or which communicate with each other. Dr. Layard, and Osmer, Engiish writers of established reputation, noticed the appearances of this disease long ago; and their descriptions are not different from the milder kind noticed (13) but in degrec. The throat is intensely sore, and the mouth ulcerated; the glands of the head swell, and sometimes these and other parts suppurate and burst. The matter from the nose is bloody, and the stench intolerable; the wealiness is also peculiarly great, and shows itself early.

16. The treatment recommended by Blaine is the carly use of malt mashes; even ale is indispensahle. Green meat should be allowed, and a very cool stall is necessary, having a free commu. nication with the open iir. As medicine, three doses are necessary, every day, of the malignant epidenic fever drink, (Vet. Ph. 160.) half a pint of yeast with a pint of ale has been given, with gond elfert, three times a day; also, to prevent the infection from spread. ing, fumigate ti: stables and all the outhouses with the preventive funigation. (Vet. Ph. 161.)

\section{Diseases of the Head.}

17. Epilepsy, megrims, sturdy, or turnsick, are epileptic attacks of greater or less violence, and which are apt to be confounded with the accidental strangulation that sometimes takes place from a collar too tight, or from driving a horse hard up hill, \&c. The epileptic fit makes its appearance by a sudden stop; if the horsm be in acuon he shakes his head, looks wild and irresolute, but after sorne time proceeds; when more violent, he suddenly falls down, is convulsed, dungs and stales insensibly, and remains some time vefore he recovers. This disease, like staggers, is generaliy the :nnsequence of two full a habit; and is, therefore, best relieved by bleeding, and a more moderate diet; and, where it is convenient, - run at grass should be allowed to alter the habit.

18 The diseases of the horse's eyes are not numerons, but they are very destructive. 'The principal are opthalmia and gutto seretha 
19. The optlatmia, lunatic, or man-lulinduess, is a very peculiar tisease anong horses, affecting their eyes generally about thein full growth, but sometimes later, and seldom earlier. It is but ittlo known anong mules and asses, and unknown in oxen and sheep. It does not, however, appear to be a disease natural to the horse, as wild, or even horses subjected to artificial restraints - not ohserved subject to it. But among others, it is become sc conmon as to have the tendency handed down in the breed; tho prugeny of snme stallions bring more prone to it than others.It is often very sudden in its attack, the eyelids being found swelled and almost closed to avoid the light; they are also very red wathin, and the haw is half drawn over the surface; the tears tow down the fice perpetually, and the whole head is hot; now and then these appearances come on gradually. The suddenness of the sttack makes the complaint to be attributed to accident, as blows, nay seeds within the eye, \&c. and it is frequently dificult to get the owner of such a horse to believe that a constitutional attack, as it usually is, can come on so suddenly. Sometimes as it comes un, so it goes off as quickly, the eye from being opaque and milky, in twenty four hours becoming clear and alnost well. When such in attack has taken place, even if nothing be done, the horso sooner or later amends, and the eye or eyes, for it is sometimes one and sometimes both that are so attucked, become again clear and well, and remain so an indefinite period, from five or six weeks io as many months. Another uttack, however, sooner or later follows, to which others succeed, each leaving increased milkiness on the outer coats, and some dimness within the pupil, either speck. iwe or diffused; and finally the horse becomes blind from cataract. When one eye goes blind totally before the other, it is often a meass of preventing the future attack on the remaining ona: which has given rise to a custom of putting out one eye to savo the nther, and which has succeeded. As this is a constitutional disense, brought on by artificial habits, as over exertion, close whealthy confinement, and heating food: so it is clear the abstrac. tiva of all these are necessary to remove the complaint, and to prevent a recurrence; but particularly the close, dark, and unven lilated state of the stahle should be attended to, as well as the remr, ral of the litter, which retains the volatile alkali of the urine, and irritates the eyes most injuriously. The food should be mila und ooling, and the exercise moderate but long continued. Under the 'reight of the attack, however, rest is adrisable, with moderate !igl', whi.h may be still further moderatei by keeping over the eyo or eyes a thick cloth, wet with goulard water. (Vet. Ph. 154.: sumetimes one quarter of vinegar to three quarters of water haz 
been found a useful application, and which ever is used, the eyea and eyebrows should be kept continually wet with it, whels ly exciting eraporation will keep the part conl. A seton may he introduced under the eye or jaw. In some cases, blistering the forehead or cheek is found useful; but in every instance bleedng is proper, which should be repeated until the disease lessens When the horse is very full and gross, physic and alteratires assist the cure. When blistering is used in any part near the eye, the greatest care is requisite to prevent the blistering matter from being rubbed into it.

20. Gutta Serena or glass eyes, so called from the peculiar glassy appearance of the eye, arise from a paralysis of the optic nerve. As the eye is not materially altered in appearance, a horse often becomes blind without its being noticed, until his cautious stepping, quick motion of his ears, \&c. give notice of the case.On examination it will be found that the pupil remains dilated. however great the light, and the eye is irrecoverably lost. In the very early stages, blisters to the forehead and stimulants to tho eyes, (as white vitriol a drachm, water four ounces,) may be tried, but with faint hopes of success.

21. Poll-evil. This complaint commonly requires the attend. ance of an experienced practitioner-but the prevention is often in the power of owners and others about horses, and to this point we shall particularly direct their attention. Poll-evil is commonly the effect of accident. Repeated small blows of the xtanger, or continued pressure from hanging back on the halter, \& c. will, if nnt remedied, produce swelling at the nape of the neck, with some tenderness. In this early state, if the collar be removed and the part be kept continually wet with vinegar and water, the swelling will often disperse-but if, in spite of this, it proceeds to suppuration, let a vent be made for the matter by a seton [116] oo that it indy readily flow out. Introduce nothing healing, but rncuurage a free discharge, and it may heal at once. When sucb us not the issue, the disease attacks the ligaments; sinuses form and the matter burrows under the skin and muscles, when seton must be introduced from the opening above and should bo brought out at the bottom; the seton should be then daily wettert with the liquid blister. (Vet. Pharm. 141.) Shculd this plan fail, escharotics will be required in the form of scalding mixture. (Vet Pharm. 165.)

22. Stungles, vives or ives. This disease has been likened to vie human measles, hecause it usually attacks every horse, and 
most of them at a yommor period, between three and five years; it is fortunate when it attacks colts at grass, as it seldom vecasions mconvenience, and which has led some persons into error by lurning their horses out as soon as attacked; but it is not found that stabled horses, thus turned out, pass through the disease mort mildly, but the rontrary, except the disease exists under its mildest fiorm. White has conjectured that colts breeding the strangles - hile at grass, are afterwards exempt from glanders, but this wants confirmation. Prosser has also afhrmed, that inoculation by tho mitter of strungles, is good, beciuse it mitigates the complaint, and renders the horse not liable to any future attack; but the practice has never gained ground: when strangles occurs in the stable, and now and then in the field, it proves a severe disease, and shows itself under the appearance of a cold, with cough, sore throat, and sweiling of the glands under the jaw, or behind and under the ears. Sime times there is not much external swelling, and the tumours nreak inwardly, and nature effects a cure; at others they break outwardly, and the disease rums off that way, and some times the swellings disperse either by nature or art, which breeders think unfurourable, as they suppose it renders the animal liable to a future attack; but many so treated, pass the remainder of their lives withont more affection.

23. The treatment of Strangles. When the swelling "ingers, and neither comes forward or recedes, poultices are pretcrable to fomentations, which, by leaving the horse wet, promote evapora tion and produce cold. Peal recommends blistering the part, as t:3 best means of promoting suppuration. 'The horse should be kept very cool, and bran mashes with warm witer should be his principal support, unless the complaint lasts long, and produses nuch weakness, when malt mishes should be substituted; bieedirg is only advisuble when the early symptoms are violent, as heaving at the flanks, extreme soreness of throat, with much swelling around it, and considerable congh, in which case bleeding, and fever medi eines are proper.

24. Vives, or ives, is supposed to he a relic of the latter com flint, and it does appear now and then that after une strangles, tho parotid or vive glands do remain enlarged $[24$,$] which nccasions the$ disease in question, resolution may be attempted by mercurial fricions, suppuration should be avoided, otherwise the gland may wo destroyed

25. Miseases of the mouth, lampass. All horses, but particuiariy

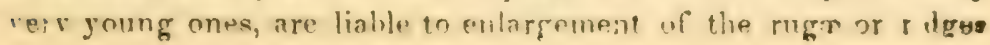


of the falate, dependent not on any local disease confined to tne part itself, but oceasionally by an affection of the whole passage o the me uth, threat, and stomach. It is usual to attend to the par only, which is sacrificed or bumt, to little purpose, when a mild dose of physic, or gentle alteratives, wonld prove nore certain expedi. ents; to which nay be added rubbing the part with bay salt, if with vinegar.

26. Bridle sores. When the bit in colt breaking, or in hard pulling horses, has hurt the bars, care is requisite to prevent the bone becoming carious. Touch daily with xgyptiacum, and cover the bit with leather, unless total rest can be allowed.

27. The teeth, which present themselves on the lower parts of the jaws, are the incisive and canine. The two front incisives are properly called nippers or gatherers. The two next adjoining separators or middle teeth, and the outer, the corners; but it would be more indefinite to say the first, second, and third inci. sives, beginning at the corner. Tusks or tushes occupy a part of the intermediate sprace between the incisive and grinding tecth.'The teeth, as criteria of age, will be seen by reference to Mason, (page 72.)

The teeth of the horse are the hardest and most compract bones of the body. There are usually forty of them in the horse, and there are thirty-six in the mare; in which latter, the tushes are usually wanting. In anatomical language, they are divided into incisores, cuspidati, and molares, or according to the language of farriers and tursemen, into twelve nippers, four tushes, and twenty. four grinders, which numbers are equally divided between the two jaws. The teeth are received into indentations or sockets between the bony plates of the jaw, called alveoli, by cone-like roots. Tho hodies of the teeth are principally composed of two substances, nne of the nature of common bone, giving bulk and form, and one sf extreme hardness, placed in man and carnivorous animals wholly without the teeth to give strength and durability: but the horse and sther granivrox, the latter particularly, is placed in the grinders, in perpendicular plates, withın the body of the teeth; by which contrivance, a rough grinding surface is kept up; for the mero mony parts wearing faster than the lamella of enamel, it follows .nat ridges remain to triturate the vegetable matter thint passes be ween the teeth.

There are two sets of teeth, a temporaneons or milk sct, and a serminent or udult sut, ir. which wise provision, man and most 
Di ites participate. The mik set are some of them, as the molurs, apyarent at birth: there being usually six grinders in each jaw, thi e on each side in the new born foal, and which number of this set s never increased. The nippers begin to appear soon atter birth, and follow a regular order of succession, until the animal is three ar four months old; at which time he begins to require suppore from herbage as well as milk. The temporanenus set re. nove s,arlually one after another; had they all been displaced at fic simn rime, or even had several of them fullen out together, the minal most have sutiered great inconvenience, and perhaps have seen starvod. This removal, which commences at the age of two fears and a half, and is completed between the fourth and filth jear, is effecend by the action of the absorbents on their fangs, ard appears to bw occasioned by the stimulus of the pressure received from the grom ing teeth under them. For although these two sets a) pear with an interval of some years between them; yet the rud. nients of both are formed at nearly the same period, and both sets mity be thus sren in a dissected jaw. Regulited by the stimulus of necessity, as soon as the temporaneous set falls out, the perma. nent appears: and that such appearance follows the necessity, is evident; for a premature or accidental removal of the colts' tecth is soon followed by the appearance of the others. Dealers and breeders aware of this, draw the milk teeth to make their colts appear as horses. It was necessary there should be two sets of teeth, for as they grow slowly in proportion to the jaws, so hiu there been but one only, the disproportion of growth between tho teeth and jaws must have separated tliern.

The forms of the teeth vary more than their structure. The inci sive or nippers are round, which is favourable for the pressure they undergo; the upper more so than the lower. On the upper surface a hollow is seen in the young touth, which, not extending through the whole substance, naturally wears out with the wear of the touh ; and as a considerable degree of regularity occurs in this wearing i ayy in all horses, it has gradually settled into the general criterion If age. The nippers are not all of them exactly similar; the corner eeth differ most in being exactly triangular, and in having an nterval wall or side, which does not become level with the rest unui ong after the others. The cusp,idate tusks or tushes are permanent. appearing at about five years, or rather earlier; those in the front faw are usually nearer the nippers than those below. Each pro. sents a slirht curve, which fullows the direction of all the camine or puguatory teeth of other mammalia. 'The jointed extremity wears awity by age, leaving merely a buttened funcess, which may 
serve as a guide to the age, when the horse onspoweed $t_{1}$. on bishoped, as it is called, from a man of that nane rne was peculiorly dexterous in imitating on old teeth the disciucure cevity of youth The molar or grinding teeth are stronger in the apper than in the iower jaw ; which was necessary, as they torm the fixed point in the process of grinding. 'The upper surtace presents nearly a long square, indented from the alteration of the enamel with the bony portions; and as the interior or upper ceeth hang over the posterior, so tho ridges of the une set are received into the depressions of the other.

Wear of the teeth. The teeth, in a state of nature, would probably present a surface opposed to each other for mastication to the latest period of the most practised life; but the removal of the animal rrom moist food to that which is hard and dry, must occasion an unnatural wear in those organs; and hence, although the teeth of the horse, even in a domesticated state, are not subject to the caries of the human; yet the grinders are liable to become thus injured by continued exertion. In the yourg or adult horse, the upper and under grinders do not meet each other horizontally; on the con. trary, they have naturally an inclination obliquely inwards, and those of the upper jaw present small spaces between each other, while those of the lower are more continuous : by which means as the food, but particularly as interrupted portions, as grain, hecome ground, they fall into the mouth to be replaced under the grinding surfuce, if necessary, by the joint action of the tongue and musel's or the chetk. This arrangement becomes in a great measure frus. trated in old horses, by t!e superior wear of the inner surfice of the upper grinders, as well as by the general misapplication of the surfaces of both upper and under teeth, by constant attrition when worn down to the gums nearly. The unfortunate animal feels sensible of this, and endeavours to remedy it hy throwing the wear on the outer edge, by an inclination of the lower jaw and of the head in general; and which is so particular in its appearance as to engage the attention of the by-standers. This defect may be in a considerable degree remedied by casting the animal, and having opened and wedged the mouth so as to keep it so, with a well tem. pered concave file to remove the inequality as much as may be. When the defect is considerable, and the horse is mild and quict, it is better to file the inequalities every day, which will gradually but peffertially wear them down. It however happens, that the inclina. ison tlms to wear is commonly resumed, and gradually the same Inss of nutriment takes place; in which case, soft moist food, as carrus, masnes, solling, or grazing, must be substituted fo, harder 
wabutances, and if corn be actually necessary, let it be brutsed II henever an old horse betrays symptoms of want of condition. . weakness and emaciation, that neither his mode of feeding nor hia ratio of work will account for, and partıcularly if whole grains should be found in his dung, his teeth should be examined carefully. This undue wearing of the teeth uccasions another evil often, which is ulceration of the cheeks, by reason of the projecting ragged surface of the uneven teeth, which can only be remedied by the removal of such portions. These projecting portions are called by farriers, wolve's teeth.

\section{Diseases of the Neck.}

28. Fistulous withers are brought on usually by pressure from 2 sarddle with too low or narrow a tree, and what has been said both with regard to prevention and cure on the subject of poll-evil, applies inere also. (116.)

29. Sore throat is common to horses in colds, in influenzas, and in strangles. $(13,22$.$) In every case, the horse finds great difficulty$ in reaching every thing that stretches his neck duwnwards or up. wards, his water therefore should be held to him, and his hay should be pulled for him; onission of these services greatly aggravates the sufferings of horses labouring under sore throat.

30. Swelled Neck. A very serious swelling sometmes follows on bleeding with a rusty or poisoned lancet, or fleam, and some. times from causes not apparent. (126.)

\section{The Chest.}

31. Inflammation of the lungs, is a disease to which the horse is peculiarly liable, as we might a prion suspect, from the vast dimensions of his circulatory system, and the vast alteration from a natural state to which we subject him, and thereby increase his p'jlmonary circulation.

3:. The causes are these deviations remete:y, hut the imm:ec ars attack is generally brought on by sudden cold, acting on a heated surface, and thus it is that knackers, and collar makers in frosty weather expect a glut of horses that die from this disease. Hard riding is a very common cause, and high feeding also; it often commences slowly; a hard dry cough has been slightly nuticsa, bu. 
occasıuning no alurm for two or three days; gradually, however the cough appears to give the horse pain; he occasionally shivers and his ears and feet feel colder than the rest of his body, he heaves at the flanks, and the lining of his wose is inflamed, and his eyelias also; the appetite now becomes aflected and although there is not much apparent pain, except when the horse coughs; yet there is much anxiety of countenance present. The pulse is usually small, but quick; if in this state the horse be taken out and exercised quickly, it is almost always futal to him; it likewise happens that this complaint is sometimes mistaken for distemper, and from a fear of profuse bleeding, the only remedy that is to be depended on, is omited, and the horse is lost. At the veterinary college, in these eases, a small dose of aloes is given every six hours, and after being bled and rowelled, the horse is turned out in the open air; and it is affirmed that many recover from this treatment. Certain it is, that the stable in which a horse is placed in this disease can hardly be tuo cool ; but when entirely turned out, his fect and legs cannot conveniently be hand-rubbed, or bandaged up to promote rircula. liun; neither can we blister a horse when turned out, so cunveniently; and on blistering we depend as the second source of cure

33. The treatment is to be commenced by attempts at lessening the action of the arterial system by early and large bleedings, as seven or eight quarts from a large horse, and which should be re. peated in five or six hours if he be not relieved in his breathing. Immediately rub into the brisket, on the chest, and behind the fore legs, the blister. ( Vet. Pha. 138, No. 1.) Give half a dose of physic, and assist it by mashes and warm water, which if not readily tiken, horn down. Back-rake also, and throw up the laxative clyster. (Vet. Pha. 143.) Avoid all exercise, clothe moderately, allow a free circulation of cool air through the stable, and rub the legs frequently, and when not under this process, keep them bandaged up to the knees, with hay bands, or woollen cloths. The terminations of this complaint are various. It is not uncommon for the hurse to appear better, to eat and to drink, and to excite every hope of a perfect recovery; but on some sudden exertion he falls down and expires. On exanination after death, it is found that effusion of a harge quantity of serous fluid has taken place in the chest.

31 Thick roind is another termination of pnenmonia l.y loaving the bronchial passages charged with coagulated blood. Moderate exeresse and soiling in the stible with mild mercurial physic, form the hest modes of treatment, but it frequently happens that the congen resists all these and termibites in broken wind. 
35. Rouring is also a termination of pneumonia, in which rase the lungs are not affected, but congealed blood, under the name st coidgulable lymph, remains in the trachea or windpipe, and obstructs the free passagre of the air ; by means of which the roaring noise is made. It is in vin to expect a cure: blistering the throat some. times slightly relieves it.

36. Chronic cough is also a termination of pneumonia, and ap pears dependent on a peculiar irritability the disease leaves in tho bronchial passages, which are tound afterwards incapable of bearing any sudien alteration of temperature; thus horses with this kind of cough are excited to it as soon as the stable door opens, and by every excrtion, by drinking, by eating, and in fact by any thing that alters the situation of the body, or is new to the part. But besides pneumonia or inflammation of the lungs producing it, it is often brought on likewise by gross feeding, which, weakening the stomach, inpoverishes the blood, and thus injures the lungs which are teil by that blood. Worms also by the same means are a cause wi chronic cough. It is thus that we expect to derive benefit by mediums acting on the stomach. Green food is often found useful, but particularly carrots. The hay should be excellent in quality and small in quantity; and it will be found that soiling in the stable, but particularly a course of carrots, forms a better plan of treatment than tuming out. If worms be suspected, treat as under that head. [57.] Formula of chronic cough balls are seen in tho Vet. Pharm. [148.]

37. Broken wind is also sometimes hought on by pneumonia, and sometimes by oceult causes. It is often occasioned by over exertion after full meals, in which the lungs become permanently weakened, perhaps ruptured in their air cells. Inexperienced per. sons find some difficulty in detecting broken wind from other chest aflections, as chronic cough, occasional colds, \&c. \&c.

38. Criteria of broken wind. The cough which accompanics oroken wind, is a short, deep, hollow, grunting noise, and the short grunting expiration is peculiarly exeited by turning a horse quickly :ound, striking him smartly with a stick at the same time, which: fiten produces a deep sonnd without the cough; and which s sc signilicant as never to be mistalien when once heard and attended to. but the principal peculiarity arises from the beating of the finks, which operite rither by three efforts than two as usual in the first, the air is drawn in, in the usual manner, and the fanks fill up as in common; but in tho next, the falirg of the tantis to 
by in means $n$ r.ural, for it is not done by a gradual sinking of tho sities, but it takes place at once, with a kind of a jerk, as thougn the norse were sighing; and then a third effort takes place by a nore slow drawing up of the muscles of the belly and flanks, ta press out the remaining air. Broken wind destroys the fecundity of the mare, and hence argues permanent alteration of structure ; it is also always incurable, but horses may be rendered very useful that have it, by feeding them very nutritiously, but with food much condensed in bulk. Little hay should be allowed, and that little should be wet; water in any other way should be given but spa. ringly, for which they are however very greedy; from which circum. stance, as well as that they are peculiarly flatulent, we learn, that the vitiation of the lungs is either aggrarated by the deranged state of the digestive organs; or, which is more probable, that the diges. tive powers become weakened from the state of the lungs.

39. Diseases of the belly. Inflamed stomach seldom attacks the horse as an idiopathic affection, but it is not unfrequent for the stomach to become inflamed by mineral poison as well as rendered inert by vegetable ones.

40. Mineral poisons inflame the stamach acutely, and produce excessive distress, and cold sweats; the animal lies down, rolls, gets up again, looks short round to his ribs, stamps with his fore feet, and his pulse beats quick and short. When arsenic or corro. sive sublimate have oceasioned the malady, a viscid mucus distils from the nose and mouth, and the breath is foetid. When copper in the form of vitriolic salts, or verdigris has been given, to the foregoing symptoms are usually added inetfectual attempts to vounit. Immediately after the poison is discovered, pour down two ounces of sulphuretted potash, in a quart of water; or in the absence of that, an ounce of common potash in the same quantity of water: or, when no better substitute is at hand, even strong soap suds are advisable. Mineral poisons have also another mode of acting. and are often received into the constitution, neither by design to do nischief, nor by mistake, but are purposely given as remedies.In this way, bota mercury and arsenic are frequently given for worms, glanders, farcy, \&c. in daily doses, which, when even of considerable magnitude, occasion for many days no inconvenience • 1. at cnce, however, the constitution becomes fully saturated with the poison, and although before diffused throughout the blood, it now appears to return and act on the stomach to the great surprise of the owner. In these cases the symptoms are not usually so relent as in the former instance, but they are equally fatal. 
minilar treatment with the one alrearly prescribed is necessary, ano as suon as the first symptoms are abated, give laxatives. In all urese cases large quantities of linseed tea should be horned fown. the back should be raked and clysters thrown up, blood shouid also oe taken away plentifully. As a preventive to this latter mode of nossoning, whenever mineral agents are used, it is prudent evay five or six days to stop a while, and then recommence, by which the constitution will part with the previous quantity.

41. Sulivation is also another mode of poisoning, and though not equally injurious to the stomach, it often proves distressing, and sometimes fatal. Whenever, therefore, mercurials are given, care. filly watch the gums, and as soon as they look red, and the horso quids his hay, give him a mild purge instead of his mercurial.

42. Vegetable poisons also inflame the stonach, but by no means In an equal degree with the mineral poisons, nor is it supposed that It is the inflammation they raise that proves destructive, but by an eflect communicated through the stomach to the nervous system. Digitalis purpurea or foxglove, taxus baccata or yew, ananthe crocata or water dropwort, cicuta virosa or water hemlock, phellandrium aquaticum or water parsley, conium maculatum or comnon hemlock, are all poisonous in a high degree to horses, and may be taken accidentally by the animal as food, or given injudiciously as medicine. Nicotiana, or tobacco, and the vegetable acid of vinegar, are also poisonous, and are sometimes productive of injurious con. sequences by over-doses, when intended as remedies. It is little known that a pint of strong vinegar has destroyed a horse. As we cannot remove the matters from the stomach, we must endeavour to neutralize their effects, by acids and demulcents, as oil, butter, \&c. Thus, when narcotics have been taken, a drachm of sul. phuric: acid or oil of vitriol may he given in a quart of ale; or six vunces of vinegar, with six of gin, and a quart of ale, may be trioo.

43. Stnmach staggers. This peculiar complaint, which is even vet but little understond, appears dependent on a particular stato af stomach, acting on particular foods; and not on what is taken in, acting on the stomach, as was supposed by Coleman, Whito. and sthers. From later communications of White, ho also now ap jears to cousider it as origrinating in "a particular state of stomach." Blaine appears always to have characterized it as "a specific inflam -nation of the stomach." It appears among horses of every descrip. ton, and 4 grass as well as in the stable, and there is reason to Luiuk it epolfentic, is it is prevalent in somo seasons moro tha* 
in uthers. It may, perhaps, he regarded now anu then as enceme diso: under which circumstance it appears confined to low wat situations, where long marshy grass is abundant, and where noxious aquatic plants mix themselves with the grasses. When it accurs at grass, the horse is found stupidly dull, or asleep with his head itsting against something. This has occasioned the disease to ne called the sleepy staggers, and it has often been confounded with $\boldsymbol{i}$ ie phrenitis or inflummation of the brain. (8.) In the stable the hrrse dozes, and rests his head in the manger; he then walks up and falls to eating, which he continues to do until the distention of the stomach becomes enormous; for the peculiarity of the complaint consists in the total stop that is put to digestion, and the ineasy feel of the distension consequent to such indigestion appears to deceive the horse, arui by a morbid excitement to force him to take in more. In this way he continues eating until the distention prevents the return of the blood from the head, and the animal dies apoplectic, or his stomach bursts with over-distention. More fre. quently, however, the stomach becones flabby, inert, and paralytic, and after death presents marls of inflammation towards the pylorus.

44. The treatment. When recovery has taken place, it has wccurred only when the disease has been very mild, and has bcen assisted by stimulating the stomach into action by purgatives, at once active and invigorating, as an ounce of aloes dissolved in a half pint of gin. When a horse of extreme value is attacked, croton jil might he tried to the amount of $: 21$ or 25 drops in two ounces of tincture of aloes. Warm water in small quantities, or mixed with cominion salt should be frequently passed down. Remove every eatable, rake, clyster, and hand rub; and if the determination to the head be extreme, bleed-otherwise avoid it.

45. Inflammation of the bowels, enteritis, or red colic, is a very distinct disease from the gripes, gullion, or fret, with which it is. however, very apt to be confinuded to the destruction of inany horses. The peritoneal inflinmiation of the bowels, the one hero treated on, is an affection of their outer covering.

46. The causes are various. It is not unfrequently brought on by a sudden translation of cold after great heats, as swimming during nunting, or from the removal of a horse from grass at once into neated stables, clothing and hard food; neglected gripes, or long continued costiveness, excessive riding, and the inmediate drinking of cold water, have brought it on. It begins by restlessness, loss of apuetite, some uneasiness; the mouth is loot and dry, i ue innes 
maribranes of the moith, nose, and eyelids are nften redider than natural As the disease advances, the pain, before not vinlent now increases so at to force the horse to lie down and rise agaun frequently; and when very violent, he kicks at his belly, or looks round at his sides, pawing his litter very frequently. The pulse is usually small, quick, or hard; sometimes it is more full and smalk but always hard. Breathing is quickened, the extremities are alternately hot and cold, but contiine longer cold than hot; and the animal is costive; sometimes pain may force away a few har. Hened balls of freces, but the principal contents are retained. Blaine has given the distinguishing features between this disease and colic, under which head we have stated them.

4i. The treatment must be active and immediate, or a futal termination m:y be expected. Begin by abstracting a considerable quantity of blood; from a large horse to the amount of 7 or 8 quarts; proceed to back-rake, throw up a large clyster of warm gruel. Give by the mouth, a pint of castor oil, mixed by the means of the yelk of two eggs, with half a pint of broth or gruel. Or, give olive ois instead, following it up in half an hour hy a gruel drench in which six ounces of Epsom salts have been dissolved. A sheep skin, im. unediately as it is removed from the sheep, may be applied to the be $j$. which should first he well rubbed with the stronger liquia Llister. (Vet. Pha. 1.41.) In four hours repeat the bleeding, if considerable improvement have not taken place, and if the bowels be not un!oaded, give more oil, and clyster frequently, having first back-raked. Avoid exercise; first hand-rub, and afterwards wrap up the extremities to tile knees. As a clear passage for the dung is found, the symptoms mitigate, and the animal slowly recovers, but he must be fed at first very sparingly.

48. Inflammation of the inner surface of the intestines is, in some measure, different from the former, which is rather an affection of their outer covering; whereas this is usually confined to their villous eurface, and may be brought on by superpurgation from over strong physic, or from mineral acids being taken in, particularly mercu. rials, which often exert more influence on the bowels than on the stomach. It differs from the former in the symptons being generally accompanied with purging; neither is there usually so much pain or uneasiness present, nor such cold extremities, but where from the volence of the inflammation these symptoms are presters sleeding to the amount of three or four quarts is a proper pre 'minary, but can hardly be with propriety continued. 'I'he sano bunulants to the outside of the brily should be used as in tno last 
Hiscase but hnre clothing is recommended as well ab warmth in the stable, as ilso hand-rubbing to keep up the circulation of the cxtremities. Cive astringent drink (Vet. Pha. 131, No. 1 or 2., with a pint of boiled starch every three hours, and give the same by clyster with two quarts of pot liquor, or tripe liquor, free from salt

49. Dysenteric inflammation of the horse's bowels is happily not very common, but now and then appears, and is then called by furriers, molten grease; they mistaking the morbid secretion from the intestines, for the fat of the body melted down and passing off thus. But dysentery is a peculiar inflammation of the mucous sur fice of the intestines, not contagious as in the human, nor epidemic, nor exhibiting a putrid tendency; but is peculiarly confined to a diseased increase in the mucous secretions, yet very different from simple diarrhea, which is a mere increase in the peristaltic motion, by which the common aliments are quickly passed through the intestines, and ejected in a liquid form by an increase in their watery secretion. Whereas in the dysentery of the horse, the mucous of the intestines separates from them in large quantities; and comes away with the dung surrounding it; but when it does not pass in this way it appears in membranous films like sodden leather, or in stringy evacuations, like morsels of fut floating in water; sometimes there is a little bloody appearance. The usual symptoms of fever ure always present, but not in a very high degree.

50. The cunses are cold, over-riding, and not unfrequently acrid substances within the intestines: change of food has necar sioned it.

51. The treatment. In the first stages beed considerably, and give as the first internal remedy six ounces of castor oil, which wall anend the fuecal evacuations considerably, afterwards administer the rollowing; powodered ipecacuanha, "d drachn; ponodered opium, a scruple; liquid arrouroot, eight ounces. Should this not check she evacuation, and should it continue as mucous as at rirst, again give castor oil, and then follow it up by either of the drinks directed int the cure of scouring or looseness. (Vet. Pha. 131.)

52. Diarrhoa or looseness. This complaint originates in an in creased peristaltic motion of the intestines, with an increase of their watery secretion, and is distinguished from dysentery by thr pusging veing complete from the first, and seldom occasioning muct covor or disturuance in the general health, unless exceedsngly . . 
fent. The stools are merely solutions of the aliment, and unnuxed with membrarous films as in dysentery or molten grease. It some. cimes succeeds to over strong physic, at others the food enters into new combinations, and forms a purge. Some horses have their bowels constitutionally weak, as lank-sided sinall carcassed ones, where the mechanical pressure hurries the contents forwards. Sali mashes and sea water will purge horses violently sometimes. It is always proper to encourage warmth in the skin, and to change the food. The change should be generally from one more moist tu one less so, as beans, \&c. Barley will sometimes stop looseness : malt usually increases it. Buckwheat is often a check to habitual diar. rhœa. Efficacious astringents will be found in the (Vet. Pha. 131) Repeat either of these night and morning. Give but little water and that little warm.

53. Colic, flutulent or spasmodic, called also gripes, fret, or gul. lion, is an important, because a frequent, disease, and because it frequently destroys either quickly by its irritation, or by its de. generating into the red or inflammatory colic, when improperly treated or long continued. It is usually very sudden in its attack.

54. The causes of colic are not always apparent. It is sometimes occasioned by intestinal stones, which accumulate to a great size, remaining for years in the cells of the colon, until some accidental displacement occasions an interruption to the peristaltic motion. Cold in its various forms is a parent of colic; but under the form of cold water given when a horse is hot, it is most common. In some horses it is so frequent as to become a constitusional ap. pendage.

55. The distinguishing marks between colic and inflammation of the bowels are gained, according to Blaine, by attending to the following circumstances. In gripes the horse has violent fits of pain, but they remit, and he has intervals of ease. The pain in red colic is more uniform and less violent. In gripes the pulse is, is general, natural; in red colic it is quicker than natural, and com. a. only small. The extremities are not usually cold in gripes; in red colır they usually are. In gripes, the horse attempts to roll on his bark, w'ich in red colic he seldom does. T'here are no marks of fever with gripes, as red eyelids, inflamed nostrils, \&c. but in red culic they are always present. When the complaint has con. timed some hours it is always proper to bieed to prevent its unding in infammation: bleeding in the mouth is quite useless. Baed rade, and throw up clystess of worm water. one after anower w 
fast as possilhe, which rften overcomes the irritation. La Fusso recommends a curious remedy, but as it can always be obtained, and has the sanction of long experience, it may be tried. An onion is pounded and mixed up with some powdered savin; in default of wini:l, use powdered ginger. . This is to be introduced up the rec tum as high as possible, and the horse is to be then moved briskly about. An onion put up the fundament whole, has long been a domestic remedy. The following is recommended by Blaine : spirit of vitriolic ether, an ounce; powdered opium, one drachm; oil of turpentine, thre ounces; warm ale, a pint. He also recommends the following more simple remedy as always at hand: the expressed juice of two or three large onions; common gin, common oil, of each half a pirt; mix and give. White recommends a pint of brandy, or of gin, with water, as an excellent carminative. Clark, who has expressly written on gripes, extols the virtues of a mixture thus made; which, if it have the qualities he attributes to it, and which there is no reason to doubt, no agriculturalist, coach, or post master should be without it: pimento berry, called also a ispice, ground rine, haif a pound; spirits of wine, and of water, $o_{j}^{-}$each a pint and $a$ half; infuse these together, and keep it for use. Give a quarter of a pint every hour until full relief is obtained; hand-rubbing, wisping, or fomenting the bowels with hot water at the time.

56. Inflammation of the intestines from wounds in the belly fre. quently occurs; and these injuries may happen in leaping over hedges or pale gates, or may be inflict.d by the horn of a cow. Sometimes the strong tendinous coverng of the belly is ruptured. while the skin remains entire: the gut then protrudes and forces out the skin into a tumour. The first thing to be done is to put the gut back, taking care at the same time, otherwise extensive infiammation follows, to remove any dirt or other matter that may be sticking to it ; for which purpose, should it be found necessary, it may be washed with warm water, but with nothing stronger. If the gut cannot be returned, from its being full of air, and the opening in the belly be too small to put it back again, such opening may be carefully enlarged to the necessary size. But if the animal cun be thrown upon his back conveniently, a great deal may be done trat cannot otherwise be accomplished; after the gut is returned, the skin only should be stitched up, and a cushion of several folds if old linen and tow being placed on the wound, it should be kept in its situation by means of a wide bandage rolled round the body, anci carefully secured. The animal should then be copiously bled, and have his bowers emptied by clysters. The only food he should vo allowed is grass, or bran mashos and that only in moderase 
4 in.ity. When the distention of the intestines wholly prevents their return, it would be prudent to puncture them with a very ine instrument, and thus to suffer the air to escape, which, although subjecting the horse to the risk of inflammation, is better than the certainty of death by having the intestines protruded.

57. Worms of horses are found, as bots, in the stomach, but which as they attach themselves to the hard insensible part of that grgan seldom do harm. Clark fancifully supposes they do good. and devises means for furnishing them when not in existence. The bot is the larva of the ostrus equi, a fly which deposits its eggs on parts of the horse himself, from whence they pass into the stomach by heing licked off. Certain it is they get there, are hatched, and there remain hanging to the coats of it by two tentaculæ, receiving the juices of the masticated food as nutriment. After a considerable time they make their way out by the anus, drop on the ground, and are first transformed into the chrysalids, and afterwards into parent flies. When bots fix themselves on the sensible portion of the stomach, they may do harm; but no medicine that we knc $w$ of will destroy them. The teres or large round worm sometimes occasions mischief, when it exists in great numbers, such as a starting coat, binding of the hide, irregular appetite, and clammy mouth. The best remedy is the spigelia marylandica or Indian pink, in daily doses of half an ounce. Tania are not common in the horse: now ant then they exist, and are best combatted by weekly doses of oil of turpentine, three ounces at a time, mixed by ineans of the yelk. of an egg with half a pint of ale. The ascaris or thread worms, are best removed by mercurial purgatives. The existence of worins may he known hy the appearance of a yellow matter under the tail, and by the disprosition the horse has to rub his fundament. Blaine recummends the following vermifuge: powdered arienic, eight grains; pewter or tin finely scraped; Venice turpentine, half an uunce; make into a ball and give every morning. He also recom. mends salt to be given daily with the food, which agrees with orer own experience as one of the best vermifuges known. It is a fact acknowledged by the residents along the sea-coast, that horseg troulled with worms will often voluntarily drink largely of se's water, and thus cure themselves.

58. The diseases of the liver are acute infammation or hepatit.18, sud chronic inflammation or yellones. Hepatitis is the acute inflim. mation of this organ, which like the lungs, stomach, and intesures, ray spontaneously take on the affection. The symptoms are nos gulike those which attend red colic, but with less violence. It $n$ 
se not however arrested, the termination will be equally fital. Ahout the third day the whites of the eyes turn yellow and tho mnuth also. Bleeding, blistering, and purgatives form the inethod of cure as practised in red colic.

59. Chronic inflammation or yellows. The liver of horses is less complex than that of any other animals, and is therefore not very liable to disease; indeed some authors affirm tat the horse is never atfected with jaundice, but that the yellowness of skin is a mere stomach affection: this is, however, erroneous, anc not only does the liver become hardened and thickener occasionally, but the bile becomes diseased, and is thrown out in that state by the blood over the body. If fever be present, bleed, but if the symptoms present no token of active inflammation, give each night, ten grains of calomel, and every ten days, work it off with a mild dose of physic. It is, however, necessary to remark; that it is not every yellowness of the skin that besokens either an acute or chronic inflammation of the liver. It is the property of every serious inflammation of any of the important organs of the chest and belly, to communicate a portion of the evil to the other organs immediately in conjunction with the liver: thus an affection of the stomich or intestines, of the uflimnatory kind, very often occasions redness of the membranes of the nose, eyelids, \&c. \&c.

60. Diserses of the urinary urgans. Inflammation of the kidneys. is an idiopathic affection, not one of frequent occurrence; but as nrought on by injuries, such as over-riding, heavy loads, or violent diuretics, it is not unfrequent: when idiopathic, it may be the effect either of cold, heating food, or a translation of some other infiammation, in which cases it comes on suddenly, and assumes the same febrile appearances that other intestine inflammations produce; but there is not often great apparent pain, but a frequent inclination to stale, the quantity made being so small as almost to amount to a atoppage of urine, which is less or more complete as one or both kidneys are affected. What little urine is made, is also at first verg thick, and then bloody. When the disease is the effect of external injury, the urine is not so scanty, but is more bloody; and this symptom precedes the other. There is usually much pain and stiffness about the loins, and we learn from Blaine, that a swelling and a paralytic affection of the land leg of ihe side of the affected kidney, sometimes is a feature in the complaint. To distingush this inflarnmation from that of the neck or body of the bladder, wirit which it may be confounded, the same author recommends shat tise hand be passed up the rectum, when if the adfection belossg 
In the kidneys. the hladder, whether full or empty, will not be ho:tes than usual; but the contrary occurs. when any pa:t of the bladde is the seat of the disease.

61. The treatment must be active, and in most respects similar to what has been iecommended for red colic, as regards bleeding emptying the bowels, and endeavouring to lessen the arterial actior. by bleeding; but here we must carefully abstain from irritating the kidneys by diuretics internally, or blisters externally. A newly srtipped sheep skin placed over the loins, or active fomentations of het water, are the only sources of counter irritation that are proper neither should dilsting liquors be pressed, on account of the dis textion they occasion, but no evil can arise from clystering.

62. Infiammation of the bladder. When the body of the bladder necomes inflamed, there is frequent staling from the very first attack; but when the neck of the bladder is the seat of the evil, tho squeezing out of a few drops will only take place when the bladder has become filled, which may be known by passing the hand up the rectum. The treatment will be alike in both cases, and is the same as recommended for the last affection. It must be evident, that warm, mild, and frequent clystering, must here be peculiarly advisable.

63. Stranguary or suppression of urine; incontinence of urine; bloody urine. Stranguary may arise from an injury done to the kidneys, or to the bladder, by strains, or by the absorption of irritating matters. In these cases, bleed if there be fever, and if not merely give the horse absolute rest; mash him, give gruel, and warm his water for drink. Bloody urine should be treated in the sane way; some horses have such a naîural or acquired weakness of the kidneys, as to stale blood with their urine on every occasion of over exertion: the nieans frequently used for relief, are sucn as aggravate the complaint, and indeed are often the occasion or it, which are diuretics. Strong diuretics injure horses more than strong physic, and benefit them less than any other of the popular means made use of. In retentions of urine, but particularly in cases of bloody urine, they are absolutely improper.

64. Diabetes, profuse staling, or pissing evil. This disease 4 more frequently forced on the horse, by iong continued diuretics, or from a similar effect. bronght on by kiln-dried oats, mow.burnt hay, or some green vegretables, than acquised from constitution: indisposition. 'The horse first stales often, and profisely, he ther? mocouses wesk and fail t. and sweats on any exertion. $10^{\circ}$ it be at all 
onstitutional, his hide is bound from the beginning, and nis urine vill have a sweet taste; but if his appetite were good and his cos: leek, bright, and elastic, when the urine was first observed to be amoderate, the evil arises from some fault in the feeding, clothing, uxercise, or other management of the horse. Examine into theso natters, particularly into the food, and next the water. Inquiro whether diuretics have been given, under an erroneous supposition of increasing the condition, and alter what may be amiss. If this do not remove the complaint, try the following, after Blaine's direc. tions: liver of sulphur, two drachms; uva ursi, four drachms; oak bark, one ounce; catechu, half in ounce; alum, half a drachm; givo as a daily drink in a pint of water.

65. Stone or gravel. Calculous concretions are not uncommon in the large intestines of horses, where they grow sometimes to an enormous size, lodged in one of the cells usually, and where they occasion but little inconvenience, except a displacement occurs, when serious evils, as colic, inflammation, or total stoppage, follow. In the bladder, stone is very seldom found; and there is reason to believe, that though gravel is a common term in the farrier's list, that it seldom if ever occurs; injuries of the kidneys and bladder being usually mistaken for it.

\section{Diseases of the Slin.}

66. Mange is a contagious diseas , not uncommon among low ored and badly kept horses, but which is seldom generated in those properly managed. When it is the effect of impoverished hlood, a different course of feeding must be substituted, not heating, but cooling, though generous; as carrots, speared oats, malt mashes, stable soiling, \&c. When it arises in full fed horses, bleed twice, lower the feeding, substituting for corn, soiling, carrots, or bran mashes. Give a nightly alterative, (Vet. Pharm. 129, No. 1 or 2) and dress with either of the mange dressings. (Vet. Pharm. 171.) After a cure has been effected, carefully clean all the apartmente with soap and water.

67. Surfeit will now and then degenerate into mange, but more generally it is brought on by a fulness of habit, acted on by sudden transitions from cold to heat, or heat to cold: it is likewise not unfre fuently the consequence of over-futigue. If it show a disposition o spread, and the slin become sealy and scurfy, treat as undes mange, otherwise treat as directed under want of condition. (4)

68. Warbles are of the nature of surfeit in many instances, in others thev are lrought on by the pressure of the sadale, which 
sitier supprirate and burst, or become indolent and remain under the name of silfasts. In the early state, bathe them with cham ber-ley or vinegar: It they proceed to suppuration, refrain, and when they neither go bick or come forward, fut on a pitch plaster, and if this do not promote suppuration, let the sitfast bo dissected out.

69. Warts are common to old horses, and had better be put up with unless they be situated in some very inconvenient or con spicuous part. In this case tie a thread tightly around the root. and the wart will drop off, or it may be cut off. Blaine recom. mends the following, when warts are too numerous to be sc removed: crude sal ammoniac, two drachms; poudered savin, one ounce; lard, an ounce and a half.

70. Hide bound is a state of the skin, where the interstitial natter between char and the fleshy pannicle is not in a state to allow of its pliancy and elasticity. The binding down of the hide thus closely, acts on the hair, which it protrur!es in a contrary direction to its naturally inclined position; and thus a staring ceat usualiy accompanies hide bindng. In considering the subject of condition (4) we have seen trat it 4 not a disease of itself, but is in every instance a symptom only.

\section{Glaruters and Farcy.}

71. The glanders is the npprobrium medicorum, for hitherto no attompts have succeeded in the cure of more than a few cases. By some peculiar anomaly in the constiution of the horse, although conclusive proot's are not wanting chat this and farcy are modi. fications of one disease, and can each generate the other; yet the one is incurable, while the other is cured every day. When glan. ders has been cured, the time and labour necessary to accomplish the end has swallowed up the value of the horse; and has also, in many supposed instances of cure, left the animal liable to fururo atticlis which have occurred. 'The experiments on glanders, pu sucd at the veterinary college and by White of Exeter, have thrown great light on the disease itself, its causes, connexions, and consequences; but have done little more. From these we are led to conclude, that glanders will produce farcy, and that farcy cap uro. fuce glanders. 'That glanders is nighly infectious, and that e.sen intection may be received by the stomach, or by the skin when it as at all abiaded or sore: and it is also probable that it is receiveu by the noses of horses being rubbed against each other. White. pxperiments go to prove that the air of a glandered stable is an 
infections. but this matter is by no means certain, and should nur be depented on without a greater body of evidence.

72. The marks of glanders are a discharge of purulent matter from ulcers situated in one or both nostrils, more often from the left than the right. This discharge soon becomes glairy, thick, and white-of-egg-like : it afterwards shows bloody streaks, and is fœetid. 'The glands of the jaw of the affected side, called the kernels, swell from an absorption of the virus or poison, and as they exist or do not exist, or as they adhere to the bone or are detached from it, so some prognosis is vainly attempted by farriers, with regard to the disease; for in some few cases these glands are not at all affected, and in a great many they are not bound down by the affection of the jaw. As there are many diseases which excite a secretion of matter from the nose, and which is kept up a considerable time; sc it is not always easy to detect glanders in its early stages. Strangles and violent colds, keep up a discharge from the nostrils for weeks sometimes. In such cases a criterion may be drawn from the existence of ulceration within the nose, whenever the disease has become confirmed. These glanderous chancres are to be seen on opening the nostril a little way up the cavity, sometimes immediately opposed to the opening of the nostril; but a solitary chancre should not determine the judgment. 'The health of ton continues good, and sometimes the condition also, until hectic takes place from absorp tion, and the lungs participate, when death soon closes the scene.

73. The treatment of glanders, it has been already stated, is so uncertain that it is hardly worth the attempt; however, when the extreme value of the horse or the love of experiment leads to it, it may be regarded as fixed by experience, that nothing but a long course of internal remedies, drawn from the mineral acids, can effect it. These have been tried in their endless variety: White recom. mends the mildest preparations of mercury, athiops mineral; under the conviction that the more acrid preparations disturb the powers of the constitution so much, as to destroy as effectually as the discase. At the veterinary college the sulphate of copper (bluo vitriol) has been long in use. Others have used the sulphates of ron and zinc. Clark recommends the daily administration of a trink or ball, composed of the following ingredients: sulphute of zinc, 13 grains; powdered cantharides, 7 grains; poudered all. vice, 15 grains; of which he gives one or two extraordinary profs of utility.

74. The farcy is a disease more easily cured than the glander of wich nur daily experience convinces us; farey, or farcin attacks 
ander distinct forms, one of which affects the iymphatios of the skin and is called the bud or button iarcy; the other is principally con. fined to the hind legs, which it affects by large indurations, attended with heat and tenderness. A mere dropsical accurnulation of water in the legs sometimes receives the name of water farcy; but this has no connexion whatever with the true disease in question: furcy is very contagious, and is gained from either the matter of farcy of from that of glanders.

75. Treatment of farcy. The distended lymphaties or buds may often be traced to one sore, which was the originally inoculated part, and in these cases the destruction of this sore, and that of all the furcied buds, will frequently at once cure the disease, which is here purely local. But when the disease has proceeded further, the virus must be destroyed through the medium of the stomach; although even in these cases, the cure is rendered more speedy and certain, destroying all the diseased buds, by caustic or by cautery Perhaps no mode is better than the dividing them with a sharp firing iron ; or if deeper seated, by opening each with a lancet, and touching the inner surface with lapis infernalis. The various mineral acids may any of them be tried as internal remedies with confidence; zven losing sight of the necessity of watching their effects narrowly, and as soon as any derangement of the health appears, to desist from their use; oxmuriate of quicksilver (corrosive sublimate) may be given in daily doses of fifteen grains; oxide of arsenic may also be given in similar doses. The subacetate of copper (verdigris) may also be tried, often with great advantage, in doses of a drachr. daily. Blaine joins these preparations, and strongly recominends the following: oxmuriate of quicksilver, oxide of arsenic, subacetate of copper, of each cight grains; sublimate of copper, one scruple; make into a ball and give every morning, carefully watching tho effects, and if it be found to occasion distress, divide, and give half, night and morning. The same author professes to have received great benefit from the use of the following: expressed juice of elevers, or gonse-grass, a strong decoction of hempsecd and sassafras, of euch six ounces; to be given after the ball. It remains to say, that whatever treatment is pursued will be rendered doubly effica. zinus if green meat be procured, and the horse be fed wholly on it provided the bowels will bear such food; but if the medicines gripe, hy being joined with green food, add to the diet bean-meal. When green meit cannot be procured, carrots usually can; and wher they cannot, still potatoes may be boiled, or the oats may be speared or malter. As a proof of the beneficia! effects of green meat, a unpes, so bad witls farcy as to be entirely despraired of, was drayo 
trey a field of tares, and nothing more was done to him, nor furtiles noice taken of him, although so ill as to be unable to rise from the ground when drawn there. By the time he had eaten all the tares within his reach, he was enabled to struggle for more; and finally 'se r.us? to extend his reach, and perfectly recovered.

\section{Diseases of the Extremities.}

76. Shoulder strains, are very rare; most of the lameness attributed to the shoulder being to other parts, and particularly to the feet. Out of one hundred and twenty cases of lameness before, Blaine found that three only arose from ligamentary or muscular extension of the shoulder, or rather of the abductor and sustaining muscles: when shoulder strain does happen, it is commonly the consequence of some slip, by which the arm is forced riolently forwards. It is less to be wondered at than at first seems probable, that farriers mistake foot lameness for shoulder strains, when we reflect that a contracted foot occasions inaction, and favouring of the limb; which thus wastes the muscles of the shoulder. Seeing that one shoulder is smaller than the other, the evil is attributed to that, and it is pegged, blistered, swam, and fired, to the torture of the animal and the increase of the foot's contraction by the confinement. In real shoulder strains, the toe is dragged along the ground while in motion; at rest it is planted forward, but resting on the point of the toe. When the lameness is in the foot, the horse points his foot forward also, but he does so with the whole limb unbent, and the foot flat. These differences are highy necessary to be attended to, as well as the peculiar difficulty there is in moving down hill, which he does with reluctance, and by swinging his leg round tc av jid flexing it. This lameness may be further brought lis the test by lifting up the fore leg considerably, which 
if the evil be in the shoulder, will give evident pain. The inuscles betwen the lore lews are likewise tumified and tender in these cases.

77. The trentinent censists, when it is recent, in blecding in the piate vein, rowelling in the ehest, and fonenting with hot water two or three tines a diay. When the heat and tonderness have subsided, first bathe ditily with the astringent wash for strains (Vet. Pha. 13., No. 1) for a wcek; and afterwards, if necessary, proceed to blister in the usual manser.

78. Sirain in the whirl bone. This important joint is sometimes strained, or its ligranents and muscles unnatumily extentied, from a greater force being applied to them than their structure is able to vear, or their power to resist; a lasion takes place of some of their fibrillæ, or in lesser injuries their elasticity is injured by heing put on the stretch beyoud their power of returning. In all such cases, the parts react, and inflanmation follows; by which heat, tonder ness, and swelling ensue.

79. Treatmont. The first indication is the same in this as in all igmentary strains, which is to moderate the inflammation by fonentations, \&.c. \&c., and when that has subsided, to endearour by astringents and bracers to restore the tone of the parts; after which, if any swelling remains, from the extravasated blood be. coming orginisci, to pomote its alisorptions by mercurial frictions, and hlistering. This applies to all strinins, and will direct tho treatment therefore of that of strain in the articulation of the thigh with the body also.

80. Strain in the stifle, is treated in the same manner.

81. Strain or clup iritie luck sinews. 'Thus is generally an injury done to the sheaths of the tensons, or of the ligaments which ond thom down. In very agrravated cases, it sometimes occurs that even the tendons thenselves are extended beyond their capacity. ihl he heat, swelling, and tenderness, are first to be combatted by fomentations, and if this be extreme, bleed also, and give a dose of physic. Next proceed to poultice with saturnine applications, until the heat and swelling are reduced: then use tonics, astringent mash, (Vet. Pha. 134, No. 1 or 2,) bandnge and exercise very carefully. If swelling remain after heat, pain, and lameness are pist; or when lamenes only remains, after all heat is gono. pro zeed to blister mildly twico In all cases of igamentiry extensiun 
when thr heat has subsided, the part may be considered as in a state of atony; and bandages judiciously applied are then proper, par ticularly during the day.

\section{Rupture of the tendons and ligaments of the leg. It is very} aeldom that the tendons themselves are ruptured, but the suspensory ligaments are more often so, and the evil is called breaking down. It is usually very sudden, and the fetlock is brought almost to, the ground. A perfect cure is seldom obtained; but the inflammation should be moderated by the means already described, and the heela should be raised. A laced stocking or firm bandage, when tho inflammation has subsided, is necessary; and firing is often prudent as a permanent bandage.

83. Strains of the ligaments of the fetlock and coffin joints often occur, and may always be distinguished by the heat, tenderness, and swelling. Treat as already described. In all strains of the leg, attended with inflammation, a goulard poultice is a convenient and useful application. The goulard water should be mixed with hran, and a worsted stocking being drawn over the foot, and up tho $\mathrm{leg}$, it is first tied around the foot; the poultice is then put in, and the stocking fastened around the leg above the injury (115.)

84. Mallenders and sallenders are scurfy, scabby eruptions, af. fecting the back of the knee, and ply to the hock; common only in coarse, low bred, and in cart horses. Wash with soft soap every day, after which anoint with an unguent formed of equal parts ot mercurial ointment, tar, and Turner's cerate.

85. Broken Knees. The usual cases or broken knees are referable to wounds in general; and the treatment of them ira no wise differs therefrom, with this caution, that here it is more immediately necessary, both for appearance and safety, that if any flap of ski.1 hang apart, to cut it off, or the wound will heal with rugosed edges. liut when the joint of the knee is broken into by the violence of the injury, it becomes of a very different nature, and is known first by the extreme lameness and swelling that occur; and next by the escape of a slippery mucus not unlike the white of an egg. If this continue to escape, violent inflammation follows, and either the iorse or the joint are lost by it. Farriers are apt to attempt to stop the flow of the joint nil, as it is called, by oil of vitriol, or other nscharotics, which treatment is usually followed by the most disastrous consequences. It is however, necessary to stop the inmediato vow, by other mnans tue best of which is by a fine buading-iron 
heated. Should the laceration be considerable, this cannot be done but the treatment must then consist of saturnine poultices, bleeding low diet, and the other anti-febrile remedies, until the swelling has bubsided, when apply tne astringent paste recommended by Clarke, made of pipe clay and alun, every day, but by no'means introduco any escharotics. On the subject of broken knees, a prejudice prevails, that a horse that has once broken his knces, is more liable to fall again than a horse that has not before fallen down; but unless the knee be injured so as to become stiff by such accident, the supposl. tion is wholly erroneous. Horses fall as often by treading on sharp otones when they have corns, as they do by stumbling; and as corrs sometimes come on rapidly by pressure, so such a horse becomes aiterwards liable to trip, and this gives rise to the opinion formed, hat when once he has been down he will ever after be liable to it.

86. Splints and bone spavin. The former are usually situated on the inner side of the canon or shank before-and as they are bituated, so they are more or less injurious. When buried, as it were, within the tendons or back sinews, they are very apt to lame the horse seriously; but when situated on the plain bone, unlese they are very large, they seldom do much injury. If a splint be eariy attended to, it is seldom difficuit to remove. Blaine recom. mends the swelling to be rubbed night and morning for five or six days, with a drachm of mercurial ointment, rubbing tt well in; after which to apply a b.ister, and at the end of a fortnight or three weeks to apply anotl er. In very bad cases he recommends firing in the lozenge form.

87. Bone spavin is ar exostosis of the hock bones, the treatment of which in no wise difers from that of splint; except that as a epavin in general is mere injurious than a splint, so it is more necessary to commence the treatment early, and to continue it energetically. It also ur. fortunately nappens, that from the ecm. plexity of structure on the hock, spavin is not so easily removed as splint, and more usually rec uires the applicati on of firing.

88. Ring bone is of the sa nature, being an exostosis or bony sircle, formed around the ci ronet, the treatment of which is the aame with splint and spavin.

89. Blood spavin, bog spavis and thoroughpin, aro all of them originally of the nature of win galls, and are nothing more than enlargements of the brusal cap ules described in the anatomy as surrounding tendons, liganents, ind bones, to furnisis them wsib 
the lubricaling medium. By over exertion or hard work these brusit bags bec sme extended, and their contents increased, and distended into puffy swellings in the hock, called, when on the ply, bog spavin. The pressure of this sometimes occasions a varicose state of the superficial vein, which passes directly over it on the inner side of the hock, and which enlargement then receives the name of blood spavin. When the brusal enlargement extence through the hock, it is called thoroughpin. When it is situated below in the bursæ of the flexor tendons, near the fetlock joint, it receives the name of wind gall.

90. The treatment in all these cases must be simlar in principle, and consists in lessening the distended sac-not as was formerly practised to the destruction of the horse often, by letting out the contents of these wind galls; but by strengthening the sides of the tumours by stimulants or by pressure. The more active stimulants are the liquid blister, (Vet. Pharm. 141,) milder ones are found in the astringent wash. (Vet. Pha.134, No.1.) Bandages assist greatly, when well applied to the part, and in desperate cases firing has been resorted to, which is nothing more than a more violent stimu. lant and a more permanent bandage.

91. Capulet is a bursal enlargement of the point of the hock, and is to be treated by friction, astringents and bandage.

92. Curb is an inflammation of the ligaments at the back of the hock, and is usually removed by astringents. (Vet. Plia. 134.) When it does not give way to these, the sweating liquid blister may be applied. (Vet. Pha. 142.)

93. Cracks and grease may be considered as modifications of ono and the same affection, and are commonly brought on by some neglect in all horses; but when they occur in any but the thick. heeled low bred animals, they are invariably so. Over feeding or under feeding, but much more frequently the former, will bring it on: A very frequent cause of it is the practice of washing the legs ot horses and suffering them to dry of themselves. In every case without exception, washing the legs should be avoided, unless they be rubbed perfectly dry afterwards. When horses have long hairs about their heels, and are washed and then left wet, the evil must ne doubled; as the evaporation going on, cools and chills the heels, and thus produces a species of chilblain; and we well know how difficult these are to heal when broken. Cracks in the heels very often occur in horses removed too suddenly into full keep from pre. $r$ ous straw o: grass of from these to a hot stable; which $L$ t the heas 
and moisture of the litter, occasions a determination of blood, and humours to the legs, and they break out into cracks or scabs, fron. which issue a bloody ichor, or a more thick matter. Between the oores the hair stares and gets pen feathered, and the horse finds defficulty and pain in moving.

94. The treatment must depend on the state in which the anima, is at the present. If there be reason to suspect the horse to be full and foul, bleed, lower his food, soll him in the stable; or mash and give him a mild dose of physic. But when some mismanagement is the sole cause, remove that, and if the case be a severe one, by means of an old stocking drawn over the foot, bury the whole heel in a poultice, made of scraped carrots or turnips; which will subdue the irritation and bring the parts into a state to bear the application of the astringent paste, (Vet. $P h a, 136$, No. 2,) or if more convenient, of the astringent wash, (V'et.Pha. 134, No. 1 or 2.) Moderate exercise should be continued, and the heels carefully cleaned from dirt by soft soap and water on each return therefrom; after which, always again apply the astringent.

95. Grease is nothing more than an aggravated state of the same - ffection, and is more common to the hind than the fore legs. Coarse fleshy legged horses are peculiarly prone to the affection from the great accumulation that takes place in their legs; and from the difficulty that the capillaries find in carrying the increased quantity of lymph upwards. In these, long stable confinement should be avoided, and when that is impossible, it s! hould be coun. teracted by exercise frequently and judiciously administered. Many cart horses never go out but to work; they often work three days incessantly, or nearly so; and they perhaps rest two days entirely Can it be wondered at, that the change occasions swelling, acting on the weakness and exhaustion of previous fatigue, and could not this be avoided by turning out for an hour, or walking for half an hour night and morning? stable soiling should be used; bleeding and physicking also in very bad cases; and when the inflammation and is ritation or soreness are great, the poultices recommended for cracks, should be apolied until thesc circumstances are removerl; when commence the use of some of the astringents recommended (Vet. Plarm. 134) White has stated two remarkable cases of grease cured by the apmlication of corrosive sublimate in the form ot a wash, as of two drachms of sublimate to ten ounces of watnr; mcreasing it to three drachms if the pain occisioned by the first be not too runsiderible. Blaine says that the elivers or gnose grass ias been known to bn of great service in bad cases of grease - haly 
- pint of the sxpressed juice to be given daily as a drink, and a proultice of the herb to be applied to the heels. In some cases of long standing when the running has ceased, a thickened state of the limb remains; which is best removed by firing, and which like wise is a preventive to a return.

\section{Diseases of the Feet.}

96. Founder of the feet is of two kinds, an acute and a chronic Acute founder is a disease that, until lately, was less understood than almost any other. After a very severe day's work, or when very much heated, if a horse get a sudden chill by standing in snow or cold water, it is not uncommon for him to be seized with universal stiffness, and every symptom of great fever. Such a horse is said to be body foundered. By degrees, however, it is observed that the animal has an extreme disinclination to remain on his feet; from whence it will appear that the whole of them are affected, when the norse draws his hind feet under him, his fore only are affected, and when he draws his fore feet under him his hinder feet are the seat of the complaint; but which is seldom the case. On feeling the feet they will be found intensely hot, and the pastern arteries beat with great violence. After a few days, unless the disease abate, a separation of the hoofs from the coronet takes place, and at last they fall entirely off.

97. The treatment. At the commencement of the disease bleed largely, as well by the neck as from the toe of each affected foot, by paring, until the blood flows freely. After which immerse each foot in a goulard poultice (115,) give the fever powder or drink, (Vet. Pha. $157 \& 158$,) litter up to the belly; and if amendment do not take place, renew the bleedings, and blister round the pasterns.

98. Chronic founder, contraction or fever in the feet. The artificial life that horses lead, subjects them to many diseases; one of the principal of which is that of contracted feet. Blaine considers a neglect of sufficient paring of the hoof, the application of artificial heat from hot stables, and hot litter, the deprivation of natural moisture, constitutional liability, and the existence of thrushes, as among the principal causes of this evil. It is more commion among blond horses, than to others, and he observes, that dark chesnuts are of all others most prone to it.

99 The treatment of contraction in the feet. It is better to pre ranc. thus to ve under the necessity of attempting to cure the and 
Prevention may be practised by avoiding the acting cousos. As soon as at all suspecterl to be likely to occur; keep the hoofs pareris low; never suffer the horse to stand on litter, nor allow the stablo to be too hot; feed moderately, and never allow the horae to go without daily exercise; whatever increases the general fulness of habit flies to the feet. Above all, keep the feet most by means o. wet cloths tied closely around the soronet, falling over the wholo hoof, but not extending beyond the edge. Then morsten repeateály, and stop the feet (166) every night. When contraction has already taken place, many plans have been recommended; as jointed shoes, by Coleman, Clark, and others, but it is not found that mechanical expansion in this way produces permanent benefit. The most effectual mode is to obviate all previous causes of contraction; and then to thin the hoofs around the heels from each quarter so thin as to be able to produce an impression by means of the thumb; in fact, to remove so much of the horn as is consistent with safety, from the coronet downwards. It is also prudent to put in a score or two from above downwards, drawn a quarter of an inch deep on each side towards the front of the hoof; but whetiter this ve done or not, the front of the hoof should be rasped thin alout an isch in width; by which means a hinge is formed, which operaier most advanta. genusly in opening the heels. After this is dore, lips should be put on, and the horse should be turned out "o grass, where he should remain three months, by which time the new formed heels will rave reached the ground, and will bear a shoe.

100. The pumiced foot is a very common consequence of acuto founder, in which the elasticity of the laminæ becoming destroyed the support of the coffin bone is removed, and it rests wholly on tho sole, which it gradually sinks from a concave to a convex surface, dirawing with it the front of the hoof inwards. In weak, bread heavy feet, this evil comes on sometimes without founder, the treatment ean only be palliative, a wide webbed shoe exactly fitted to the foot, without at all pressing on it, prevents the lameness consequent to the disease, a shoe exactly the contrary to this has been tried in some cases with benefit, the form of which has been one with a web so narrow as only to cover the crust, but so thirk es to remove the feet from accidental pressure. In other cases, 10 shoe answers so well as a strong bar shoe.

101. Corns are most troublesome aliments, to which hores are cry liable, and which injure and ruin thousands; they are wholtv accudental; no horse having any peculiar tendency to them. lus woing alwara brought on them by some improper pressure, usual,y 
of the shoe or from something getting between the shoe and tno norny heel. A shoe toc fong worn is a very common cause, and a Btill more frequent one is tha clubbing the heels of the shoe; neither ts it necessary to the production of corns that the ohoe itself should press : $n$ the sole; but they are equaliy produced when the outes horn of the heels or of the bars, is the immediate offending part rendered so by two luxuriant growth, by unequnl wear, or by secondary pressure from the shoe, or by gravel working in. It is the fleshy sole itself that is bruised, from which a speck of extravasated blood follows, and if not immediately relieved it gathers, or the part becomes habitually defective, and instead of forming healthy horn, it always afterwards forms a spongy substance of extreme sensibility, and thus aliways is liable to produce pain and lameness when exposed to pressure.

102. The treatment of corns is seldom difficult or unsiccessful at their first appearance, but afterwards it can he only palliative. Blaine dircets that by means of a fine drawing knife every portion of diseased horn should be pared away, and the extravasation underneath likewise. Having done this, he advises to introduce some butter of antimomy into the opening, to place over this some tow, which should be kept in its plice by means of a splint. If any contraction of the heels 10 present it will materially assist the cure to lower them, and .c thin the hoof a little around the quarters, and afterwards to put on a shoe without heels opposed to the corn, or a shoe chambered opposite the weak part: or a bar shoe may be applied so framed as completely to leave the heel untouched. Intro. duce the butter of antimony once or twice more, with the interval of two days between, and then turn the horse out to grass; in about six weoks time the foot will be sound. The treatment of corns, when of long standing, does not inaterially diffor: for although they are never wholly eraliicaterl, they may be rendered hut little troublesor. 'e. The diseased part must be carefully pared out at each shocing, ar. such a shoe put on as will completely free the heel fi sm pressure

103. Running thrush is always a dangernus disease, and few errors in horse management are more glaring than the common one of supposing they are neessary to carry off humours. If less food, more exrercise, cool stables, and dry standings, were substituted to correct the fulness, instead of thrushes, which invariably contract the foel whenever they continue any length of time, it would save many viluable lorses. To the cure, begin by cleaning out all the absu es of the frog from loose ragred horm, and then introduse to 
the bottom of the sinuses, by zeans of a thin piece if wond, some of the thrush paste (Vet. I'harm. 133,) smeared on tow, which wil, enable it to be held within the cleft, especially if it be guarded by splints of wood passed under the shoe; renew the dressing daily; turming nut to grass may be practised to great advantage for thrushea by this mode of dressing.

104. Sand cracks are fissures in the hoofs, commonly of tnose before, and usually towards the inner, but now and then towards the outer quarter also, from above downwards: from the crack, a litse oozing of blood or moisture is seen; and the sensible parts underneith gretting between the edges of horn, being pressed on, lane the horse. White recomments to fire the fissure crossways, so as to destroy the connection between the divided and undivided parts of the hoof.

105. Pricks or punctures of the feet are often very serious evils, either when received hy nails in shoeing, or by one picked up in the road, \&c. The danger arises from inflummation, which is always great from any injury done to the sensible and viscular parts within the foot. This inflammation quickly proceeds to suppuration; and the matter is apt to make its way upwards, unless it find a ready vent below. When it does not break out at the coronet, it will often penetrate under the sole, and finally disease the bones, ligaments, or cirtilages, and produce quittor. It is very seldom that a horse is pricked in shoeing, but that the smith is aware of it by the peculiarity of the feel on the hammer, and by the flinching of tire animal. At such times were he to immediately draw the nail a little, enlarge the opening, and introduce some spirit within the puncture, nothing wruld occur; but on the contrary, he sends the horse home to avoid trouble, who, the next, or following day, is found lame, with his foot hot, if the nail be not driven too near the sensiblo lamina, it will only require to be removed to free the horse from his evil; but if it have been driven through, and have wounded them, then suppuration ensues, and on examining the foot by the pincers when the shoe is removed, he will Hinch at the pressure on the diseased part. It is probable, on the removal of the shoe that matter will at once flow out at the immediate nail hole, if not, the drawing knife will soon detect the injury. If the heat be great, and insteas of matter, hoody dark ichor flows out, wrap the foot up in a pon: tuec: hut if healthy matter flows out this will not be necessary, sometines it is requisite to detach all the horn that is underrun bo the snatter. But when the injury has not proceeded to tnis extent, spply over the part a pledget of tow steoped in friar's balsam, tack 
or the stre lightly, and retain the dressing oy means of splints which are thin pieces of wood passed under the shoe; repeat the dressing daily, and avoid mossture, which would encourage quittor A nail picked up on the road, and which passes thruugh the Eole below or through the frog, is to be treated in the same manner, and also when the matter breaks out at the coronet; but when a nail is picked up and penetrates the coffin joint, which is known by the synovia or joint oil appearing, such opening should be inmediately stopped by paring towards the wounded joint, and then applying a heated budding-iron, not to the capsular ligament itself, but to the skin immediately near it; if this be inconvenient, jut a pledget dipped in a little butter of antimony, just within the opening, but do not press it into the cavity of the joint: if this be insufficient to stop the flow, but more particularly if the original wound be pene. twsted to the hone, it is probable that the bone itself will become in some measure diseased, which is known by the rough grating felt at the point of the probe when passed. In this case, enlarge the opening so as to be able to scrape the diseased bone away. Bruises of the sole, from whatever cause, will all fall under some of these points of view, according as the case may be.

106. Quittor and canker are the consequences of these injuries, when neglected, or originally extensive. In these cases either the bones, ligaments, or curtilages, or all, become diseased; and a cure can only be obtained by removing the diseased parts by the knife or by caustic.

107. Treads, over-reach, \&.c. A wound on the coronet is not uncommon from one foot being placed on the other; or the hinder foot may strike it, \&c. First wipe away the dirt, and remove any loose edges that cannot unite; avoid washing, unless stones and dirt are suspected to be within, and bind up, having first placed over the wound a pledget of lint or tow moistened with balsamic tincture, or tincture of myrrh, or of aloes \&c. Oner-reaching, or over-stepping, is often an injury done to tne fetlock joint before, by the hinder foot, or to the back sinew higher up. Sometimes it is simply a violent bruise, at others the laceration is extensive, in which case treat as a tread; and when no laceration has taken plice treat as a bruise or strain

108. Cutting is a defect to which some horses are liable from their form, as when they turn their toes out, or have hent legs. Others cut only when they are lean, which brings their legs nearer ogether. Weak horses cut because thev cross theil legs when 
atigued, and young unfurnished horses cut at youthful periods and grow out of it afterwards. 'The part in which a foot interleres with the opposed limb is very different. When it strikes the shank hern $n p$ it is called speedy.cut, and is best remedied by wearing knte bosts or rollers. When it is at the fetlock the cutting is at the side, or rather backward, according to circumstances. Some horses cut liy the side of the shoe, others by the hoof at the quarters; and some by the point of the heels. It is to be remarked, that it is better to put un with the evil of cutting, than to do as is too frequently done, which $1 \mathrm{~s}$, to pare away the hoof until it excites contraction. The shoe may be feather edged, or may be set a little within the cutting quarter; but by no means alter the size or form of the hoofs them. selves, and particularly avoid taking liberties of this kind with the fore feet. Boots or rollers, are but little trouble to put on, and when not buckled too tight never injure: whereas to allow a horse to continue to cut produces a callus, and often throws the animal down.

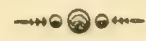

\section{VETERINARY OPERATIONS.}

109. The general practises to be here enumera $e d$ are chiefly the treatment of wounds, the application of fornentations, setons, blisters, clysters, and physicking, and the operation of castrating, nicking, bleeding, \&c

\section{Treatment of Wounds.}

110. A wound must be treated in some measure according to the part of the horse's body in which it happens: but there are some prineiples to be ohserved alike in all horse surgery. There are likewise a fow, which, as they differ from the principles of huma. surgery, should be first noticed, and which should gruice the pae tice of those who might be misled by analogy. The wound of horses, however carefully brought together and confined in thers ntuation, as well as shut out from the stimmlus of the exterma. air are seldom disposed to unite at once, or as it is called in surgical anguagre, by the first intention. It is always, therefore, necessary to $E$ xpect the supnurative process; but as the adhesive influnnatios 
dues no:w and then occur, we should never wish with water $n$ other liquids a mere laceration, if no foroign inatter, as dirt, \&o oe suspected to be lodged within it, still less should we stuff it with candle or tents of any kind. On the contrary, it should be care. rully and smoothly brought together, and simply bound $x p$ in ita nwn blood; and if it do not wholly unite at once, and by the first mtention, perhaps some portion of it may; and at all events, its riture progress will be more natural, and the disfiguration less than when stuffed with terits, tow, \&c. or irritated with heating oils or spirits. When an extensively lacerated wound takes place it is common, and it is often necessary to insert sutures, or stitches, into the lips of the wound: and here we have to notice another considerable variation from the principles of human inflammation, which is, that these stitches in the horse, ox, and dog, soon ulcerate out, seldom remaining longer than the third or fourth day at farthest. It therefore is the inore necessary to be careful, that by perfect rest, and the appropriation of good bandages we secure the wound from distortion. In this we may be assisted by strips of sticking pluster, mate with diachylon and pitch; but these strips should be guarded from touching the wound itself by means of lint or tow first put over it. When in addition to laceration in a wound, there is a destruction of substance, then the cantion of washing will not apply, as it will be necessary to bathe with some warming spirit, as, tincture of myrrh, tincture of aloes, or friar's bulsam, to assist in restoring the life of the part, and in preventing mortification Bleeding must be stopped by pressure and astringents, as powdered a!um; when it is very considerable the vessel from whence the blood eomes must be taken up. When great inflammation follows wounds or bruises, counteract it by hleeding, a cooling temperature, pening medicines, and continual fomentations to the part itself

\section{Balls and Drinks.}

111. Mode of giving a bull. Bacs the horse in his stall, and meing elevated on a stool, (nut it hueket turned upside down,) gentlg draw the tongue out of the munth, so as to prevent its rising $\omega^{\circ}$ resist the passige of the hand: the tongue should however not ho laid hold of alone, but it should be held firnly by the fincrers of the aft hand against the jaw. The ball previously oiled should ho - aken into the right hand, which should be squeezed into as narrow $\checkmark$ shape as possible, must he passed up close to the roof of the mouth. and the ball placed on the root of the tongue, when botn hands theing withdrawn, it will readily pass down. This mode is much, orutisrable, wher a pezsun is at all handy, to using a balling iron. 
119. Mode of giving a drink. Exactly the same process is pur sued, except that a horn holding tie lignuid mattr.r is forced un the mouth; the passage being raised heyond the level line, the liquad is poured out from the larger end of the horn, and when the tongue is loosened it is swallowed. Clark, however, ingeniously proposes to substitute the smaller end of the horn, the larger being closed, by which, he says, the horn can be forced up the mouth between the teeth, and poured firther back so as to ensure its not returning.

\section{Fomentations and Poultices.}

113. Fomentations are very commonly recommended of various herbs, as rhue, chamomule, St. John's wort, wormwood, bay leaves. d. but the principal virtue is to be found in warmth and moisture, which unload the vessels; but this warmith ought not to be too con. siderable, except when the inflammation is within, as in inflamed bowels. Here we foment to stimulate the skin, and cannot foment tuo hot; but when we do it at once to an inflamed part, it ought not to be more thim of hlood heat; and it should be continued long, and when removed the part should be dried or covered, or cold may bo taken, and the inflammation increased instead of diminished. Ano dyne fomentations are made of poppy heads and of tobacco, and ars frevizently of great use.

114. The method of applying fomentations is conveniently done by means of two large woollen cloths wrung out of the heated liquors, us one is cooling the other should be ready to be applied.

115. Poultices act in the same way as fomentations in allityıng 1.ritation and inflammation; but are in other respects inore conve nient because they act coutinually. It is an error to suppose that voultices, to be beneficial, should be very hot; however hot they mar be applied, they soon become of the temperature of the surrounding parts. When poultices are applied to the extremities, a stecking, as has been before stated, is a convenient method of al, p'ication. When it is drawn over the leg and bound around the lower part of the hoof, or of the pastern, or utherwise, the matter of the poultice mily be put within, and it may be then kept in its situation, If high up on the extremity, by means of tape fitstened to one part git it, and prissed over the withers or back to the other side, and ngain fistened to the stockirim. In this way, also, loose arnuges :nay be retained from slipping. Coll poultices are often useful ui the infammations arising from strains, Sc. In these cases brau a.d goulard water furm at convenient medium; but when the ous 
tice is necessarily hot, a ittle linseed ment added to tho bran wil reuder it adhesive, and give it consistence. It is a very necessary caution in this, as in every instance where bandages are wanted around the extremities, to have them broad, and only so tight as to secure the matters contained, as in a poultice, or as in common bandaging. It is often supposed that "as strong as a horse," de. notes that nothing can be too strong for him, nor any means too riolent to hurt him. The horse, on the contrary, is one or the most tender animals alive : and a string tied very tight round the leg would occasion first a fulling off of the hoc $f$, next a mortification of the rest of the limb, and lastly the deatl. of the animal; and all this as certainly as though he were shot with a bullet through the head.

\section{Setons and Rowcls.}

116. Setuns are often useful in keeping up a drain to draw what are termed humours from parts; or by their irritations on one part, thiey lessen the inflammation in another part not very remote, as when applied to the cheek for ophthalmia or inflamed eyes. 'They also in the same way lessen old swellings by exciting absorption. Another useful action they have is to make a dependen or convenient orifice for the escape of lodged matter: thus a seton passed from the upper pas if the opening of pole evil, through the upper part of the integunrents of the neck, as low as the sinuses run, will often eftect a cure without further application. 'I'he same with fistulous withers, wnich sometimes run under the shoulder blade, and appear at the arm point; in which case a blunt seton needle, of suthicient length to be passed down to that point, and to be then cut down upon, will form the only efficient mode of treatment. Setons nuy be passed in domestic farriery, with a common packing needle and a skein of thread, or piece of tape: but in professional farriery they are made by a proper needle armed with taf "or lamp cotton, or sheins of thread or silk smeared over with d, gestive ointment When the seton needle is removed, the ends of the tape should be joined together, or otherwise notted, to prevent them from coming out.

117. Rowels in their intention act as setons, and as institing a arger surface, so when a greneral drain is required they act, better, es in case of grease, \&c. but when their action is confined to a part unly, selons are more convenient. Any person may applv a rowei by muking an incision in the loose shin about an inch separating vith the finger its adhorence around, und then insoling in the 
opening a prece of round leather, with a hole in the middle, smoares with a blistering ointment. Then plug the opening with tow, and in three days, when the suppuration has begun, remove it. 'I'hs rowel leather is afterwards to be daily removed and cyeaned.

\section{Blistering and Firing.}

118. Blistering answers the same purposes as setons, and is prac tised by first cutting or shaving the hair from the part, when the blistering ointment (Vet. Pha. 138.) should be well rubbed in for ten minutes, or a quarter of an hour. Some of the ointinent after the rubbing may be smeared over the part 'The head of the horse should now be tied up to prevent his gnitu.ng or licking. If a neck cradle be at hand, it may also for sufety be put on; in which the head may be let down the third day.

119. A neck cradle for blistered horses is very convenient for cther occasions also, when the mouth is to be kept from licking or biting other parts; or to keep other parts from being rubbed agains: the head. It is of very simple construction, and may be made by a tozen pieces of wood of about an inch and half diameter, as old sroom handles, \&c. These bored at each end admit a rope to pass through; and as each is passed on, a knot may be tied to the upper part of the pieces of the cradle, two inches apart; and those which form the lower part, four inches; by which means the neck will bo fitted by the cradle when it is put on; and the horse will be pre. rented from bending his head to lick or gnaw parts to be protected. When the lower parts of the legs, particularly the hinder, required blistering, it is necessary to bear in mind that in gross full horses, particularly in autumn, grease is very apt to follow blistering; and almost certainly if the back of the heels below the fetlock be blis. tered. First, therefore, smear this part over with lard or suet, and afterwards avoid touching it with the ointment. After blistering in summer, the horse is often turned out before the blistered parts alo quite sound; in this case guard them from flies by sone kind $o$. covering, or they may become fly-blown: and likewise on the fourth or fifth day rub into the blistered part some oil or lard to prevent the skin from cracking.

120. Sueating or liquil blisters, (V'et. Pha. 142,) are only mors gontle stimulants, which are daily applied to produce the samo effects on a dismased part without removing the hair. Of course less activity is expected; yet as the action is repeated, they are often more beneficial even than blistering itself; as is old strans sme mtufinessey 
121 Firng, as requiring the assistance of an experienecd practitioner, we shall not describe; it will be prudent only to point eur that it is a more active mode of blistering; and that it acts very powerfully as a stimulant, not only while its effects last as blisters do, but also after its escharotic effect is over, by its pressure; and in this wily it is that it operates so favourably in bony exostosis, ay splints and spavins; and in this way it is so useful in old ligamentary weaknesses; because by lessening the dilatability of the skin it becomes a continual bandage to the part.

\section{Clystering and Physicling.}

122. Clystering sbould always be preceded by back-raking, which consists in viling one hand and arm, and passing them up the fundament, and by that means to remove all the dung balls that can be reached. The large pewter syringe for clystering, is neither a useful or safe machine. A much better consists in a turned box pipe, to which may be attached a large pig or ox bladder, by which four or five quarts of liquid can be administered at one time. (Vet. Plarm. 134, to 146.) 'The pipe should be previously oiled, by which means it passes more easily : the liquor should then be steadily pressed up; and when the pipe is removed, the tail should be held down over the fundament a little to prevent the return of the clyster. In sonis cases of a spasmotic nature, as gripes and locked jaw, great force is made by the bowels to return the clyster, and nothing but con. tinued pressure over the fundanent can enable it to be retained. Clysters not only act in relaxing the bowels, but they may be used as means of nutriment when it cannot be taken by the mouth; as in locked jaw, wounds of the mouth, throat, \&c. \&c. In locked jaw, it was observed by Gibson, that he kept a horse alive many days by clysters alone; and by clysters also, many medıcines may be given more conveniently than by the mouth.

123. Physicking of horses. It is equally an error to refrair. altogether from giving horses physic, as it is to give it on every occasion, as sume do. Neither is it necessary for horses to be bled and physicked every spring and autumn, if they be in perfect health, and the less so, as at this time they are generally weak and faint from the change going on in their coats-nor is it always necessary to give to horses physic when they come from grass or a utraw yard; provided the chinge from the one state to the other be sery moderately brought ahout. But on such a removal, it certanly -xpedites all the phenomena of condition, (2) and such horses aro ess Gikely to fall 10 pieces, as it is termed afterwards. (3.) In various Dorbid states puysi, is marticularly useful, as in worms, nide bound, 
from ton full a habit, \&c. \&c. It is not advisuble to physic horses in esther very cold or very warm weather. Strong physic is asways hurtful; all that physic can do is as well operated by a muld as by a strong dose, with infinitely less hazard. No horse should be physicked whose bowels have not been previously prepared by mashing for two days at least before. By these means the ply vic will work kindly, and a moderate quantity only is requisite. Most $f$ the articles put into the purging balls for horses, to assist the aloes, are useless. Jalap will not purge a horse, nor rhubarb either. Aloes are the only proper drug to be depended on for this purpose, and of all the varieties of aloes the socotorine and Cape are the best. (Vet.Pha. 163.) Rarbadoes aloes are also not inproper, but are thought more rough than the socotorine. For formulie of purging balls, see Vet. Plut. (163.) Blaine gives the following as the process:

124. Physicking process. The horse having fastod an hour or two in the morning from food, but having had his water as usual, givo him his purge, and two hours after ofier him a little chilled, but not warm water, as is often done, by which horses are disgrusted from taking any; it may he here remarked that in this particular much error is frequently committed. Many horses will drink water with the chill taken off, provided it be perfectly clean, and do not smell of' smoke from the fire, kettle or sauce-pan; but few, very few, will drink warm or hot water; and still fewer, if it be in the least degreb greasy or smoky. After the ball has been given two hours, a warm bran mash may be offered, and a very little hay. He should have walking exercise as usual moderately clothed; and altogether he should be kept rather warmer than usual. At noon mash again, and give a little hay, which should be repeated at night, giving him at intervals chilled water. On the following morning the physic may be expected to work; which if it do briskly, keep the horse quiet; but shonld it not move his bowels, or on!y relax them, wask him quietly half an hour, which will probably have the desired effect. Continue to give mashes and warm water, repeating them every two or three hours to support hinn. When physic gripes a horse, grive a clyster of warm water, and hand rub the belly, as well as walk him out. If the griping prove severe, give him four sunces of gin in half a pint of strong ale, which will soon relieve him. Un the next day the physic will probably set, but should it continue to n ork him severely, pour down some boiled starch; and of this fail, turn to the directions under diarrhca. (52.) The horse sho ld return to his disual habits of feeding and full exercise by degrees; and $\mathrm{i}^{*}$ urore than one dose is to he griven, a week should intorvene. It is often sequisite to make the socond and thurd doses rather strongar 
Lnan the !irst. A very mild dose of physic is likewise often given to horses while at grass in very warm weather, and without any injury. When worms, or skin foulness are present, and mercurich physic is deemed necessary, it is better to give two drachms $o_{*}$ calomel in a mash the previous night, than to put it into the pur ging ball.

\section{Castration, Nicking, Docking, \&c.}

125. The operations of castration, docking, nicking, aud that of cropping, (which is seldom practised,) all require the assistance os a veterinary surgeon; and it is only necessary to remark of them, that the after treatment must be the same as in all other wounds 'To avoid irritation, to preserve a cool temperature and a moderate diet; and if active febrile symptors make their appearance, to obviate them by bleeding, \&c. \&c. It likewise is proper to direct the attention of the agriculturist who attends to these matters him. self, that the moment the wound following any of these operations looks otherwise than healthy, locked jaw is to be feared, and no time should be lost in seeking the best assistance that can be rotuined (11.) See Mason, p. 148.

\section{Bleeding.}

126. Bleeding is a very common, and to the horse a very important operation, because his inflummatory diseases, on account of the great strength of his arterial system, run to a fatal termination very soon and can only be checked in the rapidity of their progress liy abstracting blood, which diminishes the momentum of circulation. Bleeding is more particularly important in the inflammatory diseuses of the horse; because we cannot, as in the human, lower the circulation by readily nauseating the stomach. Bleeding also lessens irritation, particularly in the young and plethoric, or those of full hobit: hence we bleed in spasms of the bowels, in locked jaw, \&c. with good effect. Bleeding is general or topical. General as from the neck, when we mean to lessen the general nomentum. Topical when we bleed from a particular part, as the eye, the plate vein, the loe, \&c. Most expert practitioners use a large lancet to bleed with; and when the habit of using it is acquired, it is by far the best iastrument, particularly for superficial veins where a blo'v might enray ine fleam through the vessel. In common hands the fleam as the more general instrument is best adapted to the us:al cases requiring the agriculturists notice. Care should, however, be taken not to strike it with vehemence, and the hair being first wotted and monether down, it should be pressed close betwens the hatrs, so 
that its progress may not be impeded by them. A lignture should be first passed round the neck, and a hand held over the eye, unless the nperator be very expert, when the use of the fingers will dispense with the ligature. The quantity of blood taken is usually too small. In infiammatory diseases, a large horse, particularly in the early stage of a complaint, will bear to lose eight or ten quarts : and half the quantity may be taken away two or three times afterwards, d the violence of the symptoms seem to require it; and the blood should be drawn in a large stream to do all the good it is capable of. After the bleeding is finished introduce a sharp pin, and avoid drawing the skin away from the vein whle pinning, which lets the blood escape between the vein and skin; wrap sound a piece of tow or hemp, and next day remove the pin, which might ot'lerwise inflame the neck. In drawing blood let it always be measured; letting it fall on the ground prevents the ascertaining the quantity : It also prevents any observation on tho state of the blood; which if it form itself into a cup-like cavity on its surface, and exhibit a tough yellow crust over this cavity it betokens an inflammatory state of blood that will require further bleedings, unless the weakness forbid. After the bleeding, it now and then happens fror. rusty lancets, too violent a stroke with the blood stick, or from drawing away the skin too much while pinning up, that the orifice inflames and hardens, and ichor is seen to ooze out betwees its eciges. Immediately after this is discovered, recourse must be had to an able veterinary surgeon, or the horse will lose the vein. and perlıaps his life.

TIIE VETERINARY PHARMACOPUEIA.

127. The following formule for veterinary practice have been compiled from the works of the most eminent veterinary writers of the preșent day,, as Blaine, Clark. Laurence, Peel, White, \&c.; and we can from our nwn experience also, confidently recommend the selection to the notice of agriculturists, and the owners of horses in general. It would be prudent for such as have many horses, anu particularly for such as live at a distance from the assistance of an able vetermarian, to isep the more necessary articles by them in case of emerence: some venders of horse drugs keep 
veteriuary medicine chests: and where the compositions can be depended on, and the uncompounded drugs are genuine and good, one of these is a most convenient appendage to every stable.

128. The veterinary pharmacopaia for oxen, calves and sheep has been included in the arrangement. Where any speciality occurs, or where distinct recipes are requisite, they have been carefully noticed; it will therefore only be necessary to be kept in mind, that with the exception of acrid substances, as mineral acids, \&c. which no cattle can bear with equal impunity with the horse; the remedies prescribed require about the following proportions: A large ox will bear the proportions of a moderate sized horse; a moderate sized cow something less; a calf about a third of the quantity ; and a sheep about a quarter, or at most a third of the proportions directed for the cow. It is also to be remarked, that the degrees in strength in the different recipes, are usually regulated by their numbers, the mildest standing first.

129. Alteratives.

1.

Levigated antimony, 2 drachus. Cream of tartar,

Flour of sulphur, each half an ounce.

2.

Cream of tartar,

Nitre, of each half ar ounce. 3.

Ethiop's mineral,

Levigated antimony,

Powdered resin, each three drachms.

Give in a mash, or in oats and tran, a little wetted, every night, or make into a ball with honey.

130. Tonc Alteratives.

Gentian
Aloes,

Ginger,

Blue vitriol, in powder, of each 1 drachm,

Oak bark in powder, 6 drachms. 2.

Winter's bark in powder, three drachms.

Green vitriol, do. one and a half drachms,

Gentian, do. three drachms.

Make either of these into a ball with honey, and give every morning.

\section{3.}

White vitriol, 1 drachm,

Ginger or pimento, ground, two drachms,

Powdered quassia half an ounce Ale 8 ounces.

Mix and give as a drink. 
4.

Arsenic, 10 grains,

Cytineal, 1 ounce.

$1 ! 1 x$ ant give in a mash, or moistaned oats nightly.

131. Astringent Mixtures for Diarrhoea, Lax or Scouring.

\section{1.}

Fowdered ipecacuanlaa, one drachm,

Do. opium, half a drachm,

Prepared chatli, 2 ounces,

Boiled starch, 1 pint.

2 .

Suet 4 ounces, boiled in

Milk, 8 ounces,

Boiled starch, 6 ounces,

Powdered alum, 1 drichin.

The following has been very strongly recommended in some cases, for the lax of horses and eattle.

3.

Glauber's salts 2 ounces,

Epsom do. 1 ounce,

Green vitriol 4 grains,

Gruel, half a pint.

When the lax or scouring at all approaches to dysentery or molten grease, the following drink should be first given. 4.

Castor oil, 4 ounces,

Giluuber's salts, dissolved, two ounces,

Powdered rhubarb, half a drachm, Powdered opium, 4 grains, Gruel, 1 pint.

132. Astringent balls for Ditbetes or pissing evil.

Catechu, [Japan earth] half an ounce,

Alum powdered, half a drachm, Sugar of lead, 10 grains, ball.

Conserve of roses, to make a

133. Astringent paste for thrush, foot-rot, foul in the foot, of c.
Prepared calamine,

Verdigris, of each half an ounce, White vitriol,

Alum, of each half a drachm.

'I'ar, 3 ounces . mix

\section{Astrngent washes for cracks} in the heels, wounds, foc.

1.

Sugar of lead, 2 drachms,

White vitriol, 1 drachm,

Strong infusion of oak, or eln bark, 1 pint: mix.

2.

Green vitriol, 1 drachm, Infusion of galls, half a pint, Mix and wash the parts three times a day.

\section{Powder for Cracks, \&c.} 3 .

Prepared calamine, 1 ounce, Fuller's earth, powrered, Pipe clay, do. of each 2 ounces,

Mix and put within gauze, and dab the moist surfices of tire sores frequently.

\section{Astringent Paste for Grease} 1.

Prepared calamine, 'Tutty, powdered, Charcoal, do. of each 2 ounces, Yeast enough to make a paste.

2.

To the above, if more strength be required, add of alum and ver. digris each a drachm.

137. Astringent Wosh for do. 3.

Corrusive sublimate, $P$ drachms Spirit of wine or brandy 1 ounco. Soft water, 10 ouncer.

Rub the sublimate in a mor. tar with the spirit tıll dissolved. then add the water. This is a strong preparation and has often proved successful in verp bud 
cases of grease, which have resisted all the usual remedies.

\section{Blisters.}

1. A general one.

Cantharides powdered, 2 ounces, Venice turpentine, do.

Resin, do.

Palm oil or lard, 2 lbs.

Melt the three latter articles, ugether, and when not too hot tir in the Spanish flies.

\section{2.}

139. A strong cheap blister, but not proper to be used in fevers or inflammations, as of the lungs, bowels, \&cc.

Euphorbium powdered, 1 ounce, Dil of vitriol, 2 scruples, Spanish flies, 6 ounces,

Palin oil or lard,

Resin, of each ore pound, Dil of turpentine, 3 ounces.

Melt the resin with the lard ro palm oil. Having previousiy nixed the oil of vitriol with an sunce of water gradually, as fradually add this mixture to the c celted mass; which again set on c very slow fire for ten minutes mure: afterwards remove the whole, and when beginning to cool, add the powders previously mixed together.

\section{3.}

40. A mercurial blister, for splints, spavins, and ring bones.

of either of the above, 4 ounces.

Corrosive sublimate fineiy pow. dered, half a drachm.

4.

14:. Strong liquid blister.

Spanish flies, in gross powder, 1 ounee

Oil of orıganum, 2 drachms, Oil of turpentine, 5 ounces, Dive oil, 2 ounces.

Steep the flies in the turpentine three weeks. strain off and add tho of
5.

142. Mild liquid or stoeating blister.

Of the above one ounce, Olive oil or goose grease, one and a half ounces.

\section{Clyster.}

1. A laxative one.

Thin gruel or broth, 5 quarts, Epsom or common salts 6 ozs.

\section{Clyster for Gripes.} 2.

Mash two moderate sized onions, Pour over them oil of turpent ne,

2 ounces, Capsicurn or pepper, half an oz Thin gruel, 4 quarts.

\section{Nutritious Clyster. 3.}

Thick gruel, three quarts, Strong sound ale, one quart.

$$
\text { ()) } 4 .
$$

Strong broth, 2 quarts, Thickened milk, 2 quarts.

\section{Astringent Clyster. 5.}

Tripe liquor or suet boiled in milk, three pints, Thick starch, 2 pints, Laudanum, half an ounce.

$$
\text { Or } 6 .
$$

Alum whey, one quart, Boiled starch, two quarts.

\section{Cordial Balls.}

Gentian powdered, 4 ounces, Ginger do. 2 ounces, Coriander seeds do. 4 ounces, Caraway do. 4 ounces, Oil of aniseed, quarter of an $\mathbf{o z}$ Make into a mass with honey, treacle or lard, and give an ounce and a half for a dose.

\section{Chronic Cough Balls} 1.

Ca.omel 1 scruple 
Gum ammoniacum,

Horse radish, of each 2 drachms, Bulsam of 'Tolu, Squills, each one drachm.

Beat all together, and make into a ball with honey, and give every morning fasting.

\section{Drink for the same.}

\section{2.}

$\mathbf{I}$ ar water,

Lime water, of each half a pint, 'Tincture of squills, half an $\mathbf{o z}$.

\section{Powder for the same. 3.}

Tartar emetic, 2 drachms,

puwdered foxglove, half a drachm,

Powdered squill, half a drachm,

Calomel, one scruple,

N.tre 3 drachms.

Give every night in a malt mash.

\section{Diuretic Balls.}

Resin, yellow, 1 pound,

Nitre half a pound,

Horse turpentine, half a pound, Yellow soap, quarter of a pound.

Melt the resin, soap, and turpentine over a slow fire; when cooling add the nitre. For a strong dose, an ounce and a half, for a mild one an ounce. It should be kept in mind, that mild diuretics are always equal to what is required; and that strong diuretics are always hurtful.

\section{Diuretic Powders.}

Yellow resin, powdered, 4 ozs. Nitre, dittr, 8 ounces, fream of tartar, do. 4 ounces.

Dose-6, 8, or 10 .drs. nightly, which some horses will readily oul in a mask

\section{Urine Drink} Glauber's salts, two ounces.
Nitre, 6 draclims.

Dissolve in a pilı of warm water.

\section{Embrocations-roo.urg for} inflammations.

1.

Goulird's extract, half an nunce, Spirit of wine or brandy 1 ounrs. Soft water, 1 quart.

2.

Mindererus spirit, 4 ounces,

Water, 12 ounces.

\section{For Strains.}

Bay salt, bruised, half a pound. Crude sal ammoniac, 2 ounces, Sugar of lead, quarter of an os Vinegar one pint and a half, Water, one pint.

\section{For the Eycs. 1.}

Sugar of lead, 1 drachm, White vitriol, 2 scruples, Water, 1 pint.

2.

Brandy, 1 ounce, Infusion of green tea, 4 ounces Tincture of opium, 2 drachms, Infusion of red roses, 4 ounces

\section{3.}

Rose water, 6 ounces;

Mindererus spirit, 3 ounces.

$$
4 .
$$

Corrosive sublimate, 4 grains,

Alcohol, 1 ounce,

Lime water, 1 pint.

5.

Alum, powdered, 1 drachm.

Calomel, half a drachm.

Mix and insert a little at on corner of the eyc. The custorn of blowing in s alarms the horso

\section{Fever Powders.}

1.

Tartar einetic, 2 drachms, Nitre, 5 drachms.

2.

Antimo vial powder, 2 dracnna 
Cream of tartar,

Nitre, of each four drachms.

\section{Hever Drink.}

3.

Sweot spirit of nitre, 1 ounce, Mindererus spirit, 6 ounces,

II ater, 4 ounces.

\section{Epidemic Fever Drink.} 4.

oweet spirit of nitre, 1 ounce, Simple oxymel, 6 ounces, 'Tartar emetic, 3 drachms.

\section{Malignant Epidemic Fever.} 5.

Simple oxymel,

Mindererus spirit,

Beer yeast, of each 4 ounces,

Sweet spirit of nitre, 1 ounce.

\section{Fumigations for purifying} infected stubles, sheds, f.c.

Manganese, 2 ounces,

Common salt, do.

Dil of vitriol, 3 ounces,

Water, 1 ounce.

Put the mixed manganese and salt into a bason; then, having before mixed the vitrin and water very gradually, pour them by means of tongs, or any thing that will enable you to stand at a sufficient distance, on the is. ticies in the bason gradually. $A$ s soon as the fumes rise, retire and snut up the door close.

\section{Hoof Liquid.}

0 il of turpentine, 4 ounces,

$\mathrm{I}$ ar, 4 ounces,

Whale oil, 6 ounces.

Thes softens and toughens the hoofs extremely, when brushed over them night and morning.

\section{Purging Medicines.} Balls-very mild.

Aises powdered, 6 druchms, Oil o ${ }^{*}$ turpentine, 1 drachun
Mild.

Aloes, powdered, 8 drachm Oil of turpentine, 1 drachm. Strong

Aloes, powdered, 10 drachms, Oil of turpentine, $1 \mathrm{drachm}$.

The aloes may be beaten with treacle to a mass, adding, during the beating, the oil of turpen. tine. All spices, cream of tar. tar, oil of tartar, jalap, \&.c. are useless, and often hurtful additions.

\section{Liquid Purge.}

Epsom salts, dissolved, 8 ozs.

Castor oil, 4 ounces,

Watery tincture of aloes, 8 ozs.

Mix-The watery tincture of aloes is made by beating now. dered aloes with the yelk of egg, adding water by degrees, by these means half an ounce of aloes may be suspended in 8 ounces of water, and such a purge is useful when a ball cannot be got down, as in partial locked jaw.

\section{Scalding Mixture for Poll Evil.}

Corrosive sublimate, finely pow dered, 1 drachin,

Yellow basilicon, 4 ounces.

\section{Foot Stoppings.}

Horse and cow dung, each about 2 pounds. Tar, half a poind.

167. Wash for coring out, de. stroying fungus, or proud flesh fc. of.

Lunar caustic one drachm,

Water, 2 ounces.

\section{Wash for Mange} Corrosive sublimate, 2 drachnis, Spirit of wine or brandy, 1 oz.

Decoction of tolsacco,

Do. of white helebore, of each I pint 
Disoolve the mercury in the rpirit, and then add tho decoctions.

169. Ointments for healing. 1.

Turner's cerate, two ounces,

White vitriol powdered, half a drachm, Lard, 4 ounces.

170. For Digesting. 2. Turner's cerate, two ounces, White vitriol, 1 drachm, Yellow basilicon, 5 exnces.
171. For Mange.

Sulphur vivum, 8 ounces, Arsenic in powder, 2 drachms. Mercurial ointment, 2 ounces, Turpentine, 2 ounces, Lard, 8 ounces. Mix, and dress with every morning.

172. For Scab or Shab in Sheer Mallenders and Sellenders in Horses, and foul blotches and eruptions in cattle in general. Camphor, 1 drachn, Sugar of lead, half a drachm, Mercurial ointment 1 ounce. 


\section{UH 'TIE DISEASLS GF}

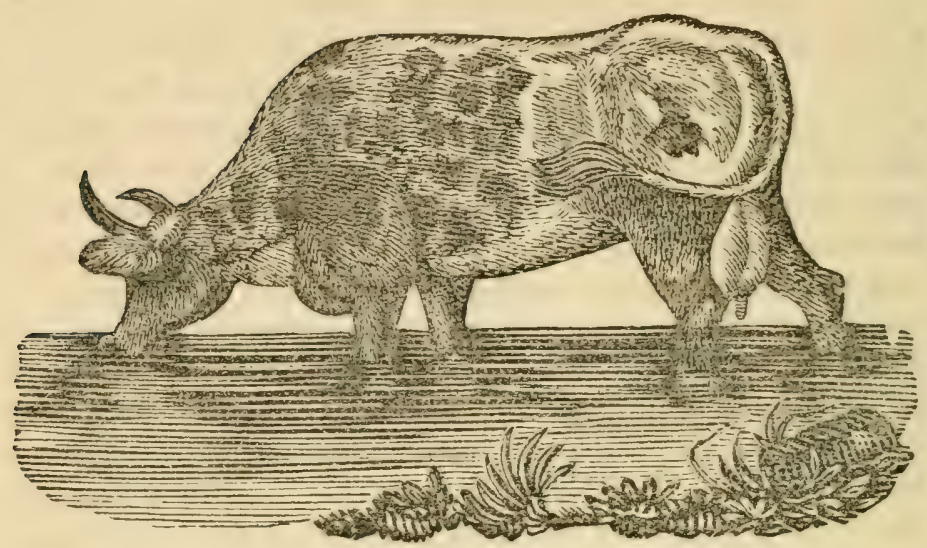

\section{HORNED CATTLE.}

173. Catlle are subject to some very dangerous dis. entses, but as their life is less artificial, and their struc. ture less complex, they are not liable to the variety of aliments which affect the horse. The general pathology of the horse and ox being little different, the funcamental rules for veterinary practice, and the requisite medicines, when not particularized, will be found in the Veterinary Plarmacopæia, already given. (126.)

174. Mild fever, pantas or pantasia. Cattle sometimes appear afected with heat, redness of the nostrils and eyelids; they refuse frod, are dull, evacuate and stale with difficulty; and the urine 19 nigh coloured. 'These symptoms are often aggravated every other day, giving it the appearance of intermittent affection. The com. plaint is often brought on by over driving in very hot weather, occasionally by pushing their futtening process too fast. If there be no appearance of malignancy, and the heaving be considerable, bleed, and give hulf an ounce of nitre in a drink night and morning; bus unless the weather be cold do not house the animal.

175. Infammatory fever is called among farriers, cow-leeches, ans graziers, by the various names of black quarter, joint felon, 
quartor es 1 , quarter ill, showing of blood, joint murrain, struking in of the ilood, \&c. Various causes may bring this on. It is some. tmes epidemic, and at others it seems occasioned by a sudden change from low to very full keeping. Over driving has brought it on. No age is exempt from it, but the young oftener have it than the mature. Its inflammatory stage continues but a few days, and shows itself by a dull heavy countenance, red eyes and eyelids: the nostrils are also red, and a slight mucus flows from them. Tha pulse is peculiarly quick; the animal is sometimes stupid, at others watchful, particularly at first; and in some instances irritable.The appetite is usually entirely lost at the end of the second day, and the dung and urine either stop altogether, or the one is hard and the other is red. About the third day a critical deposit takes place, which terminates the inflammatory action: and it is to the various parts on which this occurs, that the disease receives its various names. The deposit is, however, sometimes universal, in the form of a bloody suffusion throughout the whole skin In others, swellings from the joints, or on the back or belly; and in fact, no part is exempt from their attack. Sometimes the aninal swells generally or partially, and the air being suffused under the skin, crackles to the feel. After any of these appearances have come on, the disease assumes a very malignant type, and is highly contagious.

1\%6. Treatment of inflummatory fever. Before the critical abscess form, or at the very outset of tho disease, bleed liberally, and purge also: give likewise a fever drink (158.) If, however, the disease bo not attended to, in this early stage, carefully abstain from bleeding or even purging: but instead, throw up clysters of warm water and aalt to empty the bowels, and in other respects treat as detailed under malignant epidemic. (15.) It may be added, that four drachin of muriatic acid, in three pints of oak bark decoction, given twice a day, has proved useful. The swellings themselves may be washed with warm vinegar both before and after they burst.

177 Catarrh or infuenza in cattle, also known by the nanie of felon, is only a more mild form of the next disease. Even in this inild form it is sometimes epidemic, or prevalent among numbers, or endemical by being local. Very stormy wet weather, changing frequently, and greatly also in its temperature, are common causes. We have seen it brought on by change of food from good to naa. and from too close pasturage. It first appears by a defluxion irnm the nose; the nostrils and the eyelids aro red; the animal hosves, wo rucked up in the flanks, and on the third day he loses the sud 
There is a distressing and painful cough, and not unfrequently a sure throat also, in which case the beast almost invariably holds down his head. The treatment does not at all differ from that airected under the same disease in horses (13.) Bleetling only tho first two days, carefully sheltering, but in an open airy place, lit. tering well up.

178. The malignant epidemic influenza is popularly called mur. ain or pest; and has at various times made terrible havoc among sattie. Ancient history affords ample proof of its long existence, and by the accounts handed down, it does not seem to have varied its types materially. In 1757 it visited Britain, producing extreme tatality among the kine. From 1710 to 1714 it continued to rage on the continent with unabated fury, (Lancisiss Disputa:io His. torica de Bovilla Peste.) The years 1730 and 1731 , and from 1744 to 1746 , witnesed its attack, and produced many written descrip. tions of it, among which stands pre-eminent that of Sauvages, the celebrated professor of medicine, at Montpelier. The British visitation of the malady in 1757, elicited an excellent work from the pen of Dr. Layard, a physician of I,ondon, which was afterwards trans. lated into several languages.

179. Symptoms of the murrain. Dr. Layard describes it as com mencing by a difficulty of swallowing, and itching of the eare shaking of the head, with excessive weakness and staggering gait which occasions a continual desire to lie down. A sanious fœtir discharge invariably appears from the nostrils, and eyes also.The cough was frequent and urgent. Fever, exacerbiating, par ticularly at night, when it usually produced quickened pulse.There was constant scouring of green fetid dung after the first two days, which tainted every thing around, even the breath, per spiration, and urine were highly foetid. Little tumours or boils were very commonly felt under the skin, and if about the seventh or ninth day these eruptions become larger, and boils or buboes appear with lessened discharge of fæces, they proved critical and the animal often recovered; but if on the contrary, the scouring continued, and the breath became cold, and the mouth dark in colour, he intorms us mortality followed. Sauvages describes the murrain as showing itself by trembling, cold shivers, nose excorated with an acid dis. oharge from it; purging after the first two days, but previous to which there was often costiveness. Great tenderness about the spine and withers was also a characteristic, with emphysema, or o biowsng up of the skin by air discharged underneath it 
180. Dissections of those that have died of this disease, according to Sauvages, have shown marks of great intiammauun, and of a great putrid tendency; but the solid parts seldom ran into gan. grene. The fluid secretions however, always were sufficiently aissolved and broken down by putridity. The paunch, he says, was usually filled with undigested matter, and the other aiomachs highly inflamed: the gall bladder was also commonly distended, with acrid thick brown bile. Goelich, who likewise dissectea these subjects, describes the gall as particularly profuse and in. tolerably foctid. According to him, the whole alimentary canal, from the mouth to the anus was excorated; and Lancisi, contrary to Sauvages, found the viscera of the chest and belly, in some rases sphacelated and gangrenous. Gazola describes the murrain as accompanied with pustulous sores; and so great was the putria tendency, that even the milk, before it dried up, which it usually did before the fourth day, became fœtid.

181. The treatment of the murrain. In the very early stages, ali eminent authors recommend bleeding; hut which should not only be confined to the very early periods, as to the two first days; but also to such subjects as by their previous health and condition can oear it. The animals should be placed in an open airy place; the litter should be frequently renewed; and the place itself should be fumigated with the preventative fumigation. (161.) It has been recommended to burn green boughs with pitch as a substitute even charcoal fires occasionally carried around the place would be useful. Dr. Layard advises the body to be washed with aromatic herbs in water; but vinegar would have been better. In early stages, saline purgatives, as from ten to twenty ounces of Epsom salts are to be invariably used. If the scouring have already come on, still, however, purge; but with only half the quantity; an arti. ficial purge will carry off the morbid bile; and if excessive weakness do not come on, the same may be advantageously repeated. Setons are also recommended in the dewlap. When abscess appear, they may be opened, and their contents discharged, washing the weund with brandy or vinegar, if putrid sloughing takes place. The cm. fhysematous swellings or cracklings, may also be npened, and the aur discharged. The other essentials of medical treatment, as aetailed under malignant epidemic among horses, is here applicable in every particular. When recovery takes place, it is usually a very slow process, and requires care tu prevent otler diseases super. vening. Tho animal should continue to be housed, and neither exposed to sun or wind for some time, and the feedng should be nutritious The following infallible cure of the bloody marrain it $23 *$ 
cuttle, was given by Mr. Jones, of Gloucester county, Va. to Mr. Beniamin Harrison, of Charles City County, Va.- "A quart of tha infision of cedar berries, (containing about half a pint of the her. rins) was given at a time, and in nearly every case the good effects were almost instantaneous: a considerable discharge from the hladder and bowels followed, and in tive or ten minutes time, the animal began to eat. In nineteen cases out of twenty a perfect cure was effected. It may be necessary to repeat the drench fou or five times."

192. The prevention of the murrain, or the prevention of it spreading, in many respects is even more important than its medical treatment. Where it has already appeared, all the out-buildings but particularly the ox-lodges or stalls, should be daily fumigated with the preventive fumigation $(161 ;)$ and, even the whole of the infected districts should have fiequent fires of green wood made ir the open air, and every such district should be put under rigorous quarantine. The cattle on every farm should be carefelly examined three or four times every day, and the moment one is found to droop, he should be removed to a distance from the others. In very bad weather, while it is prevalent, the healthy cattle should be housed, and particularly well fed; and their pastures should also be changed. The bodies of those who die of the disease should be buried with their skins on, very deep in the earth, and quick lime should be strewed over them.-Prevention-Mr. Wm. Minge, (of James River, Va.) recommends the 11 ;e of a mixture of clay, salt, (in the common proportion fur siock) tar and powdered brimstone. For fifty head, one gallon of tar and half a pound of brimstone, per week, put in a trough to which the cattle had free access. 'I'he disease, it appears, is endemic in Virginia, particularly in the districts bor dering on tide water.

183. Phrenzy fever, or inflammation of the brain, called also cough, now and then, but by no means frequently, attacks cattlo The symptoms differ but little from those which attack horses.The treatment nust be exactly similar.

184. Inflammation of the lungs occasionally occurs in cattle, in which also the symptoms, progress, and proper treatment, are similar to those detailed under that head in horse pathology (31.)

185. Inflammation of the stomach sometimes occurs from poisonous matters; and in such cases, when the nature of the posson is ussevercd, the treatment detailed under poisen in horse pathology 
muat be pursued. But there is a species of iudigestun, to wiuch cattle are liable in the spring, from eating voraciously of the yum Eprouts of wood; to which some woods are more conducive thar others. 'The symptoms are heat, thirst, costiveness, lessezed urine, quick and hard pulse, with heat and redness in the nouth and nowe; the belly is hard and painful, and the stools, when they appear, aro covered with glare. When the mouth and nose discharge a serouy Guid, the animal usually dies.

186. Treatment. Bleed at first, open the bowels by saline pur. gatives (164.) After this give large quantities of nitrated water, ano clyster also largely.

187 The hove or blown in cattle is also an inflammatory affecion of the paunch, ending in paralysis and rupture of its sulstance. From the frequency of its occurrence, it has beconc a subject of investigation with almost every rational grazier, and it particular matter of inquiry with every agricultural body; from whence it is now very successfully treated by the usual attendants on cattle. when skilful; but when otherwise, it usually proves fiatal. It is oiserved to be more frequent in warm weather and when the grass is wet. When either oxen, cows, or sheep, meet with any foud: they are particularly fond of, or of which they have been long deprived, as potatoes, turnips, the different grasses, particularly rea clover; they eat greedily, and forget to liedown to ruminate; by which means the first stomach or paunch, becomes so distended as to be incapable of expelling its contents. From this inflammation follows, and fermentation begins to take place: a large quantity of air is let loose, which still adds to the distention, till the stomach cither bursts, or by its pressure on the diaphragm, the animal is sufiocated. This situation of the beast is known by the uneasiness and general swelling of the abdomen; with the circumstances or the animal being found with such food, or the presumption that is has met with it.

188. Treatment. There are three modes of relieving the com olaint, which may be adverted to according to the degree of distention, and length of time it las existed. These are internal medicines; the introduction of a probane of some kind mito the faunch by the throit: and the puncturing it by the sides. Ir. Whyatt of Edinburgh, is said to have cured eighteen out of twenty boved cows, by giving a pint of gin to each. Oil, by condensing she air, has been successfully tried. Any other substance aisn, tha: las a strong power of absorbing air, may he advantagenusly given. 
Common salt and water, made strongly saline, is a usual country remedy. New milk, with a proportion of tar equal to one-sixth 0 . the milk, is highly spoken of. A strong solution of prepared am. anonia in water often brings off a great quantity of air, and relieves the animal. Any of these internal remedies may be made use of when the hoven has recently taken place, and is not in a violent degree. But wh.n otherwise, the introduction of an instrunent is proper, and is now very generally resorted to. The one principally in use is a species of probang, invented by Dr. Munro, of Edinburgh Another consisting of a cane of six feet in length, and of con siderable diameter, having a bulbous knob of wood, has been invented by Eager, which is a more simple machine, but hardly so effica. cious. It is probable that in cases of emergency, even the larger end of a common cart whip, dexterously used, might answer the end. But by far the best instrument for relieving hoven cattle, as well as for clystering them, is Read's enema apparatus, which is alike applicable to horses, cattle, and dogs. It consists of a syringe, to which tubes of different kinds are applied, according to the pur. pose, and the kind of animal to be operated upon. 'There is a long flexible tube for giving an enema to horses and cattle, and a smaller one for dogs. To relieve hoven bullocks effectually, it is necessary not only to free the stomach from an accumulation of gas, but from the fermenting puitaceous mixture which generates it; for this pur. puse a tube is applied to the extremity of the syringe, and then passed into the animal's stomach, through the mouth, and being put in action, the offending matter is discharged by a side opening When the same operation is performed on sheep, a smaller tube is made use of. The characteristic excellency of Read's instrument, is, that there is no limit to the quantity of fluid that may not be iniected or extracted. The same syringe is used for extractnig poison from the stomach of man, for smoking insects, extinguishng fres, and syringing fruit trees. The introduction of any of these instruments may be effected by the help of an assistant, who should hold the horn of the animal by one hand and the dividing cartilage of the nose with the other; while the operator himself, taking the tomgue in his left hand, employs his right in skilfully and carefully mtroducing the instrument; the assistant bringing the head and necki into such an att.tude as to make the passage nearly straight, which will greatly fachlitate the operation. But when no instru. ments can be procurcd, or as cases may occur when indeed it is not auvisable to try them, as when the disease has existed a considerable tune, or the animal has becone outrageous, or the stomach so much distended with air that there is danger of immediate suffocation os bursting: in these instances the puncture of the maw must te 
instantly performed, which is called paunching. This may be dono with the greatest ease; midway between the illium or haunch pone, and the lust rib of the left side, to which the paunch inclines; a sharp pen-knife is frequently used, and persons in veterinary practice should always keep a long trochar; which will be found much the most efficacious, and by far the most safe, as it permits the air escaping certannly and quickiy, at the same sime that it prevents its entrauce into the cavity of the abdomen, which would occasion an equal distention. As soon as the air is perfectly evacuated, and tho paunch resumes its office, the trochar may be removed; and in whatever way it is done, the wound should be carefully closed with sticking plaster or other adhesive matter. It is necessary to observe, that this eperation is so safe, that whenever a medical assistant cannot be obtained, no person should hesitate a moment about doing it himself. After relief has been afforded, a stimulant drink may yet be very properly given, such as half a pint of common gin; or one ounce of spirit of hartshorn in a pint of ale; or two ounces of spirit of turpentine in ale, may any of them be used as an assistant stimulus. When also the cud is again chewed, still some relaxation of the digestive organs may remain; at first, therefore, feed spar ingly and give for a few mornings a tonic. [130 No. 1.]

189. Inflammation of the bowels, or red colic, is by no means unknown in cattle pathology; the symptoms of which do not differ from those common to the horse, and the treatment also, is in every respect the same. (45.)

190. Inflammation of the liver, or hot yellows, sometimes occur, in which case, in addition to the symptoms detailed under hepatitis in the horse $(58$,$) there is, from the presence of systic bile in the ox,$ a more determined yellowness of the eye-lids, mouth, and nostrils, the treatment must be similar. (58.)

191. Inflammation of the kidnies, called red water, by the cowseeches, is not uncommon among cattle, and is perhaps dependerit on the lobulated form of these parts in them. The animal to the other symptoms of fever, adds stiffness behind, and often straddles, wut always shrinks on being pinched across the oins, where fre. quently increased heat is felt, the urine is sometimes scanty, and now and then increased in quantity, but it is always first red, then purple, and afterwards brown or black, when a fatal temination may he prognosticated. The treatment has been fully detailen under rephritis in the horse pathology, (60) and which consists in plentiful weedings, \&c. but carefully alstaining from the use of äuretick, w advised by ignerant cow-leeches 
192. Blask voater is only the aggravated and latter stages of tho nbuve

193. Iuflammation of the bladder also now and then occurs, and in no wise differs from the cystisis of the horse, in consequencas and treatment. (62.)

194. The colics of cattle, arise from different causes; they aro vubject to a spasmodic colic, not unlike that of horses, and which is removed by the same means. (53.) Costiveness also brings on a colic in them, called clue bound, fardel bound, \&c. which often ends in red colic, unless early removed; the treatment of this we have fully detailed. (55.) Another colic is accompanied with relaxation of bowels.

195. Diarrhea, scouring, or scouring cow, is common in cattle, and is brought on by exposure to rain, improper change of food, over driving, and other violences. It is essentially necessary that the animals be taken under cover, kept warm and dry, and have nutritious food allowed them. The medical treatment has been detailed. (52.)

196. Dysentery or braxy, bloody ray, and slimy flux, differs from simple scouring, in a greater degree of fever attending it, and in its being an inflammation of a particular kind, and part of the intes. tines. It is frequently dependent on a vitiated putrid state of the bile, brought on by over driving in hot weather, low damp pastures in autumn, \&c. The discharge is characterized by its had smell, and by the mucous stringy patches in it, and also by its heat and smoking when voided; all which are very difierent from the mere discharge of the aliments in a state of solution in diarrhœa, and which differences should be carefully marked to distinguish the one from the other; treat as under dysentery in the horse. (49.)

197. Yellows. When active fever is not present, and yet cattlo are very dull, with great yellowness of eyelids, nostrils, \&c. it arises from some biliary obstruction, to which oxen ind cows are mure liable than horses, from their being furnished with a gall bladder, it is a more common complaint in some of the cold pro. vinces on the continent, where they are housed and stall fed all the year round, than it is in England. The treatment is the same as detailed for chronic inflammation of the liver in horses (59) adding in every instance to it, a change of pasturage, and if converusut, mo salc marshes, which will alone often eflect a care 
198. Loss of the cud. 'This enters the list of mos', cow-leeches' diseases, but is less a disease than a symptom of some other affection; indeed it is evident that any attack sufficient to destroy the appetite will generally ocension the loss of the cud. It is possible, however, that an occasional local affection or paralysis of the paunel, may occur, particularly when it is distended with unhealthy sub stances, as ac orns, crabs, the tops of some of the woody shrubs, \&c. The treatment in such cases consists in stimulating the stomach by tonics, as aloes, pepper, and gin mixed; though these, as liquids may not enter the stomach in common cases, yet in this diseast: or impaired action of the rumen, they will readily enter there.

199. Staggers, daisy or turning, are sometimes the consequences of over feeding, particularly when from low keeping, cattle ars suddenly removed to better pastarage. Treat with bleeding and purging.

200. Tetanus, or locked jan, now and then attacks cattle, in which case it presents the same appearances and requires the same treat ment as in horses. (11.)

201. Cattle surgery is in no respect different from that in prac tice among horses, the wounds are treated in the same inanner. Goring with the horns will sometimes penetrate the cavity of the belly, and let out the intestines; the treatment of which is the same as in the horse. (56.) Strains, bruises, Sc. are also to be treated like these of horses.

202. Frul in the joot. This occasionally comes on of itself, but is more often the effect of accident: cleanse it well und keep it from dirt:-apply the foot paste. (166.)

203. Wornals, or puckeridge, are tumours on the backs : $f$ cattle occasioned by a dipterous insect which punctures their skin, and deposits its eggs in each puncture. When the eggs are natcied, and the larva or maggots are arrived at their full size, they makc their way out, and leave a large hole in the hide, to prevent which the destruction of the egg should be attempter? by nipping the tumour, or thrusting in a hot wire.

201. Caflle olstetrics are not very variest; young cows of very full habits have sometimes a super-ahundant secretion of milk beforo calring, which produces fever and heat; sometimes from cild taken the same will occur after calving also: in either case, rriva miid dro frou or hay; bathe the udher also with vinegar and water, w sorao 
cases, warm fomentations do best. If the fever run high, treat as under fever in horse pathology.

205. The process of calving is usually performed without diffi. culty; sometimes, however, cross presentations take place, and Bometimes a constriction of parts prevents the natural passage of the calf. To act properly on these occasions, great patience is required, and much mildness; many cows have been lost by brutal pulling; we have seen all the men and boys of a farm mustered to pull at a rope affixed about a calf, partly protruded, which, when it was thus brought away, was forced to be killed, and the mother soon died also from the protrusion of parts this brute; force brought with the calf. A steady, moderate pull, during the thrces of the animal, will assist much; having first directed the attention to the situation. of the calf, and that the presentistion is such as not to obstruct its progress; if it does, the calt must be forced back, and turned or placed aright.

206. Whethering, or retention of the after-birth or burden. It sometimes happens that this is retained; for which no better remedy has been hitherto discovered than warm clothing and drenching with ale, administered as a forcer.

207. The diseases of calves are principally confined to a species of convulsions which now and then attacks them, and which sometimes arises from worms, and at others from cold. When the first cause operates, it is then relieved by giving a mild aluetic purge, or in defuult of that, a mild dose of oil of turpentine, as half an ounce night and morning. In the second, wrap up the animal warm, and dirench with ale and laudanum a drachm. Calves are also very subject to diarrhoea or scouring, which will readily yield to tho usual medicines. (131.)

208. Horn distemper or horn ail. A disorder incident to horned cattle, by which the internal substance of the horn (commonly called the pith, which is the spongy part of the bone) wastes away, \&.c. This disorder may be known by a dulness in the countenance, a sluggish motion, want of appetite, a desire to lie down frequently, shake their head and appear dizzy, \&c. 'To be sure of this disease, take a small gimblet and perforate the horn 2 or 3 inches above the liead: if it $1 \mathrm{~s}$ hollow and no blood follows, it is the hollow horn; This distempar s generally brought on by poverty, \&c.

Bore each horn at the upper and lower side that the drain may bave vent and admuister at least two or three doses of salts on 
some gentlo purgative; inject into the horn strong vinegar and cas:o phorated spirits of salt and vinegar: this will cleanse the horn and effect a cure. Sawing off the horn is sometimes performed, hut, the above receipt is preferable.

209. Vermin on cattle. It is found that a strong decoction o tobacco washed over a beast infected with vermin will generally drive them away. It sometimes will make the beast very sick for a short time. But a better remedy is to mix a plenty of strong Scotch snutr in train oil, and rub the back and neck of the creature with it; which will effectually kill or drive away all vermin frorn a quadruped.

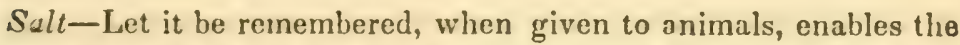
farmer to increase his live stock and keep them in health; henco it ought freely to be given to sheep and cattle of every description but, to initate nature, it should be previously dissolved and ther. mixed with pure fine clay in a mass, which is to be plimed uncer a siolter so that the animals may lap it at plaagure 


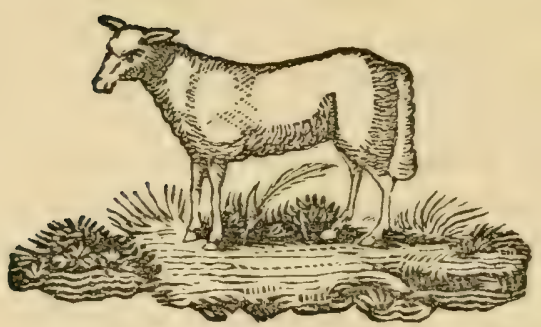

THE

\section{DISEASES OF SILEP.}

210. The diseases of sheep are numerous; for these nnimals are now so highly cultivated that ther may be regarded in some respects as artificial machines : and thus, as a natural consequence, they are subject to a variety of artificial defects and maladies.

211. The rot is a popular term among shepherds, and includes within its range diseases widely diflerent. We shall not therefore follow the custom of treating the different rots of sheep together ; but we shall allow them to fall in the natural order, according to the plan pursued with the diseases of oxen.

212. The inflammatory and putrid fever, popularly known by the names higham striking or blood striking, does not differ materially from the same disease in oxen and cows: and is in sheep also some. times epidenuc, appearing by panting, dullness, watery mucus from the nose and eyes, and great redness of all such parts as aro usually white.

213. The red water. The inflammatory fever sometmes resulves utself into an universal secretion of serum throughout all the cavi lies; in which case after a few days, the lymple tinered with bloud will come away from the nose and mouth in larre quantities. Sometimes after death the bloody serum is found suffused throughour the stin as in the blood striking of skins. 
214. The claveau or sheep pox is also another variety of this dis ease, in which it takes on a pustular form. About the third day enall variole appear: sometimes they are rather blotches than pus. tules. The weakness is usually extreme, and the putridity great. T'his form of the disease is seldom seen with us; but it is shi known on the continent, where the pastures are very poor and lo $\mathrm{N}$, and tec general keeping meagre.

215. The treatment of all these in no wise differs from that di. rected under the inflammatory putrid fever of the ox. The doses of medicines being about a thi: $\downarrow$ of what is directed for them.

216. Malignant epidemic or murrain. Sometimes an epidemic prevails which greatly resembles the murrain of oxen; in appear. ances, termination, and treatment it resembles malignant epidemic of oxen. (178.)

217. Peripneumonia or inflamed lungs, rising of the lights, glanderous rot, hose, $\& \cdot c$. These terms are all modifications of an in. flamed state of the viscera of the chest, caught by undue exposure, bad pasturage, and often from over driving. The cough, trem. blings, the redness of the eyes and nostrils, and the distillation of a fud from them, with the heavings and hot breath, are all simi. lar to those which characterize pneumonia or rising of the lights in oxen. We remember to have seen the disease strongly marked In the February of 1808 , on a farm in the neighbourhood of Streat. nam; where eleven sheep were attacked almost together, after a very stormy night. They were first affected by a loss of appetite, next with a fixed steadfist look, which was common to every one After this, they reeled about, fell backwards and became convulsed. When seen, five were almost dead, whose internal appearances sully confirmed the nature of the disease. The rest recovered by bleeding and drenching, with drenches composed of nitre and tartar emetic. Sometimes the symptoms of pneumonia do not kili immediately, but degenerate into an ulceration of the lungs; which is then called the glanderous rot. This stage is always fitt: : the others may, hy early attention, he combatted by judicious treat. ment, as detailed under the same disease in oxen.

218. A chronic cough in sheep, when not symptomatic of rus : a!ways cured by a chinge of pasturage, particularly into a sa't misli. 
cnmmon on: arises from eating noxious vegutables, and produce the affections termed tremblings. It also produces the grass $i l l$ in lambs, which latter is always accompanied with black foetid fæces, and is readily removed by an ounce of castor oil; while the for. mer usually yields to half an ounce of oil of turpentine, beaten up with the yuk of an egg. Some herbs (as Atropa belladonna) when eaten produce spasmodic affections, which are called by shepherds leaping ill: in such cases the water solution of aloes (Vet. Pha 164, ) in doses of two or three ounces is useful. Daffy's elixir we have also known to be given with good effect.

220. The hove, blast, or wind colic. Sheep are as liable to be distended with an enormous collection within the maw, as oxen. An instrument similar to that invented by Dr. Monro is also made for them; and when not relieved by these means, the same reme. dies are applicable, as are directed for oxen. (188.)

221. A wind colic will also sometimes affect sheep more from the quality than the quantity of what they eat; it is best relieved by an ounce of castor or salad oil with an ounce of gin.

222. Inflamed liver, blood rot, or hot yellows, are liver affections arising from fever settling in that organ; or from obstructed bile irritating it. Sometimes there are great marks of fever, and at others more of putridity; according to which, treat as may be gathered from ox pathology

223. Jaundice also now and then occurs, when refer to that dis:ease in oxen. (197.)

224. Dysentary, gall scour, braxy, are all affections brought on oy sudden changes of temperature, or of undue moisture acting with cold pasturage. It is often seen in sultry autumns :-Treat as sinder ox braxy. (196.)

225. Scouring is the diarrhea of sheep, and in very hot weather soon carries them off. It should be early attended to, by abstract. ing the affected and housing them. The treatment is seen under diurrhœa of oxen, 1195 ,) which it closely resembles.

226. Pinning, tag-belt, break-share. 'The two former are only the adhesion of the tail to the wool, and the excoriation brough on by darrhoa; the latter is the diarrhœa itseif, known to some oy this term.

227. 'The rot in sheep is also called great rot, and kyllopic rots qc. out it is incre popularly known by the single term of rot.- 
Many causes have been assigned for it, as the fuciola hepatzca. or fluke worm; some particular plants eaten as food; ground eanng: snails and other ingesta: but as most of the supposed deleterious herbs have been tried by way of experiment, and have failed to produce the disease, so it is attributable to some other cause.Neither is there reason to suppose that the fluke worm occasions it, since we know the biliary vessels of other animals, as horses, asses, rats, \&c. often have them; and above all, because that they are not always present in the rotted subject. From long expe. rience and the almost invariable effect produced by a humid state of atmosphere, soil, and product, we aro warranted in concluding these are the actual and immediate agents; perhaps the saturated food itself is sufficient to do it. The morning dew has been sup. posed equal to it. Bakewell, when his sheep were past service, used to rot them purposely, that they might not pass into other hanas. This he always readily did by overflowing his pasturages. But great differences of opinion exist as to the quantity, form, and varieties of moisture productive of this fatal disease. It is sald :hat land on which water flows, but does not stagnate, will not rot however moist; but this is contradicted by the experience of Bake. well, who used merely to flood his lands a few times only to rot his sheep. It is also said that they are safe from rot on Irish bogs, salt marshes, and spring flooded meadows, which experience seems to verify. It is also said that the very hay made from unsound land will rot; but this wants confirmation. When salt marshes are found injurious it is only in such years when the rain has satu. rated, or rather super-saturated such marshes. That putrid exhalations unaccompanied with moisture can occasion rot, wants con. firmation also; for these commonly go together, and it is difficult to separate their effects. It is not perhaps the actual quantity of water immediately re seived by land, but the capacity of that land to retain the moisture, which makes it particularly of a rotting quality.

228. The signs of rottenness are sufficiently familiar to persons about sheep. They first lose flesh, and what remains is flabby and pale; they lose also their vivacity. The naked parts as tho lips, tongue, \&c. look livid, and are alternately hot and cold in the advanced stages. The eyes look sad and glassy, the breath is fetid, the urine small in quantity and high coloured: and the sowels are at one time costive and at another affected with a black purging. The pelt will come off on the slightest pull in almost all cases. The disease has different degrees of rapidity, but is alwavs iatal at last This difference in degree occasicns 8 ) 
sheop (1) thrive well under its progress to a cortain stage, when they sidilenly fall off, and the disease pursues the same course witn the rust. Some graziers know this crisis of declension, as it has been called, and kill their sheep for market at the immediate nick of time with no loss. In these cases no signs of the disease are to be traced by ordinary inspectors, but the existence of the flukes, and still more a certain state of liver and of its secretions, are characteristic marks to the wary and experienced.

229. The treatment of rot is seldom successful unless when it is early commenced, or when of a mild nature; a total change of tood is the first indication, and that to a dry wholesome kind : all the farina are good, as the meals of wheat, barley, oats, peas, beans, \&c. Carrots have done good mixed with these; broom, burnet, elder, and mellilot, as diureties, have also been recommended; but it is necessary to observe, that there is seldom any ventral effusion but in the latter stages of the complaint. As long as the liver is not wholly disorganized, the cure may be hoped by a simple reinoval of the cause, which has been shown to be a va riable temperature, with excessive moisture of pasturage which may also be aided by such remedies as assist the action of the biliary system ; salt acts in this way, and thus salt mashes are good; salt may also be given in the water. Salt appears the principal ingredient in Flesh's patent restorative for sheep, for it states it to be composed of turpentine, sal ammoniac, turmeric, quicksilver, brimstone, salt opium, alkanet ront, bark, antimony, camphor, and distilled water; but in this medley none of the articles can be in sufficient quantity to prove useful, but the salt. In the more udvanced stages of the disease, when the liver has become mate. rally affected, it is prudent to rub the bellies of each sheep with half a drachm of mercurial ointment every other day for a week; give also the following, every morning; watery tincture of aloes half an ounce; decoction of willow bark, four ounces; nitric acid lwenty-five drops.

230. The pelt rot, hunger rot, or naked disease, is a variety of the former, but with this difference, that whereas the liver in the lydroptic rot, is principally affected; in this the whole of tho chylopoictic viscera are injured; the mesenteric glands are al. ways swollen and obstructed, and from thence arises the emaciafon and unhealthy state of all the secretions, by which the rot necomes incapable of receiving nutriment, and falls off leaving the body bare, and in the last stages the teeth and hurns alse coser. Indifferent, unhealthy keeping, is a very commow cause ${ }^{\circ}$ 
this inalady, and a contrary course of feeding is the best remedy when tho disease has not gone on too long.

231. The scal, shab, ray or rubbers, are sometimes arysipeliatous cruptions, and sometimes they are psoric or mangy ones. In tho fotmer instance they are universal and very red, occasioning a great heat and itching, and are thence called the rubbers: in such cases, nitre administered quickly relieves, with change of food. The eruptive scab is seldom cured without an external application cither of those directed for mange, lowered to half the strength will relieve it once. (See Vet. Pha. 171 and 172.)

232. Foot rot sheep have a secretory outlet between the claws peculiar to them, which is liable to become obstructed: their feet are also liable to become injured, and then diseased, from travel. ling or continued standing on wet soils: but the real foot rot is an endemial affection which sometimes attacks half of the flock. It must be attended to by removing all diseased portions, and then dressing with the thrush paste, or foot rot application, (Vet. $\mathrm{P} /$. 133,) and afterwards wrapping up from external exposure.

233. Staggers, gid, turnsick, goggles, worm under the horn, stur $d y$, watery head, and peudro, are all popular terms for hydatids, or an animal now known as the trenis globulus, which by some unac. countable means, finds its way to the brain and settles itself there, either in some of its ventricles or more frequently on its substance. Their size varies from the smallest speck to that of a pigeon egger, and the sheep it attacks are usually under two years old. These animals are likewise occasionally found in all the natural cavities of the body.

234. The appearances of cerebral hydatids are, stupidity, a disposition to sit on the rump, to turn to one side, and to incline the head to the same while at rest. The eyes glare, and from ovad che pupils become round. An accurate examination will now us!! ally discover some softness at a particular part of the skull, gene rally on the contrary side to that which the animal hangs the head when no softness of the skull is discernable, the hydatid usuall, exists in some of the ventricles, and the destruction of the sheey s certain and quick, from the greater disturbance to the functions of the brain; but when it is situated on the surfire., it sometumes requres many montlis to destroy; an absorption of the oone takes pace and the hyditid increase's, which produces the thro sess in tive oxull ouposite to the affected part. 
235 This disease is not incurable, as has been supposed, but it it only rolieved by a manual operation. In Franco it has been success. iully treated by the application of the actual cautery: a pointed iron, heated red hot, is forced through the skin and skull, to the eurface of the brain; the principal nicity of which, is in penetrating the hydatid with the hot iron without wounding the brain itself: In England, some shepherds are very dexterous at wiring, which they do by thrusting a wire up the nostriis till it rests against the skull. In the passage of the wire, the hydatid is usually ruptured, others elevate the skull (by means of a trephine, or even a linifo) opposite to the soften portion, and extract the hydatid, if possi ble, whole, which a little care will effect, by drawing it away with a blunt pincer, gently moving it from side to side. Tapping is merely letting out the fluid contents of the hydatid by an awl, which is practised by some shepherds with success; and if the instrument be not thrust too far, the animal is never injured; to avoid which, it is passed obliquely. A well hardened gimblet is a proper instrument, with which the skull is easily penetrated, and an opening by the twisting of the instrument is made, suff. ciently large in the hydatid itself, to discharge its contents, which is all that is sufficient to insure its destruction, and which, if no other exist, is followed by immediate recovery.

236. Frontal worms. Sheep are observed to gather together, with their noses thrust inward to avoid the attack of the œstrus uvis, or fly, that lays its eggs on the inner margin of the nose, which, having become hatched, the larva creep up into the frontal and maxillary sinuses, to the torment of the sheep. It is re. commended to cover their nostrils during the short stay of theso insects, with a gauzy substance, through which the animal can breathe, and keeping it on with some adhesive plaster, \&c. or daubing the nose often with tar, train oil, or mercurial ointment, \&c. Remedy-Take half a pound of good Scotch snuff, pour two axarts of boiling water on it, stir it and let it stand till cold, inject about a table spoonful up each nostril, with a syringe; repeat three or four times at proper intervals, from the middle of October to the first of January. Half an ounce of assafotida pounded in a littlo water added to the snuff will make it more effectual. The owner need not be alarmed after the operation to see the sheep very krunk, \&c. as they will soon recover.

237. Fluke worms are a parasitic animal, found in tl.e biliary pinuses, not only of the sheep, but of the horse, ass, goat, deer \&ce. and whose existence is rather a consequence than a cause of marbidity 
¿38. Diseıses of lambs are confined to indigestion, and eruption of secreted matter: the former shows itself in colic, which is re. Juved as in sheep, and also by diarhoea, to be likewise cured by the means detailed for them; the latter is more obstinate, begins on the rump, gradually extending along the chine, and when it becomes more universal, it usually destroys. The cure consists in giving daily drinks of half a drachm of cream of tartar, and one drachm of sulphur, in four ounces of chamomile decoction. Anount also with mild mercurial ointment and 'Turner's cerate in equa? quantities.

239. Poison. Sheep are often poisoned by eating laurel or ivy, as it is commonly called (not the magnolium.) The symptoms of which is their foaming at the mouth, then vomiting the half mas. ticated leaves and green juıce, by which the mouth of the animal is discoloured. Remedy-Take a gill of sweet oil, hog's lard, or fresh butter; mix it with $\_$pint of new milk. If taken seasonably it will effect a cure. Or, an egg given to each of the diseased, in the shape of a natural bolus, by simply breaking the egg snd slipping the yelk, and as much white as practicable, down the throat of the animal. The sheep, after swallowing the egg, will vomit ap the leaves and green juice, but none of the egg. To cows givo four times the quantity.

240. To destroy sheep ticks. Make a weak solution of arsenic, in which the lambs are to be dipped a few days after shearng the sheep, as the ticks having then no harbour on the old sheep. will resort to the lambs for shelter-this is the time to destro them. Not the smallest injury will occur to the sheep, provided you take care to keep the head out of the water. Three persons are necessary - two to hold and dip the lamb, the third to squeeze the wool while the lamb is held over the tub. Or-An ointment made of Scotch snuff and hog's lard, or train oil, will kill or destroy them by one application. One ounce of snuff to a poutd of lard or oil, is about the peuportion.

211. The castraung lambs, may be performed any time from the agn of a fortnight ur threo weeks, to that of a month or six weeks, the lambs should be in a healthy stato when it is done, as unde: any other circumstance they are likely to be destroyed by it. The operation is performed by opening the scratum or cod and draw ins out the testicles with the spermatic cord. This is orten dono with the teeth in the young state of the animal, but when the ope ration is perfomed at a later pertod, it is usual to have recourso 
to tho knife, the arteries being taken up and secured by maans of ligatures or the searing iron; the business to be done in fuir wea ther, when not too warm; the grelded lambs, \&c. should be kept in u dry shelter and quiet situation for a few days.

Sore nipples. Lambs very often die of hunger from their dam refusing them suck. 'The cause of thins is sore nipples, or sone lumour in the udder, in which viclent prin is excited by the strik. sing of the lamb. Washing with suge of lo al and wator of soirito, Wil. remove the complaint. 


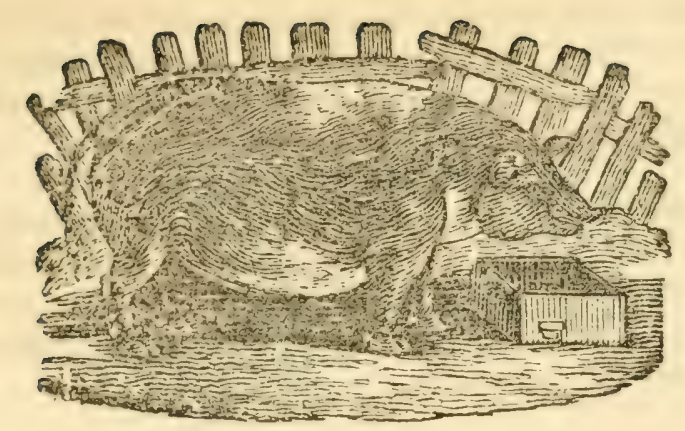

OF THE

\section{DISEASES OF SWINE.}

242. Swine are subject to varions diseases, but according 10 Ian rence, they are not easily doctored. Tirey are subject, he ways, 16 pox or measles, blood striking, staggers, quincy, indigestion, catarrh. peripneumonia, and inflammation of the luness, called heavings. When sick, pigs will eat, and they will take medicine in their wash , when they will not eat, there is no help for them. As aperients, cleansers, and alteratives, sulphur, antimony, and madder, are our grand specifics, and they are truly uscful. As cordials and tonics, reiscle and strong beer, in warm wash, and good peas and pollard. In the measles, sulphur, \&c. and, if the patient require it, give cordrias now and then; in staggers, bleeding, fresh air, and perhapg nitre; in catarrh, a warm bed, and warm cordial wash, and the same in quincy or inflammation of the glands in the throat. If external suppuration appear likely, discharge the matter when ripe, ar.d dress with tar and brandy, or balsain. The heavings or unsoundness of the lungs in pigs, like the unsoundness of the liver in lambs, is sometimes found to be hereditary; there is no remedy. This disease in pigs is often the consequence of colds fiorn wet lodging, or hasty feeding in a poor state; in a eertain stage it is highly inflam. mutory, and without remedy. Unetion with train vil, and tho internal ase cPit, have been sometimes thought beneficial.

213. Cutting and spaying. Cutting the young pig is performed at six or seven weeks old, according to their strength; in a weels after which they may be wesved. After weaning shut up the sow closely, feed weil, and on the reflux of the milk, she wiii express very loudly her desire for the company of the bour. It is necessary to state that sows are voracious, and occasionally fierce and 6avage animals, and have actually devoured young children. The sow is 
spayed while sle gives suck, and the boar safely castrated at any age. 'The operation of castrating is performed by cutting them across the middle of each stone, then pull them gently out and anoint the wound with tar. Spaying is performed by cutting in the mid flank, on the left side, with a sharp knife or lancet, in order to extirpate or cut off the parts destined for conception, and then stitch up the wound, anoint the part with tar salve, keeping the animal warm for two or three days. The usual way is to make the incision $m$ a sloping manner, two inches and a half long, that the fore finger may be put in towards the back, to feel for the ovaries, which are I wo kernels as big as acorns, one on each side of the uterus, one of which being drawn towards the wound, the cord or string is cut, and thus both taken cut. 


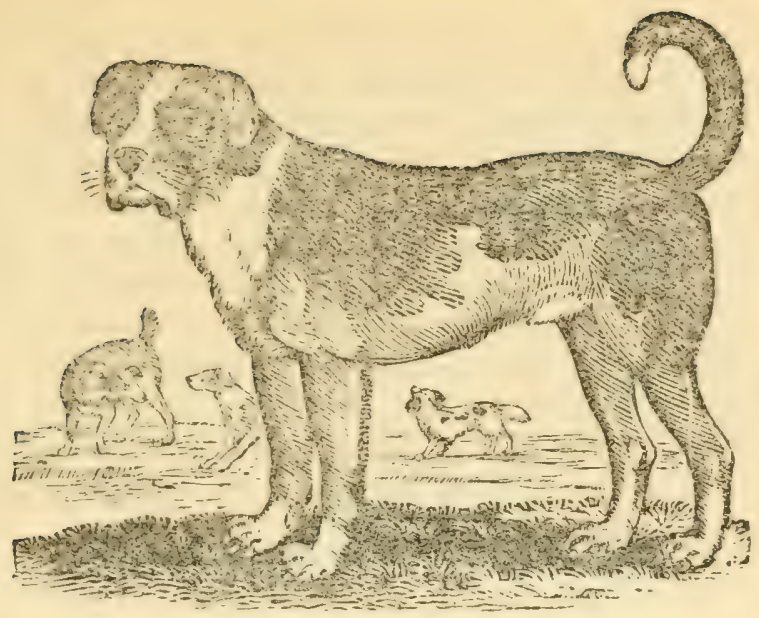

\section{"IE DISEASES OF DOGS.}

211. The diseas of dogs are very numerous. The fulowing are described by Blaine as the most prevalent, with their methods of cure.

245. The canine asthmo is hardly ever observed to attack any but either old dogs, or those who, hy confinement, too full living, and wint of exercise, may be supposed to have become diseased by these deviations from a state of nature. It is hardly possible to keep a door very fat for any great length of tinie, without bringing it on. This cough is frequently confounded with the cough that precedes and accompanies the distemper, but it may be readily distinguished from this by an attention to circunstances, as the age of the animal, its not affecting the general health, nor producing immediate ema. ciation, and its less readily giving way to medicine.

24fi. The cure is often very difficult, because the disease has in general been long neglected before it is sufliciently noticed by the owners. As it is in general brought on by confinement, too much warmth, and over feeding; so it is evident the cure must be begun oy a steady, persevering alteration in these particulars. The medi entes most useful, are alteratives, and of these occasionally emetics are the best. One grain of tartarised antimony (i. e. tartar emet:c) * 1 th two, three, or four grains of calomel, is a very useful ans valuable emetic. This duse is sufficient for a small dog, ana mav be repeated (wice a week with great success-always with palliation

247. Of diseases of the eye, dugs are subject to almost an great a variety as ourselves, many of whish end in blindness. No tross aent yet discovered will remove or prevent this complaint. 
248. Sore eyes, though not in general ending in blindness, aro very common among dogs. I $\hat{t}$ is an affection of the eyelids, is not unlike the scrofulous affection of the human eyelids, and is equally benefitted by the same treatment: an unguent made of equal parts of nitrated quicksilver ointment, prepared tutty and lard, very lightly applied. Dropsy of the eyeball is likewise sometimes met with, ont it is incurable.

249. Cancer. The virulent dreadful ulcer, that is so fatal in the human subject, and is called cancer, is unknown in dogs; yet thero is very commonly a large schirrus swelling of the teats in bitches and of the testicles (though less frequent) in dogs, that as it some times becomes ulcerated, so it may be characterized by this name In the early state of the disease discutients prove useful, as vinegan with salt, and camphor and Spanish flies, with mercurial ointment, bave sometimes succeeded; taking care to avoid irritating the par so much as to produce blister. But when the swelling is detached from the belly, and hangs pendulous in the skin, it had better be renoved, and as a future preventative suffer the bitch to breed. sichirrus testicles are likewise smetimes met with; for these no treatment yet discovered succeeds but the removal of the part, anil that before the spermatic chord becomes much affected, or it will he useless.

250. Culic. Dogs are subject to two kinds of colic; one arising from constipation of the bowels, the other is a kind peculiar to dogs, apparently partaking of the nature of rheumatism, and also of spasm. From a sudden or violent exposure to cold, dogs become sometimes suddenly paralytic, particularly in the hinder parts; having great taderness and pain, and every appearance of lumbago. In every matance of this kind, there is considerable affection of the bowels, generally costiveness, always great pain. A warm bath, external stmulants, but more particularly active aperients, remove the colic. Colic arising from costiveness, is not in general violently acute from tire pain it produces; sometimes, however, it appears accompanied with more spasm than is immediately dependent on the confinem snt of the bowels. In the former give active aperients, as calomel w th pll. cochiø, i. e. alontic pill and clysters; in the latter castor ol with laudanum and ether.

251. Cough. T'wo kinds of cough are common among dogs, a ne nccompanying distemper, the other in an asthmatic affection of the chest. (See 245, 252.)

252. Distemper. This is by far the most common and most fatal among the diseases of dogs; hardly any young dog escapes it-ane of the few who do escape it in their youch, three-1ourths are attacker with it st sune veriod afterwards: it being a mistake that poung 
dngs only have it. It inowever, generally attacks before the anima? arrives at eignteen months old. When it comes on very early, tho bhances of recovery are very small. It is peculiarly fatal to grev hounds, much more so than to any other kind of dog, generally carrying them off by excessive scouring. It is very contugious, bu: it is by no means necessary that there should be contagion presen? Ir. produce it; on the contrary, the constitutional liability to it is cnel, that any cold taken may bring it on; and hence it is very com. mon to date its commencenent from dogs being thrown into water, or shut out on a rainy day, \&c. . There is no disease which pre. ocnts such varieties as this, either in its mode of attack, or during its continuance. In some cases it commences by purging, in others oy fits. Some have cough only, some waste, and others have moisture from the eyes and nose, without any other active symptom. Moist eyes, dullness, wasting with slight cough, and sickness, are the common symptoms that betoken its approach. Then purging cones on, and the moisture from the eyes and nose from mere mucus, becomes pus or matter-there is also frequently sneezing, with a weikness in the loins. When the disease in this latter case is not speedily removed, universal palsy comes on-during the progress of the complaint some dogs have fits. When one fit succeeds another quickly, the recovery is extremely doubtful. Many dogs arf iurred off rapidly by the fits or by purging; other waste gradu. ally from the running from the nose and eyes, and these cases are always accompanied with great marks of putridity.

253. The cure. In the early statres of the complaint give emetics; they are peculiarly useful. A large spoonful of common salt dis. solved in three spoonfuls of warm water, has been recommender: the quantity of salt being increased according to the size of the dog, and the difficulty of making him vomt. While a dog remaint strong, one every other day is not too much: the bowels should be kept open, but active purging should be avoided. In case the com. plaint should be accompanied with excessire looseness, it should be immediately stopped by balls made of equa. parts of opium, guin arabic, prepared chalk, and conserve of roses with rice milk as fond Two or three grains of James' powder may be advantageosuly given at niyht, in cases where the buwels are not affected, and in the caseo where the matter from the nose and eyes betokens much putridity, we have witnessed great benefits from balls made of what is ternen Friat's balsam, gum guaiacum, and chamomile flowers in powder Doggs in every stage of the disease should be particularly well fed. A seton wo have not found so useful as is generally supposed. where the nose is much stopped rubbing tar on the upper part 
"nseful. and when there is much stupidity and the head seems sucec alfected, a blister on the top is serviceable.

Or, Take me part aloes, two parts salt petre, and four parts sul. phur, incorparate the whole together, and take as much as will lie on the point of a dinner knife, either put it into warm milk, and drench the $\mathrm{dog}$, or give it to him in slices of meat. T'io up your aog for twenty-four hours after, and repeat the same in a day or two after, should the dog not be relieved.

254. Fits. Dogs are peculiarly subject to fits. These are of various kinds and arise from various causes. In distemper, dorgo are frequently attacked with convulsive fits, which begin with a champing of the mouth and shaking of the head, gradually extending over the whole body. Sometimes an active emetic will stop their progress, but more generally they prove fotal. Worms are often the cause of fits in dogs. These deprive the animal wholly of sense; he runs wild till he becomes exhausted, when he gradually recovers, and perhaps does not have one again for some weeks. Confine ment prodnces fits and likewise costiveness. Cold water thrown sver a dog will generally remove the present attack of a fit; and tor the prevention of their future recurrence it is evident that the foregoing account of causes mut be attended to.

255. Inflamed bowels. Dogs are very subject to inflammation of their bowels, from costiveness, from cold, or from poison. When inflammation arises from costiveness, it is in general very slow in its prograss, and is not attended with very acute pain, but it is characterized by the want of evacuation and the vomiting of food taken, though it may be eaten with apparent appetite. In these cases, the principal means to be made use of, are the removal of the constipation by active purging, clysters, and the warm bath. Calomel with aloes forms the best purge. But when the inflam mation may be supposed to arise from cold, then the removal of any costiveness that may be present, is but a secondary consider. ation. This active kind of inflammation is characterized by violent banting, total rejection of food and constant sickness. There is great heat in the belly, and great pain; it is also accompanied with great weakness and the eyes are very red. The bowels should be gently open'd with elysters, but no aloes or calomel should be made use of The helly should be blistered, having first used the warm bath When the inflammation arises from poison, there is then constant sickness, the nose, paws and ears are cold, and there is a frequent 4.vacuation of prown or bloody stools. Casıor oil should be given, wi.u clysters of mutton broth thrown up, but it is seldom any treat. nont succepd:

$256^{\circ}$ In Ramed lungs. Pleurisy is not an uncominor disease 
a) , fors. It is sometimes epidemic, carrying off great numbers. Its atuck is rapid and it generally terminates in death on the third day, by a great effusion of water in the chest. It is seldom that it is taken in time, when it is, bleeding is useful, and blisters may be applied to t!ie chest.

25\%. Madness. The symptoms of madness are concisely summed up by Diniel, in the following words : "et first the dog looks dull. shows an aversion to his food and company, does not bark as usuil. but secms to murmur; is peevish and apt to bite strungers; his ears and tail drop more than usual, and he appears drowsy; after. wards he begins to loll out his tongue and froth at the mouth, his eyes seeming heavy and watery; if not confined he soon goes olf. runs panting alnng with a dejected air, and endeavours to bite any one he meets." As persons are continually alarmed at the approach of every strange dog, the following observations founded on expe. rience may be of service in knowing what dogs to avoid: I have seen many mad dogs but never knew one in that state to curl its tail. This is a certain indication of not being mad: If you see a dog dirty at the mouth, coming at a trot with his head high, and a drooping tail avoid him as a viper. Or if you see one sitting sickly and dirty at the mouth, avoid him, though it is not likely that ine will snap at you in that period of the disease. I never met a mad dog, on being pursued, (if his pursuers were not in actual reach to stone him, \&c.) to exhibit any signs of fear, he generaliy goes if not impeded, in a straight line against the wind at a brisk trut. wholly unconcerned at the shouts of the multitude pursuing hm, and never squats his tail. I never knew a dog that was not marl, on being pursued and shouted after by a number of penple, not to exhihit every symptom of terror-squatting his tail, turning his head and scampering in every direction. If a mad dog escapes heing killed, he seldom runs above two or three days, when he dies, exhausted with heat, hunger, and disease. As this is a subject of no sught importance, we shall stand excused for introducing the criteria is described by Blaine, whose account of the disease founded on long experience and attentive observation, is calculated to remove man 7 unfounded and dangerous prejudicss relitive to it. He describes it as commencing sometimes by dullness, stupidity and retreat from obsorvation; but more frequently, particularly in these dogs that are immediately domesticated around us, by some alteration in their natural habits; as a disposition to pick up and swallow every miruto ohject on the ground; or to lick the parts of another dog incessantly. or to lap his own urine, fic. About the second or third iay. the disease usually resolves itsull into one of two types. 'The one is :a. led raging afr! the other dumb madness. These distinctions aie nos 
however always clear; and to which is owing so much of diacrep ascy in the accounts given by different persons of the discase.

258. The raging madness, by its term has led to an errnneous conclusion, that it is accompanied with violence and fury, which however, is seldom the case: such dogs are irritable and snappish, and will commonly fly at a stick held to them, and are inpationt of restraint; but they are seldon violent except when irritated or worried. On the contriry, till the last moment they will often acknowledge the voice of their master and yield some obedience to it. Neither will they usually turn out of their way to bite human persons, but they have an instinctive disposition to do it to dogs, and in a minor degree to other animals also; but as before observed, seldom attack mankind without provocation.

259. Dumb madness is so called, because there is seldom any barking heard, but more particularly, because the jaws drop paralytic, and the tongue lolls out of the mouth, black, and apparently strangulated: a strong general character of the disease, is the disposition to scratch their bed towards their belly; and equally so is the general tendency to eat trash, as hay, straw, wood, coals, dirt, \&c. and it should be remembered, that this is so very common and 80 invariable, that the finding these matters in the stomach after death, should always render a suspicion formed of the existence of the disease, confirmed into certainty. Blaine is also at great pains to disprove the notion generally entertained that rabid dogs are averse to water; and neither drink or come near it. This error, he contends, has led to most dangerous results; and is so far from true, that mad dogs, from their heat and fever, are solicitous for water, and lap it eagerly. When the dumb kind exists in its ful' Force, dogs cannot swallow what they attempt to lap; but still they will plunge their heads in it, and appear to feel relief by it : but in no instance out of many hundreds, did he ever discover the smallest aversion to it. He lays very great stress on the noise made by rabid dogs, which he says is neither a bark nor a howl, but a tone compounded of both. It has been said by some that this disorder is occasioned by heat or bad food, and by others that it never arises from any other cause but the bite. Accordingly this malady is rare in the northern parts of Turkey, more rare in the southern parts of that empire, and totally unknown under the burning sky of Egypt. At Aleppo, where these animals perish in great numbers for want of water and food, and by the heat of the climate, this disorder was never known. In ther parrs of Africa and in the liottest zone in America, dogs are no. ver attacked with madness. Blaine knows of no instance of the romplasat. being cured, although he has tried to their fullest es tenth 
the popplar remedies of profuse bledings, strong mercurial ard ar. nenical doses, vinegar, partial drowning, night shade, water plan tain, \&.c. ho, therefore recommends the attention to be principally directed towards the prevention of the malady.

260. The preventive treatment of rabies or madness, is according to Blaine, always an easy process in the human subject, from the immediate part bitten, being easily detected; in which case the semoval of the part by excision or cautery is an effectual remedy. $\mathrm{B} \mathrm{t}$ unfortunate for the agriculturist, it is not easy to detect the bitten parts in cattle, nor $\mathrm{m} \mathrm{dogs;}$ and it would be therefore most desirable if a certain internal preventive were generally known. Dr. Mead's powder, the Ormskirk powder, sea bathing, and many other nostruns are deservedly in disrepute: while a few country remedies, bat littie known beyond their immediate precincts, have maintained some character. Conceiving that these must all pos. sess some ingredient in common, he was at pains to discover it and which he appears to have realized by obtaining among others the compositions of IVebb's Watford drink. In this mixture, which is detailed below, he considers the active ingredient to be the buxus or box, which has been known as a prophylactic as long as tho times of Hippocrates and Celsus, who both mention it. The reci. pe detailed below has been administered to nearly three hunared animals of different kinds, as horses, cows, sheep, swine and dugs and appears to have succeeded in nineteen out of every twenty cases where it was fairly taken and kept on the stomach. It appears also equally efficacious in the human subject; in which case ho 2dvises the extirpation of the bitten parts also. The box preventive is thus directed to be prepared:-Take of the fresh leaves of the tree-box, two ounces; of the fresh leaves of rue, two ounces; of sage, half an ounce; chop these fine and boil in a pint of water to half a pint; strain carefully, and press cut the liquor very firmly, put back the ingredients into a pint of milk, and boil again to half a pint; strain as before; mix both liquors, which forms three do. nes for a human subject. Double this quantity is proper for a horse or cow. Two-thirds of the quantity is sufficient for a large dog, half for a middling sized, and one-third for a small dog. Three do. ses are sufficient, giving each subsequent morning fasting, the quan tity directed being that which forms these three doses. As it some. times produces strong effects on dogs, it may be proper to begis with a small duse, but in the case of dogs we hold it always pru dent to increase the dose till the effects are evident, by the sick ness, panting, and uneasiness of the dog. In the human s"rbject where this remedy appears equally efficiscious, we have never win aessed any unpleasunt or artive efiects, neither are suri: obcerven 
in cattle of any kind. About forty human persons have taken this remedy, and in every instance it has succeeded equally as with an. mals : but candor obliges us to notice that in a considerable pr.s portion of these, other means were used, as the actual or potentia. cautery: but in all the animals other means were purposely omit. ted. That this remedy therefore has a preventive quality, is un. questionable, an' now perfectly established; for there was not tho mallest doubt of the animals mentioned either having been bitten, or of the dog being mad who bit them, as great pains were in every instance taken to ascertain these points.

261. To prevent canine madness. Pliny recommends worming of dogs; and from his time to the present it has had, most de. vervedly says Daniel its advocates. He tells us, that he had varions upportunities of proving the usefininess of this practice, and re. commends its general introduction. The fact, however, is, that taking out the worm has nothing to do with annihilating the dis order, although it will most certainly hinder the dog seized with it from doing any hurt to man or beast. A late author asserts, ho had three dogs that were wormed, bit hy mad dogs at three se. veral periods, yat notwithstanding they all died mad-they did not bite, nor do any mischief, that being determined to make a fill experiment, he shut one of the mad dogs up in a kenne!, and put to him a dog he did not value-the mad dog often run at the other to bite him, but his tongue was sn swelled that he could. not make his teeth meet; the dog was kept in the kennel until the mod one died, and was purposely preserved for two years af. terwards, to note the effect, but he never ailed any thing, although wo remedies were applied to check any infection that might huve been received fiom the contict of the dog. The writer has had various opportunities of proving the usefulness of worming, and mserts three of the most striking instances, under the hope of in. ducing its general practice. A terrier-bitch went mad, that was kept in a kennel with forty couple of hounds; not a single hound was bitten, nor was she seen to ofier to bite. The bitch being of a peculiar sort, every attention was prid to the gradations of tho disease (which were extremely rapidi) minutely noted; the hy. dropiobia was fast approaching before she was separated from the hounds, and she died the second day after; at first warm milk was placed before her, which she attempted to lap, but the throat efused its functions: from this period she never tried to eat or drirk, seldom rose up, or even moved, the tongue swelled very much, and long before her death the jaws were distended by it. A spanial was observed to be seized by a strange dog, and was on in the lip; the servant who ran up to part them narrouly ev 
caped, as the dog twice flew at him; a few minutes after iro dog hatd quitted the yard, the people who had pursued, gave no. tice of the dng's madness, who had made terrible havoc in a course of ten miles from whence he had set off. 'The spaniel was a great fuvourite, had medicine applied, and every precaution ta. ken; upon the fourteenth day he appeared to loathe his food, and his eyes looked unusually heavy : the day following he endeavored to lap milk, but could swallow none; from that time the tongur began to swell: he moved but seldom and on the third day he died; for many hours previous to his death, the tongue was so enlarged, that the fangs or canine teeth could not meet each othes by up. wards of an inch. The homnds were some years after parted with, and were sold in lots: a madness broke out in the kennel of the gentleman who purchased many of them, and although several of these hounds were bitten and went mad, only one of them ever attempted to bite, and that was a hound from the Duke of Port. land's, who in the operation of worming had the worm broke by his struggling, and was so troublesome that one half of it was suffored to remain; the others all died with symptoms similar to the terrier and spaniel, viz: a violent swelling of the tongue, and a stujor rendering them nearly motionless, and beth which symp. toms seemed to increase with the disease. The idea that worming prevents a dog from receiving the infection when bitten should be exploded; but the foregoing show how far it may be recommended for the restriction of a malady horrid in its effects, where a human ocing is concemed, and which to the sportsman and farmer are at. tended with such dangerons and expensive consequences. Biaine on the contrary, asserts, that the practice of worming is whol's useless and founded in error; and that the existence of any thing like a worm under the tongue is incontestibly proved to be fulse, and that what has been taken for it, is merely a deep ligature of the skm, placed there to restrain the tongue in its motions. He also observes, that the pendulous state of the tongre in whar is called dumb madness, with the existence of a partial paralysis of the under jaw, which they could not bite, hwving happened to doge previously wormed, has made the inability to be attributed to this source, but which is wholly an accidental circunstanco; and hap. pens equally to the wormed and unwormed dog.

D62. The worming of whelps is perforned with a lancet, to siat the thin skin which immediately covers the worm; a small awl is then to be introduced under the centre of the worm to raise it up, the further end of the worm will with very little force make its appearance, and with a cloth taking hold of that end, the other will be drawn out easily; cure should be taken that tho whuse u 
the worm comes away without breaking, and it rarely breaks un ess cut into by the lancet, or wounded by the awl.

263. Mange. This is a very frequent disease in dogs, and is an affection of the skin, either caught by contagion, or generated by the animal. The scabby mange breaks out in blotches along the back and neck and is common to Newfoundland dogs, terriers, pointers, and spaniels, and is the most contagious. The cure should be begun by removing the first exciting cause, if remova. ble, such as filth or poverty; or, as more general the contrary (for both will equally produce it,) too full living. Then an ap. plication should be made to the parts, consisting of sulphur and sal ammoniac : tar lime water will also assist. When there is much heat and itching, bleed and purge. Mercurials sometimes assist, but they should be used with caution; dogs do not bear them wel!. Or, fresh butter, free from salt, quarter of a puund ; red precipitate, one ounce; Venice turpentine, one ounce: mix the whole well to. gether, and put it into a pot for use, rub it on the parts affected morning and evening, keep your dog tied up, and keep him warm and dry for some days.

264. Worms. Dogs suffer very much from worms, which as in most animals, so in them are of several kinds: but the effects produced are nearly similar. In dogs having the worms the coat gen. erally stares; the appetite is ravenous though the animal frequently does not thrive; the breath smells, and the stools are singular, sometimes loose and slimy, and at others hard and dry; but the most evil they produce is occasional fits, or sometimes a continued state of convulsion, in which the animal lingers sometime and then dies; the fits they produce are sometimes of the violent kind; at otners they exhibit a more stupid character, the dog being senselese and going round continually. The cure consists while in this state, in active purgatives joined with opium, and thé warı bath; ang rough substance given internally, acts as a vermifuge to preven: the recurrence. 


\section{ADIDNDA.}

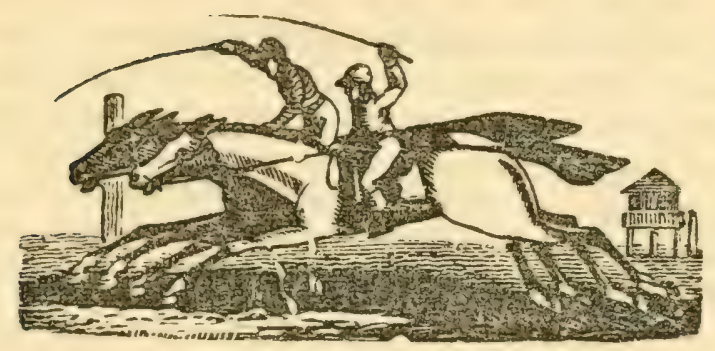

ANNALS OF THE TURF

AND

AMEIRICAN STUD BOOK,

RUI.ES OF TRAINING, RACING, dc

IRESPC'TFULI,Y INSCRIBED

TO THR

AMA'ILUR, SHORTSIIAN, AND BREEDEK

OF THE

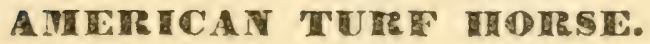




\section{EDITUR'S PIEFACE.}

Tre Publisher of the following work, with a view to an extension of its value, and to bestow on posterity a list of some of our most celebrated blood horses and mares, as well as those that have been imported, has added, with all the care the object so well merits, an American S'Tud Book, that such as may wish to breed from a particular stock, may trace the pedigree, in a way more satisfactory than vague report. The publisker thankfully acknowledges, that he is much indebted for information derived from the "American Farmer," and "American Turf Register," edited by J. S. Skinner, Esq. of Baltimore, to which works he confidently refers such of his readers as may wish further information as to the performance of many of the stud herein noticed, as well as for other particulars, perhaps too numerous for insertion in a small volume.

The publisher will not deny, that errors may unavoidably occur in a work of this sort; but he offers it with a confidence, nevertheless, that it contains a greater number of pedigrees of blooded horses, than has been ever before published in our country; and that it will be considered. at least, as meriting the consideration which should intach to a work, possibly proving an introduction to a complete Stud bonk. 


\section{ANNALS OF THE 'HURE.}

\section{Respectfully inscribed to the Amateur, Sportsman and Breeder of the American Turf Horse.}

Arnals of the Turf.-"THF transcendent consequence of tho forse to man in everv possible stage of human existence, has liev: the invariable theme of writers on the subject from the earliest records of time. Indeed it is impossible to conceive any other, out of the vast variety of animals destined by nature to human use, which can, with the least prospect of success, dispute with the fivourite horse the palm of his master's predilection and attuchuent. It is an attachment of a truly rational nature, and to a most worthy object. The very idea of being supported at ease by an auxiliary and bolrowed aubual power, and of being safely borne from place to place, at will, with a pleasant and gentle motion, or with tho rapidity of lightning, must have impressed the mind of the first discoverers of the mighty benefits of the horse, with ineffible delight. Nuch sentiments and foelines respecting this noble animal have been coustantly entertained and handed down to us from the earliest ages. 'The general beanty, the harmony of' proportion, the stauli. ness and delicacy of the superior species of this paragon of brute animals, could not fail of inspring admiration in the breasts even of sitvare and untutured men. 'Time and the mproving fitculties of man, gratualiy developed the various uses aud qualifications of the horse. Endowed by nature with a portion of intellect, with a generous pliability of disposition and fortitude of heart, with vast. and energetic bodily powers, he was fonnd capable of bearing a sort of social part in all the pleasures and labours of man. He was associnted with his master in the pleasures of the jommey and the chase; he shares willingly and with ardour in the dangers of the martial field; and with a steady prowess partook in the humble labours of cultivating the soil for nutual subsistence. By the lisost illustrious mations of either ancient or modern times, the horse has ever been esteemed of the highest worth and conseguence, and treated with a distinction and attendance hefitting his rank as the first of domestic animals, apploxinating in socisty and service to human nature It is among the most savage and debased tribes of men $01 \mathrm{l} y$, that the breed, condition, and comforts of this moble ani-nal have been neglected."

'This quotation from a very splendid Enulish work on the blord horise, is no less just in sentiment than beatutifil in language. It is proposed to treat of the value of the blood horse to our communn stocks, and of the various uses to which his conformation adapta hian. It has at every period bern fishionahle wit! a certain class of moralists, who were more rigil than correct, to decry the spoits of the turf; and, firther, fo rontend that the breed of looses having ruceived all the improvement of which it is susceptible, troun tho

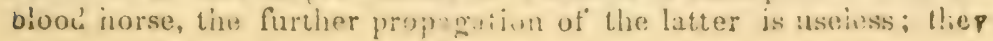


would furtlic nave horse racing abolished, and the horses applied generally as stallions. But the use which these sort of reasoners would propose to derive from the racing breed, would soon destroy atself. 'They do not consider that in racing the necessity for thor. ough blood, is obvious and imperative, and such is a sure ground of its preservation. Were the sports of the turf to be abandoned, that uncring test, by which to ascertain the purity of the blood, ind the other requisite qualities of the race horse, would be lost, and consequently, that glorious and matchless species, the thorough bred courser, would in no great length of time, become extinc among us-and with him all his noble and valuable properties, and his place be supplied by a gross, ill-slıaped, or spider legged mongrel, which would insure the degeneration of the whole race. I would ask, is not a cross of the blood horse upon the common stock in. dispensable to insure us light footed and quick moving saddle hor. ses? Where do we go for the parade or cavalry horse if it is not the blooded stock, or to those highiy imbued with that blood? Did not the speed and wind of the cavalry horses of Colonels Lee and Washington, during the revolutionary war, give those commanders a decided superiority over the enemy in the kind of warfare they waged, where celerity of movement was all important? and were not those horses procured in Maryland and Virginia, and partook of the best racing blood of those states? The value of the blood, or southern horse, from their ability to carry high weights, was strongly exemplified in the wars of the ancients; as they rode to war in heavy armour, and always selected and preferred for this purpose their highest bred horses, which were also frequently covered, like their riders, in heavy armour. In former times in England, their hunters were only half bred horses, but later observations and expe-. rience have fully convinced them that only those that are thoroum bred (notwithstanding the popular clamour of their deficiency in bone) are adequate in speed, strength, and durability, to long and severe chises with fleet hounds, particularly over a deep country, and that they will always break down any horses of an opposite description that may be brought into the field.

The value of the racing blood when crossed upon the common cart breed is also apparent in making them superior in the plough and wagon, provided they have the requisits size, arising from quicker action and a better wind particulurly in the long hot days of summer. There is the same difference of motion between the race, and the common hred horse as hetween a coach and a cart. It is moreover a fict, although not generally known, that no other horses are capable of carrying with expedition such heavy weights; and were "a thirty stone plite $(420 \mathrm{lbs}$.) to be given, and the dis. tance made fifty miles, it would be everlastingly won by the thor. ough hred horse. There is only one way in which a bred liorse wonld be bent at high weights; it would be (to use a queer phrase.) to inake it a stand still race; in thist case, I would back a cart horss; - thiık he would beat a racer by hrours."

The strength of the race horse, and his ability to carry high weights, arise from the solidity of his bones, the close texture of his fibres, the bulk and substance of his tendons, and from his wholo 
peculiar conformation. His superior speed and endurance originate from his obliquely placed shoulders, depth in the girth, deep oval quarters, broad fillets, pliable sinews, and from the superior dur. tility and elasticity of his muscular appendages.

It is also from the blood horse that we acquire fineness of skin and hair, symmetry and regularity of proportions, elegance and grandeur. As a proof of the latter qualities, the highest dressed horses of the ancient emperors are invariably of the highest cast of Arabian or Southern blood.

'The object of the preceding remarks was to show the impolic y of discouraging the sports of the turf, as being the indispensable test by which to try the purity of our blooded stock, and the only certain means of insuring its preservation: that the thorough bred horse was beyond all question, the most usuitil species of the whole genus, since he was applicable to every possible purpose of labour in which horses are used, either for the saddle, for war, parade, hunting, the road or quick draught, and even for the laborious services of the wagon and plough. It now only remains to make some remarks (as connected with the above teppics) on the standing and prospects of future patronage which the sports of the turf have in England and this country. It is an undeniable fact that the high degree of improvement to which the blood of stock horses in Eng land have attained, is mainly owing to the liberal and weighty pa tronage which has invariably been extended to the sports of tho turf in that country; it is patronised as a nationil amusement by the royal favour and munificence, and directly encouraged by tho most distinguished nolility and gentry; by men who are ranked as her chief statesmen. The decline of this sport has frequently been predicted in that country, pirticularly at unfortunate periods of war and distress ; but it has been steadily maintinined for more than a century, with few or no fluctuations, and is at this time in a high state of prosperity. Never were so many thorough bred st.llious kept in England as at present-never Was New Mitret, Epsom, on Doncaster, better attended than at the late neetings. The numbes of blood horses amnually exported fiom Fingland is unusually great, and to her, Russia, France, Austria, and the United States of America, the East and West Indies, have been long indehted fur their most valuable stocks.

In Vircrinia the sports of the turf have been revived and are ex tending over the state with great spirit, and are infusing into her citizens a due sense of their importance in giving value to the race horse. Virginia has long hald a pre-eminence over every othe. state in the Union in raising fine horses-and it is mainly to be attributed to the passion tor this fiscinating and rational ammse. ment, to the steady encomagement griven to it at all times, both during abverse and prosperous times, sinee the state lad its foum dation in a colony. 'To here the Carolinas, (ieorogia, Kentueky, and Tennessee, litve always looked for a supply of blooded stilliuns; to her they still are indebted as well as the new states of Alabama, Louisiana, Mississippi, \&e. I, then Virginia maintain and in. : rease this celebrity, by adopting all means which are calculated to promote so landable a distiuction. Let he. place and extems taw 
sports of the turf on the most liberal and equitable bisis, and let har, iis order to give increased value to her racing stock, speedily pab 1 sh a strul Book.

O) irin and progressive improvement of the race horse. It cannol but be an interesting task to inquire into the origin of the turf horse, and to ascertain the means by which he has been brough to his present high state of perfection. The English writers main tain the theory, that the horse genus was supposed to have consist. ad originally of two grand divisions or species: the silken-haired, flat, and fine bone conrser, and the full bodied, coarse, and rough. haired steed, adapted to draught and the more lahorious purposes. From these tv, original species may fairly be derived all those numerous varieties which we at this day witness in different parts of the world. Soil and climate most undoubtedly have considerable effects, through a long course of ages, in producing varieties of form, colour, character, and properties. The largest horses are generally found to be the production of the rich low lands of the temperate climates, abounding in rich and succulent food. The tine skinned, with elecrant symmetry, dry and solid hones, large tendun:, and the highest degree of musculir energy, in fisct, hearing the general charicteristics of the hlood horse, are bred under warm and southern skies, upon a rry soil, on the hills of the desert. The hypothesis is entertained, that Arabia is the native or breeding country of the conrser, and that part of Europe, formerly denomi. nated the Netherlunds, or Low Countries, the original soil of the arge drauglit horse. Other writers, however, contend, that all horses are derived from the same single primitive species, and that virieties are purely accidental and the effects of varying soil and climate. 'This opinion, however specious, is not sanctioned by ficts and experience in allowing full force to the arguments derived from the effect of soil and climate, yet it is equally true there are certain landmarls and boundaries of specific character, in both the animal and vegetable creation, which nature will never permit to be passed.

No length of time or naturalization upon the marshy soil of Bel. gium, it may safely be pronounced, would he sufficient to tiansform the high bred, silken and bounding courser of Arabia, into the coarse, blutf and fixed horse of the former country; nor would the sojournment of the latter, during any number of ages, in the south, have the effect of endowing him with these peculiar properties of bo:?, which distinguish the aborigrinal sonthern horse. The inter cha:ire just supposed, would no doult have the effect of increasirg tho bulk of the courser and relucing that of the drift horse; but the natural characteristics of each, would remain unassailable by any other medium than that of intercopulation through which we know from experience they may be merged, and in effect an. nihilated.

Arabia Deserta is allowed to be the breeding enuntry of the purest and highest bred racers; that is to sav, possessed in the highest degree of those qualities which distinguish the species; and these are arekness and flexibilicy of the skin, and general symmetry from the aran: to the lowest xtremitios. The eye full and shining, the hoad 
joined, nor abruptly, but to a curved extremity of the neck; the shoulders cipacious, deep or counter, and declining consin rably into the waist; the quarters deep, and the fore arms and thighs long, large and muscular, with a considerable curve of the latter: the legs flat and clean, with the tendon or sinew large and distinet; the pasterns moderately long, the feet somewhat deep, the substinion of the hoof fine, like that of the deer; in size not large, seldom cxceeding or reaching the height of fifteen hands.

It is in the momtainous country, among the Bedouin Arabs, that the blood and characteristic properties of this svecies of the horse, nas been preserved pure and uncontaminated by any alien mixture or cross, as they pretend, for more than two thousand years.

It is well known that the English race horse was originally bred from the Arabian, Barb, and 'Turkish stocks, and contains in his veins nearly an equal admixture of the blood of each. The Barbary horses were crenerally smaller than the Arabians, but carried more depth of carcase. "Their most prominent points are, ears fuadsome and well placed; forehand fine and long, and rising boldly out of the withers; main and tail thinly haired; with lein small head; withers fine and high, loins short and straight, flanks and ribs round and full, with good sized barrel; tail placed high ; haunches strong and elastic; thighs well turned; legs clean; sinews detached from the shank; pastern too long and bindiug; foot good and sound; of all colours, but grey the most common 'They are bred unon a similar soil and sprune from the desert like the Arabians, of which they are generally deemed a variety. In goodiness of temper and docility these horses resemble the former, and are said to be very sure footed; generally cold temperes and slow, requiring to be roused and animated, on which they will discover great vigour, wind and speed, being in their gallsp great striders.

The 'Turkish horses resembled the Parbs, and were sald to be handsome, elerantly formed, full of spirit, possessing tine tair. joft skins, gund speed, but more particulariy remarkable tior ther in. failing wind, enabing them to undergo nuch labour anc tiat gue.

It is a curious physical question, that the Arabian, Bari, and Turkish horses, should, only in particular individuals, ha*e proved valuable foal getters, and that these properties shovid he deried to the renerality of them, and that the whole of them should 21 soon the latid aside. Out of the vast number of these forcign horses imported into Fngrland in early times, but very few of them estat. lished their charicters as the propagators of high formed racers; and it may be assumed as a fact, that for some more than lialf at century past, not a solitary Arabian, Barb, or 'Turkish stallion has been lised in England; or if used at all, were found to be utter'y worthless.

England soon diseovered that from her fane clinate and soil, sho hud obtained in sime, form and speed, averv gluality which the best

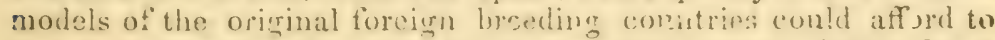
her, it is true she liad to fresort to the Arabians and Barbs for a foundation; but as soow as the stowis aring fom them had been

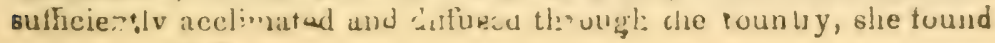


It safust in rely rupon them for all those qualities which they them seives ha acquired from their foreign progenitors.

The early English breeders found the Arabian stock to consti tute an excellent cross upon the Barb and Turk, as from the Ara hian blood was acquired speed, stoutness and stride fiom the Barb length and height from the Turk.

But of all the foreign stallions imported into England in early times, the fame of the two great Arabians, the Darley and Godol phin, has swallowed up that of all the rest; and the best English norses for nearly a century past, have been either deeply imbued in their blood, or entirely derived from it. They have produced stock of vast size, bone and substance, and at the same time en dowed with such extraordinary and before unheard of powers of speed and continuance, as to render it probable that individuals of them have reached nature's ultimate point of perfection. The descendants of these Arabians have rendered the English courser superior to all the others, not only in the race, where indeed he has long excelled, but as a breeding stock.

To such of my readers as are unacquainted with the history of that justly celebrated horse, the Godolphin Arabian, the following particulars of him may not be unacceptible. He was in colour a brown bay, somewhat mottled on the buttocks and crest, but with no white excepting the off heel behind; ahout fifteen hands high. with good bone and substance. The fame of the Godolphin Ara. bian was greatly increased by the famous picture which was taken of him by the immortal Stulbs, and which sold at his sale for 2.16 guineas. This portrait of the Godolphin is doulthess an admirable piece; it represents his crest as exceedingly large, swelling and elevated, his neck elegantly curved at the sitting on of the head, and his muzzle very fine. He lad considerable length; his ca. pacious sisoulders were in the true declining position, and of every part materially contrilutary to action, niture had allowed him an ample measure: add to this, there is in his whole appear. ance, the express image of a wild aninal, such as we may suppose the horse of the desert. Certainly the horse was no beauty, but with his peculiar and interesting figure before me, I cannot help wondering, that it should not occur to his noble proprietor, a true sportsman as he was, that the Arabian might be worthy of a trial as a stallion. This horse was imported by Mr. Coke into England, and it was strongly suspected that he was stolen, as no pedigree was obtained with him, or the least item given, as to the country where he was bred; the only notice given, was, that he was foaled in 1724. Mr. Cokp gave him to Mr. Williams, keepor of the St. James' Coffee House, who presented him to the Earl of Godolphin. In this noble lords' stud he was kept as a teazer to Hobgoblit.,during the years 1730 and 1731 , when that stallion re. fusing to cover Roxana, she was covered by the Arahan, the pro. duce of which was Lath, not only a very el-gant and beautiful horse, but, in the general opinion, the best which had appearnd on the turf since Flying Childers. The Arabian served for the re. mainder of his life in the same stud, producing a yearly succession of prodigims of the species. He died in the year 1753 , in his '2thth 
year, und was decently buried, and cakes and ale were given al the funcrai of his flesh. 'The following famous horses, some of whic: were of great size and powers, besides many others with a grea. number of capital racing and brood mares, descended from the Go. dolphin Arahian, viz: Lath, Cade, Regulus, Babran, Blank, Dismal, Bajizet, 'Titinerlane, 'Tarquin, Phonix, Śling, Blossom, Dor mouse, Shewinll, Sultan, Old Fingland, Noble, the Gower Sta] lion, Godolphin Colt, Cripple, Entrance.

Mr. Dirley, of a sporting family in Yorkshire, being a mercantiles agent in the Levant, and belonging to a huntmg club at Aleppo, mide interest to parchase a horse, one of the most valuabln ever imported in Englind, and which fully established the worth of the Arathian stock. He was a bay horse, his near foot before, with his two hind feet white, with a blaze in his fice, and about fifteen hands high; he was imported into England in the year 1703 , then four years of age.

'The Darley Arabian, (for such he was called, got Flying Chii ders, Bartlett's Childers, Almanzor, WV hitelegs, Cupid, Brisk, Dredalus, Skipjack, Manika, Aleppo, Bully Rock, Whistlejacket, \&c This horse had not that varjety of mares which annually pour ed in upon the Godolphin Arabian, indeed he covered very few except those of Mr. Darley his proprietor-but from these sprung the largest and speediest race horses which were ever known.Flying Childers and Eclipse, the swiftest beyond a doubt of all quadrupeds, were the son and great grand son of this Arabian, from which, also, through Childers and Blaze, descended samp. son, the strongest horse that ever raced before or since his time; and from Sampson was descended Bay Malton, who ran at York four miles in seven minutes forty-three and a half seconds, being seven and a half seconds less than it was ever done before over the same course.

On crossing, bresding and rearing the Turf Horse. The subject of crossing is one of the most important which has ever engaged the attention of the breeder or anateur, and it is still left in doubt whether we ourht to adhere to remote crossing in propagating the race horse, or that we may successively breed "in and in," viz. putting horses and mares together of the same family.

All that we can do is to disclose the facts which that unerring guide, experience, has established, and the exceptions to the rule which those facts have pointed out to as. Crossing, or intermix. ing the blood of different racing breals, has ever prevailed upon the turf, and experience has proven it to be a rational practice, when adopted with the view of an interchange of the requisite qualifications, external or internal; such as the union of spead and bottom, slenderness and substance, short and long shapes.

Experience tells us that the greatest success has ever attendec those brecders and that the most valuable stock hias resulted there from, who have adhered to romote crosses. The finest rumning and highest formed horses that have appeared in England were bres from the union of two distinct stocks, the flerod and Eclipse. The furmer stocks was invariatly remarkible for stontness and lasting. ness, tho latter for sueed and bo the union of these opporito 
nualities 'wlereby a remote cross was taken up,) a stock was ob. tnined in which was blended a sufficiency of the requisite quali. ties of both to make first rate running horses. There was anothe. distinct stock in England, which crossed well upon the Heroc and Eclipse branches; I allude to the Matchem or Godolphin Arabian Stock; and it may here be remarked, that there has nct been in England a first rate rumning horse on the turf for the last 70 yrars, without more or less blood of this valuable horse. How. ever necessary a remote cross may be considered, yet exceptions have arisen to it as a rule, as some of the most distinguished horses in England were bred considerably in and in-Flying Childers for instance, considered the fleetest horse in the world. Old Fox, also a celebrated racer and valuable stallion, had an affinity of blood in his pedigree, as well as other high formed racers and stallions. But these exceptions arose in Great Britain in her early days of breed. ing, when that country was enriched by the importation of par. ticular Barb, Turk, and Arabian horses that had peculiar and extritordinary properties as stock getters, as their immediate descendants constituted the best racers of those days, and demonstrated that the character of the English race horse had attined its utmost perfection at that early date.

At a later period, but little success had attended the efforts of those who have bred in and in. The Earl of Egremont has occasionally tried it, as well as Lord Derby (the owner of Sir Peter Teazle, but with little encouragement. Still the British writers are divided on the subject: Morland, in his treatise on the genealogy of the Einglish blood horse, expressly says, that incestuous reosess should be aroided, viz: putting horses and mares together of the same class; while on the other hand Lawrence, in his splendid work on the "History and delineation of the Race Ilorse," makes the following remark of an opposite tendency: "An adberence to the practice (of remote crosinge) cannot be held indispen. sably necessary on any sound theory; nor need any disadvantage be apprehended from coupling horses and mares of the same breed or family, even the nearest relative, upon the principles above and hereafter laid down. I have often heard of, and indeed seen, mis. erable legred and spindled stock resulting from such a course, but other very visible causes existed for the result.

"According to the adage, "like produces like," we, ought to follow form and qualification; and if a brother and sister, or tather and daughter excel in those respects all others within our reach, we ought to enjoin them with good expectatıons, for aught I know to the end of the chapter: and the prejudiced fear of adopting this practice, has often led our breeders into the error of aclopting an inferior form from the presumed necessity of a cross." 'The present romarks are peculiarly applicable to the breeders of the race 'arse in Virginia, for they are at this very time making the experime of hreeding "in and in," or from the sume fumily of" horses, as it is well hnown that all the turf homes now and for the last ten years prist, produced in that stite, are of the "Sir Archy stock." It wero to be wished that ihere was a greater variety of the luce blund in Wait stiate to give brecdors a wicher field for selection; a descand a' 
of Med'cy or Citizen would cross well upon the present numer-ms stock of sir dichy, and it would perhats have been a fortunate cre cumstance, could the celebrated horse Pocolet, (who was brod ana raised in Virginia, have been retained in that state

The subject of breeding is the next which claims our attention.

The business of breeding is divided into the systematic and chance medley; the formation of regular studs and observing somo fiaed principles, characterize the foriner; while the latter is a kind of random aftair, common to the whole country where foals aro raised for a man's pleasure or convenience, for which no extra pre. parations are made, or much reflection bestowed, further than to make use of any mare that may chance to be in possession, and of any horse which the vicinity aftords or custom may present.

In the formation of studs, the object generally had in view is breeding for the turf, and one of the fir:t principles is to breed from no stallions unless they be thorough bred; in plain terms, both their sires and dams must be of the purest of the 'Turkish, Barb or Arabian coursers exclusively, and this must he tested in an anthentic pedigree, throughout whatever number of descents or crosses.* 'Ihe brood mare should he equally pure or thorough bred, and particular attention should be paid to her form, as one of the prime causes of failure of most breeders is confining their altention solely to the borse, without paying suficient attention to the form of the mare, and permitting fishionable blood and the supposed necessity of a cross to have too decided a preference to correctness of shape To constitute a thorourh bred animal, and to assure the attainment of every desired quality or perfection, both the male and female ought to possess it. Experience has proven the correctuess of the principle that "like produces like," acting upon this principle, wr have the best assurunces to expect success from a junction of the best shapes or the greater number of good points we can combine. both in the horse and the mare, from such junction the average will be fitvourable, true form will resuit from the union of true form in both sire and dan; and the next general result will be, that every borse sufliciently woll formed, and fimished in the material points, will excel either in speed or continuance, or will possess an advanfageous mixture of both.

\section{Blood is blood, but form is superiority}

$r_{n}$ rearmg of turf horses, the following principles ure recon. mended by the most successful breeders: the land to be dry and soind, the harder the better, provided it be fertile: irregularity of surfice a recommendation. Fres! springs or streams, shade and shelter, and extensive range. Sufficient number of inclosures, both for each species, which it is necessary to keep apart, and to prevent too great a number of any being crowded together. IIonses

* There is a prartice in Virginia and North Carolina, in grisure the pedi erre of a stallion, to mame only one or 'wo crosses, particulaty on the dars's sinle, and thron pronounce him "the finest bred horse in the worthl." Who fan pronounce on a horse's good or bad hlood unless we krow the wholo of it He may trace to the common dray lireed of the counur for aush we know 
or sheds in the inclosures; soft and sweet herbage for the colts and "nilk mares; and finally a very liberal allowance of land in propor tion to the stock, that there may be not only ample grazing in tho grass season, but an equally imple quantity of provisions of the equisite kind during the winter.

A firm. dry, and hard soil, will have a corresponding effect upon the feet, limus, and tendinous systen of horses bred upon it; as will a dry, clear and elastic air upon their wind, animal spirits and general habit. Such are the advantages enjoyed by the horses of the mountain and the desert; but these advantages are greatly en. hanced in a country where abundant herbage and moderate tem. perature are superadded.

Ali breeders concur in the propriety of keeping colts well the first and second winters; for colts from the best shaped parents will degenerate upon insuficient nourishment, and be stinted from the palsying efiects of damp and cold in the winter, if a confortable and general shelter is not allowed them. Good keeping and warmth, during the first and second years, is indispensable, in order to invigorate the circulation of the animal's blood, to expand his frame, to phmp up and enlarge his muscles, to encourage the growth of his bones, and to impart to them that solidity and strength which pre. serves them in the right line of symmetry.

It must be interesting to the amateur, the sportsman, and the breeler, to give a correct, though concise account of the most dis. linguished turf stock of blood horses, which existed in Virgınia between the years 1750 and 1790 , a period more remarkable for fine zorses, than perhaps any ether, either prior or subsequent to thut time.

It was during this period that "races were estahlished almost at every town and considerable place in Virginia: when the inhabitants, alinost to a man, were devoted to this fascinating and rational immsement : when all ranks and denominations were fond of horses, mpecially those of the race breed; when gentlemen of fortune ex. puded large sums on their stud, sparing no pains or trouble in importing the hest stock, and improving the breed by judicious cross ing." "The effects of the revolutionary war put a stop to the spirit of racing until about the year 179() , when it began to revive, and under the most promising auspices as regarded the breed of turf horses, for just at that time or a little previous, the capital stalliors Old Medley was imported, who contributed his full share to the reputation of the racing stock, whose value had been before so wel: established. Previous to the year 1800 , but little degeneracy had taken place either in the purity of the blood, the form or perform. ances of the Virginia race horse; and in searching for the causes of a change for the worse, after this period, the most prominent one was the injudicious importation of inferior stallions from England. Alout the period of time last mentioned, Colonel Hoomes and many others, availing themselves of the passion for racing, inundated Virginı with impurted stallions, bought up frequently at low prices "u Eigland, having little reputation there, and of less approved olood. therely greatly contaminating the tried and approved stock *hicl, had long and eninontly distinguished themselves for thos 
feats on the turf, their services under the saddle, and as valualilo cavalry horses during the revolutionary war. In recommending renewed efforts to the Virginians, for the further inprovement and preservation of their stock of blood horses, the necessity und im. portance of the immediate publication of a Stud Book (and of a Racing Calendar hereafter) cannot be overlooked.

It is the wish of the writer, that the tendency of this, and the fol lowing pages, may excite a spirit and a desire for such a work, by showing that there are valuable materials extant, only requiring diligence and zeal to bring them to light, capable of being made up Into a valuable publication on this subject. The want of such a work as a stud Book, is now lamentably seen and felt in Virginia, where few pedigrees of any particular stock can be traced far back, before they are lost in the mazes of uncertainty and conjecture. It may safely be asserted that the stock of horses in Virginia never can arrive to that degree of improvomert and perfection, and moro particularly high value as to price, they otherwise would do, unless a record of this kind is published and preserved, to be resorted to for a correct knowledge of their blood. In breeding for the ture and selling turf horses, blood is every thing; as it has been found that particular strains or pedigrees of horses of this class, are re. markable for their speed and bottom, while others are miserably defective in these essential qualities of the race horse. A Stud B sok and Racing Calendar will be a starding record, always ena. bling us to avoid the bad, and to cherish those particular strains of horses, that have established their good qualities for the turf. How has Virginia been injured in her racing stock by some particular stallions, bred in that state? Potomac, for instance, who, although they raced it well, yet being badly bred, propagated an inferior raco of horses.

Let me therefore, emphatically remind the breeder of the race horse to use great particularity and caution as to the stallions from which he breeds; examine well into their pedigrees, and to the qualities of the stock from which they are descended; as an expe. rience of more than a century in England has proven the fact, that where a stallion has been stained with an inferior or "dunghill" cross, however remote in his pedigree, it is certain to lurk out and exhibit itself in his proreny, no matter how well he may have raced it himself.

We sliould breed back as much as possihle upon the good old storks of Jolly Roger, Janus, Morton's Traveller, Fearnonght, and Medley, of which I propose to give a particular account in the suc. ceeding pages. It hats been well for us that the importation of stallious fiom England has long since ceased, and I hope never to see it revived again. The sod of the Beacon course four miles and upwards) is now too little trod by the English race horse : sinort races with light weights are now too common; the consequences are, that their stock of blood horses are rapidly losing that stamina and inherent goodness of constitution or stoutness, which enablea them in former lays to carry high weights, and to support frequen. and hard running. Fifteen or twenty years ago, xhe Virginians ored altogether from injorted English stallions, arid at that iono 
also, there were more sportsmen on the turf; yet we have at this day hetter race horses, under less patronage, from American bred stallions, than at that day. Does not this prove that by adhering to our own stock, and breeding from large highly formed, full blnocled stallions, that our turf horses will soon equal or exceed any in the world? and as our race stock is considered stronger and moro active, it will be found advisable to breed them for the siddle, plongh criganon.

J.Mly Rorer, was the first horse that gave distinction to the raci: sick of Virginia. His performances on the English turf, and that of his pedigree, are recorded in the name of "Roger of the Vale." After he was imported into this country he took the name ly which he is now known; he was foaled in 1741 , and commenced covering in Virginia about the year 1748. He was got by Roundhead, who was by Fiying Chilhers, who was hy the Darlty krahian. 'Tie dam of Roundhead was the famous "plate" mare Roxana by the Bald Galloway, the dam of the celebrated racers and stallions Luth and Citce by the Godulphin Arabian. The dam of Jolly Roger was got by Mr. Croft's famous horse Partner, the best racer and stallion of his day, his grandim by Woodeock-Croft's Bay Barb; Mateless: Brimmer; Son of Dodsworth; Burton Barb mare.

Jolly Roger got many fine racers, stallions and brood mares, and is a fivourite cross in the pedigree of the Virrinia bred turf horse, and very justly too.

Jolly Rnger got Spanking Roger, out of the imported mare Jen. ny Dismal, and Longsdale out of an imported Monkey mare.

Janus was a chesuut horse, foaled in England in 17.16, and got by Janus, a bay horse foaled in 1738, fill brother to Blank and Old England, being got by the Godolphin Arabian out of the famous ' Little Hartley mare' by Burtlett's Childers, son of the Dar. ley Arabian.

Janus was imported into Virginia by Mr. MIordecai Booth, of Gloucester county, Va. in the year 1752; his dam was got by old Fox, [whose name stood eminent in the English pedigree,] his grandam by the Bald Galloway.

Although Janus partook of every cross in his pedigree calcula. ted for the distance turf horse, yet his stock were more remarka. ble for speed than bottom. Janus, from his shoulders back, was considered the most perfect formed horse ever seen in Virginia, by the most skilful connoisseurs; he was remarkable for roundness of contour, strength of articulation, and indicating great powers asd stamina in his whole conformation.

His stock partook of these qualities in an eminent degree, and lur thirty or forty years they were considered as a "peculiar stock,' as they invariably exhibited even in the third and fourth generis. tions from the old horse, the same compactness of form, strength and power. The Janus stock have exceeded all others in tho Uni. ted States for speed, durability and general uniformity of good form ; and more good saddle and harmess horses have sprung from inem than fiom any other stork. 
Celer was justly considered as the best son of old Janus, as ho propagited a stock equal in every quality to those of the stock begotten ly his sire. He was bred by Mr. Mead of Viruinia, and foaled in 1774, and died in 1802, aged 28 years.

As the pedigree on his dam's side is not generally known, I will here give it. The dau of Celer was got by the imported horse Aristotle, a brown bay, finely formed, full 15 hands high, bred by Mr. Bladen and got by the Cullen Arabian, his dam by Crab, his grandam by Ifobgoblin, great grandam by the Godol hin Arabian, out of a famous mare called White Cheeks.

Morton's imported horse Traveller contributed in an eminent derree to the improvement of the turf stock of horses in Virginia He was a bay horse, foaled about the year 1748 , and was a cover. ing stallion at Richmond court house, Va. as early as the year 1754 He was bred by Mr. Crofts, at Raby in Yorkshire (who was the for tunate breeder and owner of some of the first horses in England) and was got by his famous horse Partner, who was a grandson of the Byerly Turk, and was himself the grandsire of King Herod. The dam of 'L'raveller was by Bloody Buttocks (an Arabian) Greyhound; Makelcss; Brimmer; Place's White Turk; Dodsworth; Iayton Barb mare. Mlorton's Traveller was bred from the best ruming stock in England in that day: the famous Wetherington mare was full sister to Traveller; she bred Shepherd's Crab and other capital racers.

Morton's Traveller got Tryall and Yorick out of Blazella, in. ported, and Burwell's Travoller out of a Janus and Lycurgus; al. so Lloyd's 'Traveller out of a Jemny Cameron, and Tristam Shandy out of a Jamus, Ariel full brother to Partner, and Partner out of colonel 'I'asker's imported mare Selima.

Purtner was the best son of Morton's Traveller, proving to be not only a fine race horse, but a valuable stallion. He was foaled about the year 1755. Partner got Rockingham out of Nelson's im. ported mare Blossom, and Fitz. P'artner out of the dam of Celer and the celebrated horse Mark Anthony.

Mark Anthony's dam was by Othello, (a son of Mr. Parton's capi tal linglish horse (rab) his grandam the imported mare Moll Era. zons: she was sired ly Sipark, who was inported to this country oy Croveruor Ogle, of Marylind, and was given to him by Lord Baltimore, who received him from Frederick, Prince of iVales.

Mark Anthony was foaled about the year 1763, and did not exceed tifteen hands in height, and "vas a horse of beauty and intrinoic value, whether viewed as a racer or stallion. In the former character he was not excelled by any horse of his day, being "remarkable for his swiftuess," having at the same tine good wind. enahling him to run four miles heats in good form. In the latter cliaracter he stood deservedly celehrated, an? propagated a stock which were held in the highest estimation for thrir various valu ahle qualities, whether for the turt, the saddle or the harness.Mark Anthony got Colleceor ont of a Centinel, and Monawh nut of a thorough bred mire, and Rommlus out of a Valiant 
Yorick got Plgn out of a little Davie, and Bucephalus out of a Careless, and Junius out of an Othello.

Burwell's 'Traveller got Southall's 'Traveller out of an imported mare, and Camillus out of a Fearnought mare.

Lloyd's Traveller got Leonidas out of a Morton's Traveller mare. Junius got Spangloss out of a Jolly Roger mare.

Feurnought holds the first claim prior to the day of Medley, and is therefore entitled to the palm in preference to any stallion that had prfeeded him in giving the Virginia turf stock a standing rqual to that of any running stock in the world. The blood which flow. ed in the veins of old Fearnought must have been peculiarly rich in those qualities that make up the conformation of the race horse, as not only the whole stock got by Fearnought run well, but also his sons and his grandsons were remarkable for generally getting good running stock. There was also strength and stamina univer. sally pervading the Fearnought stock, to which may be added good size, that made them the best distance horses of their day. 'T'he fact is that the Fearnoughts run well all distances, and the oid horse stood higher than any other horse on the continent for get. ting racers; and he got more of them than any other-he also was the sire of more fine stallions thon any other horse of his day.

Old Fearnought was bred by William Warren of England, and soaled in the year 1755. He came out of $\mathrm{Mr}$. Warren's fine brood mare 'Silvertail,' and was got by Reguhus the best son of the Go. dolphin Arabian. Regulus, when six years old, won eight King's plittes. He never was beat, being very superior to any horse of liis day.

Silvertail the dam of Fearnought, was foaled in 1738, and got by Heneage's Whitenose; her dam by Rattle-Darley's Arabianche old Child mare, got by Sir 'Thomas Gresley's bay Arabian out of Mr. Cook's Vixen, who was got by the Helmsly 'Turk, out of a Royal Barb mare.

Fearnought was inported into this country hy Col. Jn. Baylor, who advertised him in the year 1765 , as "a bright bay, 15 hands i inches high, remirkably strong and active, and the full brother 11 the late Mr. Warren's invincible horse Careless." Old Fear. mought died in the fall of 1776 , at the age of 21 years.

\section{viz:-}

Among other capital stallions and racers, he got tho following

Nonpareil, out of a Janus mare.

Nimrod, out of a Partner.

America, out of a Jolly Roger.

Regulus out of the imported mare Jenny Dismal.

Godolphin, full brother to Regulus.

Shakspeare, out of an imported Cub mare.

Gallant, out of a Stateley mare.

Shakspeare, out of an imported Shakspeare mare.

Apollo, out of an imported Cullin Arabian mare.

Ularris's Eelipse, out of Baylor's inported shalsspeare mare

Laurel, out of a Fearnought.

Malchless, out of Sober John.

King Ilarod, o tt of an Othello. 
Whynot, out of in Othello.

Dandridge's Fearnonght, out of

Symmes' Wildair, out of a Jolly Reger, who proved to hes the best son of old Fearnought.

Wildair got-

Commutation, out of a Yorick marc.

Highflyer, out of a Yorick mare.

Chanticleer, out of a Pantaloon mare.

Chanticleer, the best son of Wildair, got-

Magrog, out of a Wildair.

Prestley, [full sister to Magog, the dam of Wilkes' Madison

Cornelia, the dan of Mr. Randolph's Gracchus.

'The stock of old Medley may justly be ranked as among the most emarkable and valuable that have ever signalized themselves on a Virginia race course. 'This stuck of horses lacked nothing but size to have made the best racers in the world; and yet their want of size was not manifested on the turf: as their ability to carry weight exceeded that of any other stock; they were also remarka. ble for good wind or bottom, for fine limbs and good eyes, than other race of horses that have been bred in Virginia. 'These qualities resulted in this stock [and were more peculiar to them than to any other, j from the close proximity of the points of the hips to tho shoulder, from the uncommon solidity of their bones, the close texture of their sinews, and the bulk and substance of their tendons, which always enahled them to carry the highest weights, and to endure the greatest stress on their bodily powers. To these qualities may be added their uncommon purity of blood, derived from their sire old Medley, who was one of the purest blonded horses ever bred in Englund.

Gimcrack the sire of Medley, was one of the most remarkable liorses of his day in England. He was a grey, and called the "lit. tle grey horse Gincrack," foaled in 1760, got by Cripple, a son of the Godolphin Arabian. Gimcrack was one of the severest running and hardest bottomed horses that ever ran in England; although small, yet his ability to carry weight was very great, for he frequently gave the odds as high as 28 pounds, and he con. tinued on the turf until 11 years of age, therehy showing his un. common hardiness of constitution and firmness of limbs which he richly transmatted into the veins of Medley. (iincrack at four years old won seven $50 l$. plates, 4 miles; also in 1765 , at 4 miles, $5(1)$; also 1000 guineas, 250 guineas forfeit. He beat the Duke of Cumberland's Drone, 4 miles for 500 guineas, giving hin 21 lbs. In 176,6 he was sent to France, and in 1767 returned to England, and won in that year, four $50 \%$. plates, 5 miles. In $170^{\circ} 8$, two 507 flates and the silver bowl. If beat Mr. Vernons Barber for 300 guineas giving him $28 \mathrm{lbs}$. in 1770. He beat Lord Rockingham s Tacho for 3000 guineas, giving him $28 \mathrm{lhs}$; also Lord Rockingham. Pilurim for the whip and 200 gruineas, the whip equal to the gur. neas. Gimcrack was then 10 jears of age. Earl (irosvenor had two portraits taken of Gimcrack. That of (Fimcrack preparing to giart in reckoned excellent of its kind. The two nortraits. it is win suresent thir horse in different shades of grey: "he ron 
grey of his youth, and the hoary white of his old age. Gimcrack had acquired such fume and celebrity that his last proprietor len him a length of tirve at Tattersal's for the inspection of the puolic.

'The dam of Medley was Arminda, by Snap, (full sister to Papia. ion, the dau of Sir Peter Teazle, the best in England.) Nedlev acquirer his beautiful symmetry and proportions from Snap, whc was a horse of great beauty and justness of proportion, strong, vigorous, and muscular, and was upon an equality as a racer, if not superior to any horse of his time. Medley was imported to this country by Malcomb Hart, in the year 1785. Among many other distinguished racers and stallions, Medley got the following, viz:

Boxer, out of a Fearnought mare.

Opernico, out of a Lindsey Arabian mare.

Quicksilver, out of a Wildair.

Young Medley, out of a Blue and all Black.

Melzar, out of a Wildair.

Lamplighter, out of a Longsdale.

Fitz-Medley, out of a Daudridge Fearnought mare.

Gimcrack, out of an Ariel.

Bellair, out of a Yorick.

Bellair may justly be distinguished as the best son of old Medley, not only as being upon an equality as a racer, but as having got more tine stallions, racers, and brood mares, and as being decidedly the best bred son of his distinguished sire. Bellair partook of the best b)ood that has been highly valued in Virginia, viz: of Morton's Traveller tinrough Yorick, liearnought, Partner, Mark Anthony, \&c. Colonel 'Tasker's famous running mare Selima, that was the dam of Partner, was the great grandam of Bellair; and I will here take occusion to correct an error in the pedigree of this celebrated mare, as it has prevailed for more than thirty years in all the published pedigrees which I have seen of Bellair. Col. Tasker's Selima, is represented to have come out of a mare called sintp Dragnn, by Silap; this is a manifest error: the Godolphin Arabian, who sired Selima, died in 1753; Snap was foaled in 1750 and did not com. mence covering until 6 years old, hence the first snap mares were not foaled till 1757, 4 years after the Corlolphin was dead. Col. Tasker's Selima was hred by Lord Godolphin, and came out of a mare by Old Fox, that was the dam of Dilphne, and also of the celehrated rumning horse Weasel, that was the property of Lord Ruckingham; the grandam of Selima by Flying Childers, - Maka loss - l'affolet Barb-Natural Barb mare.

I would urge upon the breeders of the Virginia Turf Horse to take in, in their different crosses, as much of the blond of old Med. ey and Bellair as possible, to give their stock firm limbs, vory much needed at this time, as the Virginia race horses of the present day irain off the turf too early.

"'. following letter aypropriate to the present subject, is from that eminent breeder and sportsman Col. John Tayloe, formerly ot Mount Airy, Virginia, now of W Vashington City.

-In reply to your favour, I shall be happy if any information 1 -m anic in give you in regard to old Medley, and such of his stocs 
as I nave owned, can be of service to you. Old Medley was in ported to this country about the year 1785, was owned by Mr. Mi2. comb Hart, and stood at Hanover Court House. He was one of the most beautiful horses I ever saw. I cannot at this remote jeriod pretend to describe him further than he was a grey horse of lio finest proportions and not more tham $141-2$ to 15 hands high. I have alivays esteemed him one of the best horses ever imported into the Lnited States, and concur with you in opinion that his stock is decidedly the best we have had. His colts were the best racers of their day, although they were generally small; but their limbs were remarkably fine, and they were distinguished for their ability to carry weight. I owned some of the best of his colts. Bellair and Calypso I bred; Grey Diomed and Quicksilver, I purchased from the profits which I realized from their successful performances on the turf. I have reason to hold Medley in grateful remembrance

"As respects Bellair, he was strong built and rather stout, good eyes and remarkable fine bony legs : rather above fifteen hands. I do not think his bottom was surpassed by any horse on record; if ever he locked his antagonist I felt confident of success. Wh hen he ran with Mr. Randolph's Gimerack, he was in excessive bad order, after a long journey, in bad weather, from Maryland, they ran three 4 mile heats, in each of which Bellair mended, and was not beat far. I refused 500 guineas for him immediately after the race.

"I concur with you respecting the old Virginia stock, which should not be lost."

Having given an account of Col. Tasker's imported mare Selima, It may not here be improper to add that of Carter Braxton's im proded mare Kitty Fisher: as those two mares bied more fine stuck in Virginia than any other imported mares brought to this cuuntry; it being well known to the sportsmen and breeders for the turf, that some of the highest formed racers and stallions bred in that State were descended from those two mares.

Kitty Fisher was a gray mare foaled in 1755, and imported by Carter Braxton in the fall of 1759. She was bought by Mr. Brax. ton, at New Market, England, in the spring of 1759 , being the:n the property of the Marqus of Granby, and stond at the time en zaged in a sweepstake for $3600 l$. for three years old fillies; but the Marquis being abroad with the British armies, he was allowed to withdraw himself from his racing engagements, and directed all his running stock to be sold. At the sale she was purchased as above and sent over to this country. She was got by Cade, (one of tho finest sons of the Godolphin Arabian) her dam by the Cullen Ara hian, out of the famous mare Bald Charlotte. (Bald Charlotte was a high bred mare, of the finest form and winner of King's plates.)

Kitty Fisher was trained in this country and run, and won casily several matches.

ft is peculiarly pleasing to recur to those periods in Virgina, when the blooder horse held such a high place in the estiunatuon of the people; when men the most distinguisned for their wealth their talents or patriotisin, were seen rying with auch otles wan 
sho'ld impoirt the finest blood horses or mares from England, o raise them from those already imported. It was the cbject of the writer, in the preceding pares, to call up those periods to review, and give an account of the most valuable stallions and mares, from which the Virginia stock were bred during those times, hoping it will serve to animate the breeders of the present day, and stimulate them to enulate their ancestors in their zeal and success in rearing the blood horse.

Justice, a chesnut horse, fifteen hands high, was bred by Wm. Manby, of Gloucestershire, England, and got by Regulus out of the Bolton Sweepstakes. Justice covered in Prince George county, Virginia, in 1761 .

Othello, a beautiful black, fifteen hands high, very strong was got by Mr. Panton's Crab, in England, out of the Duke of Somer. set's favorite brood mare. Othello covered in Virginia, on James' River, in 1761, and was a most capital stallion. He got Selim and the dam of Mark Anthony.

Crawford, a fine dapple grey, 15 hands high, was bred by his royal highness the Duke of Cumberland, and got by his Arabian. Covered in Virginia in 1762.

Juniper, a fine bay, 15 hands one inch high, fonled in 1752, was got by Babraham, one of the best sons of the Godolphin Arabian. The dain of Juniper by the Stamford Turk, \&c. Juniper covered in Charles City, Va. in 1762, and was an excellent stallion. He is a remote cross in the Virginia pedigree.

Ranter, a beautiful bay, 15 hands high, foaled in 1755 , imported into Virginia in 1762 , by Wm. S. Wadman. He was got by Dimple, a son of the Godolphin Arabian; the dam of Ranter by old Crab, Bloody Buttocks, \&c. Ranter stood in Stafford County, Va. in 1753 , and is an old cross in our pedigrees.

Aristotle, brown bay, 15 hands high, got by the Cullen Arabian, his dam by old Crab, \&c. Aristotle was one of the finest and highest formed horses imported into Virginia in his day; he pro. pagated a most valuable stock for the time he lived, having died shortly after coming into Virginia. He stood at Berkely, Charles City county, in 1764 .

Bucephalus, brown bay, 151.2 hands high, foaled in 1758, was got by Sir Matthew Wetherton's horse Locust, his dam by Old Cade, Partner, \&c. Bucephalus was a very strong horon, and stood at Tappahannock, Va. in $\mathbf{1 7 6 5 .}$

Davil, a bay'horse, 15 hands high, well made, very retive, and descended from the best stock in England Stood in Virginia in 1765.

Dotterell, a high formed horse, 151.2 hands high, a powerful atrong boned horse, was got by Changeling, his dam by a son of Winn's Arabian, \&c. Changeling was one of the finest horses in Finglind of his day Dotterell stood in Westmoreland ceunty, $\mathrm{Va}$ in 1766 .

Merry Tom, a beautiful bay, 4 feet 11 inches high, he was got ov Regulus, (une of the best sons of the Godolphin Arabian, i his diun by Locust, a son of Crab, his grandam by a son of lilying 
- milers, \&c In 1762 , he won 200 guineas sweepstakes at R.ch. laund; in 1753, he won 50/. at Durbarn, and the noblemen an! gentlemen's subseription at Cupar, in scothand. Merry 'Toun stoon in Prince Goore county, in $176 \%$; he was the sire of the note: horse Smiling Tom.

Strrling, a fine dapple grey, foaled in 1762. was got by the Bell. size Arabian, (which Mr. J. Simpson offered 1500 guineas for, ) ont of Mr. Simpson's Snake mare; she was got by Suake, a son of the Lister Turk, out of the Duke of Cumberland's famous mare, the dam c f Cato. Sterling traces down to the famous old mare bred by Mr. Crofts at Raby, in Yorkshire, and sold to the Duke of Cleveland. Sterling was a very fine horse, and became famous as a valuable foal getter. He was owned by Wm. Evans, and stood in Surry county, Va. in 1768 . Hi did not exceed 151.2 hands in height.

Lath, a bay horse, 15 hands one inch high, strong and bony, was got by Shepherd's Crab, his dam by Lath, a son of the Godolphin Arabian, \&c. Lath was landed in this cuuntry in 1768, and won that year the 50l. weight for ago" plate, at New Market, on long Island. In 1769 he won the Juckey Club purse of $100 \mathrm{l}$ at Phila. delphia, beating the then best ruming horses in that State and from Maryland. In 1770 , he also won the $100 /$. plate at the samo place. In 1771, he won the $100 \mathrm{l}$. plate at New Market, and never was beat but once, when he ran out of condition. Lath was de. scended from the most valuable blood in England, and contributed in an eminent degree to the improvement of the stock of horses of his day.

Whirligig, was a dark bay 15 hands high, and was imported from Fingland in the year 1773. He was got by Lord Portmore's bay horse Captain, (a son of young Cartouch,) his dam by the Devonshire Blacklegs, son of Elying Childers, \&c. In April 1769, when this fine horse was rising six years old, his owner received forfeit of 1000 guineas from Rapid; the same year he beat Volunteer, for 200 guineas. In October 1770, he heat Warwickshire Wag for 100 guineas; and the same year he heat Atrides for 100 gruineas, \&c. Whirligig stood to mares in Ilalifax county, N. C. in the year 1777.

Sclim. This beautiful and valuable stallion was a dark bay, a little rising 15 hands high, was got by Othello, (commonly called Black and all Black, whose sire was old Crib. 'The dam of Selim was a beautiful mare of that name, got by the Godolphin Arabiar und full sister to the celebrated horve Babrahain of England. SE. lim was a tried and approved racer, and a stallion of deserved celebrity. He stood in Virginia from the year $17 \% 0$ to 1780 , and pr spagated a valuable race of horses.

A retrospect of the older stallions of Virginia, evinces the irn. portant fact that they did not exceed from 15 to 151.2 hands in height; and yet Virginia in those days had a stock of horses equal to any in the world. They were remarkible for substance or fins stimina. This stock of horses was the mmediate descendants of the best Arabian, Batrh, or Turkish bloorl which nad been eariy 
Imported ints England from Oriental countries, and has exhibitec a degeneracy as to substauce or stamina, in proportion as it has oeen removed from this elder foreign blood.

'The above stallions were the descendants of Oriental stock, as well as Janus and Fearnougint, [who were the grandsons of the Godolphun Arabian.] During the days of those horses and their offspring, Virginia was famed for her fine saddle horses, and lheir weights on the urf was $144 \mathrm{lbs}$. for aged horses: now it is pro. verbial that the blood horse of Virginia rarely produces a fine sad. dle horse, nor have they a single turf horse capable of running four miles in groud time with their former weight. A!l their good races are now made by young horses carrying light weight, say from 90 to $103 \mathrm{lbs}$.

The same retrospect of the English stock discloses the samt facts : Lawrence remarks, that a "retrospect seens to evince great superiority in the foreign horses of former times, many of the best Fnglish racers in these days, being the immediate descendants, on both sides, of Arabs, Barbs, or T'urks, or their sires and dams. That union of substance and action, which was to be rnet with in for mer days, has been of late years still more scarce."

As evidence of the correctness of Lawrence's opinion, it may be adduced that the established weights on the English turf, in former ditys were increased to $168 \mathrm{lbs}$. and it was during this period that their horses continued to improve both in substance and speed, and notwithstanding the great weight of 168 lhs. they had to carry, they ran four miles from 7 minutes 30 seconds to 7 min utes 50 seconds. From the days of Eclipse, the weights were gral. dually reduced, and have been brought down to $1191 \mathrm{bs}$. and on no track exceeding 1:33 los. Yet there is not a racer now in England able to run his distance in as greod time as they were in former disys with their high weights.

The present rage for breeding horses to a great height should not be so much attended to as obtaining the requisite substance, and from the above list we see that from 15 to 151.2 hands in height, has combined with it that necessary union of suhstance and action which enabled the horses in former times to run in such fine form and carry such high weights. The most obvious way to insure this desirable substance or stamina in our stock, is to increase the weights of the turf to the old standard, and not to permit colts to start in public until four years old. The great su. periority of the elder English race horses is in part to be attribu. ted to the favorable circumstance of their not having started in rublic until five or six years old. This delay has the obvious fib. vorable effect of enabling the bulk and substance of their limbs and mferior joints to become strong in proportion to their weight, and their whole tendinous system consolidated and firm. Flying Chil Iers, Bay Bolton, Brocklesby, Betty, Bonny Black, Buckhunter. the famous Carlisle gelding, Eclipse, and a great number of others, die not race in public until five and six years old; and they wero :acers of the highest eminence for performance and heavy weighh of any on record in the English annals of the tarf. 
The first step towards an American Stud Book or collecting an account of our bs Jod horses, is to ascertain the number of stal. lions imported from England, with their pedigrees annexed, be. cause it is to the importation of horses and mares from that king. dom, that we are indebted not only for the foundation of our stock of 'Turf Horses, but for their present value. There is not a pedigree of a single blood horse or mare in this country, but what goes in every cross directly or remotely back to English stock 



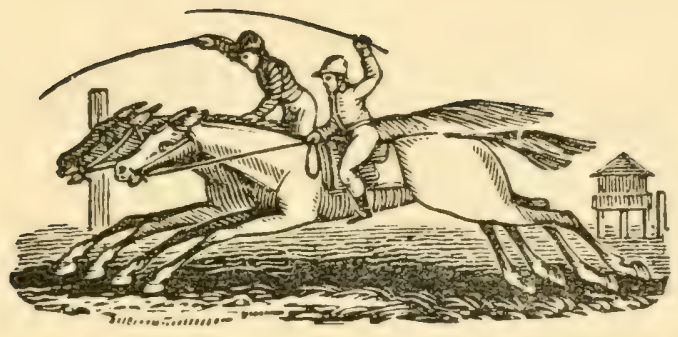

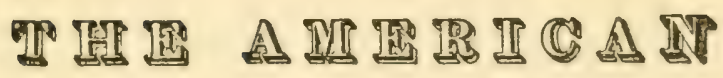
STUD B00K. 



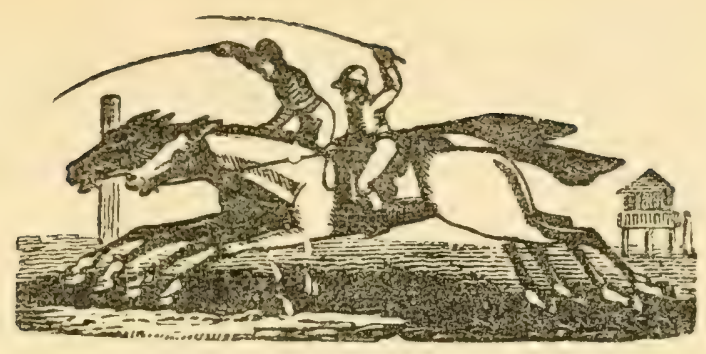

\section{AMERICAN STUD BOOK.}

A.

ABELINO, g. c. by Dragon, dam Celerrima. 1801.

John Hoomes.

ACQUITTAL, by Timoleon, dam (dam of Bolivar) by Sir Hal, \&.r.

Willian Wyune.

ACTEON, ch. h. by Dandridge's Fearnought, dam [by imp'd] Fearnoughe gr. dam by imp'd Jolly Roger, out of an imp'd mare, \&c.

Chesterfield, Va. 1712.

ch. c. by Kosciusko, dam Artless.

1829. S. Carolina.

Thos. Woolridge

Harrison

AC'TIVE, by Chatam, dam Shepherdess, [by ımp'd] Slim.

AL aMANT, b. h. by Boxer, dan by Lindsay's Arabian, g. dam by Oscar, out of Kitty Fisher. 1799.

Nicholas Wyne.

ADELINE, b. f. by Henry, dam by Old Oscar, g. dam the Maid of Nor thumberland, \&c. New Jersey.

J. Vandike.

br. m. by Spread Eagle-Whistle Jacket-Rockingham -Old Cub, \&c.

1806.

John Tayloe. 1809.

Young, hy Topgallant, dam Adeline by Spread Eagle.

ADELA, b. f. by Ratleı, dam young Adeline.

Johu Tayloe.

Dr. Irvine.

ADELAIDE, b. f. by Thornton's Ratler, dam Desdemona by Miner Ez cape, \&c.

ADRIA, b. f. by Pacific, dam Oceana. 1831.

J. Southall.

ADMIRAL NELSON, [imp'd] b. h. by John Bull, daın Olivia, by Justic -Cypher, \&c. Foaled 1795.

William Lightfoot.

AFRICAN, bl. h. by Careless, dam by Lloyd's Traveller, gi. dam vy Othello.

Flatbush. 1738.

A. Giles.

ACNES, or the Thrift mare, by Bellair, dam by Wildair, gr. dam by Fearnought, \&cc.

Williain Thrift.

- - - b. m. by Sir Solomon, (by Tickle Toby,) her dam Yourg Rnmp, by Duroc, g. dain Romp, by [imp'd] Messenger. 18:22.

Gier, Culos 
AGKiCOLA, bl. h. by Highflyer, dam by [imp'd] Dore, gr. dain Emery's aoted ruming mare. Chestertield, Va.

Reuben Short.

AGKIPPA, g. H. by the Winter A rahian, dam by Harrison's Pretender, (who was by Hyde's [imp'd] Pretender,) g. dam by (imp'd) Dioinede, \&c.

Kentucky.

AJ $\Lambda$ X, (See Kill Devil.)

R. J. Breckenridge.

AIFRED SIR, (See Sir Alfred.)

A LARICLS, by Haskin's Americus, dam (Henderson's) Young Medley, g. dam, by 'Thornton's Wildair, \&c.

ALEXANDER, [imp'd] was bred by Sir William Wynne, Bart. got by Lord Grosvenor's Old Alexander, (son of Eclipse) his dam Sweetbrier, g. dam out of Monimia's dam, who was by Alcides, her dam by Crab, out of Snap's dam, \&c.

Virginia.

Wim. Smalley.

- $[$ Imp'd $d$ got by Champion, dam Countess, \&c.

Claverick, New-York, 1797.

- _ gr. c. by Old Pacolet, dam Jenny Riland.

[by imp'd] Bedford, dam Imp'd mare Drone, \&c.

Col. Platt.

ALEXANDRIA, sor. m. [by imp'd] Alexander, dam Black Maria by Sharh. 1811. J. Tayloe.

[Imp'd] was by Alexander, her dam by Woodpecker, g. dam by Phlegnn, out of Lord Egreınont's Highflyer mare, \&c. Foaled, 1796.

Jolun Huones.

ALBEMARLE, by Diomede, dam Penelope, by Shark-Indian Queeu by Pilgrim, \&c.

ALDERMAN, $[$ Imp' $d]$ got by Pot8os, dam Lady Bolingbrooke, by Squir rell, Cypron, the dam of king Herod, \&c.

John Banks. dair mare.

1799.

J. Wickham.

ALARM, [Imp' $]$ br. m. by 'Thunderbolt, dain Tadora, \&c.

ALABAMA PACOLET, (see Pacolet Alabama.)

ALBERT, by Americus, dam by Willair, (by Fearnought,) g. dam vy Vampire, g. g. dam by [Imp'd] Kitty Fisher. 1798.

ALCIDES, b. c. by Galatin, dam Clio, [by Imp'd] Whip.

Robert Saunders.

Richard A. Rapley.

ALFRETTA, ch. f. by Christian's Hotspur, (by Timoleon,) dam Lady Al. fred, by old Sir Alfred.

1831.

ALGERINA, b. f. by Jones' Arabian dam Equa.

Hugh Camphell.

ALIDA Wallis.

ALIDA, ch. f. by Bagdad, daın Nancy Nicnol, [liy Imp'd] Eagle, her dain by Little Wonder, \&c.

W. W.

ALIERKER, a. g. by Old sir Hal, dam by Wonder, her g. dam by Bellair, g. g. dain hy Medley, \&c.

ILICE, gr. f. by Henry, dam Spirtmistress.

Queens Cy. New-York, 1829.

Wm. D. 'Taylor.

ALICE GRAY, gr. f. by Brilliaut, dam by Sir Archy.

Foaled, 1829.

Thos. Pearsall.

-l.L.AKR'JKA, b.m. by Telegraph, dan Crazy Jane by Sky Scraper. 
ALI. TrunIPS, s. m. by Sir Archy, dam [by Imp'd] Jack Arrirews.

ALL WORTHY, b. c. by Aratus, dain Miss Gatewood.

Richard Adams

ALK, NOMAC', ch. c. by Kosciusko, dam by Buzzard, g. dam [by Imp'd] Sjecuiutor, \&c.

Kentucily.

Ed. M. Blackburn.

ALZIRA, by trnhduke, dam by Bedford, g. dam by Pollyphemus, g. g. dam by : loe out of C'elesta.

AMANDA, by Grey Diomede, dain Amanda by Bedford.

Wm. Garnett. Powhatais, Va.

Wade Mosby. b. m. by Bedford, dam by Old Cade, g. dam by Col. Hickman's Independence, (by Fearnought,) out of Dolly Fine, \&c. Purchased by $\mathbf{J}$. Hoomes.

J. Broarddus.

Trumpetta, \&ec.

AMAZON, by Dictstor, dam Statira by Percy, g. dam Homespun by Romulus.

1800.

AMAZONIA, b. m by Tecumseh-Sir Harry-Celer, \&c.

Wade Hampton. Nash. Cy. N C. 1815.

AMAGAZA, b. m. [by Imp'd] Chance, dam by Carolinian-Chanticleer Flimmap-F carnought-Old Janus, \&c.

AMERICAN ECI iPSE, (or New-York, s. h. by Duroc, dam Miller's Damsel, (b) Messenger,) g. dam [Imp'd] Pot8os mare by Eclipse, \&c.

Dosiris, Loug Island, N. Y. Foaled, 1814. C. W. Van Ranst.

AMERICA or GIl.T, ch. h. by Old Feamought, dam by Jolly Roger, g. dam by Desbster.

Bred by Ralph Wormley, 1775. ch s. h. by Smiling Tor. out of a Blooded mare.

York Town, Va.

A ugustin Miller.

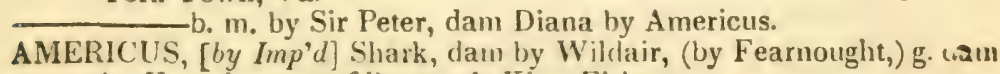

$17 \div:$. by Vdmpire, out of Braxton's Kitty Fisher.

King and Queen, Va. 1798.

John Hoskins.

$-[$ by Imp'd] Fearrought, dam [Imp'd] Blossom.

AMY ROBSAR'T, ch. f. by Gracchus, dam Lady Bunbury.

J. Randolpn.

ANAST A TIA, b. m. by Tom Tough, dam by Hoskins' Americus, g. dam by' Boxer, \&c.

ANDREW JACKSON, b. h. by Virginian, dam by Sir Arthur, g. ram by Florizell.

ANDROMICHE, by Old Cub, her dam by Sweeper, g. dam Clarissa, [by Imp'd? Ranger.

Washington, 1808.

Wm. Thornton

ANGEIINA, b. f. [by Imp'd] Norris' Paymaster, dam Shrewsherry Nan by

Bajazett.

Cecil Cy. Maryland, 1795.

ANNA, b. f. by Truxtou, dam Dido by Caur de Lion.

Th. M. Forman.

ANNETTE, by Old Shark, dam by Rockingham, g. dam by Galatin.

iNTOINE:TTE, b. f. by Marshal Ney dam Camilla by Timoleon.

I.ewis Willis

Raleigh, N. C. 1830.

C. Mauly

ANVIL, [by Imp'l] Cornorant, dam by Bellair, g1. dam an [Imp'd] แna

Landon Cartes 
1NVEI.INA, [Imø'd] b. m. Presented by Mr. O'Kelly in 1799 to Col J. Tayloe, she was by Auvil out of O'Keliy's famous mare Augusta b: Eclipse. Sold Co!. Atston of S. Carolina.

IPULLLO, dk. b. h. by Old Fearnought, dam Spotswood's [Imp'd] Culler Arabian inare.

1777.

Richard Elliott.

IPPARITION, [Imp'd] b. c. by Spectre, ram young Craid)erry, (bred by Earl Grovesnor, by 'Thunderbolt out of Cranberry, by Sir Peter, \&c. $[$ Imp'd] into New-York.

ARABIAN I.INnsAr's or RANGiR, presented by the Emperor of Morocen to the captain of an English vessel, and landed in the West Indies. there he broke three of his legs, and was made a present to a gentle. man from Connecticut, where he went by the name of Ranger. Captain Lindsay 'vas sent hy General Lee, in 1777-8, who purchased him and brought him to Virginia. See American Farmer. vol. ? page 2:3.

-Jonfs'. A dapple grey 15 hands high, black legs, mane and tail. Selected in Tunis by Major Stith, American Consul there, and purchased for Commodore Jacob Jones of the United States Navy See American Farmer, vol. 10. page 127.

-Selim, g. h. presented by Murad Bey to the late Gen. Sir F Abercrombie, and after his death he became the property of Com. nodore Barron, of whom he was purchased, and afterwards sold and carried to Kentucky.

1815.

John Tayloe

Wintren's. Was captured during the last war, $(1814$, , then one year old, by the privateer Grampus, of Baltimore, on board the brig Doris, his Majesty's transport, No. 650, on his passage from Senegal in Africa, to Portsmouth, England, and was intended as a present for the then Prince Regent, late king of England. This horse was sold, and purchased by E. J. Winter, member of Congress, from the State of New-York. This Arabian is now white, and about four feet rine inches high.

Bagnad. Was purchased by George Barclay, Esq. of NewYork, from Has6ana de Gris, Minister to England from Tripoli, who imported him to England, as a horse of the purest Arabian blood: he was purchased by a Company in Nashville, Tennessee, for $\$ 8,000$.

BussorA. [Imp'd] from the land of Job, for which $\$ 4,000$ was paid. Stood at New-York.

- - Ballesteros, dk. br. formerly the property of Ferdinand King of Spain, and still bears the Royal Mark. When the French A rmy got possession of Madrid, the steed belonging to the King of Spain, was taken by the Spanish nobles, carried to Cadiz and there sold. Amongst others was young Ballesteros-he became the pro. perty of Richard S. Hackley, Esy. Consul at that place, who dis posed of him to Captain Singleton, of Philadelphia, who broughi him to this country, and sold him to Thomas Guy of Richmond, Va he got some colts in the State of Delaware.

Broad Rock, I 1 . 1816.

William Ball.

- - Arabari, bl. [Imp'd] by Col. Lear, a large strong horse, well proportioned but not handsome; he was the sire of the dam of Fairfax.

Col. Leas.

A RABIA, bl. h. by Old Janus, from a blood mare by an [Imp'd] Horse.

Cumberland Cy. Va. 1777.

Thomas Moody.

- Fel.1x, ch. m. by Arat, dam by Shylock.

'Thomas T Tabb. 
ARAB, b. h. by Sir A rchy, dam Bet Bounce, by Sir Harry.

Brunswick Cy. Va. 1829.

ARATUS, b. h. by Director, dam (Star's dain) by Sir Harry, g. dain bo Sattram, \&c. (dead.)

ARABELLA, br. f. by Arab, dam by Virgnian, g. dam by Old Sir Irchp

\section{J. J. Harrison}

$18: 7$.

by Dare Devil, dam a Clockfast mare. Richmond, 1823.

Samuel McCraw.

ARCHER, [Imy'd.] A bay horse got by Flagergill, dam sister to Crassus, by Eclipse, Young Cade, Rib, l'artner, Greyhound, \&c.

Virginia, 1802.

T. Recves.

ARCH DUKE, [ Imp'll.] A brown bay got by Sir Peter Teazle, dan Horatio by Old Eclipse-Countless by Blank.

Richmond, 1803.

John Banks.

ARCHIBALD, [Imp'd ] bred by the Duke of Hamilton, and foaled in 1801. He was got by Walnut son of Highflyer, his dam the bay Javelin mare, her dam Young Flora, sister to Spadille by Highflyer, \&c.

William Sinalley.

A?CH DUCHESS, by Sir Archy, dam Duchess.

(Blind.)

John Randolph.

ARCHY SIR, (Benehans) by Old Sir Archy, dam by Eagle, gr. dain [oy Imp'd $\rceil$ Druid, g. g. daim by Old Mark Anthony.

[Near's] by Old Sir Archy, dam Virginia.

Mıхıкı, b. f. by Sir Archy, dam Young Minikin.

J. Jackson.

John Randolph.

Grex, (See Grey Archy.)

ARIADNE, [by Imp'd] Citizen, dan by Blank.

by Bedford, dam Manibrino.

Col. Holcombe.

J. Hroines.

-by Ball's Florizelle, dain Thunderclap, (bred by Mr. Wickham, Richmond,) g. dam Ariadne, by Beilford.

ARIEL, b. fi. by Young Contention, dam Kitty [by Imp'd] Whip.

Georgia, 1830.

Charles A. Rudd.

er's Selima, \&c.

Richnond $\mathrm{Cy}$. Va. 1754.

(or Eriel,) by American Eclipse, dam Einpress by Financier. by Old Tanner, dam by Galloway's Selim, g dam an [Imp'd.j Maryland, 1782.

APIET'TA, b. m. by Virginian, dam by Shylock.

ARION, ch. h. by Polyphemus, dam Leeds, gr. dam by Traveller cut of [Imp'd] mare Pocahontas.

Spencer Ball.

ARISTO'TLE, [Imp'd] b. h. by the Cullen Arabian, his dain by Old Crab, g. dain by Hobgoblin, Godolphin Arabian, \&c.

Charles City Cy. Va. 1764.

Hodgkin. Siud.

ARMINIA, by Medley, dam by Bolton, gr. dam Sally Wright by Yorick 1790 .

J. Hoomes.

ARIMIN.VA, by Brimmer, dam Peyton Randolph's Lovely J ass, Sic.

ARRAKOOKER, Imp'l] br. by Drone, cut of a Chatswortin mare, her aam by Engineel-Droue by Herod.

Foaied, 1789. Imported by

Irr. Tata 
ARRAKOOKRLiSS, ch. m. by Arrakooker, dam Young Hope by to mede, \&n.

ARTLESS, b. m. by a son of [Imp'd] Bedford, dam a Ratth de Cashe by Terror, he by Janus, \&c.

S. Carolina, 1809.

ASPACIA, gr. m. by Bellair, dam Polly Peachem. 1795.

Harrison.

ASSIDUOUS, [by Imp $\left.p^{\natural}\right]$ Wonder, dam by American Eagle.

J. Tayloe.

ATLAS, b. h. [by Imp'd] Ranter, dam [by Imp'd] Lansdale out of an Imported mare. Balt. Cy. 1787.

M. Nestor.

ATLANTIC, (bred by T. B. Hill,) by Archy, dam by Phoenix. (Broke down young.)

ATALANTA, ch. f by Old Slouch, dam Brilliant mare. South Carolina, 1791.

Wm. Alston. - b. m. by Hart's [Imp'd] Medley, dam Pink by Old Mark Anthony, g. dam by Jolly Roger, \&c. 1787.

James Blick.

by Sir Harry, dam by Melzar son of Medley, \&c.

by Dictator, dam Duchess by Hero, \&c.

by Lindsay's Arabian, dam Kitty Fislier by Regulus.

b. f. by Roanoake, dam Young Minikin, \&c.

ATTALUS, b. c. by Pacotaligo, dam Miss Crawler by Crawler-Melzar, \&c.

AUGUSTA, [Imp'd] by Sattram, dam by Wildair-Clockfast-ApolloJanus-Jolly Roger, \&c. Foaled, 1802.

William Rives.

AURORA, gr. m. by Gov. Lloyd's Vintzun, dam Pandora by Grey Lio mede.

b. f. by Aratus, dam Paragon [by Imp'd] Buzzard.

Thomas Emery.

[ by Imp'd] Honest Johr, dam Zelippa by Old MessengerBay Richmond, \&c.

- by Oscar, dam Pandora.

-by Marplot, dam Camilla by Percy.

AURELIA, [Imp'd] by Anville, dam Augusta by Eclipse, Herod, Bajazett, \&c. 1800. Whip.

A URA, b. f. by Ruanoake, dam Amy Robsart.

AURINE, br. f. by Whip, dam Arrakookress.

\section{J. Ranclolph.}

AUTOCRAT, [Imp'd] gr. h. sixteen and a half hands high, by Grand Duke, dam Olivetta, (by Sir Oliver,) g. dam Scotni by Delphini, Scotta by Eclipse, \&c. Grand Duke by Arch Duke out of Handmaid by Jolin Bull, \&c.

Foaled, 1822.

\section{BB.}

BA BKAHAM, [by Imp'd] Juniper, dam Col. Tasker's [Imp'd] Selima, kc Philadelphia, 1780).

Jacol Hitizheimer.

BaCCHUS, b. c. by Sir Archy, dam by Rattler, (by Shark, g. dam bq Wilda:..

Wilkinsos. 
BADGER, [Imp'd] gr. h. by Bosphorus, (a son of Bahraham) dam by Black and all Black-Flying Childers, \&c.

N. Carolina, 1777.

Gov. Eden.

- [i,y Imp'd] Badger, dam by Galloway's Selim out of an impd mare by Spot.

Maryland, 1806.

Benjamin Ogle.

BACDAD, (See Arabian Bagdad.)

BAINBRIDGE, [by Imp'd] Dion, dam Campbell's grey mare, bred ir. Ma ryland, got by Mlarcus and her dam by Moscow. (Died at 5 or 6 years old.)

BAJAZETT, $\left[I^{\prime} p^{\prime} d\right]$ by ine Godolphin Arabian, dam by Whitefoot-Leedsman-Moonah-Barb Mare.

1740.

1801.

(Litrle Devil, by Dare Devil, dam Miss Fauntleroy.

Johı Taylce.

(Young, ) b. h. by Bajazett, dam a Janus mare, (bred by B. Moore, N. Carolina.)

King and Queen, Va. 1774.

BALD EAGLE, b. c. by Spread Lagle, dam Broadnax by Old Janus, \&c. by American Eclipse, dam Lady Lightfoot.

J. Breckenridge.

BALLY SHANNON, by Wedding Day, dain Miss Fauntleroy. 1801.

J. Tayloe.

BALL HORNET, b. by Black and all Black, dam Rosetta by Shylock.

BALLESTEROS, (See Arabian Ballesteros.)

BANGO SEIB, by Bedford dam, dam of Byron by Archy.

BARONET, [Imp' $d]$ b. h. by Virtuminus son of Eclipse, his dam Penulti ma by Snap-Old Cade---Childers, \&c.

This horse was imp'd into New-York with Pot8os mare, the gr. dam of Am. Eclipse.

BAREFOOT, [ Imp'd] was by Tramp, (he by Dick Andrews out of a Gohanna mare, dam Rosamond by Buzzard out of Roseberry, sister of Huby and Tartar by Phenomenon out of Miss West by Matchen, \&c. So' 1 in England for over $\$ 12,000$.

Foaled 1820. [Imp'd] by Sir Isaac Coffin, 1825--6.

BARBARA, b f. by Roanoake, dam Wakefield.

BARONESS, b. m. by Potomac, dam by Young Baronet, gr. dam [by ımp'd, Bedford, g. g. dlam [byimp'd] Shark, \&c.

BARON BOSTROP, gr. c. by Roanoake, dam Miss Ryland. 1825.

J. Randolph.

PARON TRENCK, by Sir Archy, dam by Old Galatin, g. dam [Imp'd] by Gov. Telfair of Georgia.

Wm. Terrell. (Georgia.)

BASHAW, b. h. [by Imp'd] Wildair, dan De Lancey's [Imp'd] (Cub maro New Jersey.

Mare, dk. ch. [oy Imp'd] Bashaw, Imp'd Jolly Roger, Aris. totle, Merrypintle, \&c. dam an Imp'd mare from Lord Cullen's Stud.

RAY RICHMOND, [Imp' $d]$ by Feather, dam Matron by the Cullen Aıa. bian, Bart!ett's Childers, \&c. 1769.

BAY BOLTON, by Bolton, which was bred by the Farl of Nortn.mne, land, and owned by William Lightfoot of Charles Cis $C^{\prime} y$. V $\mathbf{z}$. dare $[$ Imp'd] Blossom.

BAY COLT, [Imp'd] a dk. b. got by ITighflyer, dam by Eclipse from Yor'ng Cade, which was the dam of Vauxhall, also dam of Dulcina, Sic 
Imported by Wm. Barksdale.)

Manchester, Va. 1797.

Jos. Sirange

- _ (Sola oy John Baylor, [by Imp'd] Tup, dam by Old Shar'k,

g. dam Betsy Pringle by Fearnought. MARF, by Bedford, dain by Old Cade, g. dam by Hickman's Independence.

RAY YANKEE, by President, dam Cora by Obscurity.

J. Broadus.

BAY BETT, b. !n. by Ratler, dam b. m. bred by lsaac Duckett of Mary land in 1809, got by Dr. Thornton's [I $m p$ 'd] horse Clifden, her dans by Richard Hall's Tom by imported Eclipse.

Gen. C. Irvine.

BAY MARIA, b. f. by American Eclipse, dam Lady Lightfoot, \&c.

BAY DOLL, by Sans Culotte, out of the dain of Spot.

BEAL'TY b.f.by Ravenswood, dam Everlastıng.

\section{J. Randolph}

John Randolpn. b. m. by Diomede, dam Virginia, full sister of Desclemona. J. M. Selden.

BECCA JOLLY, ch. f. by Sir William, dam by Ragland's Diomede, gr. dam [by Imp'd] Dion.

BEDFORD, (Imp'd] by Dungannon, (he by Eclipse,) dam Fairy by High. flyer, Fairy Queen by Young Carde, \&c.

Bowling Green, $\mathrm{V}$ a. 1792.

John Hoomes. (BLANn's) [ by Imp'd] Bedford, dam Pandora by Bellair.

MARF, [by Imp'd] Bedford, dam by imported Dare Devil.

Foaled, 1810. Greensville, Va.

Thomas Spencer.

MARE, (Old) [by Imp'd] Bedford, dam by imp'd Coeur de Lion-Fortuna by Wildair, \&c.

b. h. by Consul, dam [by Imp'd] Bedford.

R. K. Meade.

BEDLAMITE, b. m. by Cormorant, dam Madcap-Arvil, \&.c. Shepherds. 1799.

J. Tayloe.

ch. c. by Janus, dam by Young Frenzy.

J. Randolph.

BEGGAR GIRL, by Sir Archy.

b. f. [by Imp'd] Barnuet, dam Betsy Bell.

BEHENOTH, (late Hamlet) br. by Bagdad, clain Rosy Clacx.

BELLAIR, gr. h. by Old Medley, dam Selima by Yorick.

J. Tayloe.

(Соок''s) gr. h. by Bellair, dam by Independence cut of Virginia mare, \&c.

BELLARIA, by Bellair, dam Sweetest. 1796 .

___ by Bellair, dam Narcissa by Wildair.

J. Taylne. 1797.

BELLISiIMA, b. f. by Melzar, dam by Old Wildair, Fluvia, \&c. 1807.

BET.IN()A, b. m. by Escape (Alias Horn's) dam by Beciford.

BELL.ONA, by Rellair, dam Indian Queen [by Imp'd] P'ilegrim.

BELLVIr, E, by Bellair, dam Indian Quees [by Imp'd] Pilgrim.

BHLMONT, by Tamner, dam by Selim out of au [ Imp'd] mart..

BkilvIDERA, b. c. by Symme's Wildair, dam [ly lmp'd] Cluckfast, gr dam by Old Yorick, \&c.

Krunswick Cy. Va. 1798.

Hartwell 'l'ucker 
BELVIDERA, b. f. by Roanoake, dam Archy Minkin.

BEV COn Rancolph.

BEN COUPER, gr. c. by Messenger, dam Temptation by Heath's Childers 1803.

BENYOWSKI, b. h. by Anericus, (by Diomede) dam [Imp'd] Anvelina. 1802.

John Taylne.

BERGAMOT, [Imp'd] got by Highflyer, dam Orange Gir] by MatcliemRed Rose by Babraham-Blaze-Fox, \&c.

Charles City Cy. Va. 1787.

BERNADOTTE, (I'malfower) liy Bal!'s Florizelle, dam [by Imp'd] Bed. ford, g. dam by Quicksilver-Victorious, \&c.

BERTRANI), b. h. by Sir Aichy, dam Eliza [by Imp'l] Berlford, g. dam Mambrino.

South Carolina, 1827.

J. B. Richardson.

BET BOU.CE, b. t. Ly Sir Harry, dam Atalanta by Ola Medley, \&c. Foaled, 1825.

BETTY, ch. f. by Contention, dam Flora ly Ball's Florizelle. Loudon, $\mathrm{Va}$.

BETSY ARCHER, by Old Sir Archy, dam Weazle.

J. Lewis.

AxnRews, ch. by Sir A rchy, dam by Jack Andrews.

E. Irby.

Baker, gr. f. by Buzzard, dam Portia.

br. in. [by Imp'd? Shark, dam by Romulus,-St. George,

Haymes' Old Poll by Fearnought.

b. m. by Florizelle, dam Tartar mare by Old Fearnought, \&c.

Bıossom, dk. b. by Superior, (by Old Superior, dam by

Thornton's Wildair nut of a Dare Devil mare.

Bf.l., b. f by Mr. McCarthy's Cub, clam Temptation.

Haxald, (See Ruxaja.)

- - Hunr, br. m. by Sir Hal, dam by Dinn-.--Quickstep--...Shark

Wildair-...Clockfast, \&c.

Manisor, ch. f by Madison, dam Maria by Archy.

P'raksox, ch. by 'Tom Tough, dam [by lmp'd] Diomede.

Wm. D. Taylor.

Prwate, by Old Fearnought, dam [Imp'd] Jemy Dismal.

Raxsom, gr. m. by Virginian, dam Old Favourfu by Beliair.

Romssox, b. f by Thaddeus, dam Masia by Sir Archya

[/mp'd] Sir Harry....Dare Devil, sec.

A rion, g. g. dain by Romulus.

by Suuth Carolina, 1806.

B. F. Taylor.

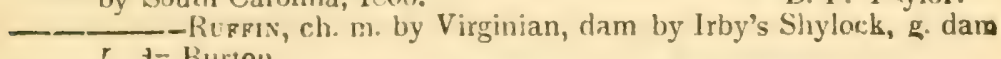

$r$ t-Burtoll.

- Satiners, gr. f. by Stickholder, aam by Pacolet.

TAlvor, ch. m. by First Cousul, dam [by Imp'd] Otscurity

Philadelphia Cy.

1827.

Wusox, by Ratray, dam ioy Uscar.

Col. Emerw.

Wıka, b. m. by Sir Archy, dau by Bedford, g. dam by Dar Devil, g. g. dam by Lamplighter, \&c.

BIG BEN, [by Imp'd] Bedford, dam Pandora by Bellair.

B cee Phenomenom, al:o Charlemont or Strange"s Tra"eller

BLACK MARIA, by Anericas Eclipse, dam Lady Lightfon.

1826.

J. C. Stepulen:

18121

by Shark, dam by Clockfast, g. dam Maria !y Pegulus, so 
BLACR MERINO, by Vintzun, dam by Cornet, g. dain by Don Carlos-a Old Figure, \&c.

BLACK GHOST, [lyy Imp'd] Oscar, dam Pill Box by imp'd Pantaloon-.Melpomone, \&ec.

by Oscar, dam Melpomone, \&z.

Dr. A. Dixon, (Va.)

BLACK EYED SUSAN, by Sir Archy, dam [by Imp'd] Druid, g. dain b? imp'd Saltrain.

1812.

C. Harrison. 1819.

by Potomac, dam by Galatin-by Diomede, \&c.

Stephen Hester.

BLACK AND ALL BLACK, hy Madison, dam Virago by Whip.

[by Imp'd] Brunswick, dam by Ariel, g. dam Brent's Ebons, g. g. dam imp'd Selima.

Penusylvariia, 1780.

Elihu Fall.

[Imp'd. $]$ (See Othello.)

BLAKEFORD, ch. c. by Gov. Wright's Silver Heels, dam Selima by Topgallant-Gabriel-Chatain, \&c.

Maryland.

Robert Wright, Jun.

BLACK J.A'K, b. c. by Carolinian, dam by Miner's Escape, (or Horn's.)

BLACK ROSE, bl. m. by Stockholder, (by Sir Archy,) dam by Hamilto. niaı, [by Imp'd Diomede,] g. dam by Columbus, (by imp'd Pautaloon) out of Lady Northumberland, \&c.

Frederick Cy. Va. 1826.

D. H. Allen.

BLAZE, [Imp'd] hy Vandall, (by Spectator, dam the sister of Chrysolite by 'Truncheon-Regulus-Partner, \&c.

York, Va. 1796.

- br. c. by Roanoake, dam Miss Peyton.

Hugh Nelson.

BI.AZELLA, $\{b y$ Imp'd $\}$ Blaze, dam Jenny Cameron.

J. Randolph.

BLACK PRINCE, by Don Carlos, (he by Figure) dain by Figure, g. dam by Dove-Othello, \&c.

Maryland, 1783.

1827.

BLACK WARRIOR, ['by Imp'd] Merryfield. by Black Warrior.

BI.AC:K TOM, by Tom Jones, dam an imp'd mare.

BLEMISH, b. m. by Gracchus, dam imp'd Duchess. 1819.

H. Burwell.

BLOSSOM, [Imp'd] by Old Slue, her dam by Regulus the sire of Fear nought, sc.

Thomas Nelsou, (Va.)

Imp'd] dap. gr. by Bordeaux, dam by Highflyer, g. dam by Eclipse out of Vauxhaii's dam by Young Cade, \&c. Pennsylvania.

BLUE SKIN, b. c. by Roanołke, dam Miss Ryland, \&c.

John Mayo.

BLUE SKIN Randolph. MARE, by Baylor's Fearnought, dam an imp'd mare.

BLUE RUIN, by Gracchus, dam Duetia, \&c.

[BI.USTER, [Imp'd] by Orlando, (son of Whiskey,) out of a Hightlyer mare sister to Escape by Pegasus, her dam by Squirrel, \&c.

Petersburgh, Va. James Dunlop.

BOASTER, [Imp'd] b. h. hy Dungannon, dam by Justice, Mariame op Squirrel ..-Miss Meredith by Cade, \&c.

t naled, 1795.

Walter Bell.

BOI.IVAR, by Sir Hal, dam by Old Diomede--.-Wildair-.. A pollo, \&c. 
BOLIVAR, gr. h. by Oscar, (by Wonder,) dam by Pacolet, Truxton, \&o. - - by Sir Robert Wilson, dam Darning Needle. b. h. by Ratler, dam by Sir Solomon.

1826.

Wright.

BOLTON, [Imp'd] b. by Shock, owned by Mr. Lightfoot of Charles City, Va.

Foaled, 1752.

Mare, ch. by Bolton, dam Sally Wright by Torick. Foaled, 1776. John Hoomes.

BOMPARD, [by Imp'd] Obscurity, dam by Pillgarlic, g. dam by Imp'd Jack of Diamonds, \&c.

BONNE'S O'BLUE, gr. f. by Sir Charles, dam Reality by Sir Archy

BONNY BLACK, b. f. by Bagdad, dam Fancy. Tennessee.

Wm. R. Johnson.

EONNY LASS, (L. Hardimans,) by Jolly Roger, dam [Imp'd] Bonny Lass.

BOV Imp'd] by Ray Bolton.

BONAPARTE, b. by Col. 'Taylue's Grey Diomede, dam by Matchem, g. dain by Marius-Silver Heels, \&c. Maryland.

Sam. Nerwogd.

BOREAS, b. c. by McCarthy's cub, dam Shrewsbury Nan, by Bajazet, \&c. Kent Cy. Mld.

1791.

BCXER, ['y Imp'd] Medley, dam by Baylor's Fearnought, g. dain by Jolly Roger, \&c. Goochland Cy.

J. Curd.

- - by Sir Archy, dam [by Imp'd] Druid-Symme's WildairAmericus, \&c.

Ohio, 1930.

P. Claiborne.

BRANDON, by Aristotle, dam by Old Janus.

BRA VO, b. c. by Henry, dam Gulnare, Scc. Queens County, N. Y. 1829.

BRENDA, ch. f. by Gracchus, dam Mariana.

Tho. Pearsall. b. m. by (Ame's) Sir Archy, dam Madanie Lavalette. Foaled, 1823.

J. J. Ambler.

BRITANNIA, [ [mp' 'l] b. m. was got by Pegasus, dain Peygy, was veiy fleet, but invariably bolted.

1800 .

John Tayloe.

- by Wildair, dam [hy Imp'd] Aristotle, g. dam by Imp'd Vampire out of Imp'd Britannia.

1792.

Col. Symme. full sister to True Briton, dam Col. Gant's Milly, full siste' to Hopper's Pacolet, \&c.

ny, Sic.

Marylaı, 1769.

BRIGHT I'HOEBUS, full brother to Miller's Damsel.

BRILIIANT, $[$ Imp'd $]$ gr. by Phenomenon, dam Fait' by Pacolet- Ats lanta by Matchem, \&c.

Foated, 1791.

1826.

br. c. by Sir Archy, aan Bet Bounce.

b. c. by Marplot, dam Brilliant mare.

1797.

J. Tayloe.

W. R Iohnsor.

Joseph Atston

Cunchr.atr.s's, by Timoleon, dam Caroine by Marshall

Fairfax County, Va. 1828. 
BPILI,IANT, ch h. hy Eden's [Imp'd] Badger, dam !y Othello, gr. dam h"! Mortou's Traveller, \&c.

Towsen's Tavern, Maryland, 1736.

J. R. Hollirlay.

\&c. MARE, [by Imp'd] Matchem, dam Imp'd was by Brilliant, 1799.

BRIMMLR, b. h. by (Harris') Eclipse, dam Polly Flaxen.

Powhatan County, Va. 1777.

Ed. Fenwick.

Clive, \&c.

T. Turpus.

[by Imp'd] Valiant, dam by Jolly Roger.

BRUADNAX, by Old Janus, dam by Apollo, g. dam by Fearnought, g. $s$ dam by Jully Roger, \&c.

1784.

BROW V FILLY, [Imp' $]$ was by Sir Peter Teazle out of the dam of Horn's. S. Carrima, 180:2.

John Mld'herson.

BRUNSWIrK, [Imp'd] (ralled Iightfoot in Englaud,) was wol by Oro). nooko, a son of Crab, (Black and All Black) out of Miss Slamerkin. Brunswick's dam by Babraham, a son of Godolphin Arahian: dic.

BRUNSINIUTT, dk. br h. by Brunswick-[Iny'd] Panter-Imp'd Dabster, \&c.

BRUNET"TE, full sister to Gohanna.

- b. f. by 'Telegraph.

b. f. by Roanoake, dam Archy Minikin.

BRYAN O'LYNN, [Imp'd] by A ston, dam by De Sang-Regulus-Port ner-Brocklesby's Betsy, by the Curwen bay Barb. Foaled, 1796. INortl, Carnlina, 1803.

BUCKSKIN, by Mark Authony, dam Brandon.

\section{- Turner.}

B. Harrison.

BUCEPHALUS, [Imp'l] br. h. got by Sir M. Witherton's Locust, dam by Old Cade, g. dam by Partier.

Foaled, 1758.

S. h. by Craig's Yorick, dam by Careless.

King Williara Cy. Va. 1777.

Archibald Ritchie.

b. h. by Symme's Wildar, \&ic.

1807.

by Granby, dam Maria Slamerkin.

Reuben Butler.

Col. Ed. Ward.

IIUFFALO, b. c. by Bagdad, dam Arisa by 'T ruxton.

BUSSORA (See Arabian Bussora.)

BLILE ROOK, (Old) [i,y Imp'd] S!:arks out of a full blooded mare.

BURK, ch. c. by Stochholder, dann Eliza by Bagdad.

BURSTER, ch. h. by Rasselas, dam by Topyallant, g. dam, [by Imp'd; Play or Pay-Bellair, \&c.

BURSTALL, by Shylock, dam Nare Devil mare.

Wm. Cleveland.

BURWELL'S 'TRA VEILER. (See Traveller Burwell's.)

BUXOMA, ch. f. by Pulaski, dam Virginia Nell. 1829.

J. Blick.

IBUZZARD, [Imp'd] ch. h. by Woodpecker, dam by Dur-Curiosity by Silap-liegulus, \&c.

1787.

J. Hocmes.

gr. h. by a son of Old Buzzard, dam Pandora by Bellair, a c. Oin, ch. m. [lyy Imp', l] Buzzard, dam by Diomede, gr. clam n\& Boxer, \&c. 
BTZZAPD, Yorxe, m. by Hainilenrian (of Va.) dam Old Buzzard [l, Imps] Buzzard, g. il by hiomerle, dic.

audier.

Gien. Jeffersn!

\section{C.}

('AllMUS, b. h. by Sir Archy, dam by Shylock, g. dam [by Imp'd] Bed ford, \&c.

Kentucky.

CAIIE, by Old Partner, dain [Imp'd] Kitty Fisher. 1788 . 1791. ch. c. by Ajax, dam Tartar maro, \&c.

N. Hutcheroft.

Wm. Lumpkin.

CAIRA, ch. by Wildais, (by Fearnought, dam by Sloe, the dam of Greg Diomede. 1796.

CALYPSO, g. m. by Medley, dam Selima by Yorick. 1793.

b. f. by Chance Medley, dam by Vintzun.

Richard Brooke.

J. Tayloe.

Col. Chambers.

by Nolimetangere, dam Lady Dudley by First Consul.

CALENDER, ch. h. by American Eclipse, dam l'rincess by Sir Archy, dam a full blooded mare.

CALISTA. gr. f. by Roanoake, dam Miss Peyton.

CALMUC, ch. c. by Timoleon, dam Fair Forester, \&c. 1831.

CANDEN, by Old Janus, dam Polly Haxen.

King and Queen, Va. 1782.

J. Randolph.

Dr. Goodwin.

CAMIL LA, [Imp'd] by Dove, \&c.

_ by 'Tanner, dam Stella by 'Tasker's Othello.

ch ๆ. by Timoleon, dam Duchess by Bedford.

Henry Carter.

Halifax, i.. C.

by Old Wildair, dam Minerva by Obscurity.

Rohert A. Jones.

Wm. Broadnax.

Sc.

Albemarle, Va.

by Old Fearnought, dam Calista.

b. m. by Bolingbreke, dam by 'Thornton's Diomede, he ty

Ball's Florizelle- $[$ Imp' $d]$ Whip, \&c.

King and Queen Cy. Va. 1826. Hugh Campbell.

Walter Coles.

ch. m. by Sumpter dam, by Robin Gray, \&c.

by Sumpter dam, by Robin Gray, \&c. Rarıdolph

Tho. Stephens

CAMILLUS, b. h. by Burwell's Traveller, dam Camilla by Old Fearnougbe Foaled, 1773.

Prince George, Va. 1782.

John Gordon.

CANDIDATE, b. c. by Cormorant, dam by Vexican out of Maria, \&c

Freds.

James Smock.

(late Eutaw.) ch. c. hy Virginius, sam Peggy by Bedford

CANTAB, ch. h. by Pantaloon, dam Selima by Yorick. 
CARDINAL PUFF, [Imp'd] by Cardinal Puff, dam by Bardy, g. dain im Matchem, \&c.

Herring Bay, Maryland, 1737.

Sam. Harrison

CARLO, [Imp'd] b. h. by Balloon, dam own sister to Peter Pindar by Jave lii, g. dain Sweetheart by Herod-Snap, \&c. 1809

Dr. Thornton.

- _ [ by Imp'd] Carlo, dam by imp'd Florizelle out of a mare raised by Col. R. K. Heath, \&c.

Major Gibhs.

CARELESS, [by Imp'd] Fearnought, dam Camilla, by Dove-OthelloSpark, \&r.

Maryland, 1776.

Rich. Sprigg. gle, \&c.

1801.

J. Hoomes

by Obscurity.

CARNATION, br. h. by Virginian, dam Rosetta [hy Imp'd] Dion.

CAROLINE WHITEFOOT, b. m. by Oscar, dan Indian fien by Othello, g. dam by Lloyd's Traveller, \&c.

Caroline Cy. Va. 1818.

Elisha Wilson.

CAROLINE, ch. f. by Mufti.

b. f. by Eclipse, dam a Janus mare.

b. m. by Old Sir Archy, dam [hy Imp'd] Dion, g. dam Misg Selden by Sorrel Diomede-Wildair, \&c. 1823.

Dr. Tho. Hall.

CAROLINA, b. f. by Saltram, dam Medley mare, g. dam Old Reality, \& c. Marmaduke Johnson.

CAROLINIAN, gr. c. by True Blue, dam Medley mare, \&c.

MARE, gr. by Carolinian, dam gr. mare by Superior, gr. dam by Quicksilver- $[$ Imp' $d]$ Shark, \&c.

b. by Sir Arcliy, dam [by Imp'd] Drud, gr. dam by Wildair by Fearnought, \&c.

CARROL, ch. c. by Sir William, dam Jennett by Muzzle Dinmede.

CARRiON CROW, by Young Royalist, dam [by Imp'd] Spread Eagle. Paris, Kentucky.

Jefferson Scott.

", S S'TIANIRA, [Imp'd] br. m. by Rockingham, dam Tabitha by Trent. ham out of the dam of Pegasus.

Foaled, 1796. Imp'd 1799.

IASTANIA, by Arch Duke, dam Castranıra. 1803.

John Tayloe.

J. Tayloe,

CASWELL, b. h. by Sir William, (by Sir Archy, dam Lady Bedford, and half brother to Giles Scroggins.

CASTAWAY, b. c. by Roanoake, dam Miss Peyton.

CATIIERINE THE GREAT, b. f. by Roanoake, dam young Granit

J. W. Jeffries. Duchess.

J. Randolph.

[ELER, [Inp'd] by Old Janus, dam Brandon by Aristotle-Cul!en Ara. bian, \&c.

loaled, 1774. (Virginia, 1798.)

- Mare, by Celer, dam by Janus, \&c.

- Meade.

CELIA, by Old Wildair, dam Lady Bolingbroke.

Green Sans Culotte, \&c.

CLIERINA, by Old Medley, dam by Old Ceher, gr. dam by Old Fea noungh, Sc. 1797 .

Edmund Har rison. 
CENTINET, [Imf'd] ch. h. by Blank out of Naylor by Cade, Spectator'y dam by Partuer, \&c.

Foaled, 1758.

CENT A UR, br. h. by Evan's Starling, dam an [Imp'd] mare.

Foaled, 1764.

CHAMBERLAIN, ch. h. by Diomede.

CHANCE, [Imp'd] b. h. by Lurcher, (son of Dungannon,) dam by Hyder Ally-Perditta by Herod-Fair Forester by Sloe, \&c. 1797.

John Tayloe.

-Nrnley, gr. h. [by Imp'd] Chance, dam by Young Diomede, (by gr. Diomede,) g. dam by Imp'd Oscar, \&cc.

: HAN'ICI.EER, by Wildair, dam by Pantaloon, g. dam by TravellerMark Anthony, \&c.

1798.

B. Wilkes.

- br. by Sir Archy, dam Black Ghost [by $\left.I m p^{9} d\right]$ Pill Box by Imp'd Pantaloon-Morton's 'Traveller.

Jas. G. Green.

FHARIES CARROLL, ch. c. by Sir Charles, dam Susan by Bond's Sir Solomon, \&c.

CHARLES STEWARD, b. h. by Tuckat. e, dain by Sir Solomon.

CHARLES MARE, by Sir Charles, dam by Young Hal, gr. dam by Bedford, g. g. dam [Imp'd] Trumpeter.

CHARIOT, [Imp'd] b h. by Highflyer, dam Potosi by Eclipse-BlankGodolphin Arabian-Snip-Partner, \&c.

Foaled, 1789. N. Carolina, 1800.

J. \& L. Lyne.

CHARLENIONT, [Imp'd] b. c. (afterwards called Big Ben) in which name he ran many races in England, and afterwards in this country calied I'raveller-he was got by O'Kelly's Eclipse, his dam by king Herno -Blank-Snip-Penton's Lady 'Thigh, \&c.

Foaled, 1786. Manchester, Va.

Jas. Strange.

CHARLtMAGNE, by Wildair, dam by Romulus by Mark Anthony, ou of Judge Tyler's Pompadour.

CFATAM, by Fitzhugh's Regulus, dam Brent's Ebony, g. d. Selima [by Imp'd] Othello.

Gunpowder Falls, 1786.

CHARLOTTE, ch. f. by Galatin, dam Anvelina.

- Brogden. by Sir Archy, dam Merino Ewe.

Temple, full sister to Gohanna.

W. R. Johnson.

CHEROKEE, by Sir Archy, dam Young Roxana by Hephestion.

CHESNUT MARE, by Diomede, dam by Alderman, g. dam by Clockfast, \&c.

CHESAPEAKE, gr. h. by Sweeper.

J. Wickham.

CHEVALIER, by Celer, dam Brandon by Aristotle.

Gittings.

B. Harrison.

CHILDERS, [Imp'd] b. by Blaze, son of the Devonshire Cnilders, dam by Old Fox, \&c.

Stafford Cy. Va. 1759.

Francis Thornton.

- Hғ.дти's, ch. h. by Baylor's Fearnought, daun an imported mare by Bajazet-Babraham-Sedbury, \&c.

b. h. [by Imp'd] Childers, dam by Traveller.

Charles' County, Maryland, 1764.

Rich. Barnes.

Furiog beo. Lee. 
CHIEF'TA'N, sh. c. by Director, dam by Hoskin's Sir Peter, gr. dam Highlander, scc.

Rich. Hill.

('HINOAN(i'TI, [ by Imp'd] Aral, dam Aurora by Imp'd Honest Joln.

LICERO, by Sir Archy, dam [by Imp'd] Dionede g. dam bv lmp'd Fear noweht-Jolly hoger, \&c.

MARF, (dam of Trifle) by Cicero, dam by Bedford, g. dam by Bellair-Shark, \&c. 1822.

Tho. Graves.

CITIZEN, [Imp'd] b. h. by Pacolet, a son of Blank, a son of the Godol phin Arabian-Fairy Queen by Xoung Cade, \&c.

Foaled, 1785.

Teimessee, 1818 .

by 'Timoleon, dam by Sir Hal, g. dam Ariadne, (Johnson's.;

CINCINNA'TS, (Bowie's) by Lindsay's Arabian, h 'dam [by Imp'd] Fi gure, g. dam 'Thistle by Imp'd Dove.

by Bay Richmoud, dam Blue Skin by Ba. or's Fearnought.

CINDERELLA, full sister to Marshal Duroc.

- Ringold.

[Imp'd] b. f by Sir Peter, her dam (Vivaldi's daum) by Mer cury, g. dam Cyuthera, \&c.

S. Carolina.

Gen. John McPlierson.

CIRCE, by Ariel, dam [Imp'd] Lady Northumberland. 1784.

Beckwith Butler

CLARA FISHER, by Kouskiruska, dam by Hephestion, g. d. by Roxana (her dam never run, having been crippled.)

b. f. Ly Virginius, dam Transport.

CLAUDIUS, b. h. by Old Janus, dam Brandon by Aristotle.

Andrew Meade.

by Meade's Claudius, dam by Cole's Eclipse.

Mare, by Claudius, dam by Bolton, g. dam Sally Wright.

1791.

J. Hoomes.

CLARISSA, b. m. by Sumpter, darn by Cook's Whip, [by Imp'd] Whip g. dam by Imp'd Spread Eagle Bellair, \&c.

CLERMIONT, by Spread Eagle, dau Peggy. (Went to the South.)

J. 'Taylne.

ch. c. by Kosciusko, dam Josephine by Young Bedfnid, \&e

S. Carolina, 1824.

J. J. Moore.

CLEVELAND, ch. h. by Bussora out of a Director mare.

CI.EMENTINA, b. f. [by Imp'd] Paymaster, dam Tulip.

J. M. Selden. Maryland, 1795.

Tho. M. Firman.

CLEOPATRA, by Druid, dam by Pegasus.

E. Haynes.

CLIFDEN, [Imp'd] b. h. by Alfred, a son of Matchem, his dam by Flo-; zelle, g. dan by Matchem.

Foaled, 1817.

Dr. Thointer.

[Imp'd] got by Abba Thulla, dain Eustatia by Hightly 3r-Wren by Woodpecker-Sir Peter 'Teazle's dam.

1797.

Hall's Tom, he by Impl'd Eclipse.

ling, \&c

$181:$ 
CLIO, [by Imp'd] Whip, dam Sultana by imp'd Sprear Fagle. ginia by Dare Devil. Foaled, 1817.
C. W. I an Ranst.

CLOCKFAS'T, [Imp'd] gr. h. by Gimcrack, (sire of Old Medley, dam $\Lambda_{2}$, Ingrạn by Regulus-Miss Doe by Sedtury-Miss Mayes by Bartlett's Childers, sc.

Foaled, 1774.

CLOWN, [Imp'd] got by Bordeaux, brother to Florizelle, dam by Eclipse Crisis by Careless-Snappiana by Snap, ifc. Foaled, 1785. N. C.

COCK OF 'THE ROCK, brother to American Eclipse.

COEUR DE LION, [Imp'd] b. h. by Highflyer out of Dido by EclipseSpectator-Blank, \&c. Foaled, 1789. (1800.)
John Hoomes.

COAI.ITION, b. h. by Shylock, dam Maria by Bay Yankee, Green's mare by Celer, \&c.

COESS, b. m. by Virginian, dam by Sir Arthur, g. dam by Bellair, g. g. dam by Medley, \& c.

COLLECTOR, by Old Mark Anthony, dam Lady Legs. Died, 1813.

COLLIER, ch. c. by Sir Charles out of a Whip mare. 1826.

\section{S. R. Carney.}

William Finney.

COLLINGWOOD, ch. c. by Thornton's Ratler, dam Vixen by Trafalgar. \&c.

COLUMBIA, by Ogle's Oscar, dam Selima by Hall's Eclipse.

Ch. f. by Sir Archy, dam Duchess by Bedford.

-b. m. [by Imp'd] Eugene, out of a Young Selima by Yorick.

Coy Imp'd] Baronet, dam by Old Cub-Partner, \&c.

COLUMBUS, ch. h. by Young Sir Harry (he $[$ by Imp'd] Sir Harry, dam Gentle Kitty by loung Postboy.

b. h. by 'Tennessee Oscar, (by Wonder) dam [by Imp'd] Dumgannon-imp'd Rapid.

Isaac Bledsoe.

s. h. [by Imp'd] Pantaloon, dam Lady Northumberland, Sce 1828.

James G. Green.

COMBINATION, by Gracclus, dam Evelina by Phenomenon.

COMMUTATION, b. h. by Symme's Wildair, dam by Yorick, g. dam by Little David, \&c.

1788.

John Beltield.

COMPETITOR, by Dragon out of Celerinia.

COMMODORE, [Imp'd] bl. b. h. 16 hands high by Caleb Quotem, (a sor of Sir Peter Teazle,) dam Mary Brown by Guilford, \&c. Geneva, N. Y.

C. A. Williamsun.

COMET, ch. by' Tayloe's Yorick, dam by Ranger, g. dam by Dove, g. g dam by 'Tasker's Othello, \&c. 1792.

John Brown. - ch. h. by Old Janus, \&c.

CONSTANTIA, gr. f. [by lmp'd] Messenger, dam Betty Bell.

$$
\text { J. Lewis. }
$$

CONSTANTIA, b. m. [l, Imp'd] Whip, dam by imp'd bedford-imp'r shark, Wormley King Herod. \&c. 1814.

CONSTLLLATION, ch. c. by Thornton's Ratler, dam Nettletop.

D. H. Allea

dk. ch. by American Eclipse, dam Olivia.

L. Berkley 
CONSUL., by First Consul, dam [by Imp'd] A racolien, Messenger, a Basnaw mare, \&c.

- Mare, by Fırst Consul, dam [by Imp*re] Obscurity, g. dam Moil by Grey Figure, \&c.

1827.

CONFESSOR, (Speculator, by Shark, dam Fluvia by Partner out of the dam of Oracle, \&c.

CONGAREE, ch. c. by Kosciuskn, dam full sister to Sally Taylor.

CONTENTION, by Sir Archy, dam a Dare Devil mare, \&z.

r.ON'TRACT, [Imp'd] cls. h. by C'otton out of Eliza Leeds, dam Helen by Hamiltoniau, gr. dam Drowsey by Drone, g. g. daun Mr. Goodrich's Old English mare, \&c.

New-York, 1829.

William Jackson.

rONVENTION, by Sir Charles, dam by Sir Alfied, Florizelle, Bedford, \&c. b. h. b. Virginian dam.

Wm. H. Minge.

CONSTITUTION, by Diomede dam, (dam of Timoleon, ) [by Imp'd] Sal. tram-Old Wildair, \&c.

CONQUEROR, b. h. [ by Imp'd] Wonder, (Cripple) his dain by SaltramDare Jevil-Pantaloon-Valiant Jumper out of a mare imp'd by Mr. John Bland.

CONTEST, ch. c. by Contention, dam Fairy by Sir Alfred. Petersburg, Va.

A. J. Davie.

William Haxall.

Dionnede, \&c.

Mecklenburg, Va.

T. Young.

CePPER BO'TTOM, c. c. by Sir Archy, dam by Buzzard, g. dam, dam o! Betsy Richards.

Edward Parker.

COPPER HEAD, by Kosciusko out of a Whip mare, g. dam by BuzzardGrey Diomede, \&c.

COQUE'T'TE, by Sir Archy, dam Bet Bonnce by Sir Harry. Vraginia, (See Virginia Coquette.)

CORA, by Bedford, dain Little Moll by Medley.

J. Tayloe.

by Dr. Brown's Ciodolphin, dam by Charles Fox, g. dam uy Hall's Eclipse, \&c.

by Ouscurity dam.

G. W. Peter.

ch. m. full sister to Virago and Nettle by Wildair by Ajax.

CORIANDER, by Diomede, dam by Shark.

Wm. B. Hamlin.

CORNELIA VANHORNE, ch. f. by Wares' Godolphin, dain Sally Bax ter, \&c.

CORNELIA; by Chanticleer, dam by Old Celer.

John Randolpli.

BEDForn, by the Duke of Bedford, (te by Bedford) dan Fj lot by Old Quicksilver.

CORNET by OId Yorick, dam by Ranger, \&c.

CORNWAIISIS, by Florizelle, dam out of Edelin's Floretta

CORMORA NT, [Imp'd] b. h. by Wooripecker, his dam Nettletop by Squs rel--Bajazet-Regulus-Lonsdale Arabian-..-Darby Arabian, \&c F saled, 1787.

Virginia, 1800

John Hoomes

COP.SICA. b. c. by John Richards, dam Selima by Topgallant.

Philin Wallis. 
CORPORAI. TRIN, ch. by Sir Archy, dam by Old Diomede, gi: rian t's Wildair, Apollo, Partner, \&ic.

\section{J. Powell}

CORPORAL CASEY, ch. c. by Virginius, dam Josephine by Blanu's Bea fort, \&: $1826^{\circ}$.

COSSACK, b. c. by Marion, dam Camilla by Timoleon.

J. J. Mooie.

COTTAGE GIRL, ch. f. by Am. Eclipse, dam Agnes by Sir Solomon. sold to T. Harrison, Boston.

COUNT BADGER, ch, c. by American Eclipse, dam by Hickory.

Coush.

COUNT BERTRAND, b. h. by Old Beitrand (of South Carolma) dat Constautia [by Imp'd] Whip.

Pipre, ch. c. by Marshal Duroc, dam [by Imp'd] Expedition, g. dam by imp'd Royalist.

Daniel Holınes.

COUNTE.SS, ch. m. by Ridgley's Young Oscar, dam oy Little Bay Post Boy, and out of the Mountain Filly, \&c.

COWSLIP, [Imp'd] by Virtumnus, dain by a son of Latham's Sıap̧, g. dam Clemeutine, \&c.

by Bedford, dam [Imp'd] Hackabout, \&c.

CRAB, I Imp'd] ch. fifteen and a half hands high by Old Fox, his dain the Warlock Galloway by Snake, \&c.

Foaled, 1739.

CREMONA, b. f. hy Spread Eagle, dam Gasteria.

CRAZY JANE, b. m. by Rob Roy, dam Josephine, \&c.

J. Lewis.

by Allen's Skyscraper, daın a Cincinnatus mare, g. daın b. Galloway's Selim.

CRA WFORD, [Imp'd] gr. h. bred by the Duke of Cumberland, and got by his A rabian.

Covered in Va. in 1762.

Robert Ruffin.

CRAWI.ER, b. h. by Highflyer, his dam Harriet by Old Matchem, \&c.

Temnessee.

CRUSADER, by Sir Archy, dam Lottery by Bedford.

South Caroliua, 1830.

CUB, [Imp'd] ch. h. fifteen hands three inches high, bred by Mr. Grenville, got by Old Fox, his dam Warlock Galloway-Curweu's bay barts c.c. Foaled, 1739.

MARE, [Imp'd] by Cub a son of Fox, her dam by Torismond, son of the Bolton Starling, her g. dam by second brother to Sinip, Sc. 1767.

-Delancy.

CUB, (called Old,) b. h. by Yorick by Silver Legs out of Moll Brazeı, \&c Westmoreland, Va.

Daniel McCarthy. ruming a race.)

CUMBERLAND, gr. h. by Pacolet, dam Virginia by Dare Devil.

J. L. Gibson.

James Jackson.

CUP'BEARER, b. h. by Bedford, dam Louisa by Harris' Eclipse.

John Tayloe.

-by Florizelle, dam by Bellair.

CURTIUS, by Diomede, dam by Bedford, g. lam by l'atrou.

CU'I' I.EG, ch. f. by Gracchus, clam Everlasting.

1818.

Jchn Rancioipo 
CUI'D OSCAR, h. h. by Erlelin's Oscar, jun. dam by Thornton's Merwury, g. dam by Bowie's Sportsman, \&c.

Pr. Geo: Maryland, 1827.

Thomas N. Baden.

CYPRON, b. m. by Van Tromp, dam Miss Madison by Lurcher.

CYPRUS, dap. gr. by Smiling Tom, dam by Silver Legs, (the dam ot McCarthy's Cub.)

C'Y PHAX, by Janus out of an [Imp'd] Mare.

Jas. City, Va. 1775.

CYGNE'T, by Cormorant out of Blossom.

John Walker.

Turner Dixon.

\section{D.}

DABS TER, [ Imp'd] by Hobgoblin-Spanker-Hautboy, \&c.

Imp'd 1741.

DAPE DEVIL, [Imp'd] b. h. by Maguet, dam Helse by Chrysolite out of Proserpine sister to Eclipse, \&c.

Foaled, 1787.

Young, [by Imp'd] Dare Devil, dam by a son of Old Partner out of a mare which was got uy an imp'd horse.

New Kent Cy. Va. 180?.

John Clopton. Mare, [by Imp'd] Dare Devil, dam Sallard's old mare by

Wildair, g. dam Picadilla by Balt \& Macklin's Fearnought. _ Irby. Mare, [by Imp'd] Dare Devil, dam Trumpeter.

J. Hoones.

DAIRY MAID, by Bedford, dam Racket by Medley. mede-Bellair, \&z.

טAFFODLL, by Dare Devil, dam Celerima.

Imip'd] Oscar, g. dam by Old Dio

J. M. Botts

T. C. Nelson.

T,AMON, dk. ch. h. by Old Celer-Babrahan-thorough bred Janus mare, \&c.

b. by Janus (by Feamought) dam by Old Fearnought out of an [Imp'd] mare Steady Sally. 1781.

John Baylor.

DAME PRESLEY, b. m. by Carolinian, dam Miss Dance.

[1PHNE, by Figure, (by Yorick) dam an Ebony mare.

I).APPLE JOHN, by Lloyd's Traveller-[Imp'l] Janus-imp'd mare.

D.ARIUS, dap. b. h. [by Imp'd] Jolly Roger-Baylor's Old shock out of a thorough bred imp'd mare.

Foaled, 1767 .

DART, ch. m. by Diomedon-Old Celer-Old Warning-Old Spa lille, \&c. out of a thorough bred mare.

1815. (Crippled.)

UARLINGTON, [Imp'd] b. h. by Clothier, dam by Highflyer, Little John, \&c.

Niecklenburg, Va.

J. Goode.

MARF, by Darlington, dam by Cludius, g. dam by Bolton, g. g. dain Sally Wright, \&c.

J. Taylse.

- Manf, ak. Iron gr. [by Imp'd] Darlington-Hart's Medle thorough bred mare by imp'd Justice, dec.

DA VII), [Imp'd] b. h. by the fower Stallion, dam by Fux Cub-Young True Blue out of the sister of Pelham's I ittle George, \&c. 1756 - Litru, (See Little J)avid.) 
DARNING NEEDL.E, b. m. by Sir Archy, dam [by Imp'd, Piomene. fioaled, 1813.

DASIIER, gr. c. by Cincinnatus, dam Shrewsbury Nan. Mary!and.

DASHALL, br. h. by Sir Archy, dam Meg Dodds. Reeds, Caroline Cy.

Thos. M. Forman.

Messrs. Corbin's.

DAUPHIN, b. by Lloyd's Traveller, dam by Old Figure, gr. dam by Love \&c.

Chas. Cy. Maryland, 1783.

DEFIANCE, hr. h. by Florizelle, dam Miss Dance by Roebuck.

J. Tayloe.

DE KALB, b. h. by Arab, dam by Virginian, g. dam Prudentia by Shylork. South Carolina, 1832.

A. R. Ruffin. br. c. Ly Kosciusko, dam Virginia Coquette. 1825.

DESDEMONA, by Dare Devil, dam Lady Bolingbroke. 1800.

J. Ferguson.

J. Tayloe. Mask. 1819.

b. m. Ly Miner's Escape, dam by Dare Devil, gr. dam by

E. G. W. Butler.

179. gr. f. by Comet, dam Kitty Fisher by Oscar. 1792.

Ramson Davis. g. dam Anvelina. 1818.

DELEGA'TE, ch. c. [by Imp'd] Valentine, dam Cornelia Van Horne, duc. $183 i$.

DELILAH, b. m. by Sir Archy, dam by Herod, \&c.

T. M. Forman.

Jas. L. G. Baker.

DENIOC:RAT, b. h. by Grey Diomede, dam by Hall's [Imp'd] Eclipse, g. dan by Don Carlos.

Walter Bowie.

hl. c. by Morgan's Shakespeare, dam Shrewsbury Nan, \&... Cecil Cy. 1794.

T. M. Forman.

DEPRO, by bay Baronet, dam [ Imp'd] ('rop.

DE WITT CLINTUN, ch. h. lyy Rater, dam (Flirt's dain) by Duroc, dam by Baronet.

DIAMOND, [Imp'd] by Hautboy, son of Old Fox, \&c.

DIANA, gr. f. by Galatin, dam by Clio [by Imp'd] Whip.

Alex. Syotswood. 1317.

b. m. by Claudius, dam Sally Painter.

br. m. by Tayloe's Hamilonian, dam by Bowie's Bellain Irish Grey, \&c.

Lexington, Kentucky, 1821.

E. Warfield

by First Consul dam, dam of Marshal Ney, g. dam by Mus senger, g. g. dam by Figure.

— by Americus (by Shark, nam Minerva by Bellair.

[by Imp'd] Sterling, dam one of Col. Willis' best niares.

Cinl. Davie..

DANA VER.YON, br. b. m. by Ratray, dam Cora [hy Imp'd] Carlo mu c Pandora.

Maryland, 1817.

DIANORA, b. f. [by Imp'd] Expedition, dam Betsy Bell.

DICK DASHALL, ch. c. by Diomede, dam Shark mare.

James Parker.

J Hoomes, Juv 
Dle:'I + TOR, [ly Imp'd] Mexican, dam by Imp'd Flimmap, g. dam Imp'd Bougist al the Duke of Bridgwater's sale in 1762.

F aled, 1790. Gen. John McPherson.

OIDO, gr. f. (bred by J. Hoomes) by Coeur de Lion, dam Araminda by Medley, g. daim by Bolton.

1798. Wildair. 1804.

by Gen. Morris' [Inp'd] Bay Richmond, dam Slamerkin by b. f. by Coeur de Lion, dam Poll by Eclipse.

I VERNON, by Old Florizelle, dam by Ogle's Oscar, g. dam by Hero, \&c.

- D Drana, by Sir William, dain Lady Burton.

DINWIDDIE, b. h. by Diomede, dain by Wildair, gr. dain by ApolloPartner-Fearnought, \&c. 1804.

Dr. Wm. Cutler.

DION, [Imp'd] by Spadille, dam Faith by Pacolet, gr. dam Atalanta by Matchen-Lass of the Mill by Oronooko-Old Traveller, \&c. 1795.

J. Hoomes. Roger, \&c. Halifax, Va. 1806.

J. Sirns.

DIOMEDE, $[$ Imp'd] ch. h. by Florizelle, dain by Spectator, g. dam sister to Horatio by Blank-Flying Childers-Miss Belvoir by Grey (iran. tham-Paget's 'Turk-Betsy Percival by Leed's Arabian. (Died in 1807,30 years old.)

- (Barr's,; [by Imp'd] Diomede, dam Mulga by Wildair.

Eagle, br. c. [by Imp'd] Eagle, dam Chesnue Mare by Dio. mede, gr. dam by Alderinan-Wilda:- dec.

1814.

J. Wickham.

- _ _ (Thorston's, ) by Ball's Florizelle, dam [by Imp'd] Whip, gr. dam by Topgallaut, \&c.

Thornton.

Marf, b. [by Imp'd] Diomede, dam by Girucrack, (alias Randolph's Roan.)

Buckingham Cy. Va. 1815.

Ediv. Curd.

- MAнF, b. by Ragland's Diomede-[Imp'd] Dion-Imp'd Highflyer- Apollo, \&c.

1816

J. Sims.

GreY. (See Grey Diomede.)

b. m. [ hy Imp'd] Diomede-Darlington-Old Medley-Clock fast, \&c.- thorough bred mare by lmp'd Justice, \&c.

Jas. Gowan.

(Seconn,) gr. [by Imp'd] Dionede, dam by Imp'd Clockfast - Old Partner-Old Regulus, \&c.

Cumberland Cy. Va.

UIOMEDA, [by Imop'd] Diomede, dam Imp'd Janette.

DIOMEDIAN, by Am. h. Saltram, (son of [Imp'd] Diomede,) dam by Hen drick's Celer, (son of Old Celer.)

DIRECTOR, ch. by Sir Archy, dam Meretrix by Magog.

Young. (See Yuung Director.)

DIREC'TRESS, ch. $\mathrm{m}$. by Director, dam by Old Potomac, g. dam by Gim crack, \&c.

1822 .

Wn. Randulph.

De)TO , .. c. by Pacotango, dam Virginia, (Coquette). J. Ferguson.
1819 .

De)TO , .. c. by Pacotango, dam Virginia, (Coquette). J. Ferguson.
1819 .

Jackson.

WLI Y FINE, 'w Old Silver Eye, aam [by Imp'd] Badger-Furester, \&o 
DOLLY PATMAN, ch. by Sir Alfied, dam by Tom Tough, E lam o: Kellis by Dandridge's Feamought.

DOLLA BELLA, b. f. by Roanoake, dam Bay Doll. 1825.

J. Randolph.

loON CARLos, [my mmp'] Valentine, dan: Fenella by Silver Heels. 1780. b. h. [ $[$ y Imp'd] Figure, dam Primrose by Dove.

Dr. Hamulten.

I ON JUAN, ch. c. by Timoleon, dam Rosemary [by Imp`d] Diomede.

Dr. Thornton.

DONGOLAH, by Mark Anthony, dam Nancy Bell by Feamought, g. dam Miss Bell.

DOMINICA, gr. h. [by Imp'd] Dove-Regulus-Aınerican horse Othellothorough bred Imp'd niare.

DORA, b. f. by Kosciusko, dain Josephine. 1825.

John S. Moore.

DORACLES, [by Imp'd] Shark, dam by Clockfast.

DOTTREI.L, [Imp'd] g. fifteen and a half hauds high, got by Changeling: his dam by a son of Wymu's Arabian.
Foaled, 1750
Westmoreland Cy. Va. 1766.
Philip L. Lee

DOUBT! ESS, by Fitz. Dionede, (son of Diomede, dam by Picture, g. dain by Sweet Su rry by Spardille.

DUUBTFUL, b. f. by Spread Eagle, dam Medley mare.

G. P. Tayloe.

John Hoomes.

DO)VE, [Imp'd] gr. by Young Cade, dam by Teazer out of a Gardiner mare, \&c.

1762.

Dr. Hamilton.

DOUCE DA VIE, b. c. by Roanoake, dam Cornelia. 1825.

J. Randolph.

URAGON, [Imp'd] by "Woodjecker, dam Juno by Si ectator, Horatio ty Blank,-Childers-Mis: Belvoir, \&c. Died 1812, aged 25 years.

John Hoomes.

[by Imp'd] Dragon-Truxton-Barry's Grey Medley-Stern -Pillgarlic, \&c.

DREADNOUGHT, ch. c. [by Imp'd] Expedition, dam Tulip.

Thos. M. Forman.

DRIVER, [Imp'd] b. h. by Driver, dam by Lord Ossary's Dorremont, g dam by Old King Herod-Shephard's Crab-Miss Meredith by Cade. Foaled, 1794.

Washington City.

Dr W. Thornton.

URUID, [Imp'd] ch. near sixteen hands high by Pox8os, (son of Eclipse, his dain Maid of the Oaks by king Herod-Matchem-Snap-lio gulus, \&c.

Foaled, 1790. (1800.)

John Hoomes.

DUE'T'A, by Silver Tail, dam Vanity by Celer.

IUUBIOUS, b. c. by Bertrand, dam Darning Needle, \&c. 1829.

I UNGANNON, [Imp'd b. h. by Dungannon, dam by Conducuo-H!me by Syuirrel-Helen by Blank-Crab) out of Old P'armer's sister. 1793. J. Tayloe 1803.

1 UFF GREEN, (Case's Colt) ir. gr. by Pacolet, dam by Royalist, gr. uare by Bompard, (son of Obscurity,) Pillgarlic, \&c.

I UKE, OF BRDFORI), [by Imp'd] Bedford, dam l'ilot by Quicksilver

I LKË)J LIMLS, (Fxperiment) by Highnyer. 
DUKE CHARLES, ch. c. by Kosciusko, däm by Financier.

DUROC, ch. h. [hy Imp'd? Diomede, dam Amanna by Grey Diomede, sca Died 1826 .

P'owhatan Cy. Va. $1810 . \quad$ Wade Mostr. \&C.

DUTCHESS, [Imp'd] b. m. bred by the Duke of Grafton, got by Grouse son of Highflyer nut of (ieorgiana, own sister to Conductor by Matchem -Babraham-Partner, \&c.

1801.

John Randolph.

_._ by Bedford, dam Thresher [by Imp'd] Shark-Twigg, \&c.

R. R. Johnson. by Hero, dam by Brutus, g. dam by Tarquiu-Old Prince, \&c.

DUMPLING, ch. f. by Gracchus, dain Everlasting. 1318.

Rich. Rapley.

DUTiFUL, ch. f. by Sumpter, dam Miss Haggin.

John Randolph.

E. Warfield.

\section{E.}

EAGLF, [Imp'd] b. sixteen hands high, got by Volunteer (a son of Eclipse) out of a Highflyer mare, her dam by Engineer-Cade-Lass of the Mill by Traveller-Miss Matchless-Partuer-Woodcock, \&c.

Foaled, 1796. Whitby, Va. 1812.

S. S. Saunciers. b. h. [by Imp'd] Eagle, dam Iris by Imp'd Sterling.

br. b. by Spread Eagle, dam Arminda, \&c.

1801. Sold to Mir. Alston, S. C.

J. Lewis

J. Hoones.

Foaled, 1796.

br. b. by Old Sir Solomon, da I Aurora by Honest Jonn, gr. dam Zelippa [by Imp'd] Messenger.

New Jersey.

EBONY Young, [Imp'd]. (See Young Elsony.)
(Impread Eagle, dam Sprdille. 1762.

EBONY, [by Imp'd] Othello, dam Imp'd Selima. Virginia.

- Brent. 1829.

J. Randolph

EASTER, ch. f. by Gohanna, dam by Napoleon, g. dam by Sir Harry. Dirmede, \&c.

1829.

Stephen Hunt.

EC:HO, ch. f. by American Eclipse, dam Maria Slamerkin. 1825.

ECONOMY, b. c by Old Rattler, dam by Topgallant-Bedford-.Prunrove. \&c.

ECLIPSE AMERICAN. (See American Eclipse,) \&c.

Wm. Clevelaud.

ECLIPSE, Fiarkis' b. h. [by Imp'd] Feamought, dam an Imp'd mare by Shakspeare, \&cc.

Died 1790.

Raised by John Baylor.

-. MARxund, dk. ch. h. by American Eclipse, dam Lady a the Lake, g. dam Maid of the Oaks.

Balt. 1829 .

Samuel Briscm 
ECILIPSE, Sotтh:Rv, ch. h. by Northampton, dam by Firsi Cimsul-Cirez Dionede-Old Ebony, \&ic.

William Thorutem.

Colfs', ch. sor. h. [by Imp'd] Obscurity, dar: by A pollo, ge dam by Old Valiant-Try All, \&c.

Prince George Cy. 1796.

Win. Cole.

[by Imp'd] Lagle, dam Lauretta by inp'd Berlford, \&c.

Kentucky, 1825.

Lewis Sheely.

Herov, [by Imp'd] Driver, dam inp'd Miss Bemnington.

Washington City, 1808.

Wm. Thomton.

Virtisia, (See Virginia Eelipse.)

\&̊c.

Warren, Ohio, 1825.

\&.c.

Ligнтғоот, bl. c. by American Eclipse, dam Lady Lightfoot,

by Virginius, dam Anvelina.

1812. 1825.

J. B. Richardson.

Mark Anthony, \&c. thorough bred mare.

Halifax Cy. N. C. 1797.

- Vaughan.

Actolphus, \&c.

Foaled, 1770. Annapolis, 1780.

Wallace \& Muire.

- Imp'd ch. was got by O'Kelly's famous Eclipse, dam l'hebe

full sister of Apollo-Phebe by Regulus, her dam by Cottingham, g dam by Sinake, \&c.

Prince George Cy.

Richard B. Hall.

EFFIF, UEA NS, b. m. Wy (Famer's) Florizelle, (hy Bali's Florizelle, dau by Clockfast, ur. dam by Jones' Coeur de Lion-Robin RedireastDare Devil, \&c.

ELECTION, c. c. by Spectator, dam Fairy by Bedford. 1811.

J. Honmes.

ELEGANT, [by Imp'd] Fearmosght, dam by Bellair-Wi]dair, \&c.

ELIZA, ch. m. by Baydiad, dans Mellwood by Topgallant.

Temnessee.

L. J. Polk.

- [hy Imp'd] Bedford, dam imp'd Mambrino, \&c.

1803.

James Ferguso:.

\&c.)

Red House, N. C.

J. W. Jeffries. A DAss, by Hornet, dam [by Imp'd] Jack Andrews.

ReIler, b. f. by Sir Archy, dam Bet Bounce.

W. H. Minge

Dr. J. Ninge

-Splotch, g. f. by Sir Archy, dam by Diomede.

WAiKer, b. f. by American Eclipse, dam by Moore's Sir Ar.

chy, g. dain Jenny Deans.

Winte, b. f. by Sir Archy, dam by Diomede.

Wharsos, b. by Director, dam by Bedford-Pruserpme

Dare Devil.

Drake, ch. f. by Shawnee, dam by Sir Ariny.

John Whire. int Jacksou

FLIZABETH, by Sir Archy, dam by Robin Reubreas.

Gers. Wringe 
ELVIKA, ch f: by Bedford, dam Virginia Sorrel.

(Sold vo H. King.)

EMIGRAN'T, by Carolinian, dam Pet by St. Tammanv.

EMPRESS, [by Imp'd] Baronet, dam by Old Messenger-Srap-Tru Briton, \&c.

Flatbush, Long Island.

FNDLESS, ch. f. by Gracchus, out of sister to Everlasting. 1819.

ENTERPRISE, b. h. by Diomede, dam Forlorn Hope.

J. Randolvh.

Henry Macklin.

by Florizelle, dam by Saltram, (the dam of Timoleon sni Constitution.)

-(See Grey Diomede.)

ENGINEER, ch. [byImp'd] Eagle, dam by imp'd Archduke nut of inp'd Castianira, \&c.

EQUA, ch. m. [by Imp'd] Chance, dain by Republican President, g. dau by imp'd Figure-Dove, \&c. 1815.

EQUINOX, ch. c. [by Imp'd] Baronet, dam Tulip. 1799.

Isaac Duckett.

T. M. Forman.

ERIEL, (or Ariel, gr. m. by Am. Eclipse, dam Empress by Financier.

E.SCAPE, (or Horis, $\left[\operatorname{Im} \mu^{\prime} d\right]$ cl. h. fifteen and a half hands high, was got by Precipitate, his dam by Woodpecker, his g. dam by Sweet Brier, out of the dam of Buzzard by Dux-Curiosity by Snap-Regulus, \&r.

Fualed, 1798.

John Hoomes.

N. B. Escape was ralled Horns in England, under which name he rased.

___ Mixre's, [by Imp'd] Escape, dam by imp'd Bedford, g. dam imp'd Gasteria.

MARF, ch. bred by Dr. Thornton in 1821 by Miner's Escape, dam Young Adeline by Topgallant.

of тиғ. Wfrs, by American Eclipse, dam Mloggy Silamican. Courtland Cy. N. Y.

Ebenezer Hopkins.

by Timoleon, dam by Sir Harry, g. dam by Old Diomede.

Bobert Saunders.

F.THIOPIA, bl.m. by Tayloe's Bedford(by Bedford) dam by Pot8os, who was by Old Medley out of a Conductor mare, g. dam Celer, Sic.

EVELINA, by Phenomenon, dam by Regulus, g. dam by Limdsay's A ra. bian, \&c.

ELDOR.4, b. m. [by Imp'd] Dragon, dam bv imp'r Clifden, g. dam by Flag of Truce-Goode's Brimmer

EXILE, ch. c. by Coeur de Lion, dam iyren Silver, s. dam Caroline tiv Eclipse, \&c.

Davidson, Teunessee. 1806

FXPECTA'TION, (See Galatin.)

EXPEDITION, or Ballinamuc, [Irip'd] fifteen hands, three and a half in. clies high, was got by Pegasus, his dam Active by Woodpecker, gr dam Laura by Whistlejacket, g. g. dan Pretty Polly hy Starlng. Foaled, 1795.

J. Humphrevs.

EXPRESS, [Imp'd] was got hy Postmaster out of a Cypron mare, $g$. daus by Natchem, g. g. dam by Snip, Regı Jus, \&c..

Foaler'. 1785. 


\section{F.}

FAIR PLA v, b. c. by Play or Pay, dam Bellaria. 180?.

by Citizen, dam by Medley.

\section{J. Hoomes}

Gen. Eaton.

FAIR FORESTER, b. m. [by Imp'd] Chance, Celia by Symmes' Old $W$ is dair-Ladly Bolingoroke, \&c.

John Raker.

FAIRFAX, (afterwards called Rattler) hy Rattler, dam Laura by Aratsarb. Imp'd by Col. Lear, an Arabian horse.

FAIR MAID, by F'irst Consul, dam Jane Lowndes, by Driver.

FAIR RACHEL, by Diomede, dam Susan Jones by Old Shark, Wil lair, \&c.

Rosamoxd, gr. m. by Sir Archy, dam Forlorn Hope.

H. Macklin.

FAIRY, by Sir Alfred, dam [Imp'd] Promise. Whig, \&c.

by Herod, dam by Diomede-Gimcrack, \&c.

Joseph Bailey.

lor's Sally.

Foaled, 1797.

FAIR STAR, b. f. by Torpedo, dam Betsy Wilkes.

Foaled, 1831.
FAN A. Blaney, U

A. Spotswood. Temuessee, 1808.

FANNY FOSTER, ch. hy Old Wildair, dam by Old Partuer-Old Feas nought--.-Old Jolly Roger, \&c.

N. Carolina, 1795. 1814.

Iohn Foster.

John Randolph.

Colf, br. b. by Francisco, dam Sting by Jack Andrews.

Benjamin Harrison. sul, \&c. Fatrmaid, ch. m. hy Rob Roy, dam Fairmaid by First Con

Hut., ch. f. by Sir William, dam Diomede mare by Ragland's Diomede, \&c:

FANTAIL, br. m. by Sir Archy, dam Sally Mc(ihee.

FANCY, br. m. hy Wilke's Wonder, dam by Mark Anthony, Fearnoug't, se.

'Tennessee, 1809.

by Jubilee, (by Independence,) dam Stella.

J. Sumner.

by Independence, (by Atkiuson's Fearnought) dam by Amen cus---[Imp'd] 'Traveller---Nonkey, \&c.

FARMER JOHN, b. c. by Sterling, dain [Imp'd] Janette.

H. Macklin.

Ricluad Huomes.

FalOURITE, [Imp'd] b. m. hy Volumteer, dam by Matchem. Hamty Da vey...Bayton, \&c. bred by Mr Fonwick.

Fosled, 1790. Imp'd 1796.

John Honne:

- y (Hd Fearnought dam.

Gien. Jones

- - - - (Old) by Bellair, dam by Bedfurd, Pantahon, d.c. (Wyehere)

F. 'Thorntou, (cf Warpen.) 
FAYETTE oy Fitzhugh's Regulus, dam by Othello, [Imp'd] Juniper, Mes ton's Trave!ler, \&c.

('harles City Cy. Va. 1788.

Presley Thornton.

FEARVOCGHT, [Imp'l] br. bay, fifteen hands three inclies high got by Regulus, (who was by the Gindolphin Arabiars) dam Silver Tail of Heneague's Whitenose, her dam by Rattler, \&c.

Died 1776, aged 21 years.

J. Baylor.

- Draxdriges, [by imp'd] Fearnought, dam - Bath \& Macklix's, [by Imp'd] Feamought, dam an imp'o mare, hought of the widow of Col. Mail near Norfolk, \&c.

Wicksford, Va. 1777.

- Edwaris.

FEATHER, ch. f. by Rattler, dam Marianna.

Fred. Cy. Va. 1827.

B. F. Whiting

FEDERA:is' $\Gamma$, by Lath, dam by Old Feamought out of Col. Titstier's 'se lima, raised by J. Tayloe.

FEIEILA, by Silver Heels, dam Black Merino by Vintzun-Comet-Dun Carlos-Old Figure, \&c.

Easton, Maryland.

G. S. Winder. ch. ni. by Smith's Alfred, dam by Dungannon-Nimiod[Imp'd] Hamilton-Bal]'s Florizelle, Sc.

[ by Cornet (by 'Tayloe's Yorick, dam by Don Carlos. Mount Calvert, 1795. John Brown. ch. f. by Stockholder, dam Rosetta by Wilke's Wonder.

FIDELITY, c. f. by sir Charles, dam by Sir Alfred-Florizelle-Dionede \&c.

Pensa.

Edward Parker.

FIGURE, [Imp'd] b. h he Grey Figure-Old Figure by an Arabian, his dam the dam of bowle's Cyrus, and got by Young Standout, his gr. dam. Old Jason, Young Figure's dam was Marianna dam of Ralph Gore's gr. mare.

1767.

Dr. Hamilton.

I $m p^{9}$ d] gr. h. by Standard, dam a Beaufort Arabian mareLord Brooke's Arabian-Brinmer-Darley's Arabian, \&c.

Foaled, 1747.

-

Mecklenberg, Va. 1777. Yousi, (See Young Figure.)

P. Skepwith.

-by Yorick, dam an Ebony mare.

FINANCIER, by Tippoo Saib, (who was by Old Messenger) dam by Old Messenger-lbashaw, \&c.

FIREFLY, ch. f. by Reigo, dam Shepherdess by Phenomenon.

Richard A dams.

FIPETAIL, [Imp'd] 1). by I'heumenon out of Columbine by Espusike's \&e. 1801.

FIREBRAND, [Imp'd] ch. c. by Buzzard out of Famm, own sister to King Fergus the sire of Hamiltonian.

FIRST CUNSUL, by Flag of 'Truce, dam [b!Imp'd] Slenter, g. dam impod Dion by famous Eclipse.

Philadelphia, 1804-5

John P. Bond.

FIRST FRUITS, rti. br. c. by Randolph's Roanoake, dam Cameleon by Virginian-Rosetta, \&c.

FITZPARTVER, by Old Partuer, dam Brandon [by Imp'd] A ristole. Albemarle, Va. 1800.

David Clarkson.

H ACELLA TOR, ch. h. by Sea Gull, dam Honesty [hy Imp'd: Expedi 'ı⿰丿, g. dan by lüp'd Messenger, \&c.

John Frost. 
FLAG UF TRUCE, (Goode's) by Goldfinder, dam by Flumnay--ArisinteFearnought, \& c.

Prince George Cy.

Col. Portress.

FLEE'TWOOD, b. c. by Washinginn, nain by Sir Robin, (he by Robiu Res?breast,) g. dam by Dare Devil, \&c.

FLIMNAP, [Imp'd] b. h. fourteen and a half hands high, by South, daur Cygnet mare, bred by Sir John Moore, g. dam by Ebony-Childers, \&c.

Sot th Carolina, 1780. Foaled, 1765.

FI.IRTILLA, b. m. by Sir Archy; dam by Robin Pedbreast-Obscurity, \&c. Sussex Cy. Va.

Win. Wyntue. [Imp'd] ch. m. by Virtumnus, O'Kelly's Flirtilla by Squirre! - Melen by Blank-Crab_out of own sister to Old Partner. (Died 1798.)

J. Tayloe.

FLORIZELLE, [Imp'i] (Helen's) dap. bay sixteen hands high by the noted Florizelle, ont of a brown mare by Alfred, his g. dam Fairy Queen by Young Cade, g. g. dam Black Eyes by Crab out of Warlock, Galloway by Snake, \&c. [Imp'd] 1794 by Helen for Ringgold \& Co.

Ech. s. [by Imp't'] Diomerle, dam by Imp'd Shark-Harris' Eclipse-Feamought-Old Jolly Roger.

Broad Rock, Va. 1806.

Wm. Ball.

- yr. c. by Grey Dimede, dam Louisa by Eclipse.

Foaled, 1795.

J. Tayloe.

(Gravfs') by Old Florizelle, dam by Old Spread Eagle, gr.

dam by Boxer, g. g. dam by Eclipse-Fearnought, \&c.

-Young. (See Young Florizelle.) John M. Burton.

Marf, ch. by Ball's Florizelle, dam [by Imp'd] Cripple-

Wonder-Old Bedford, \&c.

FLORIZELLA, br. f. [by Imp'd] Florizelle, dam Betsy Bell.

J. Selden.

\section{Foaled, 1802.}

Thos. M. Forman

(or (irey Tail) by Ball's Florizelle, dam (Dr. Cutler's race

mare) by Wilkair, g. dain by Apollo-Eclipse-Mark Anthony

$\left[\cdot \pi n p^{\prime} d\right]$ Partuer, \&c.

-

Gieorgia.

Jos. Hester.

FlORA, by Roanoake, dam [Imp d] Iaady G.

Independence, \&c.

ch. m. by Ball's Florizelle, dam Iris.

b. f. by Heath's Childers, dam Maggy Lauder.

Foaled, 1789.

T. M. Forman.

Alex. F. Rose

\section{J. Lewis.}


FLCVli, by l'aitner, dam Fluvia by Celer.

J. T'Pryloe.

FLYING DUTCHMAN, b. h. by John Richards, dam by Ec.ipse, g dar. by 'Tippoo Saib- $\left[I_{m p}\right.$ 'd $]$ Royalist, \&c.

FLYING CHILDERS, ch. h. by Sir Archy, dam (the dam of Sumpter,; by Robin Redbreast.

FORLORN HOPE, gr. m. by Bellair, dam Fancy by Independence. Wynne. Henry Macklin.

F ORTUNATUS, by Conway's Black and All Black, dam a full bred daughter of Tayloe's Yorick.

Goochland Cy. Va. 1782.

FORTUNIO, b. c. by Comorant, dam Broadnax by Old Janus, scc. 1798.

FORESTER, ch. h. by Sir Alfred out of a Hornet mare. Sold Mr. Powder, Fred. Md.

J. Tayloe.

Rich. Craddock. 1803.)

FOREST MAID, b. m. (See Maid of the Fcrest.)

FOSKARI, b. c. by Kosciusko, dain by Whip, gr. dam by Columbus, \&c Kentucky.

Ed. M. Blackburn.

FRANCISCO, [hy Imp'd] Hambleton, dam Nigbtingale by ChanticleerJolly Roger, \&c.

John Minge.

FRANKLINA, b. m. by Sir Solomon, dam [by Imp'd] Expedition-lunp'd Slender-Gen. Herd's Snap, \&c.

C. Cruser.

FRANCES PUCKETT, b. by Arab, dam by Knowsly, g. dam by Saltram, \&c.

Thos. Doswell.

FREDERICA, by Escape, (Horn's,) dam a thorough bred mare, owned by Messrs. Norwoods, Maryland.

Messrs. 'Tayloes.

FREDERICK TIIE GREAT, br. h. by Young Sir Harry, (who was out of the full sister to Defiance by Old [ Imp'd] Sir Harry, dam by Hamil tonian-Cormorant, \&c.

FREDERICKSBURG, dk. ch. by Old Gracchus, dam by Friendship-Old Paragon-[ Imp'd] Bedford, \&c.

FRENZY, by Sans Culotte, dam Minikin.

Jefferson Minor.

FliENDSHIP, sor. h. by Apollo, (he by Old Apollo,) ddim a full bred mare, sc.

1789.

Chas. Dewall.

FROLIC, b. f. by Argus, dam Amazon by Dictator-Statira by PercyHomespun by Romulus, \&c.

b. f. by Sir Charles' dam.

Rich. A. Rapley.

J. M. Selden.

FURJOSO, gr. c. by Dare Devil, dam Medley mare-Bolton-Fearnought, \&c.

FYLDE, $[$ Imp' $d]$ br. h. sixteen and a half hands high, by Autonio out $=1$ Fadlidinida, she by Sir P'eter Teazle, her dam Famny out of A inbrosia by Woodpecker, he by Herod cut of Miss Ramsden, she by Old Cade, a son of Godolphin Arabian, \&c. :mu'd 1832

John A verv. 


\section{G.}

GABRIF $I,[I m p$ 'd] b. h. got by Doremont, dain by Highfiyer, 2. dam by snap out of the dam of Chalkstone--Iris-Plariet, \&c., she by Shenherd's Crab, her dain Miss Meredith by Cade out of the littip Hartley mare. Foaled, 1790. 1799.

Joln Tayloe.

GABRIELLA, ch. m. by Sir Archy, dam by Bellair. 1826.

J. S. Garrison. 1799. b. f. by Baronet, dam Temptation.

Thos. M. Forman.

GALLENA, alias Madame Norflert, b. m. by Sir Archy, dam (a mare [Imp'l] by Thos. B. Hill of Halifax, N. C.) by Oscar, g. dain Me. lissi, \&ic.

rALLANT, b. h. by Fearnought, his dam Stately by Sober John out of an $[$ Imp'd] mare.

Robert Taylor.

GALLATIN, (Expectation) by Bedford, dam Mambrina out of a sister of Nailor's Sally, and sold to Col. Alston for $\$ 4000$. 1798.

GAMESTER, b. c. by Spread Eagle, dam Sappho by Buckskin.

J. Tayloe. 1803.

Richard A. Rapley.

GANYMEDE, by Hephestion dam.

South Carolina.

Richard Singleton.

GARRICK, by Ceier, dam by Janus, g. dam the Partuer mare, \&c. Granville, N. C. by Americus, dam [Imp'd] Kitty Fisher.

Chas. Eaton.

Benj. Hoskins.

[-ASTERIA, [Imp'd] b. f. by Balloon, (he by Highflyer,) dain a Marskn mare-her dam Cremona by Regulus, \&c.

1796.

G.isCOIGNE, by Roanoake, dam Lady G. 1824.

J. Randolph.

GATROMINA, ch. f by Timoleon, dam Nili.

GA Y, by Celer, dam by Old Partner, g. dam by Vaiiant, Col. Bjrd's [Imp'd] Tryall, \&c.

GAYOSO, b. c. by Rinaldo, dam Orange. 1829.

Thus. Massey.

GAZELLA, by Bussora, dain Hyacinth.

GEMIMA, by Bedford, dam. [ I $\left.m \mu^{\prime} d\right]$ Rachel by Drone.

GENESIS, b. c.. by Sir Archy, dam Henrietta by Sir Hal.

Wade Hampton Balt. 1827.

Pir. Wallia

GENTLE KITTY, by Young Post Boy, dam Gen. Ridgly's Dairy MIaid by Bedford.

by A rchibald dam.

GEORGE ST. (See St. George.)

GEORGIANA, by Sir Archy, dain Gattellier's mare. $1826^{\circ}$.

ch. m. by Napoleon, dam Old Poll by Druid.

Wm. W'ynne.

E. B. Hicks

GESTION, by Spread Eagle, dam Calypso. 1802.

J. Taylne.

GIANNINI, hI. b. m. by Burwell's Post Boy-[Imp d ino: oe Charii ous a? the Cumming's mare, \&c.

Granville, N. C. 1809.

GIAN', b. h. by Sir Archy, dam Anderson's Twis,. :oy Old Twig, ) g. d by Commutation-Eaton's Garrick, \&c. 
(ilfT. (See America.)

GILES SCROGGINS. by Sir Archy, dam Lady Bedforj. N. Carolina, 1828 .

GIMCRACK, ro. h. by Hart's [lmp'd] Medley, dam bv Ariel, Sic. 1788.

Peter Randoiph.

GIPSEY, ch. f. by Sterling, dain Hebe, by Dare Devil, g. dam by Old Med. ley, \&c.

Hoomes, Farish, \& Co. b. m. [by Imp'd] Bedford, dam by Soldier, g. dam by Imp'd Sea Gull, g. g. dam by King Herod, \&c.

1814. Fairfield, Va.

GLIDER, (2nd) b. c. by Glider, dam 'Temptation. 1302.

Rich. Adams.

Thos. M. Forman.

GODOLPHIN, [ by Imp'd] Diomede, dam Sally Shark by Shark, g. dam Betsy Pringle.

Newmarket, Va.

John Baylor.

ــ (Dr. Brown's) ch. h. by Godolphin, (by Diomede,) dam (Iudian Hen' [ by Imp'd] Shark, g. dam by Wormleys or Black Herod, \&c. Frederick $\mathrm{Cy}$.

James Ware. b. h. [by Imp'd] Fearnought, dam Jenny Dismal.

Dinwiddie Cy. Va. 1777.

Thos. Field. bian, \&ec.

by Sprigg's Careless, dam by Selim,g. dam by Panton's AraM I RE, by Godolphin, (by Dinmede, dam by the Pennsylva. nia Farmer, g. dam by Pegasus-Bolton, \&c. Sent to Kentucky.

Juhn Hoomes.

GOHANNA, br. b. h. by Sir Archy, dam Merino Ewe, by Jack Audrews \&c.

1829. Half Sink, near Richmond.

John M. Botts.

GOLD FINDER, by Old Fearnought, dam Kitty Fisher. velina.

GOLIAH, ch. h. by American Eclipse, dam Lady of the Lake, \&c. 1827.

W. Livingston.

GOLDEN ROD, by Mousetrap, dam Nancy Bell-bred by Gen. Jones.

GEORGE'S J UNIPER. (See Juniper George's.) [Imp'di.

FOUTY, [Im.p'd $]$ b. h. five and a guarter feet high, by Sir Peter Teazio, his dain the famous yellow mare by Tandem, g. dam Perdita, by Herod, Fair Forester by Sloe-Forester-l'artner-Croft's bay Bar -Makeless-Brimmer, \&c.

Foaled, 1796.

GRACE, b. f. by Roanoake, dam Wildfire. 1822.

Win. Rives.

GRACCHUS, ch. r. by Diomede, dam Cornelia by Chanticleer, \&c. 1806.

John Rauriolph. A pollo, \&c. Halifax, Va. 1818.

John Sims.

GKACE, b. m. by Ravenswood, dam Old Everlasting by Sans Ciriotte. 1922.

GRAND [UUTCHESS, ch. m. by Gracchus, dam [Imp'd] Dutchess. J. Randolph. J. Raudolph.

GREF.NSVILLE, g. f. by Bed.ord, dam Arminda by Medley. sold J. Jones, 1803.

J. Hoomes.

IRECRAN PRINCESS, b. m. by Virginian, her dam Calypso by Beliair, \& dain Irby's Dare Devil mare, \&c. 
LREGORY, ch. by Graculus, dam Red Eye, g. dam by Sarperion, g. \& dam by Travelier.

GREXADIER, b. h. hy Wilkes (who was by Old Figure, dan by sium Brirania, dic.

Petersburg, 1782

Thomas Exinn.

GREY MARE, by Slouch, [hy Imp'd] Merlley out of a full bred mas.

N. B. The tam of the gr. m. was sold by W. A. Lee to Dretor Irvine.

GliEY ARCHY, by Old Sir Archy, dam by Grey Medley, (son of [Imp'll] Melley,) g. dam by imp'd Mlessenger, \&c.

Temuessee, 1810.

B. Pisilips

GREY DOLL, by Spot, (before he was castrated,) dam by Stirling, (son of Volunteer) Duetta by Silver 'Tail.

John Randolph.

Menlev, (Barry's) by Old Medley, dam by Blacl, and AH Black, g. dam by Bay Bolton-Old Parmer, \&c.

N. Carolina.

George Williams.

- Alfred, by Lindsay's Arabian, dam [by Imp'd] Tom Jones.

Diomfor, gr. h. [by Imp'd] Diomecie, dam by Flas of 'Truce Brimmer-Silver Eye, \&c.

1808.

- Barksdale.

Diomfon, or Exterprisf, [by Imp'd] Medley, dami by Slue, g dam by Vampire, Scc.

Sold to J. Tayloe, 1793.

Richard Bınoke.

BEArD, by Kosciusko, dam [Imp'd] Psyche.

BADGER, by Eden's [Imp'd] Badger, dam by imp'l St'!im.

Benjamin Ogla

Chuldins, by Medley, dam by Partner.

'Thomas Eaton.

Orpuan, by Orphan, (he by Ball's Florizelle,) daus by lmp'i Diomede, dam of Grey Orphan, Mary Grey.

Joln Gist.

GREYIIOUND, gr. [by Imp'd] Spread Eagle, dam Pandora by mp'd Hed ley, \&c. 1806.

H. T. Thorntou.

GUNNILDA, [Imp'd] got by Star, by Regulus, by the Godoluhun Arabian. GULNAPE, gr. f. by Duroc, dam Sportmistress.

Queens Cy. N. Y. 1824.

Thomas Pearsall.

\section{E.}

HACKABOUT, [Imp'd] gnt by Fclipse, dam ny Cyphon and sister to Tan. dern, g. dam sister to A pollo by Regulus-Sinp, Sc. Foaled 1794. Imp'd 1798.

Jolun Houmes.

HAIL STORM, b. h. [l,y Imp'd] J'antaloon, dam Wingyfeet by Jolly Roger, g. clam Melpomone by Burwell's Traveller, \&c.

C'harles City, 1802.

Fr. H. Dancey.

MALF l'ONE, by Rattler, dam Naid of Patuxent by Magie, g. dam Ǩitty Fox, by a son of imp'd Venetian.

H. G. S. Key

HALL'S UNION, (See Union Hall's.)

HAMBLETON, or HAsurox, [ Imp'd] br. b. sixteen hands liwh by Durs gammon, his dam by Snap, gr. dam by Blank, Partues, Creyncund. sec.

Foaled, 1791.

Wm. Lightioot

HAMILTONIA , or Hamistoniax, ch. is. by Diomede, dam hy s'rak, dam by Spot by Apolia.

1801. 
HAMI.E'C, b. c. by Maryland Eclipse, dam Forest Maid. I.aurenceville, Va. 1830. \&c.

II ANOVER, by Bussora, dlam by Sir Archy, \&c.

J. H. Harrison.

HANNIBAL, by Sir William, dam Sally Currie. 1828.

J. W. Jeffries.

H.ANNAH, b. m. by Moore's Archy, dam by Buchanan's Medley-Old Celer-Hector, \&c.

IIANDEL, by Goode's Herod, (he by Diomede,) dam by Thornton's Wildair-Bellair-Symmes' Wildair, \&c.

HAPHAZARD, bv Collector, dam by Fearnouglit-Spadilla, \&c. 1805.

J. 'Tayloe.

FIARDINIA BURNLEY, bl. m. by Old Roebuck, dam by Old BedfordBellair, \&c.

W. D. Taylor.

HARMONY, [by Imp'd] Figure, dam Stclla, (the dam of Primrose and Thistle) by inp'd Dove.

b. m. by Cragg's Sweeper, dam [by Imp'd] Dove, g. dam Selima by Othello, \&c. 1784.

Walter Bowie.

HARVEY BIRCH, by Richmond, dam by Sir Alfred.

HARLEQUIN, ch. h. by Gabriel, dam by Venetian-True Whig-Cub, SEC.

HARPER, by Grey Diomede, dam Polly Peachem. 1799.

HARRIE'T, b. f. by Bedford, dam Proserpine. 1804.

J. Tayloe.

HARWOOD, by A rchy, dam Asmoplede by Diomede.

HAUTBOY, gr. c. by Gallatin, dam Sappho by Tartar. 1315.

HA Y MAKER, dk. ch. s. h. [by Imp'd] Clifden, dam Harlet by Hall's Eclipse, \&c.

Albany, 1829.

C. M. Bennett.

N. B. This horse was bred by Col. Lyles of Marylaud.

HA VOC, c. c. by Sir Charles, dam by Alfred. HAZARD, ch. c. by Tinoleun, dam [by Imp'd] Royalist, g. dam by Dio-
mede, \&c.

Tennessee, 1829.

John Swinney.

HEDGFORD, [Imp'd] br. by Filho da Puta, dam Miss Cragie by Orville, g. dam by Lurcher-Phenomenon, \&c. Filho da Puta by Haphaz ard-Waxey-Woodpecker-Squirrcl, \&c.

Foaleo, 1826. Imp'd 1832.

HEATH'S CHILDERS, (See Childers Heath's.)

HEBE, b. f. by Florizelle, dam 'Tartar mare, \&c. 1794.

Wrn. Jackson. 1796

b. f. by Dare Devil, dam Yarico by Medley.

\section{Dandy Griggs.}

J. Hoomes.

HF.LEN, b. m. [by Imp'd] Medley, dam Diaua by Specimen.

\section{J. Foster.}

HI:ARTWELL, b. m. by Sir Archy, dain by Planter, (which was rassea by Collier Harrison of Va. sired! by Pantaloon.) g. daun by SultallSinceper. \&c

H. \& H. S. Vilkinson. 
HENRY, ch. $\mathrm{n}$. by Sir Archy, dam out of Bellona hy Bellaır

II. a ch. h. by Henry, dam (the dam of Sir Lovel') [by $I m p^{\prime} d$. light Infantry-lmp'd Messenger, \&c.

Caubridge, N. Y.

HENRIETT $\Lambda$, br. m. by Sir Hal, dam Lady Burton. 1822.

Edw. Long.

b. f. by Henry, dam Agnes.

Balt. 1827.

J. W. Eppes.

Philip Wallis.

- gr. m. by Sir Archy, dam Forlorn Hope.

HEPHESTION, reds. h. by Buzzard, dam Castianira. 1809.

(Sold for $\$ 1400$. )

J. Taylue.

HEROD, $[$ Imp' $]$ gr. h. by Young Herod, son of Old Herod out of Lord Clermont's Stud, a daughter of Conductor. 1790.

J. Hoomes.

HIAZIM, ch. c. by Sir Archy, dam Jenny by Archduke.

HICKORY, ch. h. by Gracchus, dam Everlasting.

John Randolph.

br. h. [by Imp'd] Whip, dam Dido by imp'd Dare Devil, dam by Symmes' Wildair, \&c.

B. Badger.

HIGHFLYER, $\left[\right.$ I $\left.m p^{\prime} d\right]$ br. by Tattersall's Highflyer, his slam by C'yphon out of Young Cade's sister-Old Cade-Partner-Makeless-Brinmer, \&c.

Foaled, 1784. (South River.) J. Craggs. br. b. h. by Wildair, dam by Yorick, g. dam by Fitzhugh's Regulus, \&c.

Albemarle Cy. Va. 1802.

David Clarkson.

1795. S. Carolina.

Williain Alston. [by Imp'd] Sir Harry, dam imp'd Pamona. Hanover, Va. 1815.

Daniel Wade, Jun.

HICHFLYLR MARE, [by Imp'd] Highflyer-Apollo-Imp'd Jolly Ro. ger, \&c. 1790. Halifax, Va.

John Sims.

HIGHLANDER, [Imp'd] gr. by Borleaux, his dam (Tectotum) by Match. ein, g. dam Lady Bolingbroke by Siquirrel, - g. g. dam Cypron, tho dam of King Herod, \&c. bred by Mr. Douglass in England. Foaled, 1783. 1796. L. by Shark, dam Young Selima by Fearnought.

Richard Brooke.

HIPPONA, b. m. by Virginian, dam by Rockingham, (by Florizelle,) $g$ dam by Magog by Chanticleer.

S. Carolina.

P. M. Butler. 1822.

J. Randolph.

HIPPCNA, [Imp'd] b. f. by Sir Peter, dam by Woodpecker, g. dam or Sweetbrier ont of Buzzard, dam by Dux, \&c. Foâled, 1812.

(ien. McPherson

UONESPLN, by Romulus, dam Venus by Hero, g. dam Tripsey by Fear. nought.

HONEST JOIN, [ $\left.T m p^{\prime} d\right]$ hr. b. by Sir Peter Teazle, dain by Maginet-Le Sang-Rib-Hother Western by (Sinith's) Son of sakt, Scc. Imp'd 1794.

Niliton, New Jersey, 1806.

by Cid Nessenger, dam Maria Slamerkın. 
-1ONEST JOHN, hy Tuckahoe, dain Chelioangti [by Imp'd] A rab. Burdentown, N. J. 1826.

HONESTY, [hy Imp'd] Expedition, dam by imp'd Messenger, g. caan by imp'd Bay Richmond, \&c.

J. H. Vanmeter.

HONEY COMB, [by Imp'd] Jack Andrews, dam Pill Box by Pantaloon Dr. A. T. Dixon.

HO'E, [Imp'd] by Volunteer, imp'd by Dr. Tate of Philarlelphia.
.

Montiey, \&c.

by Imp'd] Shark, dam by imp'd Fearnought, g. dam by imp'd

1788.

H()I'IER BOY, g. [by Imp'd] Messenger, dam the imp'd Potsos mare, dec. HOPN'S, [Imp'd] (See Escape.)

HORNE'T, by Diomede, dan Cade's Primrose by Dove, Carle, \&c.

Gr. c. by Bellair, dam by C'eler, g. dam by Janus, Lc.

HOT'SPUR, by 'Timoleon, dain by Sir Archy, g. dain bv Old Wiliair.

HUNTRESS, ch. m. by Cherokee, daı c [by Imp'd, Buzzard, \&c. Christians.

Kentucky.

HUGO, ch. c. by Sir Charles, dam [by Imp'd] Chance, g. dam Celia hy Symmes' Wildair-Lady Bolingl roke, \&c.

HURRY'EM, [by Imp'd] Precipitate, dam Dixon's Pill Box.

Richard Adams.

HYDER ALLY, dap. gr. by Lindsay's Alabian, dam by (jhello-g. dam

Mesars. Minges.

(an imp'd mare from the Duke of Hanilton's stud) by Sipot.

Foaled, 1782.

Dr. Marshall.

HYEIVA, br. m. by Young Wonder, (full brother of Nell Saunders) out of Rosy Clack, \&c.

HYPE.RION, by Diomede, dam Patsy Walthall by Míedley, \&c.

1320.

\section{面.}

IDIORA, b. in. [by Imp'a] Citizen, dam by imp'd Sea Gull, gr. dam by Huntsman-Old Janus, \&c.

Foaled, 1810.

Charles Shiclds.

INAUGURAL, b. c. by Arab, dam Jenny by Archduke. 1829.

INCEPENDENCE, [by Imp'd] Fearnought, dam Dolly Fine, by Old Silver Eye, \&c.

\section{Tennessee.}

ch. f. by Pacolet, dam Fancy.

Col. Hickman.

by Old Potoinac-[Imp'd] St. Paul-Imp'd Old Diomedis-. Mead's Old Pilgrim, \&c.

-NDUSTRY, br. b. by Sir Archy' dam

LNDIAN QUEEN, by Pilgrim dam, dam of Belleville, and g. dam of Sir William.

W. Wilkins.

(ND, AN HEN, by Cthello, dam by Lloyd's Traveller, g. dam by Figure, g. 5. dain was imp'd by Mr. Crow of Philadelphia, and ivas fuil sister to Irish Grey, \&c.

INI!ANA, br. m. by Florizelle, dam by Thor vton's Medley, g. dam by Cragg's Highflyer-Hall Union, \&z. 


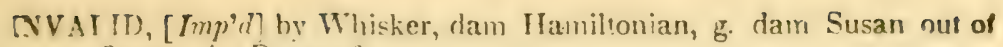
Drowsy by Drone, sce.

RIS, ch. f. by Marplot, dam Nancy Dawson, \&c.

Craig \&. Corbin 1795.

-by Punch, dain Beane's Maria.

gr f. by Sir Archy dan.

or. f. [by Imp'd] Sterling dam by [my'd Coeur Wynne. dam Mead's Oracle.

Lourlon, Va. 1830.

J. Lewis.

1828.

ch. f. by Sir William, dam Shepherdess.

Rich. Adams.

Snap mare, \&c.

IRVINA, by Virginian, dam Pandora by Bellair, \&e.

Rich. Higgins.

iSABELLA, [Imp'dl] dk. br. f. by 'Trumpeter, dan Demirip, sister to No. ble, \&c.

1802.

Gen. John McPherson.

b. m. by Sir Archy, dam Black Ghost [by l'np'd] Oscar.

b. f. by Roanoake, dam Mexican.

1825.

b. f. by Arab, dam Lady Bedford.

J. Pandolph.

IV ANHOE, b. c. by Virginian, dam Jenny by Archduke. 1824.

J. W. Jeffries.

JACK ANDREWS, [Imp'd] b. h. fifteen and a half hands high, by Joe Att-

J. C. Goode. drews, (son of Eclipse,) his dam by Highflyer-Cardinal Puff-Tattler-Snip-Godolphin Arabian, \&c. Fualed, 1794.
Charles City Cy. Va.
Win. Lighttfont.

JACK 'THE BACHELOR, [Imp'd] by Blaze, dam by Gallant-Smiling Tom, \&c.

Foaled, 1753.

JACK FROS'T, b. c. by Ranger, dam Betsy Bell. Rose Hill, 1799.

Thos. M. Forman.

JACK BULL, by Gabriel, dam Active by Chatam.

JAMES FITYJ AMLS, b. c. by Tariff, dam Norna, g. dam Lady Talman, (the dam Kate Kearney and Sussex.)

by Sir Archy dam.

Wm. D. Taylor.

JANE, b. m. [by Imp'd] Knowsley, dam ch. m. Selıma. Albemarle, Va.

_- Potter.

IANE SHORE, b. m. by Sir Archy, dam Fair Rosamond. 1827.

Walter Cules.

JANETTE, $[$ Imp'd] by Nercury, dam by Hightlyer, g. d. by' Sinip-Regn lus, sec. Foaled, 1791.

Imp'd 1798.

J. Hoomes \&c.

JANE ALFRED, b. m. by Sir Alfred, dam by Florizelle, g. dam by Oid Bedford-Lamplighter, dec.

Wm. D. Taylur.

dition, \&c. 
J.INE GREY, gr. f. by Old Slouch, dam Nancy Dawson.

- - Lownes, [by Imp'd] Driver, dam Modesty, g. d. Madge ho Hall's Union.

sANUs, [Imp,d] bl. h. fifteen hands one mch high, by Old Stirling-Oid Crab-Monkey-Basto, \&.c.

Foaled, 1754 .

Wm. Hynes'.

Died 1779-80, aged 34 .

Gloucester Cy. Va.

Mordecai Booth. ch. h. by Sir Archy, dam Frenzy by Sans Culotte. Young, b. (See Young Janus.)

1802. b. c. by Spread Eagle, dam Broadnax.

\section{J. Randolph.}

Rich. Hoomes.

MARF, ch. by Old ch. Janus, [Imp'd] dam by Dapple John ou! of a full sister to Harlot by Janus.

JFFF, br. c. by Stockholder, dam Maria Hill by Oscar. JEFFERSON, br. h. by Virginian, dam Old Favourite by Bellair, \&c.
J. J. Harrison. JEFFERSON, br. h. by Virginian, dam Old Favourite by Bellair, \&c.
1825.

Nimrod Porter. JENNY, by Archduke, dam [by Imp'd] Stirling, g. dam by Imp'd Obscurity out of Miss Slanerkin.

JENNY CAMLRON, by Lloyd's Traveller, dam bitty Fisher. 1785.

Wm. Scott.

-.. $\left[1 m p^{\prime} a\right]$ was got by Cuddy, a son of Old Fox, by Miss Bell. voir.

John Tayloe.

-Dismat, [Imp'd] by Old Dismal, he by the Godolphin Ara. bian-her dam by Lord Godolphir.'s Whitefont, dc.

Col. Baylor.

1815.

DEAxs, ch. m. by Gracchus, dam Cornelia.

J. Randolph.

Deass, br. b. by Virginian, dam by Bainbridge, g. dam by Jolly $\mathrm{A} i r, \mathrm{~g}$. g. dam by Why Not, \&c.

Wilmington, N. C.

W. B. Mears.

[Imp'd] Molly Paculet, \&c.

Rulavo, b. m. by Doublehearl, (he [by Imp'd] Diomede,) out of Polly Merlley-Mark Anthony, \&c.

Wrisfrower, ch. in. by Bernadotte, dam Kate Cole.

Cockracy, ch. m. by Potomac, dam [by Imp'd $]$ SaltramImp'd Wildair-Driver-F eamought, \&c.

1814. Kentucky.

E. Warfield.

JERRY, dap. gr. by Pacolet, dam by Topgallant, g. dam by Grey Merley, \&c.

JESSICA, b. m. by Shylock, dam [by $1 m p$ 'd] Young Si Peter 'Teazle, 8 dam Castianira, (dam of Sir Archy.)

JEZEBEL, ch. f. by Bedford, dam Miss Chance, Scc.

Rich. Adamz.

:ESSAMINE, br. f. by Dockon, dam Virginia, (Coquette.) 1324.

- ET, bl. f. by Bluster, dam Statira. 1820.

JEWESS, b. t. iyy Roanoake, dam Jessico

Mess ₹. Tayloes.

J. Fergusan

J. Rpuriouph

Jis] (CRACK. (See Gim Crack.) 
JII I, ggr. f. by Ajax, dam Nancy Darvson.

1791.

JIM CARR, br. f. by Forester, dam Forest Maid. 1831 .

JOAN, b. f. by Roanoake, dam Grey Doll.

JOHN BROWN, ch. by Sir Charles, dam Sally Brown.

Rich. 1. Meade.

J. Randolph.

JOLLYY FRIAR, by Garrick, dam descended from Gilınour's Milk Ma,d, \&c.

JOIN BULL, [Imp'd] ch. by Fortitude, dam Xantippe by Eclipse, g. daın Grecian P'rincess by Forester, \&c.

b. m. by Gabriel, dam Active by Chatam, \&c.

N. B.-She was called John Bull by Gov. Wright, from his having exchanged a bull for her with Col. Lyles of Mid.

JOHN DISMAL, ch. by Sober John, dam Jenny Dismal. Richarins, b. k. by Sir Archy, dam by Rattler, (by Shark,; g. dain [by Imp'd] Medley-Wildair-Nonpareil, \&c.

HANcock, b. c. by Roanoake, dam Roanoka by Florizelle.

1823. John Randolph. -Stanley, b. h. by Sir Hal, dam Ariadne [by Imp'd] Citizen, \&c. Foaled, 1818.

Pennsylvania.

Edw. Parker or Roanoake, b. h. by Roanoake, dam Grand Dutchess. RaNDolph, b. c. by Rinaldo, dam Portia, \&c. 1809. W, b. c. by Roanoake, dam Young Frenzy. 1825.

J. Randoloh.

JOLLY AIR, by Old Wildair, dam [by Imp'd] Flimnap-Brimmer-Imp'a Valiant, \&c.

J. J. Harrison.

JOLLY ROGER, $[I m p ' d]$ ch. called in England Roger of the Vale, got by Roundhead, (who was by Flying Childers,) the dam of Jolly Pon. ger got by Partner, his gr. dam by Woodcock-Croft's Bay BarbMakeless, \&c.

Foaled, 1741. Imp'd alsout 1748.

- Imp'd] b. c. by the Gower Stallion, Miss Harvey by Car touch-Sophia by Godolphin Arabian.

1769.

by Jolly Roger, dam by Dabster, g. dam Mary Grey. Prince Geo. County, Va. 1777.

Edm. Ruffin, Jun.

JONAH, $[$ Imp'd $]$ b. h. by Escape, dam Lavinia by Herod-Snap-Cado Bloody Buttucks-Partner-Makeless, \&c 1796.

Bush.

JOSEPHINE, b. m. by Peace Maker, dain a full bred Diomede mare, \&c. J. Lewis.

by Flying Dragon, dam by Hamiltonian-St. George-King Herod-Old Yorick, \&c.

ch. by Bussora, dam by Sir Harry, g. dam by Obscurity, de a

Wrm. D. Taylur.

JOSEPHUS, ch. c. by Rob Roy, dam Flora by Ball's Florizelle. Loudon, Va.

J. Lewis.

JUBA, b. h. by Charlemaigne, dam a full bred Fearnought mare. 1798.

Thos. Hunt

JUBILEE, by Independence, by Quicksilver, [by Imp'd] Medley, \&c.

JULIA, gr. m. by Spread Eagle, dain Calypso. 1804.

J. Tavice.

JULIF.', ch. hy Muttnomer, (he by Tom Tough, dam (by Imp'd? U's Bedford, g. dam by Bellair nut of King's Kitty Fisher.

IV. D. Taylor 
- UNIPER, (George's) [Imp'd] b. h. fifteen hands one inch high, by Bab ham, (who was by Godolphin Arabian,) dam Aurora by Stamforo Turk, \&c.

Charles City Cy. Va. 1762.

Robert Harrison. Hanover, Va. 1777.

JUNIUS, by (Craig's) Yorick, dam by Othello, g. dam by Monkey, out of a Suanish mare Imp'd by Mr. N. Harrison.

Prince Edward Cy. Va. 1777.

Edw. Watts.

JUNO, gr. f. by Grey Archy, dan Fancy by Wilkes' Wonder, \&:c. Temmessee, 1823.

D. W. Sumner.

JUPITER, h. h. by the noted Janus, bred by Capt. James Bell of Sussex remarkable for swiftuess, \&c. 1775 .

J. Mason. 1794.

JUSTICE, [Imp'd] ch. h. fifteen hands high, got by Regulus out of the Bol ton Sweepstakes, \&c.

Prince George Cy. 1761.

\section{砞.}

KATE, by Sir Alfred, dam Hurry'em.

KATYDID, [by Imp'd] Expedition, dam Impr'd Sourkrout, g. dam Match less by Gen. White's Imp'd Slender.

KATE COLE, c. m. by Barger's Hickory, dam by Bucephalus-CelerFearnought, \&c.

Pennsylvania, 1811.

C. Irvine.

Keariex, b. f. by Sir Archy, dam Lady Talman by Sir Harry, \&ce. 1826.

Col. Wymne.

KILL DEVIL, (late Ajax,) b. h. by Dare Devil, daın Atalanta by Old Medlley.

J. Tayloe.

KING HEROD, (Womley's) b. h. by Bavlor's Fearnought, dam [by Imp'd] Othello out of Imp'd Kitty Fisher.

Jersey, 1777.

- Agmpra, b. c. by Old Sir Archy, dam T. K.

Herbert Haynes.

- Hiras, [Imp'd] was by Clay Hall, dam the Prince of Wales, Rock. ingham, g. dam Yorico by Eclipse, g. g. dam Firlget by Spectator, \&zc.

Prince Geo. Maryland, 1817.

BITTY, b. m. [by Imp'd] Whip, dam Queen of May. Georgia.

Chas A. Rudd.

h IT'TY FISHER, [Imp'd] gr. m. by Cade, dam by the Cullen Arabian out of the famous mare Bald Charlotte. 1759.

Cartel Braxton.

by Lindsay's Arabian, dam [by Imp'd] Oscar, Imp'd Vam. pire out of Imp'd Kitty Fisher, \&c.

Fisher, \&c.

1789.

John Therutor.

- [ by Imp'd] Alderman, dam Hoskins' Kitty Fisher.

.- - - (Hoskins') by Symmes' Wildair, dam [by Imp’d] Vampir, g. dain Imp'd Kitty Fisher.

...._. by Virginia Carle, dam by Baylcr's Fearnought. 
BITTY FISHER, h. hy Tiller's Bedford, (hy Old Bedford, (lain by Oln Bedford-Boxer-Claudius-Mexican, \&c.

KITTY CLOVER, b. m. by Tom Tough, dam by Arcliduke-SterlingKing Herod, Sec.

Enoch Mason.

Clovfr, hl. m. by American Eclipse, dam [by Imp'd] Light Infan. try, (she is half sister to Sir Lovell.)

New-York, 1825.

M. Beach.

Crover, by Eclipse, dam Lady Bedford.

N. C.

J. W. Jeffries.

Clovir, ch. m. by Turk, (he by Expedition,) dam by Oscar.

Wright.

MedeEY, gr. m. [by Imp'd] Medley, dam Hoskin's Kitty Fislser, \&c

John Hoskins.

Bule, [Imp'd] by John Bull, dam Lord Grosvenor's Isabella by Eclipse.

KITTY FOX, by Fox, (a son of [Imp'd] Venetian,) dam by McCarthy's Cub, \&c.

ford, \&c.

King William Cy. Va.

Thomas Carter.

KNOWSLEY, $[$ Imp'd] b. h. by Sir Peter Teazle, ram Capilla by HeıdRegulus-Crab-Snake, \&c.

Foaled, 1796. Chas. City Cy. Va. 1802. Wın. Lightfoot.

KOULI KAHN, $[$ Imp'd $]$ b. h. by the Vermon Arabian, his dam Rosemary by Blossom, her dam by Ancaster Starling out of Look at me Lads, by Grasshopper. Foaled, 1772.

N. B. The above pedigree is furnished by Mr. Peter of Georgetnwn. [Imp'd] b. h. Pearson's P'artner, dam by Lord Lonsdale's Kouli Kahn-Jigg-Curwin's bay Barb-Curwin's Spot, \&c.

Imp'd in $1764-5$ by

N. B. The above pedigree given by Mr. R. N. Edgar.

Col. Baylor.

b. h. by Lloyd's 'Traveller, dam Tasker's Fatima.

Fualed, 1777.

KOSCIUSKO, by Sir Archy, dam Lottery by [Imp'd] Bedford.

\section{耳.}

LADY ADAMS, ch. f. by Whipster, dam by Buzzard.

J. Atchison.

ARCHIANA, gr. f. by Sir Archy, dam Pandora by Wryht's Silver Heels.

AMELIA, ch. m. [by Imp'd] Magic, dam by Republican Presidens g. dam by imp'd Figure, \&c.

Isaac Duckert.

- A A LRED, b. m. by Old Sir Alfred, dam [by Imp'd] Wonder, Thus. derclap, full brother to Old Chanticleer by Wildair.

H. Campbell.

$\Lambda U D L E Y$, by Tariff, dam Ethiopia by Tayloc's Bedford.

Wm. D. Taylor

-BOLINGBROKE, by Pantalnon dam, dam of King Heror!, g. uนm Primrose by Dove, (a Son of Cade.)

Col. Seliten.

-Buls, [Imp'd] by John Bull, dam by Pumpkin-Fieacatcher-Sylir. rel, \&c.

Foaled, 1796

Johr: Hounes

31 * 
LADY BUG; b. by Young Florizelle, dam by Jack Andrews-Driver-High Alyer, \&c.

Whr. D. Taylor.

Burtox, by Sir Archy, dam Sultana : she was out of the mare got by the horse sent as a present by the Bey of Tunis to 'Thos. Jeferson. 1813.

J. W. Eppes.

Benford, [by Imp'd] Bedford, dam by imp'd Dare Devil-Nercury -A pollo-Jolly Roger. (See also Bedford mare) foaled, 1810.

J. W. Jeffries.

Bunbi:Ry, [Imp'd] b. m. by Trumpeter, dam Theopha, (sister to Old

Tut) by Highflyer-Plaything by Matchem-Vixen by Regulus, \&c

Foaled, 1802.

J. Randolph.

_-Burı.rgh, by Silver Heels, dam (Sterne's Maria) by Major Gibbs

Carlo, (by imp'd Carlo,) g. dam by Ridgley's Cincinisatus, \&c.

Richard Craddocks.

Chesterfield, by Old Diomede, dam Lady Bolingbroke.

Col. Selden.

Culpfppr.r, wh. m. by Carolinian, dam full sister of Defiance and $\mathrm{R}_{\mathrm{B}}$ venge, \&c.

Md.

—Duplex, by First Consul, dam Edelin's Floretta.

H. G. S. Key.

Eagle, gr. m. [by Imy'd] Eagle, dam Spot by Bedford.

Dudley Digges.

Altemarle, 1817.

-Essex, ch. f. by Grey Diomede, dam Virginia Sorrel.

1797.

FLIRT, ch. m. by Hickory, dam by Duroc.

- Fif.Ln, b. m. by Sir Archy, dam by Diomede.

- Fif.ln, b. m. by Sir Archy, dam by Diomede.

Walter Coles.

Isaac Snedeker.

J. Tayloe.

\section{J. J. Harrison.}

-G. [Imp'd] (Magician's dam, bred by Sir Thos. Gascoigne, got by Hanbletonian, Golden Locks by Delphine, Violet by Shark, Quick's Charlotte by Blank, Crab, \&c.

Roanoake, 1804.

John Randolph.

-..-Gkr.,$[$ Imp'd] by Gohanna, dam by Grey Skin-Woodpecker-He rod-Young Hay by Skim, \&c.

Foaled, 1803.

- -Gнay, by Robin Gray, dam by Melzar-g. dam [by Imp'd] Hightly er-Fearnought, \&c.

Jasi: Gray, b. f. by Kosciusko, dam by Big Ben.

- Grensville, by C'onqueror, dam by Batt's Diomede. True Blue-Celer-Old Partner, \&c. Oxford, N. C. 1827.

- - HAl, by Sir Hal, dam Beauty by Diomede.

Maryland.

Win. M. sneed.

James Sewall.

- - Harrisox, [by Imp'd] Spread Eagle, dain by imp'd Herud, g. dam by Wildair-imp'd King Herod, \&c.

- - Hamloniax, by Sir Arthur, (he by Sir Archy, dam Bet Bounce.

-. - J JNe, [by Imp'd] Obscurity, dam Molly by Grey Figure out of the Old Slamerkin mare.

Jink, by Polomac, dam Auvelina.

N. Carolina, 1811.

Jaxt, b. f. by Shylock, dam Dutciness by Bedford.

1826.

J. B. Richardson.

- Jacksos, ch. m. by American Eclipse, dain Lady of the Lake.

- Saik Bers, (by Imy'u) Ciabriel, dam Active by ('hatau. 
I.ADY LA GRANGF, ch. f. by' Sir Archy, dam [by Imp'd] Dregcn, g. dain by inp'd Medley-Mark Anthony, \&c.

Laurenceville, Va.

R. K. Mearie.

Lifurfoor, (MIaria,) dk. br. m. by Sir Archy, dam Black Maria by

Shark, \&c.

Foaled, 1812.

пr тие. LAKf, b. m. by Kosciucko, dam by Bedford-g. dam Mellissant by Arion-Obscurity-Valiant, \&c.

S. Carolina. Foaled, 1814.

B. F. Taylor.

of тнF. LAKF, b. m. [by Imp'd] Sir Harry, dam by imp'd Diomedoimp'a St. George-imp'd Fearnought, \&c.

OF THE LAKE, by Hickory, dam Maid of the Oaks.

Lf.gGs, [by Imp'd] Centinel, dam by Spadille.

Mir, gr. m. by a thorough bred son of Bariger's Hickory, dam by

Mark Anthony-imp'd Dore-iinp'd Lath, \&c.

1818.

C. Irvine.

Makv, gr.f. by Henry, dam Miller's Maid.

MARy, by Bussora, dam Black Maria by Am. Eclipse.

- or tuE Neck, gr. im. [by Imp'd] Merryfield, dam by imp'd WonderBellair-Old Medley, \&c.

Thomas Doswell.

-Northumbr.rlaxd, [ Imp d] by Northumberland, dam by Shakspeare -Regulus_-Parker's Snip-Old Parmer, \&c.

John Tayloe.

-Richmosn, b. f. by Ball's Flurizelle, dam by Diomedle, g. dam Al derman mare, \&c.

J. Wicklıaı.

RolaNd, b. by Tariff, dam by Florizelle-Bedford, \&c.

T. Doswell.

Racker, by Sir Charles, dam by Ball's Florizelle, g. dam by Melzatr.

Relif., ch. f. by Am. Eclipse, dam Maria Slamerkin.

N. J. 1827.

Dr. E. A. Darcy

-RANDolph, by Sir Archy, dam [by Imp'd] Druid-Symmes' Wildair-Americus, \&c.

Sterlini, b. m. by Herod, dam [by Imp'd] Sterling, g. dam by King Herod-Lindsay's Ranger, \&c.

Sumine, b. f. by Shawnee, dam by Sir Archy.

Win. D. Taylor

TALMAx, by Sir Harry, dam by Bedford.

Wm. M. West.

J. A. Selden.

-Tosson, by (Elliott's) Topgallant, (he by Gallatin,) dam by Barry's Medley, (by Old Medley,) g. d. Dr. Rany's mare.

- W II.IN, by Janus, dam by Jolly Roger, g. dam [by Imp'd] Shark.

I.ABURNUM, by Lath, dam by Jolly Roger, g. dam imp'd liy Carts Braxton.

.AF'A YETTE, b. h. by Conqueror, dam Julia, g. dam by Florizelle-Re' lair-Pergasus, dic.

Teunessee.

H. Davis. b. c. by Virginian, dam by Sir Archy, g. dam by Sir Haıry

Chanticleer-Mead's Old C'eler, \&ic.

-ch. c. by Kosciusko, dam Virginia, (Coquette.)

J..M. Botts

J. Ferguson

¿AHARA, dap. gr. by Thornton's Rattler, dain by Winter's Arabian, 8 dam Alexandra by Alexander, \&uc.

C. Andrews 
LALLA ROJKH, by Handel, dam Phillis by Old Topgallant.

Geo. Chicester.

I.AMBALLE, ch. f. by Kosciusko, dam Psyche by Sir Peter Teazle, \&c. South Carolina.

Richard Singletur.

LAMPLIGHTER, b. h. by Hart's [Imp'd] Medley, dam by Lonsdale on of Kitty Fisher, \&c.

Hanover Court House, 1801.

[.ANCE, b. h. full brother to Eriel by Am. Eclipse.

Paul Thilman.

L.ASS OF THE I:ILL, gr. f. by Spread Eagle, dam A.raminda.

L.AST CHANCE, ch. f. by Sir Archy, dam Lady Bunbury.

J. Hooines. 1825 .

J. Randolph.

LATi1, [ /mp'd] b. fifteen hands one inch high; forled in 1763; Imp'd in 1768 , was got by Shepherd's (rab, dam by Old Lath, g. dam by Fly. ing Cisilders-Makeless-Taffolet Barb, \&c.

Delancev.

LAUREI, h. h. by Old Fearnought, dam by the sams, g. dain a fine blood. ed mare, \&c.

1777.

I.AURA, gr. f. by Grey Diomede, dain Polly P(ach s.n. 1798.

Geo. Baylor.

LA VENDER GIRL, b f by Henry, dam Ophelin by Little Medley, Tayloe. 1832.

LA VINIA, by Diomede, dam Lady Bolingbroke.

Col. Selden. Mead's Celer-Lee's Mark Anthony, f:c.

LAZARUS, by Eclipse, dam an Imp'd mare, le stood many years at Mount Gallant and left some valuable sturels.

LEE BOO, br. b. hy Cragg's Highlilyer, Haw Captain James Betts' mare, she was of pure blood. Maryland, 1803.

Osborn Sprigus.

LEONIDAs, b. by Sir Archy, dam I Ixe [by Imp'd] Jack Audrews raised] by J. G. Green, and sold to J. .M. Botts. b. c. by Virginian.

by Lloyd's Traveller, 'am by Morton's Traveller, out of Tasker's Selima, \&c.

Foaled, 1773.

J. P. Custis.

LEOCADIA, br. ch. m. by Virg.n, ", dam Lady Jane by Potomac, g. dam [Imp'd] Anvelina.

LEOPOLD, ch. h. by Ogle's Ose' s, dam Katydid [by Imp'd] Expedition.

LEATHER STOCKINGS, ch. h. by Rob Roy, dam Cora by Browis's Godolphin.

Georget-iwn, D. C. 1527.

'ETITIA, t. m. Uy Whip, dam by Buzzard, g. dam by Grey Diomede, dic.

Woodfd. Cy. Rentucky.

E. M. B.

- by 'Truxton, dam by Elegant, (he [by Imp'd] Feamought,) g dam by Rellair-Wildair, \&c.

rialla Tennessee.

A. B. Shelby.

H.' 'THA. T, [ Imp'd] (first called Mazercon, ch. got by Muley out of a Windle nare, g. dain by Anvil out of Virago by Snap-Muley by Grville, and he by Bemningbrough, and he by King Fergus out of a Herod mare.

foaled, 1823 Imp'd to Alabama 
LEXINGTON, b. h. by Symmes' Wildair, dam by Lonsdale, g. dan ." Jolly Roger, dc. 1800 .

Andrew Wood ey.

I,IBER'TY, by Sharp's Othello, dam by George's Juniper. Maryland.

Charles Rirlglev. Anthony, \&c 1798.

John Brownly.

IGHT INFANTRY, [Imp'd 1 by Eclipse, dam by Feather, g. nau by Childers, g. o dam Wiadrington mare, she by Old Partner.

IINDSAY'S ARAB AN. (See Arabian Lindsay's.)

LINNET, hy 'Trafalgar, dam Humming Bird by Tom Tough.

LIONEL, LA, b. m. by Coeur de Linn out of the dam of Ciucierella.

Messrs. Corbins.

LI TTLE DA VID, [by Imp'd] Childers, dam Jemny Cameron.

- Burq, by Florizelle, dam by Celer.

J. Tayloe.

W. R. Johnson.

Jivip:R. (See Juniper Littie.)

JaMEs, full brother to Garrick hy Celer.

Mfiley, [ hy Imp'd] Medley, dam Kitty Fisher by Lindsay's Ara. bian.

LIVELY, b. m. by American Eclipse, dam Haynes' Maria [by Imp'd] Dio mede, g. dam Lively by Lively - Wild Goose by Selim, \&c.

New Jersey.

LOC:HIN VAR, b. c. by Oscar, dam Virago by Shark. 1810.

Henry De Groot.

1810 . J. 'Tayloe.
L.ONSD ALE, by Jolly Roger, dam a bay nare Imp'd., she by NonkeyLonsdale's Bay Arabian, dc.

John Byrd. chus, sec.

1824.

LORENZO, by Telemachus, dam by Raymond.

LUGA., a Mahogany bay, by Sir Archy, out of the dam of Lafayctte by Virginian.

LOGANIA, [by Imp'd] Medley, dam by Feamought.

LO'I"IERY, ch. f. by Bedford, dam Anvelina. 1303.

LOUISA, b. m. by Eclipse, dam Vanity by Celer-Mark Anthony-Silveı Eye, \&c. 1789.

J. Tayloe.

LOUISIA NA, b. f. by Old Ratter, dam Desdemona. 1829.

E. G. W. Butler.

LOVELY LASS, b. f. by Timoleon, dam Lady Alfred by Old Sir Archy 1832.

LOVE LACE, by Flying Childers out of an Imp'd mare by Bosphorus.

LUBLY ROSA, b. f. by Sir Archy, dam Equa. 1830.

LUCIFER, [by Imp'd] Dare Devil, dam by Bellair-Imp'd Mledley-Lems dale, fic.

LUCY, by Young Sir Alfred, dam Nancy by Florizelle.

Locketr, o. f. by Roanoake, dam young Minikin.

- - L L 1823.

W. Coleo

J. Randolno

- - Lorkert, by Bellair, dam Old Selima by Morton's Travellet -t hhe' In, Sic. 
iUC) GWYNN, b. m. by Sir Charles, dam by Sir Harry-Bedford-Da Devil--Wildair, \&c.

- GrFy, b. f. by Washington, dam Betsy Hunter. Norfolk, 1820.

Messrs. Tayloes.

LLDEE, gr. f. by Old Slouch, dam Nancy Dawson.

E. Townes. 1798.

L''RCHER, [by Imp'd] Bedford.

L) CURGUS, a son of Morton's Traveller. 1764 .

Benj. Harrison.

I. C ZBOROUGH, [Imp'd] h. h. by Williamson's Luzborough, (a son of Si. Peter Teazle, ) whose dam was hy Dungannon, (a son of Eclipse. Luzborough's dam was out of a Dick Andrews mare, sent to France and she by Whiskey out of Eleanor, \&c. g. g. dam by Dimme,le, \&c Greensville. ¡imp'd 1832.)

John Avery.

\section{III.}

MAB, b. f. by Archduke, dam Fairy by Bedford. 1809.

MAREL, dk. b. f. by Sir James, dam Meg Merrilies.

\section{J. Hoomes.}

Lewis Rerkley.

MACBETH, bl. b. by Sir Archy, dam by Shylock, g. dam Lady Buron. Foaled, 1828.

D. H. Allen.

MACEDONIAN, b. by Roanoake, dam Statira by Alexander the Great. 1824.

MACA W, b. f. by Roanoake, dain Paroquet, \&c.

J. Randolph.

J. Randolph.

MADCAP, [Imp'd] b. m. by Anville-O'Kelly's Madcap by Eclipse-Blan\} - Blaze-Greyhound-Curwen's Bay Barb, \&c.

Trained not successfully.

MADISON, by Diomede, dam Priestley by Chanticleer.

1794.

J. Tayloe

MADAM NORFLEET. (See Gallena.)

MADAME LAVALETTE, b. m. by Peace Maker, dam by Bediford, g. dain by Medley, \&c.

1815.

J. J. Ambler.

MAGIC, [ Imp'd] ch. h. (sold for $\$ 4000$, ) by Volunteer, dam Narcella by Mainbrino-Media by Sweethrier-Angelica by Sinap-Regulus, \&c.

Prince George Cy. Maryland.

MAGOG, by Chanticleer, dam Camilla by Wildar.

J. J. Harrism.

MAGNETIC NEEDLE, $\left[I^{2} p^{\prime} l\right]$ b. by Nagnet, he hy Herod, his dam sister to the dam of Eusophroyne, she by Sweetbrier, his g. dam Parity by Matchem, \&c. Foaled, 1787.

Trenton, N. Jersey, 1804.

MAGGY' I.A UDER, by Dr. Hamilton's [Imp'd] Figure, dam by Imp'o Othello, g. dam by Imp'd Spark.

MAGNOLIA, ch. h. by Lindsay's Ranger, (Arabian,) dam by Othello by Crab, hes dam by Morton's Traveller, anci ser dam was Selima by Gorloluhil. Arabian, \&c. 1785.

Lund Washington.

MAGNLili, ch. h. by Am. Eclipse, dam by Osear, (by Diomede, g. dan by Picture, (by Imp'd Sliark, Siweet Larry, \&es.

MIAID OF ALL WORK, b. f. by Stirling, dam [Imp'd] Hackahout, \&:c. Foaled, 1800. J. Honmes.

.... or thr Fonest, br. m. by Young Ilickory, dam by Ol,' Hamine 
MAID OF THF FORFST, gr. f. hy Winter Arabian, dem Young Buzzaid mare by Hamlintonian, \&c.

or Lodr, by Virginian, dam by Potomac.

of the. Mus, by Old Hickory, dam by Young Sine:k, g. dam Majos Biddle's mare.

-ов Nokтнамтом, [by Imp'd] Clifilen, dam Jare Lowndes.

$\rightarrow$ OH OAkn.iv, [by Imp'd] Stirling, dam by Hall's Eclipse, Brent's Young Ebony, \&c.

of Onascif, by Hambletonian, (by Dumgannon,! dam by Dr. Turu ten's Duver, g. dam full sister to îantoaka by Hall's Eclipse.

James Madison.

- or rue Oaks, by Spread Fagle, dain [ Rockingham, g. g. dam by Gallant-True Blue, stc.

Fredericksburg, Va.

Lewis Willis.

of Corinth, b. m. by Virginian, dam by Sir Archy-Quick StepAmericus-Aristotle, \&c.

or Patuxest, [hy Imp'd] Magic, dain Kitty Fox.

- of WARSAW, by Gohamma, dam Chestnut mare by Trafalgar, g. daın Rosalba.

King William Cy. Va. 1831.

MALVINA, gr. in. by Stirling, ditm Calypso.

Lewis Hill.

J. Tayloe.

\&c.

Majour Bayly.

MALCOIM, b. by Sir Charles, dam by Sir Alfred-Hoomes' Tom 'Tough -Imp'd Spread Eagle, \&c.

Wm. Wynne.

MAMELUKE, br. h. by Bagdad Arabian, dam Depro by Bay Barouet$[$ Imp'd] Crop, Scc

Boston.
MAMBRINO, dk. c. by American Éclipse, dam Grand Dutchess.

Edw. Elridge

Delaware Cy. Pa. 1830.

Huinphrey Hill.

MANFRED, [Imp'd] U. foaled 1796, by Woodpecker, ciam by Mercury, g. dam by Highflyer, \&c. (Died.)

MARCELLA, b. f. by Roanoake, dam [Imp'd] Philadelphia. 1823.

J. Hoomes.

J. Randolph.

MARCELLUS, (formerly Red Rover, ch. h. by Sir Charles, dam Shep herdess by Phenomenon, \&c.

Rich. Adams.

MARIANNA, ch. m. by Telemachus, dam by Wild Medley, g. dam by Young Fearnought, \&c.

MARCIA, gr. m. by Archiluke, dam Celerima by Celer. 1810.

J. Tayloe.

MARIA ANTOINETTE, g. f. by Andrew, (by Sir Andrew,) dam by W, ley's Marok, g. dam by Old Gallatin- [Imp'd] Medley, \&c. Georgia. Foaled, 1831.

C. A. Redd.

- Fontanf, by Superior, dain by Tom Tough-Perto-Camden Brilliant, \&ec.

W. D. Trelor. -HrLl, b. m. by Oscar, (by Wilkes' Wonder, dam [hy Imp'd] Cin zell out of a Fearnougit mare by Regulus, \&c.

- Maскцr, b. m. by Sir Archy, dam by Bellair. Bellfield, Va.

\section{Ninrod Portes}

Henry Macklin

- Arruy, b. f. by Old Sir Arcley, dam [by Imp'd] Diomede - Old Liss crack, (alias Randolph's Roari.)

Buckungham Va. 1816.

Isaac Curd 
MARIA I.OLISA, by Pacolet, dam Letitia by Truxton-Gallatin, \&.c. Temessee.

- Slanerkix, c't m. by Bond's First Consul, dam by Paragon, [Imp'd] Figure, \&c. New Jersey.

MAGGY SLAMIERKIN, (Old) [by Imp'd] Wildair, dam Delancey's CLb mare. (Wildair and Cub mare were Imp'd together.)

MARIA, b. m. by Sir Archy, dam Forlorn Hope.

Col. Delancey. Sold E. Parker, Pa.

H. Macklin.

-___ Bu ıck. (See Black Maria by American Eclijse, ditto by Shark ) by Dionede, dam by Bellair.

Temnessee.

H. Haynes.

-b. f. by Monsieur Tonsom, dam Eliza by Timoleon.

North Carolind, 1829.

J. W. Jeffries.

-by Bay Yaukee, dam Green's Old Celer mare.

by Clockfast, dam Maria [hy Imp'd] Regulus.
L1:. m. by Pacolet, dam by 'Truxton.

W. R. Johnsol!.

- Bernw r.L.'s, [by Imp'l] Regulua, she by Godo]phin Arabian. by Punch, dam

by Gallatin, dam

B. Beans.

Georgia. McNellys.

by Wahut, dam by a Grey Diomede horse, g. dam by Medley, de

MARGARET, by Virginian, dam Hurry'em.

MARPLOT MARE, by Marplot, dam Betsy Baker.

MAR'TANZA, ch. f. by Sir Arthur, dam Amazonia by Tecumseh, \&c.

MARY GREY, g. m. by Amie's Sir Archy, dam by Old Bellair-SharkAristotle, \&c.

Alabama.

Levi Gist.

A g. f. [by Imp'd] Messenger, dam Tulip by Ranger, or Lindsay's White Arabian.

- (or SApro, ) [Imp'd] b. 11. by Ruler, dam by Sampson-Regulus-Greyhound mare, \&c.

Foaled, 1792.

-KING, g. In. by Muckle John, dam by Quicksilver, and he by Imp'd Medley.

Georgia, 1825.

MARY, b. f. by Coeur de Lion, dam Fanny Foster, \&c.

Charles A. Redd.

- ch. f. by Sir Archy, dam by Francisco.

1809.

Wm. Minge.

Eldringr, ir. gr. by Napoleon ?d, dam by Pacolet, g. dam [by Imp'd!

Sir Harry-Imp'd Dare Devil-Bett and Macklin's Fearnought, \& c Pulaski, Tenn.

Geo. A. Glover.

of Clovernale, by Doubtlons, dam Potomac, g. dam by Obscurity, \&c.

- J JNE, b. f. by Bertrand, dam by Arrakooker.

- Wortos, ch. f. by Cook's Royalist, dam Mary by Coeur de Lion.

- Ronssox, b. m. by Sir Archy out of the Imp'd Pot8os mare, \&c. Lancaster, Pa. RaNdolph, by Gohanna dam.

E. Parker

A1ARIGOLD, ch. m. by Tom 'Tough, dam Hoskins' Sir Peter, g. dam [by Imp'd] Beuford-Imp'd Dare Devil-Symmes' Wilriair, \&.

MARION. by OId Sir Archy, dam by Citizen-Alderman-Roebuck--evr of a Herod mare

Hailfax, N C. 1830 .

B. S Lomg. 
MARIr's, by Sekin, flam [Imp'd.]

MARK T'INL, b. by Ar. Bamdad, dam [by Imp'd] Spread Eagle -Quick silver, (by Hart's Medley,) \&c.

AARK ANTHONY, [Imp'd] by Sipectator, dam Rachel by Bland-R ogu. lus-Soreheels-Makeless-Dr. Arcy's royal mare, \&c.

Foaled, 1767. Stood in Virginia.

-dk. b. by Old Partner, dam [Imp'd] Septima by Othello, sec. Caroline Cy. Va. 1771.

1826.

I. Hardymau. (Raxdulpu's, ) bro. h. by Sir Archy, dam Roanoake.

J. Randolph.

MARLBOROUGH, by 'Thorntou's Rattler, dam Young Red Ey'e, g. dam [by Imp'd] lisedford-imp'd Gasteria, \&c.

MAR.IALUKE, b. f. [hy Imp'd] Venetian, dam Magg Lauder. Rose Hill, Maryland.

MARSKE, (or Mlask, ) by Shark, dain [Imp'd] Viragu. Orange Cy. Va. 1799. by Diomede, dam by Medley.

Charlotte Cy. Va. 1808.

Thos. A. Foreman.

Robert Young.

Charles $\mathrm{W}_{\text {yllie. }}$ mare, \&c.

y Marske, (by Diomede, Hart's Old Medley thorough bred

MARSHAI, NEY, dap gr. by Pacolet, dam Virginia by Dare Devil.

MARM11ON, by Virgmian, fam by Sir Archy-lotton's Phenomenon, (he [by Inip'd] Restless) - Whirligig by imp'd Whirligig, \&c. 1825.

MARYLAND ECLIPSE, (See Eclipse Maryland.)

hIARYLANDER, hy (Wymes') Ratler, dam sister to Sir Archy, on the dam's side by Tayloe's Topgallant, \&c.

MARSHAL, by Spread Eagle, dam Virginia Nell.

G. S.

- Duroc, by Old Duroc, darn Maid of the Oaks. 1812.

Nev, by Am. Eclipse, dam Diana by First Consul.

Bela Badger.

Samuel Hollingsworth. Elkton, Maryland, 1828.

MARS, r. h. by Mrumtaineer, dam Camilla by Peace Maker, \&c. Albemarle, 1829.

Walter Coles.

MARTIIA JEFFERSON, h. f. by Sir A ichy, dam [by Imp'd] Buzzard, imp'l Symmetry, \&c.

MATII,I)A, g. m. [by Imp'd] Jonah, dan by Grey Diomede, Whistlo Jacket, \&c.

1810 .

D. W. Sumner.

b. m. by Sir Archy, dam [Imp'd] Dutchess.

G. H. Burwell.

Potk, gr. f. by Marion, dam Parallel by Virginian, I'acolet's dain [by Imp'd] Medley, \&c.

1828.

MI'TCHEM, ch. c. by Janus, dam Any Robsart.

by Dion, dam [Imp'd] Favourite.

J. Randolph.

Joln Hoomes.

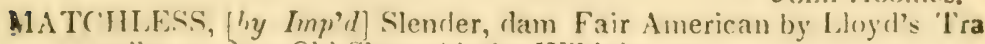
veller, g. dain Old Slamerkin by Wildair.

b. h. by Old Fearnought, dam by Sober John-Dahster, if.c.

Caroline Cy. Va. 1777.

Robt. Taliaffero.

II.1TOUCA, b. m. by (combination, dam by $N^{\prime}$ ltum in ?arro, g das b:

Green's Potcriac, \&c.

32 
MARY D ACRE, bl. f. [by Imp'd] Valentine, dam Wright's Selima. 1829.

MAY DAY, by Sir Archy, dam Eliza Adams.

b. c. by Virginian, dam by Florizelle.

Messrs. Minge.

J. K. Vanmeter.

MEDLEY, [Imp'd] gr. h. by Gimcrack, he by Cripple, \&c. dam of Medley was Arninda by Snap, \&c. Foaled, 1776.

Hanover Court House, Va. 1785.

1824.

Malcomb Hart.

W. R. Johuson.

b. c. by Bedford, dain Hebe by Dare Devil.

Farish, Coleman \& Hoomes.

MArF, bred by J. Hoomes, foaled [by Imp'd] Medley, dam by Bolton-Fearnought-Tristram Shandy out of a Sober John mare, \&ec.

Mare, ch. by Am. Eclipse, dam Clio by Sir Archy.

C. W. Van Ranst

Natchez.

gr. c. by Polafox, dam Miss Bailey [by Imp'd] Boaster.

Chascr, (See Chance Medley.)

Fitz, (See Fitz Medley.)

Grix, by Hart's [Imp'd] Medley, dam l,y Black and All Black

- Bay Bolton-Old Partner-Old Fearnought, \& c.

N. Carolina, 1795-6.

B. Williams.

-. - _ _ (Joves') by Old Medley, dam by Mark Anthony_Fearnought _Janus-Jolly Roger, \&c.

ley, \&c.

('Тнокхго's) [ by Imp'd] Punch, dam Helen by imp'd Med-

- (Thомрsox's, ) [by Imp'd] Medley, dam by imp'd Aristotle, g.

dain by Fearnought, \&c.

Stood in Scott Cy. Kentucky, 1803.

-.. W W W - by Old Medley, dain Wildair, g. dam Shandy, g. g. dain Sportley by Old Janus, \&c.

- - Young, (See Young Merlley,) (two.)

MEDORA, ch. f. by Rattler, dam Sportmistress by Old Hickory, out of Miller's Damsel, \&c.

MEAD'S ORACLE, (See Oracle Mead's.)

Butler Coles.

MEG DODDS, br. m. by Sir Archy, dam Black Ghost [by Imp'd] Oscar, \&c.

Nansimond, Va.

J. G. Green.

MEG MERRILIES, b. in. by Trafalgar, ([hy Imp'd] Mufti,) dam by imp'd Dragon-Lamplighter-Highflyer-Escape, \&c.

Loudon, Va.

Lewis Berklev.

MEG OF WAPPING, b. f. by Bedford, dam [Imp'd] Alexandria.

MELE MELE, by Virginian, dam Larly Burton. 1826.

MELPOMONE, by Burwell's Traveller, dam Virginia by Old Mark Arthony-g. ciam Polly Byrd, \&c.

MELUNTHEE, gr. c. hy Hephestion, dam Castianira, dam of Sir Arr.hy.

MELZAR, b. h. [by Imp'd] Medley, dam Kitty Fisher by Mildair, (wem to Kentucky.)

MERCURY, by Dr. Thornton's [Imp'd] Driver, dam by imp'c' Erlipse. dam by Union, by imp'd 'J raveller, \&c.

MERI:2) EIVE, bv Jack Andrews, dam Spot bv Bedfo d. 
MERLIN, by O:d Archy, dain by Old Bedford-Dare Devil- "s Sha:k, \&ec.

MENDOZA, (Brcisfr, by Boxer, dam Nancy Dawson, dam o sso wlla. 1796.

J. Tas'oe.

MERRY 'TOM, [Imp'd] by Regulus, dam by Locust, (a Son of Cran ; $\mathbf{g}$ dam by a son of Flying Childers, his gr. dan by Croft's Partner, ev. Prince George Cy. 1767.

John Baiı.

MERRYFILLD, [Imp'd] by Cockfighter, dam by Popinjay, Bourbon's dain, Ec.

MERCURY, b. by Virginian, dam by Citizen, \&c.

1777.

by Spread Eagle, dam Janetta.
Col. Williain Byrd.

J. Hoomes.

MERRYFELLUW, b. c. by W. R. Johnson's Byron, dam the dam of Ca milla, \&c. King \& Queen, Va. 1831.

MERRY GOLD, b. f. [ by Imp'd] Barefout, dam Meg Dordds. N. Jersey, 1831 .

H. Camplell.

MERETRIX, by Magng, dam Narcissa.

MESSENGER, Imp'l] gr. h. by Mambrino, dam by Turf, g. dam by Regulus out of a sister of Figurant by Stirling, out of the Fox mare, the diun of Suap, isc.

Foaled, 1780.

C. W. Van Ranst. Diroc, dk. ch. by Duroc, dam Vincenta [by Imp'd] Messen ger-imp'd Slender-imp'd Lath, \&c.

New-Yolk, 1790.

METEOR, b. c. by Comet, dam Nancy Dawson.

E. \& A. Stephens.

MEXICAN, [Imp'd] by Snap out of Matchem-Middleton, \&c.

MIDAS, by Am. Eclipse, dam by Sir Robin, (he [by Imp'd] Robin Red breast,) -g. dam by Dare Devil, imp'd Slaark-A pollo, Kc. 1828.

WII. Towndes.

MILLER'S DAMSEL, [by Inp'd] Messenger-dam the English Put8os mare by Eclipse. 1820 .

C. W. Van Ranst.

MILK MAID, by Centiriel, dam

Gen. Carney.

MILK SOP', h. f. ['y Imp'd] Justice, dam the Brilliant mare by Natchem Wright by Yorick. 1798.

J. Hoomes.

MILM()(I), by "opgallant, dam by Kenedy's Pantalons by Bedford.

MINERVA, [ b Imp'd] Obscurity, dain Diana by Claudius.

Wm. E. Broadmax

-Old Kosalba [by Imp'd] Eiagle, \&c.

of Br. sion's Kitty Fisher.

MINK, b. 1. by Roanoake, clam Cut Leggs. $18: 9$.

MINIKIV, by President-Old Celer-Tristram Shandy, \&c.

MiNlolUa, b. c. by Roanoake, dam Young Minikin.

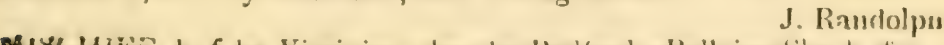

J. Raudolph

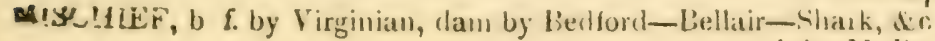


Sc: ch. m. by Rattler, dam by Ogle's Oscar-Ridgley's Haulea Fred. Maryland.

J. Powder, Jun.

MICS FORTUNE, by Am. Eclipse, dam the dam of Maryland Eclipse, \&c. J. Sewa!l.

- Chaxce, [by Imp'd] Chance, dam Roxana by Ar. Selim.

Messis. Tayloes.

-Cramırn, 1. m. [by Imp'd] Crawler, dam by Melzar-Grey Alfredimp'd Tom Jones, \&c.

BriL, [Imp'd] by Othello, dan of Dungolah.

S. Carolina, 1793-4.

H. Havnes.

Batr.y, [hy Imp'd] Boaster, dam (mothes of Maria Haney,) by Bellair-Wildair, \&c.

- Dixcr, by Roebuck, dam by Indepentence, [Imp'd] Centimel (or Flimnap,) Old Janus, \&c.

Stafford, Va.

Alexander F. Rose.

- Dor, hy Old C'eler, dain by Diomede out of Bynbam's Filly, (a noted runuing mare in Va.)

E.tilf, h. f. liy Spread Eagle, dam [Imp'd] Hackahout.

_- Fitzroy, by Roanoake, dam Wakefield.

\section{J. Pandolph.}

Fantifroy, b. m. by Wildair, dam by Yorick-Little David-Mor ton's Traveller, \&c.

—_Fık, b. f. by Roanoake, dam Wakefield.

_-Evstox, b. f. by Roanoake, dam by Gracchus.

\section{J. Randolph.}

Fortex f, ch. f. [by Imp'd] Star, dam Anvelina.

John Randolph.

S. Carolina.

James B. Pichardson.

_Frora Hamirox, b. m. by a son of old Hamiltonian, (by Diomede, dam by Old Hamiltonian, g. dium [by Imp'd] Spark, \&c.

- Gistwoon, a light b. แ. [by Imp'd] Buzzard, dain by Melzar, Shark, Union, \&c.

Lexington, Kentucky.

E. Warfield.

- Graftos, b. f. by Roanoake, dam Wakefield, \&c.

J. Randolph.

—_ Hatigix, br. m. by Blackburn's Whip, dam Blackbusn's Buzzard, g. dam by C'eler, scc.

—_Hannter, br. f. by Sir Hal, dam Miss Waxy, g. dam by Saltram, \&c Petersburg. $\quad W \mathrm{~m}$. Haxall.

- JEFFER'N, ch. f. by Diomede, dam Johnsor's Medley mare, \&c.

-Manisux, ch. m. by Lurcher, ([by Imp'd] Bedford,) dam by Ver. mont, (a son of Deceus, a son of Old Celer, ) her dam by Feariough, Old Shark, \&c.

Wm. R. Johnsun

Musrof, ch. f. by Precipitate, dam

SERA B, b. f. [by Imp'd] Serab, dam Aguns, by Sir Solomon, א.c. 1830 .

- Makflass, b. f. by Spread Eagle, dam Habe by Dare Devil, \&c.

- MAKSK E, b. f. by Berlford, dam Ciasteria.

J. Hoomes.

- Mindetov, b. f by Cormorant, flam Jantte by Mercury, \&c.

- Minwas, ch. m. by hoscirsko, dam Ruth by Big Ben, Isyche, \&c

B. F. 'T'aylor.

- -Movr. Makk. b. f. by Speculator, dam Milksop by Ćopur de l.ion 
MISS PELHAM, b. m. by Virginian, dam Sugar by Constituticn, s. dain [by Imp'd] Dragon-Atalanta, \&c.

James Bleik. Ponf, ch. f. by Dare Devil, dam Milksop by Coeur de Lion, \&e. 1806.

J. Hoomes. -Peyton, gr. m. by Gracchus, dam Telegraph by Old Wildair, Sc. 1812.

- Prland, g. m. by Gracchus, dam Duetta loy Silvertail-Vanity by Celer, sc. 1813.

-Slamfrkin. (See Maria and Maggy Slamerkin.)

J. Randolph. 'Ticker, b. f. by Arab, dam [by Imp'd] Archduke, g. dam by Preci pitate, \&c.

T'vor, b. m. by Hyperion, dam Logania by Medley, \&c. 1808.

J. Raudelph. W.xy, by Sir Archy, dam [Imp'd] Mermaid by Waxy out of Pro mise.

W. R. Johnson. WAtKER, ch. m. by Tartar, (by Diomede,) dam [by Imp'd] Mufti Flag of Truce-Old Fearnought, \&c.

Kentucky.

E. Warfield.

MODESTY, by Hall's Union, dam Madge, (by Galloway's Seliu,) g. riam an $[\operatorname{Imp} \dot{p} d]$ mare by Spot, Sec.

Benjamin Lowndes.

MOGGY, b. m. by Defiance, dain by Old Messeuger. 1820.

MOHIC'AN, b. h. by Young Topgallant, dam by Telegraph, g. dam by Medley, \&c.

Dr. E. L. Botcler.

MOLLY AYDREWS, by Jack Andrews, dam by Dare Devil, \&c.

\section{Randolph Hairsoon.}

MOLL, BRAZEN, [Iinp'd] by Spark, dam by Torismond, g. dam by secone? brother to Suip, g. g. dam by Mlogul, brother to Babraham. \&c. -by Spread Eagle, dam Nancy Medley. Fredericksburg.

James Smock.

MOLL or MOLI.Y, by (irey Figure, dam Old Slamerkin by Witrair.

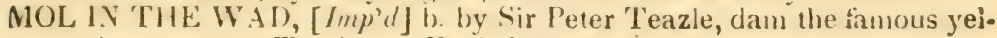
low mare by Tandem. Foaled, 1797. limp'd 1803.

John Tayloe.

MOLLY PACOLET, [Imp'd] by Pacolet, dam by Ol.] Spark, g. dain Queen Mab, \&c.

Garrett Vanderveer.

RIOLLY FISHER, b. m. by Janus, dam Gemima by Bedford, g. dam lmp'd Rachel by Drone. 1814.

MOLO, c. c. by Timoleon, dam by Tom Paine.

Gen. W. Han pton.

MOLTON MARE, light b. by Molton-Fleetwood-[Imp'd] Bashaw Impid Jolly Roger-Starling, \&c. out of a thorough bred Fing ish mare.

MONROE, [by Imp'd] Wonder, dam the dam of Madison.

AONSIELR TONSON, (or Fir Juhn, by Pacolet, (by Citizen, dam og T'opurallant, g. dau by Grey Medley-lup'd Oscar-Imp'd Fea: nought, \&c.

Thos. Watson.

MON(1.11 A, gr. m. vy Bellair, dam Sweetest by Highdver-Virago, dic. 
MONRE7, [Imp' I] by the I.onsdale Arabian--Curwen's Baty Barh - Byer ly T'urk. (This horse was 22 years old when imported, and stow. in Virginia and North Carolina, and got some fune colts.)

MONARCH, by Mark Anthony, and the pedigree of his dain side unexceptionable.

New Kent, Va. 1775.

Geo. B. Poindexter.

MOORE'S PAR'TNER. (See Fartner Moore's.)

MERDANTO, b. [by Im $\left.\mu^{\prime} d\right]$ Pantaloon, dam by Mcrtou's Traveller-Bol ton-Monkey-Jolly Roger, \&c.

MORFa U; by Bedford out of Miranda.

Young. (See Young Moreau.)

Gen Ridgley

MOUNT AIRY, by Byron, dam Roxalana.

MORTON'S TRA VELLER. (See Traveller Morton's.)

B. S. Forest.

MORGIANA, bl. f. by Sir Archy, dam by Sir Hal.

b. m. by Kosciusko, dam

J. S. Garrison.

Wm. Wynne.

MORGAN RATTLER, b. h. by Rattler, dam Iris. 1823.

J. Lewis.

MORNING BRIDE, by Spread Eagle, dam Samuel Love's roan mare.

Edw. Carter.

MOUNTAIN LEADER, ch. s. h. by Old Wildair, dam a Mousetrap mare Chesterfield, 1303.

Caleb Boush.

MIOUNTAINEER, by Spread Eagle, dam Spot by Bedford, \&c.

Wm. Dandridge. 1822.

ch. s. h. by Old Peacemaker, dam Jane by Knowsley.

Walter Coles.

ch. h. by Contention, dam Iris.

J. Lewis.

MORVENN A, b. f. [by Imp'd] Syphax, dam Brenda.

J. J. Ambler.

MOSCOW, c. c. by American Eclipse, dam Die Vernon by Old Florize"e, S.c.

Yonkers, N. Y. 1826.

W. Lyles.

MOSES, [by Imp'd] Sir Harry, dam by Waxey, g. dam by Imp'd Buzzard. \&c.

W. Haxball.

-MAr F, br. by Moses, dam Lady Harrison [by Imp'd] Spread Eagle -Herod, \&c.

MUUSE'TRAP, w Jack Rap, [Imp'd] ch. h. by Young Marske out of Gen tle Kitty by Silvio, Dorimond-Portia by Regulus-Hutton's SpotFox-Cub, \&c. Foaled, 1787.

North Carolina, 1793.

ch. h. [by Imp'd] Mousetrap, dam by Imp'd FearnoughtPartier-Imp'd Janus, \&c.

MULAT'IO MARY, by Sir Archy,

MUUAT, ch. c. by Old Madison, dam Maria Archy. 1826.

MCIII FI.ORA, b. f. hy Old Sir A rchy, dam Weazle by Shylock.

ch. m. by Kosciusko, dam by Rosicructan.

E. Irby.

J. Atchisun.

MC'CKLE JOHN, by Sir Archy, dam the dain of Sir Willam by Bellair, SLC 
MICKLE JOHIN, by Muckle John, dam Black Eyed Susan by Potrn rc, sc.

MUF'Tl, I Imp'dj was by Fitzherod, (he by King Hernd,) Mufti's dam ?'y Infant, son of the Godolphin Arabian, g. dam by Whittington ou of a fill sister of Black and All Black, fifteen hands me inch hign Foaled, 1775.

wUSIDORA, by Archduke, dam by Dare Devil.

John Tayloe.

MU. Tayloe.

MURDOCH, by Sir Charles, dam gr. m. by Bedford, her dam by Old Wil dair.

Chesterfield, Va. 1830.

Charles Graves.

MUZZLE WIOMEDE, [by Imp'd] Diomede, dam by Hymen, by Clotus, b) Peamought, sc.

MYRTILLA, br. f. by Marylander, dam Desdemona by Miner's Escape Foaled, 1828.

Dr. Crawford.

\section{N.}

NAMELESS, [Imp’d b. m. by Felho da Puta, by Haphazard, out of Mise Barnet, her dam Rosetta by Young Woodpecker-Dungannon Justice, \&c. Foaled, 1825.

Imp'd 1829. N. Y.

Chas. Green.

NANCY, b. f. by Spread Eagle, dam

b. m. by Ball's Florizelle, dam the Bedford mare Spot.

1814.

Walter Coles.

- Anerer, by Sir Archy, darn

Arr, [ liy Imp'd] Bedford, dain Annette by Old Shark, g. dam by Rockinghaın-Gailant, \&c.

Foaled, 1799. Died 1822.

James B, Ricnardson.

- Aır, b. m. by Virginius, dam Old Nancy Air.

J. B. Richardson.

-Bers, by Fearnought, dam by Imp’d Miss Bell, \&c.

Brwrl.t, [Imp'd] b. In. got by Matchem, dam by Goliah-Red Rose-Curven-Old Spot, \&c.

- Coutsis, by Young Fearnought, dam Latonia by Old Partner, gı. dam by Imp'd Jolly Roger, \&c.

1806.

J. Verrell.

- Creitintos, by Francisco, dam Molly Andrews by Jack Andrews.

Messis. Minges.

Dawsos, by Lloyd's Traveller, dami Phillis (by Fearnought,) 5 . dam a celebrated mare of Col. Baylor's by Imp'd Sober Johin.

Foaled, 1783.

Wm. Scott.

DAwsox, b. by Eagle, dam by Bellair.

MArTix, ch. m. by Bolingbroke, dam by Bedford--Selim-Tyler's Independence, \&c.

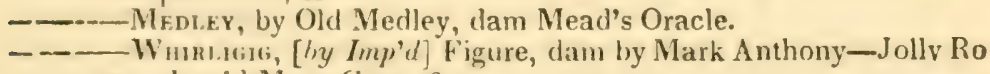
ger-lmp'd Mary Grey, \&c.

NANNY O, c. f. by Pantaloon, dam Young Selima by Yorick. 1788.

J. Tayloe.

NAOMI, ch. f. by Pulaski, dam by Young Wonder- Smikx-Giey Dis mede-Aialanta by Imp'd Mledley.

NAPOLEON, br. b. by lmp'd Diomede, dam by Eclipse, g. dam by Me:ca ry. \&cc.

7808.

H Cheshre.

'Truce, \&c. 
NAPOILEON, $\mathrm{cn}$. h. by Napoleon, (by Diomede, dam by Fiorizelle.

by Imp'r Wouder, dam hy Diomede-Hart's Medley-out or a favourite maı of Col. Selden's, \&c.

S. M. Spangler. by Sir Archy, dam by Sir Harry, g. dam by Dare Devil. by Imp'd I'unch, dam Lufiborough's Selina, the third by Hall's Eclipse.

(Killed 1805.)

Tennessec.

N. Luff borough. - by Oscar, dam Letitia by Truxtor.

A. B. Shelby.

VARCISSA, by Imp'd Shark, dam Rosetta by Wilkins' Centinel-Diana by Claudius, \&ec.

J. J. Harrison.

-by Wildair, dam Melpomone, g. waın Virginia by Mark Anthony-Polly Byrd, \&c.

J. Hoomes.

NELLY SPAPKS, br. m. by Bertrand, dam by Whip, (by Imp'd Whip)Bomparl, \&c.

Kentucky, 1828.

Edw. M. Blackburn.

NELL GWYNN, ch. f. by Thornton's Rattler, daın Vixen by Trafalgar.

- Savndrks, ch. m. by Wonder, dain by Imp'd Dare Devil-imp d Centinel, \&c.

NETTLE, ch. m. by Wildair, dam Desdemona.

full sister to Virago by Wildair, by Ajax.

Dr. E. A. Darcy.

\section{A. F. Rose.}

NETTLETOP, by Imp'd Spread Eagle, dam by Shark-Old Janus, \&c out of a thorough bred mare.

- $\quad$ ch. m. by Trafalgar, (by Imp'd Mufti,) dam Nettletop by Spread Eagle, \&c.

L. Berkley.

hy Bellair, dam by Mark Anthony-Fearnought.

Foaled, 1794.

Reeves:

- by Diomede, dam Betsy Lewis, \&c.

NERISSA, b. f. by Roanoake, dum Jessica by Shylock. 1825.

NEVERTIRE, b. f. by Roanoake, dam Endless.

Wm. Herndan.

NEY, b. h. by Mountaineer, dam Lady Eagle.

$$
1827 .
$$

NIGHTINGALE, by Chanticleer, dam Winguryfeet, (by Jolly Roger, s. dam Melpomone by Burwell's Traveller.

NILI, bl. m. by Black and All Black, dan by Careless-Augustus-Pil. grim-Fearnought, \&c. Tennessee.

H. Baldwin, jun.

NIMROD, ch. c. by Baylor's Fearnought out of a Partner mare-Imp d Janus_Imp'd Jolly Roger.

Williamsburg, Va. 1775.

Richard 'Taliaferro.

NULI ME TANGERE, by Richmond, dam Noli Me Tangere by T'opıallant. 1800.

— by Topgallant dam Castianira.

Dr. Thorntorn.

NONPAREII, dk. b. hy Old Fearnought, dam by Janus, \&e.

J. Tayloe. York Town, 1773.

Thomas Lilly.

v(ORNA, b t. by Drector. dam by Sir Harry-Bedforci-Dasy levitIVildair, S.c 
NORTH CARULINIAN, by Virginian, dam by imp'd Dion, g. dam Betsy Baker by imp'd Clown, Golden Figure, \&c.

NORTHAMP'ION, b. c. by Ogle's Oscar, dam Jane Lowndes.

NOR'THERN E.CLIPSE, (See Eclipse iNorthern.)

Gov. Sprigg.

NOR'TII LAS'T, b. c. by imp'd Highlander, dam Tulip by Ranger or Limel say's Arabian.

1797.

Thomas M. Foreman.

NOP.TH S'TAR, $\left[I m p^{\prime} d\right]$ b. by Matchem, ham Lass of the Mill by Oranm ko, g. dam by 'raveller-Miss Makeless by Young Greyhound. Foaled, 1768.

'Thomas Peter.

NORVAL, dap. gx. Ly imp'i. Spark, dam by Shakspeare, g. dam imp'd Lady Northumberland.

NOPTHUMBERLAND, by Bellair, dam by Wildair-Shakspeare,

NCLLIFIER, b. c. by Am. Eclipse, dam Roxana by Sir Harry, fec.

J. Tayloe

Messrs. Corbins.

\section{O.}

OATHMAN, b. c. by Selim, dam B, Ruler mare, (by Ruler in England,) Turk, \&c.

OAKLEY, ch. c. by Crusader, dam Josephine by Becford.
S. Carolina, 1829.
J. J. Moore

OBSCURITY, [Imp'd] dk. ch. got by O'Kelly's Eclipen, dami by Carelf. g. dam by Cullen Arabian, g. g. dam by North Country Diomede, a. Foaled, 1778.

Jolun Formas.

OCEANA, b. f. by Bagdad, dam Florida by Concueror-Rosemary, (South all's mare,) by Dionede-Celia by Willair. 1827.

J. Southall.

OCTAVIA, b. f. by Rockingham, dam Frederica by Eonere.

OCEAN, ch. o. by Timoleon, dain Anna by Truxıo.

$$
\text { utarles Tayloe }
$$

Tennessee, 1828.

OHIO, ch. h. hy Bacchus, dam Crazy Jane, \&c.

O'KELLY, [Imp'd] b. by Anvil, dan by Eclipse, g. dam Ly b'ank, g. g dam by Suip-Godolphin Arabiau, de.

1798.

Thomar Reeves. -.Tet by Haynes' Flimmaj, \&c.

OLYMPIA, bI. f. by Roanoake, dam Jet by Bluster.

OLJVIA, b. f. by Am. Eclipse, dam Brunette, (by Telegraph) Randolph. full sister to Defiance.

OROONOKO, b. c. by Hyperion, dam Minikin, \&c. 1810.

ORACLE, (MEAn's, rby Inp'd] Obscurity, dam by Cohn Randulph. Parmer-janus-Valiant, sc.

URANGE, b. m. by Cooper's Messenger, dam by Slasher, (he by Messem. ger, g. daun bred by Gen. Green of Hhiladelphia out of a Va. brec mare, \&c.

ORELIA, b. h. by Pacolet, dam by Truxon, g. dam Dr. Buc'er's Roselio by inp'd Menrloza, \&c.

OR!HAir bOY, b. h. by Am. Eclipse, dam Maid of :he Oaks, Sc. 
ORPHA N, b. c. by Cormorant, dam Darlington mare by Darlington.

- - by Ball's Florizelle, dam bv imp'd Diomede.

(NEA, br. f. by Pacotaligo, dam Virginia (Coquette.) 1821.

ONORER, b. m. by Sir Archy, dam Black Ghost.

OPHELIA, by Grey Diomede, dam Primrose by A pollo

Diomede, \&c.

Gen. Ridgley.

OPOSSUM, g. m. by Shark, dam by Old Twig-g. damby [Imp'd] Fearnought -Jolly Roger, dic.

Mark Alexander.

OPER VICO, b. h. [by Imp'd] Medley, dam by Lindsay's Arabian, g. dam by imp'd Oscar, \&c.

New Castle, Va. 1797.

Nicholas Symme

OSCAR, [Imp'd] a deep sorrel by Young Snip, dam by Lord Morton's Aıa. biau, g. dain by Old Crab, g. g. dam by the Bald Galloway, \&c. Cumberland Cy. Va. 1777.

William Gay.

- (Otile's, b. h. [by Imp'd] Gabriel, dam Vixen by Old Med. ley, g. dam Penelope by Yorick, \&c.

Bellair, Maryland, 1800.

$-\left[I m p^{\prime} d\right]$ br. h. by Saltram, dam by Highfler-Herod-MIse Middleton by Regulus-Camilla by a son of bay Bolton-Bartlett's Childers, sc.

Foaled, 1795.

William Lightfoot.

Eagle, \&c. Jux. by Ogle's Oscar, dam Edelin's Floretta by imp'd Spread

Carlisle, Pa. 1822. ik. b. h. by Wonder, (son of Diomede, dam Rosetta, (Rosy Clack, by Saltram, \&c.

(Tennessee.)

Yocig, b. h. by Tuckahoe, dam by Ogle's Oscar, g. dam by Medley, Cub, Tamerlane, \&c.

Maryland, 1824. $\frac{1829 .}{1 r}$. gr. by Roanoake, dam Lady Eagle.

ISSSORY, b. c. by Old Rattler, dam Desdemona, \&c.

Charles Ridgley.

Walter Coles.

J. Tayloe.

OTHO, dk. b. h. [byImp'd] Shock, imp'd Morton's Traveller, imp'd Jus. tire, imp'd Jumiper, imp'd Othello, imp'd Childers out of a thorougb bred mare purchased from the stud of King George II. Foaled, 1765.

George Branham.

UT HEI,LO or BLACK AND ALL BLACK, [Imp'd] a beautiful black got by l'ortmore's Crab, out of the Duke of Somerset's favourite nare Niss Slamerkin, \&c.

Foaled, 1743. Imp'd 1755-6. Gov. Sharpe, (Maryd.)

\section{P.}

PACRINGHAN, by Florizelle, dain by Magng, g. dam by Flimnap-Mark Anthony, \&c.

"ACIFIC, b. h. by Sir A rchy, dam Eliza, (full sister of (rallatin,) by imp'd Bedford out of imp'd Mambriso, \&c.

Nashville, Temmessee.

D. W. Sumner.

P aCOTA TIGO, [hy Imp'd] Bedford, dam Milksop by Justice. 
PAL H UX, by Express, dam by Cub-Heath's Childers-ao. Traveller-Old Dove-Othello, \&c.

r. h. by Old Diomede, dam Eppes' Tippoo Saib mare, \&r.

PACOLET MARE, [Imp'd] by Pacolet, dam Whiteneck by Crab-Godo. phin Arabian-Conyer's Arabian, \&c

Imp'd into P'ennsylvania.

Hiltzheimer. by Pacolet, dam by Dragon, g. dam by Truxton-B'mpardPillgarlick, \&ic.

Tennessee, 1824.

PACOLET, by Old Pacolet, dam by Albrack, (bj Truxton.)

Reuben Cage.

st. Louis, Mobile.

B. McMenomy.

$\left(\mathrm{OLn}_{\mathrm{n}}\right)$ [ by $\left.\mathbf{I m p} \mathrm{p}^{9} \mathrm{~d}\right]$ Citizen, dam by Tippoo Saib, (the dam of

Palafox by Old Diomede, Wilkes' Wonder, \&c.) Died 1825, sged

17 years.

Sumner Cy. Tennessee.

Geo. Elliott.

Shakspeare, \&c.

PANDORA, by Bellair, dam by Soldier, g. dam by imp'd Oscar, Merry Tom, \&c.

E. A. Massey.

Marion.

or Sally Gee, b. f. by Archy, dam a Citizen inare, dain of

II. by Gov. Wright's Silver Heels, dam Equa.

West.

F. Wallis.

by Grey Diomede, dam the dam of Floretta.

Gov. Wright

by Hart's imp'd Medley, dam by Lonsdale out of Braxton imp'd Kitty Fisher.

Lonisiana.

, imp' Benford, ec

['ANTALOON, [Imp'd] b. by King Herod, out of W. Fenwick's N'u. cracker who was by Matchem, \&c.

Foated, 1799, Brandon, Va. 1787. Benjamin Harrison.

[Imp'd] b. h. by Matchem, dam Curiosity by Snap-Reguli,g

-Bartlett's Childers-Honeywood's Arabian, dam of the two 'Truto Blues.

1767.

PANTONIA, by Bedford, dain by Dare Devil-Shark-Pilgrim, \&c.

PARROT, b. f. by Roanoake, dam Paroquet. 1811.

John D. Macklin.

PAROQUET, b. f. by imp'd Merryfield, dan Popinjay, Bourbon's dam. 1819.

J. Raudodph.

PARTNER, [Imp'd] b. h. hy the Duke of Hamilion's Figure, Old FigureStandard, Scc. Partiter's dam was Britannia, full sister of Col. Hop per's Pacolet, g. dam Queen Mab, \&c.

Hanover, Morris Cy.

John Blanchard. (Mоонғ's, [Imp'd] by Croft's Partner, daum (sister to Starling; by Bay Bolton son of the Brownlow 'Turk by the L'ulliam Arabiau. icc.

1760 . (Otn, ) by Morton's Traveller, dam Tasker's imp'd Selima.

b c. by Roanoake, dam the dam of Wildfire.

$\therefore$ Randolph.

aRAGON, g. b. by Sprearl Eag,e, dam by Bellair out of Andrew Mead。 ()racie.

1308.

Raiph Wormileg 
- - - b. h. by Virgnıa Eclıpse, dam Virgmia hy Tınoleou of Ma. ryland out of the Mlaid of Oakland by imp'd Stirling, \&c. $18: 29$.

— - - by Timolenn, dam by Brutus, (by Bellair,) g. dam by Old D1 omede, \&c.

(Huntsville, Ala.)

Gabriel Moore.

by Old Flimuap, dam Camilla by Burwell's 'Traveller, \&c Sold to Col. Fenwick.

Foaled, 1788.

W. Hainpton.

- Mare, by imp'd Buzzard, dam by Columbus, (by imp'd Pan. taloon,) out of Lady Northumberland, g. dan by Paragrm, if .

E'AR'TNERSHIP, ch. h. by Volumteer, dam Rosy Clack by imp'd Saltram - Camilla by Old Wildair, Sic.

\section{Arthur Cotton.}

\section{b. c. by Ogle's Oscar, dam}

PATRIOT, by imp'd Fearnought, dam by Fearnought, g. dam by Aristo tle, g. g. dam by Valiant, \&c.

PATTY SNAGGS, ch. f. by John Richards, dam Selima by Topgallant, \& c

$$
\text { P. Wallis. }
$$

PATSY WALTHAL, by Medley, dam Maria by Diomerle, g. dam hy Bellair, \&c.

H. Haynes.

एAUL JONES, by Specimen, dam by imp'd Wildair, (which was taken back to England,) g. dam Delancy's Cub mare.

Young, (See Young Paul Jones.)

Gen. Morgan. ch. by Sir Charles, dam by Tom Tough-Ball's Flnrizelle, imp'd Hamilton, \&c.

Jefferson, Cy. Va.

S. \& J. Strider.

PUL, [Imp'd] ch. fifteen hands high, by Saltrain, dam Virago by Snap, Paul's dain Purity by Matchem, g. dam the Old Squirt mare.

Powhatan, Va. 1807.

Thoinas Harris, Jun.

PAYMASTER, [Imp'd] b. by Old Paymaster, dam by Otho-Herod-Duke of Northumberland's A rabian out of own sister to Skim, \& c.

York River, 1791.

N. B. No runners from this horse.

Henry Norriss

PARALLEL, by Virginian, dam by Medley.

PARIS, by Highflyer, dam a Cade mare.

PARTIZAN, a light bay by Virginian, dam Diomedian by Am. horse Saltram, (son of imp'd Dionede,) gr. dam by Hendrick's Celer (son of Mead's Old Celer.)

Horace Royster.

PAMUNKEY, by Am. Eclipse, dam Bellona by Sir Archy - dam by Sir Harry-Melzar, \&c.

Thomas Doswell.

PEACOCK, (Youns's) by imp'd Citizen-imp'd Sterling-imp'd Mousetrap, \&c.

1828.

(BERKLey's, by Old Janus, dam alı intp'd Spanish mare.

'E.ACE MAKER, dk. b. h. by imp'd Diomede, dam Poll by Young Black and all Black, out of a N.ercury mare, g. d. Nanny by Black and all Black, g. g. dam by imp'd Oscar-Old Partner, \&c. 1807.

J. Taylue.

- by Old Volunteer of Tennessee, (he by Gallatin,) dam hr Old Peace Maker-Dutchess by Coeur de Lion, \&c. 
P\&CAaUS, o. f. by Pegasus, dam Sally Wright. $1-7 \%$

J. Honmes.

I'EGGY, (Yorwi) ch. m. by Gallatiu, dam Trumpetta by Hephestion, \& dian l'eggy by Bedford.

Kentucky.

E. Warfield.

— ch. in. by Imp'd Bedford, dam Imp'd Peggy. 1893.

Waile Hampton.

____ Imp'tl] by Trumpeter, dam by Herod out of l'eygy, (sister to Postmaster.)

Foaled, 1788. Died 1805.

J. Tayloe

PEGGY MADEE, gr. f. by Sir Hal, dam Fair Rosamond, \&c 1823.

PFYDENISS, gr. h. by Volunteer, dam Ariadne by Ball's Florizelle.

PENELOP'E, by Yorick, dam by Ranter, g. dam by Old Gift, \&c.

ch. f. by Timoleon, dam Rosetta by Wilkes' Wonder.

J. Tayloe.

-PENNSYLVANIA FARMER, by l'artner out of a full bred mare. 1775.

J. Tavloe.

ton, \&e.

Mare, by Pa. Farmer, dam by Pegasus, g. dar.. ๖y Bol.

J. Hoomes.

PELHAM, b. c. by Gracchus, dam Mary by Whip. Falmouth, Va.

Enoch Mason.

PEY EYE, b. c. by Bedforl, dam Milksop, \&c. 1804.

PET, b. f. by St. Tammany, dam Miss Dance by Roebuck. gr. f. by Gracchus, dam Mouse by Sans Culotte.

J. Randolph

PETRUCHIO, by Shakspeare, dam Miss Chance by Chance-Roxalaua, \&c.

Mt. Airy, Va.

Wm. H. Tayloe.

PHEXOMENON, or Big Ben, by Inı'd Wonder, dam by Dare Devil, \&c

J. Mayo.

1824.

b. h. by Roanoake, dam Young Frenzy.

John Randolph.

PIENOMENA, b. f. by Sir Archy, dam Lottery by Bedford, \&c. 1827.

R. Singleton.

PIIOEBE, by Bright Phrobus, (full brother of Miller's Damsel,) dam hy Republican Presicient, (he by Cragg's Highflyer, g. dam by Lind say's Arabian-limp'd Ranger, \&c.

PHOEVIX, [Imp'd] ch. \}. bred by the Duke of Bedford, got by Dragon, his dam Portia by Vi:lunteer-Florizelle-King Herod, \&c. Foaled, 17.99.

North Carolina, 1803.

Thos. B. Hill.

- - b. h. by Imp'd Venetian, dam Zenotia by Don Carlos-Juniper, \&ec.
Balt. Cy, 1794.
G. Fitzhugh.

PII LADELPHIA, [Imp'd] b. m. by Washington, dam Miss 'Tutteridge of Dumgamon-Marcella by Mambrino-Nedia by Sweeibrier-An gelica by Snap, \&c. 808 .

PHILIP, ch. c. by Rattler, dain by Flag of Truce.

J. Randolph.

PHiLris, Fowisend.

P'HILI,IS, by Fearnought, dam a celebrated mare of Col. Baylor's got by Imp'd Sober Jolin, Stc. 
PHILLIS, by Old Tispgailant, dam by Grey Diomede, g. dam alsu by Gie: Dionede out of a therough bred mare. 1811.

Geo. Chicester.

PICTURE, by Imp'd Shark, dam by Siweet Larry, by Spadille-Janus dec.

PILFRI II, $\left[\right.$ I $\left.m p^{\prime} d\right]$ bl. h. by Samson-Regulus-Greyhound mare-Brows Traveller, the grandam of Matchein, \&c.

Foaled, 1762.

-_ by Yorick, (hy Morton's Traveller, dam a Little Davie mare, g. dam by Old Traveller out of Muslin Face, \&c. 1777 .

Wm. Snith.

_- -lap. gr. hy Fearnought, dam Brandon by Aristotle, \&c. Foaled, 1774.

B. Harrison.

PILOT, b. c. by Sir Archy, dam by Gallatin.

r. c. by Flimnap, dam Hope by Shark.

J. J. Harrison.

b. c. by Sir Henry, dam Slow and Easy by Duroc.

Slierman.

PIRATE, by Sir Archy, dam Lady Hamilton by Sir Arthur-VledleyMark Anthony, \&c

W. R. Johnson.

PILLGARLIC, by Old Janus, dam by Imp'd Jolly Roger, g. dam by Silver Eye, \&c.

PILL BOX, (Dr. Dixon's) by Imp'd Pantaloon, dam Melpomone by Burwell's Traveller, g. dam Virginia by Mark Anthony.

PINK, by Lee's Mark Anthony, dain by Jolly Roger-Jenny Cameron, \&c.

PINK OF RETREAT, ch. by Young Tom Tough, (by Old Tom Tough,) dain by Buzzard, g. dam by Jones' Wildair.

IIROUETTE, [Imp'd] ch. f. by Tenier's dam Marcondotti by Muley, \&c. Craig \& Corbin.

I'LAY or PAY, [Imp'd] b. h. got by Ulysses, dam by King Heror-Regu. lus-Poyal George's dain by Rib-Snake-Coney Skins-Hutton's Barh, \&c.

Foaled, 1791.

J. Hoomes.

IILENIPOTENTIARY, gr. c. by Ogle's Badger, dam Shrewsbury Nan, by Bajazet, \&c.

Rose Hill, Md. 1789.

Thos. M. Forman.

by the Arabian Dey of Algiers, dam Cora by Bedford.

POCAHONTAS, b. f. by Randolph's Janus out of the dam of P'owhatan. by Topgallant, dain Pocahontas by Vintzun.

Gov. Wright.

-- by Vintzun, dam Pandora by Grey Diomede-Old Medley,

\&c.

b. m. by Sir Archy, dain Young Lottery, (by Sir Archy,) out of Lottery-Bedford, out of Imp'd Auvelina. 1819.

POCOTALIGO, by Imp'd Bedford, dam Milksop by Justice.

R. Singleton

Gen. McPlierson.

P'OLLYPHEMUS, ny Tayloe's Yorick, dam Selima by Old Fearnought.

IOLL, ch.f.'by (A.Young's) P'eacock, (by Citizen,) dain Dutchess by Bed forc:-Thresher-Twigg, \&c.

- - by Partner, dan by Mark Anthony-Old Parner, Sc.

b. f. by Eclipse, dan. Janus mare.

H. Hagri.

Fit.I. (if I'I,YMOUTH, ch. f. by Archduke, dam Imp.d Alexandria. 
ROELY BYRD, by dristotle, dam Young Bonny Lass by Oid Jelly Reger, g ram Boniny Lass.

Brooks, h. f. by Imp'd Valentine, dam Sally Baxter.

- FLIXFN, by Joily Roger, dam Imp'd Mary Grey.

Thos. M. Forman.

H. Ganes.

Hopkiss, b. m. by Virginian, dam Jenny by Archduke-Imp'd Stirling-Imp'd Obscurity, \&c.

Col. Wyure.

-Martix, b. m. by Benehan's Sir Archy, dam by Imp'd Dion.

Capt. Geo. A. Bkiney.

Mfnlex, b. m. by Thornton's Medley, dam hy Thornton's Mercury-Bowie's Sportsman, \&c.

Pracutм, by l'atriot by Isabella, (the gr.dam of Page's famous Isabella.)

Peachum, b. f. by John Richards, dam Fair Forester, \&c.

1826 .

John Baker.

Powfle, by Virginian out of a full sister to Napoleon.

PONIPADOUR, by Valiant, dam Imp'd Jenny Cameron.

Juige Ty!er.

PONONA, [Imp'l] b. m. by Worthy, (own brother to Waxey, ) dain Co medy by Buzzard, her dam by Highflyer, \&c.

P'etersburg, Va.

Wm. Haxall.

POOR CHANCE, ch. c. by Archduke, dam Milksop by Coeur de Lion.

PORCUPINE, ch. by Imp'd Diomede, dam Diana by Claudius. J. Hoomes. 1804.

Will. E. Broadnax.

PORTO, [Imp'd] by King Herod, dam by Snap-Carle-own sister in Natchem's dam by Partmer-Makeless-Brimner, Sc. Bred hy iir. Crofts, and foaled 1731.

PORTO BELLO, by Commutation, dam by Walker's Flimnap, \&c.

Dinwirldie Cy. Va. 1796.

Thos. Fnode.

Belf. Starke.

PORTIA, b. m. by Clipper, (a son of Old Messenger, her dam the dam of Moggy by Defiance. 1825.

J. Randolph.

POST BOY, by Gabriel, dam by Hyder Ally, g. dam by the Old Grey Ara bian, g. g. dam by Ariel-Othello, \&c.

by Wrangler, dam

Ridgley.

POTOMAC, b. h. by Imp'd Diomede, dam by Pegasus, \&c.

Mecklenburg, Va. 1804.

Kentucky.
POT8OS, by Old

B. Wilkes

$\mathrm{M}_{\mathrm{ARE}}$, by Potomac, dam by Gallatin.

Rich. Dennis.

Jefferson Scoth.

POTsor, hy Oli Medley, dam by Conductor, g. dam oy Celer, \&c. Foaled, 1792 .

Win. Constable.

POWHATAN, by Oscar, (he by Assiduous, ) dam a Bashaw mare. Spotsylvania Cy. Va.

John Ho!liday. gr. h. by Old Pacolet, dam by Powhatan, by Imp'd Diomerio mane, biomede, dam by lmp'd Shark-Old Celes -lmi.' mare, \&c.

rOWWA:CY, by Sir Alfred, dam Virgo by Imp'd Young Sir l'eer Tee

$\mathbf{x}$, g. dam Castianira. 
I'RECIFI $\Gamma A^{\prime} \Gamma E,\left[I m p^{\prime} d\right]$ a sorrel horse, fifteen and a nalf hands high hred by the Earl of Egremont, got by Mercury, dam by Herod, g. dam by Matchem out of Mr. Pratt's Old Squirt mare, \&c.

Foaled, 1787. Imp'd 1804.

Wm. Lightfont.

PRESTLEY, by C'hanticleer, dam Camilla by Wildair, g. dam Mlimerva b甲 Obscurity, \&c.

PRESIIDENT, by Old Celer, dam by Mark Anthony out of Bouny Iass. -dap. gr. by Imp'd Clockfast, dam Haines' Old Poll by Fearnought-Moore's Partuer, \&c.

Dinwiddie Cy. Va. 1796.

Drury Jones.

PRIMROSE, (Dr. Stockett's) by Grey Medley, dam by Apollo, g. da'm by Imp'd Granby-Hamilton's F igure, \&c.

- - by Dove, dam Stella by Othello, Imp'd Selima.

Dr. Hamilion.

gure, \&c.

PRIMERO, by Mason's Rattler, dam Kitty Russell.

Thomas Carter.

PRINCE FREDERICK, [Imp'd] a bay fifteen and a half hands high, was got by Formuio by Flororet, dam by Lexicon, g. dam by Sportsman, g. g. dam Golden Locks by Oronooko-Valiant, \&c. Boston, 1798.

Edw. Davis. Enward, ch. by Muckle John out of a Whip mare, \&c. Georgia, 1828.

C. A. Rudd. -Rerkit, by Tom Tough, dam by Imp'd Sir Hary. King $W$ m.

Thos. Carter.

PRINCESS, by Sir Archy, dam a full blonded mare, bred by Lemuel Long of North Carolima, \&c.

['RIZE FIGHTER, by Imp'd Expedition, dam Zelippa by Imp'd Messenger, sc.

PROMISE, [ Imp'd] ch. m. by Buzzard out of a Precipitate mare, the dain of Wizart, her dam out of Lidly Harriet by Mark Anthony, Sc.

Win. Haxall.

by Grey Medley, dam by A pollo, g. dam by Imp'd Granby, \&c.

Gell Ridgley.

PROSERPINE, by Dare Devil, dam a Clodius mare, g. dam by Boltor, g. g. dam Sally Wright by Yorick, \&c. 1797.

J. Hoomes.

b. m. hy (Tenn.) Oscar, dam by Pacolet, second Diomede by Imp'd Diomede-Wildair, \&c.

Temessee, 1823.

J. C. Guild.

PSYCHE, [Imp'd] gr. m. by Sir Peter Teazle, dam Bab by Bordeaux wut of Speranza, own sister to Saltram by Eclipse-Snap, \&c. Imp'd by (ien. Mcl'herson.

South Carolina. Foaled, 1802.

I'UNCH, [Imp'd] got by King Herod, dam by Old Marske-Cullen Arabian-Black Eyes by Regulus-Crab-Wailock-Cialloway, \&:. 1.99.

Win. Powers.

PLPCHINELLA, [Imp'd] by Punch, dain Craig's Highflyer by Highflyer of Tattersalls, g. dam by Galloway's Selim, dec.

Washington City, 1808.

Wm. Thornton.

:'JRI'T'Y, gr. m. by Sir Archy, dam by Bedford, g. dam (dam of Trifle) by Bellair-Shark-Wildair, \&c.

Foaled, 1827.

Chas. Botts \& T. Larroon.

I' KF: (,OLD, by Stirling, dam hy Escape, g. dam wy Lord I ouvaine's Percy Arabian-King Herod, \&c. 
PULASKl, cls. h. hy Virginian, dam Constitution (by Diomede,) g. (lau the dam of Lady Lagrange by imp'd Dragon, Bet Bounce, $\mathbb{S}$ :

Thomas S. Goodrum.

\section{2.}

QUAKER LASS, by Jumper, nam imp'i Molly Pacnlet. by Kouli Kahı1. dam by Valiant, g. dam imp d by Wintiam Byrd, and fualed 1769 .

Thenterick Bland.

QUEEN ISABELLLA, br. m. by First Consul, dam Nancy Dawson by Old Messenger.

MIAB, [Imp'd] by Musgreve's Grey Arabian, dam Harrison's Arabian, g. dam by his Chestnut Arabian, Leeds, \&c.

Imported by

Gov. Ogle. 1789.

QUICKSILVER, (formerly SxAP,) s. h. by imp'd Medley, dam by Wildaur, g. dain t,y Spark out of Col. Overton's Jolly Roger, and Valiant mare sold to $\mathrm{H}$. Heath.

1789 . 1783.

by Mercurv, dam Brondon iy Aristutle.

J. Tayloe.

QUIETUS, b. c. by Sir Henry, dam Slow and Easy by Duroc, \&cc.

Benjamin Kiarrison. 1808.

b. c. by Speculator, dam Alexandria. - Sherman.

John Hoomes.

QUIDNUNC, b. c. by Arabian Bagdad, dam Rosy Carey, (by Sir Arciny, g. dam Sally Jones by imp'd Wrangler-inp'd Traveller, \&c. Tennessee, 1826.

Rev. H. M. Cryes.

\section{IR.}

RABBI, g. c. by Winter's A rabian, dam by one of the best sons of Hambletonian, g. dam by Spread Eagle.

Alabama.

J. \& A. Gist.

RACHEL FOSTER, gr. m. by Virginian, dam by Palafox-Betty Mufti by imp'd Nufti, \&c.

RAFFLE, ch. m. by Bellair out of a full sister to Narcissa. 1798.

Samuel Tyler.

RANIOLPH, gr. c. by Rinaldo, dam (Ridgley's) Ophelia by little Medley, \&c.

RANGER, [Imp'd] a Milk White horse got by Regulus, (son of Godolphur Arabian,) his dam by Mercury, Andrew, her dam by Steady, Scc. (Unsuccessful in racing.)

Dr. Hanilton. b. c. by Roanoake, dam Never Tire.

John Rantolph. (See A rabian Lindsay's.)

dh. b. by Bussora, dam Alarm.

ci. c. by Heath's Childers, dam Tulip by Lindsay's Whut A rabian, imp'd Othello, George's Juniper, \&c. 1793.

Thos. M. Formak.

RANTER, [ T mp't] b. foaled 1755 , got by Dimple, (son of the Ciodolphin A rabian, ) dam by Crab out of Bloody Buttocks, Sc. Imp'(l it. 962 and stood in Stafford County, Va. in 1763.

-...-Yousci, (See Young Ranter.)

-A SSELAS, by sir Arehy, dam by imp'd Play or Pay, g. dam to Sellau, imprel Pnntaluosi, sir.

33 * 
RAT'TLER, or (RATTLE, by imp'd Shark, dam Lady Leges, (the dam os Collector, by Centinel-imp'd Fearnought and imy?'n mare, dic. N. Carolina, (foaled, 1796.) bignell. Ch. h. by Rattler, (by Sir Aschy.) dam by Old P'rize Fighter, g. dam Luffborough's Spread Eagle mare.

Lancaster, Pa. 1829.

Edward Parker. by Sir Archy, dam by imp'd Robin Redbreast, g. dau ?: mu'd Obscurity, Oİd Slamerkin, \&c.

-_ch. by Thomton's Rattler, dam Maid of the Mill. - Wynne. Walter Livingston. by Rattler, (by Shark, dam Polly McCulloch. Peebles (See Fairfax.) ch. c. by Kosciusko, dam by Archer.

Kentucky.

Edward M. Blackburn. (Alias Stafford, ch. h. by Timoleon, dam Constitution (b Diomede,) g. dam imp'd Saltram, Old Wildair, Fearnought, \&c. MARE, c. m. by Rattler, dam Jenny Windflower. E. Mason.

C. Irvine.

RATRAY, by imp'd Cliften, dam by Fitzpartner out of Ariminna by Brimmer.

RAPLEY, gr. c. by Bassino, darn Clio by imp'd Whip.

RAPID, by Columbus, dam by Sir Archy.

$$
\text { Gen. Taylor, (Georgia.) }
$$

RAPPAHANNOCK, by Richmond, dam by Sir Alfred, g. dam by Sey mour's Spread Eagle, Pautasoon, \&c.

Pennsylvania, 1830.

RAVENSWOOD dk. b. h. by Sir Harry, dam Dutchess by Grouse. 1815.

J. Raindolph.

REALITY, by Sir Archy, dan by Medley, g. dain by Centinel, Mark Authony, Janus, \&c.

REALHOOK, by Old Sir A rchy, dam Irby's Dare Devil mare.

RECRUTT, va by Ouscurity, g. g. dain Diana by Claudius, \&c.

Hickory. Hill, 1807 .

RED MURDOCK, (See Murdosk.)

RED ROVER, ch. h. (See Marcellus.)

Ch. h. by Caroliniau, daın Sycorax.

RED FOX, by Virginian, dam by imp'd Knowsley.

REFORM, br. h. by Marylander, (by Thornton's Rattler,) dam by Ricb mond-Ogle's Oscar-Grey Diomede-Hall's Union-I eoniclas, \&.c Prince George Cy. Maryland.

Geo. Simms.

b. $t$. by Tariff, dam the dam of Chieftain.

REGULUS, (L. Burwell's) [Imp'l] got by Regulus, (a son of the Godolphin A rabian, he was half brother to Balo Parmer by Smiling Tom out of a Partner mare, her dam by Cupid-Hautboy-Bustler \&c. Foaled, 1747.

- by Silver E, e, grand sire Valiant, g. g. sire Jolly Roger, dec Vork Cy. Va. 1770. Janes Shields.

_.... (Firzhugh's,) b. h. by imp'd Fearnought, dam imp'd Jenny Disma!. Chatam near Freily. 1774.

RF.INDEFF, b. c. by Arai Jam by Marske, \&c. 1828 . 
P.FMUS, [imp'd] hy Dove-Spanker-Flying Childers-out f Betsy L.ed, - (sister to Leeds,) by the Leeds Arabian, \&ic.

N. Carolina, 1777.

John Baird.

RENOVATOR, g. c. by Chichester's Brilliant, dam Indiana hy Florizelle. 1831.

H. A. Tayloe.

REPCEI,ICAN, hy True Whig, dam Young Selima sister to the noten Chatam, \&c.

William Brent.

bl. by imp'd Shark, dam by Fitzhughs' True Whig-Worm ley's King Herod-im:p'd Silver Eye, \&c.

REPUBLICAN I'RESIDENT, by imp'd Highlyer, dam by imp'd Venitias -Don Carlos-imp'd Ranger-imp'd Dove, \&c. 1805.

Isaac Duckett.

RESTIESS, [Imp'd] a dk. brown sixteen hands high, got by Phenomenon, his dain Dutchess, she by Lesang, her dam Caliope by Slouch-Oro nooko, \&ic.

Foaled, 1788.

Win. Lightfoot.

by Virginian, dain Roxana, (formerly Betsy Haxall.)

RFVENGE, ch. c. by Florizelle, dam Britannia. 1812.

Wm. R. Jolinson.

J. Tayloe. or Youvg J Asus, by Sir Archy, dam Frenzy by Gracchus.

\section{J. Randolph.}

RHODIAN, gr. m. by Ragland's Diomede, Quicksilver, imp̧'d Pantalurn, imp'd Fearnought, \&c.
Halifax Cy. 1816.
Robert Easley.

RHEA, by Chatam, dam by Eclipse, (who was the sire of Brimmer, \&c.? g. dam by imp'd Shark, g. g. dain by imp'd Silver Eye.

RICHMIOND, ch. c. by Ball's Florizelle, dam Chestmut nare by Diomede, \&c. Sold Dr. Thoruton. 1812.

J. Wickham.

RIEGO, bl. h. by Francisco, dam by imp'd Sir Peter Teazle, g. dam imp'd Castianira.

RIOT, b. h. by Sir Archy, dam by Burdett.

Hector Davis.

RINALDO, b. h. by Sir Archy, dam Miss Ryland by Gracchus.

Richard Long,

J. Randolph.

RINALDINI, ch. c. by Baronet, dam 'Temptation by Heath's Chilcters, \&o 1804.

Thos. M. Formas.

RIPLEY, ch. by Sir Charles, dam Betsy Rohinson by: Thaddeus.

ROAN COL'T, $[$ Imp'd $]$ got by Sir Peter Teazle, dam by Mercury, g. dam Cytherea by Herod, g. g. dam by Blas:k, \&c.

Foaled, 1802. Imp'd by

John McPherson.

ROANOAKE, b. h. by Sir Archy, dam Lady Bumbury by Trumperer, \&zc. 1817.

g. c. by Magic, dam Johnson's Old Merlley mare.

J. Randolph.

Jonx, b. h. hy Ravenswood, dam Flora by Am. Eagle. Essex, Va.

Jefferson Minor.

ROANOAK $\mathrm{A}$, ch. f. by Ball's Florizelle, dam Comelia by Chanticleer Vanity by Celer, \&c.

1815.

J. Randolpht

ROEBICK, by Sweeper, (son of Beaver's great Drives,) dam by imp'd Be jazett.

1733.

Otheslo.

Win. M. Wikias 
ROEBCCK, by Roebuck, (who was got by Powell's Selim, a son of (1in Selim, dan of Young Roebuck by imp'd Druid, Shark, Figure; Mask Anthony, \&c.

Bremo. Foaled, 1810. Joln H. Cocke, Sen

ROBERT BURNS, or Sir Archy, (See Sir Archy.)

by im?p'd Bedford, Hart's imp'd Medley.

ROB ROY, ch. h. by Gracchus, dam inp'd Lady Bunbury. by Sir Archy, dam imp'd Psyche.

\section{J. Randulph.}

Col: Singleton.

gr. h. by Winter's Arabian, dam by Young Baronet, g. dano by imp'd Damon, Ec.

ROBIN ADAIR, by Sir Archy, dain Lady Burton by Sir Archy.

Dr. Wm. Terrell, (Geo.)

ROBIN REDBREAST, [Imp'd] b. h. by Sir Peter Teazle, his dan Wren by Woorlpecker out of Papillon by Snap, (the dam of Sir Peter Teazle,) Woodpecker by Herod, Sir Yeter by Highflyer, Herod, Sc. Foaled, 1796.

ROBIN GRA Y, by imp'd Royalist, dam by Grey Diomede, g. dam by inıp'd St. George, Cassius, \&c.

ROBIN HOOD, b. c. by Tippno Sultan, dam Rosalia by imp'd Express, \&c.

ROCHESTER, b. c. by Aldeman, dain Thresher.

ROCKINGHAM, b. h. by OHd Partuer, dam imp'd Blossom. 1775.

Gen. Nelsol.

by Sir Archy, dam by Rattler, g. dam by Medley, (Iost hus eyes at 2 years oid.)

RODERICK, by Dare Devil, dam by Bellair, g. dam by Wildair.

J. D. Amis. 1808.

John Thornton.

by $W$ inter Arabian, dam by Lorenzo, g. dam by Blaze, Scc. Lexington, Kentucks:

RODERICK DHU, b. h. by Sir Charles, dam by Lectford, g. dam by Bei lair, Shark, Wildair, \&c.

T. Cary

RODERICO, ro. h. by mp'd Monkey, imp'd Silver Eye, imp'd mare, \&c.

RODOLPHO, bl. h. by imp'd Hob or Nob, dam an imp'd mare, foaled 1768. N. Carolina. John McDermut.

ROGER OF THE VALE, (See imp'r Jolly Roger.)

ROMAN, [Imp'd] b. h. got by Camillus, dam by Eagle, g. dam by Trumpe ter, g. g. dam by Highflyer, g. g. g. dam by Srap out of Miss Cleve land by Regulus, \&c.

Imported into N. York, 1823.

S. Willians.

gr. h. by Roman, dam Ariel's dam Empress.

b. h. by Roman, dam Pinkney's mare.

ROMP, b. f. by Leander, dam Rusalia by Express.

Sherman.

T. M. Forman

by imp'd Messenger and full sister to Miller's Damsel.

Livingsson.

RGMUL,US, s. h. by Mark Anthony, dam Pompadour by Valiant-Jenny Cameron, \&c.

Charles City Cy. Va. 1775.

Peter Dunr.

\&c. 1789.

y Ariel, Othelio

Win. Stewart.

ROLUA, by Trafalgar, dan Faucy by Jubilee.

Hanoves. la.

N. Rerkley 
ROSALBA, b. f. by Spread Eagle, dam Alexandria. 1801.

by Trafalgar, dam Rosalba by Spread Eagle.

$\therefore$ Hoomes.

ROSAIAA, b f. by mp'd Lxpress, dam Betsy Bell by Old Cub.

ROSALIE, gr. f by Knowsley, dam Calypso.

Thos. M. Forman.

ROSABELLA, ch. m. by Topgallant, dam by imp'r Play or Pay, g. diu.s by Old Bellair-imp'd Pantaloon-Janus, \&c.

Southampton Cy. Va. 1819.

James Kochelle.

ROSALINDA, gr. m. by Tayloe's Oscar, dam by imp'l Expedition-mp' I Grey Highlander-imp'd Traveller, \&.c.

New Jersey.

ROSAMUNDA, b. f. by Bedford, dam Gasteria. 1804.

Jacob Vandyke.

J. Hoomes.

ROSEMIARY, by imp'd Diomede, dam Celia by Old Wildair, g. dan Lady Bolingbroke, \&c.

ROSET'A A, by imp'd ('entinel, dam Diana by Claudius.

DoSE imp'd Dion, dam by imp'd Druid-Old Shark-imp'd Mer ley-imp'd Fearnought, \&c.

-ch. f. by Sir Archy, dam Bet Bounce by Sir Harry.

'-ch. m. by Wilkes' Wonder, dam Rosy Clack by Saltram, \&c

Tennessee.

Lewis J. Polk.

hy Columbus, dam Lady Northumberland.

L. Butler.

by Sir Harry, dam Spot by Bedford, \&c.

ROSICRUCION, b. c. by Dragon, dam imp'd Anvelina.

$\mathrm{Wm}$. Dandridge. 1803.

ROSY CLACK, by imp'd Saltram, dam Camilla by Wildair.

ROSY CAREY, by Sir Archy, dam Sally Jones by imp'd Wrangler.

KOSELLA, b. m. by Obscurity, dam Maggy Lauder. 1817.

ROWENA, br. m. full sister to Lafayette by Virginian.

Thos. M. Forman.

- ch. m. by Sumpter, dam Lady Grey by Robin Gray, \&c.

ROXALANA, gr. f. by Selım, (the Arabiau, dam Britannia by Peçasus, dec.

1806.

J. 'Tay!oe.

ROXANA, by Sir Solomon, 'dam Aurcra.

by Hephestion, dam by imp'd Archer-Dare Devil, \&c.

-by Sir Harry, dam by Saltram, g. dam by Wildair-Fearnought

-Driver, \&c.

- blood b. by Gohanna, dam Kitty Clover.

or Bersy HAXEx, by Sir Harry, dam the dam of Timoleon by Sir Archy, \&c.

ROYAL CHARIJE, dk. ch. by Arastus, dam Aurelia by Hephestion.

RUYALIST, $[$ Imp'd $]$ b. h. by Saltram, dam by King Herod, g. dam by Marske-lilank-Dizzley Driver-Smiling Tom, \&c.

Foaled, 1790. Died in Temmessee, aged 24.

ROYAL OAK, bl. h. by imp'd Othello, (or Black and All Black.) His dan was Dr. Maglather's Lovelace by Flying Childers, wear the city of Aropolis, his gr. dam an imp'd mare by Busphorus, dic.

Salem Cy. New Jersey, 1777. Wim. Riddte.

Re'STY l:OBIN, c. by Dionede, dam by Shark, g. dam Black Eyed susan, \&.c.

Thos krook

RULEK MARE, [Imp'd] by Ruler, dam by Turk, (he by Recinius, \& aar by Snake, \&d. 
YLANU, b. c by Roanoake, dam Miss Ryland. 1824.

\section{J. Randolph}

\section{S.}

SAI.LY BARONET, by Dungannon, dam bv Michan's Celer, g. daın by Celer-Old Fearnought, \&c.

- Brows, gr. by Buck Rabbit, dam by imp'l Knowsley, g. dam by Bellair, \&c.

Wm. D. Taylor.

-.. B.xxter, b. f. by Ogle's Oscar, dam Dianora by imp'd Expedition.

Thos. M. Forman.

-.-Currie, ch. m. by Matchless Diomerle, (he by imp'd Diomede,) dam by Celer, g. dam by imp'd Shark, \&c.

-Dufrer, gr. m. by Dionede, dam Forlorn Hope, \&c.

H. Macklin.

-Hopf, ch. f. by Sir Archy, dam a bay mare imp'd by Dunlop of P:? tersburg, was by Chance, and was own sister to Grimalkin, that was sold to the Emperor of Austria for $\$ 7933$, her gr. dam by Phenomenon, \&c.

Honset, b. f. by Sir Charles, dam by Hornet.

- Hapvie, by Virginian, dam an Archy mare.

Hector Davis.

g. dam l'roserpine by imp'd Dare Devil, \&c.

1818 .

Magic. (See Pandora.)

- Mark., b. m. by Carolinian, dam by Jack Andrew_imp'd Drive - Highflyer, \&c.

- Morris, b. by Superior, dam by Tom Tough-Bedford, \&c

W. D. Taylo-

- Mrlville, b. f. by Virginian, dam Bet Bounce.

- Vallor, by imp'd Wonder, dam Primrose by Dove.

Nallor, vy Spread Eayle, dam -

PanTer, gr. m. by Evans' Stirling, dam Old Silver by Bellsıze Ara bian.

- SMiтH, by Virginian, dams a Gallatin mare.

- - Szovcr, bl. m. full sister to W. R. Johnson's Star.

- Sнarк, by imp'd Shark, dam Betsy P'ringle by Old Fearnought, \&ec TAYLOR, ch. m. full sister of Betsy Robins.

S. Carolina.

TreNr, ch. m. sister to Gohanna.

B. F. Taylor.

W. R. Jolınson!.

Wussox, br. m. by Blackburn's Whip, dam by Hamiltonian by imp'd Diomede.

Wricнт, by Yorick out of a full bred mare. J. Tayloe.

WALkF, by Timoleon, dam by Dragon out of Honevcomb by Jack Andrews-Pill Box by Pantaloon, dic.

F. I'. Cortin.

- - by Muckle John, (by Muckle John,) dam Black Eyed Susan hy Por tomac.

Georglu.

J. Heister.

BALTRAM, [Imp'd] dk. b. h. fifteen hands three inches hygl, (was neas 20 years old when inp'd,) was got by Eclipse, his aan Virago by suap, g. dain by Regulus out of own sistes to Black and All Black sire of 'Tuung's Polly, \&c

Fualed, 1780

Wy ry inhtfoos 
SAI.TRAM, ᄂ, Stirling, dam Marcia by Shark. 1800 .

SALADIN, b. c. by Crusader, dam Onea by Drckon.

\section{A.ex. Spotswuori.} 1830.

James Ferguson.

SALVADOR, by Singletom's Cinymede, dam Chio by mpia Whip, y. dan Sultana by Spread Eagle, \&c.

SAMBO, ch. c. by Sir Archy, dam by imp'd Buzzard, g. dam mip d sym metry by Trumpeter.

SAM PA'TCH, by Rot Roy, dam by Telegraph,g.dam by Oscar, g.gr iaur: Riclyley's Primrose. 1826.

SAMSON, bl. h. by Traveller out of a fine English hunting mare. 1767.

John Wormler.

SANS CULOTTE, ch. s. by Old Celer, dam Logania by imp'd Nedley, doc. Charlotte Cy. Va. 1802.

Stephen Davis.

SAPPHO, by Buckskin, dau Dutchess by Hero-Brutus-Tarquin-Old Prince, \&c.

1791.

- -.- gr. f. by Tartar, dam Sultana by Spread Eayle.

SARAH JANE, ch. m. by Virginian, dain Lady Jane by Potomac.

SASSAFRAS, b. c. by Ware's Godolphin, dam Rosalia by Express.

SATE.LLITE, by Citizen, dam an imp'd mare by Waxy, imp'd by Cm Bland of Prince George $\mathrm{Cy}$.

SAUCY PAT, f. by Cormorant, dam Minerva. Eagle's Nest, 1803.

SAXE WIEMAR, full brother to Crusader and Kosciusko.

SCARIOUS, by Roanoake, dam Miss Yeyton. 1829.

SCREAMER, ch. f. by Henry, dam Lady Lightfont.

SEAGULL, [Imp'i] by Woodpecker, dam Midrilesex by Snap-Mise Cleveland by Regulus out of Midge, \&c.

Foaled, 1786.

B. Grymes. - by Sir Archy, dam Nancy Air by Bedford. Kentucky.

SECOND DIOMEDE. (See Diomede Second.)

SELAH, dap. gr. by Bussora Arabian, dam by imp'd Messenger out of a full bred mare.

FELIMA, by Topgallant, dam Jack Bull by Gabriel.

C. W. Van Ranst.

-s. m. by Spread Eagle, dam Virago by Shark.

T. Murpliy.

bl. n. by Old Fearnought, dam imp'd Selima.

J. Taylpe. - by mip'd Othello, dam imp'd Selina, \&c. 'Julip Hill.

Samuel Galloway. -ch. s. m. by Dandridge's Fearnought, dam by Bolton-MonteyDirt, dec.

b. m. by Yorick, dam bl. Selima, (by Fearnought.)

Walter Colrs.

(Taskr.n's) [Imp'd] was by the Codolphin Arabian, dam by U10 Fox-Flying Childers, sc.

Foaled, 1772 .

- Yonvi. (See Young Selima.)

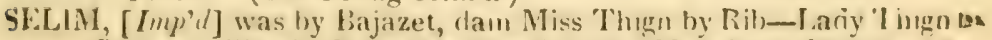
Partuer-Bloody Buttocks-(ireyhound-Mahreless-brimmer, tr Foaled, 1760 . 
SELIM, dk b. h. by Othello, (or Black and All Black, dam Selim mare dic.

$17 \% 0$

Gailoway.

-. Marf, jet slack, by imp'd Selim-imp'd Hod or Nob-imp'd Evans Stirling-imp'd Merry Tom-imp'd Bucephalus out of a thoronga bred mare, \&c.

North Carolina. Foaled, 1774. Died, 1781.

- gr. h. (See Aratwan Selim.)

SENECA, by Olyl Rattler, dam Cora by Brown's Godolphin. Georgetow'11, D. C.

G. W. Peter.

SENATOR, b. c. by imp'd Paymaster, dam Tulip by Lindsay's Arabian

SEPTIMA, [Imp'd] by Othello, dam Moll Brazen hy Shark, \&c.

SEPTIMUS, ch. c. by Gohama, dam Vixen by Tiafulgar.

SERAB, [Imp'd] by l'hantom out of Jesse, hy Totteridge, \&c. : her dam

Cracker by Hightlyer, out of Nutcracker by Matchem-Regulus-

Crali-chilciers-basto, \&c.

Foled, 1821.

S. \& I. Coffin

Sold in England for $\$ 14,000$.

SEVERITY, by Napoleon, dam by old Pacolet.

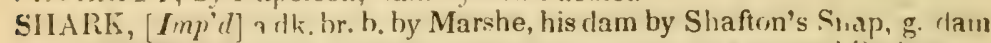

by Nartbornugh, (brother to Babraham, out of a natural Barb mare. Foaled, 1771:

Nottingham near Fredg. Va. 1767.
br. h. by Sir Andrew, dam Kitty by imp'd Whip.

MARE, by inp'd Shark, dau _-

1793.

-bl. c. by American Eclipse, dam Lady Lightfoot.

Alex. Spotswout. 1830.

MArf, ch. by Shark, dam Fetnah by Grey Diomede-OLd Medley

E. Branch.

SHAKSPEARE, dk. br: h. by Baylor's Fearnought, dam Stella by Othel lo, \&c.

1777.

Rolert Baylor rlap. gr. h. by Baylor's Fearnought, dam imp'd, was by Cub, a son of Old fox, \&c.

North unberland, Va. 1776.

P. P. Thornton

b. h. by Virginiar, dam by Shenandoah, hy Potomac.

SHAWNEE, by Tecumseh, dam by Citizen, full sister of the dam of Ma rion.

SHENANDOAH, by Potomac, dam Hill's hay mare by imp'd Febrifuge-Grey Diomede-Wildair, \&c.

- gr. c. by Pilgrim, dam Sivan by imp'd Eagle.
1828.
J. Randolph.

SHEPHERDESS, bl. m. by Swerper, (by Hamilton's Figure, dan b? 'Tasker's Othello-Morton's Traveller, \&c. 1829 .

T. J Hallson.

- s. m. by Phenomenon, dam by imp'd Dionede-imp'd Shark-imp'd Medley, \&s.

Richard Adams. by imp'd Slim, dam Shrewsbury by Old Figure, g. dam by Dove-Selima by Othello, \&c.

New York.

sHOCK, [ Imp'd] b. h. by Jig, dam by Snake, (irey Wilkes by IIautboy, Miss D'Arcy's Pet mare, daughter of Sedbury Royal mare. Foaled, 1729.

BHOWMAN, hy imp'd Fearnought, dam imp'd Jenny Dismal 
SHRE WTSBRY, by Hamilton's Figure, dam Thiste by unp'il lonve, s daın Stella by imp'd Othello.

-_ N N mare by Babraham.

1784.

T. M. Forman.

SHYLOCK, b. h. by imp'd Bedford, dam by Old Diomede, g. dam by imp'd St. George, Feamought, ! olly Roger, \&c.

Edm. Irby.

MARE, by Shylock, dam by Sting, g. dam Cades by Wormley's King Heror! by imp'd Fearnought, \&c.

SIII HANIET, br. h. by Virginian, dam Lady Burton by Sir Archy, \&c. Foaled, 1825.

SIGNORA, b. f. by Roanoake, dam Miss Peyton.

1824.
SII,K STOC

S. Davenport. Consul.

SILVER, [Imp'l] dap. gr. by Mercury, (who was by Eclipse, ) dam by He. rod, g. dam Young Hag by Skim, Crab, Childers, Basto, \&c." (Did not succeed as a stallion.)

MARE, [Imp'd] by Belsize Arabian. Surry Cy. Va.

John Drew.

Wm. Evans.

SILVER EIE, [Imp'd] got by Cullen Arabian, dam by Curwen's Bay Barb, Curwen Spot, White Legys, \&c.

ch. h. by imp'd Silver Eye, dam an imp'd mare.

SILVER LEGiGs, by Morton's Traveller, dam Jemny Caneron, \&c. 1770.

SII,VER HEELS, dap. gr. by Ogle's Oscar, dam Pandora by Grey Dio mede.

Robert Wright.

by John Richards, dain by Sir Solomon, g. dain Trumpeter. N. J. 1828.

J. Davison.

hy Jolly Friar, Whitacre's Mark Anthony, Lee's Old Mark Antmony, Spadille, imp'd mare.

SILVER TAII, by imp'd Clockfast, dam Young Primrose by Wormlev's King Herod, \&c.

by Sir Archy, dam Coquette.

$18-29$.

Thos. Branch.

by Old Tanner, dam by Selim, Panton's Arabian, \&c. 1781.

SIR ARCHY, or ROBERT BURNS, b. h. by Old Diomede, dam imp'd Castianira.

J. Tayloe.

Aucur, jun. b) b. by Sir Archy, dam by Alhemarle, (sun of Diomedo) our of l'enelope by Shark.

Arсну, b. h. by Sir Archy, dam Transport by Virgi, ıus, \&c. Kéntucky.

Ameny Young, (See Young Sir Archy.)

William Dickey

Aним, (Moore's, by Amis' Old Sir Archy, dam by Litt?e Drues. imp'd Bay Richmond, Janus mare, \&c.

- Archy Mostano, by Sir Archy, dam Traısport by Virgm,us

- Aarox, ch. c. by 'lormentor, dam by Revenge.

Axnkirw, gr ly Marste, (by Old Diomede, dam Virago by mụ'd

Whip, l'altuer, ic.

(ieorgia, 1\&16.

'oh) T" te:nas. 
SIR ANDREW o c. by 'Thomas' Sir Andrew, dam Blach Eyed St san by Potomac.

A rтиuk, by Sir Archy, (Old,) dam Green's Old Celer mare, \&c.

Anthur MAre, ch. by Sir Arthur, dam Sally Nailor.

W. R. Johnson.

AlBf.re, by Rattler, dam Laura by Col. Lear's imp'd Barb horse.

Alrked, g. by Sir Andrew, dam Lady Alfied, (Haxall's) dam o Waxey, \&c.

Alfred, b. by Sir Harry, darr Lady Chesterfield.

George A. Rudo.

Alared Youxg, (See Young Sir Alfred.)

Wm. Haxall.

Bolisgrokr, by Selden's Old Superior, dain by Hyde's imp'd Pie tender, Highflyer, Shark, \&c.

Charles Pinckney, by Sir Charles, cam Pawnee.

H. Campbell.

-Charles, ch. by Sir Archy, (Old,) dam by imp'd Citizen, g. dam by

Commutation, imp'd Dare Devil, imp'd Shark, inp'd Fearnought.

Charles, ch. by Duroc, dam Maria Slamerkin.

W. R. Johuson.

Charles, by Robin Adair, dam Black Eyed Susan by Potomac, \&c

- Dudeey, ch. c. by Rob Roy, dam an Oscar mare.

James Hester.

- Simmes.

-HAL. br. by imp'd Sir Harry, dam by imp'd Saltram, g. dam by imp'd Medileý, Young Aristotle, dcc.

- Harry, [Imp'l] br. by Sir l'eter Teazle out of Matron by Alfred, g. dam (dam of P'ilot, ) by Marske, Regulus, Steady, P'almer, Grey hound, sc. foaled, 1794.

Petershurg.

Wm. Haxall.

- Harr, ch. by Bussora Arabian, dam imp'd Maria by imp̣'ci I.ively. Selin, \&c.

Van lianst:

- -

Halifax.

- - - Henrr, by Pacolet, dam Madam Tonson.

J. Nelmes.

- Humprex, by Old Tickahoe, dam the dam of Maryland Eclipse.

J J AMs, dk. bl. b. by Sir Archy, dam by Diomede; Pilgrim, Old Fear nought, \&c.

- Jonv Mooke, by Young Bedford, dam by Melzar, g. dam Betsy Ba ker by Medley, \&c.

-Loveli, b. h. by Duroc, dain Light Infantry by Messenger.

Prer 'TFazle, [Imp'd] b. h. by Old Sir P. Teazle, dam Lucy by Con ductor, Spectator, Blank, Flying Childers, \&c.

- Peтr. by imp'd knowsley, dam by Bellair, Wildair, Vampire, imp'd Kitty Fisher, dcc.

- - Peter, br. h. by John Stanley, dain Lady Chesterfield.

-Pexton, by Shylock, dam by Citizen.

- Rosis, by imp'd Robin Redbreat, dam by imp'd Dare De il, Shark, A pollo, \&c.

- - Richañ, gr. h. full brother to Monsieur Tonson by Pacolet, Ec. Temussee, 18:30.

Richart, by Sir Archy, dam Lady Jame, g. dam Anveliua.

- Somonos, loy imp'd T'ichle 'Tolsy, clan Vesia by Deraduought, Clock fast, dic. Died $\mathbf{1 8 2 9}$.

1305

James Nackliu

_ Somomon Younc, (See Young Sir Solomon.) 
SIK WITLIAM, by Amazom, dam Plack Eyed Susan by Iotomac, Sic. WיLı , ch.'th. (Clay's) by Sir Areliy, dam by Belliair, g. dam by Jil grim, \&ic.

William, by Sir Archy, dam Transport by Virginus, \&c.

L. Long.

Wrim.1 W.r.ace, by Sumpter, dam by Whip (of Keuty.)

WM. W'ALLACE, ch. h. by Oscar, dam

Van Meter.

W. W. WLACF, by Kosciusko, dam l'jamingo, her dam Lee's O I Va. mare.

Kentucky.

SIMON PURE, bl. h. by Sir Archy, dam Philadelphia.

E. M. Blacliburn.

SKIM, (Alias Fakmf.r or Lord Portmores' Skim,) [Imp'd] gr. by Sturlirg out of Miss Mayes by Bartlet's Childers.

Foaled, 1746.

SKY LEAPER, br. b. by Sir James, dam Vixen by Trafalgar.

- Scraper, by Lamplighter, dam Miss Doe.

S A AMERKIN, (See Maria Slamerkin and Maggy Slamerkin.)

\section{Ailens}

SLF VDER, [Imy'l] b. hy King Herod, dam Rachel by Blank, g. dam by Regulus, Sore Heels by Basto, Make!ess, \&c. Foaled, 1779.

Sans Souci, N. Y.

- b. m. by Sir Charles, dam Reality by Sis Archy.

W. R. Johnson.

SLIM, [Imp'd] a dik. ch. by Wildman's Babraham, dam by Roger's Balıra liam, g. dam by Sedhury out of Ebony, \&c.

Marcus Heok, N. Y. 1775.

A. Dick.

SLOVEX, $[$ Imp'd $]$ bl. h. foaled 1756 by Cub, dam by Bolton Sterling, Ga dolphin Arabian, Bonmy Black, Sce.

SLOE, by imp'd Partuer, dam (Nelson's) imp'd Blossom.

Thos. M. Forman.

SLIP JOINT, b. c. by Messenger, dam Temptation, g. dam by Heath's Childers, \&c.

SMILAX, ch. m. by Grey Dinmede, dam Atalanta by Old Medley.

Jan!es Blick.

SMILING BILLY, by Ariel, dann by Tasker's Othello, g. dan uy Spark, \&c. 1767.

H. Duvall.

SMILIX(; TOM, ch '. hy' Coeur de Lion, dam Betsy Baker by imp'd Spark, dic.

1806.

1775.

SNAP, by imp'd Figure, dam Gien. Heril's Netrle.

SNAP DRAGON, br. h. by Collector, dam by Fearnought, Spadille, Fa bricius, \&c.

Foaled, 1798-9.

SNIP, gr. c. by Roanoake, dam Blue Ruin.

J. Tayloe.

by Oscar, dam Britamma, \&c.

J. Rancospa.

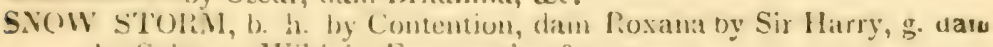
by Saltrain, Wildair, Feanought, Sc.

Foaled, 1825.

SOL.DHER, ch. c. by Bedford, dam Raffle by Bollair.

1803

E. Warnelr!, (Keuty.)

: Houmes 
SUPIfY WINN, b. m. by Blackburn's Whip, dam by Buzzard, g. dam by Columbus, Celer, \&c. 1822.

E. Warfield.

SOI RKROUT, [Imp'd] b. by Highfyer, dain Juvell by Squirrel, Sophia by Blank, out of Lord Leigh's Diana by Second, \&c. Foaled, in 1736. Stood in Tennessee.

SUUTHERN ECLII'SE, (See Eclipse Southern.)

SPADILLE, [Imp'l] by Highflyer, dam Flora by Squirrel, Angelica by Snap, Regulus, Bartlet's C'hilders, \&c. 1784.

SPANGLOSS, by (Winstou's) Junius, dam by Jolly Roger, g. dan by Feamought, \&c. 1797.

Benj. . Toller.

SPARK, [Imp'd] was imp'd by Gov. Ogle, and given to him by Lord Balti nore, who received him as a present from Frederick, Prince o. Wales; Spark's dain was Miss Colvill.

SPANKING ROGiER, by Jolly Roger, dam imp'd Jenny Dismal.

SPECIMEN, by Old Fearnought out of Jenny Dismal.

SPECULATOR, [Imp'd] br. h. by Dragon, dam sister to Sting by King Herod, g. dam Florizelle's dam by Cygnet, g. g. dam by Cartuuch, g. g. g. dam Ebony by Childers, \&c. Foaled, 1795. Keutucky.

R. J. B. 1795.

SPIRANZA, own sister to Saltram by Eclipse.

SPO'T, [Imp'd] (See Young Spot.)

-by A pollo, dam Jemny Cameron. try, sc.

ch. c. ly Shylock, dain by Buzzard, g. dam by imp'd Synmo -by Bedford, dam by Cade, g. dam an Alfred main

SPOT MARE, Imp'd] gr. by Lockhart's (irey spot, dam by 'T'raveller, $g$. dain by Sedbury, Cartouch, Bartiett's Childers, \&c. Iny'd 1765. South River.

John Craggs.

SPORTSMAN, b. h. by Bussora Arabian, dam Sportmistress by Hickory, \&c.

Boston.

Ed. Eldridge.

bl. h. by Galloway's Selim, dam by imp'd Dove, g. dam by Othello out of T'asker's Selima.

Prince George Cy. Maryland. F. Bowie.

SFORTMISTRESS, g. m. by Hickory, dau Miller's Damsel by Messenger, \&c.

Queens Cy. N. Y. 1818.

Thos. Pearsall.

SI'RF.AD EA( 'LLE, [Imp'd] by Volnnteer, (one of the best sons of Exlinse? his dam by Highfyer, Engineer, Carle, Lass of the Mill by Old 'Tra veller, Young Greyhound, \&c. Foaled, 1792. Bowling Green, Va.

SPRITE ch. f. by Sir Wilnam, dam Maria Archy.

SPRLVG HiLL, by Sii Archy, dam Miss Monroe by Precipitate, \&c.

SQUIRTII.IA, b. f. by Buxer, dam Louisa by Eclipse. 1796.

STAFFURI), (See Ratler, alias Stafford.)

J. Tayloe

S'I'ANLEY, by Sober Johu, dam imp'd mare.

STANDARD, b. c. by Sir Archy, dam au Archy mare. 1895.

J. Hooines.

STAR, (Jmp'a dk. b. hy Highflyer, dam by Snap, g. dam by R:ddlo by

Wray \& Simnie. Ma:cinem. Foaled 1785 Died 1811. 
STAR, b. h. by Virginian, dam Roxana by Sir Harry.

STATELY, by imp'd Sober John, dam imp'd Strawbery.

Wm. R. Joinson.

STATIRA, [Imp'd: ch. m. by Alexander the Great, (sister to Lycurgus b Buzzard,) Rose by Sweetbrier-Merleton by Snap. Foaled, 1809.

S'TELLA, b. f. by Marplot, dam Betsy Baker.

J. Randolph. by Tasker's Othello, dam Selima, (sister of Galloway's Sel.111.)

STERNE'S MARIA, by (Gibbs') Carlo, dam by Ridgley's Cincinuatu-I. Beard's Badger out of Black Snake, \&c.

STEUBE.V, by Kosclusko, dam Irvina by Virginian-Pandora by Bellair, \&c. 1825.

J. Ferguson.

STOCKHOLDER, b. by Sir Archy, dam by Citizen-imp'd Stirlin-Harris' Eclipse, \&c.

\section{b. h. by Sinckholder, dam Bryant's Diomede mare.}

Mare, by Stocktiolc!er, dam Pautaloon, g. dam by Magng, \&. c.

S'TORM, b. c. by Commrant, dain Darlington mare by Darlington, \&c. 1799.

$J$. Huones.

Sr. GEORGE, [Imp'd] br. b. fifieen hands three inches high, foaled 1789 , was got by Highflyer, fam by Eclipse-Miss Spindle Shanks by Oman-Godolphin Arabian, \&c.

ST. TAMMANY, full brother to Florizelle.

Alex. F.'Rose.

Sr NI'CLAUS, b. c. by Roanoake, dam the dain of Arch Dutchess.

J. Randolph.

Sr. PAUL, [Imp'd] ch. h. by Saltram, dam Purity by Matchen, uut of the Old Squirt mare.

Foaled in 1791. Imn'd tn Va. 1804.

Harris.

STING, by Jack Andrews, dam Mirigold by Dungamron, out of a thurount. bred mare.

STIRLING, [Imp'd] b. h. by Volunteer, dam Harriet by Highflyer, $\mathrm{g}$. dam by Young Cade, g. g. dam Childerkin by Second, out of the dam of Old Snap, \&c.

Foaled, 1792.

J. Hoomes.

[ Imp'd] dap. gr. by the Belsize Arabian out of Mr. Simpson's Snate nare, she by Snake nut of the Duke of Cumberland's famous mare, dam of Cato, sc. Foaled, 1762.

Surry County, Va. $1768 . \quad W m$ Evans. Balt. 1787.

MARE, by Stirling, dain imp'd Mambrino.

WII. Patterson

J. Ferguson.

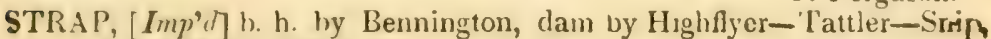
sc. Foaled, 1800.

Nerth Carolina, 1808.

H. Cotton.

STRE'TC'H, gr. f. by Putsos, dain Thresher by Shark.

S'IUMI' 'THE DEALER, by Old Diomede, dain by Shark 1804 .

Tros. Hamlin.

by Bryan O'Lynn, dam by Grey Diomede-Olo Wildair-Spadille-Old Janus, \&c.

SUKEY 'TAWIORY, b. f. by imp'( Stirling, dam Nancy Medley. King Geo. Va. 1800.

Charles Stuart

SUL'TANA, by Black Sultan, dain Barb mare.

by Spread Eagle, dam Orelia og Percy.

S. Carolina.

J. W. Eppes

34 *

Ru h. A. Raples 
SI. I.TANA, by Wildair. Delancy.

SUMPTER, ch. by Sir Archy, dam by Robin Redloreast, own sister to the dam of Ratter-Flying Childers, \&c.

SIJPERIOR, by (Cook's) Whip, dam a Union mare. Ken,ucky.

E. M. Blackburn. 1811.

J. M. Selden.

MAre, gr. by Superior, dam by Quicksilver, g. dam oy imp'd Shark, \&c.

West Teunessee.

R. C. Dickincon

SURPRISE, by Old Sir Solomon, dam Potter's Oscar, Jun. by Ogle's Os car. ch. c. by Americus, dam Calypso. Foaled, 1801.

Wm. Alston

SUSAN, ch. m. by Bond's Sir Solomon, dam Columbia by imp'd Baroner -Old Cub-Partner, \&c.

SUSAN FA VOURITE, gr. m. by Sir Hal, dam Wynnes' Young Favourite by Bedford.

SUSAN MARY, b. m. by (Cook's) Whip, dam by Buzzard, g. ciam Porter's fine mare.

SUSANNA, ch.m. by Multnomer, dam by imp'd Knowsley, g. dain by Boxer-Symmes' Wildair-Old Janus.

Wm. D. Taylor.

SUSSEX, by Sir Charles, dam a Sir Harry mare, dam of Kate Kearney, S.c.

J. M. Selden.

SUWARROW, b. by Columbus, dam by imp'd Venitian-imp'd FigureSlamerkin by Wildair, \&c.

SWEEPER, by imp'd Figure, dam by Tasker's Othello-Morton's Traveller-Tasker's Selima, \&c.

Prince Geo. Cy. Maryland, 1780.

Joseph Pience.

Imp'd ] bl. by Sloe, rlam by Mogul-Partner-Coney' Skins, \&c. Foaled, 1751. limp'd into N. C.

SWEET ERIN, ch. f by American Eclipse, dam Maria Slamerkin, \&c. New Jersey, 1829.

Dr. E. A. Darcy.

§WELT SURRY, by Spadille, dam by Janus, g. dam by Jolly RogerMlonkey, \&c.

SWEETEST'WHEN NAKED, gr. m. by Tattersall's Highfyer in England, dan gr. m. Virago, imp'd by Mr. Hyde. (She was foaled in Anerica, and bred by Alexander Spotswood.) 1817.

SYLVIA, b. f. by Spencer's Moreau, dam Romp by Leander.

$$
\text { J. Tayloe. }
$$

SYLPH, b. c. by Roanoake, dam Witch. 1828.

SYREN, ch. f. by Silver, dam Caroline by Eclipse.

J. Randolph. Tennessee, 1800.

\&YMME'TRY, [Imp'd] ch. m. bred by Lord Clermont, fnaled 1799, got by Trumpeter, dam Young Doxy by lmperator, g: dam Old Doxy iy King Herod.

- - b. f. by Gibbs' Flimnap, dəm Bri'.iz.st mare. 1789.

I.

IALMA, gr. c. by Henry, dam Sportr. o!r.ss + y liskury.

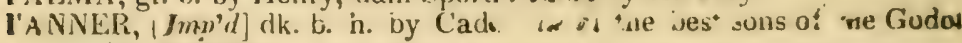
puir Arahian.

176i.. Marvland

Dan Violstriliolino 
TANNER, by imp'd Tanner, dam Camilla by Othello

'TAKE IN, b. c. by Gracchus, dam Young Frenzy. 1823.

TALLYHO, by Tuckahoe, dam by imp'd Diomede.

J. is Raniolpe

T ARIFF, dk. b by Sir Archy, dam Bet Bounce.

Win. R. Johnson.

TARTAR, go c. by Winter Arabian, dam Young Buzzard mare.

by Diomede, dam by Celer, g. dam by ump'b Bay Richmond. Amelia, Va.

James Hill

b. c. by Bedford, dam Atalanta by Dictator.

Foaled, 1805.

MARE, by Flimnap, dam by Old Pharaoh, g. dam imp'd by M

Fenwicks, sen. got by Tartar-Young Sweepstakes.

Foaled, 1780.

Edw. Fenwick.

'TECLNSEH, by Sir Archy, dam the imp'd Gamenut mare out of Alls grante by Pegasus.

by Rob Roy, dam Thistle by Oscar.

A. J. Davie.

by Florizelle.

Dixon.

TELEGRAPH, $[$ Imp' $d]$ br. h. hy Sir Peter Teazle, dam Fame by Panta loon out of the dam of Diomede by Spectator, \&c.

Foaled, 1795.

Baldock. ingham, \&c.

King Wm. Cy. Va. 1800.

Wn. Anderson.

- by Old Wildair, dam Lagonia by Medley.

J. Randolph.

\&c.

- y imp'd Spread Eagle, dam inp'd Janette by Precipitsta

TELEMACHUS. by Old Diomede, dam by imp'd Dare Devil, g. dam bj Commutation-Damon, \&c.

Brunswick, Va.

Merrits

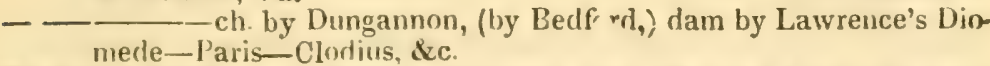

TEMPTATION, b. by Heath's Childers, dam Maggy Lauder by imp'd Fearnought, \&c.

1786.

T. M. Forman.

TERROR, by Janus-Mark Anthony-out of an imp'd mare. br. c. by American Eclipse, dam Lady Lightifoot. 1829.

Stephens.

THADDEUS, by Ball's Florizelle, dam Dare Devil mare, g. dam wy Uld Wildair, \&c.

Eider. Irby.

THALESTRIS, gr. f. by Elliot's Jerry, dam Comelia Bedford by the louko of Bedford, \&c.

THISTLE, by imp'd Dove, dam Stella by imp'd Othello, g. d. Tasker : Selima.

- ch. m. by Oscar, dain by imp'd Clifden. Pr. Geo. Maryland.

E. B. Duva.1

rHOR, $\mathrm{b}$. h. by Diomede, dam by Wildair, g. dam by Clockfast. fec.

THORN, b. c. by Sir James, dam Nettletop.

Philip Rodgers.

THORNTON MEDLEY. (See Medley Thonnton.)

T'HRESHER, gr. m. full sister to Opossum.

Messrs. Tavloes.

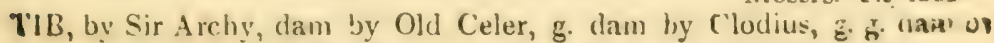
imp'd fearnought, \&c. 
TICHICUS, sh. c. by Cliftnn, dam Miss Chance by Chance, \&c.

TICKLE 'TOBY, [Iinp'd] br. foaled 1785, got by Alfred, dain Celia by Ho rod, out of Proserpine by Marske, \&c.

TIMOLEON, ch. c. by Sir Archy, dam by imp'd Saltram-Old WildairDriver, \&c.

by Grey Diomede, dam Bonny Lass.

(Called Timoleon of Maryland.) 1830.

TIGFR, by (Cook's) Whip, dam by Paragon, imp'd Figure, \&c.

IIPPOO SAIB, gr. h. by Old Messenger, dain imp'd mare-(Thompson's) Northumberland.

_- - by Lath, dam Brandon by Aristotle, \&c.

1780.

-by Lindsay's Arabian, dam Lady Bolingbroke.

Sultan, b. h. by Tippoo Saib, dam Rosetta by Bajazett.

TOBY, [Imp'd] ch. h. by Old Janus-Old Fox-Bald Galloway, \&c. To by was full brother to Old Janus, \&c.

N. Carolina.

b. c. by Cannon's Ranger, dam Sally Baxter. 1822 .

Col. Alston.

T. M. Forman.

IOKEAH, ch. f. by (Dr. Thornton's) Don Juan by Rattler, dam Frederica oy Escape, (Horn's.)

r. K. b. m. by a son of imp'd Wonder, dam Similax.

1818.

Messrs. Tayloes.

rOMASIA, by Young Alfred, dam ny Old Tom Tough-Lamplighter, \&c.

IOM JONES, [Imp'd] gr. h. fifteen hands high, by Croft's Partne-True Blue-Cyprus Arabian. Foaled, 1745.

Richmond County, Va. Sir M. Beckwith.

James Blick.

Maryland, 1764

TOM, by imp'd Eclipse, dam an imp'd mare.

TOM TOUGH, ch. c. by imp'd Escape, (Horn's,) dain Fairy by Bedford, \&c. - Marf, by Toin Tough, dam by Lawrence's Diomede, g. dam by Lamplighter, \&c.

rOM TACKLE, br. c. by Archduke, dam Fairy by Bedford. 1805.

'IOM PIPER, by Janus, dam Ethiopia by Bedford, (he by Teller's Bedford, g. dam by imp'd Bedford.

TOOTH DRAWER, b. c. by Dare Devil, dam Virginia by Medley, \&c.

TOPAZ, ch. c. by Rob Roy, dam Flora by Ball's Florizelle.

J. Hoomes. 1826.

D. c. by Roanoake, dam Jet. 1828.

Joseph Lewis.

TOPrALLANT, b. h. by imp'd Diomede, dam by Shark-Harris' Eclips - Mark Anthony-Janus, \&c.

Fualed, 1800.

J. Taylne. All Black, (or Othello.)

Doy imp'd Druid, dam by Bedford, (sire of Rosabella.)

TORPEDO, by Sir Alfred, dam by Potomac out of the dam of Madison and Monroe.

TuU(!ISTONE, [Imp'd] by Clothier, (by Natchem) out of Rethell's mare Pist-Riot by Regulus-Matchem by Cade out of a l'astue, maro, \&. dau's side uot givel. 
TRANSPOF $T$, br. 1. by Virginius, dam Nancy Air. 1812.

J. B. Richardson

TRAFA LGAR, by imp'd Mufti, dam Calypso, sister of Eellair.

TRAFFIC, g. by Sir Charles, dam Sally Brown.

Lewis Berkley.

Thomas Doswell.

TRA VELLER, (Morton's) [Imp'd $d]$ b. h. by Partner, who was a grantisas, of the Byerly 'Turk-Traveller's dain was by Bloody Butto:ks, an Arabian, Greyhound, Makeless, \&c.

Richmond Cy. Va. 1754.

Foaled, 1748.

-(Strange's, $[$ [Imp'd] was by Eclipse, see Charlemont, \&c.

-(Lloyd's, by Mortou's 'T raveller, dam Jenny Cameron

mare. gus, \&c.

(Burwell's,) by Morton's Traveller, dam by Jauus, Lycurch. h. by Sir Charles, dam by Sir Archy, g. dam Whaley"d imp'd Sunfower.

1701 (Young,) by Morton's Traveller, dam Miss Colville.

1761.

Col. Tasker.

TROUBLE, ch. c. by Duroc, dam Sportmistress, ¿̀c. 1821.

TROUbLESOME, b. c. by Monsieur, dam Jenny by Archoluke.

'TRIPSY, by Figure, da+n Homespun by Romulus, Venus by llero, \&c. 1800 .

TRIMINER, by Hall's Fclipse, dam by imp'd Slim, Old Figure, \&r. Prince George, Md. 1791.

Wim. Lyles

TRISTRAM SHANDY, by Morton's Traveller, dair. vy Oid Jainus Ou: o. a fine English mare.

Caroline Cy. Va. 1777.

TRUE WHIG, by Fitzhughs' Regulus dam, dam of A pollo.

TRUE BLUE, [ Imp'd $]$ b. h. by II alume, dam liy King Fergus, Celia by llerod out of Proserpine by Marske.

Foaled, 1785.

James Turner John, Messenger, \&c.

TRUE BRITON, b. hy Tasker's Othello, ram Milley by Spark, and was full sister to Col. Hopper's Pacolet, her dam Queen Nal). 1761.

TRUFFLE YOUNG, (See Young Truffe.)

TRUMIPE.T"TA, [Imp'd] b. m. by Trumpator, dam by Highfler, g. dam by Eclipse out of Vauxhall's clam, who was by Young Cade. Foaled, 1797.

J. Tayloe

- by Hephestion, lam P'ergy by Bedford, g dam imp'd l'eggr by Trumpator, \&c. 1816.

TRUMP'ATOR, b. c. by Dragon, dam imp'd Trumpetta. 1804.

J. Tay'ne. Kentucky, 1829.

T'RUMP, ch. c. by Janus, dam Last Chance.

TRUX'TON, b. c. by Old Diomede, dam Nancy Coleman.

Samuel Davenpor:

TRY ALL, by Morton's Traveller, dam Blazella.

Ancirew Jackson

TRY, b. m. by imp'd Wonder out of a Chanticleer mare. 
CUCKAHOE, by Florizelle, dam oy ımp'd Aldermar, g: dam by Cloce fast, \&c. Va. 1827.

J. Wick:ıain.

- b. h. by Tuckahoe, dam by imp'd Expedition, imp'd S'cr. Jer, Herd's Suap, \&c.

N. Jersey.

Corns. Cruser.

IUBEROSE, ch. f. by Timolenn, (sire of Sally Walker, dam Rhodian by Radland's Diomede, \&c.

TULIP, ch. by Lindsay's Whise Arabian, (Ranger,) dam by imp'd Othello, g. dam by Gorge's Juniper, \&c.

1782.

1830.

TURK, bl. c. by Arab, dam by Florizelle, g. dam Maria by Bay Yankee, \&uc.

TUP, [Imp' $d]$ b. h. by Javelin, dam Flavia by Plunder, out of Miss Euslace by silap, \&c.

Foaled, 1796.

TWIG, by imp'd Janus, dam Puckett's Switch, also by Janus.

Thomas Hudson.

\section{U.}

[NCAS, ch. c. by Sir Archy Montario, daın Leocadia by Virginius.

$\frac{1828 .}{1827 .}$ ch. c. by Stockholder, dam by Powhatan.

- 1827 . ch. c. by Stockholder, dam by Powhatan.

J. B. Richardson.

CNION, (Hall's, by imp'd Slim, dam by imp'd Figure by Dove by Othello, out of 'Tasker's Selima.

1777.

Dr. Hamilton.

(Chesley's,) b. h. by Shakspeare, dam by Noupareil, g. dam by Norton's Traveller, \&cc.

1783.

[NCLE SAM, b. by John Richards, dam Sally Baxter by Oscar, imp'd Expedition, Old Cub. 1828.

Thomas.M. Forman.

UPTON, b. c. by May Day, dam Jesse by Telegraph.

C. S. W. Dorsey

\section{V.}

VALERIA, b. f. by Nonsieur Tonson, dam Betsy Wilkes, \&c. 1832.

G. A. Blaney.

VALENTINE, [Imp'd] by Magistrate, dam Miss Forester by Diomede, Alexander, the dam of Captain Absolute by Sweet William. 1826.

Thomas Connagh.

VALIANT, [Imp'd $]$ got by Dormotse, dam by Crab, Partner, out of Thwrait's dun mare.

V ARIFTY, b. f. by Wilkes' Potomac, dam Dutchess by Bedford, g. dam Thresher.

VAMPIRE, [imp'd] by Regulus, dam by Steady, son of Flying Childers, \&c..

Foaled, 1757.

b. c. by Bedford, dam Britannia by Wildair.

VA viTY, b. t. by Sir Archy, dam by Old Medley, (full sister of Reality, (broke her neck on New Market track.) Eye, \&c. 
VANSICKLER, (Bela Richards;) b. c. by John Richards, dam Coven mare oy Am. Eclipse.

VAN TROMP, by Sir Hal, dam by Coeur de Lion.

VELOCITY, by Rob Rov, dam Simmes' (Mab) bay mare by Ogle's Oscar, g. dam Edelin's Floretto, dcc.

1827.

VILLAGE MAID, full sister to White Stockings by Silver Heels.

VENITIAN, ch. h. by Rob Roy, dam Maid of Patuxent by imp'd Magic, g. dam Kitty Fox by Fox, and he by imp'd Venitian, \&c.

Simms.

$\left[I^{\prime} d\right]$ b. c. by Doge, dam by Matchem, her dain by Smals Bones, sister to Squirrel.

Foaled in 1774 .

N. B. This horse was sent back to England.

VESTA, by Dreadnought, dam by Clockfast, Americus, Traveller, \&c.

VESTAL, dk. br. f. by Monsieur Tonson, darn Fair Forester by imp'd Cliance, \&c.

VETO, ch. c. by Contention, dam Columbia by Sir Archy.

VICTOR, ch. by Contention, dam by Minor's Escape, g. dam by Sans Cu lotte, Mahomet out of a thorough bred mare.

VICTORIOUS, by imp'd Fearnought, dam by Clevis, (he by Fearnought,; g. dam by Hunting Squirrel. Imp'd by Gen. Nelson.

VIGNETTE, ch. f. by Sir Richard, (hy Sir Aichy,) dam Desdemona by Virginius, \&c.

J. B. Richardson.

VIOLET FAME, by Contention, dam by Tom Tough, her g. dam by Strange's 'Traveller out of a full bred Wildair mare.

VINCENTA, by imp'd Mlessenger, dam by imp'd Slender, g. dam by imp'd Lath, \&c.

VIOLA, gr. f. by Gallatin, dam Clio by imp'd Whip. 1820.

Wade Hampton.

VIOLANTE, ch. f. by imp'd Young Peter Teazle, dam Selima by Spreasl Eagle, \&c. $1809 . \quad$ J. Tayloe.

VINTZUN, by imp'd Diomede, dain Maria by Clockfast, Maria by Regu lus, \&c.

(Siold for $\$ 2,750$.)

Gov. Lloyd.

VIRAGO, [Imp'd by Star, dam Virago by Panton's Arabian out of Crazy by Lath, which was sister to Snip, \&c. Orange Cy. Va.

Robert Young. ch. m. by imp'd Shark, dam imp'd Virago.

Foaled, 1791.

J. Tayloe. -ch. m. by Wildair, (who was by . Ijax, ) dam by imp'd Hars ilton, g. dam by Spread Eagle, \&c.

A. F. Rose.

by imp'd Whip, dam by Partner a full brother to Trionas Queen of May, and out of a mare by imp'd Shark, \&c.

Mann. Page.

VIRGO, br. f. by imp'd Sir Peter Teazle, dam Castianira.

J. Tayloe.

VIRGINIA, (Coquette,) by Virginius, dain Dorncles by imp'd Shark, Ciock fast, \&c.

J. Ferguson.

1790.

r. f. by Medley, dain by Pegasus, g. dam Sally Wright, \&da by Dare Devil, dam Lady Bolingbroke.

J. Hoomer

Col. Seires

_-... - iy Old Mark Anthonv, dam Polly Burd. 
VIRGLNIA, by skyscraper, dam Polly Ready Money by Bowis'a C:xsm natus out of a $\mathrm{Va}$. mare. teria, \&c.

b. f. by Marylander, dam Belinda by Escape, Bedrüud, Gas

E. G. Butler.

by Timoleon, (by Grey Diomede,) dam Maid of Oakland ty imp'd Stirling, Hall's Eclipse, \&c.

- ch. m. by Sir Hal, dam Beauty by Dimnede, Virginia by Ma rylander, \&c.

Lafaymtte, (See Janette.)

J. M. Selden.

TAYLoR, b. f. by Sir Arcliy, dam Coquette.

Wm. R. Johninson.

-Echipse or American, by imp'd Eagle, dam Malvina by l'recipitate, \&c.

- _ NeLt, by imp'd Highflyer, dam by Gallant.

G. Chichester.

nought.

1798.

J. Tayloe.

Sorrel, ch. m. by Virginia Sorrel, dam Black Selima by FearSornf., s. h. by Black and All Black, (Othello, dam by Tay loe's Yorick, g. dam by imp'd Whittington, imp'd Silver Eye, \&c. P. Conway.

Wrsv, ch. by Charles, dam by Tom Tough, imp'd Hamilton, Wildair, Fearnought, \&c.

VIRGINIAN, b. h. by Sir Archy, dam Neretrix by Magog, Narcissa by Shark, Rosetta by Centinel, Diana by Claudius, \&c. Foaled, 1815.

J. J. Harrison.

- VIRGINILS, by imp'd Diomede, dam Rhea by Chatam, g dam by Eclipse, (who was the sire of Brimmer, Wilton Roan, \&c.) imp'd Shark. Silver Eye, \&c.

-... ch. by Virginius, dam Transport.

1826.

J. B. Richardson.

VIOLAN'TE, s. m. by Sir Peter Teazle, dam Selima by Spread Eagle, \&c. 1810.

J. Tayloe.

VIVIAN GREY, Ir. gr. by Lonsdale, dam Meg Merrilies by Trafalgar, \&c. VIXEN, full sister to Netiletop by Trafalgar.

by Old Medley, dam Penelope by Yorick.

L. Borkley.

VOLANTE, [Imp'd $]$ by Volunteer, dam Lava by Sulphur, g. dam Marı by Blank, Snip, Lath, \&c.

Foaled, 1797. Imp'd 1799.

J. Hoэmes.

VOLTAIRE, by Similing Tom, dam by Silver Legs out of Moll Brazen. Northumberland Cy. Va. 1781.

J. Thornton.

"OLUNTEER, [Imp'd] ch. h. by Volunteer, ciam by Whipcord, on'n b w. ther to Woodpecker, Blank, Old Crab, Childers, \&c. 1794.

Jchn Tay'oe.

- by First Consul, (by imp'd Slender,) dam by imp'd Arztina ker, imp'd Messenger out of a Bashaw mare, \&c.

Kentucky.)

1799.

J. Hcomes.

\section{W.}

WABASH, by Sir Williain, dain by Eagite.

U AKEFIEL.D, br. f. by Sir Hal, dam Grand Duteness. 
MA IT VT, ny imp'd Archihald, dam Cremona by Syread Engle, g dan. (iasteria by Balloou.

Ii.Alitith. dk. ch. by Anerican Eclipee, ram Princess by Sir Archy, g. dam by P'ecbles' Rattler, g. g. ctan Dangela.

WA AfllitrTON, gr. by l'acolet, dam Old Rosy Clack by imp'd Saltram, isc.

O. Shelt $\%$.

ch. h. by Timoleou, dam Ariadne by Citizen.

Forth Carolina, 1899.

-_ _ ch. by Rattler, (he by Sir Archy, dam Lady Jane ny mp'd Obscurity, g dam Molly by Grey Figure, \&c.

N IXEY, b. hy Sir Archy, dam by sir Alfed, g. dain by Haxall's imp'd mare Primrose by Buzzard.

NA VERLEY, b. c. by Sir ( hatles, dam Insephine by Flying Dragon, g. dam by Hamiltonian-st. George-King Herod, \&c. 1829. Winchester, Va.

J. M. Brome.

NEAZEL, by Shylnck, dam Irby's Dare Devil mare.

בch. f. ly imp'd Wrangler, dam Threstser.

WEDDIYG DAY, (The) r. h. by Bellair, dam by Fearuought. Foaled, 1791.

J. Tayloe.

WEEHAWK, by Shawnee, dam by Gallatin.

WHALEBONE, br. c. Ly imp'd Allerman, dam Atalanta by Hart's Old Medley.

WHIG, by Fitzhughs' Regulus out of the dam of Apollo.

WIII', [Imp'd] br. h. fifteen hands three inches high, got by Saltran, his dam by King Herod, g. dam by Oronooko-Cartouch, \&c.

Foaled, 1794. Imp'd 1801. Richard Bland (Cook's) by imp'd Whip, dam by Spread Eagle-Bellair, \&c.

WIIIRLIC:IG, [!m. $\left.)^{9} d\right]$ (k. h) fiften hands high, by Lord Portmore's horse Captain, he by (artouch, Sc. his dam by the Devonshire Blacklegs, son of flying Childers, \&c.

1774.

WIITE FEATHER, by Conqueror, dam by Diomede.

WH'TE. I.EATHER, b. c. hy Roanoake, dam Everlasting. 1824.

L. Long.

J. Randolph.

WHTH: STOCKIYGS, by Silver Heels, dam Snip by Oscar out of Bri Lamia, \&c.

Miaryland.

Robert Wright.

WIISTLI JACKET, by Diomede, dam Luey Lacket by Bellair, de. ton's 'Traveller, \&c. out of a thorough bred imp'd mare, \&c.

WHISKEY, by C'hanticleer, dam Poll by Partner.

Capt. Tinueswood. (Wasmuxiros's) g. by Saltram, dam by Bellair, g. dain by Willair-imp'd Driver, dec.

WIIY NOT, b. h. by Old Fearnought, dam by Othello, g. dam by Spark, icc.

(iloucester, N. Jersey, 1780.

James Tailnan.

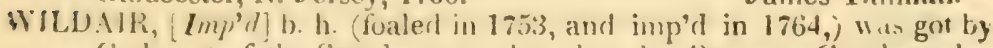
Cade out of the Steady mare, her dam by Partue:-GreyhoumdMatchless, dic. Mildair Was imp'd by Mr. Delancy of siew York. and afterwards reshipued to England.

(Srmuts') br. b. h. by Old Fearmongnt, dain by Joliy Roger on of Kitty Fisher, r. c.

liockv Mills, Hanover Cy. Va.

Col. johr Sunımm 
WILDAIR, ( ( 1 เs') b. l. by imp'd Wildair, dam by Ariel, g. dam by imp'a Othello, \&c.

Maryland, 1778.

Col. Jos. Sims

- by John Symmes' Wildair, dam by Handell, g. d. by Camden -Jolly Roger, \&c.

Forks of Hanover, Va. 1804.

John Thornton.

- - - by Ajax, dam by linowsley, g. dam by Highflyer, g. g. dam yㅣ Old Wildair, \&c.

R Walker. (Jowfs') blood b. by Symmes' Wildair, his dam by Flimna!' cur of a Fearnought mare.

Wylic Jones.

-__ - by Rochester, (a son of Cripple, $\pi$ howas a son of Old Janus,) dain by Butler's Fearnought, by Old Fearnought, \&c.

Temessee.

WILD MEDLEY. (See Medley Wild.)

WILD FIRE, b. f. by Roanoake, dam Wildfire by Gracchus. by Gracchus, dam Everlasting by Sans Culotte.

J. Randosph.

J. Ranctospn.

WILD CAT, ch. m. by Play On, (who was full brother to Stump the Deal er, and by Old Diomede,) dam by Mercer's Janus-Shark, .cc.

Wir. D. 'Taylor.

WILD DEVIL, h. h. by Old Dare Devil, dam by Symmes' Wildair-Rock ingiam-Spanking Rodger, \&c.

Hanover Town, Va. 1803.

John Anderson.

WILTONIA, by Stirling, dam Little Molly by Medley.

WINGY FEET, by Ruffin's Jolly Roger, dam Melpomone.

Wm. Randolph.

WVILBERFORCE, br. c. by Pacotaligo, dam Miss Crawler.

WINDFLOWER. (See Bernardotte.)

WITCH, ch. m. by Gracchus, dam Everlasting, \&c.

WITCHCRAFT, b. c. by Roanoake, dain Witch, \&c.

J. Ranaolph.

J. Randolph

WINTER ARABIAN. (See A rabian Winter.)

WONDER, $\left[I m p^{\prime} d\right]$ dk. cls. h. fifteen hands three inches high, got by Pho. nomenon nut of Brown Fanny by Old Diomede, g. dain by MIarsks - Skim-Crab-Childers-Basto, \&c.

Foaled, 1794. Imp'd in 1802.

Ey imp'd Dionede, dam by 'Tippoo Saib-Brimmer-Silver Eye-Jolly Roger mare, \&c.

br. c. by Old Flimnap, dam Kitty Fisher by Ossar.

by inp'd Wonder, dam by Diomede. 1815.

G. R. A. Brown.

WORMWOOD, gr. c. hy Sir Archy, ram a Clifton mare.

W DODLARK, b. f. by Roanoake, dam Parǫ̧uet.

HOODPECKER, ch. by imp'd Dragon, dam (Irby's) Dare Devil nare old Wildair-Fearnought, \&c.

1804.

C. Sallard.

wOOSKY, ch. f. by Dragon, dam Raffle by Bellair. 1805.

J. Hoomes.

WORTHY, g. m. by Sir Hal, dam by Sir Archy.

Maryland, 1814.

WRANGLLR, by imp'd Dionede, dam Lady Bolingbroke.

J. Powder, jun.

Col. Selden 
WRANGLER, b. b. hy Sir Alfred, dam Clio by Sir Archy-Beauty by Diomede-Virginia by Dare Devil, dec.

1824.

C. W. Van Ranst.

- $\left[I^{\prime} p^{\prime} d\right]$ b. h. by Diomede, dam Sir Charles Sedhury's Flea. catcher by Gold Finder-Siquirrel, \&c.

Foaled, 1794.

WREN, b. m. by Thornton's Rattler, dam by Sir Archy, g. dam Noli Me Tangere, g. g. dan Castianiru, \&c.

G. A. Blaney, U. S. A.

W YANDOT" $\Gamma$, ch. hy Platt's Alexander, dam Honest Jane--Älexander $t y$ imp'd Bedford-Honest Jane by imp'd Honest John.

\section{Y.}

YANKEE DOODLE, by Virginian, dam the dam of Maid of Lotı.

YANKEE MAID, ch. $f$. by Sir Archy, dam J. J. Harrison.

YARICO, by Medley, dam by the l'enusylvania Farmer, g. dam by Pega sus, g. g. dain by Bolton. 1790.

J. Hoomes.

YEI.IOW ROSE, ch. m. by Wildair, (by Ajax, dam Pet.

YORICK, ch. c. by Bellair, dam Virginia Sorrel. 1795.

J. Tarloe. (Oı,n) by Morton's imp'd Traveller, dam imp'd Blazella by Blaze (In England.) 1767 .

John Craigs.

Manf, ch. hy (Cld) Yorick, dam by Lath, g. dam by FearuoughtSober Johin, \&c.

D. Patterson.

YOUNG ARCH DUTCHESS, by Janus, dam Arch Dutchess.

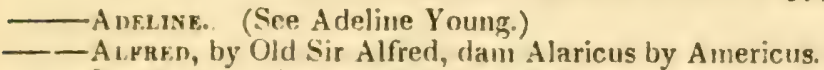

J. Rancolph.

- - Sir Al.FreD, ch. s. by Old Sir Alfred, dam Jane by Kinowsley, des.

Walter Coles.

_- Sir Archг, by Sir Archy, dam Virginia, full sister of Desdemona, \&c.

Benforn, by imp'd Bedford, dam by Harris' Eclipse.

Baroxet, hy imp'd Baronet, dam by imp'd Othello, g. dam by impe Figure, \&c.

Basazetr. (See Bajazent Young.)

Bowsr Lass, by Old Jolly Roger, dam Hardiman's Old Bonny Lase

Bussora, b. h. by Bussora out of a Duroc mare.

Canandaigua, $\mathrm{N}$. Y.

Cohmorast, b. c. by Cormorant, dam Virginia Nai.

Clows, by imp'd Clown, dam Old Black Snake, g. dam by Nonpo reil.

Dare Devil. (See Dare Devil Young.)

Dios, dam Bainbridge.

Dressaf., b. c. by Drummer, dam Ressy Balı, \&c.

Hamburg, 1808.

Thos. M. Fonman.

- Duomfon, by Tayloe's Grey Diomede, dam hy impid Gatriel out of Active by Chatam-out of stranherdess ty imp'd Slim, sc

-Dirfcror, sor. h. hy Old Director, (of Va.) dan by Tarlar-agund kap!e-l'ercy, dc. 
IOUNG DC POC, h. hy OId Duror, tam by Imped Cabripl, g. dain ing Iindsay's A rabian, \&r. P'ennsylvania.

John Snyder.

- - Fafilf, by imp'd Eagle, dam A rabella by Dare Devil out of a C'lock. fast mare, dec.

Richmond, Va. Samuel McCraw.

- Ekoxv, [Imp'd] gr. m. by Muley, (an Arabian,) dam by Pantoris Old Crab-Devonshire Childer-Basto-Black Earb, \&c. 1762.

- Eclipsf, ch. by American Eclipse, dam by OJd Bajazett, (formerly Young Tanner,) g. dam by Old Mercury-imp'd Messenger, Sc. Cambridge, New Jersey.

- Favourite, by imp'd Bedfort, dam by imp'd Diomede- BeilairClock fast, \&c.

- Fe_rnought, by Gay, dam by Old Fearnought, g. dam by the same, g. g. dam by I olly Roger.

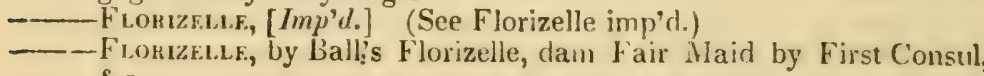
Sc.

Gov. Sprigg.

- Figirrf, blood b. h. by imp'rl Highnlyer, dam by Odd F'igure, y. dar by Camillus, \&c.

- FreNzr, by Gracchus, dam Minikin, \&c.

-. - Grasn Dutchess, by Sir Archy, dam Old Grand Dutchess.

J. Randolph.

Hickory, by Hickory, dam Lavinia.

J. Randolph.

Axtus, b. h. by Hynes' imp'd Janus, dam a Lycurgus mare-mp's Crawforcl-imp'd Justice, Sc.

J_-Jaxs. (See Revenge, or Young Janus.)

Wim. Hynes

- Lorrens, by Sir Archy, lam Lottery by Bediford.

- Mamsox, hy Madison, dam Minerva hy Dionede.

_- Mlemsx, by Cup Bearer, dam by Old Medley, g. dam by Harns' Eclipse, Lonsclale, imp'd shark.

Frederick $\mathrm{Cy}$.

Mantherw Page.

Mrant.y, Ir. gr. by Bellair, dan by Fennsylvania farmer out of a Partuer inare, \&c.

Thomas Wells.

Mонғас, by Ridgley's Moreau, dam Virginia ty Skyscrapter, \&c.

- Msikw, by Gracchus, dam Old Minikin, \&c.

- spencers.

J. R. Narcisss, b. f. by Play or Pay, dam Old Narcissa by Wildair, \&.c. $131: 2$. Oriak, (See Oscar Young.)

J. Hoomes. Pall. Joxrs, by Old P'aul Joues, dam by Marius, theronging to (Charles Carroll of Carrolltum,) gr. dam by Old silver Heels, Crab, \&ic.

Samuel Norwcost.

- P'arolft, gr. by Pacolet, dam by imp'd Coeur de Lion, Juha, l'ea cock, Ola Partier, dec.

... Prowiv, ch m. hy Gallatin, dam Trumpetta hy Hephestion, g. dam Pegegy by Bedford.

foraled, 1821.

W. Hampton, jum.

- Pont Bur, hy Ridgrey's Pust Bos, his dam out of the Hountain filly, de inetin:ps called selime. 
POUNG RANTER. br. h. by Ranter, dam a fine blooded nare.

- Fons, (dam of I,jingstou's Camilla,) hy Duroc, dam Romp by mp'l Messeuger.

Siнank, by Shark, dam by Eclipe, g. dam by Folipse out of Britannia. Sktma, by Old Fearnought, dam Ehony by Othello.

Srot, [Inty'd] ch. by Old Spot and he by Blank, Spot's 'am by Maı timrlales' Regulus, Jig, Goliah, \&c.

Imp'd by Mr. Hyde of Fredericksbg.

-Sik Pfter Trazic, (Imp'll) (See Sir Peter Teazle.)

- Sir Solomox, jun. by Uld Sir Solomon, dam Maid of Northamp on oy imp'd Clifden.

1823.

Henry Lazier

- Supkror, by Superior, dam Pirate by Lamplighter, fcc.

- Tom Torin, by Old Tom Tough, dam by imp'd Buzzaru, g. dam by Jomes' Wildair.

-Tнгғfг, [Imp'd] br. h. bred by the Duke De Guiche, was got by Trufle out of Helen by Whiskey, her dam Brown Justice lyy Jus tice, Old Trufle was got by Sorcerer out of Hornby Lass by Buz zarrl, \&c.

Orange Cy. Va. 1830.

Travellfir, (See Travel' $\cdots$ "' "ung.)

Toprstlant, by Old Topsd.. „, dam by Shark, g. dam by Harri Eclipse, Mark Anthony, \&c.

Virtisian, b. h. by Virginian, dam by Enterprise (by Florizelle.)

Yonick, by Tajloe's Yorick, dam by Figure, g. dam by Dove, Task er's Othello out of Selima, \&c.

1783.

Fielder Bowie.

\section{2.}

ZABUD, by the Winter Aratuan, dam by imp'd Spread Eagle, g. dam Sir Peyton, (by Shylock.)

Kentucky.

R. J. Breckenririge.

ZAMIOR, gr. by Silver Heels, (by Ogle s Oscar,) dam Aurora (by Vintzun, g. dam Pandora, (by Grey Dionede,) g. g. dan by Hall's Union, I.eonidas, \&c.

ZFNOB!A, by Don Carlos, dam by George's Juniper.

LKLIEKA, ch. m. by Gracchus, dam Miss Chance by imp'd Chance.

Messrs. "Tayioes.

ZFLIPPA, by Old Messenger, dami Dido by impld Bay Richmond, g. daro

Cld Slanerkin, (by Wildair,! g. g. dam imp'd Cub nare, Scc. 



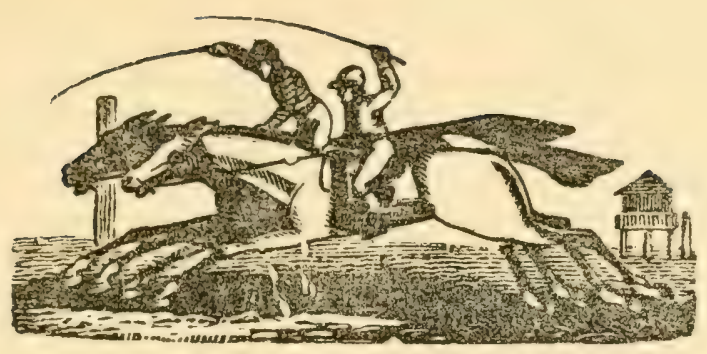

\section{INSTRUCTIONS FOR TRAINING,}

\section{BY CHARLES DUVALL.}

S t the horse be in good flesh when you put him up; night ane mu, ling walk him four miles, well clothed with one blanket and a suit of horse clothes, for eight days; water him between the walk. Ing with forty swallows; feed him at nine in the morning, at twelve o'clock, at six in the evening, and at nine at night, with three quarts of oats and chopped corn, one-fifth chopped corn, giving him one bundle of blades after feeding in the morning, at twelro o'clock, and at six o'clock: after feeding at nine at night, give him two bundles of blades. Let him be well rubbed before each feed with straw as to his body, and his legs with woollen rubbers; let him have a good bed of straw; let his feet and legs, night and morning, before you take him in, be washed with warm water and Castile soap: then for eight days more, in the morning, gallop two miles before wa. tering and one mile after, and in the evening one mile before wa. tering and one mile after, clothing and rubbing before each feed as before. After that prepare him for sweating, by feeding with two quarts at six o'clock, and at nine o'clock the same, giving him no blades, and having him well muzzled; let him be well rubbed and have a good bed of straw, always keeping his feet well stuffed with cow-dung. Let your turf be kept well harrowed and soft. At day-break take him to his training ground with three, four, or fivo blankets, and his borly-clothes; let him go four miles, the first three half-speed, the fourth mile at a sweeping rate with a tight rein. and a rider not exceeding the weight the horse should carry. Then strip him on the field, carefully scraping, rubbing, and brushing hım till dry ; then put on his usual clothes and walk him an hour; then rake him to the stable; then scald a gallon of bran, add cold water to it till milk warm, and let him drink what he will of it. 'Ther: I't him be well rubbed and dressed; then scald two quarts of bran, and two quarts of oats; mix them, putting among them a tablo spoonful of flour of sulphur and as much antimony as will lie on a cent, and let the horse eat it warm; then take two bundles of stemmed blades, and sprinkle them with salt and water, and give -un; then take some warm bran and water and wash nis legs, rub 
bing them dry with straw and woollen rubbers; then leave hum till twelve o'clock; then feed as usual with three quarts at twelve; at four in the evening brush him and let him walk an hour; then water him with water aired or branch water; then walk him a quar. ter of an hour, take him in and have him well cleaned and rubbed; then feed at six and nine with three quarts of grain; then muzzle him. In the morning after his sweat take him to the ground and strip him as for a race; then run him two mues with a tight rein, and continue him two miles more in a loose; then clean him and rub him dry; clothe him and walk him till cool, then take him in, wash his feet, and rub them dry, cleaning him, rubbing him, stuff. ing his feet, and feeding as usual: so continue to gallop every night and morning, as before directed, to wit: In the inorning first galsop two miles, second gallop one mile, and in the evening one mile each gallop; sweat every eight days. Train your colts in martin. gales; bleed after the first sweat, and if necessary after the second sweat. Those are the rules $I$ observe in training.

\section{CHARLES DUVALI.}

\section{$\rightarrow 000$}

From which, the rules observed by Mr. Thomas Larkin, of Virginia, varied in these particulars: he feeds in the morning with fonr quarts, at twelve with two quarts, and at night with four quarts; sime blades as Mr. Duvall. Morning gallops first two miles and at half, second two miles. Evening, gallops first two miles, second one mile and a half. Sweats five miles, and brushes his horse before he takes him in ; after cleaning, and rubbing, and drying him, two miles. He washes with cold water, exceyt when he sweats his horse, and waters after the horse comes in and is clean, just before feeding, forty swallows morning and evening, and twelve swallows at twelve o'clock; mixes a spoonful of sulphur in the mash, after sweating, but no antinony; walks before galloping. .wo miles; between the gillops, one mile.

Mr. Duvall, in 1797, gave me the foregoing rules: Mr. Larkin trained for me two years. And as a sportsman, that all horses maly run in the best order, and that their superiority of foot and bottum alone may entitle them to the palm, I with pleasure comply with vour request, that through. your inestimable paper, all excuses by gentlemen having fine horses, as to the mode of training them, may be removed, and the friends of the turf gratified with fine sport.

American Farmer.

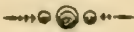

\section{[FROM THE AMERICAN TURF REGISTER.]}

Mr Editor-The within was recently found among the papers of an sld sportsman of the turt, (a pencil memorandum) in the shape of answers to questions, by a gentleman well known to the Varguia turfites, who was at that time about to begin his racing cureer. I have examined it with a trainer of long experience, und with few alterations hand it to you for publication in the Sporting Magazme

A Virginian 
A horse when put in training should be fat: his exercise sughr is commence with walking about eight miles a diay; three in thy mormmg, two at twelve o'clock, and three in the evening. 'Thus shoulc be continued at least four weeks. A light gallop of a mile in the morning, should now be added, and at the end of a week, a mile st the evening. In another week, half a mile more morning and evening. [Ie will now be in condition for his first sweat; his exercise may now be the same as the last week, except a "burst of heels" once or twice in the week, of three or four hundred yards; at which time he will be ready for his second sweat. This given, the horse should have, every other morning, a move of a quarter o a mile; this continued for a week, and his third sweat may be given. After this his exercise may be increased to two miles, morn. ing and evening; one mile of which (in the morning) should be at half-speed, with a dash of a quarter every other molning, more or less according to his appetite. 'The sweats should vary according to the high or low condition of the animal. At the end of the week, after the fourth sweat, he may, perhaps, require a draw, ${ }^{*}$ and another a day or two before he runs. I do not approve of physicing generally; when there is much grossness, or general bad health, a purge miay be necessary. Race-horses should be watered regularly three times a day, in a clear brook, in the morning after exer. cise, at twelve o'clock, and in the evening: after exercise walking them until perfectly cool, previous to watering. They should be fed with hominy and nats, (the first divested of its mealy particles,; in the proportion of one of the first to two of the latter. Sometimes, when the condition of the horse is low, he should be allowed a greater proportion of hominy; as horses when in training must feed well, every thing in the food way must be tried to make them do so: as hominy alone, oats, corn in the ear, meal, cut oats, \&e. 1 once trained a mare, and ran her successfully, feeding her three days in the week on meal with chopped or cut oats. They should be fed tive times a day : at day-break, after the morning exercise, at eleven o'clock, a little before the evening exercise, and at night : one (juilt at first, three the second time, three at eleven o'cluck. one the fourth time, and three the last, with about nine pounds of blitles without preking, divided as the grain. Some horses eat more inin others, and should be allowed accordingly. $\dagger$ When there is enstiveness, sprinkling the fodder with water, or a mash must be given: a bucket of salt and water is also sometimes useful. Sweat. ing slould be done by heavy clothing and gentle exercise, giving the horse a swallow or two of water with a little meal stirred in it two or three times during the sweat. 'T'o put a horse in order, at least twelve weeks are necessary; for a colt, nine weeks. A colt, to be in condition to run a good race, should just be low enough to feel his ribs pretty plainly, but they should not be seen: a horse should be much lower The usual preparation for a sweat is a mash at night, muzzled, hea

- A very light sweat.

+ Particularly large lorses: small horses sometimes will eat fourteen on rifiesen ruarts a diy. I think thirteen enough for the latte:-more is apt, I think, to give them gorty legs, idc. 
$\nabla y$ clothing, (three or four blankets)-the next morning, after break fast, walk three or four miles, and gallop one slowly; give a mouth ful or two of water,* and gallop two or more, as the weather is warmer or colder: carry him then to the stable, take out the unde. blanket, rolling the cover up, half at a time, scrape well, rub body and legs until perfectly dry, put on blanket and hood, and walk for an hour or two, occasionally giving a mouthful of water with a handful of meal in it, about milk warm at first. His legs, when per fictly cool, should be washed with warm water and soap, rubbed $d r y$, and the horse put to rest and given a mash, $\uparrow$ (scalded oats, in the evening walked four or five miles.

The quantity of exercise mentioned, is for horses, after four years old, and upwards; few colts require more than three miles a day. Every eight or ten days the horses should be taken from the exerise ground and walked on the road. A careful trainer will always know the condition of his horse's legs every morning before gal. loping, and decide whether they receive their work or be sent, if their legs be feverish, to have the fever extracted by standing in the water, to the pond. To keep up the appetite, I have known nothing better than a table spoonful of the powder of poplar bark, (the liriodendron tulipifera, ) every day or two when it is observed that they are mincing their food: sali should be given once a week.

[It will be seen by a comparison of the above instructions, which correspond with the system now usually pursued in the South, that it is much milder than the system laid down by Mr. Duvall of the olden time. It is wonderful, (observes our correspondent,) how their horses could stand such severe training: and he supposes that the greater fleetness of the horses of the present day may be ascrib. ed, in some measure, to changes which have been adopted in the eystem of training. It is true that many of our fine horses are let down and trained off at an early age, but that may be attributed to the severe trials to which they are put at a tender age-four milo neats, in quick time at three years old !]

- Milk-warm, with a little meal stirred in it.

$f$ 'Not always necessary, except there is much eostiveness. 


\title{
RULES AND REGULATIONS
}

\author{
OF THE \\ RICHMIOND JOCKEY CLUB.*

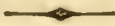

Wuerras it is necessary that all well-regulated associations ahould have some Rules for their government, and the Ricusiosn Jockr: Cuub being sensibly impressed with this truth, Therefore, Resolved. that the following be the Rules and Regulations of the Richm und Jockey Club :

1st. There shall be two regular meetings of this Club, at Tree Hill, each year, and each to continue four days, to be called Spring and Full Mectings. The Spring Meeting shall commence on the second Tuesday in May, and the Fall Meeting the third Tuesday in October.

2d. There shall be a President, Vice-President, Secretary, Treasurer, and four Stewards, appointed by ballot.

$3 d$. It shall be the duty of the President to preside in all meet. ings of the Club; to act as Judge in each day's race; appoint his assistant Judges on the evening preceding each day's race; report the result of each day's race, and stand as Judge in all sweepstakes, with such other persons as the parties may appoint.

$4 t h$. It shall be the duty of the Vice-President to attend all mectings of the Club; assist the President in the discharge of his duty act as President pro tem. in the absence of the President.

$5 t h$. It shall be the duty of the Secretary to attend the Judges on eaoh day's race; assist them with his counsel; keep a book, in which he shall record the members' names, the Rules of the Club, and add to them any Resolutions which may change the character of either; also record the proceeding s of each meeting; the entries of horses; an account of each day's race, including the time of run. ning each heat; publish the races, and after they are over, publish the result; for this service, he shall be exempt from paying his cubscription.

6th. The Stewards shall he appointed by ballot, and serve for one meeting next succeeding their appointment. They shall wear a white rose on the left side of the cape of their coat. It shall be cheir duty to attend on the course, preserve order, clear the track, seep off the crowd from horses coming to the stand after the close of a heat ; may employ able-bodied men to assist them, wno s!? paid out of any money in the hands of the 'Treasurer, and they to designated by a red sash.

* The Rules of New-Market, (near Petershurg, Va.) Broad Rock, and must of the courses in Virginit, are nearly the sane. 
7th. There shall be three Judges in the starting stand, the Presi dent and two assistant Judges, whose duty it shall be to keep the stand clear of any intrusion during the pendency of a heat, except the officers, trainers, and weigher, and also see that the riders are dressed in jockey style.

8 th. All disputes shall be decided by the Judges of the day, from whose decision there shall be no appeal, unless at the Judges' dise sretion; and no evidence to be received of foul riding, except from Vistance Judges and Patroles.

9th. There shall be two Distance and three Patrole Judges, who shall repair to the Judges' stand after each heat, and report the nags that are distanced, and foul riding, if there be any.

10th. The distance of the Proprietor's Purse shall be three mile seats, and be run for on the second day of each regular meeting The purse shall be $\$ 300$-entrance $\$ 15$.

11 $t h$. The distance for the Jockey Cl ̈̈s purse shall be four mile heats, spring and fall, and be run for on the third day of each regu lar meeting-entrance $\$ 20$.

12th. All Sweepstakes, advertised to be run for over the 'Tree Hill course, on any diay of the regular meeting of the Club, shall be nnder the cognizance of this Club; and that whenever at subseri. ber inakes an entry, he may change it at any time before the stak? - closes.

13th. No person shall start a horse for any purse under the control of this Club, other than a nember, he being at least one-third interested, and producing proof of his horse's age; nor shall any member start a horse, unless his entrance and subscription br paic before starting.

14th. All entries of horses to run, shall he made in open Club, on the evening preceding each day's race, by 5 o'clock, or during the sitting of the Club, and no entry made after that time shall be al. lowed; Provided, if there be no meeting, then with the Secretary or Treasurer, by 5 o'clock.

15th. No person shall be benefited by the winning of any purse, under the control of this Club, unless he be a nember or the owner of the horse.

16th. Any person desirous of becoming a member for the purpose of starting a horse, niay do so, he being approved by the Club, and vaying double entrance.

17th. The winning horse of the Jockey Club Purse shall not le pormitted to start for the Proprietor's purse, nor the winning horse of the Proprietor's purse for the Jockey Club purse, during the same meeting.

18th. No compromise or agreement between any two persons ntartıng horses. or their agents or grooms, not to opyose each 'the 
upon a promised division of the purse, shall be permitted or allowed, and no person shall run their nags in oonjunction, that is, with a determination to opipose, jointly, any other horse or horses which may run agamst them. In either case, upon satisfactory evidence produced before the Judges, the purse shall be awarded to the next best horse, mare, or gelding; and the persons so oflending, shall never again be permitted to start a horse on this course.

19th. No two riders from the same stable shall be allowed to ride in the same race; nor shall two horses, trained in the sane stable, be allowed to start in the same race.

20) th. Riders shall not be permitted to ride in a race unless dressed in the jockey style.

21st. Riders, after the hent is ended, must repair to the Judges stind, not dismount until ordered by the Judges, and then carry their saddles themselves to the scales, there to be weighed.

22 $l$. The Rider who has won a heat shall be entitled to the track, and the furemost entitled to any part of the track, he leaving a suf. ficient space for a horse to pass him on the outside, but shall not, when locked by another horse, leave the track he may be running in to press him to the outside, doing which will be deomed foul riding. A Rider may take the truck on the inside, but he must do it at his own peril, as, should he he posted in making the attempt, it will not be considered as foul. Should any rider cross, jostle, strike an adversary or his horse, or run on his heels intentionally, or do any thing else that may impede the progress of his adversary, he wiin be deemed distanced, though he come out ahead, and the purse given to the next best nag: and any rider offending against this Rule, shall never be permitted to ride over or attend any horse on the course again.

23\%. If any nag shall run on the inside of any pole, they will be deemed distanced, although they may come out first, and the purse awarded to the next best nag.

$24 \%$. The distance stand shall be sixty yards from the Judges stand for mile heats, and sixty additional vards for every nile in a heat, unless it be the best three in five, and then ninety yards to a mile.

25/h. The time between heats shall be 20 minutes for mile heats, 30 minutes for two mile heats, 40 minutes for three mile heats, and 45 minutes for four mile heats. Some signal shall be soundexi from the Julges' stand five minutes before the period of starting, after the lapse of which time, the Judges shall give the word to such riders as are ready-but should any horse be resitive in sad dling, the Iudges may delay the word a short interval, at theit uwn discretion.

26ith. A horse that does not wm a heat out of three. shall yot he Bntitled to start for a fourth, althongh he may save his distance A drawn horse shall not be considered as distanced. 
27th. No stud horse shall be exhivited within the walls of the course until the ladies have retired.

$28 t h$. All members and their families shall pass the gate free, and all who are not nembers shall pay the following tolls, viz:for every four-wheeled carriage $\$ 1$, for every gig and two-wheeled carriage, cart, man and horse, 50 cents : and for every person on foot 25 cents.

29th. Any person who may kill a dog on the course, shall be paid two dollars out of the funds of this Club, and if there be none in hand, by the Judges, out of the purse of that day on which t'ie dog or dogs may be killed.

30th. The following weights shall be carried, viz:

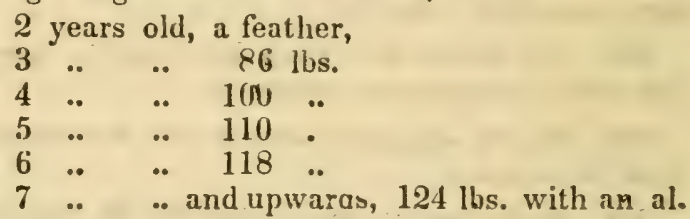

luwance of three pounds to mares and geldings. The weigher shal! see that each rider shall have his proper weight, before he starts, and that they have within two pounds after each heat.

31st. The age of horses shall be recorded by the year in which they are foaled; during the year 1800 shall be considered as a yearling; during the year 1801 , two years old; during the year 1802 , and so on.

32d. New members can only be admitted upon recommenda. tion; any person wishing to become a member, shall be balloted for and two black balls will exclude him

\section{BETTING.}

WuEN both parties are present, either party has a right to de. mand that the money be staked before the horses start; and if one refuse, the other may, at his option, declare the bet void.

If any party be absent on the days of race, the party present may declare the bet void, in the presence of the Judges, before the race commences; but if any person offer to stake for the absentee, it is a confirmed bet.

A bet made on a heat to come, is no bet, unless all the horses running in a previous lieat start again.

All bets made between horses that are distanced the same hea: are considered drawn, and when between two horses throughout a race, and neither of them win it, the horse that is best at the termi. aation of the race, wins the bets.

If an entrance horse, or subscriber die, no forfeit shall be re. qุuirod.

A premium given to another to make a bet shall not be refunded, alfongis the bet is not run for 


\section{HANDY CAP RACES.}

ist. TuE Judges for the season, on meeting with the Secretary, sinall Handy Cap.

2d. A list of all the horses, mares, and geldings which have start ad at the said meeting, shall be made, to which any others, if pro posed, and particularly described, may be added.

3d. Any horse, \&c. which has not run during the said nieeting, f.r. Sweepstakes, Jockey Club, or Proprietor's purse, shall carry the weights of the course.

4th. When the distance to be ran, the entrance required, and the prize be agreed on, the Judges and Secretary shall proceed to as. sign them their weights.

5th. No horse, \&c. shall be bound to carry more weight than the rules of the course prescribe.

$6 t h$. On the supposed best horse, \&c. his or her proper weight shall be imposed.

7th. From horses, \&c. of the 2d, 3d, \&c. rate or reputation, as much weight maly be taken as will, in the opinion of the Handy Cappers, make them equal to the first rate; in equalizing them os aforesaid, they are not bound to regard the winning horses, \& c. as a change of distance, or a hard run, may change their ability to perform.

8th. Those who Handy Cap, shall particularly mark such horses, \&c. which are started in shoes, or not allowed to exert themselves in a previous race-any such horse, \&c. shall carry the weight of the course, subject to the determination of the Juages and Secretary.

9th. As soon as the list of horses, \&c. with their weights, be prepared, the Secretary shall post up the same in the Club Room at this place to which shall be added the distance to be run, the sum to be run for, and the entrance money.

10th. When the aforesaid nine rules be complied with, until 10 o'clock P. M. shall be allowed the owner or starter to determine whether he will contend for the prize, and no longer; as they de. termine, they shall give their names to the Treasurer or Proprietor of the course, with a description of their horses, \&c. who shall make a list of them as entered, which list shall point out their places at starting-two or more to make a race.

\section{ENGLISH RULES OF RACING.}

16 struct of the lans which govern the Race Course in Great Britain, us extracted from a Liverpool puper.

Honses take their ages from May day, i.e. a horse fonled any me in the year 1823 , is one year old on the first day of Hav 1824 Four incies are a hand; fourteen pounds a stonc: two humbed aro - riy yards a distiner. 
Oath weights are, each to appoint a party to 2 ide without woighing Feather weight signifies the same. Give and take plates are werght for inches; fourteen hands to carry a stated weight, all above to earry extra, or be allowed the proportion of 7 lbs. to an inch. A Whim l'lite is a weight for age and a weight for inches. A Past Match is to insert the ages of the horses in the articles, and to run any horso of that age, without declaring till you come to the post to start. Hand Cap weights are weights according to the supposed abilities of the horses. Plates or shoes are not allowed in the weight.

The horse that has his head at the ending post first, wins the heat Riders must ride their horses back to the wiuning post to weigh ; and he that dismounts before, or wants weight, is distanced. If a rider fall from his horse, and the horse be ridden in by a jerson of sutip. cient weight, he shall take place the same as if it had not happened, provided he goes back to the place where the rider fell.

Horses not entitled to start without producing a proper certifi. cate of their age, if required; except where aged horses are included in which case a junior horse may start without a certificate, provi. ded he carry the same weight as an aged horse.

For the best of the plate, when there are three heats run, the norse is second who wins one. For the best of the heats, the horse is second that beats the other twice out of three times, though he doth not win the heat. When a plate is won at two heats, the pre. ference of the $I$ orses is determined by the places they hold in the second heat. I hen three horses have eacn won a heat, they muly must start for a fourth, and their places must be determined by it. though before no difference between them. No distance in a fourth heat. In running heats, if it cannot be decided which is first, the heat goes for nothing, and they may all start again, except it be he. tween two horses that had each won a heat. Horses drawn beforo the plate is won are distanced.

A bet after the heat is over, if the horse betted on does not start again, is no bet. A confirmed bet cannot be off, without mutual consent. Either party may demand stakes to be made, and on refusil may declire the bet void. If a party be alsent on the day of running, a public declaration of the bet may be made on the course, and a demand whether any person will make stakes for the absent party; and if no person consent to do so, the bet may be declared void. Bets agreed to be settled in town, or any particular place, cannot be declared off on the course.

The person who bets the odds, has a right to choose the horse of the field. When he has chosen the horse, the field is what starts aganst him; but there is no field unless one starts with him. If oilds are net without mentioning the horse before the race is over it must be determined as the odds were at the time of making it. Bets made between particular horses are void if neither of them be the winner, "nless specified to the contrary.

At New Marke:, if a bet be made for any particular day in any nueting, and the parties afterwards change the day, all bets must stand; int if altered to another meeting, bets made before the alteris son are void. Bets deterninea, though the horse does not starb 
when the words "absolutely, run or pay," or "play or pay," are made use of in betting. For example; i bet that Mr. Udny's ch. mare, Mirandela, absolutely wins the king's plate at Chelmsford, in 1824. I lose the bet though she does not start, and win though she goes over the course alone.

All double bets are considered as play or pay.

Since Epsom Ratces, 1812, all bets are made in pounds, and not in guineas, as formerly.

IIorses running on the wrong side of a post, and not turning back, are distanced. Horses distanced if the riders cruss or jostle. Horseg that forteit are beaten horses, where it runs or pays. Bets mado on any horses winning any number of plates that year, remam in force till the first day of May. Money given to have a bet laid, not returned if not run. All matches, bets, and engagements are void on the decease of either party before determined. An untried stillion or mare, is one whose produce had not started in public at the time of closing the engagement.

In estimating winnings, it is the practice to consider the clear sum ginned only, and consenuently to exempt the winner's stalses. A wimner of sweepstakes of 20 guineas each (three subscribers) is, therefore, not disqualified from rumning for a tifty pound piate, ex pressod to be for horses that never won a plate, match or a sesp stake of that value. 



\section{SU P PLEM EN T}

To

\section{A S O N A N D H I N D'S}

POPULAR SYSTEM OF

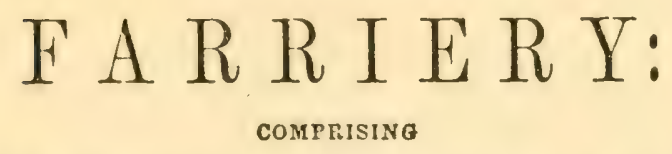

AN ESSAY ON DOMESTIC ANIMALS,

ESPECIALLY THE HORSE;

WIT B

REKARKS ON TREATMENT AND BREEDING:

TOGETHER WITH

\section{TROTTING AND RACING TABLES.}

\section{SHOWING}

I'HE BEST TIME ON RECORD, AT ONE, TWO, THREB. ANU FUUR MILE HEATS;

PEDIGREES OF WINNING HORSES, SINCE 1839;

AND OF THE MOS'T

CFLEBRATED STALLIONS AND MARES; WITH

USEFUL CALVING ANI) LAMBING TABI,N8, ETC., ETC.

\section{BY J. S. S K IN NER,}

Edinr now of the Furmers' Litrary, New Yurk: Founder of the Amn:rican Farmer. in 18 is sud of the Turf Register and Sporting Masazme, in 1829: being the first Agricultural aud the tirst Sporting Penodicals establistied in the United States.

P H L A D E L II I A : CLAXTON, REISEN \& HAFEELFINGER, 1873. 
Entered, according to Act of Congress, in the y

CLAXTON, REMSEN \& HAFFELFINGER,

in the Office of the Librarian of Congress, at Washington.

STPRBOTYPED BY J. FAGAN \& SON, PHILADELPHIA. 


\title{
D E D I C A T I O N.
}

Wirnour going through the formality of asking leave to say " by his gracious permission," which, if sought, might hare been withheld, this Supplement to Mason and Hind's Popular Systims of Farrifiry is respectfully dedicated to Col. Balie Perton.

It is not that a contribution so inconsiderable is deemed worthy of him, or the subject so interesting; but that the Author would fain embrace any fair occasion to manifest to him, and through him to their common friends at New Orleans, his grateful remembrame of their kindness when anong them.

There would be, morenver, an essential propriety in dedicating to Col. P. a mose adequate offering of this sort; as he is known to be a breeder and warn amateux of the high-bred horse; and, in his own spirit and cha racter, exemplary of what is best bred and most excel lent among men.

\author{
J. S. S. \\ NEW YeAn's DAT, 1848. \\ For the nonce at Annapolis, $\mathrm{Md}$
}





\section{PREFACE.}

Truugh, 'under aver fluctuating but sometimes pro pitious circumstances, the very climax of eçuestrian power may have been reached in a few cases in the United States, as in the country from which we derived our skill and material, is it not still worthy of all consideration how we may contrive to belay, as the sailors say, what we have gained in that important branch of Rural Industry-not only as a means of individual enjoyment, but as a prolific, indispensable source of National power and wealth?

However serious and apparently insurmountable may be the difficulties that stand in the way of farther improvement of domestic animals, and especially the Horse - either in the general absence of the necessary means and appliances, and of adequate encouragement for the care and expense attendant on the production of Horses of ligh qualities, there ought, surely, anong well-informed men, to be no obstacle arising from ignorance of the art of breeding. Hence it is that in sending forth the Ninth Edition of this popular work on Farriery, while nothing seemed to be needed in the way of description or treatment of the diseases of domestic animals, and while the author of this Supplement was only called on to extend the stud-book in a manner to embrace the pedigrees to which breedess and dealers might have occasion to refer, he could not forego the opportunity 
to offer some such additional matter as, to him at least, seems to be of sufficient value to render it acceptable and useful.

In the introductory remarks on the relations existing between Man and the animals destined for his use and amusement, and the obligations these relations impose, the writer has but expressed the sentiments he has ever entertained, of duty on our part to respect the feelings and comfort of the humblest among them; and has endeavoured to encourage continued exertions for their melioration by showing how successful and progressive such efforts have been, even up to the present time.

To these obserrations of his own are appended those of writers of acknowledged judgment and authorityaccompanied by such notes as appeared to be apposite and well-founded; and to these, again, have been superadded a few tables and other items which might not elsewhere be conveniently met with. His undertaking, kind reader, " hath this extent, no more." All, then, that the author of the "Supplement to Mason's Farrier" has to ask of you is that you will bear in mind that there has been no engagement to write anything-much less a Book on Farriery: for that there was no call or necessity. With this intimation, the reader will please accept for what it is worth and with all due allowances, the little that has been volunteered-by one who may claim to have been all his life an amateur if not a connoisseur of the Horse.

J. S. S.

Edit. Farmers' Library 


\section{ONTENTS.}

Nat the relations between Man and the Domestic Animals, especially the Horse, and the obligations they impose, Page 9 On the Form of Anirals .................... 18

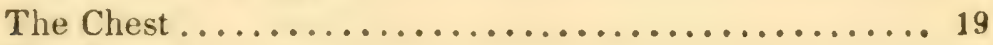

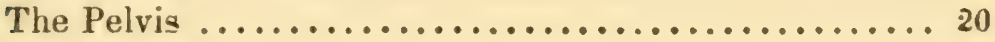

The Head .............................. 20

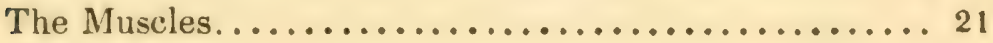

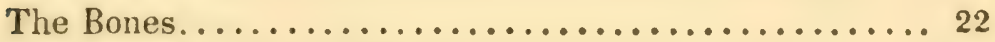

On the Improvement of Form................ 22

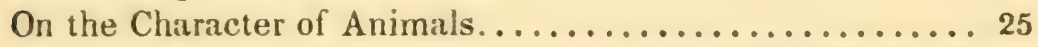

Examples of the good and bad effects of crossing the breeds 26 On the importance of more attention to the Principles of Breeding-the Stallion and the Brood Mare.......... 31 An Essay on the Condition of a Stallion............ 41 Tables-Weights and Measures................49 List of Medicines .......................... 50 A pparatus for Compounding Medicines............ 5C Instruments........................... 5C Calving Table............................ 51

Lambing Table ......................... 51

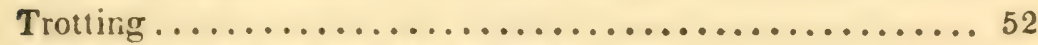

Best Trotting Time, at Mile Heats............... 53

At Two Mile Heats....................... 53

At Three Mile Heats....................... 53

At Four Mile Heats...................... 53

Racing-Best Time on Record at Mile Heats........... 54

At T:wo Mile Heats..................... 54

At Three Mile Heats..................... 56

At Four Mile Heats.................... 57

The St. I.eger.......................... 58

Average Speed for the Doncaster St. Leger ........... 59

Pedigrees of Winning Horses, since $1839 \ldots \ldots \ldots \ldots \ldots \ldots 60$

Calebrated Stallions and Brood Mares............. 89 



\section{SUPP LEM ENT, ETC.}

ON THE RELATIONS BETWEEN MAN AND THE DO. MESTIC ANIMALS - ESPECIALLY THE HORSE - A ANL THE OBLIGATIONS THEY IMPOSE.

"La connaissance de la conformation exterieure du cheval est beaucaup moins répandu qu'on ne le pense vulgairement : elle repose sur deg etudes d'anatomie de physiologie, de mecanique, et d' histoire naturelle dont peú de personnes se font une juste idée."

If animals were classified by naturalists in the order of their intelligence, docility and usefulness, the Horse and the Dog would occupy, in relation to Man, the juxtaposition they have assigned-on the ground of physical structure-to the impracticable baboon and the grotesque and chattering monkey; and in lieu of groping in the darkness of antiquity for the period when they are supposed to have been entrapped or subdued, by fraud or violence, we should the rather conclude that Nature placed all the domestic animals where we have ever found them - in close association with Man, administering to his pleasures and wants; lightening his toils and sharing his danger: , and constantly advancing, like Man himself, under the improving influence of civilization and the arts that belong to it.

In contemplating the whole animal kingdom, does not Man-standing preeminently at the head of it, surrounded by the domestic races - present everywhere the most 
lusti ous spot on the varied map of living creation? From the everlasting snows of the north to the burning sands of tropical deserts, his faithful dog follows at his foot; the horse is at his side - submissive to his will; - the patient ox bows his neck to the yoke; and the sheep and the hog are present to supply his clothing and his food. Far otherwise is it with untameable and predatory birds and beasts. Restricted to particular regions by an allwise Providence, the absence of food and climate congenial to their nature forbids them to roam beyond limits comparatively circumscribed. And do not these arrangements for our benefit, and which give us "dominion over all the earth and every creeping thing that creepeth upon the earth," enjoin on us the duty of studying their habits, their economy, and all the laws of their existence -with a view to their improvement for our advantage, in every way consistent with kindness to them and with gratitude to Him,

"Who in his sovereign wisdom made them all "

And while these considerations teach us to be merciful ourselves, do they not convey the admonition

"Ye therefore who love mercy, teach your sons To love it too!"

The very fact that to them has been denied the power of speech, and the necessity of uncomplaining submission under every hardship, ought to put us constantly on our guard against practising, or permitting to be practised, gny, the smallest measure of abuse or ill treatment. 'Thus every man of common humanity will study their comfort in all things, consistently with the purposes for which they were designed, and will never even mount his faithful horse without seeing that whatever is needed has peen done to give an easy set to his saddle-and, still more, tnat all is right about his feet! 
Doctur Rush, in a beautiful and benevolent eulogy op the Horse, in one of his lectures, related a touching anecdote of a highly intelligent and successful Pennsylvania farmer, who, stricken down suddenly with apoplexy in his barn-yard, expired on the instant-with this last direction to his herdsman on his lips: "Take care of the creatures!" And the biographer of an eminent English C'hancellor relates, as from himself, how his beloved son had preferred to him, in his very last moments, a petition in favour of his faithful terrier; "And Father, you'll take care of poor Pilcher, won't you?" Nevertheless, after all the care that can be taken, we should probably be amazed if we could know the amount of pain unwittingly inflicted on animals dedicated to our service, and some of whose bodies are at last consumed to afford usas some would contend-supertluous nourishment, refer ring back as they do to that golden age when

“ Man walked with beast-joint tenant of the shade ;

The same his table and the same his bed-

No murder clothed him, and no murder fed."

Even all unnecessary harshness of reproof should be avoided - for it is well known that some animals are even more susceptible of painful and violent emotions, from various causes, than some men, whose hardened nature and familiarity with vice, render them as insensible to the reproaches of others as to the stings of their own conscience. Those, for instance, who have studied the character and affections of the horse-with a view to his diseases and moral susceptibilities - need not be told that while sharp and threatening words will so disturb him as to quicken his pulse some ten beats or more in a minute,"

* The natural constitution of different varieties of the game class of onimals is worthy of close attention. In small and thorough-bred horses, :or instance, the pulsations of the heart are about 40 to 42 -while in the largyer, cold-blooded cart-horse, they do not amount to more than $\mathbf{3 E}$. But when ill treated, as hefure suggested. their pulsations are inrreased 
ne tas in very memorable cases been known to fall dead under the excitement of the sexual and other passions. 'That he is sometimes animated by the strongest spirit of rivalry, and a noble ambition to excel, has been occasionally evinced by violent attacks on his passing rivals on the turf-and very recently the case occurred with a noble animal which fell dead at the very winning-post, in vainly struggling for victory, on the Pharsalia course at Natchez. The contest which had this melancholy issue was between Col. Minor's Jenny Lind and Col. Bingaman's Black Dick :

" Dick was the favourite at odds. Some even bets were made that he would win at three heats-and some, if the heats were broken, would not win. Jenny drew the track, and after some little manceving, they got off logether, but Dick outfooted her and took the track on the turn; at the half-mile post she had got her head to his hips, and they ran locked round the upper turn; at the head of the front stretch she began to draw clear of him, and spurs were applied. 'Then burst his mighty heart,' for he soon was seen to reel, but he still struggled on ; his jockey Mat, leaped unharmed from his back, and the noble animal fell dead within ten feet of the winningpost, which he had left not two minutes before in perfect health and the firest condition. No shout of triumph hailed the winner: all was sympathy and regret. Two

say, ten in a minute. The natural circulation of the sheep is about 70 per minute. The average pulse of a full-grown $o x$, in a state of health, in England, is atout 40 - but this increases in a climate of higher tem. perature. Doctor James Smith (Journal of Agriculture, vol. ii. p. 92,) fiuds that in the climate of I,ouisiana the pulse of the ox, in its natural atate, is from 68 to 75 -rising on the slightest excitement to 80 . Every one knows how destructive is the moral influence of fright to a flock of sheep-when, for instince, they have been hadly scared by dogs. It uften happens that they never recover from its effects.

For all farmers wh, nave occasicn to fatten animals, we must tako som fo: three wor-1s-uarmith, cleanliness, and quietude. They aro the veni-vidi-vici, in their fields of action. 
of our most talented medical gentlemen immediately made a post-mortem examination, and came to the conclusinn that the death of the horse was produced by apoplexy, caused by congestion of the heart, brought on by over-excitement and violent exertion."

The annals of domestic animals abound in cases in show how liable they are to acute affections and suffering, far beyond the apprehension of the most considerate and humane.

Thus much, good reader, have we gladly seized the opportunity, and even gone a little beyond the requirements of our publishers, to say in the way of appeal in behalf of speechless creatures, as alive to pain as to a sense of gratitude for generous treatment; and having already adverted to the obligation we are under to study the laws of their existence, and the means of their melioration, it may now, even be insisted that in the whole range of the occupations and interests of breeders of their own stock, there are ferr things that demand more consideration and skill than woes this very branch of rural industry.

The study and the pride of every one should be, not merely to maintain them at a point of excellence already acquired, but to have them progressivcly improving in whatever constitutes economy and value; for why should any man indolently conclude that his stock has already artained the ne plus ultra in the way of ameliorations however superior it may be? Such is not the fact, nor, it may safely be affirmed, would it be consonant with the orders of Providence, or even with our own interests, that it should be so. To man has been given dominion over the beasts of the field-that, like the earth itself, he should cultivate and improve them; and for that, among other purposes, was he endowed with the great, distingrishing, and godlike power to prosecute intellecruas 
investigations into every department of nature and $\mathrm{nn}$ dustry. Doubtless our ancestors, more than a century ago, were ready to believe-what indolence is erer ready to whisper - that the several races of domestic animals most immediately under their care, had then already been carried up to the maximum of improvability; yet which of them has not been vastly bettered in the meantime, in all their valuable points-and that, too, not by any sudden or accidental accession of one or more good qualities, but constantly and progressively; by a closer study and a better knowledge of the laws of animal and vegetable physiology, and by the application of other appropriate sciences. In the plain English of the motto chosen for these reflections what is there said of the Horse may apply to other animals :

"The knowledge of the external conformation of the horse is much less extended than is generally supposed. It reposes on the study of anatomy, of physiology, of mechanics, and of natural history, in a manner of which few persons have a just conception."

In 1710 , by the estimate of Dr. Davenant, - a writer of unquestioned candour and authority, - the weight of "black cattle" (so called, because, at that day, most cattle were of that colour) averaged but 370 pounds; the weight of the calf was estimated at 50 pounds; and the average of sheep and lambs, taken promiscuously in the I.ondon market, was only 28 pounds. After the lapse of 120 years, - with far less of science applied to the subject than at this time, - M'Culloch, in his dictionary, so highly characterized by the accuracy of its statements, puts the average of cattle at 556 ; sheep and lambs at 50 ; and calves at 105. But the late accomplished Professor Youatt, in his able work on cattle estimates the average weight now at Smithfield at 656 ; that of sheep and lambs at 90 ; and calves at $144 ;$ - the weight of 
each having doubled in 130 years; and that, as before said, not by any accidental importation from abroad, or fortunate cross at home, but by a course of careful, systematic, and sagacious attention to the laws and principles of breeding and feeding. The horse, standing at the head of the list,--sharing and supporting man in all his most pleasurable as well as toilsome and dangerous enterprises,-naturally engaged his earliest attention and most assiduous care, to cherish and improve to the high. est pitch, his noble faculties of strength, speed, and endurance; and thus may have been already brought to the zenith of his capabilities, if indeed he has not passed the culıninating point; but see what must have been achieved by the stimulus of the turf, and art in the breeding-stud, to raise the bred horse of England to a height of perfection, even above the wonderful capacity of his south-eastern ancestry, - the very " drinkers of the wind" themselves! - for we have the high authority of Nimrod, the crack writer of England on all fieldsports, for saying that, on the best Indian authorities, " the best Arab, on his own ground, has not a shadow of a chance against an imported English racer, in anything like a good form." 'The celebrated race on the Calcutta Course, between Pyramus and Recruit, - the former the best Arab of his year; the latter a secondrate English race-horse, by Whalebone, the property of che Marquis of Exeter,- - settled this point, inasmuch as allowance was made for the comparatively diminutive size of the Arab, - it being what is termed a give-and take match, or weight for inches; in which Recruit carried 10 stone 12 (152) pounds; and Pyramus only 8 stone 3 (115) pounds, an extra allowance of 7 pounds tiaving been given to him as an Arab.

Pyramus, says the reporter of this race. is as groni 
an Arab (he had previously beaten all the best Arabs in Calcutta for the gold cup) as has appeared for many years. His condition was undeniable; the distance was all in his favour, and he was ridden with superior judgmentso that the result of his match with Recruit may be considered to have established this an axiom : that no allowance of weight, within the bounds of moderation, can bring the best Arab-even in a climate most congenial to him-upon a par with an English thorough-bred horse of moderate goodness. In addition to all these circumstances in favour of Pyramus, it must be remembered that Recruit only landed on the 28th May, (the race was run in January), after a voyage of five months."

In England, where the progress of improvement was greatly accelerated by a seasonable infusion of Arabian and barbaric blood, the bred-horse-standing, in respect of the equîne race, as the capital on the Corinthian pillar-has reached a point of perfection that, if it can be kept up, we can hardly dare hope will ever be excelled I that country, four-mile races are nearly abolished, and it has been said with every show of reason, that early training, light weights and short distances, are impairing the stoutness of tie English race-horse and hunter, and their capacities to stand up and go the pace as in the palmy days of the English turf. In our own country, the annals of the course show, that our climate is highly congenial to the constitution and physical development of the horse - and that whenever the sport has been fashionable and the rewards adequate, he has ever been ready to meet all reasonable expectations-rather advancing tnan falling oack.

When Floretta won her race in Washington-winning the $2 \mathrm{~d}$ heat in 7.52, against such nags as Oscar, Topgallant and First Consul, it was deemed a mar.ollo:is 
perform ince; ${ }^{*}$ ard sportsmen thought that the arme of speed and bottom had been reached in our country in the days of Sir Charles and Eclipse, yet have not their best achievements been eclipsed by two illustrious and yet living rivals of each other - Boston and Fashion? But what have we not to apprehend should what seems to be threatened come soon to pass, and the turf - the only sure test of speed and stoutness, be allowed to go down? We remember once at a dinner-party at the British Minister's in Washington, to have inquired of the late John Randolph of Roanoke, whether the Old Dominion maintained, unimpaired, her claim to a superior race of horses? "No, Sir; no, Sir," was his shrill-toned prompt reply; "Since we gave up horse-racing and foxhunting, and turned up the whites of our eyes, our hor ies as well as our men have sadly degenerated."

Finally-justice, truth, and a sense of obligation for the assistance derived from his labours, in the small contribution we are here making to the breeders and amateurs of the Horse, demand of us to say, at the least, that if the American Turf should decline, it will not be for want

* This was one of the most memorable contests that ever came off on the Washington Course. Horses were horses, and men were men, in those days. Fair-top boots, powdered heals, and golden "guineas" were all the go-and for fairness and houvur, a "stain was felt like a wounil."

The horses were thus placed :

Dr. Edelin's c. m. Floretta, by Spread Eagle, 6 years old, 51 I

Gen. Ridgely's b. h. Oscar, by Gabriel, 6 yrs. old, 222

J. B. Bond's b. h. First Consul, by Flag of 'Truce, aged 433 Col. 'Taylue's b. h. Topr-gallant, by old Diomed, 6 yrs. old, 144 M. Brown's b. m. Nancy, hy Spread Easle, 6 years old. 3 dr.

In this race Floretta was closely run by Oscar and First Consul -. each heat was run under 8 minutes, and thesermd in 7.52. Each horso made play from the score, and the time was better than bad heen made on that Course even up to 1829. Has such a field of men ant horses come to that post since?

In another pace-the trot-it was deemed marvellous that old Top" whould go his mile with 150 pounds weight in 2.45. But Irady Suffolk - well dashed with the old Messenger blowd - has lone hers w 2.28 s. and is yet in full if not improving vigour. 
of an able, industrious, and tasteful advocate and illus. trator of its advantages and uses, as long as W. 'T. PokTER shall continue to animate and guide the "SPIRIT of rHE Trmes." Extensive acquaintance and coextensive popularity-the just fruits of accomplished manners and an obliging temper-have made him the focus of a most varied and recherché correspondence: while his own tact, scholarship and nice appreciation of what is good in the literary and the sporting world, enable him to turn all his rich resources to the best account, for the enjoyment of his numerous and refined readers-for the most part, gentlemen of blood and metlle.

\section{ON THE FORM OF ANIMALS,}

BY HENRY CLINE, ESQ. SURGEON.

WITH NOTES BY J. S. SKINNER.

The form of domestic animals has been greatly improved by selecting with much care, the best formed for breeding-but the theory of improvement has not been so well understood, that rules could be laid down for directing the practice. There is one point particularly, respecting which the opinions of breeders have much varied, which is, whether crossing the breed be essential to improvement.

It is the intention of this communication to ascertain in what instances crossing is proper, and in what prejudicial; and the principles upon which the propriety of it depends.

It has been generally supposed that the breed of animals is improved by the largest males. This opinion bas done considerable mischief, and would have done more injury had it not been counteracted by the cesire of selecting animals of the best form and proportions, which are rarely to be met with, in those of the largest size 
Experience has proved that crossing has only succeeded in an eminent degree, in those instances in which the females were larger than in the usual proportion of females to males; and that it has generally failed when the males are disproportionally large.

The external form of domestic animals has been much studied, and the proportions are well ascertained. But the external form is an indication only of internal structure. 'The principles of improving it must therefore be founded on the knowledge of the structure ind use of internal parts.

The lungs are of the first importance. It is on their size and soundness that the health of an animal principally depends. The power of converting food into nourishment, is in proportion to their size. An animal with large lungs, is capable of converting a given quantity of food into more nourishment than one with smaller lungs, and therefore has a greater aptitude to fatten.*

\section{The Chest.}

The external indication of the size of the lungs is the form and size of the chest; the form of which should

\footnotetext{
* In tarther explanation of this principle, it may be added, from an au. thor who had evidently read and relied on this able Essay of Surgeon Cline, that muscular exertion facilitates the return of veunus blood to the right side of the heart, and in long continued and violent exertion, the respiration being quickened, the lungs-if small_are unable to arteriulize and get rid of the bhool as fast as it is pumped into them ; consequently, if there is not rom for the hloml. congestion takes place, anil the horse becomes what is termed .. hlown"-the lungs heing gorged ath hloud, and sometimes the animal is destroyed hy it. In Eurland it is sail to he "svell understimel that a majority of horses that perish under a hard press "acruss the country, are nomme-chestea!" 'The conical form, not of the holly, but of the chest. as laid dorn in the next paragraph, is very observahle in the hest paintings of Fashion. 'T'here, and in her quarters and hocks, appear to us in lie the great sources of fer yet in this country uneugualled speed and stoutne'ss. - I. \$. S.7
} 
- have the figure of a cone, baving its apex situated between the shoulders, and its base towards the loins.

The capacity of the chest depends upon its form more than on the extent of the circumference; for, where the girth is equal in two animals, one may have much larger lungs than the other. A deep chest therefore is not capacious unless it is proportionally broad.

\section{The Pelvis.}

The pelvis is the cavity formed by the junction of the haunch bones with the bones of the rump. It is essential that this carity should be large in the female, that she may be enabled to bring forth her young with less diff.culty. Wren this carity is small, the life of the mother and of her offspring is endangered.

The size of the pelvis is chiefly indicated by the width of the hips and the breadth of the twist, which is the space between the thighs.

The breadth of the loins is always in proportion to that of the chest and pelvis.

\section{The Head.}

The head should be small, by which the birth is ficilitated. Its smallness affords other advantages, and generally indicates that the animal is of a good breed.

Horns are useless to domestic animals. It is not dif. ficult to breed animals without them. The breeders of horned cattle and horned sheep, sistain a loss more extensize than they may conceive; for it is not the homs alone, but also much more bone in the skills of such anımals to support their horns; besides there is an additional quantity of ligament and muscle in the neck which is of small value.

The skull of a ram with its horns, weigh $c d$ fire times more than another skull which was hornless. Boih tinese skulls were taken from sheep of the same aq̧;, exch be ng 
fnur years old. The great difference in weight depended chiefly on the horns; for the lower jaws were nearly equal, one weighing seven ounces, and the other six ounces and three quarters; which proves that the natural size of the head was nearly the same in both, independent of the horns and the thickness of the bone which supports them.*

In a horned animal, the skull is extremely thick. In a hurnless animal it is much thinner; especially in that part where the horns usually grow.

To those who have not reflected on the subject, it may appear of little consequence whether sheep and cattle have horns-but on a very moderate calculation it will be found, that the loss in farming stock, and also in the diminution of animal food, is very considerable, from the production of horns and their appendages. A mode of breeding which would prevent the production of these, would afford a considerable profit in an increase of meat and wool, and other valuable parts.

The length of the neck should be proportioned to the height of the animal, that it may collect its food with ease.

\section{The Muscles.}

The muscles and tendons, which are their appendages: should be large; by which an animal is enabled to travel with greater facility.

* [It is matter of surprise that among the varieties of cattle imported, vo one should bring the celpbrated Suffolk pulled or hornless cattle. Besides the alvantage here enumerated, valuable animals are sometimes killed by heing gored. In respect of this breed, Yountt speaks very bighly. He says they sometimes give 32 quarts of milk, and 24 is not uncommon, in a day-and adds:- "There are few short-horn cows ; although far superior in size to the Suffulls, and consuming nearly double the quantity of fond; that will yiehl more milk than is usuallo obtained from the smaller p.)lled hremt." Formerly the sutfolk polleo cattle were generally of a dun colour, and thence commonly called suiolk duns, but that colour has of late heen repudiated.-J. S. S.] 


\section{The Bones.}

The strength of an animal does not depend upon the size of the bones, but on that of the muscles-Many animals with large bones are weak, their muscles being sinall. Animals that were imperfectly nourished d iring growth, have their bones disproportionately large. If such deficiency of nourishment originated from a constitutional defect, which is the most frequent cause, they remain weak during life. Large bones, therefore, generally indicate an imperfection in the organs of nutrition.

\section{On the improvement of Form.}

To obtain the most approved form, two modes of breeding have been practised-one, by the selection of individuals of the same family-called breeding $i n$-andin. The other by selecting males and females from different varieties of the same species; which is called crossing the breed.

When a particular varicty approaches perfection in form, breeding in-and-in may be the better practiceespecially for those not well acquainted with the principles on which improvement depends. *

*[Professor Youatt says, on this subject [brceding in-and-in]: "It is the fact, however some may deny it, that strict confinement to one breed, however valuable or perfect, produces deterioration." By what he afterward says, as will be seen, he must have meant confinement to one family or strain of the same breed. The rule should be this: that valuable qualities being once established, which it is desirahle to keep up, should thereafter be preserved by occasional crosses with the hest animal tc be had of the same breed, hut of a different family, This is the secret which has maintained the hred Horse in his great superiorityfor although, as Nimrod avers, the immediate descentants of eistern horses have, almost without an excepution, proved so deficiont of late years that breeders will no more have recourse to them than the farmer would go for immediate improvement to the natural or original oat ; yes the breecier is glad to cross his stock with one of another strain or family of the same blood, taking care never to depart from the blood of the south. eastern courser which flows in the heart of all families of Horses of th. bighost capabilities. 
When the male is much larger than the fernà.e, the oflspring is generally of an imperfect form. If the female be proportionally larger, the offspring is of an improved form. For instance, if a well-formed large rain be put w ewes proportionally smaller, the lambs will not be so well shaped as their parents; but if a small ram be put to larger ewes, the lambs will be of an improved form.

It is here worthy of remark that Nicholas Hankey Smith, who resided a long time among the Arabs, in a work entitled "Observations on Breeding for the 'Turf," gives as his opinion that colts bred in-and-in show more blood in their heads, are of better form, and fit to start with fewer sweats than the English turf-horse; but when the incestuous intercourse has continued a few generations, he says, the animal degenerates.

'This plan of breeding in-and-in, says Youatt farther, when speaking "f cattle : has many advantages to a certain extent. It may be pursued antil the excellent form and qualities of the breed are developed and established. It was the source whence sprung the cattle and the sheep of Bakewell, and the superior cattle of Colling-and to it must be traced the speedy degeneracy, the absolute disappearance, of the new Leicester or Bakewell cattle; and in the hands of many an agriculturist, the im. pairment of constitution and decreased value of the new Leicester sheep and the Short-Horn beasts. It has therefore become a kind of principlo with the agriculturist to effect some change in his stock every second or chird year-and that change is most conveniently eflected by introducing a new bull or ram. These should be as nearly as possible of the same sort coming from a similar pasturage and climate, but possessing no relationship, or at most a very distant one, to the stock to which he is introlucel" —and these remarks "apply to all descriptions of live-stock," says Professor Johnston, author of the Farmer's Cyclopedia.

This is the secret whereby Mr. Geonge Patrinson, of Maryland, has not only kept up but improved the size ard beauty of his North De. vons. Every "two or three years," a new bull the best to be had in England, is introduced to his cows. The neglect of this precaution, and breeding in-and-in too closely, are the true reasons why we so rarely see the descendants of imported stock in this country equal to the originals. Too close breeding tells in Man as well as in beast; hence the famous lines of Lord Byron when speaking of the nubility :

" They breed in-and-in as might be known,

"Marrying their cousins, nay. their aunts and nieces,

"Which ulways spoils the breed, if it increases."

But, after all, we must look closely to the form of the parents as well in Horses as cattle-for, let the world dispute as it may, whether "blood ss everything," or "blood is nothing." - be the blood what it mav, who bas ever seen, as Apperley asks, an instance of a mishlialen horse ard ill-formad mare proulucing winners?_. J. S. S.] 
The proper method of improving the form of animals, consists in selecting a well-formed female, proportionally larger than the male. The improvement depends on this principle, that the power of the female to supply he: offspring with nourishment is in proportion to her size, and to the power of nourishing herself from the excellence of her constitution.

The size of the fotus is generally in proportion to that of the male parent; and therefore, when the female parent is disproportionately small, the quantity of nourishment is deficient, and her offspring has all the disproportions of a starveling. But when the female, from her size and good constitution, is more than adequate to the nourishment of a fœtus of a smaller male than herself, the growth must be proportionately greater. The larger female has also a greater quantity of milk, and her offspring is more abundantly supplied with nourishment after birth.

To produce the most perfect formed animal, abundant nourishment is necessary from the earliest period of its existence, until its growth is complete.

It has been observed, in the beginning of this paper, that the power to prepare the greatest quantity of nourishment, from a given quantity of food, depends principally upon the magnitude of the lungs, to which the crgans of digestion are subservient.

To obtain animals with large lungs, crossing is the most expeditious method; because well-formed females may be selected from a variety of a large size, to be put to a well-formed male of a variety that is rather smaller. By such a method of crossing, the lungs and heart become proportionately larger, in consequence of a peculiarity in the circulation of the fœtus, which causfs a larger proportion of the blood, under such circumstances, to be uistributed to the lungs than to the other parts of 
the body; ard as the shape and size of the chesi denenc? upon that of the lungs, hence arises the remarkably large chest, which is produced by crossing with females thas are larger than the males.

The practice according to this principle of improve. ment, however, ought to be limited; for, it may be carried to such an extent, that the bulk of the body might be so disproportioned to the size of the limbs as to prevent the animal from moving with sufficient facility.

In animals where activity is required, this practice should not be extended so far as in those which are required for the food of man.

\section{On the Character of Animals.}

By character in animals is here meant, those external eppearances by which the varieties of the same species are distinguished.

The characters of both parents are observed in their offspring; but that of the male more frequently predominates.*

* To the contrary of this, as to Horess, T. B. Johnson, author of the Shooter's Companiun, and a writer of high authority, says : "although It is a maxim universally admitted, that an equal degree of precaution should be used in respect to the Horse, it is doubly and trebly necessary with the mare-because strict observation has demonstrated that nearly or full two out of every three foals, display in their appearance more of the dan, than the sire; and that there are more fillies than colts fallen every ycar will not admit of a doubt."

'I'his positively asserted predominance of females over males, may be sccounted for on the principle established by very numerous experinents in France with sheep, if not with other animals-on the results of which the experimenter, whose name is not remembered, hased and confidently asserted his theory, that the sex of the offspring, in all cases, depends much on the comparative vignur of the parents. By putting old ewes to young rams in the prime of life, he never failed to get arge proportion of ram lambs; and, vice versa, when young ewes is their prime were put to a ram lamb, which had not yet attained his tull growth anc development, or to old ones far gone in the down-hill of life, then a very large proportion were females. A great number of experiments wero given corroborative of the doctrine. Is it not reasonable to suppose that an influence sulficient to control the sex. would have an effect on exter 
This naty le illustrated in the breeding of horned $a_{\mathbf{x}} \mathrm{i}$. mals; among which there are many varieties of sheep, and some of cattle, that are hornless.

If a hornless ram be put to a horned ewe, almost all the lambs will be hornless; partaking of the charaster of the male rather than of the female parent.

In some countries, as Norfolk, Wiltshire, Dorsetshire, most of the sheep have horns. In Norfolk the horns may be got rid of by crossing with the Ryeland rams; which would also improve the form of the chest and the quality of the wool. In Wiltshire and Dorsetshire, the same improvements might be made by crossing the sheep with South Down rams.

An offspring without horns might be obtained from the Devonshire cattle, by crossing with hornless bulls of the Galloway breed; which would also improve the form of the chest, in which, the Devonshire cattle are often deficient.

Examples of the good effects of crossing the breeds.

The great improvement of the breed of horses in England arose from crossing with those diminutive Stallions, Barbs, and Arabians; and the introduction of Flanders mares into this country was the source of improvement in the breed of cart-horses.

The form of the swine has also been greatly improved, by crossing with the small Chinese boar.

Examples of the bad effects of crossing the breeds.

When it became the fashion in London to drive large bay horses, the farmers in Yorkshire put their mares to

nal iorm and colour? It may be a reason why some of our very popular suliions, being overtasked, have had so few of their get to rival them In power and fame. Every realer may cast ahout for himself, for instances, to see L.ow far and to what other animals the principle applies. After all, in an economico-agricultural view, it is much more important that the stallion should be all right because it is his hleod that is to bo diffused far and wide.-.J. S. S.] 
nuch larger stallions than usual, and thus, did infinite mischef to their breed, by producing a race of small chested, long legged, large boned worthless animals.*

A similar project was adopted in Normandy, to enlarge the breed of Horses there by the use of stallinns from Holstein; and, in consequence, the best breed of Horses in France would have been spoiled, had not the farmers discovered their mistake in time, by observing the offspring much inferior in form, to that of the native stallions.

Some graziers in the Island of Sheppey, concelved that they could improve their sheep by large Lincolnshire rams, the produce of which, however, was much inferior in the shape of the carcase, and the quality of the wool; and their flocks were greatly injured by this attempt to improve them.

Attempts to improve the native animals of a country, by any plan of crossing, should be made with the greatest caution; for, by a mistaken practice extensively pursued, irreparable injury may be done.

* ['This was the effect experienced in Maryland, by the use of Exile, a Cleveland bay, of the highest breeding of his sort in England, imported by the late Robert Patterson about the year 1820. At three years old, ne was advertised for sale, and stated to be then upward of 16 hands high.

They may do very well, with their long legs, long backs and long tails, for the heavy, lumbering slow coaches of millionaires, to drive to shurch, and occasionally to make a swell in town, but they are not fitted for the country - and especially not for this courstry. True, for the coach-horse we want substance, but we want that substance well placed, deep, well-proportioned body, rising in the withers, and slanting shoulders, short back well ribbed home, and broad loins; sound, flat, shurt legs, with plenty of bone under the knee; and sound, open, tough feet. "In fact, coach-horses should be nothing more than large hackneys, rarying in height from 15 hands 1 inch to 16 hands 1 inch." turuch lorses, of good colour, and well matched, will always command a ti: rh figure from the swelled heads in our large cities-men who have grous rich as the conduits of exchange. hetween the producer and the ine numer of Agriculture and Manufactures. - '. S. S.] 
In any country where a particular race of animals uas contmued for centuries, it may be presumed that their constitution is adapted to the food and climate.

The pliancy of the animal economy is such, as that an animal will gradually accommodate itself to great vicissitudes in climate and alterations in food; and by degrees undergo great changes in constitution; but these changes can be affected only by degrees, and may often require a greater number of successive generations for their accomplishment.

It may be proper to improve the form of a native race, nut at the same time it may be very injudicious to attempt to enlarge their size.

The size of animals is commonly adapted to the soil which they $i$,habit; where produce is nutritive and abundant, the animals are large, haring grown proportionally to the quantity of food which for generations they have been accustomed to obtain. Where the produce is scanty, the animals are small, being proportioned to the quantity of food which they were able to procure. Of these contrasts the sheep of Lincolnshire and of Wales are examples. The sheep of Lincolnshire would starre on the mountains of Wales.

Crossing the breed of animals may be attended with bad effects in various ways; and that, even when adopted in the beginning on a good principle; for instance, suppose some larger ewes than those of the native breed were taken to the mountains of Wales and put to the rams of that country; if these foreign ewes were fed in proportion to their size, their lambs would be of an improved form and larger in size than the native animals; but the males produced by this cross, though of a good form, would be disproportionate in size to the native ewes; and therefore, if permitted to mix with them, wouls? be pro luctive of a standing ill-forned prugems 
Thus a cross which, at first, was an improvement, would, by giving occasion to a contrary cross, ultimately prejudice the breed.

'The general mistake in crossing has arisen from an attempt to increase the size of a native race of animals; being a fruitless effort to counteract the laws of nature.

The Arabian Horses are, in general, the most perfect in the world; which probably has arisen from great care in selection, and also from being unmixed with any variety of the same species, the males have therefore never been disproportioned in size to the females.

'The native Horses of India are small, but well proportioned, and good of their kind. With the intention of increasing their size, the India company have adopted a plan of sending large stallions to India. If these stallions should be extensively used, a disproportioned race must be the result, and a valuable breed of Horses be irretrievably spoiled.

From theory, from practice, and from extensive observation, whicn is more to be depended upon than either, it is reasonable to form this conclusion, that it is wrong to enlarge a native breed of animals; for in proportion to their increase of size, they become worse in form, less hardy, and more liable to disease.*

- For this plain reason, our farmers should have recourse to well-formed bulls of a smaller or middling size, rather than to those of a larger brend than the average size of their own cattle, and also why it is far better to empliny compact, short-backed, well-formed, thorough-bred stallions, than cold-blonded stallions of larger size.

Essential difference has been found, by analysis in France, hewwen the blund of the ordinary Horse and that of the aristocratic iace descended from the south-eastern courser. It is stated to be less serous than that of the common Horse. One cannot lut almire the ardour with which, in France, they are now applying the sciences to enlighten all branches of agriculture, as it has been so much more and more successfully applied to other inilustrics. A society of the first men of that country is devoted to the mrliurution of the Hurse, and they under take to predict the time nut distant when "la science "lu shev'al," tho 
science of the anatomy and physiology of the Hursp - wih he as well understood and agreed upon as any principles in lieometry.

The reason that, in our country, agriculture has henetited so much less by the application of the sciences, is that the policy of the government has a tendency to disperse them, while it concentrates other classes Instead of compelling the consumer - the shoemaker, the tailor, the wheelwright, and all manufacturing consumers to come frotn abroad as well as at home, and settle down nearest to them, the agriculturists Coster a policy which compels them-over bad roads-to expend half tho produce in carrying it to the fashioner and consumer. - J. \$. \$.] 
BN THE MPORTANCE MF MORE ATTENTION TO THE. PRINCIPLES OF BREEDING-TLE STALLION AND THE BROOD MARE.

To every lover of the Horse, possessed of a knowledge of his fine points and capabilities, it must be lamentable to perceive how miserably ignorant and careless the mass of breeders of that noble animal appear to be, as to all the precantions which are indispensable to maintain him at the point of excellence which is known to be attainable -much less by well-digested and rational systems of breeding and rearing throughout the country, to meliorate his form and invigorate his constitution; and on no one roint is there, seemingly, more pernicious indifference displayed than in regard to the condition of the stallions they employ, as set forth in the Essay which these remarks are intended to introduce.

Well has it been said, in the introduction to the " $A n$ nales des Haras ei de l'Agriculture," that if the importance of a question is to be measured by the number of those who are occupied with it, that of the multiplicat. and of the amelioration of the Horse ought to hold the first rank in Political and Rural economy. The traditions of antiquity - those of nations, whether barbarous or prlightened-writings the most ancient as well as the zost modern-prove to us i e estimation which Man, m all times, has attached to this his most noble conquest, to use the expression of Bufrov. The Horse, as there alleged, is in truth the most fruitful scurce of the riches of States, by his indispensable instrumentality in the cultivation of the soil. He is one of the most direct ugents of their power by the use that is made of him in armies, whether in peace or in war; and has contributed zuch move than is generally considered, to the civiliza 
ton of communities, by facilitating intercourse betwees. them and the individuals of whom they are composed.

It is not, then, astonishing that in the abstract, so much importance should be attached to the multiplication and improvement of an animal so useful; but is it not smazing that this universal admission of his value, and the general interest of society in cultivating his finest qualities, should give rise to no association or system in our country, based on reason, and guided by scientific principles? On the contrary, everything is left to chance, to ignorance, and to narrow and sordid calculations of economy. True, we have societies that group the Horse with every other animal and thing, and offer petty pre miums for the mere exhibition of the best that may happen to be convenient to, or purchased for the show: but shou'd not an object so important be made the sub ject of special associations, and of legislative encouragement, directed to a thorough investigation of the princ1 ples to be followed in all enlarged and judicious plans for the melioration of the whole race? Look at the amount of capital involved in the whole Union-4,365,669 horses. Value these at an average of $\$ 50$, and we have a capital of $\$ 218,283,450$, which, with anything like judgment or system, might be brought to an average improrement of at least twenty per cent. in a few years. What is the number lost by exposure to sudden ricissitudes of weather - to lad shoeing - in short, to ill treatment and ignorar:e of the management and the remedies prescribed in this work, no one can venture to estımate. Youait sets down the loss of cattle by disease annually in England at $\$ 50,000,000$ !- and the loss of sheep at one-tenth of the whole number; and though there the veterinary art is taught as a science in the endowed colleges, and regrular professors practise it Lhoughour the kingdom, he says it is difficult to say 
wI " $\mathrm{A}$ is the greater source of this inmense loss to the agriculture of the country - " the ignorance and obstinacy of the servant and the cow-leech, or the ignorance and supineness of the owner." The Horse, in a state of nature, even the colt-until subjected to ignorant handling and cruel management, is much healthier than after he comes under the hands of him who ought to be his kindest friend.

If such be the immense mortality in England, what nust it be among Horses in this country, where not one farmer in a hundred knows how to tell the colic from the botts, or the thrush from the scratches - ignorant alike of symptoms and of treatment?

Properly appreciating the importance of a constant supply of Horses for their cavalry, as one of the most efficient arms of her military power-the French Government takes it upon itself to supply its thirty-six thousand communes with stallions, whose services are put at the lowest rate, the arerage being set down at 5 or 10 francs, (one or two dollars,) and these stallions are required to be not under a certain age-four at the least-nor under a certain standard of height, according as they are thorough-bred, half-bred, or slow draft: $1 \mathrm{~m} .49$ centimes, or a fraction over 14.2 for thorough-bred; $1 \mathrm{~m} .55 \mathrm{c}$. for half-bred; and $1 \mathrm{~m} .55 \mathrm{c}$. for heavy draft stallionsand undergo every year rigid inspection, to guard not only against palpable deformity of shape, but against any latent or transmissible diseases. Opposed as is the genius of our political institutions to regulations, too minute, of individual industry and concerns, yet it is hard to say why a planter's tobacco or his butter should be subjected to rigid inspection, and condemned and taken from him for bad quality or short weight, and yet that any fat, lazy, lounging rapseallion should be allowed to set up a public stallion without spirit or antion, anu 
to often tainted with some hereditary disorder or defec: of body or temper-to deform and poison everything he ss allowed to touch. The Arabians, after having brought their breed of Horses to the highest degree of perfection of which they consider them capable, are said to have preserved their splendid qualities of great endurance. with highly organized matter and natural soundness of limb, by prohibiting the use of stallions until approved by a public inspector. "Breeders of all kinds of Horses," says Nimrod, "but of the race-horse above all others, scarcely require to be cautioned against purchasing or breeding from mares, or putting them to stallions, constitutionally inferior. By constitutionally inferior is chiefly implied, having a tendency to fail in the legs and feet during their training, which too many of our present racing breed are given to-although the severity of training is not equal to what it was some years back. It would be invidious to particularize individual sorts; but, says he, we could name stallions and mares from which the greatest expectations were raised, whose progeny have sacrificed thousands of their owners' money, entirely from this cause." After instancing numerous cases to show the heritableness of diseases-glanders among others - of horses, sheep, and cattle, " these considelations," continues an eminent French writer, Professor Dupuy, on the Veterinary art, "are to us of the greatest moment, since we have it in our power by coupling and srossing well-known breeds, to lessen the number of animals predisposed to these diseases. Acting up to these ideas, our line of conduct is marked out. We must hanish from our establishments, designed to improve the breed, such animals as show any signs of tuberculous disease or any analogous affection."

Thus much have we felt called upon to say, introductory of the following able dissertation or the condition 
of the stallion - anonymously written by some geutle. man who has evidently observed the precaution tow often neglected; to understand his subject, before he oegan to speak upon it. It is taken from the "Farmers' LiBRARy," for which it was written, and where, it may be needless to say, such writers will always be truly ..elcome. As against the assertion of Surgeon Cline, with whom the author of this Essay agrees as to the predominant influence of the male in character.zing the progeny, we have, in another place, arrayed the opinion of Mr. Johnson, it is but fair here to adduce, in support of the affirmative side of the proposition, the all-powerful testimony of Mr. Apperly, who says: "Virgil, in his excellent remarks on breeding Horses, tells those of his readers who wish to gain prizes to look at the dam; and until of very late years, it was the prevailing opinion of Englishmen that in breeding a racer the mare is more essential than the Horse, in the production of him in his highest form; and we know it to have been the notion entertained by the late Earl of Grosvenor-the most extensive though not perhaps the most successful breeder of thorough-bred stock that England ever saw. The truth of this supposition, however, has not been confirmed by the experience of the last half century, and much more dependence is now placed on the stallion than on the mare. The racing calendar, indeed, clearly proves the fact.

"Notwithstanding the prodigious number of very highly bred and equally good mares that are every year put to the horse, it is from such as are put to our very best stallions that the great winner's are produced. This can in no other way be accounted for than by such horses iaving the faculty of imparting to their progeny thr: peculiar external and internal formation absolutely assen. sial to the first-rate race-horse; or, if the trorm 'blona' 
be insisted on, that certain innate but not preternatura virtue peculiarly lelonging to some horses, but not to others, which, when it meets with no opposition from the mare-or, in the la:nguage of the stable, where 'the cross nicks' by the mare admit of a junction of good shapesseldom fails in producing a race-horse in his very best form."

After all, when the reader shall have carefully perused the following disquisition, he will, we think, be apt to concur with us in the belief that incalculable loss and deterioration ensue from an almost universal want of attention to the condition of the stallion, and from ignorance in what true condition consists. The maxim of the feeder of the ox may be embraced in the words warmth, cleanliness and quiet. Not so with the grazier of stock-cattle-for they may be kept too warm; nor with the owner of a Stallion; yet too generally they manage him as if he had nothing to do but to eat, drink, and sleep-except when suddenly aroused to go through violent agitation to the opposite extreme.

-On the subject of the comparative agency of the male and female parent in the modification of the progeny in form and character, as sir Roger expressed it " much may be said on both sides." There needs no citation is instances to show the influence of the male progenito: in modifying the exterior form and colour, of the off spring, and may we not infer it in regard to its internal structure, its temner and character? Neither can we ueny the share of the female parent in the same influences - see how ofien the calf, in its marks, exhibits an exact cupy of its dam. But there are cases of what is called superfotation, which go to show some extraordinary power of the male in transmilting his influence even tc the second and third generation on the fruits of subsequent concentions from sexual intercourse between the 
sane dam and other males. No fact in Natural Itistory need to be better proved; and circumstances lead us is believe, though we are not aware that the question has occurred to naturalists, that this always occurs with the first or virgin conception; and if so, it admonishes the breeder to be especially particular in the selection of the male to which is granted the high privilege of the first access. Out of many cases that might be referred to, the reader's memory may be here refreshed as to two that are somewhat familiar.

Twenty-six years ago, in the London Farmer's Journal was recorded the ease which had then lately appeared in the Philosophical Transactions, on the authority of Eari Moreton, stating that his lordship possessed a male animal called Quagga by the Hottentots - in whose mountains they abound. It closely resembles the Zebra, but of a smaller size. He determined on obtaining a foal by this animal, from a chestnut-coloured mare of seven-eighths blood, which had never been bred from. This gross prostitution-as we should call it-took place, and accordingly a female hybrid progeny was produced, which bore, in form and colour, decided indications of mixed blood, but proved incapable of breeding-as is almost universally the case with mules; but not quite, as the writer has proved in his edition of Youatt on the Horse, (Lea \& Blanchard,) on the most unquestionable testimony.

This mare of seven-eighth Arabian blood was soon after sold to Sir Gore Ousley, who afterward bred from her, by a very fine black Arabian stallion, two colts. These Lord Mloreton went to see and examine,- the one a two-year old filly; the other a yearling colt-both of which were as strongly characterized by Arabian bloos as might be expected where there was fiftern-sixtentha of it present-but both in their colour ard has of thei manes, they showed a striking resemblawe t the (u igga 
The whole statement was fully verifie to the Society by Doctor Woolaston, a member of it, who examined both the filly and colt, and who was "distinguished for his very extensive knowledge."

Following the cornmunication of Lord Moreton $i_{1}$ the Transactions, is one from Dr. Woolaston, relating the case of a black and white sow, of Mr. Western's celebrated breed of hogs (she being the property of a $\mathrm{Mr}$. Giles) which was put to a wild boar, of a deep chestnut colour, that was sonn after by accident drowned. The pigs produced, which were the sow's first litter-partook in appearance of both boar and sow, but in some the chestnut colour of the boar strongly prevailed. This sow was afterward put to a boar of Mr. Western's breed. The pigs produced were some of them stained and clearly marked with the chestnut colour which had prevailed in the former litter. Her next litter, by a boar of Mr. Western's spotted, black and white breed, were also stair.ad with marks of the wild boar - although in no other .nstance, with any other sow, had the least tinge of the chestnut colour been observed.

Another very striking instance of the transmissible infuence which survives the $f$ st and impresses itself on subsequent conceptions, oce red under the observation of the writer of this, and wa it is believed, related in a small volume scribbled and hlished under the title of " The Sportsman and his Dog." "The case was that of a beautiful coach-dog bitch, Annette, presented to him by that earnest and efficient promoter of agricultural improviment, Gormam Parsons of Massachusetts, along with her full brother, Lubin. Though closely watchec for the first signs of sexual anpetite, with a view to a litter of the genuine breed for the great pleasure of giving them to friends to whom they were promised, a stray log, of large size, of white colour, except his tlack ears 
contrived $\therefore$ steal the first access to the bitch, and in all subsequent litters, by Lubin, one pup always appeared to aitest the indelible impression made in the enthusiasin of a first cmbrace. It may gratify curiosity to note such facts, and may serve, beyond all dispute, to show how cautious every breeder should be in the choine of the male-especially the one first employed.

But how vain to endearour to account for these things! Nature invites us to study her ways, and science is most efficiently applied to every art and every industry, when it most closely conforms to her laws: but she has certain arcana of her own, which she keeps in reserve, and which defy the scrutiny of the most curious and importunate inquirer. We see enough to know that her laws are enacted by an All-Wise and Overruling Power; and can never be too grateful for the faculties that enable us, so much above other created beings, to study and understand them, and yet more for that hopeful thirst for knnwledge which is leading us on from one discovery to another, until, in view of what science is revealiris from year to year, who shall say how near we mas Le permitted to approach the Supreme Intelligence? Os that our love of peace and of each other, may kefp, way wist our progress in knowledge!- - for of those to whom much is given, much shall be required-else, ras it been wes ssked,

"why was Man thus emistently raised

A mill the vast creation? Why err.poswered,

Through life and death, to cast his $\alpha$ atchiful eye

With thought beyond the limits or his frame-

But that the Omaipotent might sand him forth

In sight of angels and approvity worlds:

Might send him forth the soveraign good to learn ,

'To chase each meaner passion from his freast,

And through the storms of prassion and of sense

'To hold straight on, with constant heart, and eye

sitill fixed upou Man's cverlasting palm,

'The approving smile of Heaven." 
'There is, as elsewhere intimated, if we consult Natire, always acting for the best, - reason to conclude it was mtended, with domestic animals, that the male should exert the greater influence over the form and qualities of the progeny. Were it not so, how slow and incffectual would be all attempts at amelioration, for it is through one male that blood and form and qualities are imparted to great numbers-while, with the female, but a solitary effect or result can be accomplished during a whole period of gestation. In herds of wild Horses, Nature allows troops of mares to be engrossed by the stallion of most courage and strength, thus guarding against the inevitable degeneracy of promiscuous intercourse-and he again, after a season or two, is supplanted by some rebellious young rival, stronger if not braver than he, before time enough has elapsed to stamp the whole race by that degeneracy which follows in.est tous intercourse long continued. Here again we are iıvited to follow, and, as art may always do, improve upon, if we do follow, the laws of Nature. But, alas, of breeders of animals it may be said, "6 they have sought out many inventions" that violate her laws, and the consequence is, a miserable race of ill-formed, decrepit garrans, it neither for harness nor saddle, for the road or the r'sase, for peace nor for war, nor tos anvthing but-dog's meat. 


\section{AN ESSAY ON TIIE CONDITION OF A STALLION}

The word condition is used by horsemen in a differeni sense from that in which it is understood as applied to. cattle by the mass of farmers. By condition the farmer often means a high state of fatness; the horseman, on the contrary, makes use of the word to indicate the greatest health and strength produced by reducing all superfluous fat, bringing the mere flesh into clean, hard and powerful muscle, and invigorating the lungs and other internal organs, so that they may promptly discharge their respective functions, and suffer no damage from uncommon stress-the whole in order to the animal's performing labours and sustaining a continuance of action to which he would not be adequate without such especial preparation.

By the Condition of a Stallion is meant the state of the system in which the male horse should be kept, in order to deriving from him the greatest excellence in the progeny.

Too many persons are content to breed their mares to a horse whose figure suits them, without regard to his condition. The mention of one prominent instance alone will be sufficient to show that good condition is essential to the production of a valuable progeny. A remarkable case ocrurred in England some years since, in so high a quarter as to attract public attention, and consequently th 2 fact of the account's obtaining currency without contradiction is a fair evidence of its correctness. The Prince of Wales, who afterwaru's became George the Fourth, owned, and was in the habit of riding as a hunter, an entire horse of unequalled excellence. In consequence of this horse's superior qualities, His Royal Highness eaused a few of his own mares to be bred is 
nim in the spring, after he had been kept in the highesi condition as a hunter throughout the winter, and the produce, on growing up, proved every way worthy of their sire. When His Royal Highness, as Prince Regent, became seriously engaged in the cares of Government, and therefore relinquished the pleasures of the chase, being desirous to perpetuate the fine qualities of this stock, he ordered the horse to be kept at Windsor for public covering, prorided the mares should be of the first quality; and in order to insure a sufficient number of these, directed the head groom to keep him exclusively for such, and to make no charge, with the exception of the customary gronm's-fee of half a guine'a each. The groom, anxious to pocket as many half guineas as possible, published His Royal Highness's liberality, and raunted the qualities of the horse, in order -o persuade all he could to avail themselves of the benefit. The result was, the horse being kept withou. his accustomed exercise and in a state of repletion, anc serving upward of a hundred mares yearly, that the stock, although tolerably promising in their early age, shot up intu lank, weakly, awkward, leggy, good-for-nothing creatures, to the entire ruin of the borse's character as a sire-until some gentleman, aware of the cause, took pains to explain it, proving the correctness of their statements by reference to the first of the horse's get, produced under a proper system of brededing, and which were then in their prime, and among the best horses in England.

Almost every observing farmer in this country has semarked that whenever, within his knowledge, an ordinary work-horse has, by chance, covered a tolerably good mare, the foal thus produced has, at maturity, almost invariably become a better animal than it was expected to be, and in many cases proved quite superior to the get of the high-priced and highly pampered stal- 
uous of the neighbourhood. What was the cause of this: Condition. The work-horse, by constant aud severe exercise, was brought into health and strength, and his stock partook of the state of his system at the time or copulation. Why is it that many experienced farmers, after having tried the best stallion within theis knowledge, frequently resort to the keeping of one of theis own colts or farm-horses entire, for the service of their mares, and actually obtain as large and as good and saleable stock from such a one, as that fiom the public stallions of far superior size, form, blood, and all other qualities, except this indispensable condition?

It may be stated that, generally, whenerer the get of a stallion has proved, at maturity, to be of remarkable excellence comparatively with the sire, such horse has been, at and previously to the time of getting such valuable stock, kept without pampering, without excessive sexual service, and with a good share of exercise or lacuur.

To show the effect of a peculiar state of the system in the parents at the time of copulation, instances may be cited from various sources. We will content ourselves with two-and first take a lamentable case in the human species as given in the raluable work on "The Consti. tution of Man," by George Combe:

"In the summer of 1827 , the practitioner alluded to was called upon to risit professionally a young woman in the immediate neighbourhood, who was safely delivered of a male child. As the parties appeared to be respectable, he made some inquiries regarding the ausence of the child's father, when the old woman told him that her daughter was still unmarried; that the child's fathor belonged to a regiment in Ireland ; that last autumn ne had obtained leave of absence to risit his friends in this part of the country, and that, on the eve of his de 
parture tis join his regiment, an entertainment was given, at which her daughter attended. During the whole evening she and the soldier danced and sang together; when heated by the toddy and the dance, they left the cottage and after the lapse of an hour were found together in a glen, in a state of utter insensibility, from the effects of their former festivity; and the consequence of this interview was the birth of an idiot. He is now nearly six years of age, and his mother does not believe that he is able to recognise either herself or any other undividual. He is quite incapable of making signs whereby his wants can be made known, with tr. is exception, that when hungry he gives a wild shriek. This is a case upon which it would be painful to dwell, and I shall only remark that the parents are both intelligent, and that the fatal result cannot otherwise be accounted for than by the almost total prostration or eclipse of the intellect of both parties from intoxication."

For another instance of a peculiar constitution derivec from a parent at the time of copulation, and owing to $\varepsilon$ temporary excitement of the animal, a respectable farmer related to the writer of this Essay that he witnessed the effect of pain and nervous agitation on a stallion just before the moment of covering, in the production of a wild, timid, violent and worthless colt. 'The sire was in repute as one of the best horses ever kept in the dis trict; and his stock afterward justified the opinion. The groom became angry and beat him in his stall in a cruel manner, and then led him out and allowed him to cover the mare, which was one of a perfectly quiet and ordmrly temper. The consequence was the production $n^{*}$ an animal totally valueless, as above mentioned.

That the doctrine here held is no " new thing uncler the sun" is evident from many venerated authors. Plutarck, says "The adrice which I am now about to give, 
is indeed no other than what hath been given by those who have undertaken this argument before me. You wll ask me what is that? 'l'is this, that no man keep company with his wife for issue sake, but when he is sober-as not having before either drunk any wine, or, at least, not tc such a quantity as to distemper him; for they usually prove wine-bibbers and drunkards whose parents begot them when they were drunk; wherefore, Diogenes said to a stripling somewhat crack-brained and half-witted, 'Surely, young man, thy father begot thee when he was drunk?" "

Shakspeare intimates the same belief in making a hero insult his enemies with the taunt

\section{"For ye were got in fear."}

On no other known priıciple than this condition, or a peculiar state of the system at and before the time of copulation, can be explained the important fact which forms at once a criterion of skill in the scientific breeder, and a stumbling-block to the ignorant and unreasonable one, who would expect success without giving himself the trouble of investigating the natural laws which govern the subject of his operation: such a person is too apt to argue within himself that because the same parents at different times produce offspring of opposite characteristics, there can be no certain rules by which to create determinate qualities in the progeny: such a one would maintain that, because all the children of one married couple are usually somewhat different in characteristics from each other, there can be no means of predicting, with an approach to certainty, the qualities to be produced in the offspring by a particular sexual intercourse Now this law of condition accounts for the diflerence between individuals produced at several births from the same parents. The case of twins, in the human species, Rerves to strengthen this argument, inasmuch as the twn 
frersons produced at one birth usually beas a close resem ilance to each other, in all respects.

It is known that ideal impressions on the femal parent, subsequent to conception, frequently take permanent effect on the offspring. That such causes do not usually give the leading characteristics to the progeny, is evident from these considerations:

1st. The consequences of such impressions on the female, are usually somewhat of an unnatural or monstrous order, being different from the traits of either parent, and from the common nature of the variety to which the animals belong.

$2 d$. It is a settled point with breeders that the pro geny is more strongly characterized by the traits of the male, than by those of the female parent. This fact is well known; and indeed it can hardly be expected otherwise than that the sex which bears so much the stronge. impress of character, should impart the more visible re. semblance to the offspring.

$3 \mathrm{~d}$. It is an ascertained law of Nature, that peculiar. ities of climate, food, occupation and most other circurn stances affecting the well-being of an animal, produce in its constitution a change such as is necessary for the welfare of the species; and that this proceeds throughout many generations, until the animal becones completely adapted to the circumstances of its existence. [The same thing occurs in the regetable lingdom.]

This last consideration, of the gradually aliered state of an animal through successive generations, is a strong instance of the effect of condition ; and it is by a regard to this invariabie law of Nature, of self-adaptation to circumstances, that the cultivation or improvement of any oreed is to be effected. "Hence the most acid and worthless grape is by skilful culture rendered sweet and uscinus, flowers without attraction are gradua!ly mist ured 
into beauty and fragrance; the cat may be made to present all the rich colours of the tortoise-shell, and the pigeon may be "bred to a feather." "

Let us now endearour to deduce a useful, practical conclusion from the foregoing arguments. If our loctrine be correct, the horse-breeder will depend upon the condition of the stallion, in order to the producing of valuable stock from him, as well as upon his other qualities of pedigree, speed, action, bottom, wind, temper, spirit, form, style, size, colour, \&c.

The next practical question is, how this condition is to be attained, and how the animal is to be kept at the required standard in this respect. The requisite condition is only to be attained by truining for health and strength in a great measure according to the system of training for races: supplying an abundant nourishment of the best quality, allowing sufficient periods of repose for $\mathrm{d}_{\mathrm{l}}$ gestion, and giving regular and strong exercise, the whole with such variations as only experience and close observation, under constant practice, can dictate.

The aptitude of an animal to benefit by training is often inherited, like other qualities, from its parentage; and judicious breeding alone can insure a continuance of the desirable quality, or create a propensity for it by proper crossing, when it does not exist in the parents.

The age at which the horse is best adapted to undergo a course of training, is just at the close of his most ripid period of growth, while the system is in its greatest freshness and vigour. This period is at abo $\sim$ five years old. The powers of a horse will augment by suitable treatment in this respect until about the age of nine years: and, in order to obtaining the most valuabie stock, a sta!lion should not be put to service before attaining a fuil deiglopment of his powers, nor kept at it after his furm or energies appear to be affected for the 
worse. He should be, then, between five and fifteen years of age, if of an ordinary constitution; but if of remarkable energy and endurance, and exhibiting no symptom of debility, may be continued until past twenty.

Trainers find their endeavours to produce the highest state of strength, in an animal, greatly impeded by any excitement of the sexual appetite. It is then the more necessary to keep the horse in a state of training throughout the year, impressing most forcibly a tone of health and strength upon his system at the time when his nerves are liable to the least distraction; and continuing the course carefully thoroughout the season of copulation; never allowing such excess of service, or of the excitement of sexual appetite, as to induce a disturbance of spirit or temper, or a relapse from the most thoroughly strong, healthy and regular tone of the systrim.

G. B. 


\section{T A B I E S.}

TuE following Tables may be so often useful to the classes of persons for whom this work is intended, that it has been thought expedient to give them a place.

The list of medicines embraces such as ought to be kept constantly on hand, not only in every traininto and livery stable, but by every farmer and breeder who aspires to good management, and to deserve the praise of all men who happen to visit his establishment, and who know, as the French say, what is comme il faut. Some other medicines might well be added, but it is thought best not to leave any excuse to the indolent and improvident to say tna: too much is required-but we will begin with

\section{WEIGHTS AND MEASURES.}

A pothecaries' or Troy weight is most usually employed in medi cing. In this, a pound contains twelve ounces:

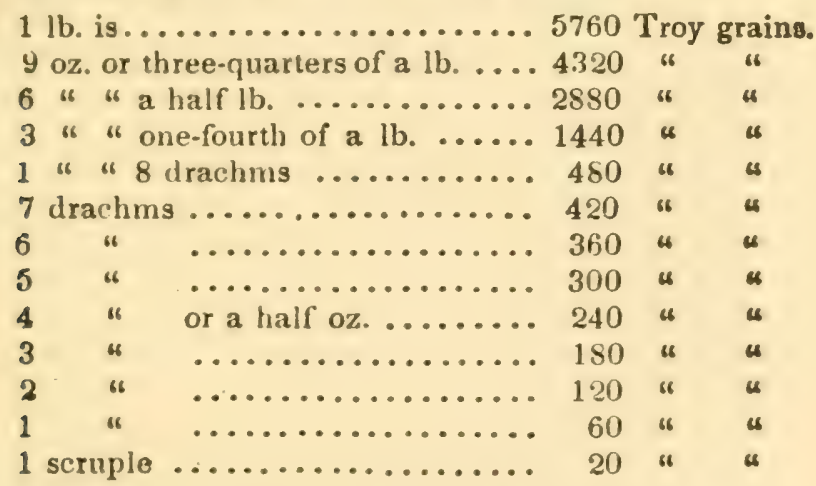

APOTHECARIES' WEIGHT.

Twenty grains ................ one scruple

Three scruples ................. one drachrs

Eight drachms ................ one ounce.

Twelve ounces ................. one pound.

MEASUIE OF FLUIDS,

Sixty drops ............... one fluid drachn.

Eight fluid drachms .......... one fluid ounce.

Four fluid ounces ........... a measure or nagy.d.

Sixteen fluid ounces .......... one flitid plizt.

Eight tluii pints............. one gallon. 


\section{I.IST OF MEDICINES,}

And otier articles which ought. to be at hand about every training and livery stabie, and every Farmer's and Breeder's estaolishment:

MEDICINES.
Aloes, Barbadoes,
Aluni,
Arrow Rnot,
Bas:icon, yellow,
Cimphor,
Castile Soap,
Goulard's Extrach
Honey,
Hog's Lard,
Linseed Meal,
Nitre,
()il of Caraway,
Oil, Castor,
Oil of Cloves,
Dil of Olives,
Harwhorn,

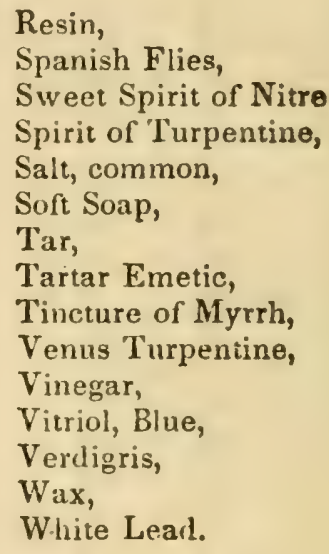

Apparatus for Compounding Medicines.

A box of small weights and scales, for the weighing of medicines in small portions, as from a grain to two drachms - the weights marked with.English characters.

One pair of two-ounce scales; one pair of pound scales, one pound of brass box-weights.

A gradnated glass for the measure of fluids, marked with English tharacters.

One large and one small pestle and mortar.

One marble slab, a font and a half square, for mixing ointments.

One large and one small ladle.

One large and one small pallet knife-to mix and spread plasters

Articles necessary to be kept for admunistering and applying Medicines.

Improved Ball Iron.

Drencining horn.

Flannel-for the app.ying of fornentations and poultices.

Woollen and linen bandages.

Tow, and broad coarse tape.

\section{Instruments.}

Stomach-pump,

Eiasti: tube,

Fleam and blood stick,

Anscess lancet,

looth rasp, with a guard,
Seton, and curved needles,

Improved easting lobbles,

Brushes, surryermbs, \&c., of course 


\section{CALVING TABLE.}

\begin{tabular}{|c|c|c|c|c|c|c|c|}
\hline Day Bulied. & IWill Calve. & Day Bulled. & Ivill Calve. & Day isulled. & IWill Calve. & Day Bulled. & $\left|w_{1}\right|$ \\
\hline Jan'y 1 & Oct'r 8 & April 1 & Jan'y 6 & July 1 & April 7 & Oct'r 1 & July \\
\hline & " 14 & 7 & " 12 & 7 & " 13 & 7 & " 15 \\
\hline " 14 & " 21 & 14 & 19 & " 14 & 20 & 14 & 22 \\
\hline 6. 21 & " 28 & 21 & 26 & " 21 & " $2 S$ & 21 & 29 \\
\hline " 28 & Nov. 4 & " 28 & Feb'y 2 & $\begin{array}{ll} & 2 S\end{array}$ & May 4 & “ 28 & Aug. 5 \\
\hline " & & " 30 & 4 & " 31 & 8 & " 31 & 8 \\
\hline Feb'y 1 & & Hay 1 & 5 & Ang. 1 & 9 & Nov. 1 & 9 \\
\hline & "14 & & 11 & 7 & " 15 & "6 & 15 \\
\hline " 14 & " 21 & " 14 & $1 \mathrm{~S}$ & " 14 & " 22 & " 14 & 21 \\
\hline " 21 & " 28 & " 21 & " 25 & " 21 & " 29 & “ 21 & 29 \\
\hline “ 28 & Dec'r 5 & " 28 & Mar. 4 & “2S & June 5 & " 28 & Sept. 5 \\
\hline Mar. 1 & "6 6 & " 31 & & " 31 & 8 & 30 & \\
\hline & " 12 & June 1 & 8 & Sept. 1 & & Dec'r 1 & 8 \\
\hline " 14 & " 19 & & 14 & 7 & " 15 & 7 & 21 \\
\hline 21 & “ 26 & 14 & 21 & " 14 & " 22 & " 14 & 21 \\
\hline 28 & Jan'y 2 & 21 & “ 28 & 21 & " 29 & 21 & 28 \\
\hline 31 & & " 28 & April 4 & $2 s$ & July 6 & 28 & Oct'r 5 \\
\hline & & 50 & & 30 & " & 31 & \\
\hline
\end{tabular}

\section{LAMBING TABLE.}

\begin{tabular}{|c|c|c|c|c|c|c|c|}
\hline$\underset{\mathbf{R}}{\mathbf{W}}$ & Will Lamb. & R & to. & to & Wil! & to & an \\
\hline & & & & & & & \\
\hline & & 14 & & " 14 & & " 14 & 10 \\
\hline 'y 1 & 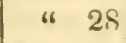 & May 1 & " 22 & Aug. 1 & 26 & Nov. 1 & 26 \\
\hline " 14 & July 12 & " 14 & Oct'r S & "6 14 & Jan'y 8 & "6 14 & April 9 \\
\hline Mar. 1 & " 26 & June 1 & “ 25 & Sept. 1 & " 26 & Dec'r 1 & \& 25 \\
\hline 10 & Aug. & 14 & , & "6 14 & , & 14 & . May \\
\hline
\end{tabular}

\section{TO THE PUBLISHERS.}

Snouln you have anywhere a spare corner, please enter a protest in my uame, against the cruel practice recommended, of firing for the lampas; which talies its name from the brutal custom among ofd farriers, but now alsandoned in England, of brorning the swe.ling down with a red-hot lamp-iron. In most cases, it will soun oubsicle of itself, especially if a few mashes be glveu, aided by a gentle alterative. If need be, a few moderate cuts may be malle across the bars with a pen-knife.

Founder may be cured, and the traveller pursue his journey the next day, oy giving a table-spoonful of alum! This 1 got from Dr. P. Thornton, of Montpelies, Rappaliannoc county, Virsinia, as founded $\mathrm{cn}$ his own observation in sevesal cases. 


\section{TR 0 T T IN G.}

Tars s a gait held in high estimation in the northern parts of the Onited States, and in Canada; especially when a horse can go his mile within three minutes. Then, as he falls by seconds, his value rises by guineas. In the south, gentlemen don't "cotton" to sucts action; though a passion for this sort of equestrian display is travel!ing towards the land of the marnolia grandiflora, with some other changes less compatible with their ancient high-born chivalry.

On the good old track at Charleston, among gentlemen who have never let the old Huguenot fires go down, you rarely see a snuffiebridle, or what is called a "goer!" They have an eye and a hear" for a good horse; but choose to retain the power of throwing him on his haunches when occasion may demand it.

It is, we belicve, a rule on all courses in the United States, that the jockey's weight, in a trotting race, whether in harness or saddle, must be not under 145 pounds.

In harness, simply signifies a sulky, as light as the owner may choose. They generally weigh from 75 to $125 \mathrm{lbs}$. The weight of a trotting wagon is from 125 to 200 lbs. Hiram Woodruff's weiglat was about $160 \mathrm{lbs}$.

An interesting investigation is now going on in Fingland to ascertain whether Том Теимв, the celebrated American trotter, ever performed 20 miles within the hour. Large bets are pending on the result. If he has ever accomplished such a feat, it has not been, within our knowledge, officially recorded. Many of the parties betting on Tom 'Thumb having performed the above feat, failing so procure satisfactory proof thereof, have paid their bets.

Fanny Jenks trotted 101 miles in harness, over the Bull's Head rourse, Albany, in 9 hours, 42 minutes, 57 seconds, on the 5 th of May, 1845.

Fanny Murray trotted 100 miles, in harness, in 9 hours, $41 \mathrm{mi}-$ nutes, 25 seconds, on the 15th of May, 1546, over the Bull's Head course, Albaniy. 


\section{BEST TROTTING TIME, AT MILE HEATS.}

\begin{tabular}{|c|c|c|c|c|}
\hline Name. & $\begin{array}{l}\text { Saddle or } \\
\text { Haruess. }\end{array}$ & Tine. & Course. & Date. \\
\hline Aggy Down..... & saidle & $\left\{\begin{array}{c}227,299 \frac{1}{2}, 230, \\
230,231\end{array}\right\}$ & Beacon Course, N.J. & Sep. 25, $18 \leq 5$ \\
\hline Beppo...... & " & $\left\{\begin{array}{c}232 \frac{1}{2}, 231 \frac{1}{2}, 233, \\
238,\end{array}\right.$ & Beacon Course, N. J. & Juac 20, 1843 \\
\hline Confilence...... & harness & $\begin{array}{r}235,237,236 \ldots \\
0\end{array}$ & Beacon Course, N. J. & June - 1841 \\
\hline $\begin{array}{l}\text { Dutchinan. } \\
\text { Dutchman. }\end{array}$ & (2) & $\left\{\begin{array}{l}235,232,235 \\
236,235,233 ;\end{array}\right.$ & Beacon & July - 1839 \\
\hline Dutchman ...... & saudie & $\left\{\begin{array}{l}233,240, \\
20,\end{array}\right.$ & Trenton, N. & Sep. - 1836 \\
\hline Edwin Forrest... & " & $231 \frac{1}{2}, 233 \ldots \ldots$ & Centreville, L. I.... & May - 1834 \\
\hline Jady Suffolk.... & “6 & $\left\{\begin{array}{c}228 \frac{1}{2}, 228,228, \\
229,232,\end{array}\right\}$ & Beacon Course, N. J. & July 4, 1843 \\
\hline Lady Suffolk.... & " & $226 \frac{1}{9}, 227,227$ & Beacon Course, N. J & July 12,1843 \\
\hline Norman Leslie.. & " & $\left\{\begin{array}{c}2.38,236 \frac{1}{2}, 238, \\
239,238,\end{array}\right\}$ & Trenton, N. J. ..... & June -1836 \\
\hline
\end{tabular}

\section{TWO MILE HEATS.}

\begin{tabular}{|c|c|c|c|c|}
\hline $\begin{array}{l}\text { Americus....... } \\
\text { Americus....... } \\
\text { Black Maria... }\end{array}$ & $\begin{array}{l}\text { harness } \\
\text { saddle }\end{array}$ & $\begin{array}{lllll}5 & 13, & 5 & 11 & \ldots \\
5 & 17 \frac{1}{2}, & 5 & 17, & 5 \\
5 & 19 \frac{1}{2}, & 5 & 12 \frac{1}{2} & \ldots\end{array}$ & $\begin{array}{l}\text { Union Course, L. I } \\
\text { Uumting Park, Pa. } \\
\text { Cambridge Park ... }\end{array}$ & $\begin{array}{l}\text { Oct. 8, } 1846 \\
\text { Oct. 17, } 1846 \\
\text { June 18, } 1845\end{array}$ \\
\hline Confilen & harness & 8. & Centreville, L. I & May - 1811 \\
\hline D. D. T'om & saddle & $516 \frac{1}{8}, 511$. & Cent & Oct. \\
\hline Dutchi & & = & Beacon Cou & April - \\
\hline Dute & harness & 511,516 & Beacon Course, N. J. & Oet. - \\
\hline EA & sartale & 505,506 & Hunting Park, Pa. . & May -1840 \\
\hline Edwin Por & harness & $517,513,51$ & Hunting Park, Pa. & Oct. -18.38 \\
\hline & & $594,519,5$ & Ig P'ark, Pa. & June 2,18 \\
\hline Jat! & “ & $516,516 \frac{1}{9}$ & Course, L. I & Nov. 18,18 \\
\hline Suffo! & saddle & $459,503 \frac{1}{2}$ & reville, L. I & Sep. - 1 140 \\
\hline Lat & harness & 510,5 & Cent & Maty $\ldots 1842$ \\
\hline $\mathrm{I}$,a & 4 & $517,519,51$ & Bearon Course, N. J & May 21, 1844 \\
\hline Ripton . & " & $510 \frac{1}{x}, 512 \frac{1}{2}$ & Beacon Course, N. J & May - 1842 \\
\hline Ri & " & 517,515 & Hunting Park, Pa. . & May - 1842 \\
\hline Ripton & " & ( & unting Park, Pa. . & I May \\
\hline
\end{tabular}

\section{THREE MILE HEATS.}

\begin{tabular}{|c|c|c|c|c|}
\hline Columbus. . & sadulle & 758,807 & Hunting Park, Pa. & $\mid$ June $-18.34 \mid$ \\
\hline Dutchman ...... & " & $732 \frac{1}{9}$. & Bencon Course, N.J. & Aug. - 1839 \\
\hline Dutclmıan...... & harness & $741 \ldots \ldots \ldots$ & Beacon Course, N.J. & July $-183 ! !$ \\
\hline Dutchman & sadille & $\left\{\begin{array}{c}75+\frac{1}{2}, 750,802, \\
821 \frac{1}{2} .\end{array}\right.$ & Beacon Course, N. J. & Oct. -1838 \\
\hline $\begin{array}{l}\text { Dutchmnan ...... } \\
\text { I,atly suffolk... }\end{array}$ & " & $751,751 \ldots \ldots \ldots$ & $\begin{array}{l}\text { Hunting Park, Pa. } \\
\text { Hunting Park, Pa. }\end{array}$ & $\begin{array}{l}\text { May }-1840 \\
\text { May }-1841\end{array}$ \\
\hline Kipton ........ & harness & $800,756 \frac{1}{2} \ldots$ & Beacon Course, N. J. & Aug $\infty \mathrm{C} 4 \mathrm{~A}$ \\
\hline
\end{tabular}

\section{FOUR MILE HEATS.}

\begin{tabular}{|c|c|c|c|c|}
\hline Dutelman & sallile & 1119,1051 & Centreville, I، I. & May - 1836 \\
\hline Iady suffolk & " & 1115,1158 & Centreville. I. I. & Jine $-1 \% 40$ \\
\hline Larli Suffolk & “ & 1122,1134 & Cambrilge Park & Nov. - j839 \\
\hline Sir Peter .... & harness & 1193,1127 & Hunting Park, P'a. & cret. - 182!! \\
\hline Ellu Thoingenn & sadille & 115.5 .11 .33 & Beacon Course, N.J. & $112 y-18|2|$ \\
\hline
\end{tabular}




\section{R A C I N G.}

\section{BEST TINEE ON RECORD AT MILE HEATS.}

\begin{tabular}{|c|c|c|c|}
\hline Name. & Time. & Course. & Date. \\
\hline & & , & ec. 25,1842 \\
\hline & $150,147,152 \frac{1}{2}$ & New Urleans, La. & Nar. 19, 18:3 \\
\hline Bendigo .... & & Lexington, Ky... & Sep. 24, 1810 \\
\hline Bendigo ...... & $148,150,148,149$. & New Orleans, La. & Mar. 21,1811 \\
\hline Beta & $145,145,157,201$. & Nazhville, Tenn.. & Hay $22,16+1$ \\
\hline Big Alick... & $157,147 \frac{1}{2}, 150,151$ & Louisville, Ky... & June $4,184 ?$ \\
\hline Cipt. McHeath. & $149,148,150$ & Columbus, (ra. & May 4, 1839 \\
\hline $\begin{array}{l}\text { Cassantra...... } \\
\text { Colt by Levia.) }\end{array}$ & $148,149 \frac{1}{4} \ldots$ & Washington, D. C. & June 1,1241 \\
\hline $\begin{array}{l}\text { Colt by Levia. } \\
\text { than, D. F. }\end{array}$ & $148,147 \frac{3}{4}, 150$ & New Orleans, La. & A pril 1. 1846 \\
\hline $\begin{array}{c}\text { Kenner's, } \\
\text { Creath ........ }\end{array}$ & 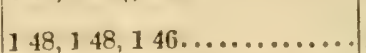 & & \\
\hline $\begin{array}{l}\text { Creat } \\
\text { Crot }\end{array}$ & $151,154 \frac{1}{2}$ & New Orleans, La. & Dec. 30,1846 \\
\hline Croton & & New Or & Niar 15,1846 \\
\hline IcIntyre.. & $151 \ldots$ & Georgete & A pr. 28,1842 \\
\hline Fre & $\frac{1}{2}, 150,153 \frac{1}{2}, 152 \frac{1}{2}$, & Lou & Oct. 9,1846 \\
\hline Fre & $\left.\begin{array}{l}52,147 \frac{1}{2}, 132,148, \\
1,57 \frac{1}{2}, 156 \frac{1}{2},\end{array}\right\}$ & New Orleans, La. & Dec. $6,1844^{\circ}$ \\
\hline Gild & $151,149,153,156 \ldots \ldots$ & Versailles, $\mathrm{Ky}$ & Sep. $18,1840^{\circ}$ \\
\hline & 15 & &, 1844 \\
\hline & 14 & New Or & Mar. 18, 1840 \\
\hline $\mathrm{Ja}$ & 14 & s, La. & (Oet. 29,1845 \\
\hline & 15 & Ky. & May 21,1841 \\
\hline Jo & $153 \ldots$ & H. Va. & Sep. 18, 1839 \\
\hline & 202 & e, Md. & May 17, 184t \\
\hline & $148,148 \ldots \ldots$ & Lexing & May 19, 1841 \\
\hline & $148, \ldots \ldots \ldots \ldots$ & $\begin{array}{l}\text { E. Fel } \\
\text { Batrds }\end{array}$ & $\begin{array}{l}\text { Apr. 24, 1844 } \\
\text { Oct. 12, 1839 }\end{array}$ \\
\hline rd's) & $148,151 \ldots \ldots \ldots$ & $\begin{array}{l}\text { n, Ky.... } \\
\text { ti, Ohio. }\end{array}$ & $\mid \begin{array}{l}\text { Oct. } 12,1839 \\
\text { Oct. } 19,1839\end{array}$ \\
\hline & ............ & $\begin{array}{l}\text { Cin } \\
\text { Lot }\end{array}$ & $\begin{array}{l}\text { Oct. 19, } 1839 \\
\text { June 4, } 1839\end{array}$ \\
\hline & $\ddot{1} 48, \ddot{1} 50,15 i)$ & NeV & $\begin{array}{l}\text { June } 4,1839 \\
\text { Dec. } 12,1841\end{array}$ \\
\hline & 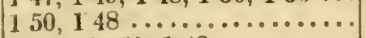 & Nev & Mar. 17, 1842 \\
\hline & $146 \frac{1}{8}, 148$. & New Orleans, La. & (Dec. 20,1844 \\
\hline ice.... & 14 & le, Ky. & Oct. 7,1844 \\
\hline & 153. & N. J. & May 25,1841 \\
\hline Sa & 148. & a, ky & Oct. $25,1-39$ \\
\hline & 200 & $\mathrm{k}, \mathrm{ky}$ & Oct. $25,1<39$ \\
\hline St. & $147,156,155 \ldots \ldots \ldots$ & e. H., Va. & Sep. 15, 1841 \\
\hline & $146 \frac{1}{8}, 147,147$ & (Mrleans, La. & Mar. 24, 1844 \\
\hline & 155,15 & Ha & - A pr, 30, 1843 \\
\hline The & $148,155 \frac{1}{2}, 153 \frac{1}{2} \ldots$ & Trenton, N. J, . & May 31, 1839 \\
\hline & $145 \frac{1}{2}, 148,147 \frac{1}{2} \ldots$ & $\begin{array}{l}\text { E. Feliciana, La. } \\
\text { Kanawha, Va... }\end{array}$ & $\begin{array}{l}\text { Apr. 27, } 1744 \\
\text { June } 7,1839\end{array}$ \\
\hline & & & June 7,1839 \\
\hline
\end{tabular}

\section{BEST TIME ON RECORD AT TWO MILE HEATS.}

\begin{tabular}{|c|c|c|c|}
\hline Name. & Time. & Course. & Date. \\
\hline Alarick..... & 354,339 & Lexington, $\mathrm{Ky}$ & Sep. 26, 1845 \\
\hline Ann Hayes. & $343 \frac{1}{2}, 342 \frac{1}{2} \ldots$ & New Orleans, La. & Nov. 21, 1844 \\
\hline Ann Stuart. & $350,344,345 \ldots$ & Memphis, Tenn. . & Nov. 14,1843 \\
\hline $\begin{array}{l}\text { Arraline.... } \\
\text { Attakapas.. }\end{array}$ & $\begin{array}{l}344 \frac{1}{2}, 349,349,350 \\
346,352, \ldots \ldots \ldots .\end{array}$ & $\begin{array}{l}\text { Louisville, ky. . . } \\
\text { Columbis, Ga. ... }\end{array}$ & 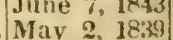 \\
\hline Balie Peyton & $354,345 \ldots$ & Broal Rock, Va. & A pr. $26,1 \varepsilon 39$ \\
\hline Bee's.Wing . & 344,347 & New Orleans, La. . & Mar. 26,1839 \\
\hline $\begin{array}{l}\text { Betsey Archy, } \\
\text { filly, }\end{array}$ & $353,344 \ldots \ldots$ & Washington, D. C. & May 31, 1841 \\
\hline $\begin{array}{l}\text { Riar-k.Nose . . } \\
\text { Brown K'tty }\end{array}$ & $349 \frac{1}{2}, 345$, & Georgetown, Ky. & Sep. 18, 1841 \\
\hline $\begin{array}{l}\text { Brown K'tty } \\
\text { Buc'-Eve.... }\end{array}$ & $349 \frac{1}{2}, 344,345$. & New Orleans, La. & Dec. 1, 1846 \\
\hline Butterfly filly & $348,350,340$ & Lf:xinten, Ky... & $\mid$ Sep. $27,1845 \mid$ \\
\hline
\end{tabular}




\section{GEST TIME ON RECORD AT TWO MILE HEATS.}

\begin{tabular}{|c|c|c|c|}
\hline Nance. & Time. & Course. & Dale. \\
\hline & & & Not \\
\hline ath. & 3,34 & lisvil & if 8,18134 \\
\hline ath & $1,341 \ldots \ldots$ & $\begin{array}{l}\text { New Orleans, La... } \\
\text { Louisville, Ky, ... }\end{array}$ & $\begin{array}{l}\text { Mar. 24, 184? } \\
\text { June 1, .81? }\end{array} \mid$ \\
\hline thili: & 3,345 & Havana......... & $\mid \begin{array}{l}\text { June 1, .842 } \\
\text { Apr. 2(j. 1843 }\end{array}$ \\
\hline oII & $\therefore 4+\frac{1}{2}, 3$ & v Orleans, La. & Apr. 13, 1945 \\
\hline $\begin{array}{l}\text { ou } \\
\text { on }\end{array}$ & $\frac{1}{4}, 343 \frac{1}{2}, 343 \frac{1}{2}$ & Wrleans, La. & Apr. 2, intsi \\
\hline on. & $7 \frac{1}{2}, 346 \ldots$ & is, La. & Apr. 16, 1846 \\
\hline & $\cdots \cdots \cdots$ & $\begin{array}{l}\text { Louisville } \\
\text { New Orle: }\end{array}$ & $\begin{array}{l}\text { ct. } 1,1839 \\
\text { ar. } 23,1842\end{array}$ \\
\hline$\ldots$ & & Lexingtor & $\begin{array}{l}\text { Mar. } 23,8421 \\
\text { May } 23,1840\end{array}$ \\
\hline iv & 2 & & Dec. 10, 1841 \\
\hline & & & $1,1 \in+0$ \\
\hline 3 & to & $N^{N}$ & 840 \\
\hline & $\ldots \ldots \ldots$ & & \begin{tabular}{|} 
War. 18,1839 \\
Feb. -1843
\end{tabular} \\
\hline 3 & $\because$ & se, $\mathrm{L}$. & Feb. -1843 \\
\hline & & & Apr. $3,1,45$ \\
\hline & 5,3 & & May $20,1-41$ \\
\hline$t n$ & & D. C. & (1et. 2,1845 \\
\hline & 3 & d.... & у $9,18-1 t$ \\
\hline (1) & & " & 15,1844 \\
\hline & & & 26,1844 \\
\hline & & $\ldots$ & \begin{tabular}{r|}
-1842 \\
23,1842
\end{tabular} \\
\hline & $\begin{array}{l}351 \ldots \\
355 \ldots\end{array}$ & a. & $\begin{array}{r}2 \because, 1842 \\
4,1344\end{array}$ \\
\hline & $\begin{array}{l}3 \\
3\end{array}$ & ia. & Dec. $25,18.14$ \\
\hline & & & c. $9, \quad 1840$ \\
\hline $\mathrm{v}$ & 351 & & $22,18+i$ \\
\hline & $\ldots \ldots$ & & 845 \\
\hline se &, $344 \ldots$ & $T$ & 25,1839 \\
\hline & & & 28,1846 \\
\hline & & & $\begin{aligned}-339 \\
-339\end{aligned}$ \\
\hline & & IN & 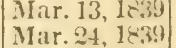 \\
\hline Nru & $\because \ldots \ldots$ & & $\left.\begin{array}{l}1839 \\
1839\end{array}\right]$ \\
\hline . & 347 & $\begin{array}{l}\mathrm{C} \\
\mathrm{T}\end{array}$ & $\begin{array}{l}\text { Cet. } 14,1839 \\
\text { Iay } 29,1839\end{array}$ \\
\hline & $\frac{1}{2}, 442 \frac{1}{8}$ & L & (1) 29,1839 \\
\hline & & & 9,1845 \\
\hline & & $\mathrm{F}$ & Sep. 7,1842 \\
\hline & $41 \frac{1}{2}$ & & Dec. 3,1846 \\
\hline & & & 17,1842 \\
\hline & $\cdots \cdot$ & & p. 16,1841 \\
\hline & $\ldots$. & & $\begin{array}{l}\text { ay } 8,184 \\
\text { p. }-181\end{array}$ \\
\hline & & is & A pr. 24,1839 \\
\hline 5 & & & Oct. 30,1845 \\
\hline & & lea & 184 \\
\hline & & & $2 \pi, 1843$ \\
\hline & & & Jan. 30, 1844 \\
\hline & & & Oct. 4, 1844 \\
\hline & & & May 4, 1844 \\
\hline & 1 & & May 28,1840 \\
\hline & & Un & Oct: \\
\hline & 5. & $\begin{array}{l}\text { Let } \\
\text { E. }\end{array}$ & $\begin{array}{l}\text { Sep. 2!, } \\
\text { Apr. 25, } 1844\end{array}$ \\
\hline l's Too \} & 5 & Lexington, $\mathrm{Ky} . .$. & May 23,18 \\
\hline & & & 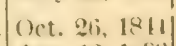 \\
\hline & & & 8 \\
\hline & & & Oct. 2, $183 !$ \\
\hline & & $\mathrm{Ca}$ & $\begin{array}{l}\text { June } 5,184: \\
\text { Dec. } 7,184 t\end{array}$ \\
\hline & & & \\
\hline
\end{tabular}




\section{BEST TIME ON RECORD AT THREE MILE HEATS.}

\begin{tabular}{|c|c|c|c|}
\hline Name. & Time. & Course. & Date. \\
\hline & 19:- & & Sep. \\
\hline & $42 \frac{2}{9} \cdots$ & 17. & \\
\hline & $51 \ldots$ & Louisville, Ky, & June 6,1814 \\
\hline & $44 \ldots \ldots \ldots \ldots$ & Washington, D. C. & June $3,18+1$ \\
\hline $\begin{array}{c}\text { ck-Nose } \ldots \\
\text { ck-Nose } \ldots\end{array}$ & & Frankfort, Ky..... & Sep. 24,1840 \\
\hline $\begin{array}{l}\text { k-Nose } . . . \\
\text { Dick ..... }\end{array}$ & $546 \ldots$ & Hes & S. 1$) .98,1840$ \\
\hline Dick ... & $538 \frac{1}{1} \ldots \ldots \ldots \ldots$ & Trentou, N. J. & Nay 19,1842 \\
\hline ck...... & $\begin{array}{l}1 \\
, \cdots\end{array}$ & morsa, D. C. & June 3, 184: \\
\hline B & $\begin{array}{l}5 \\
5\end{array}$ & H & May 6, 1844 \\
\hline & $\mid \begin{array}{l}5 \\
5\end{array}$ & K, & $\begin{array}{l}\text { li, } 1843 \\
7,18: 34\end{array}$ \\
\hline & 54 & rse, I. I. & Apr. $9,18: 39$ \\
\hline & 557,543 & Lourisville, ky, .... & Oct. 15,1841 \\
\hline$:$ & & mo & 3,1843 \\
\hline & 5 & HI & Apr. \\
\hline $\begin{array}{l}\text { Ualvert. } \\
\text { il ...... }\end{array}$ &, 5 & & Oct. 29, 1841 \\
\hline 11 & 5 & id. & Oct. $16,1846 \mid$ \\
\hline e & & & , 1849 \\
\hline e 1 & 9,552 & $\mathbf{N}$ & 1843 \\
\hline & & & 1839 \\
\hline I & 55 & Va. & May \\
\hline & & 1 &, 1843 \\
\hline n & & & 1841 \\
\hline & IO & & , 1844 \\
\hline & & $M$ & 1843 \\
\hline & 5 & & 1842 \\
\hline & & $\mathbf{P}$ & 8,1843 \\
\hline & & Ne & Dec. 4, 1846 \\
\hline & 5 & E. & 6,1844 \\
\hline & & C & 1,1841 \\
\hline Henry & $0,556,6$ & & 1834) \\
\hline & $\cdots$ & C. & 844 \\
\hline & & & 0,1842 \\
\hline$P$ & & C & Mav 2, 1839 \\
\hline & 5 & C & 17,1839 \\
\hline & 5 & & Nay 22,1840 \\
\hline & & $B$ & Oct. 20,1842 \\
\hline & & Ls & Oct. 8, 1840 \\
\hline & 546,552 & & Sep. 24, 1844 \\
\hline & & Li & Mar. 22,1844 \\
\hline She & 50,557, & Lex & Sep. 21, 1842 \\
\hline & $543 \frac{1}{9}, 548$ & Pin & $\begin{array}{l}\text { Feb. 8, } 1843 \\
\text { A pr. } 21,1842\end{array}$ \\
\hline $\ln 8+2+3$ & 551,545 & ... & $\begin{array}{l}\text { Apr. } 21,1812 \\
\text { May 19, } 1842\end{array}$ \\
\hline ell ... & .......... & $\begin{array}{l}\text { IS } \\
\mathbf{R}\end{array}$ & ep. 16,1840 \\
\hline T & 1,549 & 1.0u & June 2, 1842 \\
\hline & & , N. J. & Nov. 27,1845 \\
\hline & & Union Course, L. & June 5, 1840 \\
\hline & & & Oct. 5,1842 \\
\hline & & & \\
\hline
\end{tabular}




\section{BEST TIME ON RECORD AT FOUR MILE HEATS.}

\begin{tabular}{|c|c|c|c|}
\hline Name. & Time. & Course. & Date. \\
\hline & & & Nov. $7,18: 39$ \\
\hline & 7 & No & Mar. 23,1844 \\
\hline 然 & & & May 15,1840 \\
\hline an: & $813,746,7581$ & Course, L. I. & May 13, 1845 \\
\hline & & D. C. & 6,1842 \\
\hline$\ldots$ & 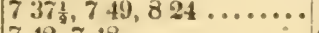 & se, L. I. & May 27, 1843 \\
\hline in & & & Uct. 28,1841 \\
\hline iion & 45 & Course, L. I. & May \\
\hline n & & Ca & Uct. 2!), 1842 \\
\hline hion ... & $736,749 \ldots$ & & 4,1842 \\
\hline on ... & 73 & & $.20,1843$ \\
\hline 1 & & , L. I. & 23,1845 \\
\hline & & & 46) \\
\hline $\operatorname{Mar}$ - & & a... & 843 \\
\hline$m$ & & & $1+43$ \\
\hline & 74 & Ne & 6). 1841 \\
\hline & 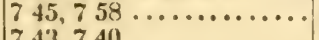 & & June 24,1844 . \\
\hline 1 & & $\mathbf{N}$ & A pr, 5, 1845 \\
\hline Li & & & $\therefore 12,1845$ \\
\hline 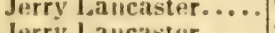 & & & Oct. 21, 1846 \\
\hline Jet & 7: & $N \in$ & Dec. 5, 1841: \\
\hline 1 & 8 & $\begin{array}{l}\mathbf{N} \\
\mathbf{N}\end{array}$ & $\begin{array}{l}\text { Mar. 19, 1842 } \\
\text { Mar. 26, 1842 }\end{array}$ \\
\hline 5 & & & Sep. 25,1842 \\
\hline oote $>$ > & $7:$ & $N$ & 1)ec. 24,1842 \\
\hline & & & Dec. 11,1840 \\
\hline & 74 & Ney & Jan. 5,1844 \\
\hline 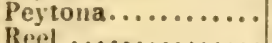 & & Uni & May 13, 184j \\
\hline & 16 & $\begin{array}{l}N \\
N\end{array}$ & $\begin{array}{l}11,18+1 \\
\text { r. } 18,1843\end{array}$ \\
\hline & 7 & $\mathrm{~N}$ & Dec. 28,1844 \\
\hline & & $N e$ & Mar. 17, 1841 \\
\hline | & & 年 & $\mathrm{Ma}+15,1$ \\
\hline
\end{tabular}




\section{THE ST. LEGER.}

T're Doncaster St. Leger (in England prono rse sellenger,) is the most important stake in Great Britain, amou ing to frou eighteen to twenty-four thousand dollars, and is run for, arnually, by three year old colts and fillies: the former carry 19 pounds, tho latter 114.

With these tables in view, a comparison of the speed of Englisb and American horses can easily be made, haring due regard to weight, age, and the distance run. The St. I eger is a race of one ntraight heat, and the horse has only to do his "est for that single run.

J.S. S.

The following table will show the read the distanse per secrud veraged by horses running at any dista ce:

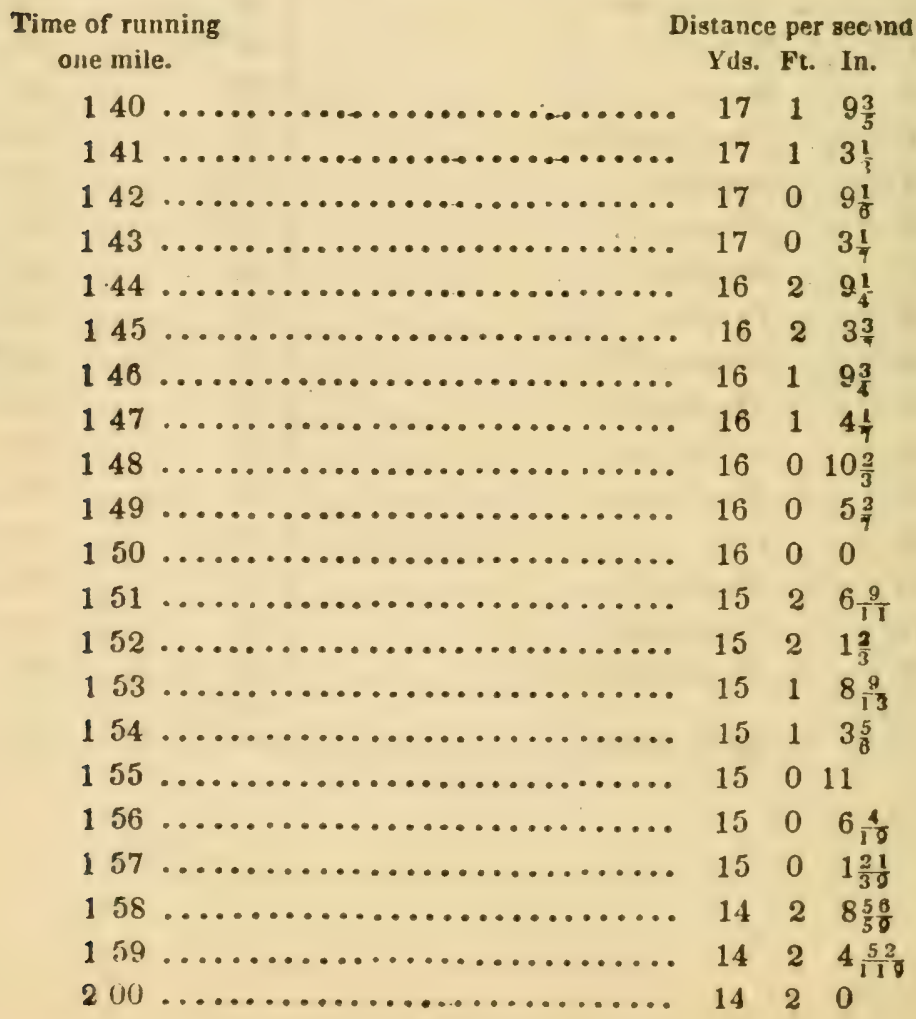




\section{AVERÅ̈E SPEED FOR THE DONCASTER ST. LEGER.}

Distance 1 mile 6 furlongs 132 yarda.

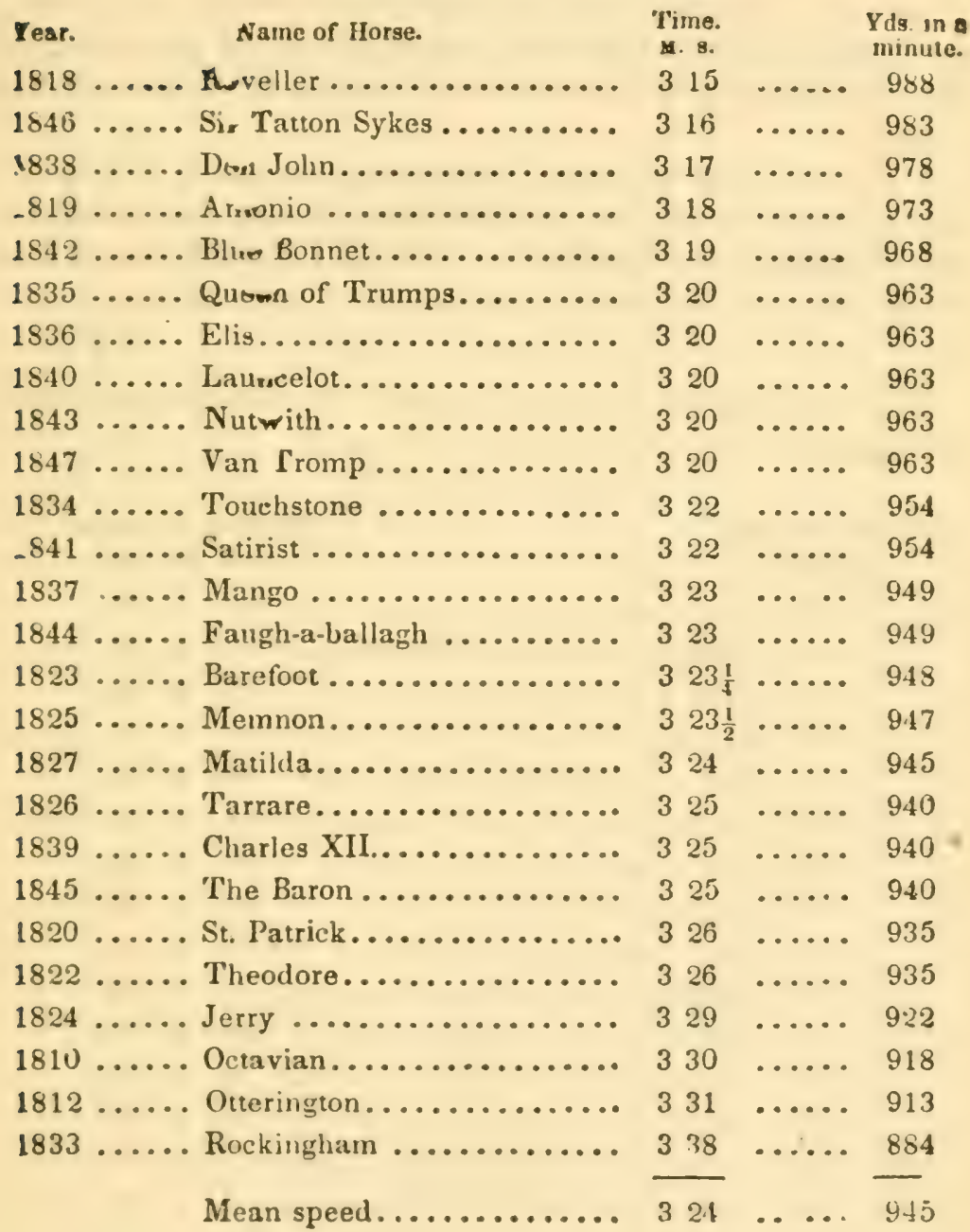




\section{PEDIGREES}

\section{OY \\ W INNING HORSES,}

SINCE 1839.

\section{Being an Appendix to Mason's Farrier}

A.

A ARON, b. h. by Tennessee Citizen, dam by Timoleon.

ABBEVILLE, b. h. by Nullifier, dam by Gallatin.

ABNER HUNTER, b. h. by Medoc, dam by Blackburn's Whip.

ACALIA, b. m. by Luckless.

ACHILLES, gr. h. by Boxer.

ADELA, b. m. by The Colonel, dam [Imp.] Variella by Blacklo, $\mathbf{k}$.

ADELAIDE, b. $m$. by [Imp.] Leviathan, dam by Napoleon.

ADELLA, b. m. by Mons. 'Tonson, dain by Sir Archy.

ADRIAN, ch. h. by [Imp.] Luzborough, dam Phenomena, by Sir Archy.

ADUELLA, ch. m. by [Imp.] Glencoe, dam Giantess by [Imp.] Loviathan.

FSOP, ch. h. by [Imp.] Priam, dam Trumpetta by Mons. Touson. AT'N A, b. m. by Volcano, dam Rebecca by Palafox.

AHIRA, b. h. by Medoc, dam by Tiger.

AlLSEY SCROGGINS, ch. m. by Giles Scroggins, dam by Pirate. AJARRAH HARRISON, ch. m. by Eclipse, dam by Gallatin.

AJAX, gr. h. by [Imp.] Leviathan, dam by Pacolet.

A. J. LAWSON, b. h. by [Imp.] Hedgford, dam Kitty Fisher by Gallatins

A L.AMODE, ch. h. by [Imp.] Margrave, dam by Timuleon.

A LARIC, b. h. by Mirabeau, dam by [Imp.] Tranby.

A LATOONA, b. m. hy A reyle, dam Viola by Gallatir.

A J.BION, [Imp.] bl. h. by Cain or Actixon, dam by Comus or Blarb lock

A LIBORAC, b. h. by Telegraph, dam by Monday.

ALDERMAN, ch. g. by [Imp.] Langford, dam by Sir Clarles.

A LL.EGRA, b. m. Ly Stockholder, dam by Pacolet.

AI.I.EN BROWN, ch. h. by Stockholder, dam by [Imp] Fagle 
ALEXANDER CAMPBELL, b. h. hy Collier, dam by Kosciusku.

ALEXANDER CHURCIILL, b. h. by [Imp.] Zinganee, dam by Bertrand.

ALICE, b. m. by Conqueror, dam by Wild Medley.

b. m. by [Imp.] Sárpedon, dam Rowena by Sumpter.

ALICE ANN, gr. $m$. by Director, dam by Gallatin.

ALMIRA, gr, m. by Eclipse dam by Stockholder.

ALTORE, b. h. by [Imp.] Fylde, dam by Virginian.

ALWILDA, gr. m. Lv Monmouth Eclipse, dam by John Richards.

AMBASSADOR, ch. h. by Plenipotentiary, dam [Imp.] Jenny Mills

by Whisker.

AMELIA, br. m. by Bluster, darn by Messenger.

AMERICA, b. m. by Stockholder, dam by Democrat.

b. m. by [Imp.] Trustee, dain Di Vernon by Florizel.

AMERICAN CITIZEN, b. h. by Marion, dam by Harwood.

EAGLE, gr. h. by Grey Eagle, dam by Waxy.

S'T AR, cl. h. by Cramp, dam by Pulaski.

AMY THE ORPHAN, ch. m. by [Imp.] Nonplus, dain by Comet.

ANIRE,WANNA, b. m. by Andrew, dam by Gallatin.

ANUREWE'TTA, gr. m. by Andrew, dam by Oscar.

ANDREIV HAMET, b. h. by Sidi Hamet, dam by Trumpator.

ANN B.ARROW, b. m. by Cock of the Rock, dam by Virginian.

ANN BELL, ch. m. by Frank, dam Jonquil by Little John.

ANN BLAKE, b. m. by Lance, dam by Blackburn's Whip.

ANN CALENDAR, ch. m. by Eclipse, dam Grand Duchess by [Imp.] Gracchus.

ANN GILLESPIE, br. m. by McCarty's Henry Clay, dam Susan by Sir William.

ANN HARROD, ch. m. by Hickory John, dam by King William.

ANN HAYES, b. m. by [Imp.] Leviathan, dam by Pacific.

A:N INNIS, ch. m. by Eclipse, dam (the dam of Mary Morris) by Sumpter.

ANN KING, b. m. by [Imp.] Sorrow, dam Lady of the Lake by Henry Tonson.

ANN STEVENS, ch.m._by [Imp.] Trustee, dam (an imported mare) by Muley.

ANN STEWART, ch.m. by Eclipse, dam Kitty Hunter by Paragon

ANNE ROYALE, br. m. by Stockholder, dam Alice Lee by Sis Henry Tonson.

ANTOINETTE, ch. m. by [Imp.] Leviatıan, dam Multiflora bv Director.

AN'TH'ATOR, ch. h. by Tychicus, dam Ciub Foot by Napoleon.

A N VII, b. h. by [Imp.] Contract, dam by Eclipse.

ARAB, b. h. by Arab, dam by Sir Archy.

ARABELLA, b. m. by Collier, dam by Gallatin.

ARABIAN MARK, b. h. l,y [Imp.] Fylde, dam by Sir Charles.

A RGFNTILE; b. m. by Eertraud, dam Allegrante by [Imp.] Truffe

ARGYLE, br. h. by Mons. Tonson, dam Thistle by Ogle's Oscar.

ARII.LA, gr. m. by O Kelly, dam by Medley.

ARK ALUKA. ch. h. by [Imp] Leviathan, dam Silly McGehee 
A ROOSTOOK, b. h. hy Wheeling Rodolph, darn by Moses.

A RRALINE, ch. m. by [Imp.] Le viathan, dam by Stockholider

ARRAH NEAL, ch.m. by [Imp.] Leviatian, dam Martha Wash ington by Sir Charles.

ARSENIC, ch m. by [Imp.] Leviathan, dam Mary Farmer by Con queror.

ASHLAND, ch. h. by Medoc, dam Lady Jackson by Sumpter.

ASTOR, b. h. by Ivanhoe, dam Tripit by Mars.

ATTAKAPAS, ch. h. by [Imp.] Luzborough, dam by Arab.

ATTILA LECCNITE, b. $m$ by [Imp.] Glencoe, dam Extant by [Imp.] Leviathan.

ATLAN'IC, b. m. by Blood and Turf, dam Old Fly.

AUNT PONTYPOOL, cls.m. by Rertrand Junior, dam Gold Finder by Virginius.

AUSTER, br. h. by Westwind, dam by [Imp.] Leviathan.

AUTHENTIC, ch. h. by [Inty.] Leviathan, dain Timoura by Timoleon.

B.

BALD HORNFT, ch. g. by Bald Hornet, dam by Bertrand.

BALIE PEYTON, b. h. by Andrew, dam (Master Henry's dam) by Eclipse.

BALTIMORE, b. h. by [Imp.] Inzborough, dam by Gohanna.

BAND BOX, gr. m. by O Kelly, dam Lucy Brooks by Bertrand.

BANDIT, b. h. by [Imp.] Luzhorough, dam by Virginian.

BAN.JO BILL, b. h. by [Imp.] Sarpedon, dam by Darnaby's Diomed. BAND OF MUSIC, ch. $m$. by O Kelly, dam by Oscar.

BARBARA ALLEN, ch. m. by Collier, dain Lady Jackson by Sumpter.

BASSINGER, bl. h. by [Imp.] Fylde, dam by Randolph's Roanoke. BAYWOOD, b. h. by Editor, dain by Pacolet.

BEACON LIGHT, ch. m. by [Imp.] Glencoe, dam Giantess by [Imp.] Leviathan.

BEATRICE OF FERRARA, $m$. by Stockholler, dam by Duroc.

LEAU-CATCHER, ch. m. by Leopold, daın Cranberry.

BEE'S-WING, ch. m. by [Imp.] Leviathan, dam Black Sophia by Topgallant.

BELFIELD, b. h. by [Imp.] Priam, daın [Imp.] Bustle by Whalebone.

BELLISSIMA, b. m. by [Imp.] Belshazzar, dam Wingfoot by Rat tler.

BEILE OF WINCHESTER, ch. $m$. by Stockholder, dam by Sir Archy.

Carlo by Sir Arcliy.

BEJLE TAYLOR, b. m. by Medoc, dam by Sumpter.

BEN BARKLEY, b. h. by Push P'in, dan 1 iss Wakefield by sir Hal.

BEN BUSTER, b. t. by Cherokee, dam by Whip.

BEN FRANKLIN, ch. h. by Flagellator, dam Merloca by Ecel pse. ch. h. by Woodpecker, dan by Frankliu Reaucy 
BEN FRANKLIN, ch. h. hy [Imp] Loviathan, dam by Stosklolder BENDIGO gr. h. by Timoleon, dam by Sir Charles.

b. h. by Medoe, dam by Sir Arcliy.

BENGAL, ch. h. by Gohama, dam sportsmistress (or Gulnare) by Duroc.

BFRENICF, ch. m. by Skylark, dam Kathleen by [Imp.] Leviaıan. BETA, ch. m. by [Imp.] Leviathan, dam by Kosciuslio.

BETHESDA, b. m. ly Pacific, dam by Sir Henry Tonson.

BE'THUNE, br. h. by Sidi Hanet, dam Susette by Aratus.

BFI'SEY COLEMAN, ch. m. by Goliah, dam Melinda.

BE'TSEY COODEY, ch.m. loy [Imp.] Leviathan, dam by Sir Charles.

BF'TSYY HUN'TER, ch. m. by sir Cimton, am by Hamiltonian.

BE'SEY LAUDERDALE, ch. m. by [Imp.j Leviathan, dam by Sir Richard.

BETSEY MILLER, gr. m. by [Imp.] Leviathan, dam Jane Shore by Oscar.

BETSEY RED, ch. m. by Red Rover, dam Betsey West by [Imp.] Buzzard.

BFTSEY SHELTON, b. m. by Jackson, dam Harriet Haxall by Sir Hal.

BET SEY WATSON, br. m. by Jefferson, dam bv Sir Henry Toneon.

BE'TSEY WHITE, ch. m. by Goliah, dain by Sir Charles.

BIG ALECK, ch. h. by Medoc, dam by Tiger.

BIG ELLEN, b. m. by Medoc, dam by Old Whip.

BIG JOHN, ch. h. by Bertrand, dam by Hamiltonian.

BIG NANCY, ch. m. by Jackson, dam by Gallatin.

BHLLY AYNESWORTH, eh. h. by Traveller, dam Helen by Ti noJeon.

BILLY BLACK, b. h. by Volcano.

BILLY BOWIE, b. h. hy Drone, dam Agility by Sir James.

BILLY GAY, b. h. by [Imp.] Hedgford, dam Mary Francis by Di rector.

BILLY TONSON, gr. h. by Mons. Tonson, dam by Cherokee.

BILLY 'TOWNES. b. h. by [Imp.] Fylde, dain by Virginian.

BILLY WAJKER, clı.h. by [Imp.] Valparaiso, dam by Sir Richa=d

BILLET, ch. h. by Mingo, dan by Mambrino.

BILOXE, ch. h. Ly Dick Chimu, dann Extio by [Imp.] Leviathan.

BLACK BOY, bl. h. by [Imp.] Chateau Margaux, dam by [Im ] Cliance.

by Vau Tromp.

BLACK DICK, b. Һ. by [Imp.] Margrave, daın by Pamunky.

BLACK FOOT, cli. h. by Medoc, dam by Blackburn s Whip.

ELACK HAWK, bl. h. by Juclustry.

BLACK JACK, Ll. h. by Tom Fleteher, dam by Baronet.

BLACK I.()CUST, bl. h. l,y [Imp.] Luzborongh, dam by Sir Archy.

BLACK N(OSE, ch. b. by Medoc, dam Lucy by Orpaas.

RLACK PLINCE, bl. h. by [Imp.] Fylde, dam Fantail by Sir At:hy 
BLACK RABBI'T, bl.h. by [Imp.] Nonplus, dam (Fair Ellen's da!n)

by Virginius.

BLACK ROSE, bl. m. by [Imp.] Leviathan, dam by Arab.

BLAZING STAR, b. h. by Henry, dam by Eclipse.

BLOODY NATHAN, gr. h. by [Imp.] Leviathan, dam by Pacoler.

BLOOMFIELD RIDLEY, b. h. by Bell-Air, dam Cedar Suags.

BLOOMSBURY, ch.m. by [Imp.] Fylde, dam by Giles Scroggins,

BLUE BONNET, gr. m. by [Imp.] Hedgford, dain Grey Fanny by

Bertrand.

BLUE DICK, gr. h. by [Imp.] Margrave, dam by Lance.

BLUE JIM, ch. h. by Muckilejohn.

BLUE SKIN, b. by Ms 'mion, dam by Tecumseh.

BOB BUSH, ch. h. by Medoc, dain by Bertrand.

BOB LETCHER, b. h. by Medoc, dam by Rattler.

BOB LOGIC, br. h. by [Imp.] Langford, dam by Mambrino.

BOB RUCKER, ch. h. by Eclipse, dam by Sir Charles.

BOIS D'ARC, ch. h. by Eclipse, dam Hortensia by Contention.

BONNY BLACK, bl. m. by [Imp.] Valentine, dam Helen Mar by

Rattler.

BORAC, ch. h. by Pacific, dam by Bagdad.

BOSTON, ch. h. by 'Timoleon, dain (Robin Brown's dam) by Ball's Florizel.

BOSTON FILLY, m. by Boston, dam by [Imp.] Priam.

BOWDARK, b. h. by Anvil, dam by Bagdad.

BOXER, b. h. by Mingo, dam by Eclipse.

BOYD M'NAIRY, ch. b. by [Imp.] Leviathan, dam Morgiana by Pacolet.

BRACELET, ch. m. by Eclipse, dam [Imp.] Trinket.

BREAN, ch. h. by Goliah.

BRILLIANT, b. h. by Sidi Hamet, dam Miss Lancess by Lance.

BRITANNIA, [Imp.] b. m. by Actron, dam by Scandal.

BROCKLESBY, ch. h. by [Imp.] Luzborough, dam by Roanoke.

BROKER, b. h. by [Imp.] Rowton, dam Jane Bertrand by Bertrand.

BROTHER TO HORNBLOWER, b. h. by Monmouth Eclipss, dam Music by John Richards.

BROTHER TO PEYTONA, ch.h. by [Imp.] Glencoe, dam Giantess by [Imp.] Leviathan.

BROTHER TO VICTOR, b. h. by [Imp.] Cetus, dam [Imp.] My Lady by Comus.

BROWN ELK, b. h. by Buck Elk, dam by Whip.

BROWN GAL, br. m. by [Imp.] Leviathan, dam by Virginian.

BROWN KITTY, br. m. ly Birmingham, dam by Tiger.

BROWN LOCK, br. h. by Pacific, dain by Sir Hal.

RROWN STOUT, be ... by [Imp.] Sarpedon, dam Feathers by Mons. Tonson.

BROWNLOW, br. h. by [Imp.] Merman, dam (Glenare's lanu) by [Imp.] Leviathan.

BRUCE, ch. h. by [Imp.] Nonplus, dain La rubal'e by Kusciuskr

RUBB, $b \mathrm{~m}$. by Bertrand, dam by Whig. 
aUCK EY E, h. h. hy Critic, dam Am Page by Orie's Oscar.

dian. b. h. by Lafayette Stock!older, dain Old Squaw by In

BELLE, ch. $m$. by Medoc, dam by Sumpter.

LAD, ch. h. by Bertrand, dam by a Son of Spread Ea gle.

BUCK RABBIT, b. b. by [ Imp.] Nonplus, dam (Fair Ellen's dam) by Virginius.

BILGGR BROWN, b. h. hy Lance, dam by Jenkins' Sir William.

BI:NKUM, ch. g. by Hyazim, dam by Gallatin.

BURLEIGH, b. h. by Sir Archie Montorio, dam Mary Lee by Con tention.

BUSTAMENTE, ch. h. by Whalebone, dan Sarah Dancy by Timo leon.

BU7. FUZ, gr. h. by Medley, dam by [Imp.] Luzborougl:

CADMUS, b h. by Cadmus.

\section{C.}

C.ALANTHE, b. m. by [ $1 \mathrm{mp}$.] Leviathan, dam by Jackson.

CALAN'I'HE, ch. m. by Medoc, dain by Sumpter.

CAMANCHE, ch. h. by Grey Eagle, dan by Rattler.

CAMDEN, br, h. by Shark, dam [Imp.] Invalid by Whisker.

CAMEO, b. m. by [Imp.] 'T'ranby, dam by Buzzard.

CAMEL, ch. h. by Birmingham, dam by Whip or Sumpter.

CAMILLA, br. m. by [Imp.] Hedgford, dam (Picayune's dam) by $\mathbf{g}_{\mathbf{1}}$ William of Transport.

CAP'TAIN BUR'TON, br. h. by Cherokee, dain by Green Oak.

CAPTAIN M'HEATH, ch. h. by [limp.] Leviathan, dam Miss Bailey by $[\operatorname{Imp}$.$] Boaster.$

CAPTAIN THOMAS HOSKINS, b. h. by [Imp.] Autocrat, dam by Tom 'Tough.

CAPTAIN (The) b. h. by Sir Archy Montorio, dam Ophelia by Wild Medley.

CAP'TAIN WHITE-EYE, h. h. hy Chifney, dam by Sumpter.

CAROLINE MALONE, (Col. Thomas Watson's), ch. m. by [Imp.] Leviathan, dam Proserpine by Oscar.

than, dam by Sir Richard. (Col. J. C. Guild's), b. m. by $[\operatorname{Imp}$.] Levia. (Col. Thomas Watson's), b. m. by [Imp.] ILeviathan, dam by Jerry.

CASHIER, ch. h. by Goliah, dam by Sir Charles.

CASKET, b. m. by [Imp.] Priam, dam hy Constitution.

CASETTA CHEF, ch. h. hy Andrew, dam by Wildair.

CASSANDRA, b. m. by [ $1 \ldots n$ ] Priam, dam Flirtilla Jr. by Sir Archy.

CASTIANIRA, ch. m. hy [ I mp.] Leviathan, dam by Stockholder.

CA'l'AI,PA, b. m. hy Frank, dam by John Richards.

CATARAC'T', h. h. by Mommouth Eclipse, dam by Jón lichards.

CATHERINE, b. m. by Bertrand, dam Black-eyed Susan by 'Tiger.

CATHERINE FFiNWICK, gro m. by Muckicjohn, dan by 3axo

IV eimur 
1:ATHERYY RECTOR, ch. m. hy Pxcitic, dam Mary Tonson.

C.IVALIER SERVAN'TE, gr. h. by Bertram, dam by Andrew.

CYDikl; b. h. by [lmp.] Priam, dam Countess Plater by Virginian.

Cid, ERIIY, ch. m. by [ Tmp.] Leviathan, dam Patty Puff by Pacolet. CHAMPACNE, b. h. by Eclipse, dam by Sir Archy.

CHARJ ES, b. h. by [Imp.] Rowton, dam Leocalia.

CHARLFS ARCHY, ch. h. by Sir Charles, dam by Eclipse.

SHARIASS MAI,COLM, ch. h. by Malcolm, dam by Albert Gialiatin.

1:HARLEY ANUERSON, ch. h. by Medoc, dam by Mercury.

CHA RI,EY FOX, b. h. by Waxy, dam by Buckner's Leviathan.

CHARI,EY NAYLOR, b. b. by Medoc, तum by 'Tiger.

CHARIOO'TE BARNES, b. m. by Bertrand, dam by Sir Archy.

CHARI,OT'IE (JLAIBORNE, b. m. by Havoc, dam by Conqueror

CHARLOT'TE HILL, b. m. by Hephestion, dam by Cook's Whip.

CIHARI'Y GIBSON, ch. m. by [Imp.] Leviathan, dam by Sir Charles. CHATEAU, [Imp.] b. m. by Chateau Margaux. dam Cuirass by Oiseau.

CHFMISE'T'TE, b. m. by [Imp.] Glencoe, dam by Arab.

CHEROKEE MAID, gr. m. by Marmion, dam by 'Tecumseh.

CHESAPEAKE, b, or hr. h. hy [Imp.] leviathan, dam by Thadjeus.

(JHICOM.4H, ch. m. by [Imp.] Leviathan, dam White Feather by

Conqueror.

CHICOPA, ch. m. by Tuscahoma, dam Fortuna by Pacolet.

CHIEFT'AIN, b. h. hy Gololphin, dam Young Lottery by Sir Archy.

CHO'TAUK, br. h. by Pamunky, dam by Arab.

CHURCHILI, b. h. by [lmp.] Zinganee, dam by Buzzard.

CINDERELLA, b. m. hy Pacific, dam Mary Vaughan by Pacolet.

ClLARA BOARDMAN, b. m. by [Imp.] Consol, dam Sally Bell by Nir Archy.

CLARION, ch. h. by Monmouth Eclipse, dam by Ogle's Oscar.

CLARISSA, ch. m. by Monmouth Eclipse, darn (Clarion's dam) by Ogle's Oscar.

CLEAR THE TRACK, ch. h. by [Imp.] Luzborough, dam by Stockholder.

Cl.EUPATRA, b. m. by [Imp.] Leviathan, dam by Pacolst.

CLEVELAND, gr. h. by [Imp.] Enancipation, dam by [Imp.] Leviathan.

COAI, BLACK ROSE, bl. m. hy [Imp).] Leviathan, dam by Arab.

COLUMBLS, Junior, b. h. by Cislumbus, dam by Bertrand.

COMPROMISE, b. $m$. by Nullitier, dam by Anti-Tariff.

CONCHITA, ch. m. by [Imp.] Leviathan, dam Miss Bailey by [Imp. Boaster.

(:ONSOL, Junior, br. h. hy [Imp.] Consol, dam [Imp.] The Nun's Daughter by Filho da Puta.

1:ORA, [Imp.] ch. m. by Muley Moloch, dam by Champios.

(')RA MUNRO, ch. m. by Hugh L. White, dam by Crusher.

CORDFLIA, ch. m. by [Imp.] Leviathan, dam by Sir Archy.

loRK, b. h. by [Imp.] Leviathan, dam Caledonia by Jerry.

:i)RNFLIA, b. in. by Skylark, dam by Arab.

i, IRONA'TION, ch. h. bv Laplander, dam by Oscar. 
COTTON PLANT, gr. m. by Bertrand, dam by Pacolet.

COWBOY, ch. h. by Meduc, dam by Virginian.

CRACKAWAY, ch. h. by Marmaduke.

CRACOVIENNE, gr. m. by [ $\operatorname{Imp}$.] Glencoe, dam [Imp.] Gallopado by Catton.

CREATH, b. h. by [Imp.] Tranby, dam by Sir Archy Montorio.

CRICHTON, ch. h. by Bertraud, dam by Phenomenon.

CRIPPLE, gr. m. by [ $I m p$.] Philip, dam (Gamma's dam) by Sir Richard.

CROCKETT, b. h. by Creckett, dam by Sir Archy.

CRO'TON, gr. h. by Chorister, dam by Mucklejohn.

CIRUCIFIX, ch. m. by [Imp.] Leviathan, dam Virginia by Sir Archy.

CLB, ch. m. by Medoc, dam by Sumpter.

CUMBERI.AN D, b. h. by [Imp.] Leviathan, dam by Sir William.

CURCULlA, ch. m. by Medoc, dain by Sumpter.

CZARINA, gr. m. by [Imp.] Autocrat, dam Aurora by Arab.

\section{D.}

UANDRIDGE, b. h. by Garrisun's Zinganee, dam by Walnut or Lafayette.

DAN MARBLE, ch. h. by Woodpecker, dam (a sister to West Florida's dam) by Potomac.

DAN M'IN'TYRE, ch. h. by Medoc, dam by Sumpter.

DAN TLCKER, ch. h. by [I I p).] Belshazzar, dam by Pulaski.

DANIEL BUCK, ch. h. by Cullier, dam by Pacolet.

DARIUS, b. h. hy Orphan Boy, dam bv Rimberland.

WARKNESS, bl. m. by Wagner, das sally Shannon's dam) he Sir Richard.

D.1RYLEY, ch. h. by John Richards, dam Lady Gray by Sir Richard. DAR'T, b. h. hy [Imp.] Doncister, dam Jane Gray by Orphan Boy.

DAVE PATTON, ch. h. by Sumpter, dam by Hamiltonian.

DAVID FYLUE, b. h. by [Imp.] Fylde, dam by Clay's Sir William.

1) A Y DREAM, br. $m$. by [Imp] Luzlorough, Jam by Sir Archy.

DAYTON, ch. h. by Tormentor, dam by Tuckahoe.

DECATUR, ch. h. by Henry, dam Ostrich by Eclipse.

DECEPTION, b. h. by Stuckholder, dam by $[I m p$. $]$ Leviathan.

DE LAT'TRE, br. h. by [ lmp.] Consol, dam [ Imp.] Desirn by Tramp.

DELAWARE, b. h. by Mingo, dam by John Richards.

DEI,PHINE, ch. m. by Sumpter.

DEMCCRA'T, ch. h. by [Imp.] Luzhorough, dam by Easle.

DENMARK, br. h. by [Imp.] Hedgford, dam Betsey Harrison by A ratus.

DENIZEN, [Imp.] b. h. by Actæon, dam Design liy Tramp.

DEVIL, JACK, ch. h. by [lmp.] Leviathan, dam Lady Burton by 'limoleon.

DTANA CROW, hl. m. hy Mark Antony, dam hy [Botts' Lafayette.

DIANA SYNTAX, br.m. by Doctor Syntax, dam [Imp.] Diana bo Éatton.

DICK COLLIER, ch. h. hy Colier, dam hy Whip.

DICK MENIFEL, br. h. hy Lance, dam by sir Willian of Transpo.t 
DUCTOR UUDLEY, b. h. by Bertrand, dam hy Rohin C.ray.

1)OCTOR DUNCAN, ch. h. by Cadmus, dam by Old Court.

DOC'TOR FRANKLIN, ch. h. hy Frank, dam Althea by Big Archy.

DOCTOR WILSON, ch. h. by Juhn Bascombe, dam Bolivia by Bo livar.

DULLY DIXON, b. m. by [Imp.] Tranby, dam Sally House by Vir. ginian.

DOLLY MILAM, b. m. by [ $1 \mathrm{mp}$.] Sarpedon, dam by Eclipse.

DONCAS'TER, [Imp.] bl. h. by Longwaist, dam by Muley.

DONNA VIOLA, b. m. by [Imp.] Luzborough, uam (Jack Downing's dam) by Mons. Tonson.

DUAN NA, gr. m. by [Imp.] Sarpedon, dam Goodloe Washington ly Washington.

DUBLIN, gr. h. by [Imp.] I,eviathan, dam by Jerry.

DUCKIE, b. m. by [Imp.] Sarpedon, dam Mary Jones by Kosciusko.

DUKE SUMNER, gr. h. hy Pacific, dam hy Girey Archy.

DUNGANNUN, b. h. by Mingo, dam by John Stanley.

DUNVEG.AN, b. h. by [Imp.] Trustee, dam Jemima by Rattler.

\section{E.}

EARL OF MARGRAVE, b. h. by [Imp.] Sarpedon, dam Duchess of Marlborough by Sir Archy.

ECLIP'TIC, ch. h. by Felipse, dam (Rodolph's dam) by Moses.

EDISTA, b. h. by [Imp.] Rowton, dain Einpress.

EDWARD EAGLE, ch. h. by Grey Fagle, cian by Director.

EFFIE, b. m. by [Imip.] Leviathan, dam by Stockholder.

FL BOLERO, br. h. by Stockholder, dam by [Imp.] Leviathan.

EL FURIOSO, b. h. by [Imp.] Hedgford, dam Rattlesnake by Ber trand.

ELIAS RECTOR, b. h. by [Imp.] Luzborough, dam Kate Blair.

ELI ODOM, br. h. by [Imp.] Leviathan, dain Clıuckfahila by Bertrand.

ELIZA CULVERT (or Calvert), ch. m. by Cymon, dam Lady Surn ner by Sliawnee.

ELIZA HUGHES, b. m. by Marmion, dam by Whip.

F.LIZA JANE, b. m. by [Imp.] Monarch, dam Big Jinny by Rattler.

ELIZA ROSS, b. m. by Marmion, dam by 'Tiger or Whip (or Tigor Whip).

ELIZABETH GREATHOUSE. b. m. by Masaniello, dam by Waxy.

ELIZABETH JONFS, $m$. by Pateific, dam by Mons. Touson.

ELLA, ch. m. by Young Virginian. dam by Harwood.

ELLEN HUTCHINSON, ch. m. by [ $[m p$.] Leviathan, dam by Ber trand.

ELLEN CARNELL, ch. $m$. by [Imp] Belshazzar, dam by [Imp., Leviathan.

ELLEN JORDAN, b. m. by (Imp.) Jorkar, dam Ellen Tiee tp Henry.

ELLEN PERCY, ch. m. by Godolphin, dam by (Imp.) Bedford. ch. m. by Godolphin, dam by Financier.

ELLEN WALKER, b. m. by (Imp.) Consol, dam (Imp.) Plenty ur Emilus.

CLLISIS, L. in. Ly Platoff, dam by Mucklejohr. 
EI.IIPTIC. chr. h. by Monmonth Eolipse, dam dmanda by Revenue FL()I:E, ch. m. by (Imp).) Luzborough, dam Mary Wasp by Dcu Quixotte.

ELVIRA, ch. m. by Red Gauntlet, dain by Rob Roy.

E.IERALD, b. m. Ly (Imp.) Iseviathan, dam (Imp.) Eliza by Ru bens.

EMIGRAN'T, gr. h. by Cadet, dam by (Imp.) Contract.

E.HILY, ch. m. by Medoc, dam Spider by Almanzar.

- br. m. by (Imp.) Priam, dam by 'lom 'lough.

- (Imp).) b. in. by Einilius, dam Elizabeth by Rainbow.

F.MILY SI'EED, ch. m. by (Imp.) Leviathan, dam by Pacolet.

EMMET, b. h. by Bertrand, dain by Gallatin.

ESMERALDA, b. m. by P'ressure, dam by Murat.

ESPER SYKES, (Imp.) br. h. by Belshaziar, dam Capsicum by Emilias.

FSTA, gr. m. by Bolivar, dain by ( $I m p$.) Barefoot.

ESTHER WAKE, gr. m. by (Imp.) Luzborough, dam by Stcckholder.

ETHIOPIA, bl. m. by Dashall, dam by (Imp.) Expedition.

EUDORA, br. m. by Jeflerson, dam by Oscar.

EUCLID, br. h. by (Imp.) Luzborough, daun by Sir Archy.

EUT AW, b. h. by (Imp.) Chateau Margaux, dam by Sir Charles.

EVFRGREEN, ch. m. by Wild Bill, dain by Sir Clıarles.

EXTIO, b. m. by (Imp.) Leviathan, dain (Imp.) Refugee by Wan. derer.

\section{F.}

FANCY, br. m. by (Imp.) Fylde, dam by Sir Archy.

FANDANGO, gr. m. by (Imp.) Leviathaı, dam (Imp.) Gallopade by Catton.

FANNY, ch. m. by Eclipse, dam Maria West by Marion.

ter.

W (Joseph Alston's), b. m. by Woodpecker, dam Fan by Trumpatur.

FANNY B.AILEY, ch. m. by Andrew, dam by Bertrand.

FANNY FURE×TER, b. m. by (Imp.) Esuancipation, dam by In elustry.

FANNY GREEN, b. m. by (Imp.) Trustee, dam Betsey Archy by Sir Archy.

FANNY KING, b. m. by (Imp.) Glenene, dam Mary Smith by Sir Richard.

FANNY LIGHTFOOT, b. m. by Stockliolder, dam by Sumpter.

FANNY ROBERTSON, b. m. Ly (Imp.) I'riam, dam Arieta by Vir giniatu.

FANNI NTRONG. ch. m. by (Imp.) Leviathan, dam Sally Bell ty Sir Archy.

FANNY WYATT, ch. m. by Sir Charles, dam by Sir Hal.

FANTAIL, ch. m. hy Waxy, dam by sumpter.

FAIRLY FAlR, ch. m. by (Imp.) Luxhorminh, dam ly Peter leazlo

FAlTH, b. ra. by (Imp.) Tranby, dam Latly Painter by Latse

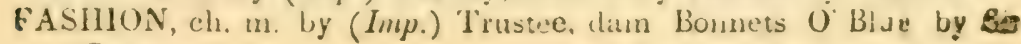
Charles. 
FEATHF:RS, ch.m. by (Imp.) Leviathan, dam (George Kendalr`s dam) by Stockholder.

FECTIVITY, b. h. by (Imp.) Leviathan, darn Magnolia by Mons linson.

FIA 1', b. m. by (Imp.) Hedgford, dam Lady Tomplins by Eclipse. FIFER, b. h. by Monmouth Eclipse, dam Music by John Richardz.

FILE-LEADER, ch. h. by (Imp.) Barefoot, dam Saluda by Timo. leon.

FINANCE, b. m. by Davy Crocket, dam by Sir Henry Tonson.

FLASH, b. m. by (Imp.) Leviathan, dam by Conqueror.

FLAXINELLA, gr. $\mathrm{m}$. by (Imp.) Leviathan, dam by Virginian.

FLEETFOOT, gr. m. hy (Imp.) Barefoot, dam Dove by Dliroc.

FLETA (James L. French's) br. m. by (Imp.) Sarpedon, dam by Rasselas.

- (G. B. Williams's), ch. h. by (Imp.) Leviathan, dam by Clay's Sir William.

FLIGHT, ch. m. by (Inp.) Leviathan, dam by Sir Charles.

FLORA HUN'TER, gr. m. by Sir Charles, dam by Duroc.

FURDHAM, ch. h. by Eclipse, dam Janette by Sir Archy.

FORTUNATUS, ch. h, by Carolinian, dam by Sir Cliarles.

FORTUNE, b. in. by (Imp.) Tranby, dam by Maryland Eelipse.

FRANCE AMANDA, ch.m. by Pennoyer, dain Sally MeGrath.

FRANCES TYRREL, b. m. by Bertrand, dam by Rockingham.

FRED KAYE, b. h. by Grey Eagle, dam by Moses.

FRESHET, ch. m. by Toin Fletcher, dam Caroline (or Catherine) by Pacific.

FREE JACK, br. h. by (Imp.) Luzborough, dam (Imp.) Tinsel by Nirpoleon.

FROSTY, ch. h. by Eclipse, dam Martha Holloway by Rattler.

FURY, bl. m. by 'Terror, dam by Smith's Bedford.

(Col. Wade Hampton's), ch. m. by (Imp.) Priam, dam (Imp.) sister to Ainderby by Velocipede.

\section{G.}

GABRIF.L, ch. h. by Napoleon, dam Harpalyce by Collier.

GALANTHA, b. m. by (Imp.) Leviathan, dam by Jackson.

GANMA, gr. m. by Pacific, dain (Melzare's dam) by Sir Richard.

GANO, b. h. by Eclipse, dam Betsey Richards by Sir Archy.

GARRICK, gr. h. by (Imp.) Shakspeare, dam by Eaton's Columbus

GARTER, b. m. by (Imp.) Glencoe, dam by 'Trumpator.

GAS-LIGHT, br. h. by (Imp.) Merman, dam by Mercury.

riAZAN, b. h. by Sir Leslie, dam Directress by Director.

GENERAL DEBUYS, ch, h. by (Imp.) Leviathan, dam (Im».

Nanny Killam by Voltaire.

GENERAL RESUL'T, b. h. by (Imp.) Consol, dam by Timoleon.

GENEVA, clı. m. by Mecloc, dam by Arab.

'iEORGE BURBRIDGE, b. h. by (Iiip.) Chateau Margaux, dam hy Mons. 'Touson.

6EORGE ELLIOTT, br. 1. by (Imp.) Leviathan, dam by Lawrence

liEORGE LIGHTFOOT, b. b. by Eclipse Lightfot, dam Mity Logan by Arab. 
GHORGE MARTIN, b. h. by Garrison's Zinganee, dam Gabriolla by Sir Archy.

GEORGE W. KENDALL, ch. h. by Medoc, dam Jenuy Jevers by Stockholder.

GEROW, ch. h. by Henry, dam Vixen by Eclipse.

GERTRUDE, b. m. by (Imp.) Leviathan, dam Parasol by Napoleon

GIF'I, ch. m. by Dick Chinn, dam Milch Cow.

GIPSEY, b. m. by Nullifier, dam by Anti-Tariff.

GLENARA, b. h. by (Imp.) Rowton, dam Nell Gwynne by Tramp. Kitty Clover by Sir Charles.

- (Dr. 'Thos. Payne's,) b. m. by (Imp.) Leviathan, dam Jane Shore by Sir Archy.

GLIDER, ch. h. by (Imp.) Valparaiso, dam by Clifton.

GLIMPSE, b. h. by Medoc, dain by Tiger.

FLORVINA, ch. m. by Industry, dam by Bay Richmond.

GLOVER ANN, gr.m. by (Imp.) Autocrat, dam by Bolivar.

GiUD EAGLE, ch. h. by Grey Eagle, dam Eliza Jenkins by Sir William.

GOLD FRINGE, ch. h. by (Imp.) Glencoe, dam (Imp.) Gold Wire.

GONE AWAY, b. h. by (Imp.) Leviathan, dam by Virginian.

GOSPORT, br. h. by (Imp.) Margrave, dam Miss Valentine by (Imp.) Vaientine.

GOVERNOR BARBOUR, b. h. by (Imp.) Truitle, dam by Holmes Vampire.

GOVERNOR BUTLER, ch. h. by Argyle, dam Mary Frances by Director.

GOVERNOR CLARK, ch. h. by Medoc, dam by Old Court.

GOVFRNOR POINIEXTER, ch. h. by (Imp.) Leviatıan, dam Eliza Clay (the dam of Giantess,) by Mons. Tonson.

GRACE DARLING, ch. m. by (Imp.) Trustee, dam Celeste by Henry.

GRAMPUS, b. h. by (Imp.) Whale, dam by Timoleon.

br. h. by Shark, clam by Mons. Tonson.

GRAT"IAN, b. h. by (Imp.) Chateau Margaux, dan Fıra by Mary. land Eclipse.

GREY ELLA, (A. G. Reed,) gr. m. by Big Areliy, dam by Bertrand. - - (A. G. Reed,) gr. m. by Collier, dam by Gallatin

GREY FRANK, gr. h. by Frank, dam by Buzzaru.

GliEY.HEAD. (J.L. Bralley's,) b. h. by Chorister, dam by Sumpter jolin.

GREL MARY, gr. in. by Ben. Sutton, dam by Hamiltonian.

GliEY Mlone, gr. h. by Medne, dam Grey Fanny by Bertrand.

GRFiY MOMUS, gr. h. by Hard Luek, dam by Mons. Tomson.

GIIFA-C() B, br. h. by Merlin, dam by Grey-tail Florizel.

GULNARE, b. m. by (Imp.) sarpedon, dam by sir William a 'Transport.

FUSTAVUS, b. h. by Sussex, dam by Thornton's Rattler

GUY OF WAFWICK ch. h. oy Frank, dam 'y Hamilionian 


\section{I1.}

HANNAH HARRIS, b. m. by Bertrand, dam Grey Gonse oy Pacolet HA NNIBAL, b. h. by O Kelly, dam Roxana by Sir Charles.

HA'-PENNY, b. m. by Birmingham, dam Picayune by Medoc.

HARDENED SINNER, b. h. by (Inip.) Ptsilip, dam by (Imp.) Biuster.

HARD CIDER, b. h. by (Imp.) Tranby, dam by Sir Charles.

HARK-AWAY, ch. h. by Emilius, dain (Intp.) Trapes.

HARPALYCE, ch. m. by Collier, dam by Sea-Serpent.

HARRIET, ch. m. by Eclipse, dain by Shylock.

HARRY BLUFF, bl. h. by (Imp.) Autocrat, dam by Pakenham.

HARRY CARGILL, ch. b. by (Imp.) Leviathan, dam (Imp.) Florentine by Whisker.

HARRY HILL, b. h. by (Imp.) Chateau Margaux, dam (Imp.) Anna Maria by Truffle.

HARRY WHITEMAN, ch. h. by Orphan Boy, dam by Sir Archy.

HAWK-EYE, ch. l. by Sir Lovell, dam Eliza Jenkins by Sir William.

HEAD EM, b. h. by (Inp.) Trustee, dam Itasca by Eclipse.

HEALER, ch. m. by Monmouth Eclipse, dam by Sir Archy of Transport.

HEBE, ch. $m$. by Collier, dam by Bertrand.

HECTOR BELL, gr. h. by Drone, dam Mary Randolph by Gohanna.

HEIRESS, (THE) ch. m. by (Imp.) Trustee, dain by Henry.

HELEN, (Imp.) b. m. by (Imp.) Priam, dam Malibran by Rubens.

HFNRY A. WISE, br. h. by Dashall, dam by Hickory.

HENRY CLAY, br. h. by Cock of the Rock, dam by Virginian.

HENRY CROWELL, b. h. by Bertrand Junior, dam sister to Mucklejohn Jurior.

HERALD, ch. h. by Plenipotentiary, dam (Imp.) Delphine by Whisker.

HFRMIONF, ch.m. by (Imp.) Non Plus, dam Leocadia by Virginian. HERO, ch. h. by Bertrand Junior, dam (Imp.) Mania by Figaro.

HIT-OR-MISS, b. m. by (Imp.) Somonocodrom, dam (Imp.) Baya. dere. [These horses are owned in Canada.]

HOOSIER-GIRL, ch. m. by ( $I m p$.) Langford.

HOPE, ch. h. by the Ace of Dianonds, dam (The Captain's dam,) by Oscar.

HORNBLOWER, br. h. by Monmouth Eclipse, dam Music by John Richarits.

HOURI, (Imp.) ch. m. by Langar, dam Annot Lyle by Ashton.

HUGUENO'T, ch. h. by Convention, dam (Imp.) Marigold.

HUMMING-BIRD, br. m. by Industry, dam Virginia by Thorr.ton's Rattle .

HUNTSMAN, gr. h. by (Imp.) Leviathan, dam by Pacolet.

HYNE PARK, ch. h. by (Imp.) Barefout, clam Saluda by Timolnc

I.

IAGO, bl. h. by Othello, dam (Sartin's dam, ) by Timolcon. CEI.AND, ch. h. by Medoc, dam Lady Jackson by Sump.er ILLINCIS, b. h. by Medoc, dain by Bertrand. 
IOWA, ch. h. by (Imp.) Barefoot, dam (Imp.) Woodbine.

IRENE, ro. m. by P'rinter, dam Mckinney's Roan.

ISEE TURNER, ch. m. by (Imp.) Leviathan, dam by Stackholder

IsIDORA, b. m. by (Imp.) Blacklock.

ISOLA, ch. m. by Bertrand, dain Susette.

\section{J.}

JACK DOIVNING, b. h. by Pacific, dam by Mons. Tonson.

JACK PENDLEIUN, ch. h. by Goliah, dum (Philip's dam,) by Tra falgar.

JACK WVAKER, ch. h. by Cymon, dam by (Imp.) Luzborough.

JAMliS ALLEN, ch. h. by (Imp.) Leviathan, dam Donna Maria by Sir Hal.

JAMIES CROWELL, br. h. by Bertrand, dam by Sir Charles.

JAMES JACKSON, ch. h. by (Imp.) Leviathan, dam Parasol by 'liger.

JAMES F. ROBINSON, ch. h. by Medoc, dam by Potomac.

JAMES K. POLK, b. h. by (Imp.) Luzborough, dam Oleana by Telegraph.

b. h. by Telegraph, dam by Buzzard. ch. h. by Buck-eye, dam by Medoc.

JANE ADAMS, b. m. by (Imp.) Tranby.

JANE FRANCIS, b. m. by Granby, dam by Tecumseh.

JANE MI'TCHELI, ch. m. by (Imp.) Leviathan, dam by Conqueror. JANE ROGERS, ch. m. by (Imp.) Leviuthan, dain by Sir Charles.

JANE SMITH, b. m. by Jolin Dawson, dam by Pacolet.

JANE SPLANE, gr.m. by (Imp.) Autocrat, dam Helen McGregor by Mercury.

JEANET'TE BERKLELEY, ch. m. by Bertrand jr., dam Carolina by Young Buzzard.

JEANNETTON, ch. m. by (Imp.) Leviathn, dam by Stockholder.

JENNY.ARE-YOU.THERE, ro.m. by Sir Archy Montorio, dam by Potomac.

JENNY RICHMOND, ch. m. by Medoc, dam by Hamiltonian.

JENNY ROBER'TSON, b. m. by (Imp.) Luzborough, dam by Marcus.

JEROME, b. h. by (Imp.) Luzborough, dam by Sir Charles.

JERR Y, yr. h. by Jerry, dam by Blackburn's Sir WVillian.

JERRY LANCAS'TER, ch. g. by Mark Moore, dain Maid of Warsan by Gohanna.

JIM BELI, b. h. by Frank, dam Jonquil by Litıle John.

JIM ROCK, ch. h. by Young Echipse, dim by Potomac.

JOB, b. h. by Liclipse, dam Jemima by Rattler.

JOE, ch. h. by Medoc, dam by Sir Arehy Montorio.

J()E ALLEN, ch. 1. by Goliuh, dam by Sir Charles.

JOE CIIAIMERS, ch. h. by (Imy.) Consol, dam (Imp.) Rachel by P'artisan (or Whalebone).

JOE INVIS, b. h. by Eclipse, dan Virginia Washingtun by Saxo Weimar.

JOE GA'l'ES, ch. h. by Marlborough, dam by Eclipse.

JOE MURRAY, br. h. by Waxy, dim hy Hamiltonian.

'UE S'TLligis, ch. h. by Jum Bascombe, dam by 'Thomas s Andrew.

JOL WINFIELD, h. h. by John Dawson, dam Sally Diliard. 
IOIIN ANDERSON, b. h. by (Imp.) Luzborough, dam by Bagdad.

by $(\operatorname{Imp}$.) Cagle.

JOHN ARCHY, ch. h. by Joln Richards, dam by Old Whip.

JOHN BEI,L, b. h. by Shark, dam Kate Kearney.

IOHN BENTON, gr. h. by (Imp.) Leviathan.

JOIIN BLEVINS, ch. h. by The Colonel, dam (Imp.) Trinket.

JOHN B. JONES, b. h. by Bertrand, dam by Director.

JOHN BLUNT, b. h. by Marion, dam (Mary Blunt's dam, by Alfred.

JOHN CAUSIN, b. h. by (Imp.) Zinganee, dam Attaway by Sir James.

JOHN C. STEVENS, ch. h. by Medoc, dam by Sumpter.

JOHN DUNKIN, b. h. by Mucklejohn, dam Coquette.

JOHN FR ANCIS, ch. h. by Francis Marion, dam Mary Doubleday by Sir Henry.

JOHN HAMPDEN, ch. h. by Goliah, dam hy Director.

JOHN HUNTER, b. h. by Shark, dam Coquette by Sir Archy.

'OHN KIRKMAN, ch. h. by Birmingham, dam by Sir Henry Tonson.

JOHN LEMON, ch. h. by Uncas, dam by Oscar.

JOHN MALONE, ch. h. by (Imp.) Leviathan, dam Proserpine by Tenriessce Oscar.

JOHN MARSHALL, b. h. by (Imp.) Luzborough, dam Lady Bass by Conqueror.

JOHN R. GRY MES, gr. h. by (Imp.) Leviathan, dam Alice Grey by Pacolet.

than, dam Fanny Jarman by Mercury.

JOHN ROSS, bl. h. by Waxy, dam by Topgallant. ch. h. by (Imp.) Leviathan, dam by Oscar.

JOHN VALIANT, bl. h. by Valiant, dam by King's Archer.

JOHN YOUNG, b. h. by John Richards, dam by Trumpator.

JOHNSON, br. h. by Star, dam Vanity by Grigsby's Potomac.

JOSHUA BELI, ch. h. by Frank, dam Jonquil by Little John.

JOYCE ALLEN, b. m. by (Imp.) Emancipation, dam Leannah by Seagull.

JULIA, b. m. by (Imp.) Rowton, dam by Roscius.

JUI,IA BURTON, ch. m. by Gohamna, dam by Tom Tough.

JULIA DAVIE, ch. m. by (Imp.) Rowton, dam by Koscinsko.

JULIA FISHER, ro. m. by (Imp.) Luzborough, dam Polly Bellew by Timoleon.

JULIUS, ch. h. by (Imp.) Luzbornugh, dam by Jackson.

JUMPER, ch. h. by Timoleon, dam Diana Vernon by Herod.

\section{K.}

KANAWA, ch. h. by Medoc, dam by Rattler.

KA'TE, b. f. by Monmouth Eclipse, dam Shepherdess by Apollo.

KATE ANDERSON, b. m. by Columbus, dam Eaglet by (Inp.) Engle.

KATE AUBRFY, gr. m. by Eclipse, dam Grey Fanny by Be:trnud. KATF, CONVERSE, b. m. by (Imp.) Non Plus, dain Paisy bq Kosciusto.

KATE COY, b. m. by Critic, dam Nancy Bone by Sussex.

IATE HAUN, br. m. by Stockholder, dam by Timoleon 
KATE LtCKE'TT, b. m. by Monmouth Eclipse, dam Shepherdess by Apollo.

KATE NICKLEBY, br. m. by'(Imp.) Trustee, dam by Teniers. than. b. m. by (Imp.) Glencoe, dam by (Imp.) Levia

KA'TE SEYTON, br. m. by Argyle, dam Pocahontas hy Sir Archy.

KATE SHELBY, ch. m. by ( $\operatorname{Imp}$.) Leviathan, dam Maria Shelby by Stockholder.

KAVANAGII, b. or ch, h. by Bertrand, dam by Director.

KEW ANNA, b. m. by (Imp.) Cetus, dam (Imp.) My Lady by Comus

IIITTY HARRIS, gr. m. by (Imp.) Priam, dim Ninon de l'Linclos by Rattler.

KIT'TY THOMPSON, gr. m. by (Imp.) Margrave, dam Ninon do l'Enclos by Rattler.

\section{L.}

LA BACCHANTE, ch. m. by (Imp.) Glencoe, dam by Bertrand.

LA BELLA COMBS, ch. m. by Andrew, dam by Directur.

LADY CAN'TON, gr. m. by (Imp.) 'T'ranby, dam Mary Randolph t. Gohanna.

LADY C.AVA, ch. m. by Bertrand, dam Betsey Echols by Archy Montorio.

LADY FRANCIS, b. m. by Trumpator, dam (Pressure's grandam.)

LADY FRANliLIN, b. m. by (Imp.) Luzborough, dam Sting by Con querur.

LADY IIARRISON, b. m. by Sir Henry, dam by Mucklejohn.

LADY JACKSON, -, m. by Sumpter.

LADY JANE, gr. m. by (Imp.) Leviathan, dam Lady Grey by Orphan Boy.

IAADY PI.AQUEMINE, ch. m. by Little Red, dam by (Imp.) Eagle.

LADY PLYMOU'III, b. m. by Flugellator, dam Black Sophis uY Eclipse.

LADY SKIPETH, m. by (Imp.) Leviathan, dam by Truxton.

LADY SLIPPER, ch. m. by (Imp.) Leviathan,

LADY STOCK, ch. m. by Stockholder, dam by Potomac.

LADY SUSAN, b. m. by Cramp, dam by Pantaloon.

LAFI'T'TE, gr. h. by O'Kelly, dam Caroline Wilson by Timolecn.

I ANDSCAPE, b. h. by (Imp.) Margrave, dam by Sir Archy.

LANGHAM, ch. h. by Medoc, dam by Cumberland.

LANEVILLE, ch. h. by Eclipse, dam by Arab.

LASSO, b. m. by Mucklejohn, dam by Giallatin.

LAURA, b. m. by Medoc, dam by Moses.

LAURA LECOH'TE, b. m. by Tarquin, dam Sarah by (Imp.) Sax. pedon.

I.AURET'TE, ch, m. by Jerseyman, dam Maria Harrison.

LAVINIA PIPER, ch. m. by (Imp.) Leviathan, dam by Murphy a Pacolet.

IAAVIT'A, b. m. by Medoc, dam by Blackburne's Buz7aril.

LAWYER MCCAMPEELL, b. h. by Lord Byron, dus: Warping Burs by Rattle the Cash.

LEDA, ch. m. by 'Tiger, dam by Sumpter.

LEESBLRG, ch. h. by Red Rover, dam by Tuckahoe.

LEG-BAIL, ch. h. by Jackson, dam by Marshal Ney.

LEG.TRE.ASI RER, ch. h. by Medoc, dam by Cumberland. 
I.EIIGH, ch. h. by (Imp.) Skylark, dam Nelly Webb by Industry.

I.EN NOX, b. h. by (Imp.) 'I'rustee, dim (Imp.) Rosalind by Pawlowitz. LESI,IE, ch. h. by (Imp.) Leviathan, dam by Stockholder.

LE'TTY FLOY D, ch. m. by (Imp.) Rowton, dam Palmetto by Rob Roy

LEVI, - h. by Star, dam by Walnut.

LEVITHA, ch. m. by (Imp.) Leviathan.

EXXIHILI, ch. m. by Hugh L. White, dam by Pacolet.

LIATUNAH, ch. m. by (Imp.) Ainderby, dam (Imp.) Jenny Mills Whisker.

I.IBERALITY, ch. h. by Maryland Eclipse, dam by Sir Alfred.

LIBC:R'TAS, ch. h. by Eclipse, dam by Director.

LIEUTENANT BASSI VGER, br. h. by (Imp.) Fylde, dam by Roanoke.

LIKENESS, (Imp.) ch. m. by Sir Peter Lely, dam Worthless by Walnut.

LILY, gr. m. by Tychicus, dam Laura by Rob Roy.

LIMBER JOHN, ch. h. by Ḱosciusko, dam by Moses.

LINWOOD, ch. h. by Wild Bill, dam by Pacolet.

LIT'I'LE BAR'TON, h. h. by Bertrand, dam by Hamiltonian.

LIT'TLE BIJIE, gr. h. by Marmion, dain by 'Tecumseh.

LITTLE MISERY, b. m. by Anvil, dam (Imp.) Anna Maria by Truffle.

LITTLE PRINCE, gr. h. by John Bascombe, dam Bolivia by Bulivar.

LI'T'TLE RED, ch. h. by Medoc, dam by Sumpter.

LITTLE 'TRICK, b. h. by (Imp.) Tranby, dam (Occident's dam,) by Florizel.

LIVE OAK, b. h. by (Imp.) Luzborough, dam by Pacific.

LIVINGS'TON, gr. h. by Medley, dam by Van 'Tromp.

LIZ LONG, br. m. by (Imp.) Merman, dam by Alpheus.

LIZ TILLETT, ch. m. by Frank, dam by Medoc.

LIZZY HEWIT'T, b. m. by Ivanhoc, dam Princess Ann by Mons Tonson.

LOG.CABIN, ch.h. by Frank, daun by Hamiltonian.

LONG TOM, ch. h. by Pacific, dam by Jerry.

LORD OF LORN, br. h. by Argyle, dan Maria by Virginian.

- br. h. by Argyle, dam Duck Filly by Virginius.

LORD OF THE ISLES, gr. h. by Pacific, dam by Jerry.

LORENZO, b. h. by Bertrand, dam by Whip.

LORINDA, ch. m. by Havoc, dam by Conqueror.

LOUISA JORDAN, ch. m. by (Imp.) Jordan, dam Betsey Marshal by John Richards.

LOUISA WINSTON, b. m. by Waxy.

LUCRETIA NOLAND, br. m. by (Imp.) Hedgford, dam Franceo Ann by Frank.

LUCY A. MEYER, b. m. by Pacific, dam by Sir Richard.

LUCY BENTON, br. m. by Hugh L. White, dam by Moloch.

LUCY DASHWOOD, gr. m. by (Imp.) Leviathan, dam Miss Bailey by (Imp.) Buaster.

I.CCY FULLER, ch. m. by Eclipse, dam by Pakenham.

LL'CY LONG, m. by John Richards, dam by Diomed. b. m. by Latitude, dam by Whip.

LICY WEIBB, ch. m. by Medoc, dam by Sumpter. 
I.UDA, b. m. by Medoc, dam Duchess of Marlborough by Sir Archy LUNA DUE, ch. m. by (Imp.) Leviathan, dam Telie Doe by Pacifie L'INUIIURS'T, ch. h. by (Imp.) Leviathan, dam by Wonder. LYNEDOCH, ch. h. by (Imp.) Leviathan, dain by Wonder.

\section{1.}

MABEL WYNNE, b. m. by (Imp.) Rowton, dam by Sir Archy.

MADA.ME ARRALINE, ch. m. by Medoc, dam by Cadmus.

MAFFI'I, b. h. by Frank, dain by Aratus.

MAGNATE, clı. h. by Eclipse, dam Cherry Elliott by Sumpter

MAID OF A'THENS, b. m. by (Imp.) Priam, dam by Arab.

MAID OF NOR'THAMPTON, gr. m. by (Imp.) Autocrat, dam bj Rattler.

MAJOR BOOTS, br. h. by (Imp.) Merlin, dam by Alborak.

MANALOPAN, gr. h. by Medley, dam by John Richards.

MANGO, (Imp.) ch. m. by Taurus, diım Pickle by Emilius.

MARCHIONESS, ch. m. by (Imp.) Rowton, dam (Fancy's da.m) by Sir Archy.

MARCO, b. h. by Sir Leslie, dam by Lance.

MARGARE'T CAR'TER, b. m. by Medoc, dam Lady Whip by Sis Archy.

MARGARET BLUNT, b. m. by Eclipse, dam by Contention.

MARGARET WOOD, b. m. by (Imp.) Priam, dam Maria West by Marion.

MARIA, ch. m. by (Imp.) Jordan, dam Polly Powell by Virginian.

MARIA BLACK, (Imp.) br. m. by Filho da Puta, dam by Smolensko.

MARIA BROWN, br. II. by (Imp.) Luzborough, dam Brunette by Sir Hal.

MARIA COLLIER, br. m. by Collier, dam by Gallatin.

MARIA MILLER, br. $m$. by Stockholder, dam by Midison.

MARIA PEYTON, ch.m. by Balie Peyton, dam by Tariff.

MARIA SHELTON, ch. m. by Andrew, dam (Ajarrah Harrison'a dam) by Gallatin.

MARIA SPEED, ch. m. by (Inp.) Leviathan, dam by Pacific.

MARIA WILLIAIS, ch. m. by (Imp.) Leviathan, dam by Napoleon

MARINER, bl. h. by Shark, dam Bonnet's o' Blue by Sir Charles.

MARION, b. m. by (Imp.) Autocrat, dam by Rob Roy.

MAR'THA BICKER'IUN, b. m. by Pamunky, dam by Tariff.

MARTHA CARTER, ch. m. by Bertrand, dam Sally Naylor by Gal. latin.

ch. $m$. by Bertrand, dam by Oscar.

MARTIIA CALVIN, b. m. by Agrippa, dam by Walnut.

MAR'TIA MALONE, b. m. by' (Imp.) Leviathan, dam Tatchecan by Bertrand.

MARTIIA RANEY, b. m. by (Imp.) Luzhorough, dam by Sumpter.

MIARTHA ROW'TON, ch. m. by (Imp.) Rowton, dam Marha Griffin by Phenomenon.

MARTIIAVILLE, b. m. by Dick Singleton, dain Black. Eyed Stisan

MA'TCHE.I, ch. h. by (Imp.) Luzborough, dam by Plind Jackson.

MAR'TIN'S JLDY, br. m. by Young's Mercury, dam by Eclipse.

MIARTIN VAN BJREN, 3. h. by Lafayette Stockholder, dam by In diar

MARY, gr. n. by Old Saul, dam by Free Mulitto. 
MARY, gr. m. by (Imp.) Consol, dam Sally Bell by Sir Archy. MARY INN FURMAN, br. m. by (Imp.) Sarpedon, dum by Era. trand.

MARY BEECHLAND, b. m. by Sir Leslie, dam by Potomac.

MARY BELL, b. m. by Seagull, dam (Vidocq's dam) by Stockholder MARY BRENNAN, b. m. by Richard Singleton, dan by Hamiltonian. MARY BURNHAM, b. m. by Archy Montorio, dam by Stockholder. MARY CHASE, b. m. by (Imp.) Felt, dam by Sir Archy. MARY CHURCHILL, b. m. by (Imp.) Barefoot.

MARY DOUGLAS, gr.m. liy Jerry, dam by Stockholder. MARY ELIZABETH, ch. m. by Andrew, dam by Gallatin.

MARY ELLEN, b. m. by Woodpecker, dam by Sumpter.

MARY HEDGFORD, br. m. by (Imp.) Hedgford, dam Mary Francis by Director.

MARY JONES, ch. m. by (Imp.) Barefoot, dam by Eclipse.

MARY LEW IS, ch. m. by (Imp.) Leviathan, dau Pruserpine by $\mathrm{C}_{\mathbf{8}}$ car.

MARY LONG, b. m. by (Imp.) Tranby, dam Lady Pest by Carolinian

MARY LUCKETT, ch. m. by Marion, dam (Charles Archy's dam) by Eclipse.

MARY MASON, br. m. by Pirate, dam by (Imp.) Consol.

MARY MEAIJOWS, ch. m. by Stockholder, dam by 'I'imoleon.

MARY MILLER, ch. m. by Arab, dam by Peacemaker.

MARY MORRIS, b. m. by Medoc, dam Miss Obstinate by Sumpter.

MARY OUSLEY, br. m. by King's Bertrand, dam by Pacolet.

MARY P(IRTER, ch. m. by Mucklejohn, dam by Printer.

MARY REED, br. m. by Industry, dam by Rattler.

MARY RODGERS, b. m. by (Imp.) Hibiscus, dan Ten Broeck's dam.

MARY SCOT'T, b. m. by Bertrand, dam by Blackburn's Whip.

MARY SHERWOOD, b. m. by Stockholder, dam by (Imp.) Levia. than.

MARY STEWART, b. m. by ( $I m p$.) Valentine, dam by Henry.

MARY THOMAS, b. m. by (Imp.) Consol, dam Parrot by Roanoke.

MARY TRIFLE, ch. m. by Medoc, dam by Hamiltonian.

MARY VAUGHAN, b. m. by Waxy, dam by (Imp.) Bluster.

MARY WALTON, ch. m. by (Imp.) Leviathan, dam Miss Bailey by (Inp.) Boaster.

MARY WATSON, gr. m. by Robin Hood, dam Bolivia by Bolivar.

MARY WELLER, ch. m. by Sterling, dam Discord by (Imp.) Iuazborough.

MARY WICKLIFFE, b: $m$. by Medoc.

MARY WYNNE, b. in. by Eclipse, dam Flirtilla Jr. by Sir Archy.

MASTER HENRY, b. h. by Henry, dam (Balie Peyton's dam) by Eclipse.

MAT. MCRPHY, ch. h. by Pete Whetstone, dam by Rattler.

MEDINA, b. m. by (Imp.) Barefout, dam by Director.

MEDOCA, ch. m. by Medoc, dam by Doublehead.

MEDORA WINSTON, b. m. by Telegraph, dam by Pacolet.

MELISSE BYRON, b. m. by Cherokee, dam by Barnett's Jiomed.

MELODY, ch. m. by Medoc, dam (Randolph's dain) by Haxall's Mnses

MERCER cn. h. by Woodpecker, dam by Hamiltoman 
MVRIDIAN, ch. h. by (Imp.) Barefont, dam by Evlipse.

MF'I ARIF, ch. m. by Frank, dam (Misserboris's dim) by Kosciusko.

MElEOR, ch. h. by (Imp.) Priam, dam (Baltimure's dam) by Go hanna.

McIN'TYRE, ch. h. by Medoc, dam by Sumpter.

MIDNI(;H'I, bl. m. by Sıark, dam Meg Dods, by Sir Archy.

MIDAS, b. h. by (Imp.) Rowton, dam by Roanoke.

MIL'ION HARRISON, b. h. by Orange Boy, dam by Quicksilver.

MINERVA ANDERSON, ch. Wr. by (lmp.) Luzborough, dam by Sir Charles.

MINERVA PROFFIT, ch. m. by ( $I m p$.$) Luzborough, dam Sophia$ Bess.

MINISTER, b. h. by Medoc, dam by Alexander.

MINSTREL, b. m. by Medoc, dim by Bedford's Alexander.

MINT JULEP, br. h. by Godolphin, dam Isora by Dockon.

MIRABEAU, b. h. by Medoc, dam Ann Merry by Sumpter.

MIRIAM, b. m. by (Imp.) Autocrat, dam Laura by Rob Roy.

MIRTH, b. m. by Medoc, dam (Minstrel's dam) by Bedford's Alexan. der.

MISKW A, ch. m. by Dick Chinn, dam Linnet by (Imp.) Leviathan.

MISSISSIPPI, b. h. by John Dawson, dam by Partnershiţ.

MISSOURI, ch. m. by Eclipse, dam by Director.

MISTAKE, b. m. by Eclipse, dam by Timoleon.

MISS ACCIDENT, (Imp.) b. m. by Tramp, dum Florestine by Whis ker.

MISS ANDREW, ch. m. by Andrew, dam by Gallatin.

MISS BELL, b. m. by (Imp.) Censol, dam (Imp.) Amanda by Morisea

MISS CHESTER, b. m. by (Imp.) Sarpedon, dam Delilah by Tiger.

MISS CLARK, ch. m. by Birmingham, dam by Cumberland.

MISS CLASH, ch. m. by Birmingham, dam by Stockholder.

MISS CLINKER, (Imp.) b. m. by Humphrey Clinker, dam Mania by Maniac.

MISS FOO'TE, b. m. by (Imp.) Consol, dam (Imp.) Gabriella by Oscas (or Oiseau).

IIISS JACKSON, ch. m. by Oakland, dam by Diomed.

MISS LETTY, b. m. by (Imp.) Priam, dam Patty Burton by Marion.

MISS MACARTY, b. m. by IVaxy.

MISS RIDDLE, ch. m. by (Imp.) Riddlesworth, dam Lady Jackson by Sumpter.

MISS IVILLS, gr. m. by (Imp.) Zinganee, dam Sorrow by Rob Roy.

MOBILE, b. h. by (Imp.) Cousul, dain (Imp.) Sessions by Whalebone.

MOLLY LONG, ch. m. by Tom Fletcher, dam by (Imp.) Janus.

MOLLY WARD, b. m. by (Imp.) Hedgford, dam by Bertrand.

MOLOCH, (Imp.) b. h. by Muley Moloch, dam Sister to Puss by Te niers.

MONARCH, (Imp.) b.h. by Priam, dam Delphine by Whisker.

MONGRELIA, ch. m. by Medoc, dam Brownlock by Tiger.

MONKEY DICK, b. h. by Dick: Singleton, dam by Sumpte:

MORDAC, ch. h. by Eclipse, dam by Whip.

MORGAN, ch. h. by John Bascombe, dam A:ny Hamilton.

MORGIANA, ch. in. by Red Gauntlet, dam by Joe Ken:

MORT'IMER, ch. h. by Mommouth Eclipse, dam by Ogle's CIscras 
MOSELLE (Colonel Gavan's), b. m. by Telegraph, dam (Imp.) Jano Shore.

MOSELLE (E. P. Dave's), b. m. by (Imp.) Luzborough, dam (Imp.) Jane Shore.

MOTH, ch. m. by (Imp.) Glencoe, dam (Imp.) Jessica by Velocipede. MO'T'TO, ch. m. by (Imp.) Barefoot, dam Lady Tompkins by Eclipse, MOUNTAINEER, ch. h. by Yorkshire, dam by Rattler. MOUNTJOY, b. h. by (Imp.) Tranby, dam by Sir Charles.

MUD, gr. h. by (Imp.) Leviathan, dam by Pacolet.

MUSEDORA, ch. m. by Medoc, dam by Kosciusko.

MUSE SANDFORD, b. h. by Hickory, dam by (Imp.) Contract.

MUSIC, gr. h. by (Imp.) Philip, dam Piano by Bertrand.

\section{N.}

NANCY BUFORD, ch. m. by Medoc, dam by Thornton's Rattler.

NANCY CLARK, b. m. by Bertrand, dam Morocco Slipper by Timo leon.

NANCY DAWSON, ch. m. by Frank, dam by Voltaire.

NANCY O., ch. m. by Flagg, dam Milly Tonson by Mons. T'onson.

NANCY ROWLAND, b. m. by (Imp.) Rowton, dam by Rob Roy.

NANNY, b. m. by (Imp.) Trustee, dam Miss Mattie by Sir Archy.

NARCISSA PARISH, ch. m. by Stockholder, dam by (Imp.) Eagle.

NARINE, ch. m. by (Imp.) Jordan, dam Louisianaise.

NAT BRADFORD, gr. h. by Bertrand, dam Morocco Slipper by Ti moleon.

NATHAN RICE, br. h. by Birmingham, dam by Whipster.

NED WEI_LS, b. h. by O'Connell, dam by Stockholder.

NEPTUNF, ch. m. by (Imp.) Jordan, dan Louisianaise.

NIAGARA, ch. h. by (Imp.) Trustee, dam Gipsey by Eclipse.

NICK BIDDLE, b. h. by Score Double, dam Highland Mary.

NICK DAVIS, ch.h. by (Imp.) Glencoe.

NICON, ch. h. by Pacific, dam by Jackson.

NOBLEMAN, ch. h. by (Imp.) Cetus, dam (Imp.) My Lady by Comus.

NORFOLK, br. h. by (Imp.) Fylde, dam Polly Peachem by Juhn Richards.

NORMA, ch. m. by Longwaist, dam (Imp.) Novelty by Blacklock.

NORTH S'TAR, ch. h. by Emilius, dain Polly Hopkins by Virginıan.

\section{o.}

UC'TAVE, b. m. by (Imp.) Emancipation, dam Polly Kennedy.

OGLENAH, ch. h. by Medoc, dam Maria by Hamiltonian.

OII SEE, ch. h. by (Imp.) Foreigner, dam by Mons. Tonson.

UI,D DOMINION, ch. h. by Eclipse, dam Isabella by Sir Archy.

( LD MISTRESS, ch. m. by Count Badger, dam Timoura by Timo leon.

()LEAN, ch. m. by (Imp.) Leviathan, dam by Truxton.

OLEANDER, ch. m. by (Imp.) Glencoe, dam Aranetta by Bertrand.

OLIVIA WAKEFIELD, gr. m. by Patrick Henry.

OLYMPUS, ch. h. by Eclipse, dam Flirtilla Junior, by Sir Archy.

OMEGA, gr. m. by Timoleon, dam Daisy Cropper hy Ogle's Osear.

DMOHONDRO, ch. h. by Robin Brown, dam by Mason's Rattler.

OR EGON b. I by (Imp.) Philip, dam by (Imp.) Luzborough.

ORIANA, br $\mathrm{m}$. hy (Imp.) Longwaist, dam (Imp.) Orleana by Buza $\operatorname{mad}$ 
ORIFI.A.MIE, ch. h. by Mons. Tonson, dam by Sir Hal.

GRIOLE, b. m. by $(\operatorname{lmp})$ Leviathan, dam Object by Marshal Ney.

OR!EANS, ch. h. by Cock of the Rock, dam hy 'I'imoleon.

ORSON, ch. h. by (Imp.) Valentine, dam Ethelinda by Marshal Ber. trand.

DS'I'RICH, ch. h. by Collier, dam by Shakspeare.

OSCAR, (Josiah Chambers's), ch. h. by Ulysses, dam by Bertrand.

OsCEOLA, b. h. by Pacific, dam by Oliver H. Perry. ch. h. by Wild Bill, dam by 'Timoleon. ch. h. by Collier, dam by Sumpter.

O'THELLO, ch. h. by Waxy, dam by Hickory.

(NUR MARY, br. m. by (Imp.) Langford, dam Ostrich by Eclipse.

\section{P.}

P.IIXHAN, b. h. by (Imp) Felt, dam Mary Hutton.

PALAIERSTON, b. h. by (Imp.) Merman, dam (Imp.) by Cadmus.

PANIC, ch. h. by Eclipse, dam Aggy-up by Timoleon.

PARIS, bl. h. by (Imp.) Priam, dam Water-Witch.

PARTNER, ch. h. by Medoc, dam by Doublehead.

PASSENGER, (Imp.) b. h. by Langar, dam My Lady by Comus.

PASSAIC, (Imp.) ch. h. by Reveller, dam Rachcl by Moses.
b. by Balie Peyton, dam by Pamunky.

PATRICK H. GALIVEY, ch. h. by (Imp.) Jordar, dam Duchess of Ashland by Shalsspeare.

PATSEY AN'THONY, b. m. by (Imp.) Priam, danı (Josephus's dam) by Virginian.

PATSEY BUFORD, b. m. by Mazeppa; dam by Pattler.

PATSEY CROWDER, gr. in. by Patrick Henry, dam Hillon by Antelope.

PATSEY DAVIJ, ch. m. by Count Pady's, dam Timoura by Tima leon.

PAT'SEY STUART, b. m. by Bertrand, Jis $n$ by Redgauntlet.

PEDLAR, ch. h. by (Imp.) Leviathan, rorı by Pizarro.

PEGGY IIALE, ch. m. by (Imp.) Skylar'k, dam by Sir Charles.

PENELOPE, (Imp.) ch. m. by Pleripo, dain Brazil by Ivanhoe.

PENSEE, gr. m. by Lauderdale, dam by Lightning.

PEORIA, ch. m. by Medoc, dam by Whip.

PETER PINDAR, ch. h. by (Imp.) Daghee, dam by (Imp.) Barefoot

PETER SPYKE, ch. h. by Ec! pse, dam by (Imp.) Jack Andrews.

PETWAY, b. h. by (Imp.) Glencoe, dam Iítty Clover by Sir Charlea br. h. by (Imp.) Glencoe, dam by Sir Archy.

PETWORTH, b. h. by (Im.p.) Philip, dam (Kinlock's dam) by Shaw. nee.

PEY'TONA, ch.m. by (Im.p.) Glencoe, dam Giantess by (Imp.) Levia. than.

PHI N'IOM, b. h. by (Imp.) Contract, dam by Potomac.

PHII. BROWN, (Imp.) ch. h. by Glaucus, dam Bustle by Whalebone.

PICKWICK, b. h. by Pacific, dam by Pacolet.

PICOLO, br. h. by Lord Byron, dam Highland Marv iNick Biddle's dam).

PILOT, b. h. hy Wild Bill, dam by Oscar.

PI.ENIPO, (Imp.) b. h. by Plenipo, dam Polly IJoprins hy Virginian

POKEROOT, gr. h. hy William Tell, dim liy ritizen 
POLLARD BROWN, b. h. by Wild Bill, dam Hippy by Pacolet. POLLY ELLIS, m. by (Imp.) Trustee, dam Rosalind by Ogle's Oscaz POLLY GREEN, br. m. by Sir Charles, dam Polly Peachem by Juha Richards.

POLLY HUNTER, ch. m. by Andrew, dam by Crusader.

POLLY MILAM, b. m. by (Imp.) Sarpedon, dam by Escape.

POLLY PILLOW, b. m. by (Imp.) Leviathan, dam by Sir Archy.

POLLY PIPER, ch. m. by Count Piper, dam by Consul or Sumptes

PONEY, ch. h. by (Impp.) Leviathan, dam by Stockholder.

PONOLA, ch. h. by Hannibal, dam by Sir Archy.

POR'TSMOUTH, br. h. by (Imp.) Luzborough, dam Polly Peachem by John Richards.

POSTMASTER, (The) b. h. by (Imp.) Consol, dam Country Maid by Pacific.

POWELL, ch. h. by Medoc, dam by Alexander or Virginian.

PRENTISS, (S. S.) b. h. by (Imp.) Fylde, dam by Washington.

PRES'TON, br. h. by Telegraph, dam (Olivia's dam).

- b. h. by (Imp.) Leviathan, dam Parrot by Roanoke.

PRIMA DONNA, b. m. by (Imp.) Priam, dam Lady Rowland by T. riff.

PRINCE ALBERT, ch. h. by (Imp.) Margrave, dam (Eutaw's dam, by Sir Charles.

PRINCESS, ch. m. by (Imp.) Priam, dam Sally Hope by Sir Archy.

PRINCESS ANN, b. m. by (Imp.) Leviathan, dam by Stockholder.

PRISCILLA MAR'TIN, ch. m. by (Imp.) Leviathan, dam by Arab.

PROMISE, ch. m. by Wagner, dam by Lance.

PROSPECT, ch. h. by Monmouth Eclipse, dam by (Imp) Expedition. Stockholder.

PRYOR, b. h. by (Imp.) Priam, dam Queen of Clubs by Virginian.

PURITY, b. m. by (Imp.) Ainderby', dain Betly Martin by Gileo Scroggins.

PUSS, $\mathrm{b}$. $\mathrm{m}$. by (Imp.) Priam, dam by Virginian.

\section{Q.}

QUEEN ANNE, (Imp.) bl. m. by Cam-l, dam by Langar.

QUEEN ELIZABE'H, br.m. by $\left(I m_{\text {s. }}\right.$.) Leviathan, dam by Sir Archy QUEEN MARY, ch. m. by Bertrand, dam by Brimmer.

QUININE, ch. m. by Red Tom, d', m by Bertrand.

R.

RAGLAND, ch. h. by (Imp; Keviathan, dam by Stockholder.

RALPH, b. h. by Woodpe oker, dam Brown Mary by Sumpicr.

RANCOPUS, ch. m. by r'lagellator, dam Molly Longlegs.

RAN PEY'TON, ch. t.. by (Imp.) Leviathan, dam by Stockhclder.

RAPIDES, ch. h. by (Imp.) Skylark, dam Margaret May by Pacific. RASP, gr. h. by (Imp.) Fylde, dam by Director.

REBECCA KENNER, b. m. by (Imp.) Skylark, dam Lady Halston by Bertrand.

REBEI, ch. h. by Gohanna, dam (Ohio's dam).

P.EU BILI, ch. h. by Medoc, dam Brown Mary by Sumpter.

RED BREAS'l, ch. h. by (Imp.) Priam, dam Fanny Wyatt by Sis Charles. 
REL) BUCK, ch h. by (Imp.) Rovion, dim I,ady D cerpond.

RED EAGLE, br. h. by Grey Eigle, dam by Moses.

RED HOX, ch. h. by (Imp.) I.uzborough.

RED GAUN'TLET, ch. h. by (Imp.) 'Trustee, dım (Imp.) Vaga.

RED HAIVI, ch. h. by Medoc, dam by Sumpter.

RED IIEAD, b. h. by Wondpecker, d im by Whipster.

RED MOROCCO, ch. m. by Medoe, dam Brownlock by 'Tiger.

RED ROSE, br.m. by (Imp.) Leviath

RED 'TOM, ch. h. by Bertrand, dain Duchess of .Marlborough by Sip Archy.

RFEI, gr. m. by (Imp.) Glencoe, dam (Imp) Gillnpade by Catton.

REGENT, b. h. by (Imp.) Priam, Jam Fantail by Sir Archy.

REGISTER, gr. h. by (Imp.) Priam, dam Maria Louisa by Mons Tonson.

RELIANCE, b. h. by (Imp.) Autocrat, dam Lady Culpeper by Caroli. nian.

RESCUE, br.h. by (Imp.) Emancipation, dam Louisa Lee by Medley. REVEILLE, b. m. by Bertrand, dim Sally Mclville by Virginian.

- b. or br. h. by Young Virginian, dam by Harwood.

REVERIE, b. or br. m. by (Imp.) Ainderty, dam by Giles Scrogging.

RHYNODINO, gr. h. by Pacific, dam by Hamiltonian.

RICHARD OF YORK, b. h. by Star, dam by Shy!ock.

RICHARD ROW'TON, b. h. by (Imp.) Rowton, dam by Falstaff.

RIENZI, b. h. by (Imp.) Autocrat, dam by Sir Charles.

- b. h. by (Imp.) Autocrat, dam Peggy White by (Imp.) Sy phax (or Diomed).

RINGDOVE, b. m. by (Imp.) Merman.

RIPPLE, b. m. by Medoc, dam Belle Anderson by Sir William.

ROANNA, ro. m. by Archy Montorio, dam by Potomac.

ROBERT BRUCE, b. h. by Clinton, dam by Sir Archy.

ROBIN COBB, ch. h. by (Imp.) Felt, dam Polly Cobb.

ROCKER, b. h. by Eclipse, dain by Virginian.

ROCKETT, b. h. by Sir Leslie, dam Miss Lancess by Lance.

RODERIC:K DHU, gr. h. by Merlin, dam by (Imp.) Bardad.

RODNEY, br. h. by (Imp.) Priam, dam Medora.

ROSABELLA, b. m. by (Imp.) Shakspeare, dam by Timolenn.

ROSA VERTNER, b. m. by Sir Leslie, dam Directress by Director.

ROSCOE, b. h. by Pacific, dam by Grey Archy.

ROTHXXII.D, b. h. by (Imp.) Zinganec, dam by Tiger.

ROVER, b. h. by IVoodpecker, dim Sally Miller by Cherokee.

ROW'IONELIA, ch. m. by (Imp.) Rowton, dam Sally Hupking by Kosciusko.

RUBY, b. m. by (Imp.) Rowton, dam Bay Maria by Eclipse. - ch. m. by Duke of Wellington, dain Lively by Eclipse

RUFFIN, b. h. by (Imp.) Hedgford, dain Duchess of Marlborough by Sir Archy.

\section{S.}

SAII,OR BOY, b. h. by Jim Cropper, dam by Marshal.

DAIADIN, h. h. by John Richards, dam by Henry.

SAIKAIIACHIE, b. m. by Vertumnur, dim Silly Richardson by Kosciusko.

SA S'TRICKLANI), ch. m. by (Imp.) Leviathan, dam tio Pacoles 
SALLY BARTON, ch. m. by Jickson, dain by Gallatin.

SALLY BROWN, b. m. by Jackson, d im by G.llatin.

SALLY CARR, b. m. by Stockholder, dam by

SALLY CRESSOP, ch. m. by Echijse, dim by Arab.

SALLY DILLIARD (or HILLIARJ), gr, m. by U'kelly, dam by Shawnec.

SAI.I.Y HARDIN, b. m. by Berirand, dan Peggy Stewart by Whip

SALLY HAR'T, m. by (Imp.) Luzborough, dim Clear-the-Kitchá by Shakspeare.

6LLY McGHEE, ch. m. by Giscoigns, dam Thisbe.

SALLY MORGAN, b. 11 . by (Imp.) Einancipation, dam Lady Mor gan by John Richards.

SALLY SHANNON, b. m. by Woodpecker, dam (Darnley's dam, by Sir Richard.

SALLY WARD, m. by John R. Grymes, dam by

SAMBO, ch. h. by Equinox, dam by Aratus.

SAM HOUSTON, b. h. by (Imp.) Autocrat, dam by (Imp.) Major.

SANDY YOUNG, b. h. by Medoc, dam Natchez Bell by Seagull.

SANTA ANNA, ch. h. by Bertrand Junior, dam Daisy by Kosciuska.

SAN'TEE, ch. h. by Wild Bill, dim Sally McGhee by Timoleon.

SARAH BLADEN, ch. m. by (Imp.) Leviathan, dam Morgiana by Pacolet.

SARAH BURTON, m. by Pacific, dam by Timoleon.

SARAH CHANCE, rh. m. by Lafayette, dam by Sir Archy.

SARAH JACKSON, JUNIOR, b. m. by Piamingo, dam by Arab.

SARAH MORTON, b. m. by Sidi Hamet, dam Rowena by Sumpter.

SARAH IVASHINGTON, b. m. by Garrison's Zinganee, dam by Contention.

SARTIN, br. h. by (Imp.) Luzborough, dam Julia Fisher by Tima leon.

SCARLET, ch. h. by Uncas, dam by Pacolet.

SENATOR, ch. h. by (Imp.) Priam, dam Ariadne by Gohanna.

SFRENADE, b. h. by Woodpecker, dam by Cook's IVhip.

SEVEN.UP, b. m. by (Imp.) Chateau Margaux, dam by Arab.

SHAMROCK, (Imp.) ch. h. by St. Patrick, dam Delight by Ro veller.

SHARATOCK, ch. h. by Medoc, dam by Trumpator.

SHEPHERDESS, ch. m. by Lance, dam Amanda by Revenge.

SIGNAL, hl. h. by (Imp.) Margrave, dam by Mons. Tonson.

SIMON BENTON, ch. h. by Medoc, dam by Rattler.

SIMON GURTY, ch. h. by Mark Moore, dain by Tiger.

SIMON KEN ION, ch. h. by Eclipse, dam by Ratller.

SIR ARISS, g h. by Trumpator, dain Ophelia by Wild Medleg.

SIR ELI.IO'T'T, b. h. by (Imp.) Leviathan, dam Lady Frolic by Sis Charles.

SIR JOSEPH BANKS, b. h. by (Imp.) Luzborough, dam by Sir Archy.

SIR WILLIAM, b. h. by Sir William, dam by Rattler.

SISSY, b. m. by (lmp.) I, eviathan, dim (Imp.) Gistty by Whalebone.

8ISTER 'TG 'THORNHHLL, ch. m. by (Imp.) Glencoe, dam (Imp.' Pickie hy Einilius.

ELEFPER, gr. h. by (Imp.) Sarpedon, dam Flora by Grand Seıgnor. 
SLELPER (TIIE), gr. h. by (Imp.) Sarpedon, dam by C... : a Mer senger.

SLEEPY JOIIN, b. h. by John Dawson, dam Sally Dillized by Vir. ginian, (or Phenomena).

S.MOKE, ch. h. by (Imp.) Trustee, dam Bianca by Medley.

SNAG, ch. h. by Medoc, dam by Rattler.

SNOWBIRD, gr.h. by (Imp.) Č́hateau Margaux, dam Forsaken Fillg by Jerry.

SOPIIIA LOVELL, b. m. by Sir Lovell, dam Eliza Jenkins by Sis William.

SORROIV, (Imp.) ch. h. by Defence, dam Tears by Woful.

SPLIN'T, ch. m. by Hualpa, dam by Phenomenon.

STACKPOLE, ch. h. by (Inp.) Leviathan, dam by Stockholder.

S'IAGE-DRIVER, b. h. by Lance, dam by Bertrand.

STANHOPE, ch. h. by Eclipse, dam Helen Mar by Rattler.

S'I'ANLLY, ch. h. by (Imp.) Leviathan, dam Aronetta by Bertrand. ch. h. by Eclipse, dam by Busiris.

ECLIPSE, ch. h. by Busiris, dam by John Stanley.

S'TAR, b. h. by (Imp.) Skylurk, dam Betsey Epps by Timoleun.

STAR OF THE WES'T, b. m. by Bertrand, dam by Whip.

trand.

STEEL, b. h. by (Imp.) Fylde, dam Dimont by Constitution.

STHRESHLEY, ch. h. by Medoc, dam by Paragon.

S'TRANGER, b. h. by Lance, dam by Whip.

STOCKBOROUGH, ch. h. by (Imp.) Luzborough, dam by Stuckholder.

ST. CIIARLES, ch. h by (Inp.) Jordan, dam by Mercury.

ST. CLOUD, ch. h. by (Imp.) Belshazzar, dam by Old Partner.

ST. LOUIS, gr. h. by Altorf, dam Fleta by Jackson's (u\& Johnsun'a) Medley.

ST. PIERRE, bl. h. by Pamunky, dam by Lafayette.

SUFFERER, b. h. by Eclipse, dam Meg Dods by Sir Archy.

SUFFOLK, b. h. by Andrew, dam Ostrich by Eclipse.

SUNBEAM, ch. m. by (Imp.) Leviathan, dam Alice Grey by Mercury. ch. h. by (Imp.) Langford, dam Gipsey, (sister to Medoc)

SUSAN HILL, ch. m. by (Imp.) Glencoe, dam Susan Hill by Tina leon.

SUSAN TYLER, b. m. by (Imp.) Sarpedon.

SUSAN VANCE, ch. m. by Salidin, dam by Sir William.

SIVALLOW, b. m. by (Imp.) Leviathan, dani Object by Marshal Neg

SWEET HOME, ch. m. by Medoc, dam by Hamiltonian.

SWISS BOY, br. h. by (Imp.) Swiss, dam by Stuckholder.

SYLPIIDE, (Imp.) b. m. by Emilins, dam Polly IIopkins by Virg. nian.

SY.IIUL'IR Y, b. m. hy (Imp.) I'riam, dam Phenomena by Sir Arehy

T.

TABITHA, ch. m. by Hualpa, dam by Phenumenon.

TARIIONI, ch. m. by (Inp.) Priam, dam by Sir Charles.

TALLEY, ch. h. by 'Talleyrand, dam by Bertrand.

TALLULAH, ch. m. by Hyazim, dam by Gallatin.

TAMERI.ANE, ch. h. by Cowper, dam by Directur. 
TAMMANY, b. h. by (Imp.) Trustee, dam Camilla by Henry.

TARANTULA, ch. m. by (Imp.) Belshuzzar, dam Mary Jane Davis by Stockholder.

T.ARLTON, b. h. by Woodpecker, dam by Rohin Grey.

TARQUIN, b. h. by ( $1 m p$.) Consol, dam Jeannie Deans by Powhattar

TATTERSALL, ch.h. by (Imp.) Emancipation, dam (Volney's dam) by Sir Archy.

TAY LOE, b. h. by (Imp.) Autocrat, dam Peggy White.

T AZEW ELL, b. h. by (Imp.) Fylde, dam by Gallatin.

TEARAWAY, b. h. by (Imp.) Trustee, dam Jemima by Thorntan's Rattler.

I ELAMON, ch. h. by Medoc, dam Cherry Elliott by Sumpter.

TELIE DOE, b. m. by Pacific, dum Matilda by Greytail.

TELLULA, ch. m. by Eclipse, dam by Whip.

TEMPEST, ch. h. by (Imp.) Trustee, dam Jeanette by Sir Archy.

TEMPLAR, b. h. by (Imp.) Sarpedon, dam by Timoleon.

TEN BROECK, ch. h. by Eclipse, dam by Bertrand.

T'ENNESSEE, b. m. by (Imp.) Felt, dam Berenice by Archy Junior.

TEXANA, b. m. by (Imp.) Hedgford, dam Goodlee Washington by Washington.

T'EXAS, b. h. by (Imp.) Fylde, dam by Potomac.

THE COLONEL, ch. h. by (Imp.) Priam, dain (Imp.) My Lady by Comus.

T'HE COI.ONEL'S DAUGHTER, b. m. by The Colonel, dam (Imp.) Variella by Blacklock.

THE DUKE, ch. h. by Monmouth Eclipse, dam by (Imp.) Expedition.

THE MAJOR, b. h. by Othello, dam by Citizen.

THE MERCER COLT, br. h. by (Imp.) Mercer, dam Miss Mattis by Sir Archy.

THE PONEY, ch. h. by (lmp.) Leviathan, dam by Stockholder.

'THE POSTMAS'TER, b. h. by (Imp.) Consol, dam Country Maid by Pacific.

THE QUEEN, (Imp.) ch. m. by Priam, dam Delphine by Whisker.

THOMAS HOSKINS, b. h. by (Imp.) Autocrat, dam Minerva by Tom T'ough.

THOMAS R. ROOTS, b. h. by (Imp.) Tranby, dam Eliza Jenkins by Sir William of 'Transport.

THORNHILL, ch. h. by ( $(m p$.) Glencee, dam (Imp.) Pickle by Emilius.

TIBERIAS, b. h. by (Imp.) Priam, dam Fanny Wright by Silverheels.

TJPPECANOE, ch. h. by Eclipse, dam by Rattler.

TISHANNA, b. m. by Benbow, dam Fidget by Eclipse.

'IISHIMINGO, b. h. by (lmp.) Leviathan, dam Maria Shepherd br Sir Archy.

TOBY, b. h. by Bertrand, dam by Eagle.

TOM AND JERRY, ch. h. by Heart of Oak, dam by Lafayette.

'TOM BENTON, b. h. by Wild Bill, dain by Pacolet.

'TOMI BUCK, ro. h. by (Imp.) (xlencoe, dam Lady Sykes by Timoleor.

Tr,M CHILTON, ch. h, by (Imp.) Leviathan, dam by Childers.

TOM CORWIN, b. h. hy (Imp.) Enancipation, dam by Lottery.

TOM CRINGLE, ch. h. by Carolinian.

TOM DAY, b. h. by Bertıand, dam Sally Melville by Virginan.

J'OM MARSHAL, (Col. Bingaman'r.) gr. h. by (!mp.) Leviathan, dare Ianny Jarman by Mercury. 
TOM MABSHAL, (Col Buford s, ) b. h. hy Mtedoc, dam by smenper.

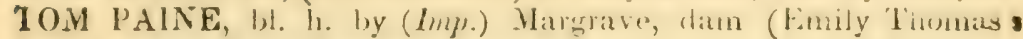
dam) by Tom 'Tough.

TOM THURMAN, b. h. by (Imp.) Fylde dam by Citizen.

TOM WALKER, ch. h, by Marylander, dam by Rattler.

TOMMY WAKEFIELD, ch. h. by Drone, dam by Eclipse.

TORCH-LI(xHT, ch. m. by (Imp).) Giencoe, dum Wax-light loy (Imp. Leviathan.

TORNADO, (h. h. by Eclipse, dam Polly Hopkins by Virgrinian.

TRANBYANNA, m. by (Imy'.) Tranby dain Lady Tumpkins by Eclipse.

TR.ANSI'T, b. h. by (Imp.) Hedgford, dam (Molly Ward's dam) by Bertrand.

TREASURF.R, b. h. by (Imp.) Roman, dam Dove by Duroc.

'TRENTON, o. h. by Falipse Lightufont, dain by Tuckahoe.

TROUBADOUR, bl. h. hy (Imp.) Luzhorongh, dam by Stockholder.

TRUXTON, b. h. by (Imp.) Barefoot, dam Princess by Defiance.

TUSKENA, b. h. by Mons. Tonson, dam Creeping Kate.

TYLER, b. h. by (Imp.) Trustee, daun Kitte Kearney by Sir Archy.

UNCAS, ch. h. by Diomed.

\section{U.}

- b. h. by (Imp.) Jorian, dain by Pacific.

UNI'TY, ch. f. by Genito, dam Lady Pest by Carolinian.

\section{v.}

VAGABOND, ch. h. by (Imp.) Ainterby, dam (Imp.) Vaya.

VAGRANT, ch. h. by (Imp.) Trustee, dam (Imp.) Vaga.

VANITY, b. m. by Traveller.

VAN TROMP, h. by Van Tromp, dam by Mucklejohn.

VASHTI, b. m. by (Imp.) Leviathau-Sla y hy Bullock's Mucklejohn.

VELASCU, b. h. by Shark, dam by Virginian.

VELOCITY, ch. m. by (Imp.) Leviathan, dam Patty Puff by Pacoler

VERTNFR, ch. h. hy Hedoc, dam Laty Ailams by Whipster.

VETU, ch. h. by Eclipse, dam by Diomed.

- h. by (Imp.) Luzborougl, dam Litly Washington by Wash. ington.

VICTOR, br. h. by (Imp.) Cetus, dam (Imp.) My Lady by Comus.

VICTORIA, gr. m. by Sir Kirkland, dain by Tippoo Saib.

- b. m. by (Imp.) Luzborough, dam by 'Timoleon.

ROWTON, ch. m. by (Imp.) Rowton, daun by Phenı

inenon.

VIC'TREsis, b. m. by Grey Eayle, dain by Royal Charley.

VIIOCQ br. h. by Medoc, dain by sinckholder.

VI(iLA, ch. m. by (Imp.) Leviathan, dim Mary Longfit by Pac fic. VIR(ilNIA, ch. m. ly (Imp) Leviahan, dam by sir Richd Tomsun.

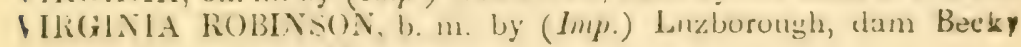
by Marquis (or Marcus).

V()LTAIRE, eh. h. by (Imp.), Leviatham, dam by Lertrand.

\section{W.}

W ACOUSTA, ch. h. by Jerseyman. dam Lady Vixen.

WADI)Y TH(1) falgar. 
WATrER, ah. h. by Sir Charles, dam Maria West by Marios.

WALK IN-THE-WATER, h. h. by Collier, dam by Bertrand.

WALTER L., b. h. by (Imp.) Fylde, dain by sir Charles.

WANION WILI, b. l. by Brmswick, dam by Prince Edward.

WARSAW, ch. h. by Eclipse, dam by Arab.

WARWICK, ch. h. by Stocliholder, lam by (Imp.) Leviathan.

WASHENANGO, ch. h. by (Imp) Sorrow, dam by (Imp.) Leviathau

WA IKINS, ro. h. by John Richards, dam by Whip.

WAXETTA, br. m. by Waxy, dam by Kennedy's Diomed.

WEBSTER, b. h. by (Imp.) Priam, lam Fairy.

WELLINGTON, b. h. by (Imp.) Sarpedon, dam (Volney's dam) l/y Sir Archy.

W ESLEY MALONE, b. h. by (Imp.) Leviathan, dam by Sir Richard.

WEST FLORIDA, b. m. by Bertram, dam by Potomac.

WEST-WIND, br. h. by (Imp.) Chateau Margaux, dam Mambrina by Bertrand.

WHALFBONE, b. h. by (Imp.) Cetus, dam by Gohanna.

WHISKFR, b. h. by (Imp.) Emancipation, dam by Walnut.

WILL-GO, b. or br. h. by (Imp.) Lizborough, dam by Eclipse.

WILLIAM R., b. h. by Goliab, dam by Sir Alfred.

WILD BURK, ch. h. by Medoc, dam by (Imp.) Bluster.

WILLIS, eh. h. by Sir Charles, dam by (Imp.) Merrytield.

WILI.IS P. MANGUM, b. h. by Shark, dain Aggy Down.

WILTON BROWN, gr. h. by (Imp.) Priam, dam Ninon de l'Enclos by Rattler.

WINCHESTER, ch. h. by Clifton, dam by Contention.

WINFIELD (or WINFIELD SCOT'T), ch. h. Ly Andrew, dam by Eclipse.

WONDER, b. h. by Tychicus, dam Nancy Marlborough by Rob Roy. WOOI)COC'K, b. h. by (Imp.) Emancipation, dam by Slyylock.

WORKMAN, ch. h. by (Imp.) Luzborough, dan by Timoleon.

Y.

YAZOO TRAPPER, ch. h. by Sir William.

YELLOW ROSE, ch. m. by Andrew, dam Tuberose by Arab.

YORKSHIRE, h. h. by St. Nicholas, dam Moss Rose by Tramp.

YOUNG DOVE, gr. m. by (Imp.) Trustee, dam Dove by Duroc.

YOUNG FRAXINELLA, gr. m. by (Inp.) Autocrat, dam by Virginian.

YOUNG MEDOC, ch. h. by Medoc.

\section{Z.}

ZAMPA, ch. h. by (Imp.) Priain, dam Celeste by Henry.

ZEBA, ro. m. by Eclipse, dam Miss Walton by Mendoza.

ZFMMA (or ZAMOUR), ch. h. by Ulysses, dam hy Stocklolder

ZENITH, b. L. by Lelinse, dam Belle Anderson by Sir William of

Transpor:

7.ENOBIA, c.. m. by (Imp.) Roman, dam Dove by Duroc.

¿OE, ch. m. by (Imp.) howton, dam (Litle Venus's dam,) by Siı Willinm.

GORAIDA. b m. by Vırginius, dam by Comet. 


\section{CELEBRATED STALLIONS AND BROOD MARES.}

A.

ABD ALLAH, b. h. by Mrmbrino, dam Amazonia.

ABJER, [ Imp.] got by Ohl Truftle, dam Briseis by Beringbrough, gr. diam Lady Jane by Sir Peter'Teazle - Panlina by Florizel, \&c.- foaled 1817, died 1828. - Alabama. James Jackson.

ADMIRAL, [Imp.] b. h. got by Florizel, dam the Spectator mare, (who was also the dam of Old imp. Dioned) - foaled 1779.New York.

J. Delancy.

AFRICAN, bl. h. by [Imp.] Valentine, dain by Marshal Bertrand.

ALLEN BROWN, ch. h. Ly Stockholder, dam by [Imp.] Eagle.

ALL FOURS, [Imp.] got by All Fours, son of Regulus-BiankBolton Starling-Miss Meynell by Partror-Greyhound-Cur. win's Bay Barb, dec. imp. into Massachusetts or Connecticut.

ALONZO, ch. h. by Eclipse, dam by Sir Archy.

AINDERBY, [Imy.] ch. h. hy Velocipede, dam Kate by Catton.

ALTORF, b. h. by [ $[\mathrm{mm}$.] Fylde, dam Countess Plater by Virginian. AMBASSADOR, [Imp.] b. h. by Emilius, dain [Imp.] Trapes by Tramp.

AMERICUS, [Imp.] b. h. got by Babraham-Creeping Molly by So cond-General Evans' Arabian Cartouch-foaled 1775.

William Macklin.

ANDREW, ch. h. by Sir Charles, dam by Herod.

ANDREW JACKSON, b. h. by Timoleon, dam by [Imp.] Whip.

ANN PAGE, m. by Maryland Eclipse, dam by Tuckahoe.

ARAMINTA, b. m. by May-Day, dam Tripit by Mars.

ARGYLE, br. h. by Muns. Tonson, dam Thistle by Ogle's Oscar.

AUTOCRAT, [Imp.] gr. c. got by Graw Duke, dim Olivetta by Sir Oliver-Sicutina by Delphi-Scota by Eclipse-foaled 1822.New York.

William Jackson.

13.

BABKAHAM, [Imp.] b. h. got by (Oli Fearnought (son of Godolphin Ar.) - Silver - imported into Virginia by Willian Evans of Surrey comnty, and got by the Belsize Arabian in England, and foaled 1759.-Va. 1765.

William and George Evans. [Imp.] b. h, got ly Wildair-Babraham-Sloe-Bart lett's Cliilders - Counsellor - Suake, \&c. - foaled 1775. - Va 1783. Augustine Willis 
BALIE PEYTON. I, h. by Andrew, dam Pocalunntas by Felıpse

BAY MIDDI. E:TON, b. h. hy [Imp] Fylde, dam by Potomac.

BELLE ANDERSON, 111. by Wiliain of 'Transport, dam Butterfy

BELSHAZ\%AR, [Imp.] ch. by Blacklock, dam Manuella by Dick Audrews.

BERNER'S COMUS, [Inip.] b. h. by Comus, dam Rotterdam b) Juniper.

BER'TRAND Junior, ch. h. by Bertrand, dam 'Transport by Virgi. nius.

BETSEY MAJANE, m. by Stockholder, dam by Potomac.

BIANCA, m. by Medley, dain Powancey by Sir Alfred.

BIG JOHN, ch. h. by Bertrand, dain by Hamiltonian.

BILL AUSTIN, b. h. by Bertrand, dam by Timoleon.

BIRMINGHAM, br. h. by Stockiolder, dam Black Sophia by Top gal!ant.

BLACK ARABI \& N, [Imp).]-Presented by the Emperor of Morocco to the United States Government.

BLACK PRINCH, b. h. by [Imp.] Fylde, dam Fantail by Sir Archy. [Imp.] bl. h. got by Babralıam - Riot by Regulus -Blaze-Fox, \&c.-foaled 1760.-New York. A. Ramsay.

BLOODY NA'THAN, ch. h. by [Imp.] Valentine, dam Daphue by Duroc.

BOHEMO'TH, Junior, b. h. by Old Bohemoth.

BONNYFACE, [Imp.] (also called Master Stephen) dk. b. h. got by a son of Regulıs out of the Fen mare, got by Hutton's Royal colt-Blunderbuss, \&c.-foaled 1768.-Va.

French.

BOSTON, ch. h. by 'Timoleon, dam (Robin Brown's dain) by Ball's Florizel.

BRITANNIA, [Imp.] m. by Muley, dain Nancy by Dick Andrews.

BUFF COAT, [Imp.] dun h. got by Godolphin Arabian - Silver Locks by the Bald Galloway-Ancaster Turk-Leeds A rabian, \&c.-foaled $1742 .-V a .1761$.

Joseph Wells.

BULI.F ROCK, [Imp.] got by the Darley Arabian - Byerly Turk, out of a natural Arabian mare, \&c.-foaled 1718.-Virginia, 1735-6.

Samuel Patton.

BUSIRIS, ch. h. by Eclipse, daın Grand Duchess hy [Imp.] Gracchus.

BUSSORAH ARABIAN - Imporied by Abraham Ogrden, Esq., of New York.

BUTTERFLY, m. by Surpier, daın by [Imp.] Buzzard.

¿'.

CALMUS ch. h. by Eclipse, dam Di Vernon by Ball's Florizel

CAMDFiN, b. h. by [Imp.] Sarpedon, dam by Old Cherokee.

CAMILLA, m. by [Imp.] Philip, dain Roxana by Timoleon.

CANNON, [Imp.] br. h. got by Dungannon-Miss Spindleshanks by Omar-Stariıng, \&c.-foaled 1789.-Boston. Gen. Lyman.

CAROLET, ch. m. by [Incp.] Leviathan, dam Peg Caruthers by Arab.

CaROLINE, m. by Eclipse, dam Miss Mattie. 
C.IRVF.R, [Imp.] b. h. got l,y Young Suap - Blank - Babratan Alwaster Starling - Grasshopper, \&e. - foaled 177U.-Norfolk county, Va.

Dr. Charles Mayle.

CET A, n. by [Imp.] Cetus, dam Harriet Heth by Mons. Tonson.

CETUS, [Imp.] b. h. by Whalebone, dam Lamea by Gohanna.

CHARLEY NAILOR, b. h. by Medoc, dam by Tiger.

CHARLOTTE PAGE, m. by Sir Archy, dam by [Imp.] Restless.

CHATEAU MARGAUX, [Imp.] dk. br. h. got by Whalebone, (best son of Waxy, ) dam Wasp by Gohanna - Highflyer - Eclipse, \&c.-foaled 1822.-Va. 1835.

J. J. Avery \& Co.

CHTROKEF, h. by Sir Archy, dam Roxana by Hephestion.

CHESTERFIELD, b. h. Ly Pacific, dam by Wilkes' Madison.

CHIFNEY, ch. h. by Sir Charles, dam by Sir Archy.

CHILTON, b. h. by Seaguli, dam by Hazard.

CINDERELLA, b. in. by Saladin, dam by Aratus.

CIPPUS, bl. h. by Industry, dam by Randolph's Mark Antony.

CIVIL JOHN, gr. h. by Tariff, dam by Pakenham.

CLARF.T, [Imp.] got by Chateau Margaux, dam by Partisan-Silver

Tail hy Gohanna-Orville, \&c.-foaled 1830.-N. Carolina.

Wyatt Cardwell.

CLARINET, ch. in. hy Kentucky Sir Charles, dam Mary Grindle Ly Echipse.

CLARION, ch. h. hy Monmouth Eclipse, dain by Ogle's Oscar.

COCK OF 'THE ROC' $K$, b. h. hy Duroc, dain by Romp.

COLORADO, h. by Eclipse, dam by Sir Archy.

COMENCEMENT, m. by Arat, dam by Francisco.

COMMODORF, b. h. by Mambrino, dam by True American.

CORONE'T, [Imp.] b. h. by Catton, dam by Paynator.

COR'IES, h. by Old Rattler, dam by Jack Andrews.

COUNT BADGER, ch. h. by Eclipse, dam Arabella by Hickory.

COUNT ZALDIVAR, ch. h. by Andrew, dam by Timoleon.

COUNTESS BERTRAND, m. by Bertrand, dam Nancy Dawson by

Platt's Alexander.

CRIPPLE, b. h. by Medoc, dam Grecian Princess by Whip.

CRI'TIC, ch. h. by Eclipse, dam by Eclipse Herod.

CUSSETA CHIEF, ch. h. by Andrew, dam Virago by Wildair or Wonder.

CYMON, ch. h. by Marion, dain Fair Forester by [Imp.] Chance.

D.

D.AGHEE, [Imp.] b. h. by Muley, dam by Arabian Sheik.

DAMASCUS, h. by [ Imp.] Zilcali, daun Dido by [Imp.] Expedition.

DANCING MASTER, [Imp] b. h. got by Womlpe ker-Madcap by Snap-Miss Meredith by Cade, \&c.-forle:l 1785. - S. Caroluna.

DANIEL OCONNELL, gr. h. by sir Henry Tonon, dam by [Imp.] Sir Harry.

DAVY CROCKETT, h. hy Constitution, dam by Suttor's Whip

DEBASH, [Imp.] b. h. got by King Fergus-Highllyer-Madcap by Snap-Miss Meredith by Ciule, dec- - foaled 17i2. Imlorted into Massachusetrs. J.nes. 
DECATUR, en i. by Henry, dain Ostric'l by Eclipse.

DERBY, $[I m p$.$] dr. b. h. got by Peter Lely out of Urganda. formeri$ Lady Eteanor, she by Milo, dam by Sorcerer sut of Twins, dec - foaled 1831.

R. D. Shepherd.

DIANA, m. by Mons. Tonson, dam by Conqueror.

DJANA, [Imp.] m. by Catton, dam Trulla by Sorcerer.

DIANA, m. by Mercury, dam Rarity.

DUNCAS'IER, [Imp.] b. h. by Longwaist, dam by Muley, grandain Lady Ern by Stamford.

DON QUIXOTE, [Imp.] ch. h. by O'Kelly's Eclinse-Grecian Prin cess by Forester - Coalition colt - Bustard, \&c.- foaled $17 \mathrm{4}$. Imported into $\mathrm{Va}$.

DORMOUSE, [Imp.] dk. b. h. got by Old Dormouse, dam by White. foot - Silverlocks by Bald Galloway, \&c. - foaled 1753.-Va. 1759.

POSORIS, ch. h. by Henry, dam (Goliah's dam) by Mendoza.

IRONE, [Imp.] b. h. got by King Herot-Lily by Blank-Peggy by Cade-Croft's Partner-Bloody Buttocks, \&c.-foaled 1777.Duchess county, New York.

ch. h. by Mons. Tonson, dam Isabella by Sir Archy.

DUANE, br. h. by [Imp.] Hedgford, dam Goodloe Washington by Washingtor.

DUCHESS, b. m. by [Imp.] Coronet, dam by Tariff.

DUCHESS OF YORK, [Imp.] ch. m. got by Catton, dam by Sancuo - Coriander-Highilyer, \&c.-foaled 1821.-Va.

R. D. Shepherd.

DUKE SUMNER, gr. h. by Pacific, dam by Grey Archy. DUNGANNON, ch. h. by Sumpter, dam by Duke of Bedford.

E.

ECLIPSE, (American,) ch. h. by Duroc, dam Miller's Danisel by [Imp.] Messenger.

FCLIPSE THE SECOND, b. h. by Eclipse, dam Lady Nimble by Sir William.

ELIZA ARMSTRONG, m. by Flying Chitders, dan Gipsey by Florizel.

ELIZA MILLER, m. by Miller's Bertrand, dam Lncy Forester by Marshal Ney.

ELLEN GRANVILLE, b. m. by [Imp.] Tranby, dam by Contentiou. EMANCIPATION, [Imp.] br. h. hy Whisker, dam by Ardrossan.

ENGLISHMAN, (Imp. by Mr. Watter Bell of Va., in his datn,) by Eagle (also imported)-PotSos-Pegasis-Small Bunes by dus. tice, \&e.-forled 1812.

ENTERPRISE, h. by John Richards, dam by Don Quixote.

hUGENIUS, [Imp.] ch. h. by Chrysolite, dam Mixhury by Regulus - Little Bowes by a brother to Mixbury-Huttons Barb, \&ufoaled 1770 .

LXILF h by [Imp.] Leviathan, dam [Imp.] Refugee by Waudoser 
F.

FAIRF P.X ROANE, [Imp.] (alias Strawberry Roan) ro. h. got by Adolphus, dam by smitlis lartar (a son of Crofts Partner) dam by Milge (son of Snalie) - Hip, \&c. - foaled 1764-Va. - Fairfax.

FANNY WRIGHT, m. by Silverheels, dam Aurora by Governoı Wright's Vingtun.

FFLT, [Imp.] b. h. by Langar, dam Steam by Waxy Pope.

FESTIVAL, ch. h. by Eclipse, dam by Timoleon.

FIFER, b. h. by Mommouth Eclipse, dam Music by John Richards.

FLAT"TERER, [Imp.] b. h. by Muley, dam Clari by Marmion.

FLORANTHE, m. by Johu Richards, dam Fanuy Wright.

FOP, [Imp.] gr. h. by Stumps, dain by Fitz James.

FRANCIS MARION, ch. h. by Marion, lam Malvina by $S_{A}$ Archy FRANK, ch. h. by Sir Charles, dam Betsey Archy by sir Arehy.

\section{G.}

GANDER, gr. h. by Wild Bill, dam Grey Goose by Pacolet.

GANO, b. h. hy Fecipse, dam Betsey Richards by Sir Archy.

GENERAL MABRY, h. by [Imp.] Leviathan, dam Galen by Pacific.

GEROW, ch. h. by Henry; dam Vixen by Eclipse.

GLFT, [Imp.] b. h. got by Cadormus, dam by Old Crab - Second Starling, \&c.-foaled 1768.-New Kent county, Va.

Colonel Dangerfield.

GILFS SCROGGINS, b. h. by Sir Archy, dam Lady Bedford by [Imp.] Bedford.

GLFNCOE, [Imp.] ch. h. by Sultan, dam Trampoline by Tramp.

GLOSTER, b. h. by Sir Charles, dam by Alfred.

GOHANNA, h. by Sir Archy, dam Merino Ewe by [Imp.] Bedford. GOLD BOY, b. h. by Indistry, dan (Buck Eye's dam) by Medoc.

GOLDWIPE, [Imp.] br. m. by Whalebone, dam Young Amazon by Golıanna.

GOVERNOR HAMILTON, gr. h. by Sir Anirew, dam by Bonaparte.

GRANBY, [Imp.] b. h. got by Blank-(Old Crab-Cyprus Ar.-Commoner-Makeless - Brimmer, \&c.- loaled 1759. - Powhatan county, Va.

Samuel Watkins.

GRECIAN PRINCFSS, m. l,y Virginian, dam Calypso by Bell-Ais -Dare Devil_old Willa. - D'iceadilla by Fearuought - Go dolphin-Hob or Nob, \&c.

GREY EAGLE, gr. h. by W'volpener, dam Ophelia by Wild Med ley.

GREY MEDOC, gr. h. by Medne, dam Grey Famy by Bertand. GROUSE, br. h. by Eclipse, dam hy Firie.

GUM lil. STIC, b. h. by Waxy, dam by Read'spipreal Eugle

\section{I.}

HALO, h. by Sir Archy Montorio, clam Semiramis.

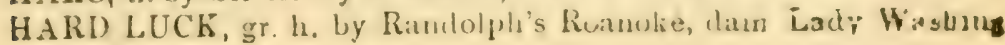
was. 
HAYWOOD, h. by [Imp.] Leviathan, dam Black Sophia by Tosgal lant.

HEC'TOR, [Imp.] bl. h. got by Lath - Childers-Basto - Curwin' Bay Barb, \&c.-foaled 1745. Colonel Marshall.

HEDGFORD, [Imp.] br. h. by Filho da Puta, dam Miss Craigie by Orville.

gle. (Young) h. by [Imp.] Hedgford, dam by [Imp.] Ea

HERCULES-a grey draft horse, imported into Louisville, Ky.

HERO, [Imp.] b. L. got by Blank-Godolphin Ar. \&c.-foaled 1747. - Va.

John S. Wilson.

HIAZIM, ch. h. by Sir Archy, dam Janey by [Imp.] Archlule. HIBISCUS, [Imp.] b. h. by Sultan, dain Duchess of York by Waxy. HICKORY JOHN, ch. h. by John Richards, dam Kitty Hickory by Hickory.

HIGHLAND HENRY, ch. h. by Henry, dam Highland Mary by Eclipse.

HORNBLOWER, br. h. by Monmouth Eclipse, dam Music by John Richards.

HUGH LUPIS, [ Imp.] b. h. by [Imp.] Priam, dam Her Highnese by Moses.

\section{I.}

IBARRA, b. h. by [Imp.] Hedgford, dam by Virginian.

IBRA HIM PACHA, [Imp.] - a pure Bedouin Arabian-importel by Captain James Riley.

\section{J.}

JACK OF DIA MONDS, [Imp.] dk. b. h. by Cullen's Arabian-Darley Ar. - Byerly Turk, \&c. - Va. 1763. Imported by Colonel Siottswood.

Solomon Dunn.

JACK PENDLETON, ch. h. by Goliah, dam by Trafalgar.

JANE. GRAY, m. by Orphan Boy, dam Rosalind by Ogle's Oscar.

JEROME, br. h. by [ Imp.] Luzborongh, dam by Sir Charles.

JESSICA, [Imp.] ch. m. by Velocipede, dam by Sancho.

JIM JACK $\supset O N$, ch. h. by [Imp.] Leviatl.an, dam by Conquemr.

JOB, b. h. by Eclipse, dam Jemima by Thornton's Rattler.

JOHN BA.COMBE, ch. h. by Bertrant, dam Grey lioose by Pacolet JOHN BULL, [lmp.] b. h. by Chateau Marganx, dam by Woful.

JOHN DAWSON, b. h. by Pacific, dam by Grey Archy.

JOHN GASCOIGNE, h. by Ramblpli's Gascoigne, dam by Tirgi nian.

JOHN RICHARDS, b. h. by Sir Archy, dam by Rattler, gr. dam by [Imp.] Medley.

JORDAN, [Imp.] eh. h. by Langar, dain Matilda by Comus.

'UNIUS, [ Imp.] bl. h. got by Old Staring - Old Crab - MnnkeyCurwin's Bay Barb-Spot, \&c.-foaled 1754.-Va. 1759.

SISTTICE, [Imp.] b. h. got by Blank, dam Aura by Stamford Turk, g. dain by a bother to Conqueror-Childers, \&c.-Va. 1780.

Grorge Gould. 
:USTILE, [Imp.] got by Old Justice (son of King Herod) - Old Squirt mare - Mogul - Camilla by Bay Bclton, \&c. - foaled 1782.-S. Carolina.

Major Butler.

\section{$\mathbf{K}$}

KANGAROO, ch, h. by Uncas, dam by (Irphan.

KATE NICKLEBY, m. by [ Imp.] Trustee, dam Lady Mostyn by Teniers.

EING WILLIAM, [ Imp.] red sor. h. got by Florizel, dam Milliner by Matchem -Cassandria by Blank, \&c.-foaled 1781.-Chester county, $\mathrm{Pa}$.

Dr. Norriss.

[Imp.] b. h. by King Herod, dam Madcap by Snap - Miss Meredith by Old Cade, \&c.- oaled 1777. - Con. necticut.

Skinner.

EITTY BRIM, b. m. by Old Conqueror, dam by Gallatin; gr. dam by Hightlyer.

L.

LADY CLIFDEN, $m$. by Sussex, dam Betsey Wilson.

LADY CULPEPER, m. by Carolinian, dam Flora by Ball's Florizel.

LADY MORGAN, m. by John Richards, dam Matchless by [Imp.] Expedition.

LADY MOSTYN, [Imp.] m. by Teniers, dam Invalid by Whisker.

LADY NIMBLE, $m$. by Eclipse, dam Transport by Kosciusko.

LADY SCOTT, [Imp.] br. m. got by Ardrosson, dam Dido by Vis. count-Brilliant by Whiskey, \&c. R. D. Shepherd.

LADY WHIP, $m$. by Whip, dam by Alonzo, gr. dam by [Imp.] Buz zard.

LAFAYETTE, b. h, by Conqueror, dam Julia by Sir Arthur.

LANGFORD, [Imp.] br. h. got by Starch, out of Peri by Wanderer, her dam 'Thalistris by Alexander, out of Rival by Sir PeterHorne by Drone -Manilla by Goldfinder-foaled 1833.

F. P. Corbin.

l.APLANDER, ch. or br. h. by Flagellator, dam Medora.

LEOPARDESS, $\mathrm{m}$. by Medoc, dam by Haxall's Moses.

LEVIATHAN, [Imp.] ch. h. by Muley, dain hy Windle.

Diomed.

I.ILY, $\mathrm{m}$. by Eclipse, dam Garland by Duroc.

LIMBER JOHN, ch. h. hy Kosciusko, dam by Moses.

LOFTY, [Imp.] b. h. by Godolphin A rabian-Croft's Partner-Bloody Buttocks-Greyhound, \&c.-foaled 1753.-Virginia, Chesterfield county.

'Thomas Goode.

LOUISA, ch. m. by [Imp.] Bluster, dam by Hamiltonian.

LIFCHER, [ $1 \mathrm{mp}$.] gro h by Grey Leg, dam Harpalyce by (iohanna LLZBOROLGH, [Imp.] br. h. by Williamson's Ditto, dam by Dick Andrews. ter.

LYCURGIS. [Imp.] ch. h. by Blank-Snip-Lath, \&r.-foaled $176^{\bullet}$ -V\&. 1776

Gico. H Harrison 
LYNFDOCH, ch. h. by [Imp.] Leviathan, dain Kusetta by Wilke Wonder.

\section{M.}

MAGNUM BONUM, [Imp.] ro. h. by Matchem-Swift-RegulusDairy Maid by Bloody Buttocks, \&c. — foaled 1774. - Hartiord Conn.

F. Kilborne.

MANALOPAN, gr. h. by Medley, dam by John Richards.

MARIA DAVIESS, ch. m. by Sir Charles, dam Mary Grindie ly Eclipse.

MARIA VAUGHAN, $m$. by Pacific, dam Mary Vaughan by Pacolet.

MARION, b. h. by Sir Archy, dam by [Imp.] Citizen.

MARGRAVE, [ $1 m p$.] ch. h. by Muley, dam by Election.

MARK MOORE, ch. h. by Eclipse, dam Lalla Rookh by Gabriel Oscar.

MARMION, br. h. by [Imp.] Merman, dam by Crusader.

MARPLOT, [Imp.] by Highflyer-Omar-Godolphin Arabian, \&z.

MARTHA BICKERTON, b. m. by Pamunky, dam hy Tariff.

MARSHAL NEY, h. by Pacolet, dam Virginia by Dare Devil.

MARY BIDDLE, $\mathrm{m}$. by [Imp.] Priam, dam Flora by Mons. Tonson.

MARY VAUGHAN, gr. m. by Old Pacolet, dam by Old Chanticleer.

MAS'TER ROBERT, [Imp.] ch. h. by Star, dam a young Marsko mare-foaled 1793.

MASTER SOLOMON, b. h. by Reveller, dam by Lord Berrers.

MATCHEM, [Imp.] b. h. by Matchem-Lady by Sweepstakes-Patriot-Old Crab, \&c. - foaled 1773._S. Carolina.

MATCHLESS, [Imp.] b. h. by Godolphin Arabian - Soreheel Makeless, \&c.-S. Carolina.

MATILDA, gr. m. hy Greytail Florizel, dam by [Imp.] Jonah.

MAXIMUS, b. h. by Bertrand, dam Miss Dance by [Imp.] Eagle.

MAYZOUBE - a gr. horse imported from Arabia by Captain James Riley.

MELZARE, br. h. by Bertrand, dam by Sir Richard.

MENDOZA, [Imp.] b. h. by Javelin - Paymaster - Pamona by King Herod.

MERMAN, [Imp.] hr. h. hy Whalebone, dam by Orville.

MERRY PINTLE, [ $1 \mathrm{mp}$.] gr. h. by Old England, dam by Old Merry Pintle-Skipjack, \&c.-foaled 1752.-Va. $1775 . \quad$ J. Strong.

MERRY TOM, [Imep.] b. h. by Regulus - Locust - a son of Flying Childers_Croft's Old Partner, \&c-foaled 1758.

MERCER, [Imp.] b. h. by Emilius, dam Young Mouse hy Godolphin. MERWICK BALL, [ $\mathbf{I m p}$.] ch. h. by Regulus-dam a Traveller mare - Hartley's blind horse-foraled 1762 .

MINOR, b. h. by Mons. Tonson, dam by Topgrallant.

MISS ANDREWS, [Imp.] h. In. hy Catton, dam by Dick Andrews.

MISS MATTIE, m. by Sir Archy, dam Black Ghust by Pantaloon.

MISS ROSE, $[\operatorname{Imp}$. $]$ h. m. by Tramp, dam by Sanchi, gr. dam by Coriander, \&c.-foaled 1826 .

R. D. Shepherd.

MISS VALENTINE, m. hy [ $\operatorname{lmp}$.] Valentine, dam by John Richarda M('NARCH, [Imp.] b. h. hy Priam, dam Delphine hy Whisker.

MONMOUTH, b. h. by Juhn Richards, dam by Duroc. 
MONMOUTH ECLIPSE, ch. h. by Eclipse, dam Honesty hy [ $1 \mathrm{mp}$.

Expedition.

MONS. TONSON, gr. h. by Pacolet, dam Madame Touson by Topgallant.

MORDEC.AI, [Imp.] h. h. by Lottery, dam by Welheck.

MORVEN, [Imp. $]$ ch. h. by Rowton, dam Nanine by Selim.

MIOSES MARE (Chas. Buford's) by Haxall's Muses, dam by Cook's or Blackburn's Whip.

N.

NANCY THATCHER, $m$. by Medoc, dam by Archy of Transport.

NELI, GWY NNE, [Imp.] m. hy 'Tramp, dam by Beningbrough.

NE'T'TY, $[$ Imp.] ch. m. by Velocipede, dam Miss Rose.

NICHOL.AS, [Imp.] h. by St. Nicholas, dam Miss Rose.

NIMROD, [Imp.] b. h. by King Fergus - O'Kelly's Eclipse - Old Marske, \&c.-Philadelphia, 1788.

NON PLUS, [Imp.] b. h. by Catton, dam Miss Garforth by WaltonHyacinthus, \&c.-foaled 1824.-S. Carolina. R'd. Singleton.

NORTH BRI'TAIN, [Imp.] b. h. by Alcock's Arabian-Northumber lanil Arabian-Hartley's blind horse.-Philad. 1768. Crow. NOVELTY, $[$ Imp.] m. by Blacklock, dam Washerwoman by Walton.

\section{O.}

O'KELLY, ch. h. by Eclipse, dam by Oscar.

DLIVER, h. by May-Day, dam Young Betsey Richards by John Richards.

ONUS, [ $\operatorname{Imp}$. ] br. h. by Camel, dam The Etching by Rubens.

ORLEANA, [Imp.] m. by Bustard, dam Laureola hy Orville.

OROUNOKO, [ Imp.] bl. h. by Old Crab, dam Miss Slammerkin by Young True Blue-Bloody Shouldered Arabian, \&c.-foaled 1745 -S. Carolina.

OTHELLO, br. h. by [Imp.] Leviathan, dam by Sir Archy.

J. Mathews.

P.

PACIFIC, b. h. by Sir Archy, dam Eliza hy [Imp.] Bedford.

PACOLE'T, [Imp.] h. hy Sparke, dam Queen Mab-Hampton Court Childers-Harrison's Arabian, \&c-Va. 1791. 'Thos, Goode.

PAC'TOIUS, ch. h. by Pacific, dam Mary Vaughan hy Pacolet.

PAMUNKY, b. h, hy Eclipse, dam Bellona by Sir Harry.

PALL CLIFFORD, h. by Eclipse, dain Betsey Richards by John Ri chards.

PETE WHETSTONE, b. h. by [ $1 \mathrm{mp}$. ] Leviathan, dam by Stock holder.

PIIARAOH, [ $1 m p$.$] b. h. hy Moses, dam by Godolphin Arabian$ Smockface by Old Snail, \&c.-foaled 1753-S. Caroina.

PHILIP, [ Imp.] hr. h. hy Filho da Puta, dam 'Treasure by Camillus Trafalgar.

PICTON, hr. h. by [Imp).] Luzhornugh, dam Isaliella by Sir Archy.

PlaATOFF, b. h. by Kosciusku, dam hy Hephestion. 
PONEY, (The) ch. h. by [Imp.] Leviathan, dam by Stockholder.

PORTLAND, [Imp.] ch. h. by Recovery, dam by Walton.

POR'T'SMOU'TH, br. h. by [Imp.] Luzborough, dam Polly Peachem by John Richards.

POST BOY, ch. h. by Fienry, dam Garland by Duroc.

POWHAT'TAN, b. h. by Arab, dam by Whip.

PRESTO, b. h. by [Imp.] Leviathan, dam by Stockholder.

PRIAM, [Imp.] b. h. by Emilius, dam Cressida by Whisker.

Junior, h. by [Imp.] Leviathan, dam by Sir Archy.

PRINCE, [Imp.] b. h. by Herod, dam Helen by Blank-Crab, \&c.foaled 1773. -S. Carolina.

PRINCE FERDINAND, [Imp.] by Herod, dam by Matchem - gr. dam the Squirt mare, \&c.

PRUNElLA, [Imp.] m. by Comus, dam by Partisan.

PUZZLE, [Imp.] b. h. by Reveller, dam by Juniper.

\section{Q.}

QUEEN OF THE WEST, br, m. by Shark, out of Lady Mostyn by Teniers, gr. dam Invalid by Whisker.

\section{R.}

RATTLER, ch. h. by Sir Archy, dam by [Imp.] Robin Red Breast.

RED BILL, b. h. by Medoc, dam Brown Mary by Sumpter.

RED BUCK, b. h. by [Imp.] Leviathan, dam Sally Bell by Contration.

RED TOM, ch. h. by Bertrand, dam Duchess of Marlborough by Sir Archy.

REINDEER, ch. h. by Henry, dam Sportsmistress by Hickory. ch. h. by Sussex, dam by Oscar.

REPLIBLICAN, [ $1 \mathrm{mp}$.] ch. h. by Wentworth's Ancaster - Old Royal Changeling-Bethel's Arabian, \&c._Va. 1797.

Charles Young.

RICHARD SINGLETON, b. h. by Bertrand, dam Black-Eyed Susan by 'Tiger.

RIDDLESWORTH, [Imp.] ch. h. by Emilius, dam Filagree by Soothsayer.

ROANOKE, b. h. by Sir Archy, dam by Cœur de Lion.

ROBIN BROWN, ch. h. by Mons. Tonson, dam (Boston's dam) by Ball's Flurizel.

RODOLPH, b. h. by Archy of 'Transport, dam by Haxall's Moses.

RODERICK DHU, [1mp.] by Sir Peter Teazle, dam liy Young Marsko - Matchem-Tarquin, \&c. Imported into New York.

ROSALBA, m. hy Old Trafalgar, dam Rosalha by Spread Eagle.

ROSIN THE BOW, b. h. by Bertrand, dam Lady Grey by Robin Groy RUBY, [Imp.] b. h. by Emilius, dam Eliza by Rubens.

RUSHLIGHT, ch. m. by Sir Archy, dam Pigeon by Pacolet.

S.

SALLY BARBOUR, m. by [ $1 \mathrm{mp}$.] T'ruffle, dam by Ball's Florizel.

BAl.LY HYDE, m. by Sumner's Grey Archy, dam by Medley. 
S.IM HOUSTOON, ch. h. by Barney O'Laynn, dam Judy Bakewell by Eagle.

SAN'TEE, b. h. by Roh Roy, dam Betty by [Imp.] Buzzard.

GARACEN, b. h. by Eclipse, dam sally Slouch by Virginian.

SARPEDON, [Imp.] br. h. by Emilius, dam Icaria by 'The Flyer Parma by Dick Andrews, \&c.

SCIPIO, b. h. by [Imp.] Leviathan, dam Kitty Clover by Sir Charles.

SCOUT, [Imp.] br. h. liy St. Nicholas, dam by Blacklock.

SEAGULL, b. h. by Sir Archy, dain Nancy Air by [Imp.] Bedford.

SHADOW, bl. h. by Eclipse Lightfoot, dam Sally Slouch by Virginian.

SHADOW, [Imp.] b. h. got by Labraham-Bolton Starling-Cough ing Polly by Bartlett's Childers, \&c.-foaled 1759. - Va. 1771.

T. Burwell.

SHAKSPEARE, [Imp.] br. h. by Smolensko, dam Charming Molly by Rubens.

SHARK, bl. h. by Eclipse, dam Lady Lightfoot by Sir Archy.

SHAMROCK, [ Imp . ] ch. h. St. Patrick, dam Delight by Reveller.

SHEPHERDESS, [ Imp.] b. m. by Young Blacklock, dam Spermaceti by Sligo Waxy.

SHERIFF PACHA, b. h. Nedji bred_imported by Com. Elliott.

SHOCK, [Imp.] got by Shock-Partner-Makeless-Brimmer, \&cc$\mathrm{Va}$. Caroline county.

SIDI HAME'T, b. h. by Eclipse, dam Princess by Defiance.

SIDNEY, b. h. by Sir Char!es, dam Virginia by 'Thoznton's Rattler.

SIR CHARLES, ch. h. by Saladin, dam by Cultivator

SIR JOSEPH, br. h. by (Imp.) Luzborough, dam Sally Maclin by Sir Archy.

SIR LESLIE, b. h. by Sir William, dam by (Imp.) Buzzard.

SIR MEDLEY, ch. h. by Medley, dam by Sir Charles.

SIR PETER TEAZLE, (Imp.) ro. h. got by Sir Peter Teazle-Mercury-Cythera by King Herod-Blank, \&c.-foaled 1802.-\$. Carolina.

Gen. Jno. McPherson.

SIR ROBERT, (Imp.) b. h. by Bobadil, dam Fidalma by Waxy Pope.

SIR WILLIAM, h. by Sir William, dam by Tiger.

SKYLARK, (Imp.) br. h. by Waxy Pope, dam Skylark by Musician.

SI.OUCH, (Imp.) ch. h. by Cade, dam the little Hartley mare by Bartlett's Childers - Flying Whig by Woodstock, \&c.-foaled 1747. - S. Carolina.

SOURKROUT, (Imp.) b. c. by Highflyer, dam Juwel by Sqquirrel Sophia by Blank, \&c.-foaled 1786.

SOVEREIGN, (Imp.) b. h. by Emilius, dam Fleur do Lis br Bourbon.

STARLING, (Imp.) by Young Starling-Regulus---Snake, Partnes \&c.-foaled 1756.-Va. 1762. Carlisle \& Dalton.

STANHOl'E, ch. h. by Eclipse, dam Helen Mar by hatler.

STEEL, b. h. by (Imp.) Fylde, dam Diamond by Constitution.

STOCKHOLDFR, b. h. by Sir Archy, dam by (Imp.) Citizen

ST. LEGER, gr h. by Eclipse, dam (Ariel's dam,) by Finannies. 
ST. PAUL, (Imp.) sor. h. by Old Saltram, dam Purity by Matchem,

Pratt's famous Squirt mare, \&c.-foaled 1789.-Va. 1804.

STRAWBERRY ROAN, (see Fairfax Roan).

Wm. Liglitfoot.

SWISS, (Imp.) b. h. by Whisker, dam by Shuttle.

SYMMETRY, ch. m. by (Imp.) Ainderby, dam Ellen Douglass br Bertrand.

\section{T.}

T\& RGET, ch. h. by (Imp.) Luzborough, dam Becky by Marquis.

TA.RLTON, b. h. by Woodpecker, dam by Robin Gray.

TARQUIN, br. h. by Henry, dam Ustrich by Eclipse.

- - h. by (Imp.) Luzborough, dam Hackabout by Timoleon. (Imp.) L. by the Hampton-Court Chesnut Ar. out of Fair

Rosamond by Cade-Traveller, \&c.-foaled 1720.

TELIF, DOF, $m$. by Pacific, dam Matilda by Grey-tail Florizel.

'TENNESSEE CITIZEN, ch. h. by Stockholder, dam Patty Puff by Pacolet.

THOMAS H. BENTON, br, h. by Waxy, dam Virginia by Matapone.

TITRY, (Imp.) ch. m. by Langar, dam Zephyrina by Middlethorpe.

TOBACCONIST, b. h. by Gohanna, dam Yankee Maid by Ball's Flori\%el.

TOM MOORE, h. by Contention, dam Pocahontas by Virginian.

TORNADO, ch. h. by Eclipse, dam Polly Hopkins by Virginian.

TRANBY, (Imp.) br. h. by Blacklock, dam by Orville-Miss Grim. stone by Weazle-Ancaster, \&c.-foaled 1826.-Va. 1835.

J. J. Avery \& Co.

TRIPIT, br. m. by Mars, dam by Post Boy.

TRUFFLE, (Imp.) b. h. by Truffle, dam Helen by Whiskey.

TRUSTEE, (Inp.) ch. h. by Catton, dam Emma by Whisker.

v.

VALPARAISO, (Imp.) ch. h. by Velocipede, dam Julianna by Ge hanna.

VERTNER, ch. h. by Medoc, dam Lady Adams by Whipster

VERTUMNUS, b. h. by Eclipse, dam Princess by Defiance.

VICEROY, ch. h. by Eclipse, dam Saluda by 'Timoleon.

VOLCANO, b. h. by Stockholder, dam Forest Maid by Ratray.

VOLNEY, b. h. by Mons. Tonson, dam by Sir Archy. Phantom.

(Imp.) b. h. by Velocipede, dam (Voltaire's dam,) by

\section{W.}

WACOUSTA, ch. h. by (Imp.) Leviathan, dam Lady Lightfoot by Oscar.

WAGNER, ch. h. by Sir Charles, dam Maria West by Marion.

WASHENANGO, ch. h. by Timoleon, dam Ariadne by (Imp.) Citizen.

WHALE, (Imp.) by Whalebone, (who was by Waxy,) dam Rectory by Octavius-Catharine by Woodpecker.-N. Carolina.

Edward Townes.

WHALF:BI)NE b. h. hy Sir Archy, dam by Pacolet 
WILD BILL, b. h. ly Sir Archy, dam Maria by Gallatin.

WILLIAM H. HARRISON, gr. h. by Truinpator, dam by Doublo head.

WILLIS, ch. h. by Sir Chirles, dain by (Imp.) Merryfield.

WANDER, ch. h. by Mommouth Eclipse, dain Powancey by Altrer. WOODPECKER, b. h. by Bertrand, dam by (Im\%.) Buzzard.

\section{Y.}

ORKSHIRE, (Imp.) got by St. Nicholas, dam Miss Rose.

YOUNG GOHANNA, h. by Gohanna, dam by Pacolet.

R. D. Shepherd.

YOUNG MEDLEY, h. by Potomac, dam by Medley.

YOUNG TRAMP, (Imp.) h. by Barefoot, dam Isabella by. Comus. YOUNG WONDER, $h$. by Cock of the Rock, dam Nell Sanders.

Z.

ZINGANEE, (Imp.) b. h. by Tramp, dam Folly by Young Drono. Chance. (Garrison's, ) b. h. by Sir Archy, dam Atalanta by (Ino.) 


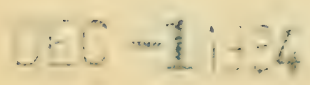







\section{LIBRARY OF CONGRESS}

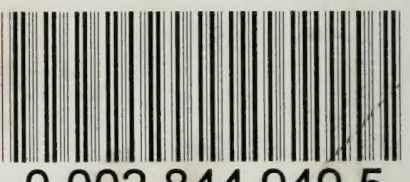

00028449495 